\title{
Inequality and the Value of Nature An Economic Analysis
}

\section{DISSERTATION}

\author{
eingereicht an der Lebenswissenschaftlichen Fakultät \\ der Humboldt-Universität zu Berlin
}

vorgelegt von

Jasper Nikolaus Meya, M.Sc., M.Ed.

Präsidentin der Humboldt-Universität zu Berlin: Prof. Dr.-Ing. Dr. Sabine Kunst Dekan der Lebenswissenschaftlichen Fakultät: Prof. Dr. Bernhard Grimm

\section{Gutachter:}

1. Prof. Dr. Klaus Eisenack, Lehrstuhl für Ressourcenökonomik, HU Berlin

2. Prof. Dr. Stefan Baumgärtner, Lehrstuhl für Umweltökonomie, Universität Freiburg

3. Prof. Dr. Mikołaj Czajkowski, Lehrstuhl für Mikroökonomie, Universität Warschau

eingereicht: Berlin, 11. Juli 2018

verteidigt: Berlin, 01. November 2018

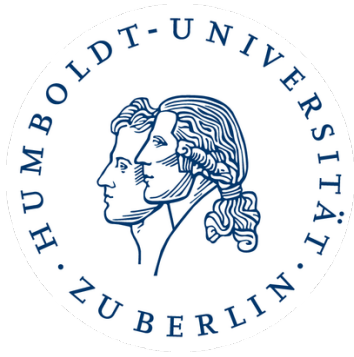




\begin{abstract}
This doctoral thesis presents seven research papers in environmental and resource economics. I study how the economic value that society attaches to nature depends on the distribution of income or the provision of environmental goods, within or across generations. To this end, three novel environmental economic models are developed on how the distribution affects aggregated willingness to pay for pure public environmental goods, local environmental goods or natural capital. The analyses show that for many environmental goods the economic value is the higher the more equal incomes or environmental good endowment are distributed. For practical applications theory-based adjustment factors are derived. These allow to estimate societal willingness to pays from secondary data or to conduct inequality-adjustments in cost-benefit analysis. In a series of applications - to global biodiversity conservation, forest protection in Poland or water quality improvement in the Baltic Sea - inequality adjustments are quantified and empirically tested. Turning to international environmental agreements, a simulation study shows that uncertainties about the regional distribution of climate change damages can increase the stability of climate coalitions if transfer schemes are implemented. Finally, a case study on the deepening of the Weser estuary highlights that accounting for environmental costs can substantially change the results of cost-benefit analyses in transportation infrastructure planning. Overall, this dissertation shows that the distribution of economic and natural resources within and across generations substantially affects the economic value that society attaches to nature. I thereby contribute to the development of economic methods that aim not only at efficiency, but also at equity and distribution, and thus follow the vision of a sustainable development.
\end{abstract}




\section{Zusammenfassung}

Diese wirtschaftswissenschaftliche Dissertation bündelt sieben Forschungsarbeiten zur Ökonomie des Natur- und Umweltschutzes. Dabei untersuche ich, wie der ökonomische Wert, den die Gesellschaft der Natur beimisst, von der Verteilung des Einkommens oder der Ausstattung mit Umweltgütern abhängt. Eine solche integrierte Analyse ist angesichts zweier großer gesellschaftlicher Herausforderungen des 21. Jahrhunderts bedeutsam: dem dramatischen, sich beschleunigendem Verlust von natürlichen Ökosystemen und Biodiversität einerseits, und der seit den 1980er Jahren in vielen Ländern zunehmenden wirtschaftlichen Ungleichheit andererseits.

Dazu entwerfe ich in meiner Dissertation drei umweltökonomische Modelle zur Frage, wie die gesellschaftliche Zahlungsbereitschaft für Natur- und Umweltschutzpolitik von der Verteilung des Einkommens oder der Ausstattung mit Umweltgütern, innerhalb oder über Generationen hinweg, beeinflusst wird. Es zeigt sich, dass für viele Umweltgüter der ökonomische Wert umso größer ist, je gleichmäßiger das Einkommen oder die Ausstattung mit Umweltgütern zu einem Zeitpunkt verteilt sind. Für reine öffentliche Umweltgüter, wie Existenzwerte der Artenvielfalt, ist der Grad der Substituierbarkeit durch menschgemachte Güter auschlaggebend für den Effekt der Einkommensungleichheit. Für lokale öffentliche Güter, wie Stadtparks oder Wälder, hängt der ökonomische Wert zudem von der Verteilung des Zugangs zum Umweltgut und dessen Korrelation mit der Einkommensverteilung ab. Für Naturkapitalbewertung ist darüber hinaus die intergenerationale Verteilung, gegeben die Raten des Naturverlustes sowie des Einkommenswachstums, entscheidend.

Mit diesen theoretischen Fundierungen entwickelt meine Dissertation modellgestützte Methoden zur Berücksichtigung von Verteilungsaspekten in ökonomischen Analysen von Politiken und Projekten mit Umweltauswirkungen zur öffentlichen Entscheidungsfindung. Insbesondere werden eine Reihe von Korrekturfaktoren hergeleitet, die es erlauben, monetäre Werte für Veränderungen in der natürlichen Umwelt hinsichtlich einer intra- oder intergenerationalen Zielverteilung von Einkommen oder Umweltgütern anzupassen. Diese Korrekturfaktoren eignen sich etwa zur Anwendung in öffentlichen Kosten-Nutzen Analysen, wie sie beispielsweise im Verkehrssektor eingesetzt werden, oder sozio-ökonomische Berichtssystemen, wie der Umweltökonomischen Gesamtrechnung. Anhand einer Reihe von Fallbeispielen - zum globalen Biodiversitätsschutz, Walderhaltung in Polen oder einer Wasserqualitätsverbesserung in der Ostsee - werden die Ungleichheitskorrekturen praktisch veranschaulicht und Anpassungsbedarfe beziffert.

Drei empirische Forschungsarbeiten runden die Dissertation ab. Erstens erfordert eine systematische Inwertsetzung von Leistungen der Natur in öffentlichen Entscheidungen die Verwendung von Sekundärdaten. Dazu wird in einer länderübergreifenden Studie aller Ostseeanrainerstaaten statistisch nachgewiesen, dass eine Berücksichtigung von Unterschieden in der Einkommensverteilung tatsächlich die Vorhersage gesellschaftlicher Zahlungsbereitschaften für Naturschutzpolitik verbessert. Zweitens ist internationale Kooperation für die Lösung vieler Umweltprobleme notwendig. In einer Simulationsstudie wird gezeigt, dass die gegenwärtigen Unsicherheiten über die regionale Verteilung von Kosten- und Nutzen des 
Klimaschutzes eine Chance für globalen Klimaschutzabkommen bieten können, wenn zwischenstaatliche Ausgleichszahlungen implementiert werden. Drittens stellt sich die Frage, ob Umweltauswirkungen überhaupt in einer ökonomisch relevanten Größenordnung im Vergleich zu anderen Projektauswirkungen liegen - beispielsweise bei der Prioritätensetzung in der Bundesverkehrswegeplanung. In einer Studie zur Vertiefung des Weserästuars wird nachgewiesen, dass bereits die monetäre Berücksichtigung weniger Umweltfolgen zu einer drastischen Verschlechterung der Profitabilität dieses Verkehrsprojektes führt.

Insgesamt zeigt meine Dissertation, dass die Verteilung von wirtschaftlichen und natürlichen Ressourcen innerhalb und zwischen den Generationen den ökonomischen Wert, den die Gesellschaft der Natur beimisst, wesentlich beeinflusst. Es ist daher wichtig, bei der Durchführung von ökonomischen Analysen im Kontext des Natur- und Umweltschutzes Verteilungsaspekte zu berücksichtigen. Diese Dissertation entwickelt mehrere methodische Vorschläge, wie dies geschehen kann. Damit leistet meine Dissertation auch einen Beitrag zur Entwicklung volkswirtschaftlicher Methoden, die nicht nur auf Effizienz, sondern auch auf Gerechtigkeit und Verteilung zielen, und damit dem Leitbild einer nachhaltigen Entwicklung folgen. Ich hoffe, dass meine Dissertation damit etwas zur Findung gerechterer und effizienterer gesellschaftlicher Entscheidungen in einer Welt beitragen kann, die an ihre biophysikalischen Grenzen stößt. 


\section{Acknowledgements}

The research presented in this dissertation benefited from exchanges with numerous colleagues and has been supported by a range of people and institutions over the years.

Especially, I am grateful to

- Klaus Eisenack for innumerable support, trust and intellectual freedom, as well as for an excellent and stimulating research environment at his Resource Economics Group;

- Stefan Baumgärtner for continuous advise over the last years and an inspiring Sustainability Economics College that opened up this fascinating topic to me;

- Mikołaj Czajkowski for kindly being the third thesis referee;

- my chapter co-authors Stefan Baumgärtner, Nils Droste, Moritz Drupp, Nick Hanley, Ulrike Kornek, Kai Lessmann, Jan Munz and Martin Quaas for exciting collaborations;

- colleagues from the Department of Economics at Carl von Ossietzky University Oldenburg, the Department for Agricultural Economics at Humboldt-Universität zu Berlin, as well as the RESILIENCE-Project for great research environments, and to Carsten Helm for his generous support throughout the last months;

- all members of the Resource Economics Group at HU Berlin and of the Environment and Development Economics Group at University Oldenburg for stimulating debates, mutual support and a good time. In particular, I am grateful to Catharina Schramm, Ines Jeworski, and Sigrid Heilmann for their great, tireless support and to my office colleague Paul Neetzow for a grandiose spirit throughout the years;

- Moritz Drupp and Nils Droste for starting together almost a decade ago on to this exciting journey of economics for a more sustainable development;

- my wonderful friends and family for their love and for inspiration along this way;

- Wendla for being on my side.

Jasper Meya 


\section{Contents}

List of Figures $\quad$ x

List of Tables xiv

I Introduction $\quad 1$

1 Nature Conservation and Equity 2

2 Economic Inequality and the Value of Nature $\quad 19$

2.1 Introduction . . . . . . . . . . . . . . . . . . 20

2.2 How does the distribution of income affect the valuation of environmental goods? . . . . . . . . . . . . . . . . . . . 2 21

2.3 Implications . . . . . . . . . . . . . . . . . . . . . 23

2.3.1 Account for income inequality in value or benefit transfer . . . . . . 23

2.3.2 Adjust mean WTPs for an undesired degree of income inequality . . . 24

2.3.3 Consider the incidence of non-market benefits from environmental policies . . . . . . . . . . . . . . . . . . 26 26

2.4 Perspectives for further research . . . . . . . . . . . . . . . . . 27

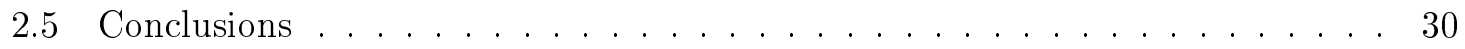

$\begin{array}{llr}\text { II Theory } & 39\end{array}$

3 Income Inequality and Willingness to Pay for Environmental Public Goods 40

3.1 Introduction . . . . . . . . . . . . . . . . . . 41

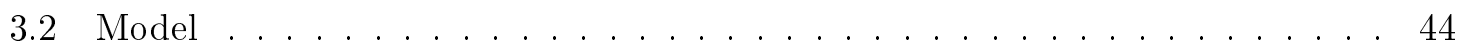

3.3 Results of model analysis . . . . . . . . . . . . . . . 47

3.3.1 How does mean WTP for the environmental public good change if mean income changes? . . . . . . . . . . . . . . . . . . 47

3.3.2 How does income inequality affect mean WTP for the environmental public good? . . . . . . . . . . . . . . . . . 48

3.3.3 What has a larger influence on mean WTP for the environmental public good - mean income or income inequality? . . . . . . . . . . . . 51

3.3.4 How to adjust the WTP for the environmental public good for changes in the income distribution? . . . . . . . . . . . . . . 52

3.4 Empirical analysis . . . . . . . . . . . . . . . 55 
3.4.1 Data description and processing . . . . . . . . . . . 56

Existence of large predator species in Sweden . . . . . . . . . . 56

Global biodiversity conservation . . . . . . . . . . . . . 58

3.4.2 Results of empirical analysis . . . . . . . . . . . . . 6 60

3.5 Discussion . . . . . . . . . . . . . . . . . . . 64

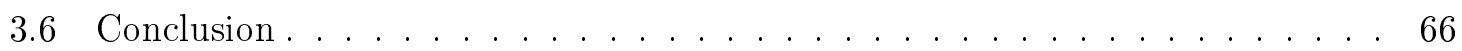

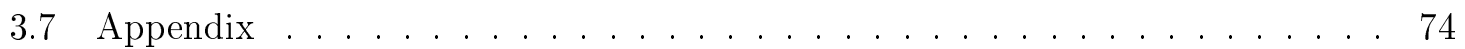

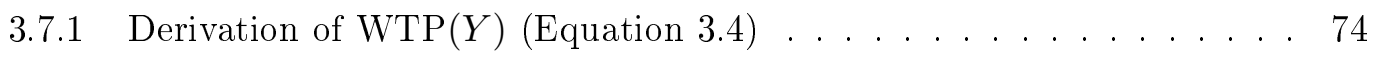

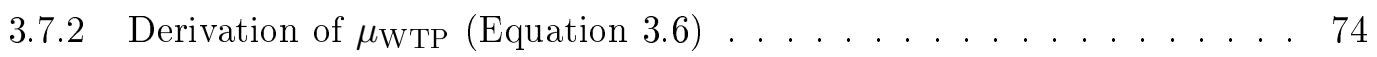

3.7.3 Proof of Proposition $3.1 \ldots \ldots \ldots \ldots \ldots$

3.7 .4 Proof of Proposition $3.2 \ldots \ldots \ldots \ldots \ldots \ldots$

3.7 .5 Proof of Proposition $3.3 \ldots \ldots \ldots \ldots \ldots$

3.7 .6 Proof of Proposition $3.4 \ldots \ldots \ldots \ldots \ldots$

3.7 .7 Proof of Proposition $3.5 \ldots \ldots \ldots \ldots \ldots$

3.7 .8 Proof of Proposition $3.6 \ldots \ldots \ldots \ldots$. . . . . . . . . . . . 80

3.7 .9 Proof of Proposition $3.7 \ldots \ldots \ldots \ldots$. . . . . . . . . . . 84

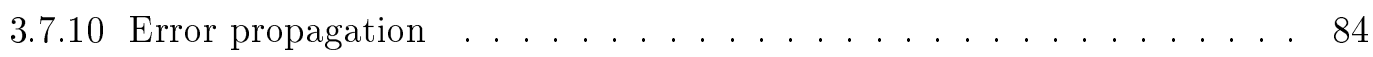

3.7 .11 Heterogenous preferences . . . . . . . . . . . . 85

3.7 .12 Generalization of main result $\ldots \ldots \ldots \ldots$. . . . . . . . 85

4 Environmental Inequality and Economic Valuation $\quad 90$

4.1 Introduction . . . . . . . . . . . . . . . . . . . . . 91

4.2 Model . . . . . . . . . . . . . . . . . . . . . . . . . . 93

4.3 Results of model analysis . . . . . . . . . . . . . . . . 98

4.3.1 Societal WTP for environmental local public goods . . . . . . . . . . . 98

4.3.2 Benefit transfer and environmental local public goods . . . . . . . . 106

4.4 Empirical application . . . . . . . . . . . . . . . . . . 108

4.5 Discussion . . . . . . . . . . . . . . . . . . . . . . . . . . 114

4.6 Conclusion . . . . . . . . . . . . . . . . . . . . 117

4.7 Appendix . . . . . . . . . . . . . . . . . . 127

4.7.1 Derivation of household's total WTP, WTP $\left(Y_{i}, E_{i}\right)$ (Eq. (4.3)) . . . 127

4.7.2 Derivation of mean WTP, $\mu_{\mathrm{WTP}},($ Eq. (4.9)) . . . . . . . . . . 129

4.7 .3 Proof of Proposition $4.1 \ldots \ldots 130$

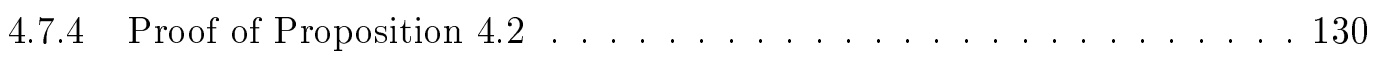

4.7 .5 Proof of Corollary $4.1 \ldots \ldots \ldots 131$

4.7 .6 Proof of Proposition $4.3 \ldots \ldots \ldots 131$

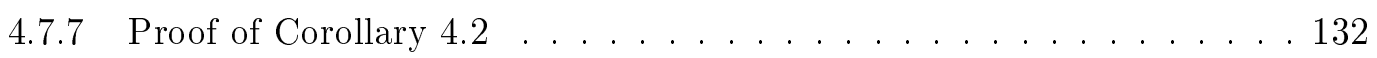

4.7.8 Household sorting with respect to the distribution of the environmental

local public good . . . . . . . . . . . . . . . . . 132

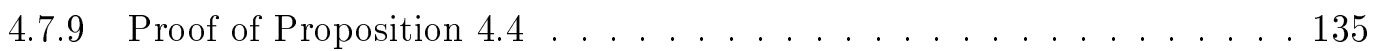

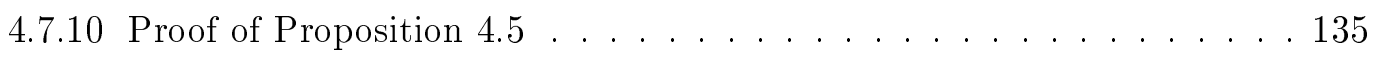

4.7.11 Histograms on $Y$ and $E$ in empirical application (Section 4.4) $\ldots 137$ 
5 Inter- and Intragenerational Distribution and the Valuation of Natural Capital

5.1 Introduction . . . . . . . . . . . . . . . . . . . . . . . . . . 141

5.2 Model . . . . . . . . . . . . . . . . . . . . . . . . . . . . . . 144

5.3 Valuation concepts . . . . . . . . . . . . . . . . . . 148

5.3 .1 Individual Valuation . . . . . . . . . . . . . . . . . . 148

5.3 .2 Societal Valuation . . . . . . . . . . . . . . . . . . 151

5.4 Results . . . . . . . . . . . . . . . . . . . 153

5.5 Application: Global biodiversity conservation . . . . . . . . . . . . . . . . . . . . . . . . . . . . . . .

5.5 .1 Data . . . . . . . . . . . . . . . . . . 159

5.5.2 Quantification of main results . . . . . . . . . . . . . . 163

5.6 Discussion . . . . . . . . . . . . . . . . . . . . . . . . 169

5.7 Conclusion . . . . . . . . . . . . . . . . . . . . . . . 172

5.8 Appendix . . . . . . . . . . . . . . . . . . . . 181

5.8.1 Endogenizing the growth and interest rates in a general equilibrium endogenous growth model . . . . . . . . . . . . . . . . 181

5.8.2 Derivation of the intertemporal utility function (Eq. 5.6) . . . . . . 183

5.8.3 Derivation of the compensating surplus measured as a single payment,

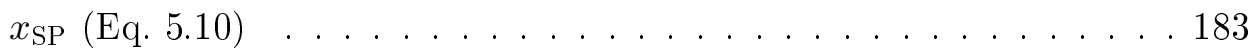

5.8.4 Derivation of the compensating surplus measured as a constant payment fraction, $x_{\mathrm{CPF}}($ Eq. 5.11) $\ldots \ldots \ldots \ldots \ldots$

5.8.5 Derivation of WTP as a single payment for a marginal change in the initial environmental good, $\mathrm{WTP}_{\mathrm{SP}, d E}(\mathrm{Eq} .5 .12) \ldots \ldots . \ldots 186$

5.8.6 Derivation of WTP as a single payment for a marginal change in the

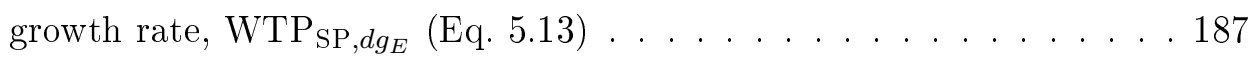

5.8.7 Derivation of WTP as a constant payment fraction for a marginal change in the initial environmental good, $\mathrm{WTP}_{\mathrm{CPF}, d E}$ (Eq. 5.14) . . 187

5.8.8 Derivation of WTP as a constant payment fraction for a marginal change in the growth rate of the environmental good, $\mathrm{WTP}_{\mathrm{CPF}, d g_{E}}$ (Eq. 5.15) . . . . . . . . . . . . . . . . . . . 188

5.8.9 Derivation of mean WTP as a single payment for a marginal change in the initial level of the environmental good, $\overline{\mathrm{WTP}}_{\mathrm{SP}, d E}$ (Eq. 5.17) . . 189

5.8.10 Derivation of mean WTP as a single payment for a marginal change in the growth rate of the environmental good, $\overline{\mathrm{WTP}}_{\mathrm{SP}, d g_{E}}$ (Eq. 5.18) . 191

5.8.11 Derivation of mean WTP at time $t, \overline{\mathrm{WTP}}_{\mathrm{CPF}, d E ; t}$ (Eq. 5.21), and the present value of mean WTP, $\overline{\mathrm{WTP}}_{\mathrm{CPF}, d E}$ (Eq. 5.22), as a constant payment fraction for a marginal change in initial level of the environmental good . . . . . . . . . . . . . . . . . 192

5.8.12 Derivation of mean WTP at time $t, \overline{\mathrm{WTP}}_{\mathrm{CPF}, d g_{E} ; t}$ (Eq. 5.23), and the present value of mean WTP, $\overline{\mathrm{WTP}}_{\mathrm{CPF}, d g_{E}}$ (Eq. 5.24), as a constant payment fraction for a marginal change in the growth rate of the environmental good . . . . . . . . . . . . . . . 193

5.8 .13 Proof of Proposition $5.1 \ldots \ldots . \ldots 194$

5.8 .14 Proof of Proposition $5.2 \ldots \ldots \ldots$

5.8 .15 Proof of Proposition 5.3 . . . . . . . . . . . . . . 196 
5.8.16 Conditions for WTP that declines with income growth . . . . . . . 198

5.8 .17 Proof of Proposition $5.4 \ldots \ldots$. . . . . . . . . . . . 199

5.8 .18 Proof of Proposition $5.5 \ldots \ldots \ldots$. . . . . . . . . . . . . . . . .

III Empirical applications

6 Income Inequality and the International Transfer of Environmental Values 204

6.1 Introduction . . . . . . . . . . . . . . . . . . . 205

6.2 Theory-driven benefit transfer factors . . . . . . . . . . . . . . . 208

6.3 Data . . . . . . . . . . . . . . . . . . . . . . 212

6.4 Empirical strategy . . . . . . . . . . . . . . . . . . 215

6.5 Results . . . . . . . . . . . . . . . . . . . . . 217

6.5 .1 Main result . . . . . . . . . . . . . . . . . 217

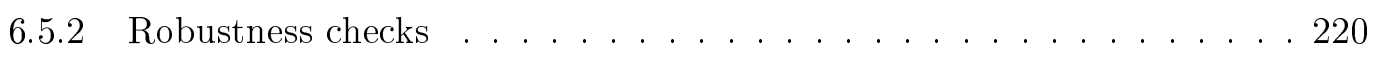

6.6 Discussion . . . . . . . . . . . . . . . . . . . . . . . . . 223

6.7 Conclusion . . . . . . . . . . . . . . . . . . . . . . 226

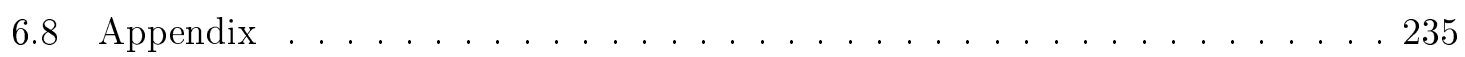

7 How Empirical Uncertainties Influence the Stability of Climate Coalitions 237

7.1 Introduction . . . . . . . . . . . . . . . . . . 238

7.2 Formation of climate coalitions . . . . . . . . . . . . . 241

7.2 .1 Coalition stability . . . . . . . . . . . . . . . . 241

7.2 .2 Coalition performance . . . . . . . . . . . . . . . 242

7.3 The numerical model and uncertainty distributions . . . . . . . . . . . 243

7.3.1 Model of International Climate Agreements . . . . . . . . . . . . . 243

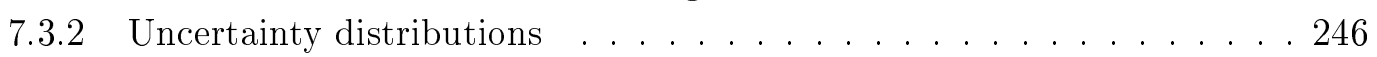

Level of abatement costs . . . . . . . . . . . . . . 246

Level of damages . . . . . . . . . . . . . . . . . . . . . . 247

7.3.3 Curvature of the damage function . . . . . . . . . . . . . 249

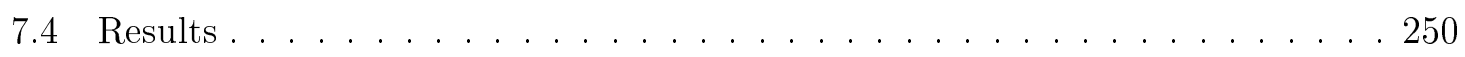

7.4 .1 Coalition performance . . . . . . . . . . . . . 251

7.4.2 Coalition stability without transfers . . . . . . . . . . . 251

7.4.3 Coalition stability with transfers . . . . . . . . . . . . . . 255

7.5 Conclusion . . . . . . . . . . . . . . . . . . 260

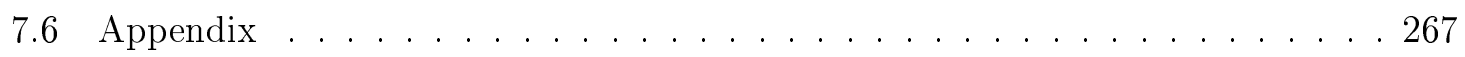

8 Ecosystem Services in Infrastructure Planning $\quad \mathbf{2 7 2}$

8.1 Introduction . . . . . . . . . . . . . . . . . . 273

8.2 Critical review of the German federal infrastructure planning process . . . . . 274

8.2.1 Cost-benefit analysis in infrastructure planning processes . . . . . . . . 274

8.2.2 Classification of costs and benefits . . . . . . . . . . . . . 275

8.2.3 Valuation of environmental impacts . . . . . . . . . . . . 277

8.3 Integrating ecosystem services into a cost-benefit analysis of the projected deepening of the Lower Weser . . . . . . . . . . . . . . 278

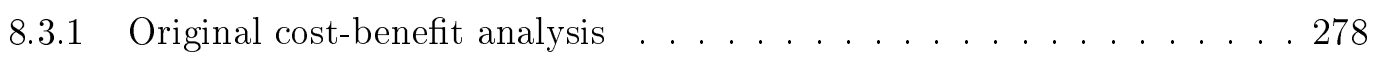


8.3.2 Valuation of affected ecosystem services . . . . . . . . . . . . 279

8.3.3 Ecologically extended cost-benefit analysis . . . . . . . . . . . . 283

8.3 .4 Sensitivity analysis . . . . . . . . . . . . . . . . 284

8.4 Discussion . . . . . . . . . . . . . . . . . . . 285

8.5 Conclusion . . . . . . . . . . . . . . . . . . . . 287 


\section{List of Figures}

2.1 Income inequality affects mean willingness to pay (WTP) for environmental public goods of two households. Compared to a more unequal distribution of income $\left(Y_{A}, Y_{B}\right)$, with a mean WTP $(\overline{\mathrm{WTP}})$, a more equal distribution of income $\left(Y_{A}^{\prime}, Y_{B}^{\prime}\right)$ increases mean WTP $\left(\overline{\mathrm{WTP}^{\prime}}\right)$ for the same mean income $\left(\Delta \mathrm{WTP}=\overline{\mathrm{WTP}^{\prime}}-\overline{\mathrm{WTP}}>0\right)$, if the constant income elasticity of WTP is below unity . . . . . . . . . . . . . . . . . 23

3.1 Histogram of the distribution of disposable annual household income in Sweden [in 1,000 SEK], as used by Broberg (2010), and best-fitting log-normal

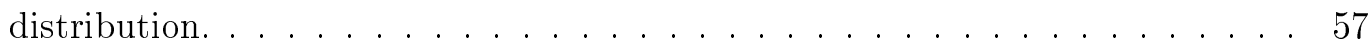

3.2 Best-fitting log-normal distribution of annual household income worldwide [in units of 1,000 2006-PPP-USD], based on Pinkovskiy and Sala-i-Martin (2009). 59

3.3 Relationship between mean WTP for global biodiversity conservation, $\mu_{\mathrm{WTP}}^{\mathrm{GLO}}$, and mean world household income, $\mu_{Y}^{\mathrm{GLO}}$, with an error margin of one standard error of the income elasticity of WTP (shaded in grey), for a given coefficient of variation of income of $\mathrm{CV}_{Y}^{\mathrm{GLO}}=1.61$. The adjustment factor $\mathcal{T}_{\mu}\left(2 \mu_{Y}^{\mathrm{GLO}}, \mu_{Y}^{\mathrm{GLO}}\right)$ for a (hypothetical) doubling of mean income corresponds to an increase in mean WTP, $\Delta \mu_{\mathrm{WTP}}^{\mathrm{GLO}}$, of $30.13 \% \ldots \ldots \ldots 1$

3.4 Relationship between mean WTP for global biodiversity conservation, $\mu_{\mathrm{WTP}}^{\mathrm{GLO}}$, and the coefficient of variation of world household income, $\mathrm{CV}_{Y}^{\mathrm{GLO}}$, for a given level of mean world household income $\mu_{Y}^{\mathrm{GLO}}=37,552$ in 2006-PPP-USD, with an error margin of one standard error (shaded in grey). The adjustment factors $\mathcal{T}_{\mathrm{CV}}\left(0, \mathrm{CV}_{Y}^{\mathrm{GLO}}\right)$ and $\mathcal{T}_{\mathrm{CV}}\left(\mathrm{CV}_{Y}^{\mathrm{SWE}}, \mathrm{CV}_{Y}^{\mathrm{GLO}}\right)$ correspond to an (hypothetical) increase in mean WTP, $\Delta \mu_{\mathrm{WTP}}^{\mathrm{GLO}}$, of $16.29 \%$ and $11.11 \%$, respectively. While the former is the WTP-adjustment for the extreme case of complete income equality, the latter is the WTP-adjustment for income inequality between the global situation to the setting in Sweden. . . . . . . . . . . . . .

4.1 Spatial distribution of distance to forests in Poland and respondents' income. Circle sizes represent mean household income stated by respondents in the $10 \times 10 \mathrm{~km}^{2}$ grid square of their residency. The average Euclidean distance from each point in a $10 \times 10 \mathrm{~km}^{2}$ grid square to the nearest forest is shown in green. . . . . . . . . . . . . . . . . . . . . 111 
4.2 Relationship between the transfer factor to adjust societal WTP for differences in the distribution of the environmental local public good and income, $\mathcal{T}_{\mathrm{CV}_{Y}, \mathrm{CV}_{E}, \rho}$, and different degrees of substitutability. In the hypothetical transfer depicted, the societal WTP for forest protection in Poland is adjusted to a situation where proximity to forests and income is distributed equally over the population. . . . . . . . . . . . . . . . . . . . 114

4.3 Histogram of the distribution of net monthly household income [in 2011-PLN] in Poland as assessed in the forest preservation survey by Czajkowski et al.

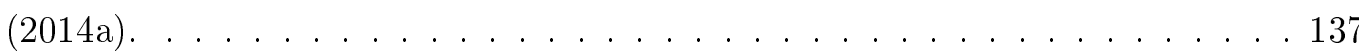

4.4 Histogram of the distribution of the inverse average Euclidean distance to the nearest forest ('forest proximity') from any point of the $10 \times 10 \mathrm{~km}^{2}$ grid square where respondent lives as used by Czajkowski et al. (2017). . . . . . 138

4.5 Relationship between the transfer factor to adjust societal WTP for differences in the distribution of income and the local environmental public good, $\mathcal{T}_{\mathrm{CV}_{Y}, \mathrm{CV}_{E}, \rho}$, and different correlations of income and endowment with the environmental good at the policy site $\rho^{\mathrm{p}}$. In the hypothetical transfer depicted, the societal WTP for forest protection in Poland is adjusted to a situation where income inequality and environmental inequality is identical at study and policy site, but the correlation between $Y$ and $E$ differs. . . . . . . . 139

5.1 Minimal value for $g_{E}$ in case of complements, $\theta<1$, (left side) and maximal value for $g_{Y}$ in case of substitutes, $\theta>1$, (right side) to ensure the existence of a closed-form intertemporal utility function (Eq. 5.3) for different values of the discount factor, $\rho$, and the elasticity of substitution, $\theta$. The shaded area depicts the set of growth rates $g_{E}$ (left side) or $g_{Y}$ (right side) that meets the growth path condition (Eq. 5.7b or 5.7a) for the transfer factor for the mean pure time discount factor,$\rho=0.989 \ldots \ldots \ldots \ldots 2 \ldots \ldots \ldots \ldots$

5.2 Effect of mean income, $\mu_{Y_{0}}$, (left side) or relative intratemporal income inequality, $\mathrm{CV}_{Y_{0}}$, (right side) on the present value mean WTP for a one percent increase in global non-use environmental goods measured as a constant payment fraction, $\overline{W T P}_{\mathrm{CPF}, d E}$, for different degrees of substitutability between the consumption and the environmental good, $\theta \ldots \ldots 164$

5.3 Effect of global per-capita income growth rate, $g_{Y}$, (left side) or growth rate of non-use environmental goods, $g_{E}$, (right side) on the present value mean WTP for a one percent increase in global non-use environmental goods measured as a constant payment fraction, $\overline{W T P}_{\mathrm{CPF}, d E}$, for different degrees of substitutability between the consumption and the environmental good, $\theta$. Grey coloured lines indicate parameter combinations that do not meet the growth path condition for the closed-form intertemporal utility function (Eq. 5.7a). . 165 
5.4 Transfer factor to adjust mean WTP for a one percent increase in the level of the environmental good from a study site with a growth rate of $g_{E}^{\text {study }}=$ -0.0052 to the growth rate at a policy site. Colours depict different degrees of substitutability between the manufactured consumption and the environ-

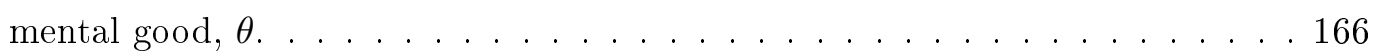

5.5 Transfer factor to adjust societal WTP for a one percent increase in the level of the environmental good from a study site with an income growth rate of $g_{Y}^{\text {study }}:=g_{Y}^{\text {mean }}=0.017$ to an income growth rate at a policy site, such as the lower bound growth rate $g_{Y}^{\mathrm{lb}}=0.001$. Coloured lines depict different degrees of substitutability between the manufactured consumption and the environmental good, $\theta$. Grey coloured lines indicate parameter combinations that do not meet the growth path condition for the closed-form intertemporal

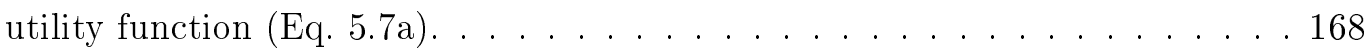

5.6 Transfer factor to adjust mean WTP for a one percent increase in the level of the environmental good from a study site with a market interest rate of $\delta^{\text {study }}=0.977$ to the market interest rate at the policy site when the income growth rate at both the study and policy site is identical. Colours indicate different levels of the income growth rate common to the study and policy site.169

5.7 The derivative of mean WTP for a constant payment fraction with respect to the growth rate of income and how its sign and magnitude depend on the elasticity of substitution, $\theta$, and the pure time discount factor, $\rho$. The remaining parameter values are those of the central calibration in the global biodiversity conservation case study (Table 5.2), in particular the time horizon

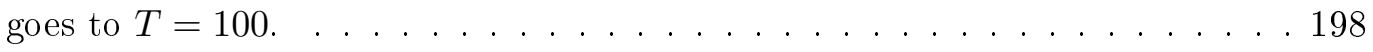

5.8 The derivative of mean WTP for a constant payment fraction with respect to the growth rate of income and how its sign depends on the elasticity of substitution, $\theta$, for different pure time discount factors, $\rho$, (left subplot) or market interest rates, $\delta$ (right subplot). In the left subplot the sign of the derivative is only depicted where the growth path conditions are fulfilled (Eqs. 5.7a and $5.7 b)$. In the right subplot the convergence condition given by Eq. 5.95 is not fulfilled for the upper bound interest factor, $\delta^{\mathrm{ub}}$, and therefore the supremum $\delta^{\text {sup }}=\left(1+g_{Y}^{\text {mean }}\right)^{-1}$ is depicted. Results are given for $t \rightarrow \infty$ by populating Equation 5.96 with the parameter values of the central calibration in the global biodiversity conservation case study (Table 5.2) . . . . . . . . . . 199

6.1 Relationship between the transfer factor for income inequality $\mathcal{T}_{\mathrm{CV}}(\cdot)$ and the ratio of income inequality in the study and policy country for $\eta=0.28$ and $C V_{Y}^{s}=0.56 \ldots \ldots \ldots \ldots \ldots \ldots \ldots \ldots \ldots \ldots \ldots \ldots \ldots \ldots \ldots \ldots \ldots$

6.2 Countries neighboring the Baltic Sea with mean WTP for water quality improvement, $\tilde{\mu}_{\mathrm{WTP}}^{c}$, and income inequality, $\tilde{C V}_{Y}^{c}$, of surveyed population. . . . 214 
6.3 Relationship between the transfer factor for income inequality $\mathcal{T}_{C V}(\cdot)$ and the ratio of income inequality in the study and policy sites, for Estonia (Sweden) as the study site in the left (right) panel. Each blue dot represents a possible benefit transfer. . . . . . . . . . . . . . . . . . . . . . 218

6.4 Relationship between reductions in transfer errors after additional income inequality adjustment, $|T E|_{\mathcal{T}_{C V, \mu}}-|T E|_{\mathcal{T}_{\mu}}$, and the ratio of income inequality in the study and policy country for $\tilde{\eta}=0.28 \ldots \ldots . \ldots . \ldots 220 \ldots$

7.1 Mean welfare performance $(W P)$ and environmental performance $(E P)$ and corresponding $95 \%$ confidence intervals (whiskers) for uncertainty in abatement costs $\left(b_{1}\right)$, global damages $\left(\theta_{1}\right.$-glo), regional damages $\left(\theta_{1}\right.$-reg $)$ and curvature of the damage function $\left(\theta_{2}\right)$. The figure shows results for the coalitions Europe and USA (EU), OECD and 'major emitters'. Black boxes indicate welfare performance and environmental performance for the deterministic case. 252

7.2 Internal stability likelihood and corresponding confidence intervals (whiskers) by coalitions for uncertainty in abatement $\operatorname{costs}\left(b_{1}\right)$, global damages $\left(\theta_{1}\right.$-glo), regional damages $\left(\theta_{1}\right.$-reg) and curvature of the damage function $\left(\theta_{2}\right)$. Black boxes indicate the internal stability likelihood for the deterministic case. . . . 253

7.3 Potential internal stability likelihood and corresponding confidence intervals (whiskers) by coalitions for uncertainty in abatement costs (b1), global damages $\left(\theta_{1}\right.$-glo), regional damages $\left(\theta_{1}\right.$-reg) and curvature of the damage function $\left(\theta_{2}\right)$. Black boxes indicate the potential internal stability likelihood for the deterministic case. . . . . . . . . . . . . . . . . 2 . 256

7.4 Mean surplus relative to the absolute estimate in the deterministic case (ratio) and corresponding confidence intervals (whiskers) for uncertainty in abatement costs $\left(b_{1}\right)$, global damages $\left(\theta_{1}\right.$-glo $)$, regional damages $\left(\theta_{1}\right.$-reg $)$ and damage curvature $\left(\theta_{2}\right) \ldots \ldots \ldots \ldots \ldots \ldots \ldots \ldots \ldots \ldots$

7.5 Histogram of the realization of the abatement cost factor $k \ldots \ldots 268$

7.6 Histogram of the realization of $\theta_{1}$ in case of uncertainty in global damages for

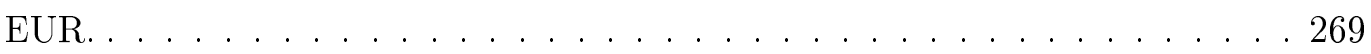

7.7 Histogram of the realization of $\theta_{1}$ in case of uncertainty in regional damages

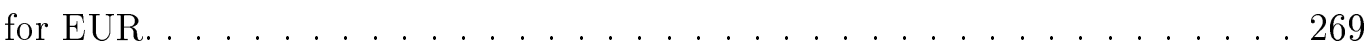

7.8 Histogram of the realization of $\theta_{2} \ldots \ldots \ldots \ldots \ldots$

8.1 Schematic representation of the planning procedure within the 2003 Federal Transportation Infrastructure Plan (adapted by the authors from Petry and

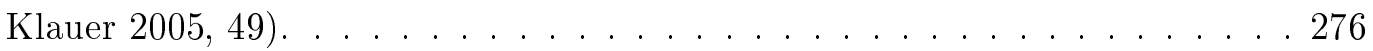

8.2 Results of the Monte-Carlo simulation of ecologically extended CBA ( $N=$ 10,000), with mean at dashed line. . . . . . . . . . . . . 286 


\section{List of Tables}

3.1 Descriptive statistics for the two case studies. . . . . . . . . . . . . 60

3.2 Elasticities of mean WTP with respect to mean income as well as relative and absolute income inequality for the model with relative income inequality (Equations $3.58,3.59$ ) and the model with absolute income inequality (Equations $3.74,3.78)$, with $i=\mathrm{SWE}, \mathrm{GLO} \ldots \ldots \ldots \ldots$. . . . . . . . 61

3.3 Changes in mean WTP for environmental public goods $\Delta \mu_{\mathrm{WTP}}^{i}$ in percent corresponding to the adjustment factors $\mathcal{T}$, with $\Delta \mu_{\mathrm{WTP}}^{i}=\mathcal{T}-1$, and $i=\mathrm{SWE}$ GLO . . . . . . . . . . . . . . . . . . . 6 64

4.1 Parameter values used in empirical application. . . . . . . . . . . . . . . . 112

4.2 Resulting transfer factors to correct WTP for differences in the distribution environmental local public good and income. . . . . . . . . . . . . 112

5.1 Overview of the four studied WTP cases. . . . . . . . . . . . . . . 148

5.2 Variable and parameter values used in the application . . . . . . . . 160

6.1 Sample statistics by country . . . . . . . . . . . . . . . 215

6.2 Mean differences in transfer errors (in percentage points) for pure and additional income inequality adjustment, $\Delta|T E|_{\mathcal{T}_{C V}}$ and $\Delta|T E|_{\mathcal{T}_{C V, \mu}}-\Delta|T E|_{\mathcal{T}_{\mu}} \cdot 219$

6.3 Transfer errors $|T E|$ (in percent) for unit transfer . . . . . . . . . . . 235

$6.4 \Delta|T E|_{\mathcal{T}_{C V}}=|T E|_{\mathcal{T}_{C V}}-|T E|_{\text {unit }}$ (in percentage points) $\ldots \ldots \ldots . \ldots 235$

$6.5 \Delta|T E|_{\mathcal{T}_{\mu}}=|T E|_{\mathcal{T}_{\mu}}-|T E|_{\text {unit }}$ (in percentage points) $\ldots \ldots \ldots \ldots . \ldots . . \ldots 235$

$6.6 \Delta|T E|_{\mathcal{T}_{C V, \mu}}=|T E|_{\mathcal{T}_{C V, \mu}}-|T E|_{\text {unit }}$ (in percentage points) . . . . . . 236

6.7 Transfer error changes for additional income inequality adjustment $\quad \Delta|T E|_{\mathcal{T}_{C V, \mu}}$

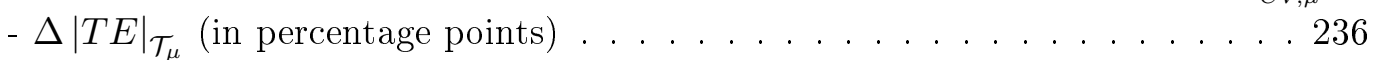

6.8 Transfer errors $|T E|$ summary statistics (in percent) $\ldots \ldots \ldots$. . . . . 236

6.9 Transfer errors $|T E|$ summary statistics (in percent) when also adjusting for differences in the level of the environmental good, $\tilde{E}^{c} \ldots \ldots 236$

7.1 Composition of the studied coalitions . . . . . . . . . . . . . . . 244

7.2 Distribution of $\theta_{1, i}$ for uncertainty in global and regional damages . . . . . . . 248

7.3 Overview on modelled uncertainties . . . . . . . . . . . . . . . . 250 
7.4 Summary statistics (mean [min; max]) for uncertain parameters in runs in which the OECD coalition is internally stable relative to means across all Monte-Carlo runs. . . . . . . . . . . . . . . . . . . . . . . 254

7.5 Correlations between the heterogeneity in abatement costs $\left(\mathrm{CV}_{\Lambda}\right)$ or damages $\left(\mathrm{CV}_{\Omega}\right)$ and coalition stability without transfers $(I S)$ and with transfers (surplus) . . . . . . . . . . . . . . . . . . . 259

7.6 Makeup of regions studied in the Model of International Climate Agreements 267

7.7 Summary statistics of the surplus distributions - by coalition and scenario . . 271

8.1 Original and ecologically extended cost-benefit analysis, present values in mil-

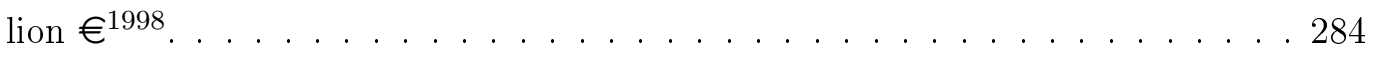


Part I

\section{Introduction}




\section{Nature Conservation and Equity}

"Environmental degradation is everyone's problem, but it's especially a problem for the poor." - Joseph E. Stiglitz (2012: 36)

At the beginning of the 21st century, societies face two fundamental challenges, among others: First, the loss of biodiversity and many ecosystem functions is widespread and accelerating. Second, the distribution of economic resources within societies is becoming increasingly unequal. For policy-making aiming at both sustainability and hence distributive justice, as well as at economic efficiency in attaining this normative goal both challenges are interlinked. The distribution of both income and environmental goods may affect the value a society attaches to nature, while nature conservation policies but also political inactivity generally change the allocation of resources in society. Against this backdrop, my thesis aims at developing and testing economic methods to understand and account for distributional aspects in the context of nature conservation.

The mounting evidence that current economic activities are unsustainable has sparked my personal interest in economics as a field of study a decade ago. My own research efforts, cumulating in this thesis, are driven by a strong concern that the prevailing high rates of biodiversity and ecosystem service losses are neither just nor efficient. Thereby, I see my research guided by the normative vision of sustainability, understood as justice within and across generations of human beings as well as justice towards nature (Baumgärtner and Quaas 2010). While the concepts of intra- and intergenerational justice reflect an anthropocentric notion of sustainability, assigning an instrumental value to nature, the normative goal of justice towards nature encompasses nature conservation for its own sake, acknowledging nature's intrinsic value. ${ }^{1}$

\footnotetext{
${ }^{1}$ The famous and widely accepted definition of sustainable development from the Brundlandt-Report reflects an anthropocentric idea of sustainability that focusses on satisfying current and future human needs and wants: "Sustainable development is development that meets the needs of the present without compromising the ability of future generations to meet their own needs" (WCED 1987: 41). In the Convention of
} 
The loss of biodiversity is widespread and at alarmingly high rates. Species extinction and habitat losses have accelerated over the past four decades, while at the same time pressures on biodiversity have continued to increase (Butchart et al. 2010). Since the beginning of the industrial revolution human activity has altered processes in the natural environment so fundamentally that geologist see a new epoch of earth history, the 'Anthropocene' (Crutzen 2002). Human activity has already pushed the planet's biophysical system over several critical thresholds, most pronounced being the loss of biodiversity measured by the rate of species extinction (Rockström et al. 2009). As a consequence, many goods and services humans derive from functioning ecosystems underpinned by biodiversity are in decline (MEA 2005). Since 2017 also public concerns about biodiversity loss gained some momentum in several European countries (e.g. DIE ZEIT 2017a,b), fuelled by a study on substantially declining insect abundance in German protected areas (Hallmann et al. 2017). ${ }^{2}$

Nature's contributions to human well-being are manifold, but not adequately reflected in market prices. Many benefits people derive from nature - often referred to as ecosystem services (MEA 2005) or nature's contributions to people (Pascual et al. 2017) - have public good characteristics. Consequently, market prices fail to appropriately represent the economic value of most ecosystem services (OECD 2018), and decentralised market forces tend to create a world with evermore abundant manufactured goods but a diminishing variety of natural life. Current regulation, in which the implicit price for many ecosystem services is often close to zero, does not reflect that over the last decades the world has become a place where the natural environment is no longer plentiful. As long as nature was relatively abundant and human activity was relatively low, this might have set desired incentives for societal development (cf. Daily et al. 2000). However, as nature is becoming relatively scarce setting price signals that appropriately reflect trade-offs becomes vital. To top it off, the prices of a "cowboy economy" (Boulding 1966: 7) are probably the wrong prices for the Anthropocene. ${ }^{3}$ Pricing or valuing nature needs to be done, applied and communicated

Biological Diversity adopted a few years later the states of the world also highlight nature's value independent of humans. The very first words of the convention read "[c]onscious of the intrinsic value of biological diversity" (UN 1992: 1).

${ }^{2}$ While public concerns recently got momentum, biodiversity loss gathered public attention before. For instance, Rachel Carson's (1962) book 'Silent Spring' brought concerns about the effect of pesticide use on the natural environment to the American public and inspired the environmental movements in the 1960s and 1970s.

${ }^{3}$ In a by now seminal contribution Boulding (1966) argues that there is no longer something like a frontier of human activity, beyond which an infinite natural environment waits. For centuries natural sources and sinks were perceived as infinite, and the mode of a "cowboy economy", in which throughput of natural resources meant success, was reasonable. However, as sources and sinks became limited, today's economies are closed rather than open systems. This requires a fundamental paradigm shift: in such a "space ship economy" stock maintenance rather than throughput maximization becomes crucial. 
carefully to avoid 'selling out' nature - a danger that comes along with the substitutability of nature or weak sustainability suggested by monetary values. Despite these caveats, expressing nature's benefits in monetary terms can be worthwhile - as one tool among others - to inform public decision making and policy instrument design about the opportunity costs associated with environmental consequences, or as the OECD (2018: 37) coins it "[u]ncovering the true value of goods [...] to ensure decisions contribute to improving human well-being is a defining rational for economics analysis".

There is a range of reasons for nature conservation and people hold diverse values for nature. These values depend on peoples preferences as well as on cultural and institutional contexts (e.g. Pascual et al. 2017). Nature may have an intrinsic or universal value independent of humans. Human activity towards nature might be valued by whether it is morally good or bad, for instance by principles of an Kantian ethic, or by judging the process rather than the outcome of a human-nature interaction. Beyond this, nature also holds instrumental values for humans. The value nature has as a means to satisfy human ends, by definition depends on human objectives. Following the utilitarian ethic underlying modern economics, the economic value of nature is given by its contribution to the objective of maximising human well-being. Economic valuation thereby maps the consequences of different actions for human well-being into a comparable unit. This allows to inform policy making that faces trade-offs between competing uses of scarce resource, such as land or public finance. While the right level of nature conservation and the choice of policy instruments is ultimately up to public deliberation and the political process, figures on economic cost and benefits might inform societal decision making. The research presented in this thesis focusses on the benefits nature offers to humans, being conscious of non-anthropocentric values, other ethical approaches and alternative inputs to societal decision making. Put another way, the presented research is concerned with economic arguments for nature conservation.

Environmental economics developed as an academic field and subdisciplin of public economics parallel to the environmental movements in the 1960 and 1970s. Up to now environmental economics has mostly been concerned with the development of policy instruments to attain efficiency or cost-effectiveness. To this end, environmental valuation aims at measuring the value of environmental goods in units of market-traded consumption goods and thus money in order to inform optimal decision-making or efficient policy instrument design, often with the aim of internalising externalities. However, policy makers and the wider public are frequently more concerned with equity than with efficiency (c.f. Phaneuf and Requate 
2017: 716). I hope the work in this thesis ultimately contributes towards the development of environmental economic methods that are not only concerned with efficiency, but also with distributive justice. In this sense, this thesis adds to the emerging field of 'sustainability economics' (Baumgärtner and Quaas 2010, Drupp 2017), by studying how the interand intragenerational distribution affects the efficient allocation of resources. Beyond this my thesis adds to various strands of economic research, in particular to environmental and resource economics, ecological economics and public economics.

Nature degradation and environmental inequalities interplay with economic inequalities. Over the last four decades, human-made goods and services became increasingly unequally distributed in most parts of the world. Since 1980, there have been sharp increases in income inequality in North America, China, India, Russia and to a moderate extend also in Europe (Alvaredo et al. 2018). Rising economic inequalities in OECD countries (OECD 2016, Stiglitz et al. 2010), might thereby mark the end of the postwar egalitarian regimes (Piketty 2014). Nature degradation is deemed to be in particular a problem for the poor (Stiglitz 2013), but economic inequalities might also be a problem for nature. Inequalities tend to erode social cohesion and thereby adversely affect the management of public environmental goods or common pool resources, for instance through deteriorating social capital (cf. Ostrom 2009). Societies that are more equal tend to hold a higher value and demand for nature conservation (Stiglitz 2013), which might in turn reduce economic inequalities. Moreover, the goods and services people derive from nature and conversely the effects of environmental degradation are themselves potentially unevenly distributed and this might correlate with the distribution of economic resources. For instance, in the U.S. industrial air pollution has been found to be more unequally distributed than income (Boyce et al. 2016) and frequently lower income households have a greater exposure to environmental pollution (Ash and Fetter 2004, Heblich et al. 2016). Also within their Strategic Plan for Biodiversity the states of the world acknowledge the incidence of nature degradation: "While the harshest impacts will fall on the poor, [...] no-one will be immune from the impacts of the loss of biodiversity" (UNEP 2010: 7).

A considerable part of this thesis is devoted to the effect of inequalities when inferring societal values from individual values. Aggregating individual values to obtain societal values is an integral part of each environmental valuation exercise. As such environmental valuation touches upon "some of the oldest problems in economics: revealing and aggregating preferences" (Daily et al. 2000: 396). The presented research studies how inequalities 
affect societal willingness to pay (WTP) within the standard cost-benefit analysis (CBA) approach, that is simply summing up all individual WTPs (OECD 2018). In this sense I study a purely statistical effect of inequalities when aggregating WTPs, without altering the normative decision of weighting all individuals' WTPs equally. Beyond this 'aggregation effect' of inequality on the societal value of nature there are certainly several other channels through which inequalities affect societal values of nature, some of which are discussed in the subsequent Chapter 2.

I believe that studying the nexus of inequality and environmental valuation is a societally valuable endeavour. Firstly, environmental values are powerful when they inform or even determine decision-making. In particular, environmental values (i) are applied in social costbenefit analysis, for instance in the transportation sector (OECD 2018); (ii) determine the level of price instruments, for instance water prices under the European Water Framework Directive (NDS 2013); (iii) are increasingly included when monitoring societal development, for instance in natural capital accounting (UN et al. 2014); and (iv) can be a bases to estimate liabilities in judicial decision making, prominent examples being the U.S. lawsuits on the Exxon Valdez or the BP oil spill (Bishop et al. 2017). In these cases it is relevant for policy to understand how the monetary figures depend on the prevailing distribution and to enable the use of inequality-corrected estimates. In words of the Stiglitz-Sen-Fitoussi Commission on the Measurement of Economic Performance and Social Progress "[w] hat we measure affects what we do; and if our measurements are flawed, decisions may be distorted" (Stiglitz et al. 2010: 7). Secondly, the benefits of biodiversity and their distribution are central for the public perception and political economy of conservation policies. Public debates are often dominated by concerns about the cost of specific environmental policies and how they are distributed across social groups. Therefore, various actors have increasingly stressed the (economic) benefits of nature conservation, for instance the EU Commission repeatedly communicated the economic benefits of the Natura 2000 sites (European Commission 2013). Beyond total numbers, it might be instructive to also understand and communicate how the non-market benefits of biodiversity conservation are distributed.

This thesis consists of seven independent research papers, ${ }^{4}$ which are grouped in three parts. Part I, titled Introduction, is rounded off by Chapter 2, which sets the scene and sketches out the research program on economic inequality and environmental valuation. Part II, titled Theory, develops three theoretical approaches on how the economic value

\footnotetext{
${ }^{4}$ Except for assigning unique numbers to figures, tables, sections, footnotes and so on, presentations in the chapters correspond to the original research papers wherever appropriate.
} 
society attaches to nature is affected by the distribution of income or the provision of environmental goods within or across generations. Chapter 3 studies how society's willingness to pay (WTP) for public environmental goods depends on the intragenerational distribution of income. Chapter 4 adds the dimension of environmental inequality by studying how the distribution of environmental amenities with local public good affects societal WTP. Chapter 5 extends these to the intergenerational distribution by studying how income growth and the rate of environmental degradation affects society's WTP. Part III, titled Applications, turns to three prominent fields of environmental valuation. Chapter 6 studies whether accounting for income inequality can improve the transfer of environmental values from a study context to a policy context. Chapter 7 studies how uncertainty affects the distribution of benefits and cost of climate change mitigation among world regions within a regionalized integrated assessment framework. Finally, Chapter 8 provides a case study on how environmental values could be used in environmental cost-benefit analysis to inform infrastructure planning.

In the following I briefly present each chapter and report its publication status. ${ }^{5}$

Chapter 2, titled Economic Inequality and the Value of Nature, discusses how economic inequality affects the value society attaches to nature. We argue that from a sustainability perspective, economic valuation should not only seek to determine society's willingness to pay (WTP) for environmental goods to devise an efficient allocation of scarce resources, but should also account for distributional effects to ensure justice. Yet, we find that how economic inequality affects the value of non-market environmental goods remains understudied. Focussing on standard economic valuation approaches and inequality in income this Chapter reviews the sparse existing literature on the nexus of inequality and valuation, discusses implications for environmental valuation, management and policy-making and identifies a number of fruitful areas for future research.

In particular, we can derive some fist conclusions on the benefit incidence of nature conservation policies. It is well known that the distributional effects of nature conservation are determined by the income elasticity of WTP (Ebert 2003, Flores and Carson 1997, Kriström and Riera 1996). The vast majority of existing valuation studies that report income elasticities of WTP finds that the income elasticity of WTP is below unity. In this case the non-market benefits of nature conservation are distributed in favour of poor households. We conclude that encompassing assessments of the distributional effects of environmental

\footnotetext{
${ }^{5}$ The summaries of Chapters 2-8 heavily borrow from the chapters and in particular their abstracts.
} 
policies should consider the distribution of non-market environmental benefits.

Chapter 2 is joined work with Moritz Drupp, Stefan Baumgärtner and Martin Quaas. It has been published in Ecological Economics (Drupp et al. 2018).

Chapter 3, titled Income Inequality and Willingness to Pay for Environmental Public Goods, studies how the distribution of income affects the societal value of environmental public goods. To this end the chapter presents a novel model, in which households have identical preferences over a consumption good and an environmental public good represented by a constant-elasticity-of-substitution utility function and differ in log-normally distributed income. One key contribution of this chapter is to relate the effect of income inequality to the substitutability of environmental goods. Subsequent chapters extent this model framework for local public goods (Chapter 4), the management of natural capital (Chapter 5) or test the implications for benefit transfer empirically (Chapter 6).

We show that societal willingness to pay (WTP) for environmental goods decreases (increases) with income inequality if and only if environmental goods and manufactured goods are substitutes (complements). Moreover, we derive theory-driven adjustment factors for benefit transfer to control for differences in income distributions between a study site and a policy site. For illustration, we quantify how societal WTP for environmental public goods depends on the respective income distributions for empirical case studies in Sweden and the World at large. We find for the case of global biodiversity conservation that income inequality adjustment increases societal WTP by up to 16 percent depending on society's preferences for equity.

Chapter 3 is joined work with Stefan Baumgärtner, Moritz Drupp, Jan Munz and Martin Quaas. It has been published in the Journal of Environmental Economics and Management (Baumgärtner et al. 2017a).

Chapter 4, titled Environmental Inequality and Economic Valuation, studies how the joint distribution of environmental goods and income - and in particular environmental inequality - affects the valuation of local public goods. As the majority of environmental goods considered in non-market valuation are unevenly distributed over households, it is crucial to extend the model developed in Chapter 3 to local public environmental goods. Therefore, I build on and extend the pure public good model by assuming environmental goods are provided heterogeneously among members of a society approximated by a lognormal distribution. This enriches the analysis by the dimension of environmental inequality and by how this interplays with the distribution of income. 
I find that the effect of environmental inequality on societal willingness to pay (WTP) for environmental local public goods is determined by their substitutability as well as how their provision is correlated with income. Moreover, I show that sorting of richer households into places with higher levels of the environmental good increases (decreases) societal WTP if and only if it is a substitute (complement) to manufactured consumption goods. I obtain novel closed-form adjustment factors for benefit transfer to control for differences in the distribution of environmental local public goods. An empirical illustration for forest preservation in Poland shows that societal WTP is up to 4 percent higher for an equal access to forest and up to 8 percent higher for an equal distribution of both income and access to forests.

Chapter 4 is a single-authored paper. It is accepted for presentation at BIOECON 2018.

Chapter 5, titled Inter- and Intragenerational Distribution and the Valuation

of Natural Capital, studies how the intra- and intertemporal distribution of income and environmental scarcity affect the economic valuation of non-use environmental public goods derived from natural capital. Therefore, we generalize the static model presented in Chapter 3 to an intertemporal setting. We focus on non-use environmental services, such as the existence value of biodiversity. We assume income to be log-normally distributed in each period and a time-constant relative income inequality. To focus the model on valuation, we consider exogenously given time paths of income and the environmental good, and specifically study their exponential growth and decline. To allow for closed-form solutions, we make a restrictive assumption on how the elasticity of substitution between the environmental good and consumption goods relates to the intertemporal elasticity of substitution. In this model we study WTP for two different payment types (a single payment in the initial period or constantly paid fraction of income) and for two different marginal changes to the provision of the environmental public good (level or growth rate).

We show that societal mean WTP for natural capital decreases (increases) with intragenerational income inequality if environmental goods derived from natural capital and consumption goods are substitutes (complements). We further find that the intergenerational distribution affects the intertemporal valuation of environmental goods derived from natural capital. Specifically, societal WTP elicited as a constant payment fraction increases with income growth for complements or the Cobb-Douglas case. However, it is possible that WTP declines with income growth in the case of substitutes. Moreover, we show that societal WTP increases (decreases) with the growth rate of environmental goods if and only 
if environmental goods are a substitute (complement) to manufactured goods. Finally, we obtain closed-form adjustment factors for benefit transfer to control for differences in dynamic aspects between study and policy sites, such as income growth, the growth rate of the environmental goods, and interest rates. We illustrate and quantify the effect sizes of our results for a global case study on the intertemporal valuation of non-use environmental goods derived from biodiversity. The application reveals that in particular the substitutability of environmental goods and the intergenerational distribution substantially affect the societal value of natural capital.

Chapter 5 is joined work with Moritz Drupp, Stefan Baumgärtner and Martin Quaas. It was presented and appeared as a conference paper at SURED 2018 and WCERE 2018 (Meya et al. 2018a).

Chapter 6, titled Income Inequality and the International Transfer of Environmental Values, studies empirically whether accounting for income inequality can improve one of the most frequently used methods for non-market valuation: benefit transfer. Specifically, we apply theory-driven, structural transfer factors developed in Chapter 3 to systematically examine whether adjusting for income inequality affects errors made in the international transfer of environmental values. Thereby, we draw on a multi-country valuation study on water quality improvement in the Baltic Sea. We find this study to offer a unique test-bed for our theory-driven approach as the contingent valuation study employed the same survey instruments across countries with substantial differences in income distributions for a well-defined change in environmental quality that has region-wide public good characteristics. This multi-country valuation study thereby offers the possibility to compare hypothetically transferred WTPs with the actual primary valuations.

We find that income inequality adjustment decreases transfer errors by more than 1.5 percentage points on average and that income inequality adjustment becomes particularly relevant when income is more unequally distributed at the policy relative to the study site. Even though adjustment for income inequality is of second-order compared to adjusting for the level of mean income, our study shows that accounting for income inequality can further improve benefit transfers and that its application is straightforward. We show that this main finding is robust to considering a number of model variations. Finally, we show that a naive transfer adjustment for income inequality would increase benefit transfer errors, emphasizing the importance of employing structural theory-driven factors.

Chapter 6 is joined work with Moritz Drupp and Nick Hanley. It was presented at 
EAERE 2017, BIOECON 2017 and WCERE 2018, and a former version appeared as a Kiel Economics Working Paper (Meya et al. 2017).

Chapter 7, titled How Empirical Uncertainties Influence the Stability of Climate

Coalitions, focusses on another key challenge of sustainability: the inherent uncertain future. We study the effect of parametric uncertainty on the distribution of payoffs within international climate agreements in the Model of International Climate Agreements (MICA) using the technique of Monte-Carlo analysis. We extend previous studies to draw a more comprehensive picture of the effect of uncertainty on coalition stability. Firstly, we improve the numerical representation by calibrating parametric uncertainty about abatement costs and climate damages to evidence from meta-studies. A robust comparison of the magnitude of effects is thereby made possible. Secondly, we consider uncertainty not only about the level of damages but also regarding the curvature of the damages function, which reflects their sensitivity to temperature increase.

We find that the stability likelihood of coalitions is mainly driven by uncertainty about damages through various determinants. Firstly, stability is more affected by uncertainty about damages compared to uncertain abatement costs, and mostly affected by uncertainty about the interregional distribution of damages. Secondly, transfers become an important instrument when there is uncertainty about the distribution of damages. Our scenarios show that stability is sensitive to uncertainty when no transfers between regions are allowed, but that the availability of transfers increases the robustness of stability under uncertainty. Each realization of climate change damages produces distinct winners and losers within the coalition. With transfers as an additional policy instrument, worse-off regions can be compensated to remain in the coalition by winners that experience larger gains, i.e. adverse effects of the realizations of uncertainty are shared within coalitions. Lastly, we present scenarios in which uncertainty about the curvature of damages has a positive effect on stability. A higher sensitivity of damages towards a temperature increase tends to increase stability. Steeper damages resemble a critical threshold, which is known to improve the incentives to cooperate.

Chapter 7 is joined work with Ulrike Kornek and Kai Lessmann. It has been published in International Environmental Agreements: Politics, Law and Economics (Meya et al. 2018b). In a subsequent empirical study Klaus Eisenack and I have tested the effectiveness of a simulation game that conveys several key features of such a regionalized integrated assessment model to a playable game interface (Meya and Eisenack 2018). Drawing on a sample of two 
hundred students we present quantitative evidence on the effectiveness of gaming for communicating and teaching international climate politics using the board game KEEP COOL. In particular, we find that well-designed climate games can facilitate experiential learning on both difficulties and necessities of international climate cooperation and argue that effective game design does not require climate-friendly in-game behaviour as a winning condition.

Chapter 8, titled Ecosystem Services in Infrastructure Planning, is arguably the most applied research paper presented in this thesis. It studies whether considering environmental values in social cost-benefit analysis (CBA) actually matters for the largest field of applied CBA in Germany: federal transportation infrastructure planning. In OECD countries most investment in transportation infrastructure are subject to CBA (OECD 2018) and transportation projects are often associated with large environmental impacts. We conduct a case study for the projected deepening of the Lower Weser river, in which we recalculate the project's benefit-cost ratio by integrating the monetary value of changes in different ecosystem services. We find the Weser river to be a particular interesting case for several reasons: estuaries are characterised by high levels of economic activity and ecosystem functions; the Lower Weser deepening was the principle case to debate the no-deterioration rule of the European Water Framework Directive at the European Court of Justice; and the Lower Weser deepening is assessed to have the highest cost-benefit ratio of water infrastructure projects within the federal transportation infrastructure plan.

We find that by integrating the values of two major ecosystem service changes, namely, the loss of 'fresh water supply for agricultural production' in the Wesermarsch region and the loss of 'habitat and gene pool protection services' in the bio-diverse river estuary, the benefitcost ratio drops sharply (from $26: 1$ to $2: 1$ ). We conclude that ecosystem service losses can be economically substantial compared to other non-environmental project outcomes and that integrating ecosystem services into the infrastructure planning process might substantially alter outcomes.

Chapter 8 is joined work with Nils Droste. It has been published in the Journal of Environmental Planning and Management (Droste and Meya 2017). An earlier German version of this Chapter served as an expert review in the juridical process on the Lower Weser river deepening at the Federal Administrative Court. Shortly, after this Chapter was submitted for publication, the German federal government adopted a new transportation infrastructure plan - the 'Bundesverkehrswegeplan [BVWP] 2030' - that prioritizes infrastructure projects until 2030. In a subsequent article, Nils Droste, Bernd Klauer and I critically reviewed the 
updated methodological guidelines for CBA and the resulting project prioritization (Meya et al. 2016). It shows that the BVWP 2030 still insufficiently accounts for environmental impacts of transport infrastructure projects. ${ }^{6}$ Reforms to facilitate more complete welfare assessments could happen along two lines (Meya et al. 2016): (i) a cost-benefit analysis in which environmental costs are included as fully as possible in monetary terms, or (ii) an upgrading and systematic inclusion of the environmental and nature conservation assessment, so that these also affect the project prioritization.

Overall, my thesis concludes that the distribution of economic and natural resources within and across generations considerably affects the economic value that societies attach to nature. It is therefore important to consider distributional aspects when carrying out economic analyses in the context of nature conservation and environmental protection, and this dissertation develops several methodological proposals on how this can be done. In this way, my dissertation also contributes to the development of economic methods that not only aim for efficiency, but also for equity, and are thus in line with the normative vision of sustainability. I hope that, despite all the pitfalls and risks of assigning monetary values to nature, emphasising nature's contributions to human well-being can contribute to finding fairer and more efficient societal choices in a world that is rapidly reaching its biophysical limits. I would be more than pleased if this dissertation, with the methods and economic arguments for nature conservation developed here, could ultimately make a small contribution to protecting the variety of our natural environment.

\footnotetext{
${ }^{6}$ Germany's transportation planning therefore fails to implement national commitments under the Convention on Biological Diversity (Achi Target 2) according to which "[b]y 2020, at the latest, biodiversity values have been integrated into national [...] planning processes" (UNEP 2010: 8).
} 


\section{Bibliography}

Alvaredo, F., Chancel, L., Piketty, T., Saez, E., Zucman, G. (2018), World Inequality Report 2018. World Inequality Lab, available online at: http://wir2018.wid.world.

Ash, M. and Fetter, T.R. (2004), Who Lives on the Wrong Side of the Environmental Tracks? Evidence from the EPA's Risk-Screening Environmental Indicators Model. Social Science Quarterly, 85(2), 441-462.

Baumgärtner, S., Drupp, M.A., Munz, J., Meya, J.N. and Quaas, M.F. (2017), Income inequality and willingness to pay for environmental public goods. Journal of Environmental Economics and Management, 85, 35-61.

Baumgärtner, S. and Quaas, M.F. (2010), What is sustainability economics? Ecological Economics, 69(3), 445-450.

Bishop, R. C., Boyle, K. J., Carson, R. T., Chapman, D., Hanemann, W. M., Kanninen, B., Kopp, R. J., Krosnick, J.A., List, J., Meade, N., Paterson, R., Presser S., Smith, K. S., Tourangeau, R., Welsh, M., Woodridge, J. M., DeBell, M., Donovan, C., Konopka, M., Sherer, N (2017), Putting a value on injuries to natural assets: The BP oil spill. Science 356(6335): 253-254.

Boulding, K.E. (1966), The Economics of the Coming Spaceship Earth. In: H. Jarrett (ed.), Environmental Quality in a Growing Economy, 3-14. Baltimore, MD: Resources for the Future, Johns Hopkins University Press.

Boyce, J.K., Zwickl, K., and Ash, M. (2016), Measuring environmental inequality. Ecological Economics, 124, 114-123.

Butchart, S., Walpole, M., Collen, B., van Strien, A., Scharlemann, J., Almond, R., Baillie, J., Bomhard, B., Brown, C., Bruno, J., Carpenter, K., Carr, G., Chanson, J., Chenery, A., Csirke, J., Davidson, N., Dentener, F., Foster, M., Galli, A., Galloway, J., Genovesi, 
P., Gregory, R., Hockings, M., Kapos, V., Lamarque, J.-F., Leverington, F., Loh, J., McGeoch, M., McRae, L., Minasyan, A., Morcillo, M., Oldfield, T., Pauly, D., Quader, S., Revenga, C., Sauer, J., Skolnik, B., Spear, D., Stanwell-Smith, D., Stuart, S., Symes, A., Tierney, M., Tyrrell, T., Vié, J.-C., and Watson, R. (2010), Global biodiversity: Indicators of recent declines. Science, 328(5982), 1164-1168.

Crutzen, P.J. (2002), Geology of mankind. Nature, 415(6867), 23.

Daily, G.C., Söderqvist, T., Aniyar, S., Arrow, K., Dasgupta, P., Ehrlich, P.R., Folke, C., Jansson, A., Jansson, B.-O., Kautsky, N., Levin, S., Lubchenco, J., Mäler, K.-G., Simpson, D., Starrett, D., Tilman, D., Walker, B.(2000), The Value of Nature and the Nature of Value. Science, 289(5478), 395-396.

DIE ZEIT (2017a), "Ein ökologisches Armageddon". ZEIT ONLINE, 18.10.2017. https://www.zeit.de/wissen/umwelt/2017-10/insektensterben-fluginsekten-gesamtmasserueckgang-studie

DIE ZEIT (2017b), Die Wahrheit auf sechs Beinen. Ausgabe Nr. 44/2017, 26.10.2017.

Droste, N. and Meya, J.N. (2017), Ecosystem services in infrastructure planning - a case study of the projected deepening of the Lower Weser river in Germany. Journal of Environmental Planning and Management, 60(2), 231-248.

Drupp, M.A. (2017), Essays in Sustainability Economics: Economic Distribution and Valuation, Environmental Scarcity, and Ethical Behavior, Doctoral dissertation, ChristianAlbrechts Universität Kiel.

Drupp, M.A., Meya, J.N., Baumgärtner, S. and Quaas, M.F. (2018), Economic Inequality and the Value of Nature. Ecological Economics, 150, 340-345.

Ebert, U. (2003), Environmental goods and the distribution of income, Environmental and Resource Economics, 25(4), 435-459.

European Commission (2013), The economic benefits of the Natura 2000 network. Synthesis report. Luxembourg: Publications Office of the European Union, 74pp.

Flores, N.E., and Carson, R.T. (1997), The relationship between the income elasticities of demand and willingness to pay. Journal of Environmental Economics and Management, $33(3), 287-295$. 
Hallmann, C.A., Sorg, M., Jongejans, E., Siepel, H., Hofland, N., Schwan, H., Stenmans, W., Müller, A., Sumser, H., Hörren, T., Goulson, D., de Kroon, H. (2017), More than 75 percent decline over 27 years in total flying insect biomass in protected areas. PLoS ONE, 12(10): e0185809.

Heblich, S., Trew, A., and Zylberberg, Y. (2016), East Side Story: Historical Pollution and Persistent Neighborhood Sorting. University of St. Andrews, School of Economics and Finance. Discussion Paper No. 1613.

Kriström, B., and Riera, P. (1996), Is the income elasticity of environmental improvements less than one? Environmental and Resource Economics, 7(1), 45-55.

[MEA 2005] Millennium Ecosystem Assessment (2005), Ecosystems and human well-being: Biodiversity synthesis, World Resources Institute, Washington, DC.

Meya, J.N., Droste, N. and Klauer, B. (2016), Methodische Defizite der Umweltbewertung im Bundesverkehrswegeplan 2030. WasserWirtschaft, 10, 57-58.

Meya, J.N., Drupp, M.A., and Hanley, N. (2017), Income inequality and the international transfer of environmental values. Kiel Economics Working Paper, No 2017-03.

Meya, J.N., Drupp, M.A., Baumgärtner, S., and Quaas, M.F. (2018), Inter- and Intragenerational Distribution and the Valuation of Natural Capital. Conference paper at WCERE 2018: http://fleximeets.com/wcere2018/getpaper.php?fid=3377

Meya, J.N. and Eisenack, K. (2018), Effectiveness of gaming for communicating and teaching climate change. Climatic Change, accepted. DOI: 10.1007/s10584-018-2254-7

Meya, J.N., Kornek, U., and Lessmann, K. (2018), How empirical uncertainties influence the stability of climate coalitions. International Environmental Agreements: Politics, Law and Economics. 18(2), 175-198.

[NDS] Niedersächsisches Ministerium für Umwelt, Energie und Klimaschutz (2013), Ökonomische Elemente der Europäischen Gewässerschutzpolitik: Umsetzung und Herausforderungen in Niedersachsen. Niedersächsisches Ministerium für Umwelt, Energie und Klimaschutz. Referat Kommunikation, Presse, Öffentlichkeitsarbeit. Hannover.

OECD (2016), Income inequality remains high in the face of weak recovery. https://www.oecd.org/social/OECD2016-Income-Inequality-Update.pdf . 
OECD (2018), Cost-benefit analysis and the environment: further developments and policy use, OECD Publishing, Paris.

Ostrom, E.(2009), A general framework for analyzing sustainability of social-ecological systems. Science, 325(5939), 419-422.

Pascual, U., Balvanera, P., Díaz, S., Pataki, G., Roth, E., Stenseke, M., Watson, R.T., Dessane, E.B., Islar, M., Kelemen, E., Maris, V., Quaas, M.F., Subramanian, S.M., Wittmer, H., Adlan, A., Ahn, S., Al-Hafedh, Y.S., Amankwah, E., Asah, S.T., Berry, P., Bilgin, A., Breslow, S.J., Bullock, C., Cáceres, D., Daly-Hassen, H., Figueroa, E., Golden, C.D., Gómez-Baggethun, E., González-Jiménez, D., Houdet, J., Keune, H., Kumar, R., Ma, K., May, P.H., Mead, A., O’Farrell, P., Pandit, R., Pengue, W., Pichis-Madruga, R., Popa, F., Preston, S., Pacheco-Balanza, D., Saarikoski, H., Strassburg, B.B., van den Belt, M., Verma, M., Wickson, F., and Yagi, N. (2017), Valuing nature's contributions to people: the IPBES approach. Current Opinion in Environmental Sustainability, 26, 7-16.

Phaneuf, D.J. and Requate, T. (2017), A Course in Environmental Economics: Theory, Policy, and Practice, Cambridge University Press.

Piketty, T. (2014), Capital in the Twenty-First Century, Cambridge, MA: The Belknap Press of Harvard University Press. University College London.

Rockström, J., Steffen, W., Noone, K., Persson, A., Chapin III, F., Lambin, E.F., Lenton, T.M., Scheffer, M., Folke, C., Schellnhuber, H.J., Nykvist, B., de Wit, C.A., Hughes, T., van der Leeuw, S., Rodhe, H., Sörlin, S., Snyder, P.K., Costanza, R., Svedin, U., Falkenmark, M., Karlberg, L., Corell, R.W., Fabry, V.J., Hansen, J., Walker, B., Liverman, D., Richardson, K., Crutzen, P., Foley, J.A., A safe operating space for humanity. Nature, $461,472-475$.

Stiglitz, J.E., Sen, A., and Fitoussi, J.P. (2010), Report by the Commission on the Measurement of Economic Performance and Social Progress. Paris: Commission on the Measurement of Economic Performance and Social Progress.

Stiglitz, J.E. (2013), Inequality and Environmental Policy. Resources for the Future, 36-40. http://www.rff.org/research/publications/inequality-and-environmental-policy .

United Nations (1992), Convention on Biological Diversity. https://www.cbd.int/doc/legal/cbd-en.pdf . 
United Nations, European Commission, Food and Agriculture Organization of the United Nations, Organisation for Economic Co-operation and Development, World Bank Group (2014), System of Environmental-Economic Accounting 2012-Experimental Ecosystem Accounting, New York: United Nations.

UNEP (2010), The strategic plan for biodiversity 2011-2020 and the aichi biodiversity targets. Document UNEP/CBD/COP/DEC/X/2. Secretariat of the Convention on Biological Diversity, Nagoya, Japan.

[WCED] World Commission on Environment and Development (1987), Our Common Future. Oxford University Press, New York. 


\title{
2 Economic Inequality and the Value of Nature
}

\begin{abstract}
Understanding what influences the value of nature is crucial for informing environmental policy. From a sustainability perspective, economic valuation should not only seek to determine a society's willingness to pay for environmental goods to devise an efficient allocation of scarce resources, but should also account for distributional effects to ensure justice. Yet, how economic inequality affects the value of non-market environmental goods remains understudied. Combining recently developed theoretical results with empirical evidence, this Commentary shows that more equal societies have a higher valuation for environmental public goods and that non-market benefits of environmental policy accrue over-proportionally to poorer households. On this ground, we discuss implications for environmental valuation, management and policy-making and identify a number of fruitful areas for future research. We conclude that environmental valuation should explicitly account for economic inequality, and that encompassing assessments of the distributional effects of environmental policies must consider the distribution of non-market environmental benefits.
\end{abstract}

Keywords: distribution; environmental goods; income inequality; nature conservation; valuation; willingness to pay

Reference: Drupp, M.A., Meya, J.N., Baumgärtner, S. Quaas, M.F. (2018). Economic inequality and the value of nature, Ecological Economics, 150: 340-345.

This is a pre-print of an article published in Ecological Economics. The final authenticated version is available online at: https://doi.org/10.1016/j.ecolecon.2018.03.029. 


\subsection{Introduction}

Appropriately representing the value of non-market environmental goods or ecosystem services in societal decision-making poses a fundamental challenge for ecological and environmental economics. ${ }^{7}$ Accordingly, approaches to value nature's contributions to people are diverse and abound (Pascual et al. 2017). Most valuation studies follow the standard economic approach of capturing the economic value individuals attach to environmental goods by eliciting their willingness to pay (WTP) for the provision of environmental goods by use of stated or revealed preference methods, ${ }^{8}$ and then summing up individual WTPs over all members of society. ${ }^{9}$ As values for environmental goods are increasingly applied to inform regulatory or judicial decision-making (Atkinson and Mourato 2008; Bateman et al. 2013; Bishop et al. 2017), the step of aggregating individual values needs more thorough reflection.

Ecological Economics as a school of thought is not only oriented towards economic efficiency but also aims at sustainability and thus distributive justice (Costanza 1989; Baumgärtner and Quaas 2010). Therefore, the nexus of environmental valuation and economic inequality deserves particular attention. Beyond methodological concerns, it is timely to consider these two issues intertwined, as on the one hand the loss of environmental goods is widespread and accelerating (Butchart et al. 2010; Pimm et al. 2014; MEA 2005), and on the other hand concerns about economic inequalities are becoming more prevalent in science, policy and society (Stiglitz et al. 2012; Piketty 2014; OECD 2016; IMF 2017). However, with few notable exceptions, valuation studies largely ignore issues of economic distribution, even though it is known that the inequality of income or wealth may affect individual and societal environmental values (Barbier et al. 2009).

To shed light on this important nexus, this Commentary discusses how economic inequality affects the value society attaches to nature. Given the sparse literature on this issue, we

\footnotetext{
${ }^{7}$ For the sake of brevity, we make no distinction between environmental goods and ecosystem services and only refer to "environmental goods". Sections 2.2 and 2.3 focus in particular on the case of environmental public goods in fixed quantity, i.e. goods whose consumption is non-rival and non-excludable and the amount of which is exogenous to the valuation. For example, one may think of clean air, biodiversity conservation, or climate regulation.

${ }^{8}$ The value of a good is the increase in individual or societal well-being due to an increase in the good's level or quality. There are different benefit or welfare measures, such as equivalent or compensating surplus (Freeman 2003). For marginal changes and standard preferences, equivalent and compensating surplus are identical and equal WTP. Marginal changes imply that we here consider a project that is very "small" in relation to the economy; "standard preferences" are usually self-regarding (DellaVigna 2009) and thus omit, for example, altruism and relative consumption concerns.

${ }^{9}$ For any Pareto efficient allocation the amount of a public good is characterized by the Lindahl-Samuelson condition that the sum of individual WTPs within a society should equal the marginal costs of public good provision (Samuelson 1954). Equivalently, one could take the mean WTP as found in a representative study, and multiply it with the number of individuals in a society. We will thus often refer to 'mean WTP' when we speak about the 'aggregate WTP'
} 
focus on standard economic valuation approaches and the case of income inequality, as it is the most studied measure of economic inequality, and because income is typically elicited in environmental valuation studies (in contrast to wealth). The literature provides promising ways to account for economic inequality within standard economic approaches. Indeed, there is a clear relationship between mean WTP and income inequality: For most empirically relevant cases, a reduction in income inequality increases the value society attaches to public environmental goods (see Section 2.2). This implies that the incidence of environmental policies, defined as their distributional consequence across income groups, is such that nonmarket environmental benefits accrue over-proportionally to poorer households. We discuss implications of economic inequality regarding the practice of benefit transfer (Section 2.3.1), adjustment of WTP for inequality in environmental cost-benefit analysis and its relation to equity or distributional weights (Section 2.3.2), and the distributional consequences of environmental policies (Section 2.3.3). Section 2.4 points towards research needs within approaches to valuing environmental goods. Overall, we conclude that it is neither necessary nor appropriate to ignore distributional aspects in standard economic valuation approaches.

\subsection{How does the distribution of income affect the valuation of environmental goods?}

In a recent contribution, Frank and Schlenker (2016: 652) conjecture that "if preservation values increase with income but at a decreasing rate, as commonly assumed, then a more equal society will exhibit higher values for conservation. The income distribution might thus be as important as overall economic growth". Addressing this conjecture, Baumgärtner et al. (2017a) build on previous work by Ebert (2003), who has been the first to analyze the incidence of non-market environmental good provision. Specifically, they use a standard constant-elasticity-of-substitution utility function that allows for varying degrees of substitutability or complementarity between an environmental public good and a human-made consumption good. A constant income elasticity of WTP that is smaller (larger) than one implies that preservation values increase with income but at a decreasing (increasing) rate. Baumgärtner et al. (2017a) show that if the constant income elasticity of WTP is below one - as assumed in the conjecture by Frank and Schlenker (2016) - societies with a more equal 
distribution of income have a higher mean WTP. ${ }^{10}$ Indeed, empirically the income elasticity of WTP appears to be below unity in almost all cases (Drupp 2018; Kriström and Riera 1996) and it is usually estimated as a constant, as it is the case for biodiversity conservation at the global level (Jacobsen and Hanley 2009).

Figure 2.1 illustrates this result. Consider a society of two households with different incomes: household $B$ has a higher income, $Y_{B}$, than household $A$ with income $Y_{A}$. WTP increases with income, $Y$, but at a decreasing rate, such as depicted by the solid black curve. Thus, the income elasticity of WTP is below unity. Now consider a reduction in income inequality that leaves society's mean income unchanged (a "Pigou-Dalton-transfer"): the income of the relatively richer household $B$ is decreased by the amount $\Delta Y$ to $Y^{\prime}{ }_{B}$ and the income of the relatively poorer household $A$ is increased by the same amount $\Delta Y$ to $Y_{A}^{\prime}$ but still the richer household $B$ is better off $Y_{B}^{\prime}>Y_{A}^{\prime}$. An income elasticity of WTP for environmental public goods below unity implies that, with this change in the income distribution, the increase of $\mathrm{WTP}_{A}$ of the poorer household $A$ is larger than the decrease in $\mathrm{WTP}_{B}$ of the richer household $B$. Thus, mean WTP in the more equal society, $\overline{W T P^{\prime}}$, is higher than in the more unequal society $\overline{W T P}$, i.e. $\Delta \mathrm{WTP}=\overline{\mathrm{WTP}^{\prime}}-\overline{\mathrm{WTP}}>0$. It also follows for an income elasticity of WTP equal to unity - and only in this case - that the distribution of income does not influence mean WTP.

In their theoretical analysis, Baumgärtner et al. (2017a) consider not only two households, but a whole distribution of incomes within a large society. Specifically, they assume that income is distributed log-normally within society. They show that while income inequality is important, mean WTP for environmental public goods changes more elastically with mean income than with income inequality except for extreme cases. Hence, the conjecture of Frank and Schlenker (2016) can be qualified as follows: Income elasticities below one imply that reductions in income inequality increase mean WTP, but changes in mean (that is per-capita) income have a relatively stronger effect. Baumgärtner et al. (2017a) further derive correction or transfer factors that allow controlling for the effect of income inequality on mean WTP for environmental public goods, such as for differences in income inequality in different societies, or between the current unequal income distribution and normatively desired ones. We discuss three implications of these findings in the following section.

\footnotetext{
${ }^{10}$ Some environmental goods are likely to be complementary to human-made consumption goods. In this case, the mechanism would go in the opposite direction: redistribution towards a more equal society in income terms would imply a lower mean WTP for non-market environmental goods.
} 


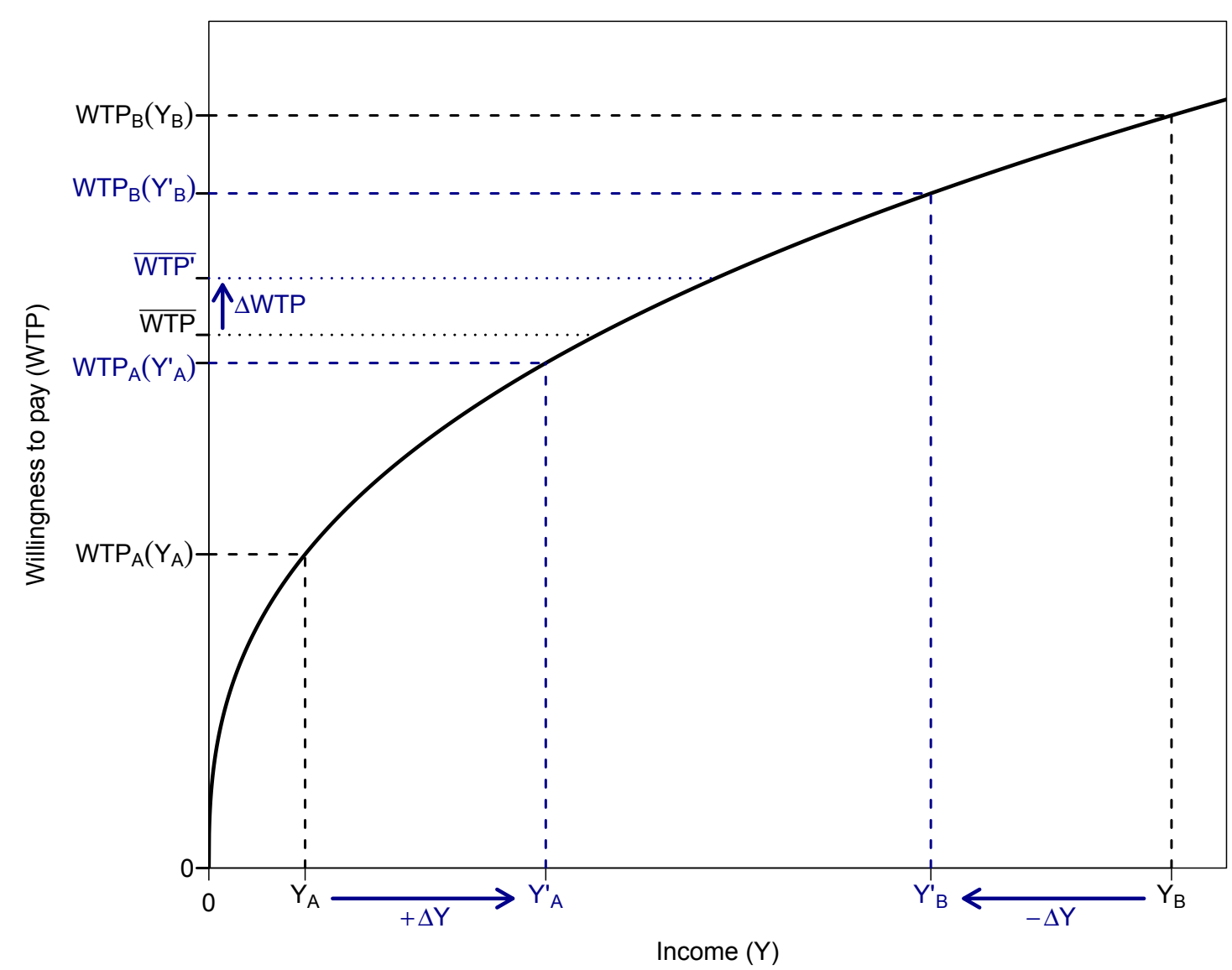

Figure 2.1: Income inequality affects mean willingness to pay (WTP) for environmental public goods of two households. Compared to a more unequal distribution of income $\left(Y_{A}, Y_{B}\right)$, with a mean WTP $(\overline{\mathrm{WTP}})$, a more equal distribution of income $\left(Y_{A}^{\prime}, Y_{B}^{\prime}\right)$ increases mean WTP $\left(\overline{\mathrm{WTP}^{\prime}}\right)$ for the same mean income $\left(\Delta \mathrm{WTP}=\overline{\mathrm{WTP}^{\prime}}-\overline{\mathrm{WTP}}>0\right)$, if the constant income elasticity of WTP is below unity.

\subsection{Implications}

\subsubsection{Account for income inequality in value or benefit transfer}

As conducting primary environmental valuation studies is time-consuming and costly, the transfer of environmental values from a study site to a policy site ("benefit transfer") has become one of the most commonly used approaches for obtaining values for environmental goods (Pearce et al. 2006; Richardson et al. 2015). Strictly speaking, it is only valid to perform benefit transfer if the study and the policy site are identical in all aspects that determine mean WTP for the environmental goods. However, in practice, benefit transfer is applied much more widely. It is therefore crucial to control for differences in important determinants of WTP in this process, including differences in the distribution of income. While a number of guidelines, such as in Germany (UBA 2012), the OECD (Pearce et al. 
2006), and the UK (Defra 2007), already suggest how to account for differences in percapita income, accounting for income inequality has been neglected so far. Baumgärtner et al. (2017a) derive closed-form benefit transfer factors to account for income inequality and show that WTP adjustments can be substantial. ${ }^{11}$ Meya et al. (2017) empirically investigate the adjustment for income inequality in benefit transfer for a multi-country valuation study. They find that adjusting for income inequality indeed increases the accuracy of benefit transfer considerably. These two studies suggest on theoretical and empirical grounds that benefit transfer studies should employ a transfer factor for differences in income inequality above and beyond controlling for differences in per-capita income. Likewise, this adjustment for differences in income inequality is relevant for scaling up mean WTP values from single sites or unrepresentative samples, to assess mean WTP for environmental goods of larger areas and actual society.

\subsubsection{Adjust mean WTPs for an undesired degree of income inequality}

Sustainability policy has the dual objectives of allocative efficiency and distributive justice (Baumgärtner and Quaas 2010). While pursuing efficiency may require a monetary valuation of non-market environmental goods, we have shown in the previous section that economic distribution influences monetary valuation in turn. Environmental valuation and the distribution of income are thus intertwined and need to be studied simultaneously. For instance, if the societally desired degree of income inequality is different from the actual distribution, and if one pursues these dual objectives, one must do two things: First, redistribute income for distributive justice, and, second, determine the Pareto-efficient amount of a public environmental good by adjusting the aggregate WTP that has been empirically estimated based on the current - unjust - income distribution. For the second task, one can employ the transfer factors derived for value transfer (see footnote 6) to adjust mean WTP estimates by using the societally desired level of income inequality instead of the existing one and then use the inequality-adjusted mean WTP estimates for social cost-benefit-analysis (Baumgärtner et al. 2017a). Such an adjustment can be substantial: Baumgärtner et al. (2017a) show that for the case of global mean WTP for biodiversity conservation it might lead to an increase in mean WTP of up to 16 percent for the extreme case when income inequality is undesired.

\footnotetext{
${ }^{11}$ The transfer factor to adjust mean WTPs for differences in income inequality between a policy and a study site, with $\overline{\mathrm{WTP}}^{\text {policy }}=\mathcal{T}_{\mathrm{CV}} \times \overline{\mathrm{WTP}}^{\text {study }}$, is $\mathcal{T}_{\mathrm{CV}}\left(\mathrm{CV}_{Y}^{\text {policy }}, \mathrm{CV}_{Y}^{\text {study }}\right)=\left(\frac{1+\mathrm{CV}_{Y}^{\text {policy }}{ }^{2}}{1+\mathrm{CV}_{Y}^{\text {study }}{ }^{2}}\right)^{\eta(\eta-1) / 2}$, where $\mathrm{CV}_{Y}^{\text {policy }}\left(\mathrm{CV}_{Y}^{\text {study }}\right)$ is the coefficient of variation of income at the policy (study) site, which is computed as the standard deviation divided by the mean of income, and $\eta$ is the income elasticity of WTP.
} 
This aggregate WTP inequality adjustment approach can be seen as an operationalization of the more general approach to account for distributional effects by using distributional or equity weights (Mäler 1974; Adler 2016; Fleurbaey and Abi-Rafeh 2016), which is recommended in the UK Greenbook (HMT 2011) and has been applied in climate change policy appraisal (e.g. Anthoff et al. 2009). In standard cost-benefit-analysis all benefits and costs are weighted equally regardless to whom they accrue. In contrast, the distributional weights approach increases the relative importance of costs and benefits accruing to lower income households through the introduction of distributional weights. In general, distributional weights have to be determined for each household by means of maximizing a social welfare function subject to economic and environmental constraints, which is a very challenging task. For a decision situation as considered here - when households differ only in their incomes, incomes are log-normally distributed, and the income elasticity of WTP is constant - the decision-maker can simply use the aggregate WTP inequality adjustment described above. The result is the same, provided the welfare-maximizing distribution of incomes is the just (target) distribution considered here. Both the use of equity weights and the aggregate WTP inequality adjustment lead to the same condition for the Pareto-efficient amount of the public environmental good. For illustration, consider the case of an income elasticity of WTP smaller than unity, i.e. when poorer households have a disproportionately high individual WTP. If society's targeted level of income inequality is more equal than it is currently, the inequality adjustment approach as described above would increase mean WTP. Likewise, when employing distributional weights, those poorer households with a disproportionately high individual WTP would receive a higher weight; the effect on aggregate WTP would be equivalent under the conditions described above. Yet, while the equity weighting literature assigns higher weights to some of the members of society in the measurement of total welfare, which may be seen as taking a strong normative stance, the mean WTP inequality adjustment builds on a descriptive relationship between mean WTP and its determinants. Furthermore, as it requires less information, the aggregate WTP inequality adjustment approach may be an easier to implement means of dealing with the problem that distributional weights seek to address. 


\subsubsection{Consider the incidence of non-market benefits from environmental policies}

Public discourse and decision-making is often concerned with the distributional consequences ("incidence") of environmental policies. Most studies focus on the incidence of different instruments for pollution control in environmental policy, often showing regressive effects of price instruments, like fuel and electricity taxes, or regulatory standards (Fullerton and Muehlegger 2017). This means that these policies put a disproportionate burden on poorer households (Bento 2013; Fullerton 2011). ${ }^{12}$ These findings have motivated the design of policy instruments with neutral or progressive distributional effects, such as through revenue recycling (Chiroleu-Assouline and Fodha 2014; Klenert et al. 2016). However, with few exceptions (e.g. Ebert 2003; Heal and Kriström 2007; Kriström and Riera 1996), this literature has so far ignored the distribution of non-market benefits resulting from environmental policies.

In order to gain an encompassing picture of how the design of environmental policies affects economic distribution it is important to not just look at the distribution of market costs of these policies, but to also consider the distribution of their non-market benefits. Indeed, our discussion on how the distribution of income affects mean WTP for environmental goods can contribute to understanding the distributional effects of environmental policy and environmental degradation. Thereby, the distributional effects of environmental policies are determined by the income elasticity of WTP (Ebert 2003; Flores and Carson 1997; Kriström and Riera 1996). If, as in Figure 2.1, societies with a more equal distribution of income exhibit a higher mean WTP than more unequal societies, the non-market benefits of environmental policies are distributed regressively, and thus in contrast to most of their market-based costs, accrue in favor of poorer households. Yet, by the same token, losses of non-market benefits due to environmental degradation also fall disproportionately on poorer households. Thus, it is crucial to consider the overall distributional effect of both market and non-market net benefits. In particular, even if net market benefits occur disproportionately in favor of higher income groups, ${ }^{13}$ the overall distributional effect may be neutral, or

\footnotetext{
${ }^{12}$ There are only few studies that find that environmental policies do not put a disproportionate burden on poorer households. For example, Bento et al. (2015) find that the benefits of air quality improvements in the United States from the 1990 Clean Air Act Amendments accrued disproportionately to lower-income households.

${ }^{13}$ For example, because market-based environmental policies, such as fuel taxes, are frequently found to bring disproportionate costs to poorer households (Frondel et al. 2015), or because the monetary benefits associated with environmental policies, such as subsidies (renewable energy support, or payment for environmental goods), require a house or land ownership and thus disproportionately benefit richer households (e.g. Haan and Simmler 2018).
} 
might even favor poorer households, if the pro-poor distribution of non-market net benefits is substantial enough.

\subsection{Perspectives for further research}

While our discussion of the sparse existing literature has already highlighted the importance of considering economic distribution for environmental valuation, further research is needed to derive more robust conclusions and to broaden the scope of the analysis. In the following, we briefly sketch a number of pertinent open research areas.

First, more elaborate theories of environmental valuation and economic distribution are required that capture heterogeneous preferences and environmental goods that are not pure public goods. For example, different individuals may put different utility weights on environmental goods, or may differ in their willingness to substitute environmental goods with consumption goods. Of particular interest with regard to impure public goods may be the analysis of a coupled spatial distribution of environmental goods and housing, since hedonic pricing is a popular valuation method for local public goods. Relatedly, in the sectors of tourism and agriculture, the provisioning of local public environmental goods largely drives private market incomes. Thus, the analysis should also depart from the assumption of a marginal project (see Dietz and Hepburn (2013) for an analysis of non-marginal projects). Particularly in those cases, valuation of environmental goods and distribution of incomes should be studied simultaneously. For instance, Heblich et al. (2017) and Lee and Lin (2017) show that the spatial distribution of environmental amenities shapes the spatial distribution of income in cities over time, with wealthier households living where environmental quality is high. Further research is needed to understand how neighborhood-sorting resulting from the distribution of environmental goods affects the valuations of theses environmental goods in turn. It may be that accounting for sorting increases the societal value of increasing environmental local public goods as households with stronger preferences for environmental goods and/or higher income are likely to locate themselves such as to consume higher levels of the environmental good. We expect that spatial sorting and its relation to income inequality depends on whether the environmental good is a substitute or complement to consumption goods.

Second, there is a need to study different concepts of economic resources that may be distributed unequally. For example, besides simple annual income, one may consider other measures of income, such as lifetime income or wealth (Heal and Kriström 2007; Teixidó 
and Verde 2017). Since sustainability concerns not only the distribution of resources within a generation at a given point in time, but, in particular, also questions of intergenerational justice, one should study the effect of relevant economic inequalities, such as inequalities in wealth or income from capital, on environmental values in a dynamic context. ${ }^{14}$ Such a dynamic theory of environmental valuation and economic distribution should pay particular attention to a project's time horizon, as the economic distribution might change in the meantime (see Section 2.3.2). In such a case, not only the economic distribution at the start of the project will matter, but also its development over time. How to account for this in measures of equivalent or compensating variation is an open question.

Third, further research should also depart from the standard assumption of atomistic, self-regarding economic agents and take into account behavioral effects as pertaining to inequality and environmental valuation, such as through other-regarding preferences. This may include, for example, investigating both theoretically and experimentally the roles of inequality aversion or relative consumption concerns (Broberg 2014; Johansson-Stenman and Konow 2010; Johannsson-Stenman and Sterner 2015). Previous research has shown that the incidence and thus the distributional impacts of environmental policies may influence individual valuation of nature if people have other-regarding preferences (Cai et al. 2010). Another question for further research is how other-regarding preferences would impact the income elasticity of WTP. Considering behavioral effects may reinforce the importance of income inequality for the value a society attaches to environmental goods.

Fourth, since sustainability economics has to deal with multiple market and government failures, it is not unreasonable to assume that much of environmental policy and actual environmental valuation are conducted in second-best settings. Thus, due to constraints it may not be possible to achieve the dual objectives of allocative efficiency and distributive justice. For example, it could be that there are certain barriers to implementing a desired degree of income inequality. ${ }^{15}$ Future research should examine if and how mean WTP should be adjusted for income inequalities in such circumstances.

Fifth, it is an open question how the distribution of economic resources affects the value

\footnotetext{
${ }^{14}$ This relates to the literature on discounting and economic inequality (e.g. Gollier 2015; Emmerling et al. 2017; Emmerling 2017), as well as on dual discounting and the relative price of environmental goods (Baumgärtner et al. 2015; Drupp 2018; Drupp and Hänsel 2018; Gollier 2010; Hoel and Sterner 2007; Sterner and Persson 2008; Traeger 2011; Weikard and Zhu 2005).

${ }^{15}$ For example, it may be that actual redistribution of income is lower than what society's inequality aversion would suggest to incentivize richer households to exert more work effort, or that distributional effects resulting from environmental policies are in practice not offset by changes to the general redistribution scheme. A number of studies accordingly model distinct social planners for environmental management and general tax policy (e.g. Barrage 2016).
} 
of environmental goods as elicited through alternative (that is: non welfare-economic) valuation approaches, such as deliberative monetary valuation, democratic valuation or other participatory valuation methods (e.g. Lienhoop et al. 2015; Schläpfer 2016; Spash 2007).

Sixth, one may consider the effect on the valuation and value of environmental goods of an unequal distribution in other 'resources' than economic ones, such as power and political influence (Boyce 1994; Boyce et al. 1999). Also, one should investigate how inequality in power and political influence affects the design of institutions, which can be viewed as determining the outcome of environmental valuation (Vatn 2009). While economic valuation may form a starting point for such analyses, such approaches will have to draw on other research methods as well.

Seventh, while we have mainly discussed the implication of economic distribution on environmental valuation, a comprehensive reflection on the interplay between the two should study whether environmental valuation might in turn affect the economic distribution (Corbera 2015; Matulis 2014, 2015).

Finally, there is a need for better data on the relationship between economic distribution and environmental valuation. In particular, better estimates of income elasticities of WTP for environmental goods are required to more robustly investigate the finding that the benefits of environmental goods are distributed in favor of poorer households and qualify the conditions under which this is indeed the case. For example, it may well be that the income elasticity of WTP varies across goods. Poorer households may value environmental goods related to local recreation disproportionately, while richer households may value the preservation of certain species or cultural ecosystem services disproportionately. This necessitates more and better data on income elasticities across different goods and services as well as across countries. Further, it requires systematic studies that assess to what degree income effects captured in environmental valuation studies are indeed informative of income elasticities of WTP for environmental goods or relate to confounding factors such as warm glow and strategic behavior etc. (e.g. List 2017; Schläpfer 2008). Lastly, this calls for more theoretical and empirical work that allows judging whether income elasticities of WTP for environmental goods are constant or whether they systematically vary with income. ${ }^{16}$

\footnotetext{
${ }^{16}$ There is some evidence that income elasticities are non-constant (Barbier et al. 2017). This could be due to a range of factors not captured in standard models, such as subsistence consumption (Baumgärtner et al. 2017b; Drupp 2018).
} 


\subsection{Conclusions}

How to value the non-market benefits of environmental policies is a crucial yet contested research endeavor. The challenge of sustainability sets further requirements on this endeavor in demanding that distributional considerations are adequately addressed. We have highlighted that the distribution of economic resources within society, notably income inequality, affects the value society attaches to public environmental goods. We find that it is crucial to consider distributional impacts not only because this is called for from a sustainability economics perspective, but because it carries important implications for environmental valuation and management already from a standard economics perspective concerned with allocative efficiency.

We have argued that while a lot more research is needed, some first clear findings emerge on how the distribution of income affects the societal value of nature. If individual WTP increases less (more) than proportionally with income, a reduction in income inequality will lead to an increase (decrease) of the mean and aggregate WTP a society attaches to public environmental goods. Given this relationship between mean WTP and income inequality, already standard valuation approaches can and should explicitly account for economic distribution. In particular, three important implications for environmental valuation, policy and management emerge: First, as the distribution of income affects mean WTP, studies that transfer environmental values from some population to another - may it be in international benefit transfer or for scaling-up environmental values from an unrepresentative sub-population - should account for how income inequality affects aggregate WTP. Second, given the dual objective of distributive justice and allocative efficiency in sustainability economics, existing aggregate WTP estimates should be adjusted according to the targeted degree of income inequality when informing regulatory bodies using cost-benefit analysis. This would likely result in an increase of the estimated benefits society derives from the public-good type services provided by nature. Third, an encompassing assessment of distributional effects of environmental policies has to account not only for direct monetary cost and benefits, but also for the distribution of non-market benefits of environmental goods. While the market-based costs of environmental policies are often deemed to favor higher-income households, our discussion has shown that non-market benefits might indeed disproportionately favor poorer households. As distributional implications are often used as an argument against more stringent environmental policies, it is particularly crucial to consider this propoor distribution of non-market benefits, which may provide a further argument for more 
stringent environmental policies.

Acknowledgments: We are grateful to two anonymous reviewers for their constructive comments. Drupp gratefully acknowledges financial support from the German Federal Ministry of Education and Research under grant 01UT1410. Meya gratefully acknowledges financial support from the Ministry for Science and Culture of Lower Saxony (Germany) and the Volkswagen Foundation under the program Science for Sustainable Development. 


\section{Bibliography}

Adler, M.D. (2016). Benefit-cost analysis and distributional weights: An overview. Review of Environmental Economics and Policy, 10(2), 264-285.

Anthoff, D., Hepburn, C., and Tol, R.S. (2009). Equity weighting and the marginal damage costs of climate change. Ecological Economics, 68(3), 836-849.

Atkinson, G., and Mourato, S. (2008). Environmental cost-benefit analysis. Annual review of environment and resources, 33, 317-344.

Barbier, E.B., Baumgärtner, S., Chopra, K., Costello, C., Duraiappah, A., Hassan, R., Kinzig, A.P., Lehman, M., Pascual, U., Polasky, S. and Perrings, C. (2009). The valuation of environmental goods. In: Naeem, S., Bunker, D.E., Hector, A., Loreau, M., and Perrings, C. (eds). Biodiversity, Ecosystem Functioning, and Human Wellbeing, Oxford University Press, Oxford, 248-262.

Barbier, E.B., M. Czajkowski and N. Hanley (2017). Is the income elasticity of the willingness to pay for pollution control constant? Environmental and Resource Economics, 68, 663682.

Bateman, I.J., Harwood, A., Mace, G.M., Watson, R., Abson, D.J., Andrews, B., Binner, A., Crowe, A., Day, B.H., Dugdale, S., Fezzi, C., Foden, J., Haines-Young, R., Hulme, M., Kontoleon, A., Lovett, A.A., Munday, P., Pascual, U., Paterson, J., Perino, G., Sen, A., Siriwardena, G., van Soest, D., and Termansen, M. (2013). Bringing environmental goods into economic decision making: land use in the UK. Science, 341 (6141), 45-50.

Barrage, L. (2016). Be careful what you calibrate for: Social discounting in general equilibrium. Working Paper.

Baumgärtner, S., Klein, A.-M., Thiel, D., and Winkler, K. (2015). Ramsey discounting of ecosystem services. Environmental and Resource Economics, 61(2), 273-296. 
Baumgärtner, S., Drupp, M.A., Munz, J.M., Meya, J.N., and Quaas, M.F. (2017a). Income inequality and willingness to pay for environmental public goods. Journal of Environmental Economics and Management, 85, 35-61.

Baumgärtner, S., Drupp, M.A., and Quaas, M.F. (2017b). Subsistence, substitutability and sustainability in consumption, Environmental and Resource Economics, 67(1), 47-66.

Baumgärtner, S. and M.F. Quaas (2010). What is sustainability economics? Ecological Economics, 69(3), 445-450.

Bento, A.M. (2013). Equity impacts of environmental policy. Annual Review of Resource Economics, 5(1), 181-196.

Bento, A., Freedman, M., and Lang, C. (2015). Who benefits from environmental regulation? Evidence from the clean air act amendments. Review of Economics and Statistics, 97(3), 610-622.

Boyce, J.K. (1994). Inequality as a cause of environmental degradation. Ecological Economics, 11(3), 169-178.

Boyce, J.K., Klemer, A. R., Templet, P. H., and Willis, C. E. (1999). Power distribution, the environment, and public health: A state-level analysis. Ecological Economics, 29(1), 127-140.

Broberg, T. (2014). Relative Income and the WTP for Public Goods-A Case Study of Forest Conservation in Sweden. CERE Working Paper 2014, 6.

Butchart, S., Walpole, M., Collen, B., van Strien, A. J. Scharlemann, E. Almond, ..., and Watson, R. (2010). Global biodiversity: Indicators of recent declines. Science, 328(5982), 1164-1168.

Cai, B., Cameron, T.A. and Gerdes, G.R. (2010). Distributional preferences and the incidence of costs and benefits in climate change policy. Environmental and Resource Economics, 46(4), 429-458.

Chiroleu-Assouline, M. and Fodha, M. (2014). From regressive pollution taxes to progressive environmental tax reforms. European Economic Review, 69, 126-142.

Corbera, E. (2015). Valuing nature, paying for environmental goods and realizing social justice: a response to Matulis (2014). Ecological Economics, 110, 154-157. 
Costanza, R. (1989). What is ecological economics? Ecological Economics, 1(1), 1-7.

[Defra 2007] Department for Environment, Food and Rural Affairs (2007). An introductory guide to valuing environmental goods. London: Department for Environment, Food and Rural Affairs.

DellaVigna, S. (2009). Psychology and economics: Evidence from the field. Journal of Economic literature, 47(2), 315-72.

Dietz, S., and Hepburn, C. (2013). Benefit-cost analysis of non-marginal climate and energy projects. Energy Economics, 40, 61-71.

Drupp, M.A. (2018). Limits to substitution between environmental goods and manufactured goods and implications for social discounting. Environmental and Resource Economics, 69(1), 135-158.

Drupp, M.A., and Hänsel, M.C. (2018). Relative prices and climate policy: How the scarcity of non-market goods drives policy evaluation. Kiel Economics Working Paper No 2018-01.

Ebert, U. (2003). Environmental goods and the distribution of income, Environmental and Resource Economics, 25(4), 435-459.

Emmerling, J., Groom, B., and Wettingfeld, T. (2017). Discounting and the representative median agent. Economics Letters, 161, 78-81.

Emmerling, J. (2017). Discounting and intragenerational equity. Environment and Development Economics, 23(1), 19-36.

European Commission (2013). The Economic Benefits of the Natura 2000 Network. Synthesis report. Luxembourg: Publications Office of the European Union.

Fleurbaey, M. and Abi-Rafeh, R. (2016). The use of distributional weights in benefit-cost analysis: Insights from welfare economics. Review of Environmental Economics and Policy, 10(2), 286-307.

Flores, N. E., and Carson, R. T. (1997). The relationship between the income elasticities of demand and willingness to pay. Journal of Environmental Economics and Management, $33(3), 287-295$.

Frank, E.G. and Schlenker, W. (2016). Balancing economic and ecological goals. Science, 353(6300), 651-652. 
Freeman, III, A.M. (2003). The Measurement of Environmental and Resource Values. Theory and Methods. Second edition. Resources for the Future, Washington D.C.

Frondel, M., Sommer, S., and Vance, C. (2015). The burden of Germany's energy transition: an empirical analysis of distributional effects. Economic Analysis and Policy, 45, 89-99.

Fullerton, D. (2011). Six distributional effects of environmental policy. Risk Analysis, 31(6), 923-929.

Fullerton, D., and Muehlegger, E. (2017). Who Bears the Economic Costs of Environmental Regulations? NBER Working Paper No. 2367\%.

Gollier, C. (2010). Ecological discounting. Journal of Economic Theory, 145, 812-829.

Gollier, C. (2015). Discounting, inequality and economic convergence. Journal of Environmental Economics and Management, 69, 53-61.

Haan, P., and Simmler, M. (2018). Wind electricity subsidies - A Windfall for landowners? Evidence from a feed-in tariff in Germany. Journal of Public Economics, 159, 16-32.

Heal, G., and Kriström, B. (2007). Distribution, sustainability and environmental policy. In: Atkinson, G., Dietz, S. and Neumayer, E. (eds). Handbook of Sustainable Development, Edward Elgar Publishing Ltd, Cheltenham, UK and Northampton, USA, 155-170.

Heblich, S., Trew, A., and Zylberberg, Y. (2016). East Side Story: Historical Pollution and Persistent Neighborhood Sorting. University of St. Andrews, School of Economics and Finance Discussion Paper No. 1613.

Hoel, M. and Sterner, T. (2007). Discounting and relative prices. Climatic Change, 84, 265280.

[HMT 2011] Her Majesty's Treasury (2011). The Green Book. Appraisal and Evaluation in Central Government. London: TSO. 114 pp.

IMF (2017). Understanding the downward trend in labor income shares In: World Economic Outlook, April 2017: Gaining Momentum?.

Jacobsen, J. and Hanley, N. (2009). Are there income effects on global willingness to pay for biodiversity conservation? Environmental and Resource Economics, 43(2), 137-160. 
Johansson-Stenman, O. and Konow, J. (2010). Fair air: distributive justice and environmental economics. Environmental and Resource Economics, 46(2), 147-166.

Johansson-Stenman, O., and Sterner, T. (2015). Discounting and relative consumption. Journal of Environmental Economics and Management, 71, 19-33.

Klenert, D., Schwerhoff, G., Edenhofer, O., and Mattauch, L. (2016). Environmental Taxation, Inequality and Engel's Law: The Double Dividend of Redistribution. Environmental and Resource Economics, doi: 10.1007/s10640-016-0070-y.

Kriström, B., and Riera, P. (1996). Is the income elasticity of environmental improvements less than one? Environmental and Resource Economics, 7(1), 45-55.

Lee, S., and J. Lin (2018). Natural Amenities, Neighbourhood Dynamics, and Persistence in the Spatial Distribution of Income. The Review of Economic Studies, 85, 663-694.

Lienhoop, N., Bartkowski, B., and Hansjürgens, B. (2015). Informing biodiversity policy: the role of economic valuation, deliberative institutions and deliberative monetary valuation. Environmental Science 63 Policy, 54, 522-532.

List, J.A. (2017). Behavioral economics and the environment. Keynote Lecture at the 19th Annual International BIOECON Conference, Tilburg, 22.09.2017.

Mäler, K.-G. (1974). Environmental economics: a theoretical inquiry, Baltimore: Johns Hopkins University Press.

Matulis, B.S. (2014). The economic valuation of nature: A question of justice? Ecological Economics, 104, 155-157.

Matulis, B. S. (2015). Valuing nature: A reply to Esteve Corbera. Ecological Economics, $110,158-160$.

[MEA 2005] Millennium Ecosystem Assessment (2005): ecosystems and human well-being: Biodiversity synthesis, Published by World Resources Institute, Washington, DC.

Meya, J.N., Drupp, M.A., and Hanley, N. (2017). Income inequality and the international transfer of environmental values. Kiel Economics Working Paper No 2017-03.

OECD (2016). Income inequality remains high in the face of weak recovery. https://www.oecd.org/social/OECD2016-Income-Inequality-Update.pdf 
Pascual, U., Balvanera, P., Díaz, S., Pataki, G., Roth, E., Stenseke, M., Watson, R.T., Dessane, E.B., Islar, M., Kelemen, E., Maris, V., Quaas, M.F., Subramanian, S.M., Wittmer, H., Adlan, A., Ahn, S., Al-Hafedh, Y.S., Amankwah, E., Asah, S.T., Berry, P., Bilgin, A., Breslow, S.J., Bullock, C., Cáceres, D., Daly-Hassen, H., Figueroa, E., Golden, C.D., Gómez-Baggethun, E., González-Jiménez, D., Houdet, J., Keune, H., Kumar, R., Ma, K., May, P.H., Mead, A., O'Farrell, P., Pandit, R., Pengue, W., Pichis-Madruga, R., Popa, F., Preston, S., Pacheco-Balanza, D., Saarikoski, H., Strassburg, B.B., van den Belt, M., Verma, M., Wickson, F., and Yagi, N. (2017). Valuing nature's contributions to people: the IPBES approach. Current Opinion in Environmental Sustainability, 26, 7-16.

Pearce, D., Atkinson, G. and S. Mourato, S. (2006), Cost-benefit analysis and the environment: recent developments. Organisation for Economic Co-operation and Development (OECD).

Piketty, T. (2014). Capital in the twenty-first century, Cambridge, MA: The Belknap Press of Harvard University Press. University College London.

Pimm, S.L., Jenkins, C. N., Abell, R., Brooks, T.M., Gittleman, J.L., Joppa, L.N., Roberts, C.M. and Sexton, J.O. (2014). The biodiversity of species and their rates of extinction, distribution, and protection. Science, 344(6187).

Richardson, L., Loomis, J., Kroeger, T., and Casey, F. (2015). The role of benefit transfer in ecosystem service valuation, Ecological Economics, 115, 51-58.

Samuelson, P.A. (1954). The Pure Theory of Public Expenditure, Review of Economics and Statistics, 36(4), 387-389.

Schläpfer, F. (2008). Contingent valuation: a new perspective. Ecological Economics, 64(4), 729-740.

Schläpfer, F. (2016). Democratic valuation (DV): Using majority voting principles to value public services. Ecological Economics, 122, 36-42.

Spash, C.L. (2007). Deliberative monetary valuation (DMV): Issues in combining economic and political processes to value environmental change. Ecological Economics, 63(4), 690699.

Sterner, T., and Persson, U. M. (2008). An even sterner review: Introducing relative prices into the discounting debate. Review of Environmental Economics and Policy, 2(1), 61-76. 
Stiglitz, J. E., Sen, A., and Fitoussi, J.P. (2010). Report by the Commission on the Measurement of Economic Performance and Social Progress. Paris: Commission on the Measurement of Economic Performance and Social Progress.

Teixidó, J.J., and Verde, S.F. (2017). Is the gasoline tax regressive in the twenty-first century? Taking wealth into account. Ecological Economics, 138, 109-125.

Traeger, C.P. (2011). Sustainability, limited substitutability, and non-constant social discount rates. Journal of Environmental Economics and Management, 62(2), 215-228.

[UBA 2012] Umweltbundesamt (2012). Methoden der ökonomischen Bewertung. Anhang A der "Methodenkonvention 2.0 zur Schätzung von Umweltkosten", Dessau-Roßlau: Umweltbundesamt.

Vatn, A. (2009). An institutional analysis of methods for environmental appraisal. Ecological Economics, 68(8), 2207-2215.

Weikard, H.-P., and Zhu, X. (2005). Discounting and environmental quality: when should dual rates be used? Economic Modelling, 22, 868-878. 
Part II

Theory 


\title{
3 Income Inequality and Willingness to Pay for Environmental Public Goods
}

\begin{abstract}
We study how the distribution of income among members of society, and income inequality in particular, affects social willingness to pay (WTP) for environmental public goods. We find that social WTP for environmental goods decreases (increases) with income inequality if and only if environmental goods and manufactured goods are substitutes (complements). We derive adjustment factors for benefit transfer to control for differences in income distributions between a study site and a policy site. For illustration, we quantify how social WTP for environmental public goods depends on the respective income distributions for empirical case studies in Sweden and the World at large. We find that the adjustment for income inequality can be substantial.
\end{abstract}

Keywords: environmental goods, public goods, income distribution, inequality, willingness to pay, benefit transfer, sustainability policy

Reference: Baumgärtner, S., Drupp, M.A., Meya, J.N., Munz, J.M., Quaas, M.F. (2017). Income inequality and willingness to pay for public environmental goods. Journal of Environmental Economics and Management, 85: 35-61.

This is a pre-print of an article published in the Journal of Environmental Economics and Management. The final authenticated version is available online at:

https://doi.org/10.1016/j.jeem.2017.04.005. 


\subsection{Introduction}

Estimation of willingness to pay (WTP) for non-market-traded environmental goods has become a major subfield of environmental economics, with growing importance for environmental management (Bateman et al. 2011, Smith 2000). Lately, this development has been particularly spurred by the emergence and now wide-spread use of benefit transfer (Kaul et al. 2013), that is, the transfer of benefit estimates for an environmental good from a study site to another context where this information is to be used for environmental management ("policy site"). Such benefit transfer requires knowledge of how the benefits provided by environmental goods depend on the context's characteristics, including environmental and socio-economic variables. With this information one can control for differences in the level of these variables when doing benefit transfer.

One important determinant of the benefits of environmental goods, as measured by the WTP for these goods, is the level of income. As individual income determines individual WTP, mean income in a society determines social WTP, that is, the sum of individual WTPs. But social WTP is also determined by the (in)equality of the distribution of income among individual members of society. While there has been substantial research on how the level of (individual or societal mean) income influences (individual or social) WTP for environmental goods, the similarly relevant question of how income inequality within society influences social WTP for environmental goods has hardly been examined.

Here, we study how the distribution of income among members of society, and income inequality in particular, affects social WTP for environmental public goods. We do this in some generality based on a theoretical model, exploring how potential effects depend on the parameters of the income distribution and of individual utility. We also provide an empirical estimate of the size of these effects.

The question of how WTP for environmental goods depends on income has been studied, so far, mainly in terms of the income elasticity of WTP. Ebert (2003), following up on previous work by Aaron and McGuire (1970), Kovenock and Sadka (1981), Kriström and Riera (1996), Flores and Carson (1997), has scrutinized the incidence of environmental benefits. Assuming a constant-elasticity-of-substitution (CES) utility function, he has shown that the income elasticity of WTP for an environmental public good has an inverse relationship to the elasticity of substitution between a composite consumption good and the environmental good in question. Hence, the income elasticity of WTP is smaller (greater) than unity if and only if the environmental good and consumption good are substitutes (complements). 
Empirical evidence, as gathered mainly from contingent valuation studies, suggests that the income elasticity of WTP for environmental goods is generally below unity - usually between 0.1 and 0.6. ${ }^{17}$ It thus follows from Ebert's (2003) result that the environmental goods assessed in these studies are substitutes to private consumption goods.

In benefit transfer studies, it is current practice to adjust WTP-estimates for differences in mean income between the study site and the policy site (Ready and Navrud 2006, Czajkowski and Scasny 2010). But the effects of income inequality are unaccounted for, so far. Indeed, we are not aware of studies on how the distribution of income among members of society, and in particular income inequality, affects WTP for environmental goods. Here, we close this gap. From our theoretical model, we derive adjustment factors to adjust WTP-estimates for differences not only in mean income but also in income inequality. We also provide an empirical quantification of the size of these factors, to demonstrate that these adjustments may be substantial.

For our theoretical analysis of this issue, we employ a specification of the model of Ebert (2003), where a continuum of individual households have identical self-regarding preferences over a market-traded private consumption good and a non-market-traded pure public environmental good, represented by a CES utility function. ${ }^{18}$ While the CES utility function is a particular functional representation of preferences, and thus of limited generality, it is an appropriate basis for our analysis for the following reasons: (1) Benefit transfer is typically based on a constant income elasticity of WTP. Our approach of deriving transfer factors from the CES utility specification yields results that are consistent with this practice. They are thus directly relevant for environmental management. (2) The CES specification is the simplest, yet rich-enough functional form that allows studying substitutability. (3) Qualitatively, our key result on how income inequality affects the mean WTP for environmental public goods holds more generally, beyond the CES functional specification. We demonstrate this in Appendix 3.7.12.

We extend Ebert's (2003) model by assuming that an exogenously given amount of total income is log-normally distributed over households, ${ }^{19}$ and consider two alternative measures

\footnotetext{
${ }^{17}$ See e.g. Kriström and Riera (1996), Söderqvist and Scharin (2000), Hammitt et al. (2001), Barton (2002), Ready et al. (2002), Horowitz and McConnell (2003), Hökby and Söderqvist (2003), Liu and Stern (2008), Scandizzo and Ventura (2008), Jacobsen and Hanley (2009), Khan (2009), Broberg (2010), Pek et al. (2010), Chiabai et al. (2011), Wang et al. (2013), Lindhjem and Tuan (2012).

${ }^{18}$ Hence, we focus on statistical effects of income inequality across a population of self-regarding individuals, and do not study the potential effect of other-regarding individual preferences or behavior.

${ }^{19}$ Also this particular functional representation of unequal distribution may be generalized to any mean preserving spread of the income distribution (see Appendix 3.7.12).
} 
of income inequality: the coefficient of variation and the standard deviation of income. These correspond to relative and absolute notions of inequality, respectively. ${ }^{20}$

We find that (i) social WTP for the environmental good increases with mean income; (ii) social WTP for the environmental good decreases (increases) with income inequality if and only if the environmental good and the manufactured good are substitutes (complements); (iii) the effect of income inequality on social WTP is the stronger, the higher the mean income; (iv) social WTP for the environmental good changes more elastically with mean household income than with income inequality, except for extreme cases of parameter values. We also derive transfer factors for benefit transfer to control for differences in income distributions between a study site and a policy site.

To illustrate our theoretical results, and to estimate the potential size of these effects, we quantify how social WTP for environmental public goods depends on the respective income distribution for two empirical case studies: (1) an environmental good of cultural importance, the existence of large predator species, in Sweden (from Broberg 2010), and (2) biodiversity conservation at the global scale (from the meta-study of Jacobsen and Hanley 2009).

As for the quantitative size of effects, a benefit transfer for biodiversity conservation from the global study with high income inequality to the case context of Sweden, a country known for its low income inequality, would entail a WTP correction for income inequality of 11 percent. We further find that in a hypothetical world of a completely equal income distribution WTP for global biodiversity conservation would be 16 percent higher than it actually is under the current unequal global income distribution.

This paper is organized as follows. We present the model in Section 3.2, and the results of the model analysis in Section 3.3. In Section 3.4, we illustrate these results with empirical data. In Section 3.5, we discuss our main assumptions. Section 3.6 concludes. All formal proofs are contained in the Appendix.

\footnotetext{
${ }^{20}$ While the coefficient of variation satisfies all standard requirements for inequality measures (weak principle of transfers, decomposability, income scale and population size independence), the standard deviation is an absolute measure and thus increases with the level of income (Cowell 2009: 72). We sketch results for the Gini coefficient, which is another popular measure of income inequality, only briefly. For, the Gini coefficient it does not satisfy the criterion of decomposability (cf. Cowell 2009: 64) and, under a log-normal income distribution, the Gini coefficient is completely determined by the standard deviation of income (cf. Cowell 2009: 153) and therefore yields fully equivalent results.
} 


\subsection{Model}

We employ the model of Ebert (2003) with a specific utility function and a specific distribution of income. There is a population of households whose well-being is determined by consumption of two goods - a market-traded private consumption good, $X$, and a nonmarket-traded pure public (i.e. non-rival and non-excludable) environmental good, E. Both goods may be composites, and their amounts are continuously scalable with $X, E \geq 0$. All households have identical preferences over these two goods, represented by the utility function

$$
U(X, E)=\left(\alpha X^{\frac{\theta-1}{\theta}}+(1-\alpha) E^{\frac{\theta-1}{\theta}}\right)^{\frac{\theta}{\theta-1}}
$$

where $\theta$ with $0<\theta<+\infty$ is the constant elasticity of substitution between the two goods, and $0<\alpha<1$. The utility function (3.1) is strictly quasi-concave, preferences are homothetic, and both the private good and the environmental public good are normal goods. An individual household's income is exogenously given and denoted by $Y$. The distribution of income over households is described by a continuous density function $f(Y)$ over non-negative incomes. While the consumption good is traded on a market at given price $p>0$, consumption of the environmental good is fixed at an exogenously given level $E>0$ which is the same for all households. ${ }^{21}$ Each household maximizes its utility subject to the budget constraint and fixed level of the environmental good: ${ }^{22}$

$$
\max _{X, E} U(X, E) \quad \text { s.t. } \quad p X=Y \text { and } E \text { fixed }
$$

We follow Aaron and McGuire (1970) and Ebert (2003) in defining the individual incomeequivalent total WTP for the environmental good at level $E$ as the willingness to pay $w$ per unit (Lindahl price) times the total number $E$ of units:

$$
\mathrm{WTP}=w E .
$$

The Lindahl price $w$ of the environmental good is implicitly defined as the virtual price that yields the environmental good level $E$ as the ordinary (unconditional) Marshallian

\footnotetext{
${ }^{21}$ Denoting by $E$ both the variable 'environmental-good-consumption' and the fixed level at which the environmental good is actually provided should not cause any confusion, as in our analysis the amount of the environmental good is never variable but fixed throughout.

${ }^{22}$ In this 'equal-preference'-model, which is standard in public economics (Buchanan 1964), households have identical preferences and differ only in terms of income, i.e. differences in the evaluation of the environmental good between rich and poor households are caused by differences in income, not by differences in preferences.
} 
demand in the hypothetical choice problem where the environmental good is considered a private market good. In this hypothetical choice problem, the environmental good can be individually chosen and must be paid for at the Lindahl price, and the household has an income of $Y$ plus the expenditures on $E$ (Neary and Roberts 1980, Hanemann 1991: Equation 11, Flores and Carson 1997: 289). With utility function (3.1), a household's total WTP for the environmental good at level $E$ then depends on income $Y$ and the other model parameters as follows (see Appendix 3.7.1):

$$
\operatorname{WTP}(Y)=\kappa Y^{\eta} \quad \text { with } \quad \kappa=\frac{1-\alpha}{\alpha}(p E)^{\frac{\theta-1}{\theta}}, \quad \eta=\frac{1}{\theta}
$$

where $\eta$ is the (constant) income elasticity of WTP and $\kappa$ is a factor that depends on all parameters of the model and on the quantity of the environmental public good.

One interesting and important implication of the underlying constant-elasticity-of-substitution utility function is that the income elasticity of WTP, $\eta$, is simply the inverse of the elasticity of substitution between the consumption good and the environmental good, $\theta$. This result, which has already been obtained by Kovenock and Sadka (1981) and Ebert (2003: 452-453), merits some attention. It means that the income elasticity of WTP is larger than one, $\eta>1$, if and only if the consumption good and the environmental public good are complements, $\theta<1$. The income elasticity of WTP is equal to one in the CobbDouglas case, $\theta=1$; and the income elasticity of WTP is smaller than one, $\eta<1$, if and only if the private and the public good are substitutes, $\theta>1$. It follows that WTP for the environmental good rises progressively (proportionally, regressively) with income if and only if the consumption good and the environmental good are complements (Cobb-Douglas, substitutes). ${ }^{23}$

While all households have identical preferences, represented by utility function (3.1), income $Y$ is distributed unevenly over households. In particular, we assume that $Y$ is $\log$ normally distributed with mean $\mu_{Y}$ and standard deviation $\sigma_{Y}$. For instance, the world income distribution, as well as the income distribution in many countries, can be described by a log-normal distribution as a good approximation (Pinkovskiy and Sala-i-Martin 2009). The log-normal distribution is handsome for analytical purposes too, as it is completely determined by its first two statistical moments, $\mu_{Y}$ and $\sigma_{Y} \cdot{ }^{24}$

\footnotetext{
${ }^{23}$ WTP for the environmental good is said to rise progressively (proportionally, regressively) with income $Y$ if and only if $d(W T P(Y) / Y) / d Y>(=,<) 0$.

${ }^{24}$ Strictly speaking, the first two statistical moments of the log-normal distribution are $m$ and $s$. These two biuniquely determine $\mu_{Y}$ and $\sigma_{Y}$ (see Equations 3.37 and 3.38 in Appendix 3.7.2).
} 
In this society, the mean (over households) total WTP for the environmental good at level $E, \mu_{\mathrm{WTP}}$, is given by

$$
\mu_{\mathrm{WTP}}\left(\mu_{Y}, \sigma_{Y}\right)=\int_{0}^{\infty} f_{\ln }\left(Y ; \mu_{Y}, \sigma_{Y}\right) \operatorname{WTP}(Y) d Y
$$

where $f_{\ln }\left(Y ; \mu_{Y}, \sigma_{Y}\right)$ is the density function of the log-normal distribution of $Y$ with mean $\mu_{Y}$ and standard deviation $\sigma_{Y}$, and $\operatorname{WTP}(Y)$ is given by Equation (3.4). This yields mean WTP as a function of mean income and absolute income inequality (see Appendix 3.7.2),

$$
\mu_{\mathrm{WTP}}\left(\mu_{Y}, \sigma_{Y}\right)=\kappa \mu_{Y}^{1 / \theta}\left(1+\frac{\sigma_{Y}^{2}}{\mu_{Y}^{2}}\right)^{\frac{1-\theta}{2 \theta^{2}}},
$$

or, equivalently, mean WTP as a function of mean income and relative income inequality,

$$
\mu_{\mathrm{WTP}}\left(\mu_{Y}, \mathrm{CV}_{Y}\right)=\kappa \mu_{Y}^{1 / \theta}\left(1+\mathrm{CV}_{Y}^{2}\right)^{\frac{1-\theta}{2 \theta^{2}}}
$$

where $\theta$ is the constant elasticity of substitution between the environmental public good and the private consumption good (cf. utility function 3.1), $\kappa>0$ is as defined in Equation (3.4), and $\mathrm{CV}_{Y}:=\sigma_{Y} / \mu_{Y}$ is the coefficient of variation of income. ${ }^{25}$ While the standard deviation $\sigma_{Y}$ measures the width of the income distribution in monetary units, the coefficient of variation $\mathrm{CV}_{Y}$, i.e. the relative standard deviation of income, measures the width of the income distribution as a percentage of mean income. Both measures of income inequality seem plausible. First, one could simply take the standard deviation $\sigma_{Y}$ as a measure of income inequality. This is in line with an idea that absolute income inequality matters, that is, inequality as a mean absolute deviation (in monetary units) from the mean. Second, one could take the coefficient of variation $\mathrm{CV}_{Y}$ as a measure of income inequality. This is in line with an idea that relative income inequality matters, that is, inequality as measured as a mean relative deviation (as a percentage) from the mean income.

In our analytical framework, changes in $\mu_{Y}$ and $\sigma_{Y}$ (or $\mathrm{CV}_{Y}$ ) can be interpreted as outcomes of some stylized, not explicitly modelled policies for the growth and redistribution,

\footnotetext{
${ }^{25}$ Denoting both functions, (3.6) and (3.7), by $\mu_{\mathrm{WTP}}$ saves notation but is, strictly speaking, an abuse of notation, as they depend on different variables. However, this should not cause any confusion, as we will always specify both arguments of the function. So, the reader will always know whether we speak of mean WTP as a function of mean income and standard deviation of income, or as a function of mean income and coefficient of variation of income.
} 
respectively, of income. ${ }^{26}$

Since the social WTP is the sum of individual WTPs, which is the mean WTP multiplied by the (constant) number of households, the mean WTP studied here (Equation 3.6 or 3.7) can be identified with the social WTP.

\subsection{Results of model analysis}

In this section, we study how the mean WTP for the environmental public good, $\mu_{\mathrm{WTP}}$ (Equation 3.6 and 3.7), changes if mean income, $\mu_{Y}$, and/or income inequality change. We do this for both relative and absolute measures of income inequality, coefficient of variation $\mathrm{CV}_{Y}$ and standard deviation $\sigma_{Y}$, in parallel. For each result, we start with the coefficient of variation as this yields simpler and more intuitive results.

\subsubsection{How does mean WTP for the environmental public good change if mean income changes?}

Proposition 3.1 (relative income inequality)

Mean WTP for the environmental public good, $\mu_{\mathrm{WTP}}$ (Equation 3.7), increases with mean household income, $\mu_{Y}$ :

$$
\frac{\partial \mu_{\mathrm{WTP}}\left(\mu_{Y}, \mathrm{CV}_{Y}\right)}{\partial \mu_{Y}}>0
$$

Proof. See Appendix 3.7.3.

Proposition 3.2 (absolute income inequality)

1. Mean WTP for the environmental public good, $\mu_{\mathrm{WTP}}$ (Equation 3.6), increases with mean income, $\mu_{Y}$, at all levels of mean income if the environmental public good and the private consumption good are substitutes or weak complements:

$$
\frac{\partial \mu_{\mathrm{WTP}}\left(\mu_{Y}, \sigma_{Y}\right)}{\partial \mu_{Y}}>0 \quad \text { if } \quad \theta \geq 1 / 2
$$

2. Mean WTP for the environmental public good, $\mu_{\mathrm{WTP}}$, decreases (increases) with mean income if the environmental public good and the private consumption good are strong

\footnotetext{
${ }^{26}$ We thereby abstract from restrictions to redistribution schemes that actual policy may face (e.g. Requate and Lange 2000), as a main application of our results - the theory and practice of benefit transfer - concerns cross-country comparisons and adjustments.
} 
complements, $\theta<1 / 2$, and mean income $\mu_{Y}$ is smaller (greater) than $\sqrt{1 / \theta-2} \sigma_{Y}$ :

$$
\frac{\partial \mu_{\mathrm{WTP}}\left(\mu_{Y}, \sigma_{Y}\right)}{\partial \mu_{Y}} \lesseqgtr 0 \quad \text { for } \quad \mu_{Y} \lesseqgtr \sqrt{1 / \theta-2} \sigma_{Y} \quad \text { if } \quad \theta<1 / 2 .
$$

Proof. See Appendix 3.7.4.

Proposition 3.1 (for WTP expressed as a function of relative income inequality, Equation 3.7) states that the influence of mean household income on mean WTP is unambiguous and straightforward: mean WTP for the environmental public good increases with mean income. This reflects the fact that both the private consumption good and the environmental public good are normal goods for all households in the population, and that, therefore, individual WTP for the environmental public good increases with individual income. Our proposition transfers this well known result about individual WTP to the context of a society with unequally distributed income, where it becomes a statement about mean variable values.

Proposition 3.2 (for WTP expressed as a function of absolute income inequality, Equation 3.6) states that, unless the environmental public good and consumption good are strong complements, the influence of mean household income on mean WTP is unambiguous and straightforward: mean WTP for the environmental public good increases with mean income. A difference to the corresponding Proposition 3.1 for relative income inequality is that, keeping absolute income inequality fixed, mean WTP may decrease as mean income increases - namely if the two goods are strong complements, $\theta<1 / 2$, and mean income is smaller than the threshold value of $\sqrt{1 / \theta-2} \sigma_{Y}$. This threshold value increases with the degree of complementarity (it goes to $+\infty$ for $\theta \rightarrow 0$ ) and with absolute income inequality, $\sigma_{Y}$.

\subsubsection{How does income inequality affect mean WTP for the environmen- tal public good?}

We now come to our key result on how income inequality affects mean WTP for the environmental public good.

Proposition 3.3 (relative income inequality)

1. Mean WTP for the environmental public good, $\mu_{\mathrm{WTP}}$ (Equation 3.7), decreases (increases) with relative income inequality, $\mathrm{CV}_{Y}$, if and only if the environmental public 
good and the private consumption good are substitutes (complements):

$$
\frac{\partial \mu_{\mathrm{WTP}}\left(\mu_{Y}, \mathrm{CV}_{Y}\right)}{\partial \mathrm{CV}_{Y}} \lesseqgtr 0 \text { if and only if } \theta \gtreqless 1
$$

2. $\partial \mu_{\mathrm{WTP}} / \partial \mathrm{CV}_{Y}$ decreases (increases) with mean income, if and only if the environmental public good and the private consumption good are substitutes (complements):

$$
\frac{\partial^{2} \mu_{\mathrm{WTP}}\left(\mu_{Y}, \mathrm{CV}_{Y}\right)}{\partial \mu_{Y} \partial \mathrm{CV}_{Y}} \lesseqgtr 0 \text { if and only if } \theta \gtreqless 1
$$

Proof. See Appendix 3.7.5.

Proposition 3.4 (absolute income inequality)

1. Mean WTP for the environmental public good, $\mu_{\mathrm{WTP}}$ (Equation 3.6), decreases (increases) with absolute income inequality, $\sigma_{Y}$, if and only if the environmental public good and the private consumption good are substitutes (complements):

$$
\frac{\partial \mu_{\mathrm{WTP}}\left(\mu_{Y}, \sigma_{Y}\right)}{\partial \sigma_{Y}} \lesseqgtr 0 \text { if and only if } \theta \gtreqless 1
$$

2. (a) $\partial \mu_{\mathrm{WTP}} / \partial \sigma_{Y}$ does not change with mean income, $\mu_{Y}$, at all if and only if $\theta=1 / 2$ or $\theta=1$ :

$$
\frac{\partial \mu_{\mathrm{WTP}}^{2}\left(\mu_{Y}, \sigma_{Y}\right)}{\partial \mu_{Y} \partial \sigma_{Y}}=0 \text { for all } \mu_{Y}>0 \quad \text { if and only if } \theta=1 / 2 \text { or } \theta=1
$$

(b) $\partial \mu_{\mathrm{WTP}} / \partial \sigma_{Y}$ decreases with mean income, $\mu_{Y}$, for $\mu_{Y}<\sigma_{Y} \sqrt{1 / \theta}$ and increases with mean income, $\mu_{Y}$, for $\mu_{Y}>\sigma_{Y} \sqrt{1 / \theta}$, if and only if the environmental public good and the private consumption good are substitutes or strong complements:

$$
\frac{\partial \mu_{\mathrm{WTP}}^{2}\left(\mu_{Y}, \sigma_{Y}\right)}{\partial \mu_{Y} \partial \sigma_{Y}} \lesseqgtr 0 \text { for } \mu_{Y} \lesseqgtr \sqrt{1 / \theta} \sigma_{Y} \text { if and only if } \theta<1 / 2 \text { or } \theta>1
$$

(c) $\partial \mu_{\mathrm{WTP}} / \partial \sigma_{Y}$ increases with mean income, $\mu_{Y}$, for $\mu_{Y}<\sigma_{Y} \sqrt{1 / \theta}$ and decreases with mean income, $\mu_{Y}$, for $\mu_{Y}>\sigma_{Y} \sqrt{1 / \theta}$, if and only if the environmental public good and the private consumption good are weak complements:

$$
\frac{\partial \mu_{\mathrm{WTP}}^{2}\left(\mu_{Y}, \sigma_{Y}\right)}{\partial \mu_{Y} \partial \sigma_{Y}} \gtreqless 0 \text { for } \mu_{Y} \lesseqgtr \sqrt{1 / \theta} \sigma_{Y} \text { if and only if } 1 / 2<\theta<1
$$


Proof. See Appendix 3.7.6.

Statement 1 of Proposition 3.3 (for WTP expressed as a function of relative income inequality, Equation 3.7) shows that the influence of relative income inequality on mean WTP crucially depends on whether the environmental public good and the private consumption good are substitutes or complements. If they are substitutes, a more equal distribution of income increases mean WTP. If they are complements, in contrast, a more equal distribution of income decreases mean WTP.

The rationale behind this result is as follows. The two goods being substitutes is equivalent to an income elasticity of WTP below unity (cf. Equation 3.4). Then, households with lower incomes are willing to pay relatively more of their income for the environmental public good than are households with higher income. This means that if a household experiences an increase (decrease) in income, their WTP increases (decreases) only by less than his income. In addition, a more equal income distribution means that some high-income households have a lower income, while some low-income household have a correspondingly higher income, and mean income remains unchanged. Taking these two effects together explains the result, as shifting income from relatively high income levels to relatively lower levels reduces the WTP of the higher income levels, and it also increases the WTP of lower incomes, and the sum of WTP increases at low-income households is larger than the sum of WTP reductions at high-income households.

The size of this effect depends on the level of mean income in the society (Statement 2 of the proposition). In particular, in the case of substitutes the negative effect of relative income inequality on mean WTP is aggravated by the mean income level: its negative effect is increased in absolute magnitude if mean income is higher.

Statement 1 of Proposition 3.4 (for WTP expressed as a function of absolute income inequality, Equation 3.6) is exactly as in the case of relative income inequality (Proposition 3.3, Statement 1). In contrast, Statement 2 now contains an additional qualification: the effect of income inequality on social WTP not only depends on the degree of substitutability but also on the level of mean income.

Our key result on how income inequality affects mean WTP is more general than stated in Proposition 3.3 and 3.4. We assumed a particular functional specification of the utility function (CES-function with substitution parameter $\theta$, Equation 3.1) and of the income distribution (log-normal distribution with mean $\mu_{Y}$ and standard deviation $\sigma_{Y}$ ), for ease of exposition and direct applicability in empirical cases (Section 3.4). Yet, a similar result 
can be casted in more general terms for any concave utility function and any regular distribution function as long as the WTP function is globally concave or globally convex (see Appendix 3.7.12 for details).

\subsubsection{What has a larger influence on mean WTP for the environmental public good - mean income or income inequality?}

Since both mean income and relative income inequality influence mean WTP for the environmental public good, we ask: which one of the two influences is relatively larger?

Proposition 3.5 (relative income inequality)

Mean WTP for the environmental public good, $\mu_{\mathrm{WTP}}$ (Equation 3.7), changes more elastically with mean household income, $\mu_{Y}$, than with relative income inequality, $\mathrm{CV}_{Y}$, except for the extreme case where the environmental public good and the private consumption good are strong complements, $\theta<1 / 2$, and relative income inequality is larger than $\sqrt{\theta /(1-2 \theta)}$. In this case, mean WTP for the environmental public good changes less elastically with mean household income than with relative income inequality:

$$
\begin{aligned}
& \left.\mid \begin{array}{l}
> \\
= \\
<
\end{array}\right\}\left|\frac{\partial \mu_{\mathrm{WTP}, \mu_{Y}}\left(\mu_{Y}, \mathrm{CV}_{Y}\right)|:=| \frac{\partial \mu_{\mathrm{WTP}}\left(\mu_{Y}, \mathrm{CV}_{Y}\right)}{\partial \mu_{Y}} \frac{\left.\mathrm{CV}_{Y}\right)}{\partial \mathrm{CV}_{Y}} \frac{\mathrm{CV}_{Y}}{\mu_{\mathrm{WTP}}\left(\mu_{Y}, \mathrm{CV}_{Y}\right)} \mid}{\left.\mu_{\mathrm{WTP}}, \mathrm{CV}_{Y}\right)}\right|=: \quad\left|\eta_{\mu_{\mathrm{WTP}}, \mathrm{CV}_{Y}}\left(\mu_{Y}, \mathrm{CV}_{Y}\right)\right| \\
& \text { if and only if }\left\{\begin{array}{l}
\theta \geq \frac{1}{2}, \text { or } \theta<\frac{1}{2} \text { and } \mathrm{CV}_{Y}<\sqrt{\frac{\theta}{1-2 \theta}} \\
\theta<\frac{1}{2} \text { and } \mathrm{CV}_{Y}=\sqrt{\frac{\theta}{1-2 \theta}} \\
\theta<\frac{1}{2} \text { and } \mathrm{CV}_{Y}>\sqrt{\frac{\theta}{1-2 \theta}}
\end{array}\right.
\end{aligned}
$$

Proof. See Appendix 3.7.7.

Proposition 3.6 (absolute income inequality)

Mean WTP for the environmental public good, $\mu_{\mathrm{WTP}}$ (Equation 3.6), changes more elastically with mean household income, $\mu_{Y}$, than with absolute income inequality, $\sigma_{Y}$, except for the extreme case where the environmental public good and the private consumption good are strong complements, $\theta<2 / 3$, and mean income is smaller than $\sqrt{2 / \theta-3} \sigma_{Y}$. In this case, mean WTP for the environmental public good changes less elastically with mean household 
income than with relative income inequality:

$$
\begin{aligned}
& \left|\eta_{\mu_{\mathrm{WTP}}, \mu_{Y}}\left(\mu_{Y}, \sigma_{Y}\right)\right|:=\left|\frac{\partial \mu_{\mathrm{WTP}}\left(\mu_{Y}, \sigma_{Y}\right)}{\partial \mu_{Y}} \frac{\mu_{Y}}{\mu_{\mathrm{WTP}}\left(\mu_{Y}, \sigma_{Y}\right)}\right| \\
& \left\{\begin{array}{l}
> \\
= \\
<
\end{array}\right\} \quad\left|\frac{\partial \mu_{\mathrm{WTP}}\left(\mu_{Y}, \sigma_{Y}\right)}{\partial \sigma_{Y}} \frac{\sigma_{Y}}{\mu_{\mathrm{WTP}}\left(\mu_{Y}, \sigma_{Y}\right)}\right|=: \quad\left|\eta_{\mu_{\mathrm{WTP}}, \sigma_{Y}}\left(\mu_{Y}, \sigma_{Y}\right)\right| \\
& \text { if and only if } \quad\left\{\begin{array}{l}
\theta \geq \frac{2}{3}, \text { or } \theta<\frac{2}{3} \text { and } \mu_{Y}>\sqrt{2 / \theta-3} \sigma_{Y} \\
\theta<\frac{2}{3} \text { and } \mu_{Y}=\sqrt{2 / \theta-3} \sigma_{Y} \\
\theta<\frac{2}{3} \text { and } \mu_{Y}<\sqrt{2 / \theta-3} \sigma_{Y}
\end{array}\right.
\end{aligned}
$$

Proof. See Appendix 3.7.8.

Proposition 3.5 (for WTP expressed as a function of relative income inequality, Equation 3.7) means, that - except for the extreme case where the environmental public good and the private consumption good are strong complements and relative income inequality is large - mean WTP for the environmental public good reacts more elastically to the mean income level than to income inequality. That is, a one-percent increase in society's mean income level will increase society's mean WTP relatively more, i.e. by more percent, than a one-percent reduction in the coefficient of variation of income. In the extreme case, the relative effect size will be the other way round, though. For the delineation of this extreme case, what is a "large income inequality", $\mathrm{CV}_{Y}$, depends on the elasticity of substitution, $\sqrt{\theta /(1-2 \theta)}$. The stronger complementary the two goods are, i.e. the smaller $\theta$, the smaller is this expression, ${ }^{27}$ and the smaller the "large income inequality" that defines this case.

\subsubsection{How to adjust the WTP for the environmental public good for changes in the income distribution?}

Finally, we derive adjustment factors for the effects of the income distribution on mean WTP. These will be useful for different applications, such as benefit transfer or sustainability policy. Here, we present these adjustment factors in the context of benefit transfer, while we illustrate the role of these adjustment factors for sustainability policy in Section 3.4.

The increasing demand for the valuation of environmental public goods on the one hand and the resource-intensity of primary valuation studies on the other hand have caused a

\footnotetext{
${ }^{27} \sqrt{\theta /(1-2 \theta)}$ monotonically increases with $\theta$, from 0 (for $\theta \rightarrow 0$ ) to $+\infty$ (for $\theta \rightarrow 1 / 2$ ).
} 
frequent application of benefit transfers, that is, the transfer of benefit measures from one site to another (Kaul et al. 2013). While benefit transfers have many limitations, they are, due to budget constrains, often the only option to account for monetary values of environmental public goods in the planning or policy process.

In the practice of benefit transfer, WTP-estimates are transferred from a study site, where a primary valuation study has been undertaken and which is characterized - in terms of our model - by site-specific variables $\left(E^{\text {study }}, p^{\text {study }}, \mu_{Y}^{\text {study }}, \mathrm{CV}_{Y}^{\text {study }}\right)$, to a policy site, where benefit measures are needed and which is characterized by site-specific variables $\left(E^{\text {policy }}\right.$, $\left.p^{\text {policy }}, \mu_{Y}^{\text {policy }}, \mathrm{CV}_{Y}^{\text {policy }}\right)$. It is widely acknowledged that a valid benefit transfer needs to correct for the difference in the amount of environmental public good available at both sites and the difference in the mean income level (e.g. Richardson et al. 2015, Ready and Navrud 2006). But so far, adjusting for the difference in income inequality has been neglected. Substantiating the concept of a benefit transfer function (e.g. Loomis 1992, Rosenberger and Loomis 2003), our model implies that the mean WTP at the policy site, $\mu_{\mathrm{WTP}}^{\text {policy }}$, can be simply obtained through multiplying the mean WTP at the study site, $\mu_{\mathrm{WTP}}^{\text {study }}$, by a transfer factor $\mathcal{T}$.

Proposition 3.7 (relative income inequality)

Assume that people's preferences $(\theta, \alpha)$ are identical in the study and the policy sites. If mean WTP for the environmental public good (Equation 3.7) is given by $\mu_{\mathrm{WTP}}^{\text {study }}$ at a study site where the quantity of the environmental public good is $E^{\text {study }}$, the private-good market price level is $p^{\text {study }}$, mean income is $\mu_{Y}^{\text {study }}$ and relative income inequality is $\mathrm{CV}_{Y}^{\text {study }}$, then mean WTP for the environmental public good in a policy site with $\left(E^{\text {policy }}, p^{\text {policy }}, \mu_{Y}^{\text {policy }}\right.$, $\left.\mathrm{CV}_{Y}^{\text {policy }}\right)$ is given by

$$
\mu_{\mathrm{WTP}}^{\text {policy }}=\mathcal{T}\left(E^{\text {policy }}, p^{\text {policy }}, \mu_{Y}^{\text {policy }}, \mathrm{CV}_{Y}^{\text {policy }} ; E^{\text {study }}, p^{\text {study }}, \mu_{Y}^{\text {study }}, \mathrm{CV}_{Y}^{\text {study }}\right) \cdot \mu_{\mathrm{WTP}}^{\text {study }}
$$

with the following disentangled transfer factor:

$$
\mathcal{T}(\ldots)=\mathcal{T}_{E}\left(E^{\text {policy }}, E^{\text {study }}\right) \cdot \mathcal{T}_{p}\left(p^{\text {policy }}, p^{\text {study }}\right) \cdot \mathcal{T}_{\mu}\left(\mu_{Y}^{\text {policy }}, \mu_{Y}^{\text {study }}\right) \cdot \mathcal{T}_{\mathrm{CV}}\left(\mathrm{CV}_{Y}^{\text {policy }}, \mathrm{CV}_{Y}^{\text {study }}\right)
$$


with

$$
\begin{aligned}
\mathcal{T}_{E}\left(E^{\text {policy }}, E^{\text {study }}\right) & =\left(\frac{E^{\text {policy }}}{E^{\text {study }}}\right)^{\frac{\theta-1}{\theta}}, \\
\mathcal{T}_{p}\left(p^{\text {policy }}, p^{\text {study }}\right) & =\left(\frac{p^{\text {policy }}}{p^{\text {study }}}\right)^{\frac{\theta-1}{\theta}}, \\
\mathcal{T}_{\mu}\left(\mu_{Y}^{\text {policy }}, \mu_{Y}^{\text {study }}\right) & =\left(\frac{\mu_{Y}^{\text {policy }}}{\mu_{Y}^{\text {study }}}\right)^{\frac{1}{\theta}}, \\
\mathcal{T}_{\mathrm{CV}}\left(\mathrm{CV}_{Y}^{\text {policy }}, \mathrm{CV}_{Y}^{\text {study }}\right) & =\left(\frac{1+\mathrm{CV}_{Y}^{\text {policy } 2}}{1+\mathrm{CV}_{Y}^{\text {study } 2}}\right)^{\frac{1-\theta}{2 \theta^{2}}} .
\end{aligned}
$$

Proof. See Appendix 3.7.9.

Proposition 3.8 (absolute income inequality)

Assume that people's preferences $(\theta, \alpha)$ are identical in the study and the policy sites. If mean WTP for the environmental public good (Equation 3.6) is given by $\mu_{\mathrm{WTP}}^{\text {study }}$ at a study site where the quantity of the environmental public good is $E^{\text {study }}$, the private-good market price level is $p^{\text {study }}$, mean income is $\mu_{Y}^{\text {study }}$ and absolute income inequality is $\sigma_{Y}^{\text {study }}$, then mean WTP for the environmental public good in a policy site with $\left(E^{\text {policy }}, p^{\text {policy }}, \mu_{Y}^{\text {policy }}\right.$, $\left.\sigma_{Y}^{\text {policy }}\right)$ is given by

$$
\mu_{\mathrm{WTP}}^{\text {policy }}=\mathcal{T}\left(E^{\text {policy }}, p^{\text {policy }}, \mu_{Y}^{\text {policy }}, \sigma_{Y}^{\text {policy }} ; E^{\text {study }}, p^{\text {study }}, \mu_{Y}^{\text {study }}, \sigma_{Y}^{\text {study }}\right) \cdot \mu_{\mathrm{WTP}}^{\text {study }}
$$

with the transfer factor:

$$
\mathcal{T}(\ldots)=\mathcal{T}_{E}\left(E^{\text {policy }}, E^{\text {study }}\right) \cdot \mathcal{T}_{p}\left(p^{\text {policy }}, p^{\text {study }}\right) \cdot \mathcal{T}_{\mu, \sigma}\left(\mu_{Y}^{\text {policy }}, \sigma_{Y}^{\text {policy }}, \mu_{Y}^{\text {study }}, \sigma_{Y}^{\text {study }}\right)
$$

with

$$
\mathcal{T}_{\mu, \sigma}\left(\mu_{Y}^{\text {policy }}, \sigma_{Y}^{\text {policy }}, \mu_{Y}^{\text {study }}, \sigma_{Y}^{\text {study }}\right)=\left(\frac{\mu_{Y}^{\text {policy }}}{\mu_{Y}^{\text {study }}}\right)^{1 / \theta} \cdot\left(\frac{1+\left(\sigma_{Y}^{\text {policy }} / \mu_{Y}^{\text {policy }}\right)^{2}}{1+\left(\sigma_{Y}^{\text {study }} / \mu_{Y}^{\text {study }}\right)^{2}}\right)^{\frac{1-\theta}{2 \theta^{2}}}
$$

and $\mathcal{T}_{E}\left(E^{\text {policy }}, E^{\text {study }}\right), \mathcal{T}_{p}\left(p^{\text {policy }}, p^{\text {study }}\right)$ as in Equations $(3.23)$ and (3.24).

Proof. In analogy to the proof of Proposition 3.7, see Appendix 3.7.9.

Proposition 3.7 (for WTP expressed as a function of relative income inequality, Equation 3.7) shows that adjusting WTP-estimates for differences in income inequality is easy, as 
the transfer factor fully factorizes into a product of variable-specific factors. So, each of the site-specific variables can be controlled for separately. As expected after Proposition 3.3, the income-inequality specific transfer factor $\mathcal{T}_{\mathrm{CV}}$ may be greater or small than one, depending on whether the environmental public good and the private consumption good are substitutes or complements, $\theta>1$ or $\theta<1$, and whether income inequality is greater or smaller in the policy site than in the study site, $\mathrm{CV}_{Y}^{\text {policy }}>\mathrm{CV}_{Y}^{\text {study }}$ or $\mathrm{CV}_{Y}^{\text {policy }}<\mathrm{CV}_{Y}^{\text {study }}$.

If the two goods have an elasticity of substitution of one, as for Cobb-Douglas-preferences, one has $\mathcal{T}_{\mathrm{CV}}=1$ so that there does not need to be any adjustment for income inequality. In this case, there is also no need to correct for differences in market prices for private goods or the endowment with the environmental public good. Yet, in the empirically more relevant case $\theta>1$, all these correction factors will in general differ from one.

As a by-product, Proposition 3.7 also states how to control for the difference in market price level, $p$, that is, the purchasing power of income, between the study site and the policy site.

In Proposition 3.8 (for WTP expressed as a function of relative income inequality, Equation 3.7), the transfer factors for the level of the environmental public good, $E$, and for the private-good market price level, $p$, are the same as for the case of relative income inequality (cf. Proposition 3.7). The transfers factors for the two moments of the income distribution, $\mu_{Y}$ and $\sigma_{Y}$, are not algebraically decomposable and, therefore, appear as a joint factor, $\mathcal{T}_{\mu, \sigma}\left(\mu_{Y}^{\text {policy }}, \sigma_{Y}^{\text {policy }}, \mu_{Y}^{\text {study }}, \sigma_{Y}^{\text {study }}\right) .{ }^{28}$

\subsection{Empirical analysis}

In this Section, we provide two empirical case studies to illustrate the theoretical results from Section 3.3, and to estimate the order of magnitude of the comparative static effects. We have chosen these cases to represent different environmental public goods and different socio-economic contexts, to demonstrate a range of potential effects. We have based selection

\footnotetext{
${ }^{28}$ As the Gini coefficient is also often used as an inequality measure, we report here the corresponding transfer function: For the case of log-nomally distributed income the Gini coefficient $(G)$ depends only on $\sigma_{Y}$ and can be represented as $G\left(\sigma_{y}\right)=2 F\left(\sigma_{y} / \sqrt{2}\right)-1$ (Cowell 2009: 153), where $F(\cdot)$ is the cumulative distribution function of the standard normal distribution $\mathcal{N}(0,1)$. Hence, the transfer factor $\mathcal{T}_{\mu, \sigma}(\ldots)$ can be expressed in terms of the Gini coefficient as follows:
}

$$
\mathcal{T}_{\mu, G}\left(\mu_{Y}^{\text {policy }}, G_{Y}^{\text {policy }}, \mu_{Y}^{\text {study }}, G_{Y}^{\text {study }}\right)=\left(\frac{\mu_{Y}^{\text {policy }}}{\mu_{Y}^{\text {study }}}\right)^{1 / \theta} \cdot\left(\frac{1+\left(\left(\sqrt{2} F^{-1}\left(\frac{G_{Y}^{\text {policy }}+1}{2}\right)\right) / \mu_{Y}^{\text {policy }}\right)^{2}}{\left(1+\left(\left(\sqrt{2} F^{-1}\left(\frac{G_{Y}^{\text {study }}+1}{2}\right)\right)\right) / \mu_{Y}^{\text {study }}\right)^{2}}\right)^{\frac{1-\theta}{2 \theta^{2}}} .
$$


on the crucial criterion of availability of recent data on the income elasticity of WTP for the environmental public goods.

The first case concerns an environmental public good of high cultural importance in a developed country: the existence of large predator species in Sweden (Section 3.4.1, based on the study described in Broberg and Brännlund 2008, and in Broberg 2010). The second case examines a global environmental public good - the existence of biodiversity worldwide (Section 3.4.1, based on the meta-study of Jacobsen and Hanley 2009).

We first describe each of the case studies separately and review how the respective data have been gathered and processed (Section 3.4.1). We subsequently present the results of our empirical analysis in an overview of both cases (Section 3.4.2).

\subsubsection{Data description and processing}

\section{Existence of large predator species in Sweden}

The existence of large predator species provides a range of culturally important services to humans, including direct use and option values for hunters or wildlife tourists and in particular bequest and existence values for the broader population. In Sweden, four large predator species were threatened with extinction at the time of the study: the wolf and the wolverine are 'critically endangerd' and 'endangered', respectively, while the populations of bear and lynx are 'vulnarable' (Broberg and Brännlund 2008: 1066).

Broberg (2010) studied the income effects on WTP for the 2009 Swedish Predator Policy, which aims at securing the survival of these predator species. His analysis builds on survey data from 872 Swedish individuals from May 2004. ${ }^{29}$ Respondents had filled out a multiple bounded payment card matrix which was based on a polychotomous-choice question that elicited WTP according to different levels of an annual tax to be paid in the next five years with nine amounts ranging from 10 Swedish krona (SEK) ${ }^{30}$ to 5,000 SEK and five uncertainty levels, from "definitely yes" to "definitely no" (Broberg 2010: 7). Mean WTP of Swedish survey respondents was found to be $\mu_{\mathrm{WTP}}^{\mathrm{SWE}}=449.67$ SEK (Broberg and Brännlund 2008: 564). ${ }^{31}$

\footnotetext{
${ }^{29}$ The survey was sent by mail to 4,050 randomly selected Swedish individuals, who were chosen on the basis of a stratification process to ensure the selection of individuals living far from, close to and within wildlife areas. Of the 2,455 respondents, those 872 were selected to estimate the WTP function who stated a positive WTP, had non-zero income, and consistently filled out the multiple bounded payment card matrix.

${ }^{30}$ One Swedish krona (SEK) was worth 0.15 US Dollars in 2004.

${ }^{31}$ Broberg and Brännlund (2008: 564) employed different estimation techniques for the WTP function, including an expansion approach where data are recoded such that "definitely yes" and "probably yes"
} 
For each survey respondent, Broberg (2010) took household income data from the income register of Statistics Sweden, which have a very high degree of accuracy. Among other income variables, he reports annual disposable household income (net income including capital income and social benefits) in 2003. Mean annual disposable household income of all 872 survey respondents is $\mu_{Y}^{\mathrm{SWE}}=304,422 \mathrm{SEK}$, with a standard deviation of $\sigma_{Y}^{\mathrm{SWE}}=174,879 \mathrm{SEK}$ and a corresponding coefficient of variation of $\mathrm{CV}_{Y}^{\mathrm{SWE}}=0.57$. The constant income elasticity of WTP for the Swedish Predator Policy using annual disposable household income was estimated to be $\eta^{\mathrm{SWE}}=0.37$, with a standard error of $\Delta \eta^{\mathrm{SWE}}=0.1$ (cf. model Mod. $3_{H N}$ of Broberg 2010). ${ }^{32}$

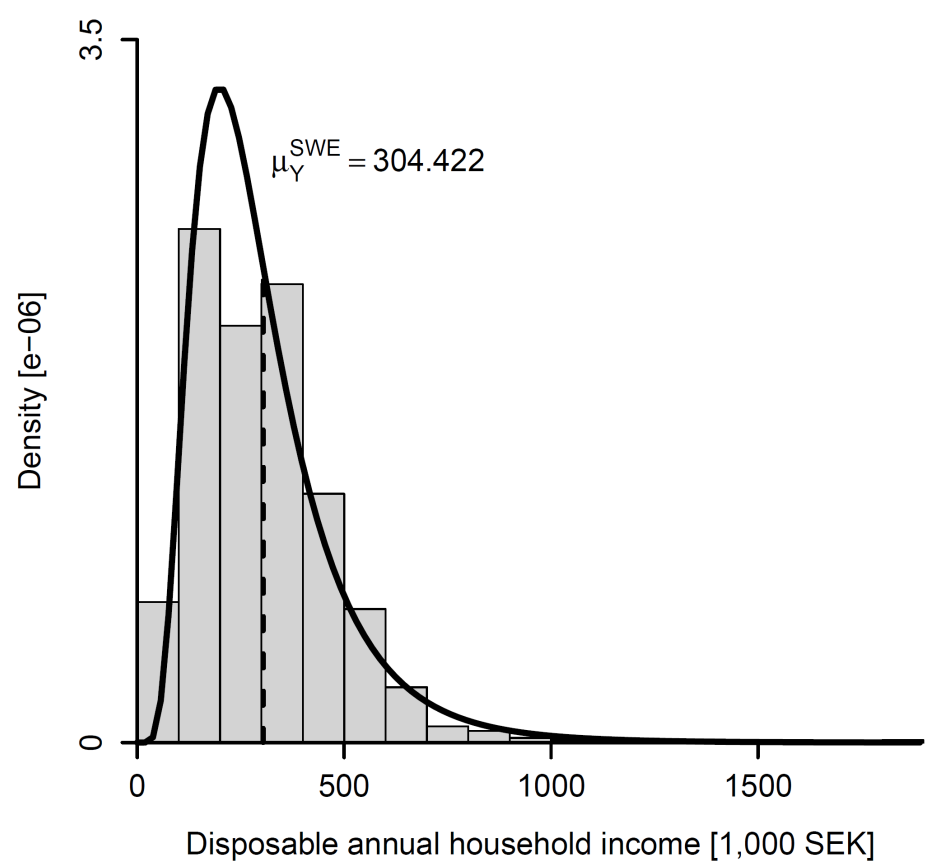

Figure 3.1: Histogram of the distribution of disposable annual household income in Sweden [in 1,000 SEK], as used by Broberg (2010), and best-fitting log-normal distribution.

Having described the case study, we now turn to how we have processed this data. In order to quantify the effects of the income distribution on mean WTP for the Swedish Predator Policy, we need to specify the inputs to Equation (3.7). As far as possible, we rely on data and estimation results provided in the original study of Broberg (2010), yielding inputs for $\mu_{Y}^{\mathrm{SWE}}, \sigma_{Y}^{\mathrm{SWE}}, \mathrm{CV}_{Y}^{\mathrm{SWE}}$ as well as $\theta^{\mathrm{SWE}}=1 / \eta^{\mathrm{SWE}}$.

means "yes", and the other answers mean "no". This approach was used by Broberg (2010) in his subsequent analysis of the income effects.

${ }^{32}$ To model the relationship between WTP and income, Broberg (2010) employed a range of functional forms (linear, quadratic, linear in logarithms), different income variables and other determining factors. He found that income has a significantly positive effect on WTP, with income elasticities of WTP ranging from 0.14 to 0.4 , depending on the functional form. The specification yielding a constant income elasticity of WTP "do[es] not have significantly worse overall fit" than other specifications (Broberg 2010: 15). 
For $\mu_{Y}^{\mathrm{SWE}}, \sigma_{Y}^{\mathrm{SWE}}$ and $\mathrm{CV}_{Y}^{\mathrm{SWE}}$ we use the data of disposable household income from Broberg (2010), which is depicted in Figure 3.1. We assume that the best fitting log-normal distribution is the true income distribution. Furthermore, we take the constant income elasticity of WTP estimated in Broberg (2010) and compute as its inverse the elasticity of substitution between consumption goods and the cultural environmental good, $\theta^{\mathrm{SWE}}$. This yields an elasticity of substitution of $\theta^{\mathrm{SWE}}=1 / \eta^{\mathrm{SWE}}=1 / 0.37=2.63$ (Equation 3.4 ). From the standard error in the measurement of the income elasticity, estimated by Broberg (2010) to be $\Delta \eta^{\mathrm{SWE}}=0.1$, we obtain corresponding errors in $\theta^{\mathrm{SWE}}$ that - through the inverse relationship - directly translate into the following upper and lower bound estimates: $\theta_{\eta=0.47}^{\mathrm{SWE}}=2.12$, $\theta_{\eta=0.27}^{\mathrm{SWE}}=3.66$.

We compute the missing residual $\kappa^{\mathrm{SWE}}$ indirectly through Equation (3.7). Rearranging Equation (3.7) for $\kappa$ as $\kappa \stackrel{\text { calib. }}{=} \mu_{\mathrm{WTP}}\left[\mu_{Y}^{1 / \theta}\left(1+\mathrm{CV}_{Y}^{2}\right)^{\frac{1-\theta}{2 \theta^{2}}}\right]^{-1}$ and using all parameters in that equation from Broberg (2010) yields a residual, calibrated factor of $\kappa^{\mathrm{SWE}}=4.24$. As $\kappa=\frac{1-\alpha}{\alpha}(p E)^{\frac{\theta-1}{\theta}}$ depends on $\theta=1 / \eta$ (Equation 3.4), we use a standard method for error propagation to determine the error in $\kappa$ stemming from the error of the income elasticity of WTP, $\eta$, (see Appendix 3.7.10):

$$
\kappa_{\eta \pm \Delta \eta}=\exp \left(\left[1 \mp \frac{\Delta \eta}{1-\eta}\right] \cdot \ln \kappa_{\eta}\right)
$$

This procedure yields $\kappa_{\eta=0.47}^{\mathrm{SWE}}=3.38$ and $\kappa_{\eta=0.27}^{\mathrm{SWE}}=5.33$ as upper and lower bounds, respectively, for $\kappa$.

\section{Global biodiversity conservation}

For our analysis of how mean WTP for an environmental good depends on the distribution of income on a global scale, we draw on the meta-study by Jacobsen and Hanley (2009), who gathered 145 WTP-estimates from 46 contingent valuation studies across six continents. These contingent valuation studies assessed WTP for different kinds of ecosystem service preservation projects, with a focus on existence values. Most studies included in the dataset are located in developed countries and have been conducted between 1979 and 2005. Jacobsen and Hanley (2009) estimated an income elasticity of WTP for global biodiversity conservation of $\eta^{\mathrm{GLO}}=0.38$, with a standard error of $\Delta \eta^{\mathrm{GLO}}=0.14$, through a double-log estimation with 'WTP per year' [in units of 2006-purchasing-power-converted-USD, “2006-PPP-USD”] as the dependent variable and 'annual household income' [in units of 2006-PPP-USD] as 


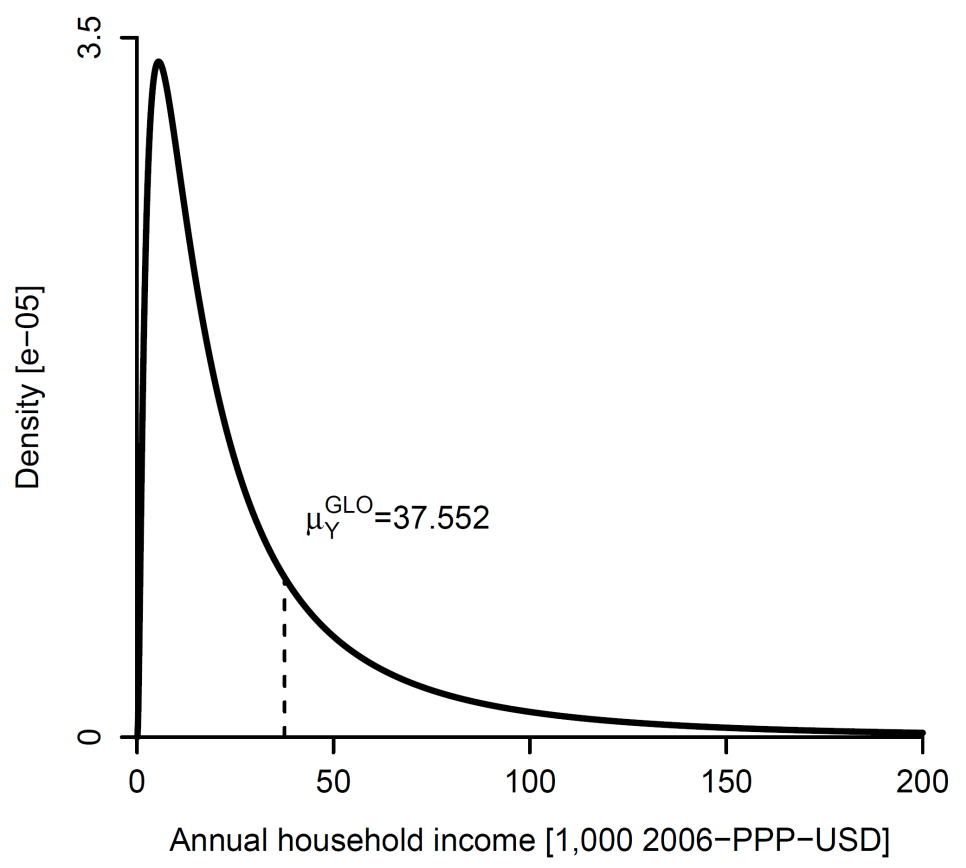

Figure 3.2: Best-fitting log-normal distribution of annual household income worldwide [in units of 1,000 2006-PPP-USD], based on Pinkovskiy and Sala-i-Martin (2009).

the explanatory variable (Table 3 in Jacobsen and Hanley 2009: 145) from 127 data pairs with household income. Their estimated mean WTP for global biodiversity conservation is $\mu_{Y}^{\mathrm{GLO}}=89.512006-\mathrm{PPP}-\mathrm{USD}$.

As there is - to our knowledge - no better estimate for an income elasticity of global WTP for environmental goods, we treat it as a proxy for the global picture. The income data in the sample of Jacobsen and Hanley (2009) consist of the mean income values of the single studies. Thus, these income data are not representative of the world distribution of household income, but reflect the arbitrary study selection, with an over-proportionate representation of studies from developed countries. We therefore generated an approximation of the world household income distribution that more closely resembles the actual distribution.

We specify the inputs to Equation (3.7) as follows. First, for the moments of the world distribution of household income, we draw on the study by Pinkovskiy and Sala-i-Martin (2009), who estimate log-normal income distributions for 191 countries as well as for the world, suggesting a global mean income per capita in 2006 of 9,550 USD and a standard deviation of 15,400 USD (Pinkovskiy, personal communication). To derive the world distribution of household income, we combine their per-capita income data with estimates on average national household size, which originate from the year 2002 (Dorling et al. 2010). Simple multiplication produces the moments of the global distribution of household income. 
TABle 3.1: Descriptive statistics for the two case studies.

\begin{tabular}{lcc}
\hline & $\begin{array}{c}\text { Existence of large predator species } \\
\text { (Sweden) }\end{array}$ & $\begin{array}{c}\text { Existence of biodiversity } \\
\text { (Global) }\end{array}$ \\
\hline \hline $\mathrm{N}$ & 872 & 127 (for WTP data) \\
$\mathrm{WTP}$ & & \\
\hline mean WTP $\left(\mu_{\mathrm{WTP})}\right.$ & 449.67 [annual SEK for five years] & 89.51 [annual 2006-PPP-USD] \\
income elasticity of WTP $(\eta)$ & $0.37_{-0.10}^{+0.10}$ & $0.38_{-0.14}^{+0.14}$ \\
elasticity of substitution $(\theta)$ & $2.69_{-0.57}^{+0.97}$ & $2.63_{-0.71}^{+1.54}$ \\
constant $(\kappa)$ & $4.24_{-0.86}^{+1.09}$ & $1.90_{-0.26}^{+0.30}$ \\
Income & & \\
\hline annual mean $\left(\mu_{Y}\right)$ & & $37,522[2006-\mathrm{PPP}-\mathrm{USD}]$ \\
standard deviation $\left(\sigma_{Y}\right)$ & 174,879 [SEK] & 60,555 [2006-PPP-USD] \\
coefficient of variation $\left(\mathrm{CV}_{Y}\right)$ & 0.57 & 1.61 \\
\hline
\end{tabular}

We find that global mean household income is $\mu_{Y}^{\mathrm{GLO}}=37,552$ 2006-PPP-USD, with a standard deviation of $\sigma_{Y}^{\mathrm{GLO}}=60,555$ 2006-PPP-USD corresponding to a coefficient of variation of $\mathrm{CV}_{Y}^{\mathrm{GLO}}=1.61$. The curve of the log-normal distribution with this mean and standard distribution is depicted in Figure 3.2. Second, $\theta^{\mathrm{GLO}}$ is given through $1 / \eta^{\mathrm{GLO}}=1 / 0.38=2.63$. Taking into account the standard error in $\eta^{\mathrm{GLO}}$ of $\Delta \eta^{\mathrm{GLO}}=0.14$, we obtain corresponding errors in $\theta^{\mathrm{GLO}}=1 / \eta^{\mathrm{GLO}}: \theta_{\eta=0.52}^{\mathrm{GLO}}=1.92, \theta_{\eta=0.24}^{\mathrm{GLO}}=4.17$. Third, as above, we calculate $\kappa^{\mathrm{GLO}}$ indirectly as 1.90 . Taking into account the standard error in $\eta$ impacting $\kappa$, through a standard error propagation estimation (Appendix 3.7.10), we obtain: $\kappa_{\eta=0.52}^{\mathrm{GLO}}=1.64$ and $\kappa_{\eta=0.24}^{\mathrm{GLO}}=2.20$.

\subsubsection{Results of empirical analysis}

We now quantify and illustrate how mean WTP for environmental public goods depends on the distribution of income in a society (Propositions 3.1 through 3.8 ) using the case studies described above. We do this in parallel for both measures of relative and absolute income inequality, the coefficient of variation and standard deviation of income, respectively. Due to the symmetry of the analysis, we only discuss in detail the results of the case study concerning the global picture (Section 3.4.1), and report the corresponding results of the other case study in Tables 3.2 and 3.3. The quantitative inputs from the two case studies to the empirical analysis are summarized in Table 3.1.

First, we examine how mean WTP for global biodiversity conservation changes with adjustments in mean world household income. Figure 3.3 illustrates this relationship for the income elasticity of WTP of $\eta^{\mathrm{GLO}}=0.38\left(\theta^{\mathrm{GLO}}=2.63\right)$, from Jacobsen and Hanley (2009), 
TABLE 3.2: Elasticities of mean WTP with respect to mean income as well as relative and absolute income inequality for the model with relative income inequality (Equations 3.58, 3.59) and the model with absolute income inequality (Equations 3.74, 3.78), with $i=$ SWE, GLO.

\begin{tabular}{|c|c|c|}
\hline & $\begin{array}{c}\text { Existence of large predator species } \\
\text { (Sweden) }\end{array}$ & Existence of biodiversity (Global) \\
\hline \multicolumn{3}{|c|}{ Elasticities of mean WTP for the model with relative income inequality (Proposition 3 ) } \\
\hline$\eta_{\mu_{\mathrm{WTP}}, \mu_{Y}}^{i}\left(\mu_{Y}^{i}, \mathrm{CV}_{Y}^{i}\right)$ & $0.37_{-0.10}^{+0.10}$ & $0.38_{-0.14}^{+0.14}$ \\
\hline$\eta_{\mu_{\mathrm{WTP}}, \mathrm{CV}_{Y}}^{i}\left(\mu_{Y}^{i}, \mathrm{CV}_{Y}^{i}\right)$ & $0.06_{-0.01}^{+0.00}$ & $0.17_{-0.04}^{+0.01}$ \\
\hline \multicolumn{3}{|c|}{ Elasticities of mean WTP for the model with absolute income inequality (Proposition 3.6) } \\
\hline$\eta_{\mu_{\mathrm{WTP}}, \mu_{Y}}\left(\mu_{Y}^{i}, \sigma_{Y}^{i}\right)$ & $0.43_{-0.11}^{+0.10}$ & $0.55_{-0.18}^{+0.15}$ \\
\hline$\eta_{\mu_{\mathrm{WTP}}, \sigma_{Y}}^{i}\left(\mu_{Y}^{i}, \sigma_{Y}^{i}\right)$ & $0.06_{-0.01}^{+0.00}$ & $0.17_{-0.04}^{+0.01}$ \\
\hline
\end{tabular}

depicted as the solid black curve, with a shaded error range of one standard error in the income elasticity of WTP, while holding the coefficient of variation of income constant at the given level of $\mathrm{CV}_{Y}^{\mathrm{GLO}}=1.61$ (Proposition 3.1).

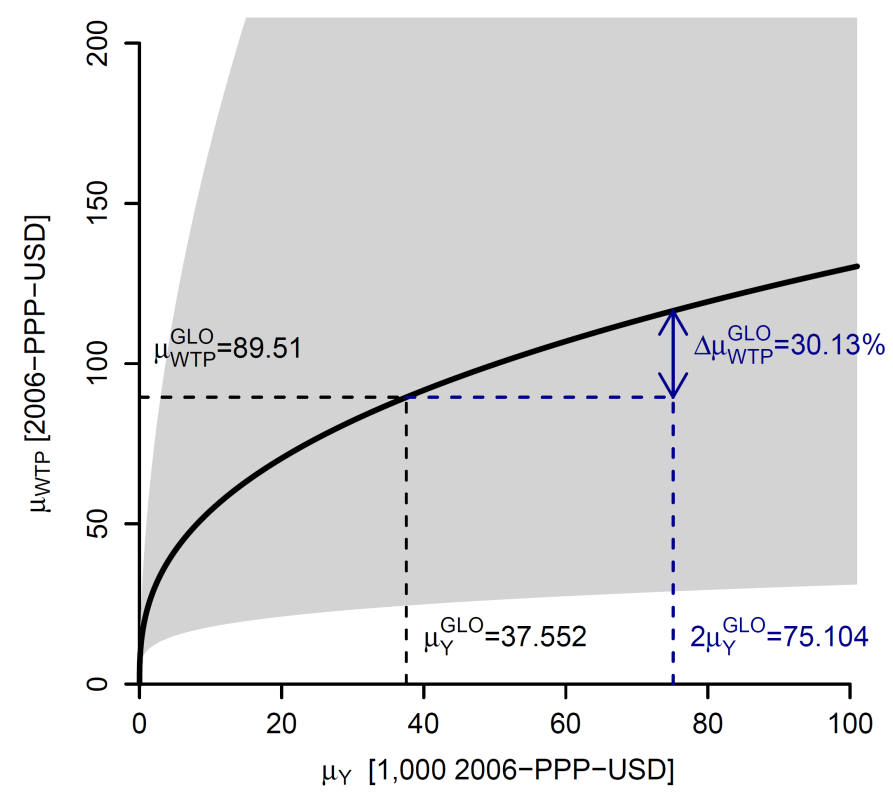

FIGURE 3.3: Relationship between mean WTP for global biodiversity conservation, $\mu_{\mathrm{WTP}}^{\mathrm{GLO}}$, and mean world household income, $\mu_{Y}^{\mathrm{GLO}}$, with an error margin of one standard error of the income elasticity of WTP (shaded in grey), for a given coefficient of variation of income of $\mathrm{CV}_{Y}^{\mathrm{GLO}}=1.61$. The adjustment factor $\mathcal{T}_{\mu}\left(2 \mu_{Y}^{\mathrm{GLO}}, \mu_{Y}^{\mathrm{GLO}}\right)$ for a (hypothetical) doubling of mean income corresponds to an increase in mean WTP, $\Delta \mu_{\mathrm{WTP}}^{\mathrm{GLO}}$, of $30.13 \%$.

Mean WTP for global biodiversity conservation is an increasing, concave function of mean world household income. If mean world household income increased by $1 \%$, and global relative income inequality stayed constant, mean WTP would rise by approximately $\eta_{\mu_{\mathrm{WTP}, \mu_{Y}}^{\mathrm{GLO}}}^{\mathrm{GLO}}=0.38 \%_{-0.14}^{+0.14}$ (Proposition 3, Equation 3.58, see Table 3.2). The reported range 
corresponds to one standard error in the income elasticity of WTP. ${ }^{33}$ A hypothetical doubling of mean world household income for a constant coefficient of variation of income, corresponding to an adjustment factor $\mathcal{T}_{\mu}\left(2 \mu_{Y}^{\mathrm{GLO}}, \mu_{Y}^{\mathrm{GLO}}\right)$, would lead to an increase in mean WTP for environmental goods, $\Delta \mu_{\mathrm{WTP}}^{\mathrm{GLO}}$, of $30.13 \%_{-12.03}^{+13.26}$ (Propositions 3.7 and 3.8 , see Table 3.3) ${ }^{34}$ For the case of a constant absolute income inequality, mean WTP would rise by $\eta_{\mu_{\mathrm{WTP}}, \mu_{Y}}^{\mathrm{GLO}}\left(\mu_{Y}, \sigma_{Y}\right)=0.55 \%_{-0.18}^{+0.15}$ if mean household income increased by $1 \%$ (Proposition 3.6 , Equation 3.74, see Table 3.2 ), and by $42.66 \%_{-15.85}^{+15.40}$ in case of a hypothetical doubling of mean income, corresponding to the adjustment factor $\mathcal{T}_{\mu, \sigma}\left(2 \mu_{Y}^{\mathrm{GLO}}, \sigma_{Y}^{\mathrm{GLO}}, \mu_{Y}^{\mathrm{GLO}}, \sigma_{Y}^{\mathrm{GLO}}\right.$ ) (Proposition 3.8, see Table 3.3).

Second, we look at how mean WTP for global biodiversity conservation changes with income inequality, as measured by either the coefficient of variation or the standard deviation of income, for a given level of mean world household income $\mu_{Y}^{\mathrm{GLO}}=37,552$ 2006-PPP-USD. Figure 3.4 illustrates this relationship for the coefficient of variation as a measure of relative income inequality. ${ }^{35}$ Mean WTP for global biodiversity conservation decreases with income inequality. Increasing either relative or absolute income inequality by $1 \%$ would decrease mean WTP by $0.17_{-0.04}^{+0.01 \%}$ (Propositions 3.5 and 3.6, see Table 3.2).

As a hypothetical scenario, reducing relative or absolute income inequality to zero and obtaining an equal income distribution, would yield an adjustment factor of $\mathcal{T}_{\mathrm{CV}}\left(0, \mathrm{CV}_{Y}^{\mathrm{GLO}}\right)$ or $\mathcal{T}_{\mu, \sigma}\left(\mu_{Y}^{\mathrm{GLO}}, 0, \mu_{Y}^{\mathrm{GLO}}, \sigma_{Y}^{\mathrm{GLO}}\right)$ that corresponds to an increase of mean WTP for global biodiversity conservation, $\Delta \mu_{\mathrm{WTP}}^{\mathrm{GLO}}$, by $16.29 \%_{-3.90}^{+1.05}$. As a more realistic scenario, we consider a benefit transfer from the global study to an application in Sweden, which is a country known for its relatively low income inequality. In this case, a transfer of a WTP-estimate from a global study context with an income inequality of $\mathrm{CV}_{Y}^{\mathrm{GLO}}=1.61$ to a policy context in Sweden with an income inequality of $\mathrm{CV}_{Y}^{\mathrm{SWE}}=0.57$, would lead to an increase in mean WTP by $\Delta \mu_{\mathrm{WTP}}^{\mathrm{GLO}}$ of $11.11_{-2.40}^{+0.62 \%} \%$. This corresponds to an adjustment factor of $\mathcal{T}_{\mathrm{CV}}\left(\mathrm{CV}_{Y}^{\mathrm{SWE}}, \mathrm{CV}_{Y}^{\mathrm{GLO}}\right)$. Third, we study whether the negative effect of income inequality on mean WTP for environmental public goods depends on the level of mean income. As shown in Proposition 3.7, the adjustment factor $\mathcal{T}_{\mathrm{CV}}$ that concerns the relationship between mean WTP for environmental public goods and relative income inequality is independent of the level

\footnotetext{
${ }^{33}$ This is the only source of error we report, as the quality of the data does not permit us to provide reliable standard errors for the estimation of the moments of the distribution of income.

${ }^{34}$ At historical or forecasted world long-term growth rates of between $1.6 \%$ and $2 \%$ (Drupp et al. 2015), such a doubling would occur within 35 to 44 years, that is, within the lifetime of one generation.

${ }^{35}$ The respective figure for the standard deviation as a measure of absolute income inequality shows exactly the same curve and error margin.
} 


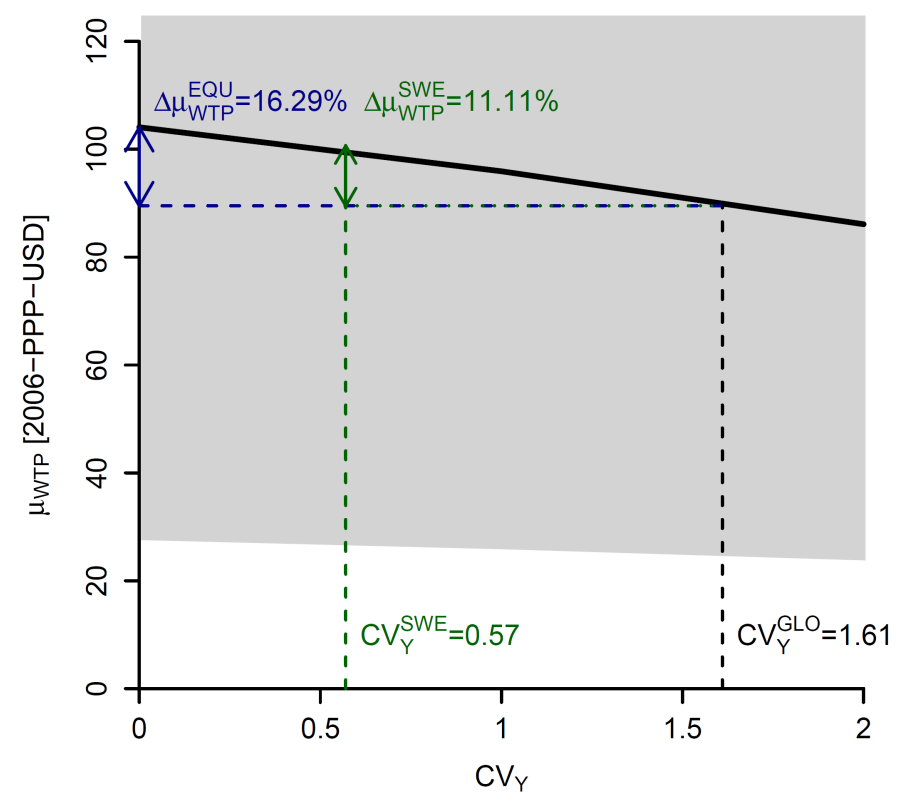

FIGURE 3.4: Relationship between mean WTP for global biodiversity conservation, $\mu_{\mathrm{WTP}}^{\mathrm{GLO}}$, and the coefficient of variation of world household income, $\mathrm{CV}_{Y}^{\mathrm{GLO}}$, for a given level of mean world household income $\mu_{Y}^{\mathrm{GLO}}=37,552$ in 2006-PPP-USD, with an error margin of one standard error (shaded in grey). The adjustment factors $\mathcal{T}_{\mathrm{CV}}\left(0, \mathrm{CV}_{\mathrm{Y}}^{\mathrm{GLO}}\right)$ and $\mathcal{T}_{\mathrm{CV}}\left(\mathrm{CV}_{Y}^{\mathrm{SWE}}, \mathrm{CV}_{Y}^{\mathrm{GLO}}\right)$ correspond to an (hypothetical) increase in mean WTP, $\Delta \mu_{\mathrm{WTP}}^{\mathrm{GLO}}$, of $16.29 \%$ and $11.11 \%$, respectively. While the former is the WTP-adjustment for the extreme case of complete income equality, the latter is the WTP-adjustment for income inequality between the global situation to the setting in Sweden.

of mean income. This means, reducing relative income inequality to zero from its original value $\mathrm{CV}_{Y}^{\mathrm{GLO}}$ raises mean WTP by $\Delta \mu_{\mathrm{WTP}}^{\mathrm{GLO}}=16.29 \%$ irrespective of the initial level of mean income. This finding does not hold for the relationship between mean WTP for environmental public goods and absolute income inequality as measured by the standard deviation, $\sigma_{Y}$ (cf. Proposition 3.8). We find that for the world mean household income level of $\mu_{Y}^{\mathrm{GLO}}$, reducing absolute income inequality to zero, corresponding to an adjustment factor $\mathcal{T}_{\mu, \sigma}\left(\mu_{Y}^{\mathrm{GLO}}, 0, \mu_{Y}^{\mathrm{GLO}}, \sigma_{Y}^{\mathrm{GLO}}\right)$, leads to an increase of mean WTP for global biodiversity conservation by $\Delta \mu_{\mathrm{WTP}}^{\mathrm{GLO}}=16.29_{-3.90}^{+1.05} \%$. In comparison, for a $30 \%$ lower world mean household income level, the same reduction of absolute income inequality, corresponding to an adjustment factor $\mathcal{T}_{\mu, \sigma}\left(0.7 \mu_{Y}^{\mathrm{GLO}}, 0,0.7 \mu_{Y}^{\mathrm{GLO}}, \sigma_{Y}^{\mathrm{GLO}}\right)$, leads to an increase of mean WTP for global

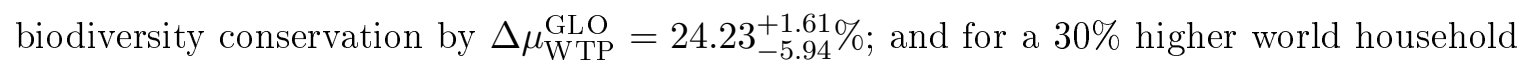
income level, corresponding to an adjustment factor $\mathcal{T}_{\mu, \sigma}\left(1.3 \mu_{Y}^{\mathrm{GLO}}, 0,1.3 \mu_{Y}^{\mathrm{GLO}}, \sigma_{Y}^{\mathrm{GLO}}\right)$, the increase is $\Delta \mu_{\mathrm{WTP}}^{\mathrm{GLO}}=11.60_{-2.73}^{+0.73} \%$ (Table 3.3). So, the negative effect of income inequality on mean WTP is more than twice as strong, in percent, when the income level doubles.

Fourth, since both mean income and income inequality influence global mean WTP for biodiversity conservation, we study which one of the two influences is relatively stronger (Propositions 3.5 and 3.6, see Table 3.2). WTP with respect to mean income for $\mathrm{CV}_{Y}$ as the 
TABLE 3.3: Changes in mean WTP for environmental public goods $\Delta \mu_{\mathrm{WTP}}^{i}$ in percent corresponding to the adjustment factors $\mathcal{T}$, with $\Delta \mu_{\mathrm{WTP}}^{i}=\mathcal{T}-1$, and $i=$ SWE, GLO.

\begin{tabular}{|c|c|c|}
\hline Adjustment factor & $\begin{array}{c}\text { Existence of large predator species } \\
\text { (Sweden) }\end{array}$ & Existence of biodiversity (Global) \\
\hline \multicolumn{3}{|c|}{ Changes in mean WTP for the model with relative income inequality (Proposition 3.7) } \\
\hline $\mathcal{T}_{\mu}\left(2 \mu_{Y}^{i}, \mu_{Y}^{i}\right)$ & $29.41_{-8.58}^{+9.20}$ & $30.13_{-12.03}^{+13.26}$ \\
\hline $\mathcal{T}_{\mathrm{CV}}\left(0, \mathrm{CV}_{Y}^{i}\right)$ & $3.39_{-0.52}^{+0.23}$ & $16.29_{-3.90}^{+1.05}$ \\
\hline $\mathcal{T}_{\mathrm{CV}}\left(\mathrm{CV}_{Y}^{\mathrm{SWE}}, \mathrm{CV}_{Y}^{i}\right)$ & 0 & $11.11_{-2.40}^{+0.62}$ \\
\hline \multicolumn{3}{|c|}{ Changes in mean WTP for the model with absolute income inequality (Proposition 3.8) } \\
\hline $\mathcal{T}_{\mu, \sigma}\left(2 \mu_{Y}^{i}, \sigma_{Y}^{i}, \mu_{Y}^{i}, \sigma_{Y}^{i}\right)$ & $32.56_{-9.23}^{+9.65}$ & $42.66_{-15.85}^{+15.40}$ \\
\hline $\mathcal{T}_{\mu, \sigma}\left(\mu_{Y}^{i}, 0, \mu_{Y}^{i}, \sigma_{Y}^{i}\right)$ & $3.39_{-0.52}^{+0.23}$ & $16.29_{-3.90}^{+1.05}$ \\
\hline $\mathcal{T}_{\mu, \sigma}\left(0.7 \mu_{Y}^{i}, 0,0.7 \mu_{Y}^{i}, \sigma_{Y}^{i}\right)$ & $6.20_{-0.96}^{+0.42}$ & $24.23_{-5.94}^{+1.61}$ \\
\hline $\mathcal{T}_{\mu, \sigma}\left(1.3 \mu_{Y}^{i}, 0,1.3 \mu_{Y}^{i}, \sigma_{Y}^{i}\right)$ & $2.11_{-0.32}^{+0.14}$ & $11.60_{-2.73}^{+0.73}$ \\
\hline
\end{tabular}

measure of relative income inequality is simply the inverse of the elasticity of substitution

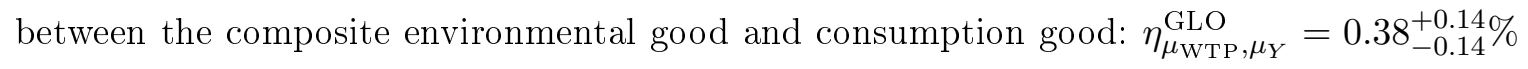
(Equation 3.58). The elasticity of mean WTP with respect to mean income for $\sigma_{Y}$ as the measure of absolute income inequality is $\eta_{\mu_{\mathrm{WTP}}, \mu_{Y}}^{\mathrm{GLO}}\left(\mu_{Y}, \sigma_{Y}\right)=0.55_{-0.18}^{+0.15 \%}$. (cf. Equation 3.74). The elasticity of mean WTP with respect to both absolute and relative income inequality is $\eta_{\mu_{\mathrm{WTP}}, \mathrm{CV}_{Y}}^{\mathrm{GLO}}\left(\mathrm{CV}_{Y}\right)=\eta_{\mu_{\mathrm{WTP}}, \sigma_{Y}}^{\mathrm{GLO}}\left(\mu_{Y}, \sigma_{Y}\right)=0.17_{-0.04}^{+0.01} \%$ (Equations 3.59 and 3.78). It thus follows that the influence of a change in mean income on mean WTP is relatively stronger than a change in either relative or absolute income inequality, while this relative effect is greater for the case of absolute income inequality.

\subsection{Discussion}

In this section, we discuss to what extent assumptions made in this analysis limit the generality of our results. First, our model applies to pure public environmental goods only. The meta-study of Jacobsen and Hanley (2009), employed in our empirical illustration, draws on contingent valuation studies that elicit WTP for biodiversity conservation with a particular focus on existence values. Although these habitat and species preservation projects will not benefit all households equally on a global scale, existence values may be regarded as a prime example of pure-public-good-type benefits. However, there are many environmental goods with only a limited spatial range of benefits, or with at least some degree of rivalry in consumption. Our analysis does not cover cases of such impure public environmental goods. 
Second, while most empirical evidence, as gathered mainly from contingent valuation studies, suggests that the income elasticity is smaller than unity, this has been challenged by Schläpfer $(2006,2008)$. He argues that the incidences of income elasticities of WTP smaller than unity may be an artifact of the design of contingent valuation studies resulting among others from anchoring effects or strategic answers. If the income elasticity of WTP were indeed greater than unity, the direction of some of our empirical results would be exactly opposite to what we have described in Section 3.4 (in line with the case distinctions for $\theta$ in the propositions in Section 3.3).

Third, the CES-utility specification implies that both the private consumption good and the environmental public good are normal goods, and not Giffen or luxury goods. It further implies that the income elasticity of WTP is constant, an assumption that is supported by some empirical evidence (e.g. Jacobsen and Hanley 2009, Broberg 2010) and adopted in most benefit-transfer applications. There is, however, also empirical evidence that the income elasticity of WTP may vary with mean income (Barbier et al. 2016, Ready et al. 2002). ${ }^{36}$ Again, our model does not capture this effect. An extension of our analysis that could capture a non-constant income elasticity is to assume non-homothetic preferences, for example by taking into account a minimum (subsistence) consumption level (Baumgärtner et al. 2017b, Drupp 2016).

Fourth, we assume that households have identical preferences and differ only with respect to income. Our results continue to hold, however, if households have different utility functions, as long as for each household the elasticity of substitution between environmental goods and market consumption goods is constant, and these elasticities as well as the other utility parameters (e.g. the relative weight of market consumption goods to environmental goods in utility) and utility-determining variables (e.g. education, social norms and relations) are not systematically correlated with the distribution of income. In particular, it is easy to show that the basic structure of the model is unaltered if the income elasticity of WTP is normally distributed over households, which is a common assumption in empirical studies (see Appendix 3.7.11). Thus, our results generalize to a setting where preferences of all households are described by a constant elasticity of substitution between the private and environmental goods, but this elasticity may be different across households.

\footnotetext{
${ }^{36}$ In an attempt to check whether the income elasticity of WTP is constant or changes with income in the global case study, we have classified the data into three income groups (low, middle, high) and have estimated the income elasticities of WTP separately for each group. We obtained inconclusive results, as there are only few observations in the lower income groups and the estimate for the large high-income group was not significant.
} 
Fifth, our analysis rests on the assumption that income is log-normally distributed among members of society. While there is sound evidence that this is the case at the global level and in many countries, there are also suggestions (e.g. by Bandourian et al. 2003, Giesen et al. 2010) that actual income distributions may have a 'fatter tail' than the log-normal distribution. As our calculation of mean WTP rests on the assumption of log-normal distribution of income, these results would quantitatively, but not qualitatively, change if one assumed a different kind of distribution (see last point of discussion).

Sixth, we have only examined the statistical effect of how the income distribution, and income inequality in particular, affects mean WTP for environmental public goods. A further channel of influence may be through behavioral responses to income inequality affecting mean WTP due to social preferences. The experimental findings provide hitherto inconclusive and contradictory results: while some studies find that heterogeneously endowed players in public good games contribute the same percentage of their income (e.g. Hofmeyr et al. 2007, Rapoport and Suleiman 1993), others find that players contribute the same absolute amount, meaning that low-income players contribute a higher relative share of their income (e.g. Buckley and Croson 2006). Furthermore, a recent study by Broberg (2014) suggests that relative income effects may play a role in determining WTP for environmental public goods. Yet, we are not aware of any study that relates (income inequality dependent) contributions to a public good to the substitutability between private consumption goods and public goods. We therefore cannot conclude whether taking into account behavioral reactions would amplify or dampen our results, which crucially depend on the elasticity of substitution. Scrutinizing the interaction of social preferences and the income inequality effects described in this paper represents a fruitful area for further research.

Finally, we have derived all our results from a particular functional specification of the model to allow for an empirical quantification. One can qualitatively derive our main result more generally, using more general concepts of utility, substitutability, and income inequality. We show this in Appendix 3.7.12.

\subsection{Conclusion}

We have studied how the distribution of income among members of society, in particular income inequality, affects the social willingness to pay for environmental public goods. We found that if income is unevenly distributed among otherwise identical households (i) social WTP for environmental public goods increases with mean income; (ii) social WTP for 
environmental public goods decreases (increases) with income inequality if and only if environmental public goods and private consumption goods are substitutes (complements); (iii) the effect of income inequality on social WTP is the stronger, the higher the mean income; and (iv) social WTP for environmental public goods changes more elastically with mean household income than with income inequality, except for extreme cases of parameter values.

Our results are relevant in several respects. First, for benefit transfer, one should correct WTP-estimates for differences in both mean income and income inequality. We provide ready-to-use adjustment factors for this purpose. With data from empirical case studies we have demonstrated that the size of this adjustment may be considerable: for example, a WTP-transfer for biodiversity conservation from a global case study with high income inequality to a society with relatively low income inequality, such as Sweden, would entail a WTP correction for income inequality of more than ten percent.

Second, as the income-inequality effect on social WTP is the stronger, the higher the level of mean income, it is more important to take it into account in studies and applications in rich countries than in poor countries. In light of this theoretical finding and the fact that our global case study over-represents studies from developed countries due to data availability, the substantial size of the global WTP-adjustment for income inequality seems more relevant for rich countries and should only be considered with caution for poorer countries.

Third, when giving policy recommendations aimed at both allocative efficiency and distributive justice ("sustainability policy", Baumgärtner and Quaas 2010), the effect of the income distribution on WTP has to be known. Assessment of allocative efficiency may require monetary valuation of non-market goods, while the distribution of income influences this monetary valuation in turn. The two aspects are thus mutually interlinked and need to be studied and addressed simultaneously. For instance, one may correct WTP-estimates for unjust income inequality, and use inequality-corrected WTP-estimates for efficiency (e.g. cost-benefit)-analysis. In the case of global WTP for biodiversity conservation this adjustment might lead to an increase in WTP of up to 16 percent, depending on the (in-)equality preferences of society.

Overall, our analysis demonstrates the importance of taking into account economic inequality and equity considerations when doing benefit transfer and economic policy in general. 
Acknowledgments: We are especially grateful to Maxim Pinkovskiy, Thomas Broberg, Jette Jacobsen and Yuyan Shi for making their data sets and analyses accessible and understandable to us. We also thank Rodrigo Arriagada, Johannes Bröcker, John-Oliver Engler, Nick Hanley, Maik Heinemann, Till Requate, Felix Schläpfer, Lilly Schön and Armin Schmutzler, as well as two anonymous reviewers of this journal and conference participants at the AURÖ 2012, BIOECON 2011 and 2016, EAERE 2012, EnvEcon 2013, ESEE 2013, ISEE 2014 and TEEB 2012 for helpful comments. Last, not least, we are grateful to the German National Academic Foundation, and to Marcus Lippe in particular, for providing a most stimulating academic environment for our working group on Sustainability Economics in the Social Sciences College 2009-2011. MD further gratefully acknowledges financial support from the DAAD and the BMBF under grant 01LA1104C. 


\section{Bibliography}

Aaron, H. and M. McGuire (1970) Public goods and income distribution, Econometrica 38: 907-919.

Bandourian, R. J.B. McDonald and R.S. Turley (2003), A comparison of parametric models of income distribution across countries and over time, Estadistica 55: 135-152.

Barbier, E.B., M. Czajkowski and N. Hanley (2016), Is the income elasticity of the willingness to pay for pollution control constant? Environmental and Resource Economics, in press, doi:10.1007/s10640-016-0040-4.

Barton, D.N. (2002), The transferability of benefit transfer: contingent valuation of water quality improvements in Costa Rica, Ecological Economics 42(1-2): 147-164.

Bateman, I.J., G.M. Mace, C. Fezzi, G. Atkinson and R.K. Turner (2011), Economic analysis for ecosystem service assessments, Environmental and Resource Economics 48(2): 177218.

Baumgärtner, S., Drupp, M.A. and M.F. Quaas (2015), Subsistence, substitutability and sustainability in consumption, Environmental and Resource Economics, 67(1): 47-66.

Baumgärtner, S. and M.F. Quaas (2010), What is sustainability economics? Ecological Economics 69(3): 445-450.

Broberg, T. (2010), Income treatment effects in contingent valuation: the case of the Swedish predator policy, Environmental and Resource Economics 46(1): 1-17.

Broberg, T. (2014), Relative income and the WTP for public goods-A case study of forest conservation in Sweden, CERE Working Paper 2014: 6.

Broberg, T. and R. Brännlund (2008), On the value of large predators in Sweden: A regional stratified contingent valuation analysis, Journal of Environmental Management 88: 10661077. 
Bronstein, I.N. and K.A. Semendjajew (1987), Taschenbuch der Mathematik, 23rd ed., Thun: Verlag Harri Deutsch.

Buchanan, J.M. (1964), Fiscal institutions and efficiency in collective outlay, American Economic Review 54(3): 227-235.

Buckley, E. and R. Croson (2006), Income and wealth heterogeneity in the voluntary provision of linear public goods, Journal of Public Economics 90(4-5): 935-955.

Chiabai, A., C. Travisi, A. Markandya, H. Ding and P. Nunes (2011), Economic assessment of forest ecosystem services losses: cost of policy inaction, Environmental and Resource Economics 50(3): 405-445.

Cowell, F. (2009), Measuring Inequality, Oxford: Oxford University Press.

Czajkowski, M. and M. Ščasný (2010), Study on benefit transfer in an international setting. How to improve welfare estimates in the case of the countries' income heterogeneity? Ecological Economics 69(12): 2409-2416.

Dalton, H. (1920), The measurement of the inequality of incomes, The Economic Journal 30(119): 348-361.

Dorling, D. M. Newman and A. Barford (2010), Atlas der wirklichen Welt: So haben Sie die Erde noch nie gesehen, Darmstadt: Primus Verlag.

Drupp, M.A. (2016), Limits to substitution between ecosystem services and manufactured goods and implications for social discounting, Environmental and Resource Economics, in press, doi: 10.1007/s10640-016-0068-5.

Drupp, M.A., M.C. Freeman, B. Groom and F. Nesje (2015), Discounting disentangled: An expert survey on the determinants of the long-term social discount rate, Grantham Research Institute on Climate Change and the Environment Working Paper No. 172.

Ebert, U. (2003), Environmental goods and the distribution of income, Environmental and Resource Economics 25(4): 435-459.

Flores, N.E. and R.T. Carson (1997), The relationship between the income elasticities of demand and willingness to pay, Journal of Environmental Economics and Management $33(3): 287-295$. 
Giesen, K. A. Zimmermann and J. Suedekum (2010), The size distribution across all cities - Double Pareto lognormal strikes, Journal of Urban Economics 68(2): 129-137.

Hammitt, J., J.-T. Liu and J.-L. Liu (2001), Contingent valuation of a Taiwanese wetland, Environment and Development Economics 6: 259-268.

Hanemann, W.M. (1991), Willingness to pay and willingness to accept: how much can they differ? American Economic Review 81: 635-647.

Hofmeyr, A. J. Burns, and M. Visser (2007), Income inequality, reciprocity and public good provision: An experimental analysis, South African Journal of Economics 75(3): 508-520.

Hökby, S. and T. Söderqvist (2003), Elasticities of demand and willingness to pay for environmental services in Sweden, Environmental and Resource Economics 26(3): 361383.

Horowitz, J.K. and K.E. McConnell (2003), Willingness to accept, willingness to pay and the income effect, Journal of Economic Behavior and Organization 51: 537-545.

Jacobsen, J. and N. Hanley (2009), Are there income effects on global willingness to pay for biodiversity conservation? Environmental and Resource Economics 43(2): 137-160.

Kaul, S., K.J. Boyle, N.V. Kuminoff, C.F. Parmeter, and J.C. Pope (2013), What can we learn from benefit transfer errors? Evidence from 20 years of research on convergent validity, Journal of Environmental Economics and Management 66(1): 90-104.

Khan, H. (2009), Willingness to pay and demand elasticities for two national parks: empirical evidence from two surveys in Pakistan, Environment, Development and Sustainability 11(2): 293-305.

Kovenock, D. and E. Sadka (1981), Progression under the benefit approach to the theory of taxation, Economics Letters 8: 95-99.

Kriström, B. and P. Riera (1996), Is the income elasticity of environmental improvements less than one? Environmental and Resource Economics 7: 45-55.

Lindhjem, H. and T.H. Tuan (2012), Valuation of species and nature conservation in Asia and Oceania: a meta-analysis, Environmental Economics and Policy Studies 14(1): 1-22.

Liu, S. and D.I. Stern (2008), A meta-analysis of contingent valuation studies in coastal and bear-shore marine ecosystems, CSIRO Working Paper Series 2008-15. 
Loomis, J.B. (1992), The evolution of a more rigorous approach to benefit transfer: Benefit function transfer, Water Resources Research 28: 701-705.

Neary, J.P. and K.W.S. Roberts (1980), The theory of household behaviour under rationing, European Economic Review 13: 25-42.

Pek, C.-K. Tee, C.-H. and P.-Y. Ng (2010), A contingent valuation estimation of hill recreational and services values in Malaysia, MPRA Paper No. 23125.

Pigou, A.C. (1912), Wealth and Welfare, Macmillan, London.

Pinkovskiy, M. and X. Sala-i-Martin (2009), Parametric estimations of the world distribution of income, NBER Working Paper No. 15433.

Rapoport, A. and R. Suleiman (1993), Incremental contribution in step-level public goods games with asymmetric players, Organizational Behavior and Human Decision Processes 55(2): 171-194.

Ready, R.C. J. Malzubris, J. and S. Senkane (2002), The relationship between environmental values and income in a transition economy: surface water quality in Latvia, Environment and Development Economics 7(1): 147-156.

Ready, R.C. and S. Navrud (2006), International benefit transfer: Methods and validity tests, Ecological Economics 60(2): 429-434.

Requate, T and A. Lange (2000), Pigouvian taxes in general equilibrium with a fixed tax redistribution rule, Journal of Public Economic Theory 2(1): 25-42.

Richardson, L. J. Loomis T. Kroeger and F. Casey (2015), The role of benefit transfer in ecosystem service valuation, Ecological Economics 115: 51-58.

Rosenberger, R.S. and J.B. Loomis (2003), Benefit transfer, in P.A. Champ, K.J. Boyle and T.C. Brown (eds), A Primer on Non-Market Valuation, Dordrecht: Kluwer, pp. 445-482.

Scandizzo, P.L. and M. Ventura (2008), Contingent valuation of natural resources: a case study for Sicily, ISAE Working Paper No. 91.

Schläpfer, F. (2006), Survey protocol and income effects in the contingent valuation of public goods: A meta-analysis, Ecological Economics 57(3): 415-429. 
Schläpfer, F. (2008), Contingent valuation: a new perspective, Ecological Economics 64(4): $729-740$.

Smith, V.K. (2000), JEEM and non-market valuation: 1974-1998, Journal of Environmental Economics and Management 39(3): 351-374.

Söderqvist, T. and H. Scharin (2000), The regional willingness to pay for a reduced eutrophication in the Stockholm archipelago, Beijer Discussion Paper No. 128.

Uzawa, H. (1962), Production functions with constant elasticity of substitution, Review of Economic Studies 29: 291-299.

Wang, H., Y. Shi, Y. Kim and T. Kamata (2013), Valuing water quality improvement in China. A case study of Lake Puzhehei in Yunnan Province, Ecological Economics 94: $56-65$. 


\subsection{Appendix}

\subsubsection{Derivation of WTP $(Y)$ (Equation 3.4)}

Total WTP for the environmental public good at level $E$ is given as the marginal WTP $w$ times the number of units of $E$ :

$$
\mathrm{WTP}=w E
$$

The marginal WTP $w$ can be derived from the agent's indirect utility function $V(p, E, Y)$ by an extension of Roy's identity (Ebert 2003: 440).

$$
w=\frac{\partial V(p, E, Y) / \partial E}{\partial V(p, E, Y) / \partial Y}
$$

With the CES-utility function (Equation 3.1) the indirect utility function is

$$
V(p, E, Y)=\left(\alpha\left(\frac{Y}{p}\right)^{\frac{\theta-1}{\theta}}+(1-\alpha) E^{\frac{\theta-1}{\theta}}\right)^{\frac{\theta}{\theta-1}}
$$

and, employing (3.32), the marginal WTP is then

$$
w=p \frac{1-\alpha}{\alpha}\left(\frac{Y}{p E}\right)^{\frac{1}{\theta}}
$$

Plugging this into Equation (3.31) yields

$$
\operatorname{WTP}(Y)=\frac{1-\alpha}{\alpha}(p E)^{\frac{\theta-1}{\theta}} Y^{1 / \theta}
$$

\subsubsection{Derivation of $\mu_{\mathrm{WTP}}$ (Equation 3.6)}

The density function of the log-normal distribution of income $Y$ with mean $\mu_{Y}$ and standard deviation $\sigma_{Y}$ is given by

$$
\begin{aligned}
f_{\ln }\left(Y ; \mu_{Y}, \sigma_{Y}\right) & =\frac{1}{Y \sqrt{2 \pi s^{2}}} \exp \left(-\frac{(\ln Y-m)^{2}}{2 s^{2}}\right) \\
\text { with } m & =\ln \mu_{y}-\frac{1}{2} \ln \left(1+\sigma_{Y}^{2} / \mu_{Y}^{2}\right) \\
s^{2} & =\ln \left(1+\sigma_{Y}^{2} / \mu_{Y}^{2}\right) .
\end{aligned}
$$


Equation (3.5) then becomes

$$
\begin{array}{cl}
\mu_{\mathrm{WTP}} \quad= & \int_{0}^{\infty} f_{\ln }\left(Y ; \mu_{Y}, \sigma_{Y}\right) \mathrm{WTP}(Y) d Y \\
\stackrel{(3.36),(3.4)}{=} & \int_{0}^{\infty} \frac{\kappa Y^{\eta-1}}{\sqrt{2 \pi s^{2}}} \exp \left(-\frac{(\ln Y-m)^{2}}{2 s^{2}}\right) d Y \\
\stackrel{\ln Y=: Z}{=} & \frac{\kappa}{\sqrt{2 \pi s^{2}}} \int_{-\infty}^{\infty} \exp (\eta Z) \exp \left(-\frac{(Z-m)^{2}}{2 s^{2}}\right) d Z \\
= & \kappa \exp \left[(\eta)\left(m+\frac{\eta}{2} s^{2}\right)\right] \\
\stackrel{(3.37),(3.38)}{=} & \kappa \mu_{Y}^{\eta}\left(1+\frac{\sigma_{Y}^{2}}{\mu_{Y}^{2}}\right)^{\frac{\eta(\eta-1)}{2}} \\
\stackrel{\eta=1 / \theta}{=} & \kappa \mu_{Y}^{1 / \theta}\left(1+\frac{\sigma_{Y}^{2}}{\mu_{Y}^{2}}\right)^{\frac{1-\theta}{2 \theta^{2}}} .
\end{array}
$$

\subsubsection{Proof of Proposition 3.1}

Taking the derivative of $\mu_{\mathrm{WTP}}$ (Equation 3.7) with respect to $\mu_{Y}$ yields

$$
\frac{\partial \mu_{\mathrm{WTP}}\left(\mu_{Y}, \mathrm{CV}_{Y}\right)}{\partial \mu_{Y}}=\kappa \frac{1}{\theta} \mu_{Y}^{\frac{1}{\theta}-1}\left(1+\mathrm{CV}_{Y}^{2}\right)^{\frac{1-\theta}{2 \theta^{2}}}
$$

which is strictly greater than zero because $\kappa, \theta, \mu_{Y}, \mathrm{CV}_{Y}>0$.

\subsubsection{Proof of Proposition 3.2}

Taking the derivative of $\mu_{\mathrm{WTP}}$ (Equation 3.6) with respect to $\mu_{Y}$ yields

$$
\frac{\partial \mu_{\mathrm{WTP}}\left(\mu_{Y}, \sigma_{Y}\right)}{\partial \mu_{Y}}=\kappa \frac{1}{\theta} \mu_{Y}^{\frac{1}{\theta}-1}\left(1+\frac{\sigma_{Y}^{2}}{\mu_{Y}^{2}}\right)^{\frac{1-\theta}{2 \theta^{2}}}\left[1-\left(\frac{1}{\theta}-1\right) \frac{1}{\frac{\mu_{Y}^{2}}{\sigma_{Y}^{2}}+1}\right]
$$

Because $\kappa, \theta, \mu_{Y}, \sigma_{Y}>0$

$$
\begin{gathered}
\frac{\partial \mu_{\mathrm{WTP}}\left(\mu_{Y}, \sigma_{Y}\right)}{\partial \mu_{Y}} \gtreqless 0 \quad \text { for } \quad\left[1-\left(\frac{1}{\theta}-1\right) \frac{1}{\frac{\mu_{Y}^{2}}{\sigma_{Y}^{2}}+1}\right] \gtreqless 0 \\
\Leftrightarrow \quad \frac{\mu_{Y}^{2}}{\sigma_{Y}^{2}} \gtreqless \frac{1}{\theta}-2 .
\end{gathered}
$$

For $\theta \geq 1 / 2$, the RHS is non-positive while the LHS is strictly positive, so that the inequality holds with $>$. Thus, $\partial \mu_{\mathrm{WTP}} / \partial \mu_{Y}$ is strictly positive for all levels of mean income $\mu_{Y}$. 
In contrast, for strong complementarity, $\theta<1 / 2, \partial \mu_{\mathrm{WTP}} / \partial \mu_{Y}$ (Equation 3.41) can have either sign. $\mu_{\mathrm{WTP}}$ attains a unique minimum at the mean income level $\mu_{Y}^{\min }=\sqrt{1 / \theta-2} \sigma_{Y}$, where $\partial \mu_{\mathrm{WTP}} / \partial \mu_{Y}$ (Equation 3.41) equals zero: $\mu_{\mathrm{WTP}}$ falls with mean income for mean income levels below $\mu_{Y}^{\min }$ and increases with mean income above $\mu_{Y}^{\min }$.

\subsubsection{Proof of Proposition 3.3}

Ad 1. Taking the derivative of $\mu_{\mathrm{WTP}}$ (Equation 3.7) with respect to $\mathrm{CV}_{Y}$ yields

$$
\frac{\partial \mu_{\mathrm{WTP}}\left(\mu_{Y}, \mathrm{CV}_{Y}\right)}{\partial \mathrm{CV}_{Y}}=\kappa \frac{1-\theta}{\theta^{2}} \mu_{Y}^{\frac{1}{\theta}} \mathrm{CV}_{Y}\left(1+\mathrm{CV}_{Y}\right)^{\frac{1-\theta-2 \theta^{2}}{2 \theta^{2}}}
$$

Because $\theta, \kappa, \mu_{Y}, \mathrm{CV}_{Y}>0$, the sign of $\partial \mu_{\mathrm{WTP}} / \partial \mathrm{CV}_{Y}$ is determined by the sign of $1-\theta$ :

$$
\frac{\partial \mu_{\mathrm{WTP}}\left(\mu_{Y}, \mathrm{CV}_{Y}\right)}{\partial \mathrm{CV}_{Y}} \lesseqgtr 0 \text { if and only if } \theta \gtreqless 1
$$

Ad 2. The cross derivative of mean WTP (Equation 3.7) is obtained by taking the derivative of (3.44) with respect to $\mu_{Y}$ :

$$
\frac{\partial^{2} \mu_{\mathrm{WTP}}\left(\mu_{Y}, \mathrm{CV}_{Y}\right)}{\partial \mu_{Y} \partial \mathrm{CV}_{Y}}=\kappa \frac{1-\theta}{\theta^{3}} \mu_{Y}^{\frac{1}{\theta}-1} \mathrm{CV}_{Y}\left(1+\mathrm{CV}_{Y}^{2}\right)^{\frac{1-\theta-2 \theta^{2}}{2 \theta^{2}}}
$$

Again, because $\theta, \kappa, \mu_{Y}, \mathrm{CV}_{Y}>0$, the sign of $\partial^{2} \mu_{\mathrm{WTP}} / \partial \mu_{Y} \partial \mathrm{CV}_{Y}$ is determined by the sign of $1-\theta$ :

$$
\frac{\partial^{2} \mu_{\mathrm{WTP}}\left(\mu_{Y}, \mathrm{CV}_{Y}\right)}{\partial \mu_{Y} \partial \mathrm{CV}_{Y}} \lesseqgtr 0 \text { if and only if } \theta \gtreqless 1
$$

\subsubsection{Proof of Proposition 3.4}

Taking the derivative of $\mu_{\mathrm{WTP}}$ (Equation 3.6) with respect to $\sigma_{Y}$ yields

$$
\frac{\partial \mu_{\mathrm{WTP}}\left(\mu_{Y}, \sigma_{Y}\right)}{\partial \sigma_{Y}}=\kappa \frac{1}{\theta}\left(\frac{1}{\theta}-1\right) \mu_{Y}^{\frac{1}{\theta}}\left(1+\frac{\sigma_{Y}^{2}}{\mu_{Y}^{2}}\right)^{\frac{1-\theta-2 \theta^{2}}{2 \theta^{2}}} \frac{\sigma_{Y}}{\mu_{Y}^{2}}
$$

Because $\kappa, \theta, \mu_{Y}, \sigma_{Y}>0$ it follows directly that

$$
\frac{\partial \mu_{\mathrm{WTP}}\left(\mu_{Y}, \sigma_{Y}\right)}{\partial \sigma_{Y}} \lesseqgtr 0 \text { if and only if } \theta \gtreqless 1
$$

This establishes the first part of Proposition 3.4. To prove the second part of the proposition, we take the cross derivative of $\mu_{\mathrm{WTP}}$ (Equation 3.6) as the derivative of (3.48) with respect 
to $\mu_{Y}$ and find:

$$
\begin{aligned}
& \frac{\partial^{2} \mu_{\mathrm{WTP}}\left(\mu_{Y}, \sigma_{Y}\right)}{\partial \mu_{Y} \partial \sigma_{Y}}=F 1 \times F 2 \times F 3 \quad \text { with } \\
& F 1:=\kappa \frac{1}{\theta} \mu_{Y}^{\frac{1}{\theta}-3} \sigma_{Y}\left(1+\frac{\sigma_{Y}^{2}}{\mu_{Y}^{2}}\right)^{\frac{1-\theta-2 \theta^{2}}{2 \theta^{2}}} \\
& F 2:=\frac{1}{\theta}-1 \\
& F 3:=\frac{1}{\frac{\mu_{Y}^{2}}{\sigma_{Y}^{2}}+1}\left(\frac{1}{\theta}-2\right)\left(\frac{\mu_{Y}^{2}}{\sigma_{Y}^{2}}-\frac{1}{\theta}\right)
\end{aligned}
$$

As $F 1>0$ for all parameter values, the sign of (3.50) depends on the signs of the factors $F 2$ and F3. As for F2 (Equation 3.52), we have

$$
F 2 \gtreqless 0 \text { if and only if } \theta \lesseqgtr 1 \text {. }
$$

As for F3 (Equation 3.53), we have

$$
F 3=0 \quad \text { if and only if } \theta=\frac{1}{2} \text { or } \mu_{Y}=\sqrt{1 / \theta} \sigma_{Y} .
$$

As $\mu_{Y}>0$ and $\sigma_{Y}>0$, we also have that for $\theta<1 / 2$ :

$$
F 3 \gtreqless 0 \Leftrightarrow \frac{\mu_{Y}^{2}}{\sigma_{Y}^{2}}-\frac{1}{\theta} \gtreqless 0 \Leftrightarrow \mu_{Y} \gtreqless \sqrt{1 / \theta} \sigma_{Y},
$$

and for $\theta>1 / 2$ :

$$
F 3 \gtreqless 0 \Leftrightarrow \frac{\mu_{Y}^{2}}{\sigma_{Y}^{2}}-\frac{1}{\theta} \lesseqgtr 0 \Leftrightarrow \mu_{Y} \lesseqgtr \sqrt{1 / \theta} \sigma_{Y} .
$$

Hence, the signs of $F 1, F 2$ and $F 3$ and, consequently, the sign of $d^{2} \mu_{\mathrm{WTP}} / d \mu_{Y} d \sigma_{Y}$ (Equation 3.50) are as follows:

\begin{tabular}{|l|l|l|l|l|}
\hline & $F 1$ & $F 2$ & $F 3$ & $d^{2} \mu_{\mathrm{WTP}} / d \mu_{Y} d \sigma_{Y}\left(\mu_{Y}, \sigma_{Y}\right)$ \\
\hline \hline$\theta<1 / 2$ & $>0$ & $>0$ & $\gtreqless 0$ for $\mu_{Y} \gtreqless \sqrt{1 / \theta} \sigma_{Y}$ & $\lesseqgtr 0$ for $\mu_{Y} \lesseqgtr \sqrt{1 / \theta} \sigma_{Y}$ \\
\hline$\theta=1 / 2$ & $>0$ & $>0$ & $=0$ & $=0$ \\
\hline $1 / 2<\theta<1$ & $>0$ & $>0$ & $\gtreqless 0$ for $\mu_{Y} \lesseqgtr \sqrt{1 / \theta} \sigma_{Y}$ & $\gtreqless 0$ for $\mu_{Y} \lesseqgtr \sqrt{1 / \theta} \sigma_{Y}$ \\
\hline$\theta=1$ & $>0$ & $=0$ & $=0$ & $=0$ \\
\hline$\theta>1$ & $>0$ & $<0$ & $\gtreqless 0$ for $\mu_{Y} \lesseqgtr \sqrt{1 / \theta} \sigma_{Y}$ & $\lesseqgtr 0$ for $\mu_{Y} \lesseqgtr \sqrt{1 / \theta} \sigma_{Y}$ \\
\hline
\end{tabular}


This establishes the second part of Proposition 3.4.

\subsubsection{Proof of Proposition 3.5}

The elasticity of mean WTP with respect to mean income can be calculated from Equations (3.7) and (3.40) as

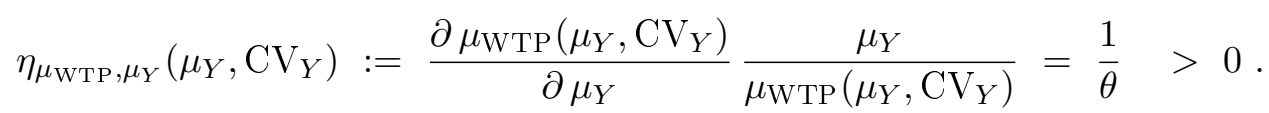

Hence, $\left|\eta_{\mu_{\mathrm{WTP}, \mu_{Y}}}\left(\mu_{Y}, \mathrm{CV}_{Y}\right)\right|=\eta_{\mu_{\mathrm{WTP}}, \mu_{Y}}\left(\mu_{Y}, \mathrm{CV}_{Y}\right)$.

The elasticity of mean WTP with respect to relative income inequality can be calculated from Equations (3.7) and (3.44) as

$$
\begin{aligned}
& \eta_{\mu_{\mathrm{WTP}}, \mathrm{CV}_{Y}\left(\mu_{Y}, \mathrm{CV}_{Y}\right)}:=\frac{\partial \mu_{\mathrm{WTP}}\left(\mu_{Y}, \mathrm{CV}_{Y}\right)}{\partial \mathrm{CV}_{Y}} \frac{\mathrm{CV}_{Y}}{\mu_{\mathrm{WTP}}\left(\mu_{Y}, \mathrm{CV}_{Y}\right)} \\
&=\frac{1-\theta}{\theta^{2}} \frac{1}{1+1 / \mathrm{CV}_{Y}^{2}} \lesseqgtr 0 \text { for } \theta \gtreqless 1 .
\end{aligned}
$$

Hence

$$
\left|\eta_{\mu_{\mathrm{WTP}}, \mathrm{CV}_{Y}}\left(\mu_{Y}, \mathrm{CV}_{Y}\right)\right|=\left\{\begin{array}{r}
\eta_{\mu_{\mathrm{WTP}}, \mathrm{CV}_{Y}}\left(\mu_{Y}, \mathrm{CV}_{Y}\right) \\
0 \\
-\eta_{\mu_{\mathrm{WTP}}, \mathrm{CV}_{Y}}\left(\mu_{Y}, \mathrm{CV}_{Y}\right)
\end{array}\right\} \text { for } \theta\left\{\begin{array}{l}
< \\
= \\
>
\end{array}\right\} 1
$$

To determine which of the two elasticities is greater in absolute terms, we have to distinguish three cases.

Case 1: $\theta>1$

$$
\begin{aligned}
& \left|\eta_{\mu_{\mathrm{WTP}}, \mu_{Y}}\left(\mu_{Y}, \mathrm{CV}_{Y}\right)\right|<?>-\eta_{\mu_{\mathrm{WTP}}, \mathrm{CV}_{Y}}\left(\mu_{Y}, \mathrm{CV}_{Y}\right)=\left|\eta_{\mu_{\mathrm{WTP}}, \mathrm{CV}_{Y}}\left(\mu_{Y}, \mathrm{CV}_{Y}\right)\right|(3.6 \\
& \frac{1}{\theta}<?>\frac{\theta-1}{\theta^{2}} \frac{1}{1+1 / \mathrm{CV}_{Y}^{2}} \\
& \Leftrightarrow \quad 1 / \mathrm{CV}_{Y}^{2}<?>-1 / \theta \text {. }
\end{aligned}
$$

As $\mathrm{CV}_{Y}>0$ and $\theta>0$, the LHS (which is positive) is always greater than the RHS (which is negative). Hence, we have

$$
\left|\eta_{\mu_{\mathrm{WTP}}, \mu_{Y}}\left(\mu_{Y}, \mathrm{CV}_{Y}\right)\right|>\left|\eta_{\mu_{\mathrm{WTP}}\left(\mu_{Y}, \mathrm{CV}_{Y}\right), \mathrm{CV}_{Y}}\right| \text { for } \theta>1
$$


Case 2: $\theta=1$

$$
\left|\eta_{\mu_{\mathrm{WTP}}, \mu_{Y}}\left(\mu_{Y}, \mathrm{CV}_{Y}\right)\right|=1>0=\left|\eta_{\mu_{\mathrm{WTP}}, \mathrm{CV}_{Y}}\left(\mu_{Y}, \mathrm{CV}_{Y}\right)\right| \text { for } \theta=1
$$

Case 3: $\theta<1$

$$
\begin{aligned}
& \left|\eta_{\mu_{\mathrm{WTP}}, \mu_{Y}}\left(\mu_{Y}, \mathrm{CV}_{Y}\right)\right|<?>\eta_{\mu_{\mathrm{WTP}}, \mathrm{CV}_{Y}}\left(\mu_{Y}, \mathrm{CV}_{Y}\right)=\left|\eta_{\mu_{\mathrm{WTP}}, \mathrm{CV}_{Y}}\left(\mu_{Y}, \mathrm{CV}_{Y}\right)\right| \\
& \frac{1}{\theta}<?>\frac{1-\theta}{\theta^{2}} \frac{1}{1+1 / \mathrm{CV}_{Y}^{2}} \\
& \Leftrightarrow \quad 1 / \mathrm{CV}_{Y}^{2} \quad<?>\frac{1}{\theta}-2
\end{aligned}
$$

As $\mathrm{CV}_{Y}>0$, if $\theta \geq 1 / 2$ the LHS (which is positive) is always greater than the RHS (which is non-positive), and we have

$$
\left|\eta_{\mu_{\mathrm{WTP}}, \mu_{Y}}\left(\mu_{Y}, \mathrm{CV}_{Y}\right)\right|>\left|\eta_{\mu_{\mathrm{WTP}}, \mathrm{CV}_{Y}}\left(\mu_{Y}, \mathrm{CV}_{Y}\right)\right| \text { for } 1 / 2 \leq \theta<1 .
$$

If $\theta<1 / 2$, the RHS is positive and

$$
\begin{aligned}
1 / \mathrm{CV}_{Y}^{2} & <?>\frac{1}{\theta}-2 \\
\Leftrightarrow \sqrt{\frac{\theta}{1-2 \theta}} & <?>\mathrm{CV}_{Y} .
\end{aligned}
$$

Hence, we have

$$
\left|\eta_{\mu_{\mathrm{WTP}, \mu_{Y}}}\left(\mu_{Y}, \mathrm{CV}_{Y}\right)\right|>\left|\eta_{\mu_{\mathrm{WTP}}, \mathrm{CV}_{Y}}\left(\mu_{Y}, \mathrm{CV}_{Y}\right)\right| \text { for } \theta<1 / 2 \text { and } \mathrm{CV}_{Y}>\sqrt{\frac{\theta}{1-2 \theta}}
$$

Considering all three cases together, we thus have

$$
\begin{aligned}
\left|\eta_{\mu_{\mathrm{WTP}}, \mu_{Y}}\left(\mu_{Y}, \mathrm{CV}_{Y}\right)\right| & \left\{\begin{array}{l}
< \\
>
\end{array}\right\}\left|\eta_{\mu_{\mathrm{WTP}}, \mathrm{CV}_{Y}}\left(\mu_{Y}, \mathrm{CV}_{Y}\right)\right| \\
& \text { if and only if }\left\{\begin{array}{l}
\theta<\frac{1}{2} \text { and } \mathrm{CV}_{Y}>\sqrt{\frac{\theta}{1-2 \theta}} \\
\text { else }
\end{array}\right.
\end{aligned}
$$




\subsubsection{Proof of Proposition 3.6}

The elasticity of mean WTP with respect to mean income can be calculated from Equations (3.6) and (3.41) as

$$
\eta_{\mu_{\mathrm{WTP}}, \mu_{Y}}\left(\mu_{Y}, \sigma_{Y}\right):=\frac{\partial \mu_{\mathrm{WTP}}\left(\mu_{Y}, \sigma_{Y}\right)}{\partial \mu_{Y}} \frac{\mu_{Y}}{\mu_{\mathrm{WTP}}\left(\mu_{Y}, \sigma_{Y}\right)}=\frac{1}{\theta}\left[1-\left(\frac{1}{\theta}-1\right) \frac{1}{\frac{\mu_{Y}^{2}}{\sigma_{Y}^{2}}+1}\right] .
$$

This is strictly positive for all levels of mean income $\mu_{Y}$ for an elasticity of substitution $\theta \geq 1 / 2$. In contrast, for $\theta<1 / 2$, it can have either sign:

$$
\frac{1}{\theta}\left[1-\left(\frac{1}{\theta}-1\right) \frac{1}{\frac{\mu_{Y}^{2}}{\sigma_{Y}^{2}}+1}\right] \gtreqless 0 \text { for } \mu_{Y} \gtreqless \sqrt{1 / \theta-2} \sigma_{Y} .
$$

Hence,

$$
\begin{aligned}
& \left|\eta_{\mu_{\mathrm{WTP}}, \mu_{Y}}\left(\mu_{Y}, \sigma_{Y}\right)\right|=\left\{\begin{array}{r}
\eta_{\mu_{\mathrm{WTP}}, \mu_{Y}}\left(\mu_{Y}, \sigma_{Y}\right) \\
0 \\
-\eta_{\mu_{\mathrm{WTP}}, \mu_{Y}}\left(\mu_{Y}, \sigma_{Y}\right)
\end{array}\right\} \\
& \text { for }\left\{\begin{aligned}
\theta \geq 1 / 2, \text { or } \theta & <1 / 2 \text { and } \mu_{Y}>\sqrt{1 / \theta-2} \sigma_{Y} \\
\theta & <1 / 2 \text { and } \mu_{Y}=\sqrt{1 / \theta-2} \sigma_{Y} \\
\theta & <1 / 2 \text { and } \mu_{Y}<\sqrt{1 / \theta-2} \sigma_{Y}
\end{aligned}\right. \text {. }
\end{aligned}
$$

The elasticity of mean WTP with respect to absolute income inequality can be calculated from Equations (3.6) and (3.48) as

$$
\begin{aligned}
\eta_{\mu_{\mathrm{WTP}}, \sigma_{Y}}\left(\mu_{Y}, \sigma_{Y}\right) & :=\frac{\partial \mu_{\mathrm{WTP}}\left(\mu_{Y}, \sigma_{Y}\right)}{\partial \sigma_{Y}} \frac{\sigma_{Y}}{\mu_{\mathrm{WTP}}\left(\mu_{Y}, \sigma_{Y}\right)} \\
& =\frac{1}{\theta}\left(\frac{1}{\theta}-1\right) \frac{1}{\frac{\mu_{Y}^{2}}{\sigma_{Y}^{2}}+1} \gtreqless 0 \text { for } \theta \lesseqgtr 1 .
\end{aligned}
$$

Hence,

$$
\left|\eta_{\mu_{\mathrm{WTP}}, \sigma_{Y}}\left(\mu_{Y}, \sigma_{Y}\right)\right|=\left\{\begin{array}{r}
\eta_{\mu_{\mathrm{WTP}}, \sigma_{Y}}\left(\mu_{Y}, \sigma_{Y}\right) \\
0 \\
-\eta_{\mu_{\mathrm{WTP}}, \sigma_{Y}}\left(\mu_{Y}, \sigma_{Y}\right)
\end{array}\right\} \quad \text { for } \quad \theta\left\{\begin{array}{l}
< \\
= \\
>
\end{array}\right\} 1
$$


To determine which of the two elasticities is greater in absolute terms, we have to distinguish the following cases:

\begin{tabular}{|l|l|r|r|}
\hline & & $\mid \eta_{\mu_{\mathrm{WTP}, \mu_{Y}}\left(\mu_{Y}, \sigma_{Y}\right) \mid=}$ & $\left|\eta_{\mu_{\mathrm{WTP}}, \sigma_{Y}}\left(\mu_{Y}, \sigma_{Y}\right)\right|=$ \\
\hline \hline 1 & $\theta>1$ & $\eta_{\mu_{\mathrm{WTP}}, \mu_{Y}}$ & $-\eta_{\mu_{\mathrm{WTP}}, \sigma_{Y}}$ \\
\hline 2 & $\theta=1$ & $\eta_{\mu_{\mathrm{WTP}}, \mu_{Y}}$ & 0 \\
\hline 3 & $1 / 2 \leq \theta<1$ & $\eta_{\mu_{\mathrm{WTP}}, \mu_{Y}}$ & $\eta_{\mu_{\mathrm{WTP}}, \sigma_{Y}}$ \\
\hline 4 & $\theta<1 / 2$ and $\mu_{Y}>\sqrt{1 / \theta-2} \sigma_{Y}$ & $\eta_{\mu_{\mathrm{WTP}}, \mu_{Y}}$ & $\eta_{\mu_{\mathrm{WTP}}, \sigma_{Y}}$ \\
\hline 5 & $\theta<1 / 2$ and $\mu_{Y}=\sqrt{1 / \theta-2} \sigma_{Y}$ & 0 & $\eta_{\mu_{\mathrm{WTP}}, \sigma_{Y}}$ \\
\hline 6 & $\theta<1 / 2$ and $\mu_{Y}<\sqrt{1 / \theta-2} \sigma_{Y}$ & $-\eta_{\mu_{\mathrm{WTP}}, \mu_{Y}}$ & $\eta_{\mu_{\mathrm{WTP}}, \sigma_{Y}}$ \\
\hline
\end{tabular}

Case 1: $\theta>1$

$\left|\eta_{\mu_{\mathrm{WTP}}, \mu_{Y}}\left(\mu_{Y}, \sigma_{Y}\right)\right|-\left|\eta_{\mu_{\mathrm{WTP}}, \sigma_{Y}}\left(\mu_{Y}, \sigma_{Y}\right)\right|=\eta_{\mu_{\mathrm{WTP}}, \mu_{Y}}\left(\mu_{Y}, \sigma_{Y}\right)+\eta_{\mu_{\mathrm{WTP}}, \sigma_{Y}}\left(\mu_{Y}, \sigma_{Y}\right)=\frac{1}{\theta}>0$.

Hence

$$
\left|\eta_{\mu_{\mathrm{WTP}}, \mu_{Y}}\left(\mu_{Y}, \sigma_{Y}\right)\right|>\left|\eta_{\mu_{\mathrm{WTP}}, \sigma_{Y}}\left(\mu_{Y}, \sigma_{Y}\right)\right|
$$

Case 2: $\theta=1$

$$
\left|\eta_{\mu_{\mathrm{WTP}}, \mu_{Y}}\left(\mu_{Y}, \sigma_{Y}\right)\right|-\left|\eta_{\mu_{\mathrm{WTP}}, \sigma_{Y}}\left(\mu_{Y}, \sigma_{Y}\right)\right|=\eta_{\mu_{\mathrm{WTP}, \mu_{Y}}}\left(\mu_{Y}, \sigma_{Y}\right)-0=1>0 .
$$

Hence

$$
\left|\eta_{\mu_{\mathrm{WTP}}, \mu_{Y}}\left(\mu_{Y}, \sigma_{Y}\right)\right|>\left|\eta_{\mu_{\mathrm{WTP}, \sigma_{Y}}}\left(\mu_{Y}, \sigma_{Y}\right)\right| .
$$

Case 3: $1 / 2 \leq \theta<1$

$$
\begin{aligned}
\left|\eta_{\mu_{\mathrm{WTP}}, \mu_{Y}}\left(\mu_{Y}, \sigma_{Y}\right)\right|-\left|\eta_{\mu_{\mathrm{WTP}}, \sigma_{Y}}\left(\mu_{Y}, \sigma_{Y}\right)\right| & =\eta_{\mu_{\mathrm{WTP}, \mu_{Y}}}\left(\mu_{Y}, \sigma_{Y}\right)-\eta_{\mu_{\mathrm{WTP}}, \sigma_{Y}}\left(\mu_{Y}, \sigma_{Y}\right) \\
& =\frac{1}{\theta}\left[1-2\left(\frac{1}{\theta}-1\right) \frac{1}{\frac{\mu_{Y}^{2}}{\sigma_{Y}^{2}}+1}\right]
\end{aligned}
$$


Hence

$$
\begin{aligned}
\left|\eta_{\mu_{\mathrm{WTP}}, \mu_{Y}}\left(\mu_{Y}, \sigma_{Y}\right)\right| \gtreqless\left|\eta_{\mu_{\mathrm{WTP}}, \sigma_{Y}}\left(\mu_{Y}, \sigma_{Y}\right)\right| & \Leftrightarrow\left[1-2\left(\frac{1}{\theta}-1\right) \frac{1}{\frac{\mu_{Y}^{2}}{\sigma_{Y}^{2}}+1}\right] \gtreqless 0(3 \\
& \Leftrightarrow \frac{\mu_{Y}^{2}}{\sigma_{Y}^{2}} \gtreqless \frac{2}{\theta}-3
\end{aligned}
$$

For $\theta \geq 2 / 3$ the RHS is non-positive. As $\mu_{Y}, \sigma_{Y}>0$, the LHS is strictly positive. It follows that $\left|\eta_{\mu_{\mathrm{WTP}}, \mu_{Y}}\right|>\left|\eta_{\mu_{\mathrm{WTP}}, \sigma_{Y}}\right|$ for $\theta \geq 2 / 3$. For $\theta<2 / 3$, the RHS is strictly positive and we have

$\left|\eta_{\mu_{\mathrm{WTP}}, \mu_{Y}}\left(\mu_{Y}, \sigma_{Y}\right)\right| \gtreqless\left|\eta_{\mu_{\mathrm{WTP}}, \mu_{\sigma}}\left(\mu_{Y}, \sigma_{Y}\right)\right| \Leftrightarrow \frac{\mu_{Y}^{2}}{\sigma_{Y}^{2}} \gtreqless \frac{2}{\theta}-3 \Leftrightarrow \mu_{Y} \gtreqless \sqrt{\frac{2}{\theta}-3} \sigma_{Y}$.

Case 4: $\theta<1 / 2$ and $\mu_{Y}>\sqrt{1 / \theta-2} \sigma_{Y}$

$$
\begin{aligned}
\left|\eta_{\mu_{\mathrm{WTP}}, \mu_{Y}}\left(\mu_{Y}, \sigma_{Y}\right)\right|=\eta_{\mu_{\mathrm{WTP}}, \mu_{Y}}\left(\mu_{Y}, \sigma_{Y}\right) & \gtreqless \eta_{\mu_{\mathrm{WTP}}, \sigma_{Y}}\left(\mu_{Y}, \sigma_{Y}\right)=\left|\eta_{\mu_{\mathrm{WTP}}, \sigma_{Y}}\left(\mu_{Y}, \sigma_{Y}\right)\right| \\
\Leftrightarrow \quad \frac{1}{\theta}\left[1-\left(\frac{1}{\theta}-1\right) \frac{1}{\left.\frac{\mu_{Y}^{2}}{\sigma_{Y}^{2}}+1\right]}\right. & \gtreqless \frac{1}{\theta}\left(\frac{1}{\theta}-1\right) \frac{1}{\frac{\mu_{Y}^{2}}{\sigma_{Y}^{2}}+1} \\
\Leftrightarrow \quad \frac{1}{\theta}\left[1-2\left(\frac{1}{\theta}-1\right) \frac{1}{\left.\frac{\mu_{Y}^{2}}{\sigma_{Y}^{2}}+1\right]}\right. & \gtreqless 0 \\
\Leftrightarrow \quad \frac{\mu_{Y}^{2}}{\sigma_{Y}^{2}} & \gtreqless \frac{2}{\theta}-3 \\
\Leftrightarrow \quad \mu_{Y} & \gtreqless \sqrt{\frac{2}{\theta}-3 \sigma_{Y}} .
\end{aligned}
$$

As $\sqrt{2 / \theta-3}>\sqrt{1 / \theta-2}$ for $\theta<1 / 2$, all three potential relations between the LHS and the RHS are feasible.

Case 5: $\theta<1 / 2$ and $\mu_{Y}=\sqrt{1 / \theta-2} \sigma_{Y}$

$$
\left|\eta_{\mu_{\mathrm{WTP},}, \mu_{Y}}\left(\mu_{Y}, \sigma_{Y}\right)\right| \gtreqless\left|\eta_{\mu_{\mathrm{WTP}}, \sigma_{Y}}\left(\mu_{Y}, \sigma_{Y}\right)\right| \Leftrightarrow 0 \gtreqless \frac{1}{\theta}\left(\frac{1}{\theta}-1\right) \frac{1}{\frac{\mu_{Y}^{2}}{\sigma_{Y}^{2}}+1} .
$$

As the RHS is strictly positive for all $\mu_{Y}, \sigma_{Y}$ and $\theta<1 / 2$, we have that

$$
\left|\eta_{\mu_{\mathrm{WTP}}, \mu_{Y}}\left(\mu_{Y}, \sigma_{Y}\right)\right|<\left|\eta_{\mu_{\mathrm{WTP}}, \sigma_{Y}}\left(\mu_{Y}, \sigma_{Y}\right)\right| .
$$


Case 6: $\theta<1 / 2$ and $\mu_{Y}<\sqrt{1 / \theta-2} \sigma_{Y}$

$$
\begin{aligned}
\left|\eta_{\mu_{\mathrm{WTP},}, \mu_{Y}}\left(\mu_{Y}, \sigma_{Y}\right)\right|=-\eta_{\mu_{\mathrm{WTP}, \mu_{Y}}\left(\mu_{Y}, \sigma_{Y}\right)} \gtreqless \eta_{\mu_{\mathrm{WTP}, \sigma_{Y}}}\left(\mu_{Y}, \sigma_{Y}\right)=\left|\eta_{\mu_{\mathrm{WTP},}, \sigma_{Y}}\left(\mu_{Y}, \sigma_{Y}\right)\right| \\
\Leftrightarrow \quad-\frac{1}{\theta}+\frac{1}{\theta}\left(\frac{1}{\theta}-1\right) \frac{1}{\frac{\mu_{Y}^{2}}{\sigma_{Y}^{2}}+1} \gtreqless \frac{1}{\theta}\left(\frac{1}{\theta}-1\right) \frac{1}{\frac{\mu_{Y}^{2}}{\sigma_{Y}^{2}}+1} \\
\Leftrightarrow \quad-\frac{1}{\theta} \gtreqless 0 .
\end{aligned}
$$

As the LHS is strictly negative for all $\theta<1 / 2$, we have that

$$
\left|\eta_{\mu_{\mathrm{WTP}}, \mu_{Y}}\left(\mu_{Y}, \sigma_{Y}\right)\right|<\left|\eta_{\mu_{\mathrm{WTP}}, \sigma_{Y}}\left(\mu_{Y}, \sigma_{Y}\right)\right| .
$$

Putting the different cases and sub-cases together we have the following results.

- $\left|\eta_{\mu_{\mathrm{WTP}}, \mu_{Y}}\left(\mu_{Y}, \sigma_{Y}\right)\right|>\left|\eta_{\mu_{\mathrm{WTP}}, \sigma_{Y}}\left(\mu_{Y}, \sigma_{Y}\right)\right|$ in the following cases:

$$
\begin{aligned}
& \theta>1 \\
& \theta=1 \\
& 2 / 3 \leq \theta<1 \\
& 1 / 2 \leq \theta<2 / 3 \text { and } \mu_{Y}>\sqrt{2 / \theta-3} \sigma_{Y} \\
& \theta<1 / 2 \text { and } \mu_{Y}>\sqrt{2 / \theta-3} \sigma_{Y}\left(\text { which implies } \mu_{Y}>\sqrt{1 / \theta-2} \sigma_{Y}\right)
\end{aligned}
$$

- $\left|\eta_{\mu_{\mathrm{WTP}}, \mu_{Y}}\left(\mu_{Y}, \sigma_{Y}\right)\right|=\left|\eta_{\mu_{\mathrm{WTP}}, \sigma_{Y}}\left(\mu_{Y}, \sigma_{Y}\right)\right|$ in the following cases:

$$
\begin{aligned}
& \square 1 / 2 \leq \theta<2 / 3 \text { and } \mu_{Y}=\sqrt{2 / \theta-3} \sigma_{Y} \\
& \square \theta<1 / 2 \text { and } \mu_{Y}=\sqrt{2 / \theta-3} \sigma_{Y} \text { (which implies } \mu_{Y}>\sqrt{1 / \theta-2} \sigma_{Y} \text { ) }
\end{aligned}
$$

- $\left|\eta_{\mu_{\mathrm{WTP}}, \mu_{Y}}\left(\mu_{Y}, \sigma_{Y}\right)\right|<\left|\eta_{\mu_{\mathrm{WTP}}, \sigma_{Y}}\left(\mu_{Y}, \sigma_{Y}\right)\right|$ in the following cases:

$$
\begin{aligned}
& 1 / 2 \leq \theta<2 / 3 \text { and } \mu_{Y}<\sqrt{2 / \theta-3} \sigma_{Y} \\
& \theta<1 / 2 \text { and } \sqrt{1 / \theta-2} \sigma_{Y}<\mu_{Y}<\sqrt{2 / \theta-3} \sigma_{Y} \\
& \theta<1 / 2 \text { and } \mu_{Y}=\sqrt{1 / \theta-2} \sigma_{Y} \\
& \theta<1 / 2 \text { and } \mu_{Y}<\sqrt{1 / \theta-2} \sigma_{Y}
\end{aligned}
$$




\subsubsection{Proof of Proposition 3.7}

The transfer function is defined as the quotient of the mean WTPs at the policy and the study sites, and is given as:

$$
\begin{aligned}
& \mathcal{T}\left(E^{\text {policy }}, p^{\text {policy }}, \mu_{Y}^{\text {policy }}, \mathrm{CV}_{Y}^{\text {policy }} ; E^{\text {study }}, p^{\text {study }}, \mu_{Y}^{\text {study }}, \mathrm{CV}_{Y}^{\text {study }}\right) \\
& :=\frac{\mu_{\mathrm{WTP}}^{\text {policy }}\left(\mu_{Y}, \mathrm{CV}_{Y}\right)}{\mu_{\mathrm{WTP}}^{\text {study }}\left(\mu_{Y}, \mathrm{CV}_{Y}\right)} \\
& \stackrel{\text { Equ. 3.5) }}{=} \frac{\frac{1-\alpha}{\alpha}\left(p E^{\text {policy }}\right)^{\frac{\theta-1}{\theta}}\left(\mu_{Y}^{\text {policy }}\right)^{\frac{1}{\theta}}\left(1+\mathrm{CV}_{Y}^{\text {policy } 2}\right)^{\frac{1-\theta}{2 \theta^{2}}}}{\frac{1-\alpha}{\alpha}\left(p E^{\text {study }}\right)^{\frac{\theta-1}{\theta}}\left(\mu_{Y}^{\text {study }}\right)^{\frac{1}{\theta}}\left(1+\mathrm{CV}_{Y}^{\text {study } 2}\right)^{\frac{1-\theta}{2 \theta^{2}}}} \\
& =\left(\frac{E^{\text {policy }}}{E^{\text {study }}}\right)^{\frac{\theta-1}{\theta}} \cdot\left(\frac{p^{\text {policy }}}{p^{\text {study }}}\right)^{\frac{\theta-1}{\theta}} \cdot\left(\frac{\mu_{Y}^{\text {policy }}}{\mu_{Y}^{\text {study }}}\right)^{\frac{1}{\theta}} \cdot\left(\frac{1+\mathrm{CV}_{Y}^{\text {policy } 2}}{1+\mathrm{CV}_{Y}^{\text {study } 2}}\right)^{\frac{1-\theta}{2 \theta^{2}}}
\end{aligned}
$$

\subsubsection{Error propagation}

Equation (3.4) shows how $\kappa$ depends on $\eta=1 / \theta$ :

$$
\kappa=\underbrace{\frac{1-\alpha}{\alpha}(p E)^{\frac{\theta-1}{\theta}}}_{=: C}=C^{1-\eta} .
$$

Taking the natural logarithm, we obtain

$$
\underbrace{\ln \kappa}_{=: y}=\underbrace{(1-\eta)}_{=: x} \cdot \ln C
$$

Taking $C$ as exactly measured, and denoting by $\Delta z$ the absolute standard error of some variable $z$, standard error propagation from $x$ to $y$ yields (Bronstein and Semendjajew 1987: 99-100)

$$
\frac{\Delta y}{y}=\frac{\Delta x}{x} \Leftrightarrow \frac{\Delta \ln \kappa}{\ln \kappa}=\frac{-\Delta \eta}{1-\eta} \Leftrightarrow \Delta \ln \kappa=\frac{-\Delta \eta}{1-\eta} \cdot \ln \kappa
$$

As $\kappa \equiv \exp (\ln \kappa)$, the standard error in $\eta$ gives rise to an interval around $\kappa_{\eta}$ - the value of $\kappa$ obtained from $\eta$ according to Equation (3.97) - the boundaries of which are given by the following values:

$$
\kappa_{\eta \pm \Delta \eta}=\exp \left(\ln \kappa_{\eta} \pm \Delta \ln \kappa\right)=\exp \left(\left[1 \mp \frac{\Delta \eta}{1-\eta}\right] \cdot \ln \kappa_{\eta}\right)
$$




\subsubsection{Heterogenous preferences}

Assuming that each household has a different elasticity of substitution, $\theta$, between the environmental public good and the private consumption good, and that $\eta=1 / \theta$ is normally distributed with mean $\mu_{\eta}$ and standard deviation $\sigma_{\eta}$, and uncorrelated with income, the mean WTP is

$$
\begin{aligned}
\mu_{\mathrm{WTP}}\left(\mu_{Y}, \sigma_{Y}\right) & =\int_{0}^{\infty} f_{\ln }\left(Y ; \mu_{Y}, \sigma_{Y}\right)\left[\int_{-\infty}^{\infty} f_{\mathrm{norm}}\left(\eta ; \mu_{\eta}, \sigma_{\eta}\right) \kappa Y^{\eta} d \eta\right] d Y \\
& =\int_{0}^{\infty} f_{\ln }\left(Y ; \mu_{Y}, \sigma_{Y}\right) \kappa Y^{\mu_{\eta}+\frac{\sigma_{\eta}^{2}}{2}} d Y \\
& =\kappa \mu_{Y}^{\mu_{\eta}+\frac{\sigma_{\eta}^{2}}{2}}\left(1+\frac{\sigma_{Y}^{2}}{\mu_{Y}^{2}}\right)^{\frac{1}{2}\left(\mu_{\eta}+\frac{\sigma_{\eta}^{2}}{2}\right)\left(1-\mu_{\eta}-\frac{\sigma_{\eta}^{2}}{2}\right)} .
\end{aligned}
$$

This expression has the same structural form as Equation (3.6), except that $\eta=1 / \theta$ is replaced by $\mu_{\eta}+\sigma_{\eta}^{2} / 2$.

Similarly, if $\kappa$ differs across households and follows some statistical distribution, for example because the parameter $\alpha$ of the utility function (3.1) has different values for different households, one has to replace $\kappa$ in Equation (3.6) by its mean value $\mu_{\kappa}$.

\subsubsection{Generalization of main result}

Our main result - that the mean willingness to pay for the environmental public good decreases (increases) with the inequality of the income distribution, for constant mean income, if and only if the environmental public good and the private consumption good are substitutes (complements) (Proposition 3.3 and Proposition 3.4, Statement 1) - can be shown to hold more generally, that is, beyond the particular functional specifications of the utility function (CES) and the income distribution (log-normal) used there. We sketch the line of argument of such a more general proof in the following.

Consider the following setting. There are $m$ private consumption goods $X_{j}$ that are market-traded at prices $p_{j}(j=1, \ldots, m)$ and a non-market-traded environmental public good $E$. There are $n$ individuals with identical preferences over the $j+1$ goods that are represented by a utility function $U\left(X_{1}, \ldots X_{m}, E\right)$ that is strictly increasing in all arguments and strictly quasi-concave. Income $Y$ is distributed over individuals according to some regular distribution over non-negative incomes. 
In order to classify the environmental public good as a "substitute" or a "complement" for the private consumption goods we build on the partial elasticities of substitution introduced by Allen and Uzawa: the partial elasticity of substitution $\theta^{A U}\left(\hat{X}_{j}, \hat{E}\right)$ between the environmental public good and the private consumption good $j$ is defined as the percentage change of the ratio of the quantity $E$ to $X_{j}$ arising from a percentage change in the price ratio $p_{j} / w$ keeping utility $U$ unchanged (cf. Uzawa 1962), where $w$ is the Lindahl price ("virtual price"), i.e. the willingness-to-pay per unit, for the environmental public good and $\hat{X}$ and $\hat{E}$ denote the ordinary (unconditional) Marshallian demand in a hypothetical setting where the environmental public good was market-traded at price $w$ and income was adjusted to $\hat{Y}=Y+w \hat{E}$, so that the consumer would choose $(X, E)$.

For the following, consider the following aggregate Allen-Uzawa elasticity of substitution between the environmental public good and the private consumption goods,

$$
\theta^{A U a g g r}(\hat{X}, \hat{E}):=\sum_{j=1}^{m} \frac{p_{j} X_{j}}{Y} \theta^{A U}\left(\hat{X}_{j}, \hat{E}\right),
$$

which is a weighted sum of the partial elasticities of substitution where the weights are the budget shares of market-traded consumption good $X_{j}$ with respect to original income $Y$. This definition of the aggregate elasticity of substitution allows us, for any utility function $U(X, E)$ and depending on the consumption levels $X=\left(X_{1}, \ldots, X_{m}\right)$ and $E$, a classification of the environmental public good as being a substitute $\left(\theta^{A U a g g r}>1\right)$ or a complement $\left(0 \leq \theta^{A U a g g r}<1\right)$ for the private consumption consumption goods, in an aggregate manner. If $\theta^{A U}\left(\hat{X}_{j}, \hat{E}\right)=\theta$ for all $j=1, \ldots, m$, as it is the case for the CES-utility function, $\theta^{\operatorname{AUaggr}}(\hat{X}, \hat{E})=\theta$.

Ebert (2003: Result 9) has shown that

$$
\eta_{W T P, Y}=\frac{\eta_{\hat{E}, \hat{Y}}}{\theta^{\operatorname{AUaggr}(\hat{X}, \hat{E})}}
$$

That is, in a hypothetical setting where the environmental public good was market-traded at the price $w$, the income elasticity of WTP depends positively on the income elasticity of demand for the environmental public good, and inversely on the aggregate Allen-Uzawa elasticity of substitution between the environmental public good and the private consumption goods. All three quantities in Equation (3.103) depend on the level of income $Y$, so that this equation generally holds for any level of income $Y$. Result (3.103) is a generalization of $\eta=1 / \theta$ (Equation 3.4) for any utility function, and for a CES-utility function reduces to 
the latter, as $\eta_{\hat{E}, \hat{Y}} \equiv 1$ and $\theta^{A U a g g r}(\hat{X}, \hat{E}) \equiv \theta$ for CES-utility functions.

Result (3.103) implies that the income elasticity of WTP, $\eta_{W T P, Y}$, increases with the income elasticity of demand for the environmental public good, $\eta_{\hat{E}, \hat{Y}}$, and decreases with the aggregate Allen-Uzawa elasticity of substitution, $\theta^{\operatorname{AUaggr}}(\hat{X}, \hat{E})$. It thus depends on both, the value of $\eta_{\hat{E}, \hat{Y}}$ and the value of $\theta^{A U a g g r}(\hat{X}, \hat{E})$, whether $\eta_{W T P, Y}$ is smaller or larger than one, that is, whether WTP increases with income in a progressive or regressive way. Ebert (2003: Section 4.3) illustrates this result with a number of examples of different kinds of utility functions.

Define

$$
\tilde{\theta}:=\eta_{\hat{E}, \hat{Y}}
$$

such that for all $\theta^{A U a g g r}(\hat{X}, \hat{E})>(<) \tilde{\theta}$ one has $\eta_{W T P, Y}<(>) 1$ and WTP increases with income in a regressive (progressive) way. In other words, WTP increases with income in a regressive (progressive) way if and only if the aggregate Allen-Uzawa elasticity of substitution is larger (smaller) than some threshold value $\tilde{\theta}$ which is given by the income elasticity of demand for the environmental public good, $\eta_{\hat{E}, \hat{Y}}$ (Definition 3.104). WTP is then a concave (convex) function of income $Y$ over that range(s) of income for which $\theta^{\operatorname{AUaggr}}(\hat{X}, \hat{E})>(<) \tilde{\theta}$ holds. In general, $\operatorname{WTP}(Y)$ may not be a globally ${ }^{37}$ concave (convex) function of income $Y$.

To define what it means to say that an income distribution is "more (un)equal" than another one we employ a fundamental axiom of inequality measurement: an income distribution that emerges from another one through a Pigou-Dalton-transfer ${ }^{38}$ is "more equal" than the original one. In a more general sense, an income distribution that emerges from another one through a sequence of Pigou-Dalton-transfers is "more equal" than the original one.

For a globally concave (convex) WTP $(Y)$-function a more equal distribution of income $Y$ implies a higher (lower) mean value of WTP, $\mu_{W T P}$. This can be seen as follows. Consider a society of $n$ individuals with income distribution $Y=\left(Y_{1}, \ldots, Y_{n}\right)$, i.e. $Y_{i} \geq 0$ is the income of individual $i$ with $i=1, \ldots, n$. Consider in particular two individuals $j$ and $k$ with $j, k \in$ $\{1, \ldots, n\}, j \neq k$ and $Y_{j}<Y_{k}$ and an income transfer $\delta>0$ from individual $k$ to individual $j$ with $Y_{j}+\delta \leq Y_{k}-\delta$ which leaves the incomes of all other members of society unaltered. This

\footnotetext{
37"Globally" here means that the WTP $(Y)$-function is concave (convex) over the entire support of the income distribution.

${ }^{38}$ Consider a society of $n$ individuals with income distribution $Y=\left(Y_{1}, \ldots, Y_{n}\right)$, i.e. $Y_{i} \geq 0$ is the income of individual $i$ with $i=1, \ldots, n$. Now take two individuals $j$ and $k$ with $j, k \in\{1, \ldots, n\}, j \neq k$ and $Y_{j}<Y_{k}$. An income transfer $\delta>0$ from individual $k$ to individual $j$ with $Y_{j}+\delta \leq Y_{k}-\delta$ which leaves the incomes of all other members of society unaltered is called a Pigou-Dalton-transfer (Dalton 1920, following Pigou 1912).
} 
Pigou-Dalton transfer generates an income distribution $Y^{\prime}=\left(Y_{1}, \ldots, Y_{j}+\delta, \ldots, Y_{k}-\delta, \ldots ., Y_{n}\right)$ which is, by definition, more equal than the distribution $Y$. Also, the following inequality holds:

$$
Y_{j}<Y_{j}+\delta \leq Y_{k}-\delta<Y_{k}
$$

Define

$$
\lambda:=1-\frac{\delta}{Y_{k}-Y_{j}}
$$

This can be rearranged into $\delta=(1-\lambda)\left(Y_{k}-Y_{j}\right)$, so that

$$
\begin{aligned}
Y_{j}+\delta & =\lambda Y_{j}+(1-\lambda) Y_{k} \\
Y_{k}-\delta & =(1-\lambda) Y_{j}+\lambda Y_{k}
\end{aligned}
$$

As $\lambda \in[0,1]$, this shows that for all possible Pigou-Dalton-transfers $\delta$, the after-transfer incomes of individuals $j$ and $k$ can be expressed as convex combinations of their beforetransfer incomes.

Under the original income distribution $Y$, mean income and mean WTP for the environmental good are

$$
\begin{aligned}
& \mu_{Y}=\left(Y_{1}+\ldots+Y_{j}+\ldots+Y_{k}+\ldots .+Y_{n}\right) / n \\
& \mu_{W T P}=\left[W T P\left(Y_{1}\right)+\ldots+W T P\left(Y_{j}\right)+\ldots+W T P\left(Y_{k}\right)+\ldots+W T P\left(Y_{n}\right)\right] / n .
\end{aligned}
$$

Under the more equal income distribution $Y^{\prime}$, mean income and mean WTP for the environmental good are

$$
\begin{aligned}
& \mu_{Y^{\prime}}=\left(Y_{1}+\ldots+Y_{j}+\delta+\ldots .+Y_{k}-\delta+\ldots .+Y_{n}\right) / n \\
& \mu_{W T P}^{\prime}=\left[W T P\left(Y_{1}\right)+\ldots+W T P\left(Y_{j}+\delta\right)+\ldots .+W T P\left(Y_{k}-\delta\right)+\ldots .+W T P\left(Y_{n}\right)\right] / n .
\end{aligned}
$$

Obviously, $\mu_{Y^{\prime}}=\mu_{Y}$, that is, the Pigou-Dalton-transfer income leaves mean income unaltered, and

$$
\mu_{W T P}^{\prime}-\mu_{W T P}=\left\{W T P\left(Y_{j}+\delta\right)+W T P\left(Y_{k}-\delta\right)-\left[W T P\left(Y_{j}\right)+W T P\left(Y_{k}\right)\right]\right\} / n
$$

Suppose the WTP(Y)-function is globally concave (convex). Then, as there exists a $\lambda \in[0,1]$ such that $Y_{j}+\delta=\lambda Y_{j}+(1-\lambda) Y_{k}$ (Equation 3.107) and $Y_{k}-\delta=(1-\lambda) Y_{j}+\lambda^{\prime} Y_{k}$ 
(Equation 3.108), one has - by definition of concavity (convexity) ${ }^{39}-$ that

$$
\begin{aligned}
& W T P\left(Y_{j}+\delta\right)=W T P\left(\lambda Y_{j}+(1-\lambda) Y_{k}\right) \geq(\leq) \lambda W T P\left(Y_{j}\right)+(1-\lambda) W T P\left(Y_{k}\right) \text { and } \\
& \left.W T P\left(Y_{k}-\delta\right)=W T P\left((1-\lambda) Y_{j}+\lambda\right) Y_{k}\right) \geq(\leq)(1-\lambda) W T P\left(Y_{j}\right)+\lambda W T P\left(Y_{k}\right) .
\end{aligned}
$$

This implies that

$$
\begin{aligned}
& W T P\left(Y_{j}+\delta\right)+W T P\left(Y_{k}-\delta\right) \\
& \geq(\leq) \lambda W T P\left(Y_{j}\right)+(1-\lambda) W T P\left(Y_{k}\right)+(1-\lambda) W T P\left(Y_{j}\right)+\lambda W T P\left(Y_{k}\right) \\
& =\operatorname{WTP}\left(Y_{j}\right)+W T P\left(Y_{k}\right)
\end{aligned}
$$

With this and Equation (3.113), it becomes obvious that

$$
\mu_{W T P}^{\prime} \geq(\leq) \mu_{W T P}
$$

That is, for a globally concave (convex) WTP $(Y)$-function a more equal distribution of income $Y$ implies a higher (lower) mean value of WTP, $\mu_{W T P}$

Putting the pieces together, we can make the following general proposition. Assume that the utility function $U\left(X_{1}, \ldots X_{m}, E\right)$ is such that the associated $\operatorname{WTP}(Y)$ function is globally concave (globally convex). Then, there exists a threshold value of the aggregate Allen-Uzawa elasticity of substitution between the environmental public good and the private consumption goods, $\tilde{\theta}$, such that the following holds: the mean willingness to pay for the environmental public good, $\mu_{W T P}$, decreases (increases) with the inequality of the income distribution for given mean income - if and only if the aggregate Allen-Uzawa elasticity of substitution is larger (smaller) than $\tilde{\theta}$.

\footnotetext{
${ }^{39} \mathrm{~A}$ real function $\phi(x)$ is called convex if for all $x_{1}, x_{2}$ from its domain and all $\lambda \in[0,1]$, it holds that $\phi\left(\lambda x_{1}+(1-\lambda) x_{2}\right) \leq \lambda \phi\left(x_{1}\right)+(1-\lambda) \phi\left(x_{2}\right)$.
}

If the inequality is reversed, i.e. it holds with $\geq$, the function is called concave. 


\title{
4 Environmental Inequality and Economic Valuation
}

\begin{abstract}
This paper studies how the distribution of environmental goods and income affect the economic valuation of local public goods. I show that environmental inequality affects societal willingness to pay (WTP) for environmental local public goods and that this is determined by their substitutability as well as by how their provision is correlated with income. Specifically, I find that in cases where environmental inequality is weakly greater than income inequality or the correlation between income and environmental good endowment is negative, environmental inequality decreases (increases) societal WTP if and only if the environmental good is a substitute to (complement for) manufactured consumption goods. Moreover, I show that sorting of richer households into places with higher levels of a given environmental good increases (decreases) societal WTP if and only if it is a substitute for (complement to) manufactured consumption goods. I obtain novel closed-form adjustment factors for benefit transfer to control for differences in the (spatial) distribution of environmental local public goods. Using forest preservation in Poland as an empirical example, I find that societal WTP is up to 4 percent higher for equal access to forests and up to 8 percent higher for an equal distribution of both income and access to forests.
\end{abstract}

Keywords: Inequality, environmental valuation, WTP, local public good, spatial distribution, scope effect, benefit transfer, forest ecosystem services

Reference: Meya, J.N. (2018). Environmental inequality and economic valuation. Oldenburg Discussion Papers in Economics, V-416-18. 


\subsection{Introduction}

Environmental policy making is increasingly informed by economic values assigned to nonmarket environmental goods, which are often distributed highly unequal among households. For instance, Boyce et al. (2016) recently found that exposure to industrial air pollution in the United States is even more unequally distributed than income. In many cases environmental inequalities reinforce prevailing economic inequalities. For centuries, wealthy citizens have tended to live in areas where environmental quality is high, while pollution has been burdened disproportionately on poor citizens. ${ }^{40}$ It is timely to study the interplay of environmental inequalities and economic inequalities, as economic inequalities are on the rise in most parts of the world (Alvaredo et al. 2017), while the loss of biodiversity and many ecosystem services is accelerating (Baumgärtner et al. 2015, Butchart et al. 2010, MEA 2005).

The monetary valuation of non-market goods has become a central challenge for environmental economics. So far, however, valuation studies have paid little attention to the implications of (spatially) coupled environmental and income inequalities (Drupp 2018). Recently, Baumgärtner et al. (2017a) presented a model of how the distribution of income affects the societal value of pure public goods at the stage of aggregating individual values. For an equal preference model set-up in which all households are endowed with the same level of an environmental good but differ in exogenously given income, they find that aggregate willingness to pay (WTP) decreases (increases) with income inequality if and only if the environmental good is a substitute for (complement to) manufactured consumption goods. As the majority of environmental goods considered in non-market valuation are unevenly distributed across households, it is crucial to extend this model framework to local public environmental goods and to analyze how environmental inequalities affects aggregate WTP (cf. Drupp 2018).

In this paper, I study how the joint distribution of environmental goods and income - and in particular, environmental and income inequality - affect the valuation of local public goods. I present a model of society's aggregate willingness to pay (WTP) for an environmental local public good where households differ in both the environmental good and income. Building on the model developed by Baumgärtner et al. (2017a) for pure public goods, I assume (a) households to have identical preferences regarding a manufactured

\footnotetext{
${ }^{40}$ For instance, Lee and Lin (2018) show that in the period from 1880 to 2010, U.S. metropolitan neighborhoods that are close to environmental amenities increase in income over time, and that cities with a pronounced heterogeneous distribution of natural amenities are also characterized by a persistent heterogeneous spatial distribution of income. Heblich et al. (2017) show that in 90 English cities, air pollution around 1880 explains a large share of both the historical and current spatial income distribution.
} 
private consumption good and an environmental good represented by a constant elasticity of substitution (CES) utility function, and (b) log-normally distributed household income. I extend their model to the case of environmental local public goods by assuming (c) that households are heterogeneous in their endowment with environmental goods, represented by a log-normal distribution. While this is certainly an approximation, the assumption of log-normality reflects that the distribution of many environmental goods across households in a society is strongly right-skewed and positive. Assumptions (b) and (c) make it possible to employ a bi-variate log-normal distribution to study different correlations between the environmental good endowment and income.

I find that the distribution of the environmental good - and how this is correlated with income - affects society's aggregate WTP. In particular, I show that (i) societal WTP for the environmental local public good increases (decreases) with the level of the environmental good ('scope') if and only if the environmental good and the private consumption good are substitutes (complements); (ii) the effect of environmental and income inequality on mean WTP is determined by whether the environmental good is a substitute for or a complement to manufactured consumption goods and by how environmental good endowment is correlated with income; (iii) sorting of richer households such that they are endowed with higher levels of the environmental good increases (decreases) societal WTP if and only if the environmental good is a substitute for (complement to) manufactured consumption goods. Based on these theoretical insights, I derive theory-based adjustment factors for benefit transfer to account for differences in the distribution of environmental local public goods and income. Finally, an application to forest preservation in Poland illustrates considerable economic effect sizes of the proposed adjustments.

My research adds to several strands of literature: First, I contribute to the development of theory-based ('structural') methods for spatial benefit transfer. Practical policy analysis usually draws on monetary values from past studies to inform policy making in a different context (OECD 2018), which is commonly referred to as 'benefit' or 'value transfer'. As the associated errors are often large, several scholars have argued that benefit transfers should be based more firmly in micro-economic theory (Bateman et al. 2011, Smith et al. 2002). Recently, there has been a growing interest in spatially explicit approaches to benefit transfer (e.g. Kuminoff 2018, Turner 2017, Perino et al. 2014, Brander et al. 2012). In the present paper, I qualify the conditions under which the transfer factors proposed by Baumgärtner et al. (2017a) and empirically tested by Meya et al. (2017) and also hold for environmental 
local public goods.

Second, I contribute to the theoretical underpinnings of primary valuation of non-market environmental goods. The sensitivity of mean WTP to the amount of the valued environmental good ('scope effect') is a common validity test for stated preference studies (e.g. Arrow et al. 1993). However, the absence of positive scope effects in several valuation studies has spurred a heated debate on the underlying reasons, leading some scholars to discard the practice of contingent valuation as a whole. ${ }^{41}$ Here, I link the existence of a positive sensitivity to scope to the substitutability of the valued environmental good by manufactured consumption goods.

Third, I contribute to the literature on spatial inequality and neighborhood sorting. My analysis is thus related to Brueckner et al. (1999), Lee and Lin (2018), Heblich et al. (2017), who show that environmental amenities induce neighborhood sorting, with higher-income households sorting into neighborhoods where environmental quality is high. The correlation between environmental quality and socio-demographic variables such as income has been scrutinized under the headline of 'environmental justice' for decades (e.g. Ash and Fetter 2004). Here, I link the effect of sorting to the societal valuation of environmental amenities by analyzing changes in the correlation between environmental goods and income.

The remainder is structured as follows. I present the model in Section 4.2, and the results from the model analysis in Section 4.3. An empirical application for a forest protection policy in Poland is presented in Section 4.4. I discuss major limitations of my analysis in Section 4.5 and conclude in Section 4.6. The Appendix contains all formal proofs.

\subsection{Model}

I build on and extend the pure public good model developed in Baumgärtner et al. (2017a) to make it applicable to local public goods. Consider a society that consists of a population of $n$ households, denoted $i=1, \ldots, n$. This might be a city, region, or country. There is a single environmental amenity, $E$, that households enjoy at different levels, $E_{i}$. Several households might be endowed with the same level of the environmental good, which is locally public. ${ }^{42}$

\footnotetext{
${ }^{41} \mathrm{~A}$ review of the extensive discussion on the scope effect is beyond the scope of this introduction. Early contributions include the study by Kahneman and Knetsch (1992) and the critical response of Smith (1992). A recent overview on the debate can be found in Whitehead (2016).

${ }^{42} \mathrm{By}$ 'environmental good' I refer to all types of goods and services people receive from nature. In the following, I study environmental goods that are locally public, i.e. they are non-excludable and non-rival but only available within a limited geographic area so that the exposure varies across households within a society. My analysis therefore applies mainly to use values as opposed to non-use values, which generally do not depend on exposure to the environmental good. For example, one may think of regulatory ecosystem
} 
A household $i$ derives utility by consuming two goods: a private, manufactured consumption good, $X_{i}>0$, traded on a market at price $P>0$, and the non-market-traded environmental local public good, $E_{i}>0$. The household cannot choose the level of the environmental good, which is rationed at quantity $E_{i}$. Household $i$ 's endowment with the environmental good, $E_{i}$, might be measured in physical units, for example 'parts per million', 'park area density' or 'distance to the nearest environmental amenity' such as an urban park or forest.

Households have equal preferences regarding these two goods, represented by a constant elasticity of substitution (CES) utility function

$$
U\left(X_{i}, E_{i}\right)=\left(\alpha X_{i}^{\frac{\theta-1}{\theta}}+(1-\alpha) E_{i}^{\frac{\theta-1}{\theta}}\right)^{\frac{\theta}{\theta-1}}
$$

where $\theta \in(0,+\infty)$ is the constant elasticity of substitution between the market-traded consumption good and the non-market-traded environmental local public good. The other preference parameter $\alpha \in(0,1)$ is the weight of the consumption good relative to the environmental good in the household's overall utility. The CES utility function is the simplest preference representation that is still rich enough to study different degrees of substitutability in the consumption of the environmental good and manufactured goods. It contains the cases where both are substitutes $(\theta>1)$, Cobb-Douglas $(\theta=1)$ and complements $(\theta<1)$.

Household $i$ 's decision problem is then to maximize utility from the consumption good, $X_{i}$, and the environmental good, $E_{i}$, subject to a budget constraint given by their income, $Y_{i}>0$, and the exogenously fixed level $E_{i}:{ }^{43}$

$$
\max _{X_{i}, E_{i}} U\left(X_{i}, E_{i}\right) \quad \text { s.t. } \quad P X_{i}=Y_{i}, \quad E_{i} \text { fixed. }
$$

I follow Aaron and McGuire (1970), Ebert (2003) and Baumgärtner et al. (2017a) by defining household $i$ 's income-equivalent total WTP for the local public environmental good at level $E_{i}$ as the marginal willingness to pay, $\omega$, per unit of the environmental good at level $E_{i}$ times the enjoyed quantity of $E_{i}: W T P\left(Y_{i}, E_{i}\right)=\omega\left(Y_{i}, E_{i}\right) E_{i}$. The marginal WTP (so called 'Lindahl price'), $\omega$, is obtained as the price the household would have been willing to pay if the level of the environmental good that household enjoys, $E_{i}$, had been freely

services such as clean air and cultural ecosystem services such as recreation opportunities provided by urban green spaces or forests. For the sake of brevity, I only refer to $E$ as environmental good in the following. Nevertheless, the analysis equally holds for a reduction in environmental bads, such as local air pollution or environmental disamenities such as hazardous waste sites or highways.

${ }^{43}$ To save on notation, I use $E_{i}$ to denote both the variable 'household $i$ 's endowment with the local public environmental good' and the actual consumed quantity, as the consumed quantity $E_{i}$ is fixed throughout the main analysis (see Appendix 4.7.9 for how this assumption might be relaxed). 
chosen on a hypothetical market. As such, marginal WTP can be derived from household $i$ 's indirect utility function at the currently enjoyed level of the environmental good, $E_{i}$, the market prices of consumption goods, $P$, and income, $Y_{i}$ (see Appendix 4.7.1).

For the CES utility function, household $i$ 's total WTP for the environmental good at level $E_{i}$ can be expressed as a function of income, $Y_{i}$, price level, $P$, and preference parameters, $\alpha$ and $\eta$ or $\theta$, as follows (Appendix 4.7.1):

$$
\operatorname{WTP}\left(Y_{i}, E_{i}\right)=\frac{1-\alpha}{\alpha} P^{1-\eta} E_{i}^{1-\eta} Y_{i}^{\eta}, \quad \eta=\frac{1}{\theta}
$$

where $\eta$ denotes the income elasticity of WTP. Except for the household index $i$ on the environmental good, Eq. (4.3) is identical to household's WTP for pure public goods derived by Baumgärtner et al. (2017a). The CES utility function implies that the elasticity of substitution, $\theta$, between the manufactured consumption good, $X_{i}$, and the environmental good, $E_{i}$, is the inverse of the income elasticity of WTP, $\eta$, (Baumgärtner et al. 2017a, Ebert 2003, Kovenock and Sadka 1981), which consequently is also constant. ${ }^{44}$ As most approaches to benefit transfer are based on a constant income elasticity of WTP, this property makes the CES utility framework the preferred functional form to deduct benefit transfer factors in the following.

Recall that there is a single environmental local public good $E$, which households enjoy at different exogenously fixed levels $E_{i}$. In order to model the local public good character, I assume that the environmental good is unevenly and continuously distributed over households, represented by a log-normal distribution,

$$
E_{i} \propto \operatorname{LN}\left(\mu_{E} ; \sigma_{E}^{2}\right)
$$

where $\mu_{E}>0$ is the mean level of the environmental good and $\sigma_{E}$ is the spread of environmental good endowment across households. The frequency of households endowed with a certain level of the environmental good is given by the corresponding density function. Assuming a log-normal distribution reflects that the endowment with environmental goods is positive and that some households in society enjoy a higher level of the environmental good than the majority of households - for instance, households living very close to environmental amenities. The assumption of log-normality is in line with empirical evidence that the endowment with environmental goods is strongly right-skewed (see Section 4.5).

\footnotetext{
${ }^{44}$ The income elasticity of WTP, $\eta$, has been elicited in a number of stated preference studies and mostly found to be below unity (Drupp 2018, Kriström and Riera 1996).
} 
Households are also heterogeneous in income, represented by a log-normal distribution

$$
Y_{i} \propto \operatorname{LN}\left(\mu_{Y} ; \sigma_{Y}^{2}\right)
$$

where $\mu_{Y}>0$ is the level of mean income and $\sigma_{Y}$ is the spread of the income distribution in the society. Empirical evidence supports this assumption of log-normality as a fairly good approximation for many national income distributions as well as the global distribution of income (Pinkovskiy and Sala-i-Martin 2009).

In this setting, society's mean WTP, $\mu_{\mathrm{WTP}}$, for the environmental local public good is given as

$$
\mu_{W T P}\left(\mu_{Y}, \sigma_{Y}, \mu_{E}, \sigma_{E}, \rho\right)=\int_{0}^{\infty} \int_{0}^{\infty} f_{\ln }\left(Y, E ; \mu_{Y}, \sigma_{Y}, \mu_{E}, \sigma_{E}, \rho\right) W T P(Y, E) d Y d E
$$

where $f_{\ln }\left(Y, E ; \mu_{Y}, \sigma_{Y}, \mu_{E}, \sigma_{E}, \rho\right)$ is the density function of the bivariate log-normal distribution for income, $Y$ - with mean $\mu_{Y}$ and standard deviation $\sigma_{Y}$ - and the environmental good, $E$ - with mean $\mu_{E}$ and standard deviation $\sigma_{E}$ - and their correlation, $\rho$.

The density function of the bivariate log-normal distribution is given by (e.g. Yue 2000)

$$
\begin{aligned}
& f_{\ln }\left(Y, E ; \mu_{Y}, \sigma_{Y}, \mu_{E}, \sigma_{E}, \rho\right) \\
& =\frac{\exp \left[-\frac{1}{2\left(1-\rho^{2}\right)}\left(\frac{\left(\ln (Y)-m_{Y}\right)^{2}}{s_{Y}^{2}}-2 \rho \frac{\ln (Y)-m_{Y}}{s_{Y}} \frac{\ln (E)-m_{E}}{s_{E}}+\frac{\left(\ln (E)-m_{E}\right)^{2}}{s_{E}^{2}}\right)\right]}{2 \pi Y E \sqrt{s_{Y}^{2} s_{E}^{2}\left(1-\rho^{2}\right)}}, \\
& \text { with } \quad m_{j}=\ln \left(\mu_{j}\right)-\frac{1}{2} \ln \left(1+\frac{\sigma_{j}^{2}}{\mu_{j}^{2}}\right), \quad s_{j}^{2}=\ln \left(1+\frac{\sigma_{j}^{2}}{\mu_{j}^{2}}\right), \quad j \in\{Y, E\},
\end{aligned}
$$

where $\rho \in(-1,1)$ is the product-moment correlation coefficient of $Y$ and $E .^{45}$ The bivariate log-normal distribution contains the cases where income and endowment with the environmental good are positively correlated $(\rho>0)$, negatively correlated $(\rho<0)$, or distributed independently $(\rho=0)$. While all three cases seem plausible, several empirical studies report a positive correlation between income and the endowment with environmental goods such as urban green spaces (Jensen et al. 2016, Tan and Samsudin 2017) or air quality (Ash and

\footnotetext{
${ }^{45}$ The product-moment correlation coefficient (often also referred to as Pearson correlation coefficient), $\rho$, is defined as $\rho(Y, E)=\frac{\mathbf{E}\left[\left(Y-\mu_{Y}\right)\left(E-\mu_{E}\right)\right]}{\sigma_{Y} \sigma_{E}}$, where $\mathbf{E}[\cdot]$ is the expected value. Applied to a sample with $\left\{Y_{1}, \ldots, Y_{N}\right\}$ and $\left\{E_{1}, \ldots, E_{N}\right\}$, the sample Pearson correlation coefficient, $r$, is $r=\frac{\sum_{1}^{N}\left(Y_{i}-\mu_{Y}\right)\left(E_{i}-\mu_{E}\right)}{\sqrt{\sum_{1}^{N}\left(Y_{i}-\mu_{Y}\right)^{2}} \sqrt{\sum_{1}^{N}\left(E_{i}-\mu_{E}\right)^{2}}}$, where $\mu_{Y}$ and $\mu_{E}$ are the sample means.
} 
Fetter 2004, Hsiang et al. 2017).

Mean WTP can then be expressed as a function of the moments $-\mu_{Y}, \sigma_{Y}, \mu_{E}, \sigma_{E}, \rho-$ of the distribution of income and environmental good endowment (see Appendix 4.7.2):

$$
\begin{aligned}
& \mu_{W T P}\left(\mu_{Y}, \mathrm{CV}_{Y}, \mu_{E}, \mathrm{CV}_{E}, \rho\right)=\frac{1-\alpha}{\alpha} P^{\frac{\theta-1}{\theta}} \mu_{Y}^{\frac{1}{\theta}}\left(1+\mathrm{CV}_{Y}^{2}\right)^{\frac{1-\theta}{2 \theta^{2}}} \mu_{E}^{\frac{\theta-1}{\theta}}\left(1+\mathrm{CV}_{E}^{2}\right)^{\frac{1-\theta}{2 \theta^{2}}} \Psi \\
& \text { with } \Psi\left(\mathrm{CV}_{Y}, \mathrm{CV}_{E}, \rho\right):=\exp \left[\rho \frac{\theta-1}{\theta^{2}} \sqrt{\ln \left(1+\mathrm{CV}_{E}^{2}\right) \ln \left(1+\mathrm{CV}_{Y}^{2}\right)}\right],
\end{aligned}
$$

where the coefficients of variation $\mathrm{CV}_{Y}:=\frac{\sigma_{Y}}{\mu_{Y}}$ and $\mathrm{CV}_{E}:=\frac{\sigma_{E}}{\mu_{E}}$ describe the spread of the distribution of income and the environmental good relative to their mean level. In the following I employ $\mathrm{CV}_{Y}$ and $\mathrm{CV}_{E}$ as measures for relative income inequality and relative environmental inequality, respectively. ${ }^{46}$ When all households are exposed to the same amount of the environmental good, i.e. $\sigma_{E}=0$ or equivalently $\mathrm{CV}_{E}=0$, mean WTP for the environmental good in Eq. (4.9), reduces to the case of a pure public good, $\forall i: E_{i}=E$, studied by Baumgärtner et al. (2017a).

When income and the environmental local public good are distributed independently, $\rho=0$, then the last term in Eq. (4.9) becomes one, $\Psi\left(\mathrm{CV}_{Y}, \mathrm{CV}_{E}, \rho\right)=1$, and the expression for mean WTP reduces to

$$
\mu_{\mathrm{WTP}}^{\mathrm{ind}}\left(\mu_{Y}, \mathrm{CV}_{Y}, \mu_{E}, \mathrm{CV}_{E}\right)=\frac{1-\alpha}{\alpha} P^{\frac{\theta-1}{\theta}} \mu_{Y}^{\frac{1}{\theta}}\left(1+\mathrm{CV}_{Y}^{2}\right)^{\frac{1-\theta}{2 \theta^{2}}} \mu_{E}^{\frac{\theta-1}{\theta}}\left(1+\mathrm{CV}_{E}^{2}\right)^{\frac{1-\theta}{2 \theta^{2}}}
$$

which is an import special case as the terms for income inequality and environmental inequality factorize. It follows directly that the key result of Baumgärtner et al. (2017a) on how income inequality affects mean WTP for pure public goods can be generalized to local public goods that are distributed independently of income.

In the following, I study the effects of marginal changes in income inequality, $\mathrm{CV}_{Y}$, and in the distribution of an environmental local public good $\left(\mu_{E}, \mathrm{CV}_{E}, \rho\right)$. Marginal changes in the distribution of the environmental good can be understood as various stylized, not explicitly modelled environmental policies: Increases in $\mu_{E}$ can be interpreted as environmental policies that increase the quality or quantity of environmental goods, whereby decreases in $\mu_{E}$ can be interpreted as environmental degradation. Increases (decreases) in $\mathrm{CV}_{E}$ can be interpreted as environmental policies that decrease (increase) equity in the endowment with environmental goods. Increases (decreases) in $\rho$ can be interpreted as environmental policies that increase

\footnotetext{
${ }^{46}$ In the remainder I focus on the coefficient of variation as measure of spread to facilitate comparisons between environmental and income inequality. Thus, I conduct a variable transformation where $\sigma_{j}$ is replaced by a function $C V_{j}\left(\sigma_{j}\right)$ which scales $\sigma_{j}$ by $\mu_{j}$ with $j \in Y, E$.
} 
(decrease) the endowment of richer households with environmental goods relative to poorer households or as the effect of some exogenous, not-modelled neighborhood sorting.

\subsection{Results of model analysis}

\subsubsection{Societal WTP for environmental local public goods}

I am now prepared to study how mean WTP for the environmental local public good, $\mu_{\mathrm{WTP}}$ (Eq. (4.9)), changes with a marginal change in (i) the mean level of the environmental good, $\mu_{E}$, (ii) income inequality, $\mathrm{CV}_{Y}$, (iii) environmental inequality, $\mathrm{CV}_{E}$, or (iv) the correlation between income and endowment with the environmental good, $\rho$.

Question 1: How does the mean environmental good level affect society's mean WTP for a marginal increase in the environmental local public good?

\section{Proposition 4.1}

Mean WTP for the environmental local public good, $\mu_{\mathrm{WTP}}$ (Eq. (4.9)), increases (decreases) with the mean level of the environmental local public good, $\mu_{E}$, if and only if the environmental local public good and the private consumption good are substitutes (complements):

$$
\frac{\partial \mu_{\mathrm{WTP}}\left(\mu_{Y}, \mathrm{CV}_{Y}, \mu_{E}, \mathrm{CV}_{E}, \rho\right)}{\partial \mu_{E}} \gtreqless 0 \text { if and only if } \theta \gtreqless 1 \text {. }
$$

Proof. See Appendix 4.7.3.

Proposition 4.1 implies that there is only a positive scope effect, defined as an increase in mean WTP for an increase in the level of the environmental good, when the environmental good and the consumption good are substitutes $(\theta>1)$, or analogously, when the income elasticity of WTP for the environmental good is below unity $(\eta<1)$. However, for complements $(\theta<1)$, or analogously, an income elasticity of WTP above unity $(\eta>1)$, there is 
not a positive scope effect but a negative one. Note that Proposition 4.1 also holds for the special case of pure public goods, i.e. where $\forall i: E_{i}=E$, which is equivalent to $\mathrm{CV}_{E}=0 .{ }^{47}$

The negative sensitivity to scope for complements can be explained as follows: Recall that a household's WTP is given as the product of marginal WTP for the environmental good at level $E_{i}$ times the quantity of the environmental good, $E_{i}$. Marginal WTP is positive and decreasing in $E_{i}$ (see Eq. 4.30). The more difficult it is to replace environmental goods by manufactured goods in a household's utility, the more convex household's marginal WTP becomes in $E_{i}$. An increase in $E_{i}$ now has two effects on a household's total WTP: a '(Lindahl) price effect' due to the decrease in marginal WTP and a 'quantity effect' due to an increase in the $E_{i}$ quantity of environmental good consumed. For complements, the negative effect of a decrease in marginal WTP on total WTP outweighs the positive effect of an increase in quantity $E_{i}$ on total WTP.

Question 2: How does income inequality affect society's mean WTP for a marginal increase in the environmental local public good?

Next, I am interested in how the mean WTP for the local environmental public good changes with a marginal change in income inequality or environmental inequality. I assume that there is some inequality in income and the environmental good has some local public good characteristics, $\mathrm{CV}_{Y}, \mathrm{CV}_{E}>0$. These assumptions are necessary to differentiate mean WTP given in Eq. (4.9) with respect to income inequality, $\mathrm{CV}_{Y}$, and environmental inequality, $\mathrm{CV}_{E}$. Note that I assume the correlation between income and the exposure to the environmental good to remain unchanged, while evaluating the sign of the mean WTP function for a marginal change in income inequality or environmental inequality. I conduct this stepwise for the case that the distribution of the environmental good is correlated with income $(\rho \neq 0)$ and for the important special case that the environmental good and income are distributed independently $(\rho=0)$, which generates simpler results.

\footnotetext{
${ }^{47}$ The same holds true at the household level: It is apparent from Eq. (4.3) that a household $i$ 's WTP increases (decreases) with the amount of the environmental good, $\frac{\partial \mathrm{WTP}\left(Y_{i}, E_{i}\right)}{\partial E_{i}} \gtreqless 0$, if and only if the income elasticity of WTP is below (above) unity, $\eta \lesseqgtr 1$, or equivalently, if the environmental good is a substitute for (complement to) manufactured consumption goods, $\theta \gtreqless 1$. Thus, if a household's endowment with the environmental good is inversely related to the household's distance to the environmental good - think, for instance, of $E_{i}$ as household $i$ 's proximity to urban green space - WTP decreases with distance ('distance decay') if and only if the income elasticity of WTP is below unity. As $\eta$ is usually found to be well below unity, my model supports the distance decay of WTP found for many environmental local public goods (Bateman et al. 2006).
} 


\section{Proposition 4.2}

Mean WTP for the environmental local public good, $\mu_{\mathrm{WTP}}$, decreases (increases) with relative income inequality, $C V_{Y}$, if and only if the environmental good and the private consumption good are substitutes (complements) and their point correlation is lower than a weighted ratio of income inequality and environmental inequality, or the environmental good and the private consumption good are complements (substitutes) and their point correlation is higher than a weighted ratio of income inequality and environmental inequality.

$$
\frac{\partial \mu_{\mathrm{WTP}}\left(\mu_{Y}, \mathrm{CV}_{Y}, \mu_{E}, \mathrm{CV}_{E}, \rho\right)}{\partial \mathrm{CV}_{Y}} \lesseqgtr 0 \text { if and only if }\left\{\begin{array}{l}
\theta>1, \rho<a \text { or } \theta<1, \rho>a \\
\theta=1 \text { or } \rho=a \\
\theta<1, \rho<a \text { or } \theta>1, \rho>a
\end{array}\right.
$$

where $a:=\sqrt{\frac{\ln \left(1+\mathrm{CV}_{Y}^{2}\right)}{\ln \left(1+\mathrm{CV}_{E}^{2}\right)}}$ and $\rho \neq 0$.

Proof. See Appendix 4.7.4.

Proposition 4.2 states that the effect of income inequality on mean WTP for the environmental local public good is determined both by whether the environmental good is a substitute for or a complement to the manufactured consumption good and by the correlation of environmental good endowment and income in the society. Compared to the case of pure public goods, which is a special case in my analysis, the latter is an additional determinant for local public goods. It shows that the key result of Baumgärtner et al. (2017a) that mean WTP for environmental goods decreases (increases) with income inequality if and only if the environmental good and the private consumption good are substitutes (complements) applies only to local public goods when the correlation with income is lower than a weighted ratio of income inequality and environmental inequality, $\rho<a$. For cases where the correlation between income and the environmental local public good is strongly positive, $\rho>a$, the reverse might be true: mean WTP increases (decreases) with income inequality if and only if the environmental good and the private consumption good are substitutes (complements).

The threshold $a$ thereby captures how unequal a society's income distribution is relative to the provision of environmental goods. The parameter $a$ is above unity when income inequality is relatively larger, $\mathrm{CV}_{Y}>\mathrm{CV}_{E}$, but below unity when environmental inequality is relatively larger, $\mathrm{CV}_{Y}<\mathrm{CV}_{E}$. I will now briefly discuss both cases in turn. 
First, if income inequality is weakly greater than environmental inequality, $\mathrm{CV}_{Y} \geq \mathrm{CV}_{E}$, it follows directly that $\rho<1 \leq a$ as $\rho \in(-1,1)$. Thus it becomes evident that for income inequality being weakly greater than environmental inequality, $\mathrm{CV}_{Y} \geq \mathrm{CV}_{E}$, mean WTP for the local environmental good always decreases (increases) with income inequality if and only if the environmental good is a substitute for (complement to) manufactured consumption goods.

Second, for the case of income inequality being lower than environmental inequality, $\mathrm{CV}_{Y}<\mathrm{CV}_{E}$, the effect of income inequality depends on the correlation, $\rho$. When poorer households are endowed with a comparably high level of the environmental good $\rho<0$, then it generally holds that $\rho<0<a$ as $a>0$. Thus, we can directly conclude that if income and environmental good provision are negatively correlated, $\rho<0$, mean WTP for the local environmental good decreases (increases) with income inequality if and only if environmental goods are substitutes (complements) to manufactured consumption goods. Only for the case of the environmental good being distributed more unequally than income $\mathrm{CV}_{Y}<\mathrm{CV}_{E}$ and richer households enjoying comparably high levels of the environmental good $\rho>0$ can the effect of income inequality become the reverse. Note that the more unequal the provision of environmental goods relative to the distribution of income, the lower $a$ becomes and the less strongly positive the correlation, $\rho$, needs to be to end up in the case where societal WTP for environmental goods increases (decreases) with income inequality if and only if the environmental good and the private consumption good are substitutes (complements).

The rationale behind the reverse effect of income inequality on mean WTP in the case of a strongly positive correlation and relatively high environmental inequality is as follows: A decrease in income inequality means that at least one of the poorer households is better off, while at least one of the richer households is worse off and mean income in the society remains unchanged. This has two opposing effects. First, the environmental good being a substitute for consumption goods is equivalent to an income elasticity of WTP being below unity, i.e. richer households are willing to pay a smaller share of their income than poorer households for the environmental local public good. A reduction of income inequality therefore increases mean WTP, as the gains in WTP of the poorer household overcompensate for the losses in WTP of the richer household. Second, a positive correlation between income and the environmental local public good means that households with higher incomes enjoy more of the environmental good than households with lower incomes. For substitutes, a higher endowment with the environmental good contributes to a higher WTP, and thus 
for a positive correlation, to a higher WTP of richer households relative to their income. Through this second channel of the 'environmental-endowment-income-correlation' effect, reducing income inequality decreases mean WTP. Hence, in cases where the environmental good provision is more unequal than the distribution of income, the second effect might outweigh the first if the correlation between income and environmental good provision is sufficiently strong.

Corollary 4.1 (E and Y distributed independently)

For the case of the environmental good and income being distributed independently ( $\rho=$ 0 ), it holds that mean WTP for the environmental local public good, $\mu_{\mathrm{WTP}}^{\text {ind }}$ (Eq. (4.10)), decreases (increases) with relative income inequality, $\mathrm{CV}_{Y}$, if and only if the environmental local public good and the private consumption good are substitutes (complements):

$$
\frac{\partial \mu_{\mathrm{WTP}}^{\mathrm{ind}}\left(\mu_{Y}, \mathrm{CV}_{Y}, \mu_{E}, \mathrm{CV}_{E}\right)}{\partial \mathrm{CV}_{Y}} \lesseqgtr 0 \text { if and only if } \theta \gtreqless 1 \text {. }
$$

Proof. See Appendix 4.7.5.

Question 3: How does environmental inequality affect society's mean WTP for a marginal increase in the environmental local public good?

\section{Proposition 4.3}

Mean WTP for the environmental local public good, $\mu_{\mathrm{WTP}}$, decreases (increases) with relative environmental inequality, $C V_{E}$, if and only if the environmental good and the private consumption good are substitutes (complements) and their point correlation is lower than a weighted ratio of environmental and income inequality, or the environmental good and the private consumption good are complements (substitutes) and their point correlation is larger than a negative weighted ratio of environmental and income inequality.

$$
\frac{\partial \mu_{\mathrm{WTP}}\left(\mu_{Y}, \mathrm{CV}_{Y}, \mu_{E}, \mathrm{CV}_{E}, \rho\right)}{\partial \mathrm{CV}_{E}} \lesseqgtr 0 \text { if and only if }\left\{\begin{array}{l}
\theta>1, \rho<b \text { or } \theta<1, \rho>b \\
\theta=1 \text { or } \rho=b \\
\theta<1, \rho<b \text { or } \theta>1, \rho>b
\end{array}\right.
$$

where $b:=\sqrt{\frac{\ln \left(1+\mathrm{CV}_{E}^{2}\right)}{\ln \left(1+\mathrm{CV}_{Y}{ }^{2}\right)}}=a^{-1}$ and $\rho \neq 0$. 
Proof. See Appendix 4.7.6.

Proposition (4.3) depicts that for environmental local public goods, environmental inequality has a similar effect on mean WTP as income inequality. The effect of environmental inequality on the mean WTP for environmental local public goods is determined both by whether the environmental good is a substitute for or complement to manufactured consumption goods and by how the correlation between environmental goods and income in the population of households, $\rho$, is related to the extent of environmental inequality relative to income inequality, $b$.

The logic behind the effect of environmental inequality on mean WTP for local public goods is as follows. For the case of substitutes, $\theta \in(1, \infty)$, which is for CES preferences analogous to an income elasticity of WTP below unity, $\eta \in(0,1)$, individual WTP for the local public good increases with environmental good endowment $E_{i}$, but at a decreasing rate (see Eq. (4.3)). Thus, households that enjoy less of the environmental good ('environmentally poor' households) have a relatively higher WTP for the environmental local public good than households that enjoy more of the environmental good ('environmentally rich' households). A more equitable environmental good provision implies that at least one environmentally poor household faces an increase in environmental good endowment, while at least one environmentally rich household faces a decrease. As a result, the gains in WTP of environmentally poor households exceed the losses in WTP of environmentally rich households so that society's mean WTP for the environmental local public good increases.

When the provision of environmental goods in society is not independent of income, the effect of environmental inequality also depends on their correlation, $\rho$, relative to a weighted ratio of environmental inequality and income inequality, $b$. For environmental inequality weakly greater than income inequality, $\mathrm{CV}_{E} \geq \mathrm{CV}_{Y}$, the condition $\rho<b$ is generally fulfilled as $b>1>\rho$. It also follows directly for a negative correlation, $\rho<0$, that $\rho<0<b$ as $b>0$. Thus, Proposition (4.3) states that in societies where environmental inequality is higher than income inequality or where the correlation between income and environmental good provision is negative, mean WTP decreases (increases) with environmental inequality if and only if the environmental local public good is a substitute for (complement to) manufactured consumption goods. The effect of environmental inequality is reverse for cases of environmental inequality lower than income inequality and a positive correlation of income 
and environmental good provision, if only if the correlation is stronger than a weighted ratio of environmental and income inequality.

Corollary 4.2 (E and Y distributed independently)

For the case of the environmental good and income distributed independently $(\rho=0)$, it holds that mean WTP for the environmental local public good, $\mu_{\mathrm{WTP}}^{\mathrm{ind}}$ (Eq. (4.10)), decreases (increases) with relative environmental inequality, $\mathrm{CV}_{E}$, if and only if the environmental local public good and the private consumption good are substitutes (complements):

$$
\frac{\partial \mu_{\mathrm{WTP}}^{\mathrm{ind}}\left(\mu_{Y}, \mathrm{CV}_{Y}, \mu_{E}, \mathrm{CV}_{E}\right)}{\partial \mathrm{CV}_{Y}} \lesseqgtr 0 \text { if and only if } \theta \gtreqless 1 .
$$

Proof. See Appendix 4.7.7.

Corollary 4.2 shows that for the case of environmental goods uncorrelated with income, the effect of environmental inequality on mean WTP, $\mu_{\text {WTP }}^{\text {ind }}$, is the same as of income inequality. This is of course due to the identical structure of the problem.

Question 4: How does the correlation between income and environmental good endowment affects society's mean WTP for a marginal increase in the environmental local public good?

Next, I study how a change in the correlation between environmental good endowment and income, $\rho$, affects the societal valuation of the environmental local public good, $\mu_{\mathrm{WTP}}$. A change in $\rho$ might result from an environmental policy altering the spatial distribution of environmental amenities or of households adapting their location to the spatial distribution of environmental goods ('sorting').

Household sorting will generally change how income and endowment with the environmental local public good is correlated within society. Richer (poorer) households moving to places where environmental quality is high will increase (decrease) the correlation, $\rho$, between income and environmental good endowment. The effect of sorting on societal WTP can thus indirectly be studied via its effect on $\rho$.

Recall that to focus my model on valuation, I treat the level of the environmental good enjoyed as exogenous from the viewpoint of the household, and therefore do not study sorting explicitly. I nevertheless sketch in Appendix 4.7.8 for a simple case of two income groups and CES preferences that in a situation where neighborhood sorting arises only from differences in the endowment with the environmental good, households with higher incomes will sort into 
places with higher environmental quality. In such a situation, sorting increases the correlation between income and endowment with the environmental local public good, $\rho$. This finding is in line with other theoretical models on how households adapt their place of residence to the spatial distribution of environmental goods. In a seminal paper, Brueckner et al. (1999) show that if households have CES preferences over a consumption good, a housing good, and an amenity, and if these goods are substitutes, then the marginal valuation of amenities increases faster than housing consumption with income, resulting in richer households living where the amenity value is high (abstracting from commuting cost). Heblich et al. (2017) and Lee and Lin (2018) study models with two neighborhoods, two income groups, and Cobb-Douglas preferences regarding environmental amenities and consumption goods, and find that richer households sort into neighborhoods where the endowment with the environmental amenity is high.

\section{Proposition 4.4}

Mean WTP for the local environmental public good, $\mu_{W T P}$, increases (decreases) with the correlation between income and environmental good endowment in society, $\rho$, if and only if the local environmental public good and the private consumption good are substitutes (complements).

$$
\frac{\partial \mu_{\mathrm{WTP}}\left(\mu_{Y}, \mathrm{CV}_{Y}, \mu_{E}, \mathrm{CV}_{E}, \rho\right)}{\partial \rho} \gtreqless 0 \text { if and only if } \theta \gtreqless 1 \text {. }
$$

Proof. See Appendix 4.7.9.

Proposition 4.4 shows that the way an increase in the correlation between income and endowment with the environmental local public good, $\rho$, affects societal WTP, $\mu_{\mathrm{WTP}}$, is determined by the substitutability between private consumption goods and the environmental good, $\theta$. An increase in $\rho$ reinforces societal WTP for the environmental good for the case of substitutes, but decreases societal WTP in the case of complements. For instances where household sorting increases the correlation of environmental good endowment and income, $\rho$, it will thus indirectly increase (decrease) societal WTP for the local environmental public good if this is a substitute for (complement to) manufactured consumption goods. 


\subsubsection{Benefit transfer and environmental local public goods}

Next, I derive structural transfer factors to account for differences in the distribution of the environmental local public good and income. These transfer factors can be used to adjust WTP estimates from primary valuation studies to inform environmental policy and management in other contexts, as well as to adjust for the socially desired distribution. In benefit transfer, WTP estimates from a valuation study conducted in one context $s$ - the 'study' site - inform policy making in other context $p$ - the 'policy' site. Based on the model set-up presented above, I specify the benefit transfer function approach (e.g. Loomis 1992) for environmental local public goods.

\section{Proposition 4.5}

Assume households' preferences $(\theta, \alpha)$ are identical at study site $s$ and policy site $p$. If at the study site mean WTP for the environmental local public good is $\mu_{\mathrm{WTP}}^{\mathrm{s}}$ (Eq. 4.9), the market price level for consumption goods is $P^{\mathrm{s}}$, mean income is $\mu_{Y}^{\mathrm{s}}$, relative income inequality is $\mathrm{CV}_{Y}^{\mathrm{s}}$, the mean quantity of the environmental local public good is $\mu_{E}^{\mathrm{s}}$, the relative environmental inequality is $\mathrm{CV}_{E}^{\mathrm{s}}$ and the correlation between income and the environmental local public good is $\rho^{\mathrm{s}}$, then at the policy site with $\left(P^{\mathrm{p}}, \mu_{Y}^{\mathrm{p}}, \mathrm{CV}_{Y}^{\mathrm{p}}, \mu_{E}^{\mathrm{p}}, \mathrm{CV}_{E}^{\mathrm{p}}, \rho^{\mathrm{p}}\right)$ the mean WTP for the environmental local public good is given as

$$
\mu_{\mathrm{WTP}}^{\mathrm{p}}=\mathcal{T}\left(P^{\mathrm{p}}, \mu_{Y}^{\mathrm{p}}, \mathrm{CV}_{Y}^{\mathrm{p}}, \mu_{E}^{\mathrm{p}}, \mathrm{CV}_{E}^{\mathrm{p}}, \rho^{\mathrm{p}} ; P^{\mathrm{s}}, \mu_{Y}^{\mathrm{s}}, \mathrm{CV}_{Y}^{\mathrm{s}}, \mu_{E}^{\mathrm{s}}, \mathrm{CV}_{E}^{\mathrm{s}}, \rho^{s}\right) \cdot \mu_{\mathrm{WTP}}^{\mathrm{s}},
$$

where the transfer function $\mathcal{T}()$ factorizes into the following transfer factors

$$
\begin{aligned}
& \mathcal{T}\left(P^{\mathrm{p}}, \mu_{Y}^{\mathrm{p}}, \mathrm{CV}_{Y}^{\mathrm{p}}, \mu_{E}^{\mathrm{p}}, \mathrm{CV}_{E}^{\mathrm{p}}, \rho^{\mathrm{p}} ; P^{\mathrm{s}}, \mu_{Y}^{\mathrm{s}}, \mathrm{CV}_{Y}^{\mathrm{s}}, \mu_{E}^{\mathrm{s}}, \mathrm{CV}_{E}^{\mathrm{s}}, \rho^{s}\right) \\
& =\mathcal{T}_{P}\left(P^{\mathrm{p}}, P^{\mathrm{s}}\right) \cdot \mathcal{T}_{\mu_{Y}}\left(\mu_{Y}^{\mathrm{p}}, \mu_{Y}^{\mathrm{s}}\right) \cdot \mathcal{T}_{\mu_{E}}\left(\mu_{E}^{\mathrm{p}}, \mu_{E}^{\mathrm{s}}\right) \cdot \mathcal{T}_{\mathrm{CV}_{Y}, \mathrm{CV}_{E}, \rho}\left(\mathrm{CV}_{Y}^{\mathrm{p}}, \mathrm{CV}_{E}^{\mathrm{p}}, \rho^{\mathrm{p}}, \mathrm{CV}_{Y}^{\mathrm{s}}, \mathrm{CV}_{E}^{\mathrm{s}}, \rho^{\mathrm{s}}\right),
\end{aligned}
$$


with

$$
\begin{aligned}
& \mathcal{T}_{P}\left(P^{\mathrm{p}}, P^{\mathrm{s}}\right)=\left(\frac{P^{\mathrm{p}}}{P^{\mathrm{s}}}\right)^{\frac{\theta-1}{\theta}}, \\
& \mathcal{T}_{\mu_{Y}}\left(\mu_{Y}^{\mathrm{p}}, \mu_{Y}^{\mathrm{s}}\right)=\left(\frac{\mu_{Y}^{\mathrm{p}}}{\mu_{Y}^{\mathrm{s}}}\right)^{\frac{1}{\theta}}, \\
& \mathcal{T}_{\mu_{E}}\left(\mu_{E}^{\mathrm{p}}, \mu_{E}^{\mathrm{s}}\right)=\left(\frac{\mu_{E}^{\mathrm{p}}}{\mu_{E}^{\mathrm{s}}}\right)^{\frac{\theta-1}{\theta}}, \\
& \mathcal{T}_{\mathrm{CV}}, \mathrm{CV}_{E}, \rho \\
& \left.\mathrm{CV}_{Y}^{\mathrm{p}}, \mathrm{CV}_{E}^{\mathrm{p}}, \rho^{\mathrm{p}}, \mathrm{CV}_{Y}^{\mathrm{s}}, \mathrm{CV}_{E}^{\mathrm{s}}, \rho^{\mathrm{s}}\right)=\left(\frac{1+\mathrm{CV}_{Y}^{\mathrm{p}} 2}{1+\mathrm{CV}_{Y}^{\mathrm{s} 2}}\right)^{\frac{1-\theta}{2 \theta^{2}}} \cdot\left(\frac{1+\mathrm{CV}_{E}^{\mathrm{p} 2}}{1+\mathrm{CV}_{E}^{\mathrm{s} 2}}\right)^{\frac{1-\theta}{2 \theta^{2}}} \\
& \left.\quad \cdot \exp \left[\frac{\theta-1}{\theta^{2}}\left(\rho^{\mathrm{p}} \sqrt{\ln \left(1+\mathrm{CV}_{Y}^{\mathrm{p}} 2\right) \ln \left(1+\mathrm{CV}_{E}^{\mathrm{p} 2}\right.}-\rho^{\mathrm{s}} \sqrt{\ln \left(1+\mathrm{CV}_{Y}^{\mathrm{s}} 2\right) \ln \left(1+\mathrm{CV}_{E}^{\mathrm{s}} 2\right.}\right)\right)\right]
\end{aligned}
$$

Proof. See Appendix 4.7.10.

Proposition 4.5 shows how to control for differences in income inequality, environmental inequality and the correlation of income and endowment with the environmental good by using a closed-form transfer factor $\mathcal{T}_{\mathrm{CV}_{Y}, \mathrm{CV}_{E}, \rho}$. The transfer factor $\mathcal{T}_{\mathrm{CV}_{Y}, \mathrm{CV}_{E}, \rho}$ captures the dynamics studied in Proposition 4.2 - 4.4. It is thus not surprising that $\mathcal{T}_{\mathrm{CV}_{Y}, \mathrm{CV}_{E}, \rho}$ can be greater or smaller than unity - implying a downward or upward adjustment of societal WTP - depending on whether income and the environmental good are distributed more equally at the study site or at the policy site, whether the income and the environmental good are more strongly correlated at the policy or at the study site, and whether the environmental good is a substitute for or complement to manufactured consumption goods. Note that for $\theta=1$, no adjustment is necessary, $\mathcal{T}_{\mathrm{CV}_{Y}, \mathrm{CV}_{E}, \rho}=1$.

This transfer factor might also be applied to account for sorting effects. Governmental project appraisal on the efficient allocation of environmental local public goods are usually done ex-ante, i.e. before project implementation, and therefore capture households' current WTP. If the project is actually implemented, the distribution of environmental goods will change and thereby induce sorting effects, changing the correlation between income and endowment with the environmental local public good, $\rho$, which in turn changes societal WTP. Welfare analyses will aim at measuring WTP both ex-ante and ex-post in order to assess welfare gains and identify who might (potentially) need to compensate whom. Thus, welfare analysis generally requires information on household WTP after project implementation and 
sorting has taken place. The transfer factor $\mathcal{T}_{\mathrm{CV}_{Y}, \mathrm{CV}_{E}, \rho}$ shows how to correct WTPs elicited ex-ante to be used for ex-post welfare analysis by specifying $\rho^{\mathrm{s}}$ and $\rho^{\mathrm{p}}$.

Moreover, the transfer factor might be applied in the context of sustainability policy that aims at the two normative goals of allocative efficiency and distributional justice (Baumgärtner and Quaas 2010). To attain the normative goal of distributional justice, resources have to be redistributed within society, and to ensure allocative efficiency, mean WTPs have to be adjusted when conducting efficiency analysis in accordance with the target distribution (Drupp et al. 2018). ${ }^{48}$ When efficiency is assessed by the means of environmental cost-benefit analysis the proposed transfer factor might be employed to directly adjust mean WTP for the desired distribution.

For $E$ and $Y$ being distributed independently $(\rho=0)$ at both sites, the transfer factor for inequalities $\mathcal{T}_{\mathrm{CV}_{Y}, \mathrm{CV}_{E}, \rho}^{\text {ind }}$, Eq. (4.22), simplifies to two disentangled transfer factors for income inequality and environmental inequality (Appendix 4.7.10):

$$
\begin{aligned}
\mathcal{T}_{\mathrm{CV}_{Y}, \mathrm{CV}_{E}}^{i n d}\left(\mathrm{CV}_{Y}^{\mathrm{p}}, \mathrm{CV}_{E}^{\mathrm{p}}, \mathrm{CV}_{Y}^{\mathrm{s}}, \mathrm{CV}_{E}^{\mathrm{s}}\right) & =\left(\frac{1+\mathrm{CV}_{Y}^{\mathrm{p} 2}}{1+\mathrm{CV}_{Y}^{\mathrm{s} 2}}\right)^{\frac{1-\theta}{2 \theta^{2}}} \cdot\left(\frac{1+\mathrm{CV}_{E}^{\mathrm{p} 2}}{1+\mathrm{CV}_{E}^{\mathrm{s} 2}}\right)^{\frac{1-\theta}{2 \theta^{2}}} \\
& =: \mathcal{T}_{\mathrm{CV}_{Y}}\left(\mathrm{CV}_{Y}^{\mathrm{p}}, \mathrm{CV}_{Y}^{\mathrm{s}}\right) \cdot \mathcal{T}_{\mathrm{CV}_{E}}\left(\mathrm{CV}_{E}^{\mathrm{p}}, \mathrm{CV}_{E}^{\mathrm{s}}\right) .
\end{aligned}
$$

Note that as $\mathcal{T}_{\mathrm{CV}_{Y}, \mathrm{CV}_{E}}^{\text {fid }}$ factorizes into two variable-specific factors, one can correct for differences in $\mathrm{CV}_{Y}$ or $\mathrm{CV}_{E}$ separately and without paying attention to the other type of inequality. In this case the transfer factors for environmental inequality is absolute analogue to the one for income inequality.

\subsection{Empirical application}

Next I illustrate empirical magnitudes for a case study on forest preservation in Poland. This application serves the purpose of assessing whether the argument developed above is associated with considerable economic effect sizes that warrant the actual use of the novel benefit transfer factor, $\mathcal{T}_{\mathrm{CV}_{Y}, \mathrm{CV}_{E}, \rho}$, in public policy making. I draw on a valuation study offering a unique case for illustration, as WTP was elicited for a single national environmental good ('Polish ecologically-valuable forest'), the access to which differs in society ('proximity to the next forest') and substantially affects households' WTPs.

\footnotetext{
${ }^{48}$ According to Lindahl-Samuelson, a necessary condition for a Pareto-efficient allocation is that the sum of household WTPs - or the product of mean WTP and the number of households - equals the marginal costs of providing the environmental local public good (Samuelson 1954).
} 
Forests are subject to high rates of degradation and deforestation globally. Until the late nineteenth century, deforestation was most pronounced in the temperate climate zone, where recent decades have seen net gains in forest area (FAO 2016). Forests serve crucial ecological functions such as carbon sequestration, water purification, and soil conservation, and offer habitats for a variety of wildlife (FAO 2016). They contribute substantially to human wellbeing (SCBD 2001), with forest ecosystem services encompassing a range of use values, such as timber supply and opportunities for recreation, as well as non-use values, such as the existence values of various rare flora and fauna. A forest's actual array of ecosystem services depends on the management regime and varies from heavily economically used forests, which are associated with high timber production but little biodiversity and recreational value, to pristine forests, which are associated with very little timber production but high biodiversity and recreational value (SCBD 2001). People live in different proximities to forests, which is likely to result in an unequal distribution of forest ecosystem services, such as recreational values. Thus, forests are likely to exhibit local public good characteristics.

Polish forests are among the largest and most valuable forests in Europe. 29.3\% of Poland's land area is covered by forest, including the Bialawiza forest, which is commonly referred to as the last lowland forest in temperate Europe with primeval fragments (CBD Fifth National Report of Poland 2014). Overall, 65\% of Poland's biodiversity resources and $50 \%$ of Poland's Natura 2000 sites are situated in forests (Czajkowski et al. 2009, CBD Fifth National Report of Poland 2014). Approximately $3 \%$ of Poland's $90,000 \mathrm{~km}^{2}$ total forest area is considered to be highly ecologically valuable, as it is still in almost pristine condition. Only half of this forest area is under effective nature protection (Czajkowski et al. 2017). The remaining half is under pressure from human use and exploited as regular economically used forests (Czajkowski et al. 2014a).

To investigate the relationship between the distribution of forest ecosystem services and income and the societal WTP for forest protection, I draw on survey and forest data studied in depth by Budziński et al. (2018) and Czajkowski et al. (2014a,b, 2017). Respondents were asked for their willingness to pay for an increase in national income taxes for different national forest management options, including protecting all of Poland's most ecologically valuable forests ( $3 \%$ of the Polish forest area). ${ }^{49}$ The survey was carried out on a representative sample of 1001 Polish adults in January 2010 employing face-to-face computer-assisted

\footnotetext{
${ }^{49}$ Respondents were informed that forest protection would mean prohibiting any human interference except recreational use.
} 
interviews. To ensure representativeness, a multi-stage sampling strategy was applied, randomly selecting first communities and then adult household members. Survey data included respondents' household income and ZIP codes. Additionally data on forest characteristics at a high spatial resolution were obtained from the European Environmental Agency's CORINE Land Cover dataset and the Polish Information System of State Forests and aggregated on $10 \times 10 \mathrm{~km}^{2}$ grid squares. ${ }^{50}$

A subset of $N=714$ respondents also provided information on their monthly net household income [in 2011-PLN], defining the sample used in the following. Income, $Y_{i}$, is distributed with a mean of $\mu_{Y}^{\mathrm{s}}=2758$ and a standard deviation of $\sigma_{Y}^{\mathrm{s}}=1857$, corresponding to a relative income inequality of $\mathrm{CV}_{Y}^{s}=0.66$. With this, the sample's relative income inequality is slightly below the national average according to official statistics. ${ }^{51}$

I use a household's forest proximity as a proxy for the endowment with forest ecosystem services, $E_{i}$. Forest proximity is measured as the inverse of the average Euclidean distance from any point in a respondent's $10 \times 10 \mathrm{~km}^{2}$ grid square to the nearest forest (Czajkowski et al. 2017). Proximity is chosen as a proxy for the endowment with forest ecosystem services as it has the strongest effect on WTP for forest protection among different forest characteristics - such as area of coniferous forest, deciduous forest, mixed forest, old or particularly biodiverse forest - with larger distances substantially reducing WTP for forest protection (Czajkowski et al. 2017). The coefficient of variation of households' forest proximity is $\mathrm{CV}_{E}^{\mathrm{s}}=0.57$. Thus, forest proximity is more equally distributed than income in Poland. The correlation between respondents' forest proximity, $E_{i}$, and household income, $Y_{i}$, is $\rho^{\mathrm{s}}=-0.1 .^{52}$ Thus, richer households tend to live further away from forests in Poland. The average distance to the nearest forest, the location of respondents, and their household income is depicted in Figure 4.1. Histograms on the distribution of $Y_{i}$ and $E_{i}$ are depicted in Appendix 4.7.11.

I complement these data from Czajkowski et al. (2017) with a parameter range for the elasticities of substitution, $\theta$, found in two global meta-studies. ${ }^{53}$ Thereby I infer $\theta$ indirectly from the income elasticities of WTP, $\eta$, as elicited in recent valuation studies. As a best guess

\footnotetext{
${ }^{50}$ For further details on the survey design, see Czajkowski et al. (2014a), and on forest data, see Czajkowski et al. (2017).

${ }^{51}$ The World Bank estimates a coefficient of variation of disposable household income for Poland of $C V_{Y}^{\mathrm{POL}}=0.69$ (Zaidi 2009), based on data from the 2006 European Union Survey of Income and Living Conditions. In a contingent valuation study on water quality improvement in the Baltic Sea conducted in 2011, a representative sample of Polish respondents exhibited exactly the same coefficient of variation of their monthly disposable income (Meya et al. 2017).

${ }^{52}$ The correlation coefficient $\rho$ is significant at the $p<0.01$ level.

${ }^{53}$ The use of an elasticity of substitution from meta-studies is in line with the model assumption that people have identical preferences. While I only aim at illustrating ranges, I admit that these general measures for
} 


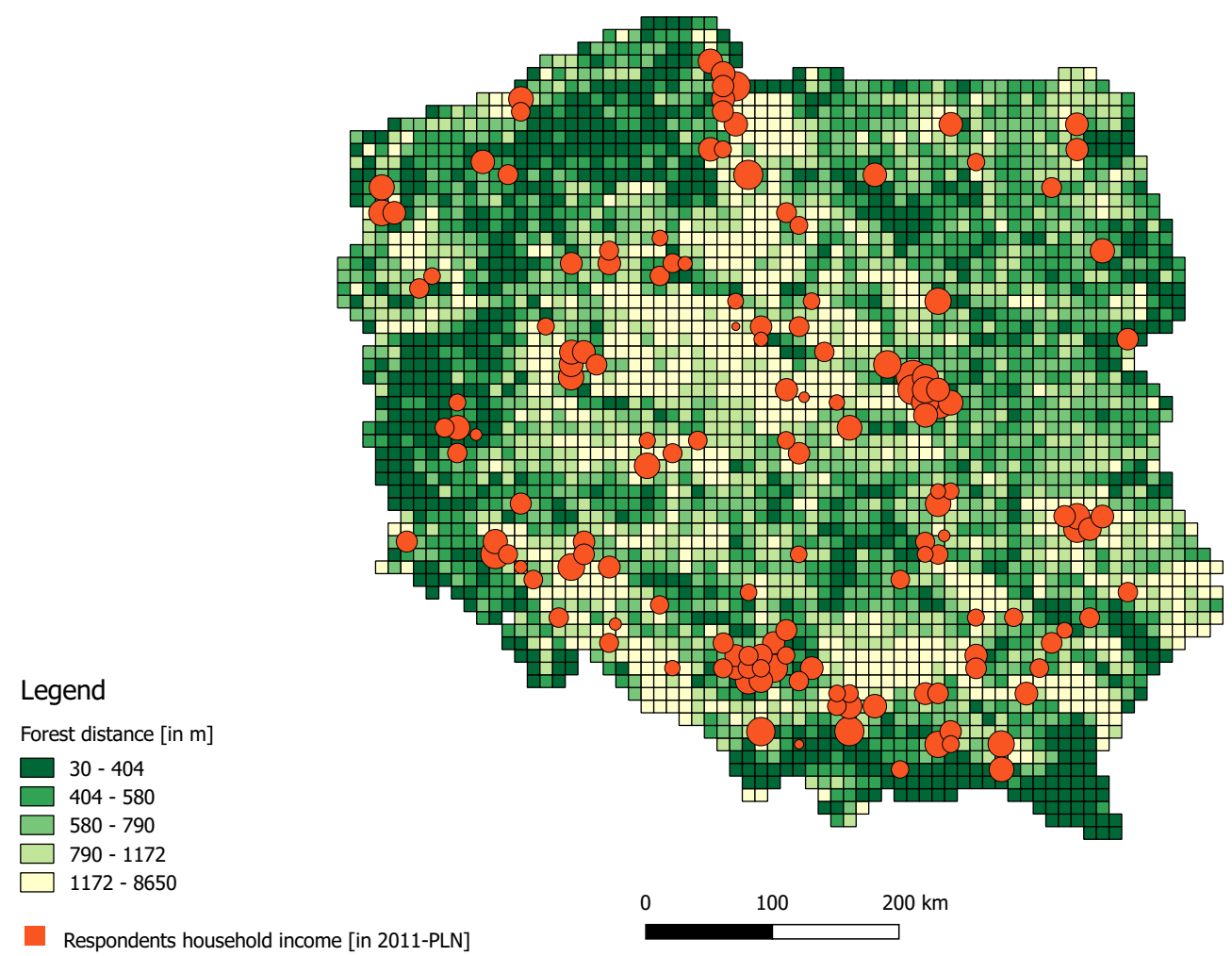

Figure 4.1: Spatial distribution of distance to forests in Poland and respondents' income. Circle sizes represent mean household income stated by respondents in the $10 \times 10 \mathrm{~km}^{2}$ grid square of their residency. The average Euclidean distance from each point in a $10 \times 10 \mathrm{~km}^{2}$ grid square to the nearest forest is shown in green.

estimate, I take the income elasticity of WTP for forest ecosystem services from Chiabai et al. (2011), who provide a global meta-study on forest ecosystem services encompassing 86 WTP estimates from 27 valuation studies. They estimate an income elasticity of WTP for forest recreation of $\eta=0.63$ and for non-use forest ecosystem services of $\eta=0.75$. As the forest preservation under question would allow for recreational use, I take the arithmetic mean of both elasticities and derive as its inverse the elasticity of substitution between non-consumptive forest ecosystem services and manufactured consumption goods, $\theta^{\text {forest }}=$ $\left(\frac{0.63+0.75}{2}\right)^{-1}=1.46 .54$ Additionally I take a range of elasticities of substitution from Drupp (2018), who reviews existing empirical estimates for the income elasticity of WTP from contingent valuation studies since 2000 for different ecosystems and services to indirectly the elasticity of substitution will most likely not be a precise estimate for the population and ecosystem service under consideration, but might arguably be more accurate for a policy site.

${ }^{54}$ Remarkably, this is close to an income elasticity elicited for another type of environmental local public good in the same region. Czajkowski and Scasny (2010) find an income elasticity of WTP of $\eta=0.64$, corresponding to an elasticity of substitution of $\theta=1.56$, for lake water quality improvements in Poland and the Czech Republic. 
TABLE 4.1: Parameter values used in empirical application.

\begin{tabular}{|c|c|c|}
\hline Variable & Value & Source \\
\hline 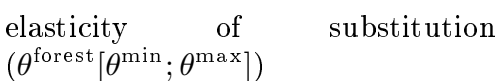 & $1.46[0.86 ; 7.14]$ & $\begin{array}{l}\text { Chiabai et al. (2011), Drupp } \\
\text { (2018) }\end{array}$ \\
\hline $\begin{array}{l}\text { coefficient of variation of forest } \\
\text { proximity }\left(\mathrm{CV}_{E}^{\mathrm{s}}\right)\end{array}$ & 0.57 & $\begin{array}{l}\text { Own calculation based on } \\
\text { Czajkowski et al. (2017) }\end{array}$ \\
\hline $\begin{array}{l}\text { coefficient of variation of disposable } \\
\text { household income }\left(\mathrm{CV}_{Y}^{\mathrm{s}}\right)\end{array}$ & 0.66 & Czajkowski et al. (2014a) \\
\hline $\begin{array}{l}\text { correlation of income and forest } \\
\text { proximity }\left(\rho^{\mathrm{s}}\right)\end{array}$ & -0.10 & $\begin{array}{l}\text { Own calculation based on } \\
\text { Czajkowski et al. (2017) }\end{array}$ \\
\hline
\end{tabular}

TABLE 4.2: Resulting transfer factors to correct WTP for differences in the distribution environmental local public good and income.

\begin{tabular}{lccc}
\hline Transfer factor & $\theta^{\text {forest }}=1.46$ & $\theta^{\text {min }}=0.86$ & $\theta^{\text {max }}=7.14$ \\
\hline \hline & & & \\
$\mathcal{T}_{\mathrm{CV}_{Y}, \mathrm{CV}_{E}, \rho}\left(\mathrm{CV}_{Y}^{\mathrm{s}}, 0,0, \mathrm{CV}_{Y}^{\mathrm{s}}, \mathrm{CV}_{E}^{\mathrm{s}}, \rho^{\mathrm{s}}\right)$ & 1.04 & 0.97 & 1.04 \\
$\mathcal{T}_{\mathrm{CV}_{Y}, \mathrm{CV}_{E}, \rho}\left(0, \mathrm{CV}_{E}^{\mathrm{s}}, 0, \mathrm{CV}_{Y}^{\mathrm{s}}, \mathrm{CV}_{E}^{\mathrm{s}}, \rho^{\mathrm{s}}\right)$ & 1.05 & 0.96 & 1.05 \\
$\mathcal{T}_{\mathrm{CV}_{Y}, \mathrm{CV}_{E}, \rho}\left(0,0,0, \mathrm{CV}_{Y}^{\mathrm{s}}, \mathrm{CV}_{E}^{\mathrm{s}}, \rho^{\mathrm{s}}\right)$ & 1.08 & 0.94 & 1.07 \\
$\mathcal{T}_{\mathrm{CV}_{Y}, \mathrm{CV}_{E}, \rho}\left(\mathrm{CV}_{Y}^{\mathrm{s}}, 2 \mathrm{CV}_{E}^{\mathrm{s}}, \rho^{\mathrm{s}}, \mathrm{CV}_{Y}^{\mathrm{s}}, \mathrm{CV}_{E}^{\mathrm{s}}, \rho^{\mathrm{s}}\right)$ & 0.94 & 1.06 & 0.95 \\
$\mathcal{T}_{\mathrm{CV}_{Y}, \mathrm{CV}_{E}, \rho}\left(2 \mathrm{CV}_{Y}^{\mathrm{s}}, \mathrm{CV}_{E}^{\mathrm{s}}, \rho^{\mathrm{s}}, \mathrm{CV}_{Y}^{\mathrm{s}}, \mathrm{CV}_{E}^{\mathrm{s}}, \rho^{\mathrm{s}}\right)$ & 0.93 & 1.07 & 0.94 \\
$\mathcal{T}_{\mathrm{CV}_{Y}, \mathrm{CV}_{E}, \rho}\left(\mathrm{CV}_{Y}^{\mathrm{s}}, \mathrm{CV}_{E}^{\mathrm{s}}, 0, \mathrm{CV}_{Y}^{\mathrm{s}}, \mathrm{CV}_{E}^{\mathrm{s}}, \rho^{\mathrm{s}}\right)$ & 1.01 & 0.99 & 1.03 \\
$\mathcal{T}_{\mathrm{CV}_{Y}, \mathrm{CV}_{E}, \rho}\left(\mathrm{CV}_{Y}^{\mathrm{s}}, \mathrm{CV}_{E}^{\mathrm{s}},-0.5, \mathrm{CV}_{Y}^{\mathrm{s}}, \mathrm{CV}_{E}^{\mathrm{s}}, \rho^{\mathrm{s}}\right)$ & 0.96 & 1.02 & 0.90 \\
$\mathcal{T}_{\mathrm{CV}_{Y}, \mathrm{CV}_{E}, \rho}\left(\mathrm{CV}_{Y}^{\mathrm{s}}, \mathrm{CV}_{E}^{\mathrm{s}}, 0.5, \mathrm{CV}_{Y}^{\mathrm{s}}, \mathrm{CV}_{E}^{\mathrm{s}}, \rho^{\mathrm{s}}\right)$ & 1.06 & 0.97 & 1.18 \\
\hline & & & \\
\hline
\end{tabular}

asses $\theta$, finding a range from $\theta^{\min }=0.86$ to $\theta^{\max }=7.14 .^{55} \mathrm{I}$ use these three estimates to explore the effect of different degrees of substitutability between forest ecosystem services and manufactured consumption goods. All parameter inputs are summarized in Table 4.1.

I now study how my model predicts societal WTP for forest protection to change if households were more (un)equal in their proximity to forests, if household income were distributed more (un)equally, or if forest proximity were more strongly negatively (positively) correlated with income. To this end, I specify the transfer factor $\mathcal{T}_{\mathrm{CV}_{Y}, \mathrm{CV}_{E}, \rho}$ (Eq. (4.22)) with the parameters in Table 4.1 for different hypothetical choices of $\mathrm{CV}_{Y}^{\mathrm{p}}, \mathrm{CV}_{E}^{\mathrm{p}}$ and $\rho^{\mathrm{p}}{ }^{56}$

The resulting WTP adjustments are considerable (Table 4.2). Hypothetically reducing environmental inequality to zero, $\mathcal{T}_{\mathrm{CV}_{Y}, \mathrm{CV}_{E}, \rho}\left(\mathrm{CV}_{Y}^{\mathrm{s}}, 0,0, \mathrm{CV}_{Y}^{\mathrm{s}}, \mathrm{CV}_{E}^{\mathrm{s}}, \rho^{\mathrm{s}}\right)$, would increase mean WTP by $4 \%$. As income inequality is larger in the status quo, reducing it to zero,

\footnotetext{
${ }^{55}$ Drupp (2018) finds a mean of $\theta^{E S}=2.31$ across all kinds of ecosystem services, which implies a slightly larger degree of substitutability than I assume here for forest ecosystem services based on Chiabai et al. (2011).

${ }^{56}$ For $\mathrm{CV}_{Y}^{p}$ or $\mathrm{CV}_{E}^{p}$ equal to zero, i.e. when the standard deviation of $Y$ or $E$ is zero, the correlation coefficient $\rho$ does not exist. I therefore assume independently distributed endowments with the environmental good and income, $\rho=0$, to evaluate these extreme scenarios.
} 
$\mathcal{T}_{\mathrm{CV}_{Y}, \mathrm{CV}_{E}, \rho}\left(0, \mathrm{CV}_{E}^{\mathrm{s}}, 0, \mathrm{CV}_{Y}^{\mathrm{s}}, \mathrm{CV}_{E}^{\mathrm{s}}, \rho^{\mathrm{s}}\right)$, would imply a slightly higher upward adjustment of WTP by $5 \%$. Adjusting for the even more extreme situation with an equal distribution of forest proximity and income, $\mathcal{T}_{\mathrm{CV}_{Y}, \mathrm{CV}_{E}, \rho}\left(0,0,0, \mathrm{CV}_{Y}^{\mathrm{s}}, \mathrm{CV}_{E}^{\mathrm{s}}, \rho^{\mathrm{s}}\right)$, societal WTP for forest protection would be $8 \%$ higher. If forest ecosystem services were complements, $\theta^{\mathrm{min}}$, the effect would be reversed, and a complete egalitarian distribution would imply a downward adjustment of societal WTP by $6 \%$.

It is also apparent from comparing $\mathcal{T}_{\mathrm{CV}_{Y}, \mathrm{CV}_{E}, \rho}\left(0,0,0, \mathrm{CV}_{Y}^{\mathrm{s}}, \mathrm{CV}_{E}^{\mathrm{s}}, \rho^{\mathrm{s}}\right)$ for $\theta^{\text {forest }}$ and $\theta^{\text {max }}$ that the required WTP adjustment does not strictly increase or decrease with the degree of substitutability, $\theta$. Figure 4.2 depicts $\mathcal{T}_{\mathrm{CV}_{Y}, \mathrm{CV}_{E}, \rho}\left(0,0,0, \mathrm{CV}_{Y}^{\mathrm{s}}, \mathrm{CV}_{E}^{\mathrm{s}}, \rho^{\mathrm{s}}\right)$ as a function of $\theta$, which has its maximum value close to the mean elasticity of substitution reviewed by Drupp (2018) for global ecosystem services, $\theta^{\mathrm{ES}}$, and decreases sharply with stronger complementarity, $\theta \rightarrow 0$, where predicted adjustments become enormous. Moreover, I find that for a doubling of current environmental inequality or income inequality - implying adjustment factors of $\mathcal{T}_{\mathrm{CV}_{Y}, \mathrm{CV}_{E}, \rho}\left(\mathrm{CV}_{Y}^{\mathrm{s}}, 2 \mathrm{CV}_{E}^{\mathrm{s}}, \rho^{\mathrm{s}}, \mathrm{CV}_{Y}^{\mathrm{s}}, \mathrm{CV}_{E}^{\mathrm{s}}, \rho^{\mathrm{s}}\right)$ or $\mathcal{T}_{\mathrm{CV}_{Y}, \mathrm{CV}_{E}, \rho}\left(2 \mathrm{CV}_{Y}^{\mathrm{s}}, \mathrm{CV}_{E}^{\mathrm{s}}, \rho^{\mathrm{s}}, \mathrm{CV}_{Y}^{\mathrm{s}}, \mathrm{CV}_{E}^{\mathrm{s}}, \rho^{\mathrm{s}}\right)$ - WTP would decrease by $6 \%$ or $7 \%$, respectively. Again, the larger effect of income inequality thereby reflects that income is more unequally distributed in Poland than forest proximity.

Finally, I find that differences in the correlation between environmental good endowment and income require remarkable WTP adjustment. All else equal, in a situation where forest proximity and income were positively correlated with a Pearson correlation coefficient of $\rho^{\mathrm{p}}=0.5$ societal WTP would be $6 \%$ higher than elicited in the present study, corresponding to a transfer factor of $\mathcal{T}_{\mathrm{CV}_{Y}, \mathrm{CV}_{E}, \rho}\left(\mathrm{CV}_{Y}^{\mathrm{s}}, \mathrm{CV}_{E}^{\mathrm{s}}, 0.5, \mathrm{CV}_{Y}^{\mathrm{s}}, \mathrm{CV}_{E}^{\mathrm{s}}, \rho^{\mathrm{s}}\right)$. For a high degree of substitutability, this would imply a WTP adjustment of $18 \%$. For complements, $\theta^{\text {min }}$, the case would be the opposite: societal WTP would be lowered by 3\%. Figure 4.5 (Appendix 4.7.11) illustrates $\mathcal{T}_{\mathrm{CV}_{Y}, \mathrm{CV}_{E}, \rho}\left(\mathrm{CV}_{Y}^{\mathrm{s}}, \mathrm{CV}_{E}^{\mathrm{s}}, \rho^{\mathrm{p}}, \mathrm{CV}_{Y}^{\mathrm{s}}, \mathrm{CV}_{E}^{\mathrm{s}}, \rho^{\mathrm{s}}\right)$ as a function of $\rho^{\mathrm{p}}$ for different degrees of substitutability.

These estimates illustrate the importance of considering the distribution of environmental goods and income when aggregating WTP for environmental local public goods and in particular when using these aggregate WTPs in benefit transfer or environmental cost-benefit analysis. ${ }^{57}$

\footnotetext{
${ }^{57}$ As expected, differences in the mean forest proximity and mean income require comparably larger adjustments. For instance, doubling mean forest proximity, $\mathcal{T}_{\mu_{E}}\left(2 \mu_{E}^{\mathrm{s}}, \mu_{E}^{\mathrm{s}}\right)$, would imply an upward adjustment of mean WTP by $24.37 \%$, and doubling mean income, $\mathcal{T}_{\mu_{Y}}\left(2 \mu_{Y}^{\mathrm{s}}, \mu_{Y}^{\mathrm{s}}\right)$, would even imply an upward adjustment of mean WTP by $60.81 \%$.
} 


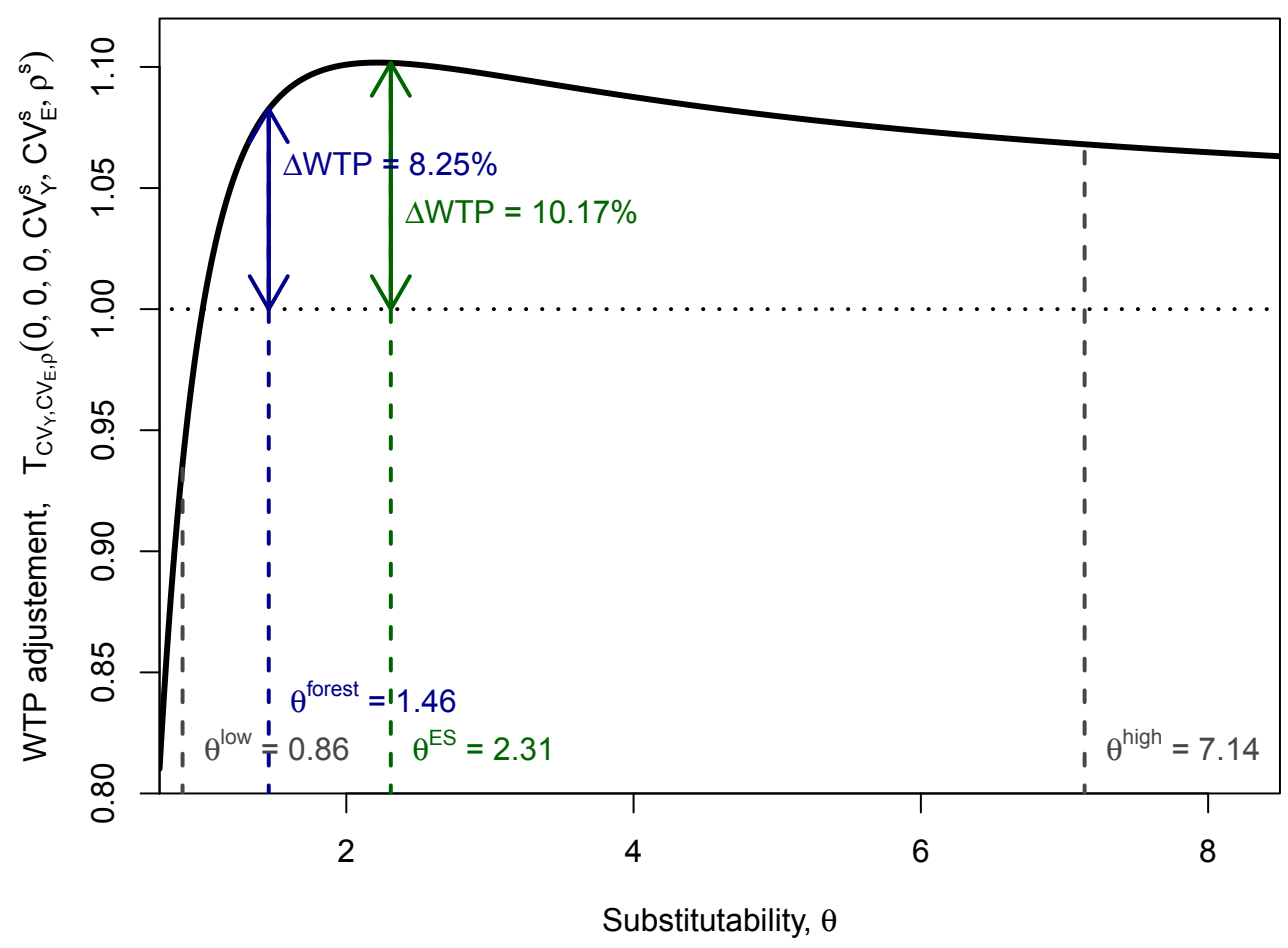

Figure 4.2: Relationship between the transfer factor to adjust societal WTP for differences in the distribution of the environmental local public good and income, $\mathcal{T}_{\mathrm{CV}_{Y}, \mathrm{CV}_{E}, \rho}$, and different degrees of substitutability. In the hypothetical transfer depicted, the societal WTP for forest protection in Poland is adjusted to a situation where proximity to forests and income is distributed equally over the population.

\subsection{Discussion}

Here I discuss several assumptions made in the analysis and the extent to which these might limit the generality of my results. These assumptions are (i) the absence of household mobility, (ii) the purely bio-physical heterogeneity in environmental good endowment, (iii) the log-normal distribution of the environmental local public good, and (iv) the coefficient of variation as a measure of environmental inequality. ${ }^{58}$

First, there is no household mobility and in particular no sorting with respect to environmental quality in the main model. The model framework studied here allows me to evaluate an exogenous change in the correlation between environmental good endowment and income (in Appendix (4.7.8), I sketch how sorting will increase this correlation under certain conditions), but does not anticipate sorting effects induced by a change in the distribution of an environmental local public good. Hence, the proposed benefit transfer factors do not account for sorting effects, and are thus valid in the short run (before sorting takes

\footnotetext{
${ }^{58}$ For a discussion of the CES utility function employed, the equal-preference framework, as well as the log-normal distribution of income, the reader is referred to Baumgärtner et al. (2017a).
} 
place), or valid for the evaluation of environmental policies and projects that are 'small' in the sense that the resulting change in the distribution of the environmental good is not large enough to motivate households to move. Turner (2017) makes a first conceptual attempt to account in benefit transfer for the possibility that people and firms change locations in response to a 'large' environmental regulation. Future research could attempt to extend my model to endogenous sorting. Since valuation studies indicate that the income elasticity of WTP is below unity, my model nevertheless suggests that sorting is likely to increase the societal value of environmental local public goods by changing the correlation between environmental goods and income in society. Whether changes in the specific environmental goods studied in the valuation literature are below or above a level that induces households to move is ultimately an empirical question that remains to be answered in future research.

Second, I studied a heterogeneous distribution of environmental benefits over households in a society arising only from an uneven distribution of biophysical quantities, ${ }^{59}$ but there are other sources of heterogeneity in environmental benefits. In particular, an uneven distribution of benefits might result from heterogeneous preferences regarding the environmental good or because vulnerability - for example, measured as 'dose-response functions' - differs across groups within a society (Hsiang et al. 2017). Moreover, it seems plausible that both preferences regarding the environment and dose-response functions differ across income groups. However, there is little empirical research to date on these sources of heterogeneity and how they are linked to income. Furthermore, empirical measurement of biophysical environmental good endowment is already challenging (Hsiang et al. 2017). For simplicity and applicability, I therefore stick to the simplest case of heterogeneity in the physical endowment with environmental goods and leave other sources of heterogeneity as an issue for future research.

Third, I approximated the distribution of the environmental good by a log-normal distribution. It is necessary to assume a specific distributional form in order to derive closed-form solutions and to develop parameterized adjustment factors for benefit transfer. Employing a continuous representation extends upon the previous dichotomous representations in stylized two-region models in the sorting literature. The assumption of log-normality is certainly only

\footnotetext{
${ }^{59}$ Measuring exposure to environmental goods and the corresponding environmental inequality is often challenging. While the unit of observation for measuring economic inequality is usually the individual or household, the exposure to environmental goods and 'bads' is usually not known on the level of the individual or household. In order to avoid errors in interfering individual exposure from aggregate data, one should aim at using small-scale data (Boyce et al. 2016). However, in primary valuation studies, it is often straightforward to collect data on the endowment with environmental goods from respondents, for instance, the distance to environmental amenities or the frequency of visits.
} 
a first approximation, and its empirical fit has to be tested in further applications. Nevertheless, the assumption of log-normal distribution is generally in line with empirical evidence that the distribution of environmental goods and 'bads' is non-negative and right-skewed, which makes it a preferred choice over symmetric distributions like a normal distribution. It has been shown, for instance, in the case of Singapore, that access to urban green spaces in cities is strongly right-skewed (Tan and Samsudin 2017), which also holds true for exposure to industrial air pollution in the U.S. (Boyce et al. 2016). Moreover, airborne particulate matter in London seems to follow a log-normal distribution (MacKerron and Morato 2009), as does historic air pollution in English cities (Heblich et al. 2017, Fig A7ab).

Finally, I employed the coefficient of variation, $\mathrm{CV}_{E}$, as a measure of environmental inequality, but there are several other measures that one could apply. Using the $\mathrm{CV}_{E}$ is in line with the idea of relative inequality, which feature prominently in scientific and public debates on distributive justice. For instance, Chancel and Piketty (2015) find that relative inequality in individual $\mathrm{CO}_{2}$-eq emissions increased over the period from 1998 to 2013 and interfere from this design options for an equitable financing of global climate adaptation. However, one might argue that when considering the endowment with environmental goods and exposure to environmental pollution, such as air pollution, water pollution or noise, it is the absolute level and hence the absolute inequality that matters for health and general wellbeing. However, employing a relative and thereby unit-less measure was advantageous for the purpose of this study, as it allows a direct comparison between environmental and income inequality (see Propositions 4.2 and 4.3). Again, I leave an extension to other measures of environmental inequality for future work. 


\subsection{Conclusion}

I have studied how environmental and income inequality affect the valuation of environmental local public goods. To this end, I analyzed a model in which households have identical preferences characterized by a constant elasticity of substitution utility function and are heterogeneous in both their endowment with a local public good and their income.

My main results are: (i) there is a positive (negative) scope effect, if and only if the environmental good and consumption goods are substitutes (complements); (ii) the effect of environmental and income inequality on mean WTP for the environmental local public good is determined by whether the environmental good is a substitute for or a complement to manufactured consumption goods and by how environmental good endowment is correlated with income; (iii) an increase in the correlation between environmental good endowment and income - for example, due to richer households sorting into places where environmental quality is high - increases (decreases) mean WTP if and only if the environmental good and consumption goods are substitutes (complements). Moreover, I derived closed-form transfer factors for application in benefit transfer and environmental cost-benefit analysis that account for differences in the distribution of the environmental good and income and which are particularly simple if both are distributed independently. Using a forest preservation in Poland as an example, I illustrated that this theory-based adjustment is associated with considerable effect sizes - increasing societal WTP by up to $8 \%$ for an equal distribution of the environmental good and income compared to the status quo. Note that these results also hold for the valuation of non-environmental local public goods, such as transportation infrastructure or historical amenities that are exogenously given.

These findings extend the recent literature on how income inequality affects mean WTP for pure public goods. In particular, I showed that the key result of Baumgärtner et al. (2017a) according to which mean WTP decreases (increases) with relative income inequality if and only if the environmental good and the consumption good are substitutes (complements) also holds for local public goods in cases where (i) they are distributed independently of income, (ii) their endowment is negatively correlated with income, or (iii) relative income inequality is larger than relative environmental inequality. Moreover, the transfer factor for income inequality proposed by Baumgärtner et al. (2017a) and empirically validated by Meya et al. (2017) for a multi-country valuation study, also holds for environmental local public goods uncorrelated with income.

My results are relevant in several respects: First, when applying benefit transfer to value 
local pubic goods one should correct for differences in environmental good provision and its correlation with income. Public policy making frequently uses secondary data in cost-benefit analysis, as primary valuation studies are time intensive and costly. Therefore, 'value' or 'benefit transfer' has become a dominant method of environmental valuation (Pearce et al. 2006, Richardson et al. 2015) and is by now "far more pervasive to policy analysis than many perhaps [..] realize" (OECD 2018, p.160). The development of benefit transfer methods in the context of environmental local public goods is of major importance for environmental policy and management, as most environmental goods are distributed unevenly. Government agencies are required to conduct environmental valuation and cost-benefit analysis on local public goods under several regulatory acts, such as the EU Water Framework Directive, the European Marine Strategy Framework Directive, and U.S. regulations like the Clean Air Act. However, even though a grounding of benefit transfers in economic theory is generally held to ensure quality (Smith et al. 2002), the practical application of such structural benefit transfers remains very limited in the domains of policy making and management, probably due to the advanced micro-economic skills required (Phaneuf and Requate 2017: 685). Here, I contribute to the development of structural benefit transfer by clarifying the conditions under which existing transfer factors may be used to value local public goods and by presenting novel transfer factors to control for differences in their distribution. I thus hope to serve the high policy demand to improve benefit transfer methods for natural capital accounting (UN et al. 2014), in particular regarding the scaling-up of site-specific WTP estimates to larger areas. ${ }^{60}$

Second, when conducting validity tests of environmental valuation studies on should also consider the substitutability of the valued environmental good. The existence of a positive scope effect is a key criterion for assessing the construct validity of stated preference studies. Against the backdrop of the controversies on contingent valuation following the Exxon Valdez oil spill, the NOAA panel suggested to cast doubt on the reliability of contingent valuation studies if the elicited WTPs show "[i]nadequate responsiveness to the scope" (Arrow et al. 1993, p.37) of the environmental good, as "[u]sually, though not always, it is reasonable to suppose that more of something regarded as good is better so long as an individual is not satiated" (Arrow et al. 1993, p.11). Many studies on scope sensitivity take the statement that economic theory predicts an increase in WTP for an increase in the environmental good as

\footnotetext{
${ }^{60}$ Another extension that it necessary to make the structural benefit transfer approach of Baumgärtner et al. (2017a) suitable for natural capital accounting is to generalize the model framework from a static to a dynamic setting, as done in Meya et al. (2018).
} 
their point of departure (e.g. Borzykowski et al. 2018, Whitehead 2016) ${ }^{61}$ However, several valuation studies do not find a sensitivity to scope or even find a negative scope effect, ${ }^{62}$ which has spurred a heated debate on the reliability of the contingent valuation method as a whole. This paper adds another explanation from economic theory to the debate on scope effects: ${ }^{63}$ The existence of a negative scope effect might result from the environmental good under examination being a complement to manufactured consumption goods, and the absence of a scope effect might result from Cobb-Douglas preferences over the environmental good under examination and consumption goods.

Third, my study highlighted the importance of accounting for the spatial distribution of environmental goods and income when aggregating WTP for local public goods in environmental valuation. It is well known that the aggregation process of individual WTPs itself can substantially shape the resulting societal values (Bateman et al. 2006, Loomis 2000, Smith 1993). Primary valuation studies should report distributional parameters on the valued environment good and income to facilitate more sophisticated environmental cost-benefit analysis and estimate income elasticities of WTP, $\eta$, to cross-validate the existence of a scope effect. In particular, primary valuation studies eliciting WTP for local public goods should report how the valued environmental good is distributed, $\mu_{E}$ and $\sigma_{E}$ or $\mathrm{CV}_{E}$, and correlated with income, $\rho$. Moreover, this analysis once more emphasizes that the income elasticity of WTP, $\eta$, which, for CES preferences, is inversely related to the elasticity of substitution between consumption and environmental goods, is crucial to determine how the distribution of both the environmental good endowment and income affects societal WTP for environmental local public goods. This points to a need for more robust empirical estimates on $\eta$.

Fourth, my findings are relevant for environmental policy makers who are concerned with both equity and allocative efficiency. When deciding where to create new environmental amenities, place new sources of pollution, or reduce existing ones, and when employing environmental cost-benefit analysis (CBA) to ensure efficiency, policy makers should use inequality-adjusted WTPs in CBA. Under certain conditions, the developed transfer factors are a specification of distributional weights (Drupp et al. 2018). They are probably easier to

\footnotetext{
${ }^{61}$ Sensitivity to scope is commonly tested by comparing mean WTP values from split samples in which WTP is elicited for different qualities or quantities of the environmental good.

${ }^{62}$ For instance, Ojea and Loureiro (2011) provide an overview of meta-studies that test the effect of the quantity of the environmental good on mean WTP. Of the 14 meta-studies reported, six find no or a negative scope effect.

${ }^{63}$ Banerjee and Murphy (2005) already show that regular preferences in general do not necessarily imply the existence of a scope effect.
} 
use, however, as policy analysts only need approximating $C V_{Y}, C V_{E}$ and $\rho$ and their target levels rather than specifying weights and assessing the distribution of environmental benefits across income groups. In the context of gentrification, for instance, policy makers might have a preference regarding the correlation of environmental goods with income, $\rho$, and aim at counteracting the distributional effects of decentralized market forces by introducing explicit measures like social housing or spatially sensitive development of urban green spaces.

Acknowledgments: I am grateful to Stefan Baumgärtner, Nils Droste, Moritz Drupp, Klaus Eisenack, Nick Hanley and Martin Quaas for helpful comments and suggestions. I am indebted to Mikołaj Czajkowski as well as all the researchers contributing to the POLFOREX project (Forest as a public good. Evaluation of social and environmental benefits of forests in Poland to improve management efficiency) for sharing their empirical data, and to its funders, the EEA Financial Mechanism, Norwegian Financial Mechanism, and the Polish Ministry of Science and Higher Education. Moreover, I thank seminar participants at Berlin DCE Colloquium 2017 and Humboldt-Universität zu Berlin 2017 for stimulating discussions. Finally, financial support from the Ministry for Science and Culture of Lower Saxony (Germany) and the Volkswagen Foundation under the program Science for Sustainable Development under grant VWZN3045 is gratefully acknowledged. 


\section{Bibliography}

Aaron, H. and M. McGuire (1970) Public goods and income distribution, Econometrica 38: 907-919.

Alder, M. D. (2016), Benefit-cost analysis and distributional weights: An overview. Review of Environmental Economics and Policy, 10(2), 264-285.

Alvaredo, F., Chancel, L., Piketty, T., Saez, E., Sucman, G. (2017), World Inequality Report 2018. World Inequality Lab.

Arrow, K., Solow, R., Portney, P.R., Leamer, E.E., Radner, R., Schuman, H. (1993), Report of the NOAA Panel on Contingent Valuation. 1-66.

Ash, M. and Fetter, T.R. (2004), Who Lives on the Wrong Side of the Environmental Tracks? Evidence from the EPA's Risk-Screening Environmental Indicators Model. Social Science Quarterly, 85(2), 441-462.

Banerjee S, Murphy JH (2005), The scope test revisited. Applied Economics Letters, 12(10), $613-617$

Bateman, I.J., R. Brouwer, S. Ferrini, M. Schaafsma, D.N. Barton, A. Dubgaard, B. Hasler, S. Hime, I. Liekens, S. Navrud, L. De Nocker R. Šceponaviciute and D. Semeniene (2011), Making benefit transfers work: deriving and testing principles for value transfers for similar and dissimilar sites using a case study of the non-market benefits of water quality improvements across Europe. Environmental and Resource Economics, 50(3), 365-387.

Bateman, I.J., Day, B.H., Georgiou, S., and Lake, I. (2006). The aggregation of environmental benefit values: welfare measures, distance decay and total WTP. Ecological Economics, $60(2), 450-460$. 
Baumgärtner, S., M.A. Drupp, J. Munz, J.N. Meya and M.F. Quaas (2017), Income inequality and willingness to pay for environmental public goods. Forthcoming in Journal of Environmental Economics and Management, http://doi.org/10.1016/j.jeem.2017.04.005.

Baumgärtner, S., A.-M. Klein, D. Thiel and K. Winkler (2015), Ramsey Discounting of Ecosystem Services, Environmental and Resource Economics 61: 273-296.

Baumgärtner, S. and M.F. Quaas (2010), What is sustainability economics? Ecological Economics, 69(3), 445-450.

Borzykowski, N., Baranzini, A. and Maradan, D. (2018), Scope effects in contingent valuation: does the assumed statistical distribution of WTP matter? Ecological Economics, $144,319-329$.

Boyce, J.K., Zwickl, K., and Ash, M. (2016), Measuring environmental inequality. Ecological Economics, 124, 114-123.

Brander, L.M., Bräuer, I., Gerdes, H., Ghermandi, A., Kuik, O., Markandya, A., Kuik, O., Markandy, A., Navrund, S., Nunes, P., Marije, S., Schafma, M., Vos, H. and Wagtendonk, A. (2012), Using meta-analysis and GIS for value transfer and scaling up: Valuing climate change induced losses of European wetlands. Environmental and Resource Economics, $52(3), 395-413$.

Brueckner, J.K., J.-F. Thisse, and Y. Zenou (1999), Why is central Paris rich and downtown Detroit poor? An amenity-based theory. European Economic Review, 43(1), 91-107.

Butchart, S., M. Walpole, B. Collen, A. van Strien, J. Scharlemann, E. Almond, J. Baillie, B. Bomhard, C. Brown, J. Bruno, K. Carpenter, G. Carr, J. Chanson, A. Chenery, J. Csirke, N. Davidson, F. Dentner, M. Foster, A. Galli, J. Galloway, P. Genovesi, R. Gregory, M. Hockings, V. Kapos, J. Lamarque, F. Leverington, J. Loh, M. McGeoch, L. McRea, A. Minayian, M. Morcillo, T. Oldfield, D. Pauly, S. Quader, C. Revenga, J. Sauer, B. Skolnik, D. Spear, D. Stanwell-Smith, S. Stuart, A. Symes, M. Tierney, T. Tyrrell, J.-C. Vie, and R. Watson (2010). Global biodiversity: Indicators of recent declines. Science, 328(5982), $1164-1168$.

Government of Poland (2014), Fifth national report on the implementation of the convention on biological diversity. Poland. 
Chancel, L., and Piketty, T. (2015), Carbon and Inequality from Kyoto to Paris: Trends in the global inequality of carbon emissions (1998-2013) and prospects for an equitable adaptation fund. Paris school of economics.

Chiabai, A., Travisi, C. M., Markandya, A., Ding, H., and Nunes, P. A. (2011), Economic assessment of forest ecosystem services losses: cost of policy inaction. Environmental and Resource Economics, 50(3), 405-445.

Czajkowski, M., Budziński, W., Campbell, D., Giergiczny, M., and Hanley, N. (2017), Spatial heterogeneity of willingness to pay for forest management. Environmental and Resource Economics, 68(3), 705-727.

Czajkowski, M., Bartczak, A., Giergiczny, M., Navrud, S., and Żylicz, T. (2014a). Providing Preference-Based Support for Forest Ecosystem Service Management. Forest Policy and Economics, 39, 1-12.

Czajkowski, M., Giergiczny, M., and Greene, W. H. (2014b). Learning and fatigue effects revisited. Investigating the effects of accounting for unobservable preference and scale heterogeneity. Land Economics, 90(2):323-350.

Czajkowski, M. and M. Ščasný (2010), Study on benefit transfer in an international setting. How to improve welfare estimates in the case of the countries' income heterogeneity? Ecological Economics 69(12): 2409-2416.

Czajkowski, M., Buszko-Briggs, M., and Hanley, N. (2009). Valuing changes in forest biodiversity. Ecological Economics, 68(12), 2910-2917.

Budziński, W., Campbell, D., Czajkowski, M., Demsar, U., and Hanley, N. (2018) Using geographically weighted choice models to account for spatial heterogeneity of preferences. Journal of Agricultural Economics, forthcoming.

Drupp, M.A. (2018), Limits to Substitution between Ecosystem Services and Manufactured Goods and Implications for Social Discounting. Environmental and Resource Economics, 69(1): 135-158.

Drupp, M.A., J.N. Meya, S. Baumgärtner and M.F. Quaas (2018), Economic Inequality and the Value of Nature. Ecological Economics, 150, 340 - 345.

Ebert, U. (2003), Environmental goods and the distribution of income, Environmental and Resource Economics, 25(4), 435-459. 
FAO (2016), State of the World's Forests 2016. Forests and agriculture: land-use challenges and opportunities. Rome.

Hsiang, S., Oliva, P. and Walker, R., (2017), The distribution of environmental damages. NBER Working Paper Series, No 25862, National Bureau of Economic Research.

Heblich, S., Trew, A., and Zylberberg, Y. (2017), East Side Story: Historical Pollution and Persistent Neighborhood Sorting.

Jacobsen, J. and N. Hanley (2009), Are there income effects on global willingness to pay for biodiversity conservation? Environmental and Resource Economics, 43(2), 137-160.

Jensen, C. U., Panduro, T. E., Lundhede, T. H., von Graevenitz, K., and Thorsen, B. J. (2016), Robin Hood in reverse? Assessing distributional effects of green space policy using a second-stage hedonic house price model IFRO Working Paper 2016, No 2016-07.

Kahneman, D., and J.L. Knetsch (1992), Valuing public goods: the purchase of moral satisfaction. Journal of Environmental Economics and Management, 22(1), 57-70.

Kovenock, D. and E. Sadka (1981), Progression under the benefit approach to the theory of taxation, Economics Letters, 8, 95-99.

Kriström, B. and P. Riera (1996), Is the income elasticity of environmental improvements less than one? Environmental and Resource Economics, 7, 45-55.

Kuminoff, N.V. (2018), Can understanding spatial equilibria enhance benefit transfers for environmental policy evaluation? Environmental and Resource Economics, 69, 591 - 608.

Lee, S., and J. Lin (2018), Natural Amenities, Neighbourhood Dynamics, and Persistence in the Spatial Distribution of Income. The Review of Economic Studies, 85, 663-694.

Loomis, J.B. (2000), Vertically summing public good demand curves: an empirical comparison of economic versus political jurisdictions. Land Economics, 76(2), 312-321.

Loomis, J.B. (1992), The evolution of a more rigorous approach to benefit transfer: Benefit function transfer, Water Resources Research 28: 701-705.

MacKerron, G., and S. Mourato (2009), Life satisfaction and air quality in London. Ecological Economics, 68(5), 1441-1453. 
[MEA 2005] Millennium ecosystem assessment (2005), Ecosystems and human well-being: Biodiversity synthesis, Published by World Resources Institute, Washington, DC.

Meya, J.N., Drupp, M.A., Baumgärtner, S., and Quaas, M.F. (2018), Inter- and intragenerational distribution and the valuation of natural capital. Unpublished manuscript. Humboldt-Universität zu Berlin.

Meya, J.N., Drupp, M.A., and Hanley, N. (2017), Income inequality and the international transfer of environmental values. Kiel Economics Working Paper, No 2017-03.

[OECD 2018] Atkinson, G., Braathen, N.A., Groom, B. and Mourato, S. (2018), Cost-benefit analysis and the environment: further developments and policy use. OECD Publishing: Paris.

Ojea, E. and Loureiro, M. L. (2011), Identifying the scope effect on a meta-analysis of biodiversity valuation studies. Resource and Energy Economics, 33(3), 706-724.

Pearce, D. Atkinson, G. and Mourato, S. (2006), Cost-benefit analysis and the environment: recent developments, Organisation for Economic Co-operation and Development(OECD).

Perino, G., Andrews, B., Kontoleon, A., and Bateman, I. (2014), The value of urban green space in Britain: a methodological framework for spatially referenced benefit transfer. Environmental and Resource Economics, 57(2), 251-272.

Pinkovskiy, M. and X. Sala-i-Martin (2009), Parametric estimations of the world distribution of income, NBER Working Paper No. 15433.

Phaneuf, D.J. and Requate, T. (2017), A Course in Environmental Economics: Theory, Policy, and Practice, Cambridge University Press.

Richardson, L., J. Loomis T. Kroeger and F. Casey (2015), The role of benefit transfer in ecosystem service valuation, Ecological Economics, 115, 51-58.

Samuelson, P.A. (1954), The Pure Theory of Public Expenditure, Review of Economics and Statistics, 36(4), 387-389.

[SCBD] Secretariat of the Convention on Biological Diversity (2001), The Value of Forest Ecosystems. Montreal, SCBD, CBD Technical Series, 4.

Smith, V.K. (1992), Arbitrary values, good causes, and premature verdicts. Journal of Environmental Economics and Management, 22(1), 71-89. 
Smith, V.K. (1993), Nonmarket valuation of environmental resources: an interpretive appraisal. Land Economics, 1-26.

Smith, V.K., Van Houtven, G., and Pattanayak, S.K. (2002), Benefit transfer via preference calibration: "Prudential algebra" for policy. Land Economics, 78(1), 132-152.

Tan, P.Y. and Samsudin, R. (2017), Effects of spatial scale on assessment of spatial equity of urban park provision. Landscape and Urban Planning, 158, 139-154.

Tiebout, C. (1956), A Pure Theory of Local Expenditures. The Journal of Political Economy, $64(5), 416-24$.

Turner, M.A. (2017), Benefit-transfer and spatial equilibrium. Environmental and Resource Economics, 69, 575 - 589 .

United Nations, European Commission, Food and Agriculture Organization of the United Nations, Organisation for Economic Co-operation and Development, World Bank Group (2014), System of Environmental-Economic Accounting 2012-Experimental Ecosystem Accounting, New York: United Nations.

Whitehead, J.C. (2016), Plausible responsiveness to scope in contingent valuation. Ecological Economics, 128, 17-22.

Yue, S. (2000), The bivariate lognormal distribution to model a multivariate flood episode. Hydrological Processes, 14, 2575-2588.

Zaidi, S. (2009), Main drivers of income inequality in central European and Baltic countries - some insights from recent household survey data. The World Bank, Policy Research Working Paper, 4815. 


\subsection{Appendix}

\subsubsection{Derivation of household's total WTP, WTP $\left(Y_{i}, E_{i}\right)$ (Eq. (4.3))}

In the following I derive the household's total WTP for the environmental local public good. In doing so, I build on Ebert (2003) and Baumärtner et al. (2017, Appendix A.1), who have already obtained the household's WTP for a constant elasticity of substitution (CES) utility function for environmental pure public goods.

From the perspective of the household, the quantity of the environmental good is fixed. Household $i$ faces the following constrained maximization problem (Ebert 2003: 439)

$$
\begin{aligned}
& \max _{X_{i}, E_{i}} U\left(X_{i}, E_{i}\right) \\
& \text { s.t. } \quad P X_{i}=Y_{i}, \quad E_{i} \text { fixed. }
\end{aligned}
$$

For the CES utility function given in Eq (6.1) and using $X_{i}=\frac{Y_{i}}{P}$ the corresponding indirect utility function reads

$$
V\left(P, Y_{i}, E_{i}\right)=\left[\alpha\left(\frac{Y_{i}}{P}\right)^{\frac{\theta-1}{\theta}}+(1-\alpha) E_{i}^{\frac{\theta-1}{\theta}}\right]^{\frac{\theta}{\theta-1}}
$$

The marginal WTP for environmental local public good $E_{i}$ can then be derived by an extension of Roy's identity from the household's indirect utility function, $V\left(P, Y_{i}, E_{i}\right)$ (Eq. (4.27)), (Ebert 2003: 440):

$$
\begin{aligned}
& w\left(Y_{i}, E_{i}\right) \quad:= \frac{\frac{\partial V\left(P, Y_{i}, E_{i}\right)}{\partial E_{i}}}{\frac{\partial V\left(P, Y_{i}, E_{i}\right)}{\partial Y_{i}}} \\
& \stackrel{(4.27)}{=} \frac{\left[\alpha\left(\frac{Y_{i}}{P}\right)^{\frac{\theta-1}{\theta}}+(1-\alpha) E_{i}^{\frac{\theta-1}{\theta}}\right]^{\frac{\theta}{\theta-1}}(1-\alpha) E_{i}^{-1 / \theta}}{\left[\alpha\left(\frac{Y_{i}}{P}\right)^{\frac{\theta-1}{\theta}}+(1-\alpha) E_{i}^{\frac{\theta-1}{\theta}}\right]^{\frac{\theta}{\theta-1}} \alpha P^{\frac{1-\theta}{\theta}} Y_{i}^{-1 / \theta}} \\
&=\frac{1-\alpha}{\alpha} P^{\frac{\theta-1}{\theta}} Y_{i}^{1 / \theta} E_{i}^{-1 / \theta} .
\end{aligned}
$$

The marginal WTP, $\omega$, can be interpreted as the virtual price the household is willing to pay in a hypothetical choice problem where the household would have voluntarily chosen quantity $E_{i}$, given income $Y_{i}$ and consumption good prices $P$. One can directly observe that marginal 
WTP, $\omega$, increases with income, but decreases with the quantity of the environmental good, as $P, E_{i}, Y_{i}>0, \alpha \in(0,1)$.

Total WTP, $\operatorname{WTP}\left(Y_{i}, E_{i}\right)$, for the environmental local public good is then given as marginal WTP, $\omega$, at levels $E_{i}$ and $Y_{i}$ times the level of the environmental good $E_{i}$ (Ebert 2003: 442)

$$
\begin{aligned}
\operatorname{WTP}\left(Y_{i}, E_{i}\right) & =w\left(Y_{i}, E_{i}\right) E_{i} \\
\stackrel{(4.30)}{=} & \frac{1-\alpha}{\alpha}\left(P E_{i}\right)^{\frac{\theta-1}{\theta}} Y_{i}^{1 / \theta},
\end{aligned}
$$

where the income elasticity of WTP, $\eta$, is the inverse of the elasticity of substitution, $\eta=\frac{1}{\theta}$. Hence, the WTP function can also be written directly for the income elasticity of WTP as

$$
\operatorname{WTP}\left(Y_{i}, E_{i}\right)=\frac{1-\alpha}{\alpha}\left(P E_{i}\right)^{1-\eta} Y_{i}^{\eta}
$$




\subsubsection{Derivation of mean WTP, $\mu_{\mathrm{WTP}},($ Eq. $(4.9)$ )}

Mean WTP, $\mu_{\text {WTP }}$ (Eq. (4.6)), can be reformulated with respect to the moments of the bivariate log-normal distribution - $\mu_{Y}, \sigma_{Y}, \mu_{E}, \sigma_{E}, \rho$ - as follows

$$
\begin{aligned}
& \mu_{W T P}\left(\mu_{Y}, \sigma_{Y}, \mu_{E}, \sigma_{E}, \rho\right)=\int_{0}^{\infty} \int_{0}^{\infty} f_{\ln }\left(Y, E ; \mu_{Y}, \sigma_{Y}, \mu_{E}, \sigma_{E}, \rho\right) W T P(Y, E) d Y d E \\
& \stackrel{(4.3)}{=} \int_{0}^{\infty} \int_{0}^{\infty} f_{\ln }\left(Y, E ; \mu_{Y}, \sigma_{Y}, \mu_{E}, \sigma_{E}, \rho\right) \frac{1-\alpha}{\alpha} P^{1-\eta} E^{1-\eta} Y^{\eta} d Y d E \\
& =\frac{1-\alpha}{\alpha} P^{1-\eta} \int_{0}^{\infty} \int_{0}^{\infty} f_{\ln }\left(Y, E ; \mu_{Y}, \sigma_{Y}, \mu_{E}, \sigma_{E}, \rho\right) E^{1-\eta} Y^{\eta} d Y d E \\
& \stackrel{(4.7)}{=} \frac{1-\alpha}{\alpha} P^{1-\eta} \int_{0}^{\infty} \int_{0}^{\infty} \frac{\exp \left[-\frac{1}{2\left(1-\rho^{2}\right)}\left(\frac{\left(\ln (Y)-m_{Y}\right)^{2}}{s_{Y}^{2}}-2 \rho \frac{\ln (Y)-m_{Y}}{s_{Y}} \frac{\ln (E)-m_{E}}{s_{E}}+\frac{\left(\ln (E)-m_{E}\right)^{2}}{s_{E}^{2}}\right)\right]}{2 \pi Y E \sqrt{s_{Y}^{2} s_{E}^{2}\left(1-\rho^{2}\right)}} E^{1-\eta} Y^{\eta} d Y d E \\
& =\frac{1-\alpha}{\alpha} P^{1-\eta} \int_{0}^{\infty} \int_{0}^{\infty} \frac{\exp \left[-\frac{1}{2\left(1-\rho^{2}\right)}\left(\frac{\left(\ln (Y)-m_{Y}\right)^{2}}{s_{Y}^{2}}-2 \rho \frac{\ln (Y)-m_{Y}}{s_{Y}} \frac{\ln (E)-m_{E}}{s_{E}}+\frac{\left(\ln (E)-m_{E}\right)^{2}}{s_{E}^{2}}\right)\right]}{2 \pi \sqrt{s_{Y}^{2} s_{E}^{2}\left(1-\rho^{2}\right)}} E^{-\eta} Y^{\eta-1} d Y d E \\
& =\frac{1-\alpha}{\alpha} P^{1-\eta} \int_{0}^{\infty} \frac{1}{\sqrt{2 \pi s_{Y}^{2}}} \exp \left[-\frac{m_{E}+\eta^{2}\left(\rho^{2}-1\right) s_{E}^{2} s_{Y}^{2}+2 \eta s_{E}\left(-s_{E} m_{Y}+\rho m_{E} s_{Y}\right)+\ln (E)^{2}}{2 s_{E}}\right] \\
& E^{\frac{m_{E}+\eta s_{E}\left(-s_{E}+\rho s_{Y}\right)}{s_{E}^{2}}} d E \\
& =\frac{1-\alpha}{\alpha} P^{1-\eta} \exp \left[\frac{1}{2}(\eta-1)^{2} s_{E}^{2}+\eta\left(m_{Y}-m_{E}\right)+m_{E}-\rho(\eta-1) \eta s_{E} s_{Y}+\frac{1}{2} \eta^{2} s_{Y}^{2}\right] \\
& \stackrel{(4.8)}{=} \frac{1-\alpha}{\alpha} P^{1-\eta} \exp \left[\frac{1}{2}(\eta-1)^{2} \ln \left(1+\frac{\sigma_{E}^{2}}{\mu_{E}^{2}}\right)+\eta\left(\ln \left(\mu_{Y}\right)-\frac{1}{2} \ln \left(1+\frac{\sigma_{Y}^{2}}{\mu_{Y}^{2}}\right)-\ln \left(\mu_{E}\right)+\frac{1}{2} \ln \left(1+\frac{\sigma_{E}^{2}}{\mu_{E}^{2}}\right)\right)\right. \\
& \left.+\ln \left(\mu_{E}\right)-\frac{1}{2} \ln \left(1+\frac{\sigma_{E}^{2}}{\mu_{E}^{2}}\right)-\rho(\eta-1) \eta \sqrt{\ln \left(1+\frac{\sigma_{E}^{2}}{\mu_{E}^{2}}\right)} \sqrt{\ln \left(1+\frac{\sigma_{Y}^{2}}{\mu_{Y}^{2}}\right)}+\frac{1}{2} \eta^{2} \ln \left(1+\frac{\sigma_{Y}^{2}}{\mu_{Y}^{2}}\right)\right] \\
& =\frac{1-\alpha}{\alpha} P^{1-\eta} \exp \left[\frac{\eta^{2}-\eta}{2} \ln \left(1+\frac{\sigma_{E}^{2}}{\mu_{E}^{2}}\right)+\frac{\eta^{2}-\eta}{2} \ln \left(1+\frac{\sigma_{Y}^{2}}{\mu_{Y}^{2}}\right)+(1-\eta) \ln \left(\mu_{E}\right)+\eta \ln \left(\mu_{Y}\right)\right. \\
& -\rho(\eta-1) \eta \sqrt{\ln \left(1+\frac{\sigma_{E}^{2}}{\mu_{E}^{2}}\right)} \sqrt{\ln \left(1+\frac{\sigma_{Y}^{2}}{\mu_{Y}^{2}}\right)} \\
& =\frac{1-\alpha}{\alpha} P^{1-\eta} \exp \left[\ln \left(\left(1+\frac{\sigma_{E}^{2}}{\mu_{E}^{2}}\right)^{\frac{\eta^{2}-\eta}{2}}\right)\right] \exp \left[\ln \left(\left(1+\frac{\sigma_{Y}^{2}}{\mu_{Y}^{2}}\right)^{\frac{\eta^{2}-\eta}{2}}\right)\right] \exp \left[\ln \left(\mu_{E}^{1-\eta}\right)\right] \exp \left[\ln \left(\mu_{Y}^{\eta}\right)\right] \\
& \exp \left[-\rho(\eta-1) \eta \sqrt{\ln \left(1+\frac{\sigma_{E}^{2}}{\mu_{E}^{2}}\right)} \sqrt{\ln \left(1+\frac{\sigma_{Y}^{2}}{\mu_{Y}^{2}}\right)}\right]
\end{aligned}
$$




$$
\begin{aligned}
& =\frac{1-\alpha}{\alpha} P^{1-\eta} \mu_{Y}^{\eta}\left(1+\frac{\sigma_{Y}^{2}}{\mu_{Y}^{2}}\right)^{\frac{\eta^{2}-\eta}{2}} \mu_{E}^{1-\eta}\left(1+\frac{\sigma_{E}^{2}}{\mu_{E}^{2}}\right)^{\frac{\eta^{2}-\eta}{2}} \exp \left[\rho\left(-\eta^{2}+\eta\right) \sqrt{\ln \left(1+\frac{\sigma_{E}^{2}}{\mu_{E}^{2}}\right) \ln \left(1+\frac{\sigma_{Y}^{2}}{\mu_{Y}^{2}}\right)}\right] \\
& \stackrel{\eta=1 / \theta}{=} \frac{1-\alpha}{\alpha} P^{\frac{\theta-1}{\theta}} \mu_{Y}^{\frac{1}{\theta}}\left(1+\frac{\sigma_{Y}^{2}}{\mu_{Y}^{2}}\right)^{\frac{1-\theta}{2 \theta^{2}}} \mu_{E}^{\frac{\theta-1}{\theta}}\left(1+\frac{\sigma_{E}^{2}}{\mu_{E}^{2}}\right)^{\frac{1-\theta}{2 \theta^{2}}} \exp \left[\rho \frac{\theta-1}{\theta^{2}} \sqrt{\left.\ln \left(1+\frac{\sigma_{E}^{2}}{\mu_{E}^{2}}\right) \ln \left(1+\frac{\sigma_{Y}^{2}}{\mu_{Y}^{2}}\right)\right]} .\right.
\end{aligned}
$$

Equivalently mean WTP can be expressed for relative income inequality, $\mathrm{CV}_{Y}:=\frac{\sigma_{Y}}{\mu_{Y}}$, and relative environmental inequality, $\mathrm{CV}_{E}:=\frac{\sigma_{E}}{\mu_{E}}$. Eq. (4.34) then becomes:

$$
\begin{gathered}
\mu_{W T P}\left(\mu_{Y}, \mathrm{CV}_{Y}, \mu_{E}, \mathrm{CV}_{E}, \rho\right)=\frac{1-\alpha}{\alpha} P^{\frac{\theta-1}{\theta}} \mu_{Y}^{\frac{1}{\theta}}\left(1+\mathrm{CV}_{Y}^{2}\right)^{\frac{1-\theta}{2 \theta^{2}}} \mu_{E}^{\frac{\theta-1}{\theta}}\left(1+\mathrm{CV}_{E}^{2}\right)^{\frac{1-\theta}{2 \theta^{2}}} \Psi \\
\text { with } \Psi\left(\mathrm{CV}_{Y}, \mathrm{CV}_{E}, \rho\right):=\exp \left[\rho \frac{\theta-1}{\theta^{2}} \sqrt{\ln \left(1+\mathrm{CV}_{E}^{2}\right) \ln \left(1+\mathrm{CV}_{Y}^{2}\right)}\right]
\end{gathered}
$$

\subsubsection{Proof of Proposition 4.1}

Differentiating $\mu_{\mathrm{WTP}}$ (Eq. (4.9)) with respect to $\mu_{E}$ yields

$$
\begin{aligned}
& \frac{\partial \mu_{\mathrm{WTP}}\left(\mu_{Y}, \mathrm{CV}_{Y}, \mu_{E}, \mathrm{CV}_{E}, \rho\right)}{\partial \mu_{E}}=\frac{\theta-1}{\theta} \frac{1-\alpha}{\alpha} P^{\frac{\theta-1}{\theta}} \mu_{Y}^{\frac{1}{\theta}}\left(1+\mathrm{CV}_{Y}^{2}\right)^{\frac{1-\theta}{2 \theta^{2}}} \mu_{E}^{-1 / \theta}\left(1+\mathrm{CV}_{E}^{2}\right)^{\frac{1-\theta}{2 \theta^{2}}} \Psi \\
& \text { with } \quad \Psi\left(\mathrm{CV}_{Y}, \mathrm{CV}_{E}, \rho\right):=\exp \left[\rho \frac{\theta-1}{\theta^{2}} \sqrt{\ln \left(1+\mathrm{CV}_{E}^{2}\right) \ln \left(1+\mathrm{CV}_{Y}^{2}\right)}\right],
\end{aligned}
$$

the sign of which is determined by $\frac{\theta-1}{\theta}$, as $\alpha \in(0,1)$ and $P, \mu_{E}, \mu_{Y}, \mathrm{CV}_{Y}, \mathrm{CV}_{E}, \Psi>0$. It holds that $\frac{\theta-1}{\theta} \gtreqless 0 \Longleftrightarrow \theta \gtreqless 1$.

\subsubsection{Proof of Proposition 4.2}

Differentiating $\mu_{\mathrm{WTP}}$ given in Eq. (4.9) with respect to $\mathrm{CV}_{Y}$ yields

$$
\begin{aligned}
& \frac{\partial \mu_{\mathrm{WTP}}\left(\mu_{Y}, \mathrm{CV}_{Y}, \mu_{E}, \mathrm{CV}_{E}, \rho\right)}{\partial \mathrm{CV}_{Y}} \\
& =k^{\prime} \frac{1-\theta}{\theta^{2}} \mathrm{CV}_{Y}\left(1+\mathrm{CV}_{Y}^{2}\right)^{\frac{1-\theta-2 \theta^{2}}{2 \theta^{2}}} \Psi+k^{\prime}\left(1+\mathrm{CV}_{Y}^{2}\right)^{\frac{1-\theta}{2 \theta^{2}}} \Psi \rho \frac{\theta-1}{\theta^{2}} \\
& \quad \frac{\ln \left(1+\mathrm{CV}_{E}^{2}\right)}{\sqrt{\ln \left(1+\mathrm{CV}_{E}^{2}\right) \ln \left(1+\mathrm{CV}_{Y}^{2}\right)}} \frac{\mathrm{CV}_{Y}}{1+\mathrm{CV}_{Y}^{2}} \\
& =k^{\prime} \Psi \mathrm{CV}_{Y}\left(1+\mathrm{CV}_{Y}^{2}\right)^{\frac{1-\theta-2 \theta^{2}}{2 \theta^{2}}}\left[\frac{1-\theta}{\theta^{2}}+\rho \frac{\theta-1}{\theta^{2}} \frac{\ln \left(1+\mathrm{CV}_{E}^{2}\right)}{\sqrt{\ln \left(1+\mathrm{CV}_{E}^{2}\right) \ln \left(1+\mathrm{CV}_{Y}^{2}\right)}}\right] \\
& =k^{\prime} \Psi \frac{1-\theta}{\theta^{2}} \mathrm{CV}_{Y}\left(1+\mathrm{CV}_{Y}^{2}\right)^{\frac{1-\theta-2 \theta^{2}}{2 \theta^{2}}}\left[1-\rho \sqrt{\left.\frac{\ln \left(1+\mathrm{CV}_{E}^{2}\right)}{\ln \left(1+\mathrm{CV}_{Y}^{2}\right)}\right]},\right.
\end{aligned}
$$


where

$$
\begin{aligned}
& \Psi\left(\mathrm{CV}_{Y}, \mathrm{CV}_{E}, \rho\right):=\exp \left[\rho \frac{\theta-1}{\theta^{2}} \sqrt{\ln \left(1+\mathrm{CV}_{E}^{2}\right) \ln \left(1+\mathrm{CV}_{Y}^{2}\right)}\right] \\
& k^{\prime}\left(\mu_{Y}, \mu_{E}, \mathrm{CV}_{E}\right):=\frac{1-\alpha}{\alpha} P^{\frac{\theta-1}{\theta}} \mu_{Y}^{\frac{1}{\theta}}\left(1+\mathrm{CV}_{E}^{2}\right)^{\frac{1-\theta}{2 \theta^{2}}} \mu_{E}^{\frac{\theta-1}{\theta}}
\end{aligned}
$$

As $\mathrm{CV}_{E}, k^{\prime}$ and $\Psi$ are strictly positive, Eq. (4.37) can only become negative if either $\frac{1-\theta}{\theta^{2}}<0$, or $1-\rho \sqrt{\frac{\ln \left(1+\mathrm{CV}_{E}^{2}\right)}{\ln \left(1+\mathrm{CV}_{Y}^{2}\right)}}<0$, while the respective other factor is strictly positive. It holds that

$$
\frac{1-\theta}{\theta^{2}} \gtreqless 0 \Longleftrightarrow \theta \lesseqgtr 1
$$

and

$$
1-\rho \sqrt{\frac{\ln \left(1+\mathrm{CV}_{E}^{2}\right)}{\ln \left(1+\mathrm{CV}_{Y}^{2}\right)}} \gtreqless 0 \Longleftrightarrow \rho \lesseqgtr \sqrt{\frac{\ln \left(1+\mathrm{CV}_{Y}^{2}\right)}{\ln \left(1+\mathrm{CV}_{E}^{2}\right)}} .
$$

The combination of the sign of both factors establishes the Proposition.

\subsubsection{Proof of Corollary 4.1}

Differentiating $\mu_{\mathrm{WTP}}^{\text {ind }}$ given in Eq. (4.10) with respect to income inequality, $\mathrm{CV}_{Y}$, yields

$$
\begin{aligned}
& \frac{\partial \mu_{\mathrm{WTP}}^{\mathrm{ind}}\left(\mu_{Y}, \mathrm{CV}_{Y}, \mu_{E}, \mathrm{CV}_{E}\right)}{\partial \mathrm{CV}_{Y}} \\
& =\frac{1-\theta}{\theta^{2}} \frac{1-\alpha}{\alpha} P^{\frac{\theta-1}{\theta}} \mu_{Y}^{1 / \theta} \mathrm{CV}_{Y}\left(1+\mathrm{CV}_{Y}^{2}\right)^{\frac{1-\theta-2 \theta^{2}}{2 \theta^{2}}} \mu_{E}^{\frac{\theta-1}{\theta}}\left(1+\mathrm{CV}_{E}^{2}\right)^{\frac{1-\theta}{2 \theta^{2}}} .
\end{aligned}
$$

As $\alpha \in(0,1)$ and $\theta, P, \mu_{Y}, \mathrm{CV}_{Y}, \mu_{E}, \mathrm{CV}_{E}>0$ the sign of this derivative is determined by the sign of $\frac{1-\theta}{\theta^{2}}$. It holds that $\frac{1-\theta}{\theta^{2}} \lesseqgtr 0 \Longleftrightarrow \theta \gtreqless 1$.

\subsubsection{Proof of Proposition 4.3}

The proof is completely analogous to the one for Proposition 4.2. Differentiating $\mu_{\mathrm{WTP}}$ given in Eq. (4.9) with respect to $\mathrm{CV}_{E}$ yields

$$
\begin{aligned}
& \frac{\partial \mu_{\mathrm{WTP}}\left(\mu_{Y}, \mathrm{CV}_{Y}, \mu_{E}, \mathrm{CV}_{E}, \rho\right)}{\partial \mathrm{CV}_{E}} \\
&= k^{\prime \prime} \frac{1-\theta}{\theta^{2}} \mathrm{CV}_{E}\left(1+\mathrm{CV}_{E}^{2}\right)^{\frac{1-\theta-2 \theta^{2}}{2 \theta^{2}}} \Psi\left[1-\rho \sqrt{\left.\frac{\ln \left(1+\mathrm{CV}_{Y}^{2}\right)}{\ln \left(1+\mathrm{CV}_{E}^{2}\right)}\right]},\right. \\
& \text { where } \quad \Psi\left(\mathrm{CV}_{Y}, \mathrm{CV}_{E}, \rho\right):=\exp \left[\rho \frac{\theta-1}{\theta^{2}} \sqrt{\ln \left(1+\mathrm{CV}_{E}^{2}\right) \ln \left(1+\mathrm{CV}_{Y}^{2}\right)}\right], \\
& \quad k^{\prime \prime}\left(\mu_{Y}, \mathrm{CV}_{Y}, \mu_{E}\right):=\frac{1-\alpha}{\alpha} P^{\frac{\theta-1}{\theta}} \mu_{Y}^{\frac{1}{\theta}}\left(1+\mathrm{CV}_{Y}^{2}\right)^{\frac{1-\theta}{2 \theta^{2}}} \mu_{E}^{\frac{\theta-1}{\theta}} .
\end{aligned}
$$


As $\mathrm{CV}_{E}, k$ and $\Psi$ are strictly positive, the sign of Eq. (4.43) is determined by the sign of the factors $\frac{1-\theta}{\theta^{2}}<0$ and $1+\rho \sqrt{\frac{\ln \left(1+\mathrm{CV}_{Y}^{2}\right)}{\ln \left(1+\mathrm{CV}_{E}{ }^{2}\right)}}<0$. It holds that

$$
\frac{1-\theta}{\theta^{2}} \gtreqless 0 \Longleftrightarrow \theta \lesseqgtr 1
$$

and

$$
1-\rho \sqrt{\frac{\ln \left(1+\mathrm{CV}_{Y}^{2}\right)}{\ln \left(1+\mathrm{CV}_{E}^{2}\right)}} \gtreqless 0 \Longleftrightarrow \rho \lesseqgtr \sqrt{\frac{\ln \left(1+\mathrm{CV}_{E}^{2}\right)}{\ln \left(1+\mathrm{CV}_{Y}^{2}\right)}} .
$$

The combination of the sign of both factors establishes the Proposition.

\subsubsection{Proof of Corollary 4.2}

Differentiating $\mu_{\mathrm{WTP}}^{\mathrm{ind}}$ given in Eq. (4.10) with respect to environmental inequality, $\mathrm{CV}_{E}$, yields

$$
\begin{aligned}
& \frac{\partial \mu_{\mathrm{WTP}}^{\mathrm{ind}}\left(\mu_{Y}, \mathrm{CV}_{Y}, \mu_{E}, \mathrm{CV}_{E}\right)}{\partial \mathrm{CV}_{E}} \\
& =\frac{1-\theta}{\theta^{2}} \frac{1-\alpha}{\alpha} P^{\frac{\theta-1}{\theta}} \mu_{Y}^{1 / \theta}\left(1+\mathrm{CV}_{Y}^{2}\right)^{\frac{1-\theta}{2 \theta^{2}}} \mu_{E}^{\frac{\theta-1}{\theta}} \mathrm{CV}_{E}\left(1+\mathrm{CV}_{E}^{2}\right)^{\frac{1-\theta-2 \theta^{2}}{2 \theta^{2}}} .
\end{aligned}
$$

As $\alpha \in(0,1)$ and $\theta, P, \mu_{Y}, \mathrm{CV}_{Y}, \mu_{E}, \mathrm{CV}_{E}>0$ the sign of this derivative is determined by the sign of $\frac{1-\theta}{\theta^{2}}$. It holds that $\frac{1-\theta}{\theta^{2}} \lesseqgtr 0 \Longleftrightarrow \theta \gtreqless 1$.

\subsubsection{Household sorting with respect to the distribution of the environ- mental local public good}

Household sorting generally affects the correlation between income and endowment with environmental goods. I outline how this can be formally proven for CES preferences and common assumptions on the housing market in the following. To this end, I present a stylized model of how the distribution of environmental goods affects the residential choice ('sorting') of households that differ in income. The endowment with the environmental good is now a choice variable in the household's decision problem.

Consider a city, region, or country with an environmental amenity, the exposure to which is distributed unevenly and continuously over locations. Following Tiebout (1956) each household $i$ is perfectly mobile and chooses its location with the aim of enjoying a desired level of the environmental good, $E_{i}>0$. For instance, the environmental good endowment $E_{i}$ could be measured as the inverse of the Euclidean distance to the environmental amenity. It is therefore illustrative to consider $E_{i} \in(0,1)$. 
As before, households have identical preferences over a consumption good, $X_{i}$, and the environmental good, $E_{i}$, represented by a CES utility function (see Eq. (6.1)). Thus, like Lee and Lin (2018) and Heblich et al. (2017), I abstract from other property characteristics (such as size) and implicitly assume non-environmental property characteristics to be identical across locations.

Household $i$ 's decision problem is then to maximize utility by choosing any combination of these goods subject to a budget constraint,

$$
\max _{X_{i}, E_{i}} U\left(X_{i}, E_{i}\right) \quad \text { s.t. } P X_{i}+R\left(E_{i}\right)=Y_{i}
$$

where $Y_{i}$ is household income and $R\left(E_{i}\right)$ is the annual rent collected by absentee landlords. Studying rents rather than property prices makes it possible to consider a static setting and abstract from dynamic effects. To save on notation, I assume $P=1$, i.e. $X_{i}$ is the numeraire good. Rearranging the budget constraint and substituting for $X_{i}$, household's utility can be rewritten as $U\left(Y_{i}-R\left(E_{i}\right), E_{i}\right)$.

In equilibrium, the rent $R\left(E_{i}\right)$ has to vary over $E_{i}$ so that utility is uniform across locations (e.g., Brueckner et al. 1999, Phaneuf and Requate 2017, 532). Let $\bar{u}$ denote the reference utility level so that

$$
\bar{u}=U\left(Y_{i}-\bar{R}\left(E_{i}\right), E_{i}\right),
$$

where $\bar{R}\left(E_{i}\right)$ is by definition the maximum household $i$ is willing to pay for a home in a location characterized by an environmental good at level $\left(E_{i}\right)$ and hence referred to as household's bid function.

The slope of the bid function or the marginal WTP for an increase in the environmental good is then given as derivative of the implicit bid function $\bar{R}\left(E_{i}\right)$ with respect to the environmental good:

$$
\frac{\partial \bar{R}\left(E_{i}\right)}{\partial E_{i}}=\frac{\frac{\partial U}{\partial E_{i}}\left(Y_{j}-\bar{R}_{j}(\hat{E}), E_{i}\right)}{\frac{\partial U}{\partial X_{i}}\left(Y_{j}-\bar{R}_{j}(\hat{E}), E_{i}\right)} .
$$

Substituting the partial derivatives

$$
\begin{aligned}
& \frac{\partial U\left(X_{i}, E_{i}\right)}{\partial E_{i}}=(1-\alpha) E^{-1 / \theta}\left[\alpha X_{i}^{\frac{\theta-1}{\theta}}+(1-\alpha) E_{i}^{\frac{\theta-1}{\theta}}\right]^{\frac{1}{\theta-1}} \text { and } \\
& \frac{\partial U\left(X_{i}, E_{i}\right)}{\partial X_{i}}=\alpha X^{-1 / \theta}\left[\alpha X_{i}^{\frac{\theta-1}{\theta}}+(1-\alpha) E_{i}^{\frac{\theta-1}{\theta}}\right]^{\frac{1}{\theta-1}}
\end{aligned}
$$


into Eq. (4.51) I obtain the slope of the bid function with respect to a change in $E_{i}$

$$
\frac{\partial \bar{R}\left(E_{i}\right)}{\partial E_{i}}=\frac{1-\alpha}{\alpha}\left(\frac{Y_{i}-\bar{R}\left(E_{i}\right)}{E_{i}}\right)^{1 / \theta}
$$

which is strictly increasing in income as by definition $Y_{i}>R\left(E_{i}\right)$ and $\alpha \in(0,1), E_{i}>0$. Note that Eq. 4.54 almost resembles the marginal WTP derived for an exogenously given $E_{i}$ (see Eq. (4.30)), except that the household has to pay rent $\bar{R}\left(E_{i}\right)$ to enjoy the environmental good at level $E_{i}$.

Now, I extend this model to a situation with two groups of households $j, k$, that only differ in income $Y_{j} \neq Y_{k}$. Without a loss of generality, I assume $Y_{j}>Y_{k}$. For the remainder, I proceed analogously to the argument presented by Brueckner et al. (1999). Landlords rent houses to the households that pay the highest rent. Thus, the income group that outbids the other income group on the housing market will live where the endowment with $E$ is high. Let $\hat{E}$ denote the threshold level of $E$ where the group's bids are equal $\bar{R}_{j}(\hat{E})=\bar{R}_{k}(\hat{E})$. The relative slopes of the bid-price curves at the threshold $\hat{E}$ determine whether the poor or the rich live in the part of the city (or region or country) where the endowment with the environmental good is high (cf. Brueckner et al. 1999: 96-97): If $\frac{\partial \bar{R}_{j}}{\partial E}(\hat{E})$ is greater (smaller) $\frac{\partial \bar{R}_{k}}{\partial E}(\hat{E})$ than the rich (poor) will live where environmental quality is higher. The differences between the slopes of the bid-functions is given as:

$$
\begin{aligned}
\Delta & :=\frac{\partial \bar{R}_{j}}{\partial E}(\hat{E})-\frac{\partial \bar{R}_{k}}{\partial E}(\hat{E}) \\
E q .(4.54) & \frac{1-\alpha}{\alpha}\left[\left(\frac{Y_{j}-\bar{R}_{j}(\hat{E})}{\hat{E}}\right)^{1 / \theta}-\left(\frac{Y_{k}-\bar{R}_{k}(\hat{E})}{\hat{E}}\right)^{1 / \theta}\right],
\end{aligned}
$$

which is strictly greater than zero, as by definition $Y_{j}>Y_{k}$ and $\bar{R}_{j}(\hat{E})=\bar{R}_{k}(\hat{E})$.

Thus, if the marginal WTP matters for sorting on the housing market and as the marginal WTP increases with income, rich (poor) households will sort into locations with high (low) environmental quality. As a result, sorting will increase the correlation between income and endowment with the environmental local public good $\rho$. 


\subsubsection{Proof of Proposition 4.4}

Differentiating $\mu_{\mathrm{WTP}}$ given in Eq. (4.9) with respect to $\rho$ yields

$$
\begin{aligned}
& \frac{\partial \mu_{\mathrm{WTP}}\left(\mu_{Y}, \mathrm{CV}_{Y}, \mu_{E}, \mathrm{CV}_{E}, \rho\right)}{\partial \rho} \\
& =\frac{\theta-1}{\theta^{2}} \frac{1-\alpha}{\alpha} P^{\frac{\theta-1}{\theta}} \mu_{Y}^{\frac{1}{\theta}}\left(1+\mathrm{CV}_{Y}^{2}\right)^{\frac{1-\theta}{2 \theta^{2}}} \mu_{E}^{\frac{\theta-1}{\theta}}\left(1+\mathrm{CV}_{E}^{2}\right)^{\frac{1-\theta}{2 \theta^{2}}} \sqrt{\ln \left(1+\mathrm{CV}_{E}^{2}\right) \ln \left(1+\mathrm{CV}_{Y}^{2}\right)} \Psi \\
& \text { where } \quad \Psi\left(\mathrm{CV}_{Y}, \mathrm{CV}_{E}, \rho\right):=\exp \left[\rho \frac{\theta-1}{\theta^{2}} \sqrt{\ln \left(1+\mathrm{CV}_{E}^{2}\right) \ln \left(1+\mathrm{CV}_{Y}^{2}\right)}\right],
\end{aligned}
$$

the sign of which is determined by $\frac{\theta-1}{\theta^{2}}$, as $\alpha \in(0,1)$ and $P, \mu_{E}, \mu_{Y}, \mathrm{CV}_{Y}, \mathrm{CV}_{E}>0$. It holds that $\frac{\theta-1}{\theta^{2}} \gtreqless 0 \Longleftrightarrow \theta \gtreqless 1$.

\subsubsection{Proof of Proposition 4.5}

The transfer function, defined as the quotient of mean WTPs at the policy site, p, and at the study site, $\mathrm{s}$, is given as:

$$
\begin{aligned}
& \mathcal{T}\left(P^{\mathrm{p}}, \mu_{Y}^{\mathrm{p}}, \mathrm{CV}_{Y}^{\mathrm{p}}, \mu_{E}^{\mathrm{p}}, \mathrm{CV}_{E}^{\mathrm{p}}, \rho^{\mathrm{p}} ; P^{\mathrm{s}}, \mu_{Y}^{\mathrm{s}}, \mathrm{CV}_{Y}^{\mathrm{s}}, \mu_{E}^{\mathrm{s}}, \mathrm{CV}_{E}^{\mathrm{s}}, \rho^{\mathrm{s}}\right) \\
& :=\frac{\mu_{\mathrm{WTP}}^{\mathrm{p}}\left(\mu_{Y}, \mathrm{CV}_{Y}, \mu_{E}, \mathrm{CV}_{E}, \rho\right)}{\mu_{\mathrm{WTP}}^{\mathrm{s}}\left(\mu_{Y}, \mathrm{CV}_{Y}, \mu_{E}, \mathrm{CV}_{E}, \rho\right)} \\
& E \stackrel{E q .4 .9}{=} \frac{P^{\frac{\theta-1}{\theta}}\left(\mu_{Y}^{\mathrm{p}}\right)^{\frac{1}{\theta}}\left(1+\mathrm{CV}_{Y}^{\mathrm{p} 2}\right)^{\frac{1-\theta}{2 \theta^{2}}}\left(\mu_{E}^{\mathrm{p}}\right)^{\frac{\theta-1}{\theta}}\left(1+\mathrm{CV}_{E}^{\mathrm{p}}\right)^{\frac{1-\theta}{2 \theta^{2}}} \exp \left[\rho^{\mathrm{p}} \frac{\theta-1}{\theta^{2}} \sqrt{\ln \left(1+\mathrm{CV}_{Y}^{\mathrm{p}}{ }^{2}\right) \ln \left(1+\mathrm{CV}_{E}^{\mathrm{p} 2}\right)}\right]}{P^{\mathrm{s}} \frac{\theta-1}{\theta}\left(\mu_{Y}^{\mathrm{s}}\right)^{\frac{1}{\theta}}\left(1+\mathrm{CV}_{Y}^{\mathrm{s} 2}\right)^{\frac{1-\theta}{2 \theta^{2}}}\left(\mu_{E}^{\mathrm{s}}\right)^{\frac{\theta-1}{\theta}}\left(1+\mathrm{CV}_{E}^{\mathrm{s} 2}\right)^{\frac{1-\theta}{2 \theta^{2}}} \exp \left[\rho^{\mathrm{s}} \frac{\theta-1}{\theta^{2}} \sqrt{\ln \left(1+\mathrm{CV}_{Y}^{\mathrm{s}}{ }^{2}\right) \ln \left(1+\mathrm{CV}_{E}^{\mathrm{s}}{ }^{2}\right)}\right]} \\
& =\left(\frac{P^{\mathrm{p}}}{P^{\mathrm{s}}}\right)^{\frac{\theta-1}{\theta}} \cdot\left(\frac{\mu_{Y}^{\mathrm{p}}}{\mu_{Y}^{\mathrm{s}}}\right)^{\frac{1}{\theta}} \cdot\left(\frac{\mu_{E}^{\mathrm{p}}}{\mu_{E}^{\mathrm{s}}}\right)^{\frac{\theta-1}{\theta}} \cdot\left(\frac{1+\mathrm{CV}_{Y}^{\mathrm{p} 2}}{1+\mathrm{CV}_{Y}^{\mathrm{s} 2}}\right)^{\frac{1-\theta}{2 \theta^{2}}} \cdot\left(\frac{1+\mathrm{CV}_{E}^{\mathrm{p} 2}}{1+\mathrm{CV}_{E}^{\mathrm{s} 2}}\right)^{\frac{1-\theta}{2 \theta^{2}}} \\
& \cdot \exp \left[\frac{\theta-1}{\theta^{2}}\left(\rho^{\mathrm{p}} \sqrt{\ln \left(1+\mathrm{CV}_{Y}^{\mathrm{p}}{ }^{2}\right) \ln \left(1+\mathrm{CV}_{E}^{\mathrm{p}}{ }^{2}\right)}-\rho^{\mathrm{s}} \sqrt{\ln \left(1+\mathrm{CV}_{Y}^{\mathrm{s}}{ }^{2}\right) \ln \left(1+\mathrm{CV}_{E}^{\mathrm{s}}{ }^{2}\right)}\right)\right] \text {. }
\end{aligned}
$$


If the environmental good and income are distributed independently at both study and policy site, $\rho^{\mathrm{p}}=\rho^{\mathrm{s}}=0$, the transfer function simplifies to:

$$
\begin{aligned}
& \mathcal{T}^{\text {ind }}\left(P^{\mathrm{p}}, \mu_{Y}^{\mathrm{p}}, \mathrm{CV}_{Y}^{\mathrm{p}}, \mu_{E}^{\mathrm{p}}, \mathrm{CV}_{E}^{\mathrm{p}} ; P^{\mathrm{s}}, \mu_{Y}^{\mathrm{s}}, \mathrm{CV}_{Y}^{\mathrm{s}}, \mu_{E}^{\mathrm{s}}, \mathrm{CV}_{E}^{\mathrm{s}}\right) \\
& :=\frac{\mu_{\mathrm{WTP}}^{\text {ind, }}\left(\mu_{Y}, \mathrm{CV}_{Y}, \mu_{E}, \mathrm{CV}_{E}\right)}{\mu_{\mathrm{WTP}}^{\text {ind, }}\left(\mu_{Y}, \mathrm{CV}_{Y}, \mu_{E}, \mathrm{CV}_{E}\right)} \\
& E q . \stackrel{(4.10)}{=} \frac{\frac{1-\alpha}{\alpha}\left(P^{\mathrm{p}}\right)^{\frac{\theta-1}{\theta}}\left(\mu_{Y}^{\mathrm{p}}\right)^{\frac{1}{\theta}}\left(1+\mathrm{CV}_{Y}^{\mathrm{p} 2}\right)^{\frac{1-\theta}{2 \theta^{2}}}\left(\mu_{E}^{\mathrm{p}}\right)^{\frac{\theta-1}{\theta}}\left(1+\mathrm{CV}_{E}^{\mathrm{p} 2}\right)^{\frac{1-\theta}{2 \theta^{2}}}}{\frac{1-\alpha}{\alpha}\left(P^{\mathrm{s}}\right)^{\frac{\theta-1}{\theta}}\left(\mu_{Y}^{\mathrm{s}}\right)^{\frac{1}{\theta}}\left(1+\mathrm{CV}_{Y}^{\mathrm{s} 2}\right)^{\frac{1-\theta}{2 \theta^{2}}}\left(\mu_{E}^{\mathrm{s}}\right)^{\frac{\theta-1}{\theta}}\left(1+\mathrm{CV}_{E}^{\mathrm{s} 2}\right)^{\frac{1-\theta}{2 \theta^{2}}}} \\
& =\left(\frac{P^{\mathrm{p}}}{P^{\mathrm{s}}}\right)^{\frac{\theta-1}{\theta}} \cdot\left(\frac{\mu_{Y}^{\mathrm{p}}}{\mu_{Y}^{\mathrm{s}}}\right)^{\frac{1}{\theta}} \cdot\left(\frac{1+\mathrm{CV}_{Y}^{\mathrm{p} 2}}{1+\mathrm{CV}_{Y}^{\mathrm{s} 2}}\right)^{\frac{1-\theta}{2 \theta^{2}}} \cdot\left(\frac{\mu_{E}^{\mathrm{p}}}{\mu_{E}^{\mathrm{s}}}\right)^{\frac{\theta-1}{\theta}} \cdot\left(\frac{1+\mathrm{CV}_{E}^{\mathrm{p} 2}}{1+\mathrm{CV}_{E}^{\mathrm{s} 2}}\right)^{\frac{1-\theta}{2 \theta^{2}}},
\end{aligned}
$$

which can also be obtained by assuming $\rho^{\mathrm{p}}=\rho^{\mathrm{s}}=0$ in Eq. 4.57 . 


\subsubsection{Histograms on $Y$ and $E$ in empirical application (Section 4.4)}

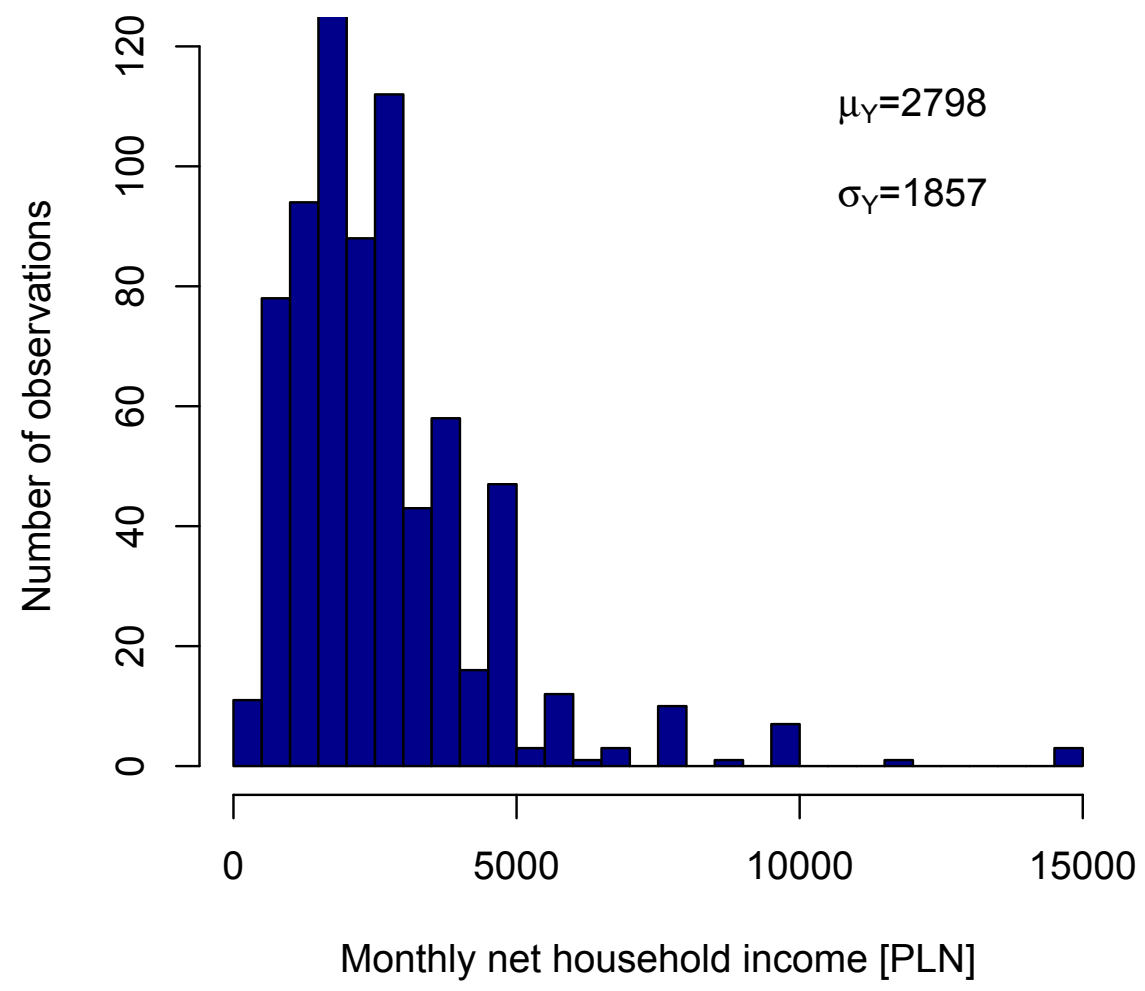

Figure 4.3: Histogram of the distribution of net monthly household income [in 2011-PLN] in Poland as assessed in the forest preservation survey by Czajkowski et al. (2014a). 


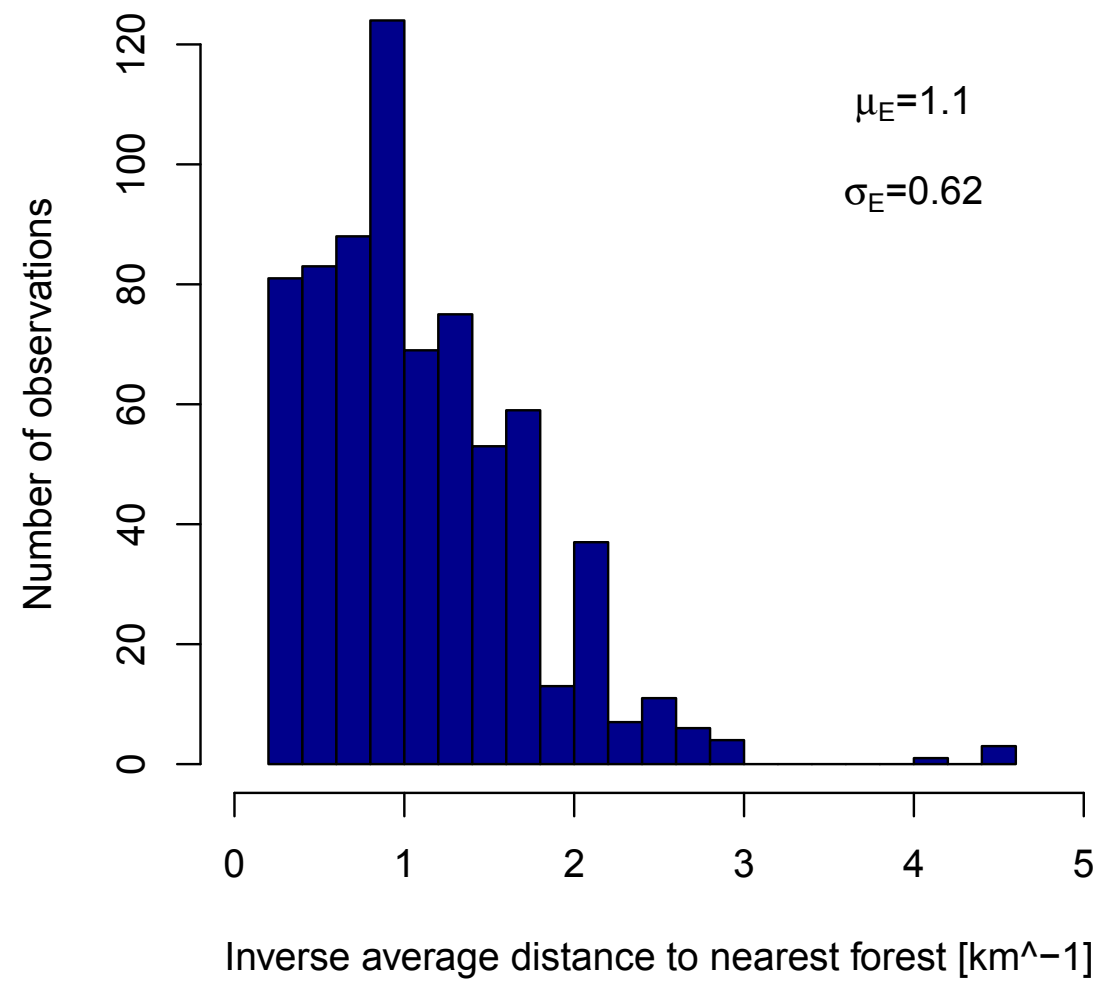

Figure 4.4: Histogram of the distribution of the inverse average Euclidean distance to the nearest forest ('forest proximity') from any point of the $10 \times 10 \mathrm{~km}^{2}$ grid square where respondent lives as used by Czajkowski et al. (2017). 


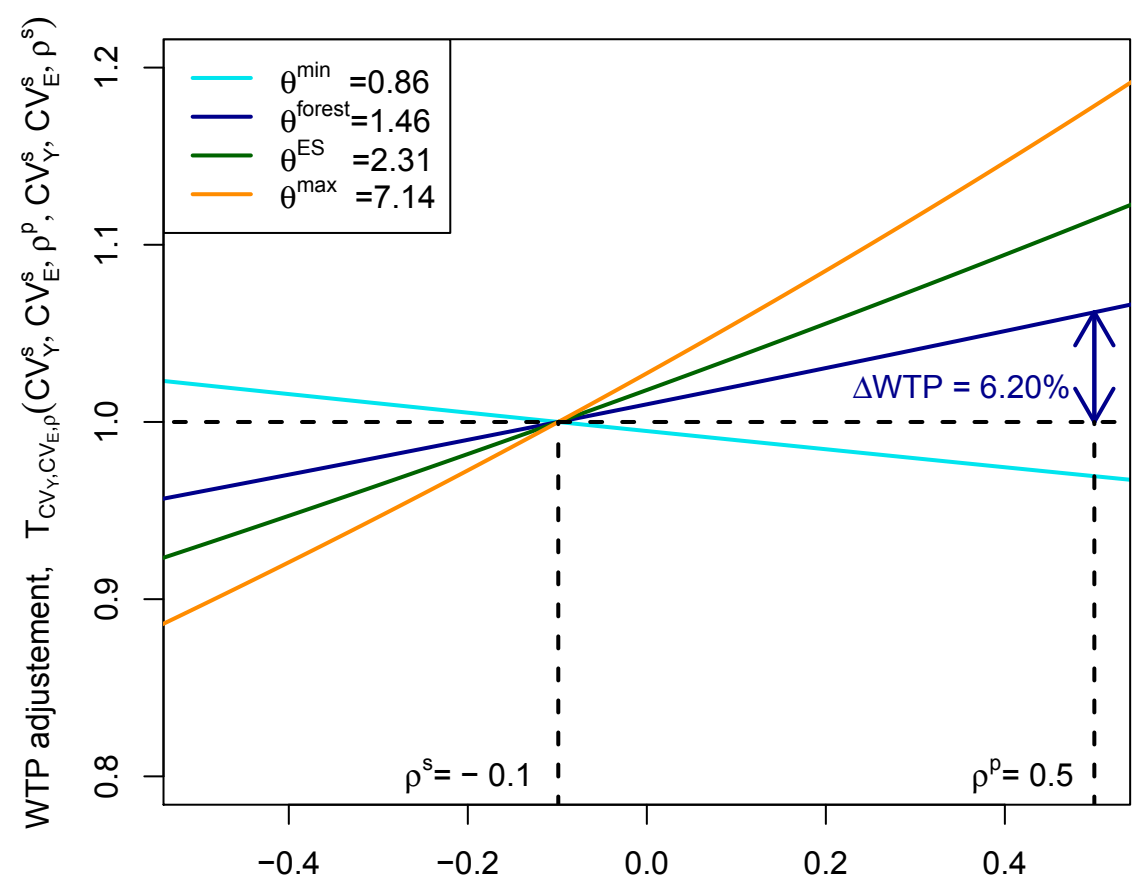

Correlation at policy site, $\rho^{p}$

FigURE 4.5: Relationship between the transfer factor to adjust societal WTP for differences in the distribution of income and the local environmental public good, $\mathcal{T}_{\mathrm{CV}_{Y}, \mathrm{CV}_{E}, \rho}$, and different correlations of income and endowment with the environmental good at the policy site $\rho^{\mathrm{p}}$. In the hypothetical transfer depicted, the societal WTP for forest protection in Poland is adjusted to a situation where income inequality and environmental inequality is identical at study and policy site, but the correlation between $Y$ and $E$ differs. 


\title{
5 Inter- and Intragenerational Distribution and the Valuation of Natural Capital
}

\begin{abstract}
This paper studies how the intra- and intergenerational distribution of income affects the economic valuation of non-use environmental public goods derived from natural capital. We show that society's mean WTP for natural capital decreases (increases) with intratemporal income inequality if environmental goods derived from natural capital and consumption goods are substitutes (complements). We further find that the intergenerational distribution affects the intertemporal valuation of environmental goods derived from natural capital. Specifically, societal WTP elicited as a constant payment fraction increases with income growth for complements or the Cobb-Douglas case. However, it is possible that WTP declines with income growth in the case of substitutes. Finally, we obtain closed-form adjustment factors for benefit transfer to control for differences in dynamic aspects between study and policy sites, such as income growth, the growth rate of the environmental goods, and interest rates. These results are in particular relevant for natural capital accounting and management.
\end{abstract}

Keywords: Environmental valuation, inequality, natural capital, ecosystem services, environmental goods, WTP, benefit transfer

Reference: Meya, J.N., Drupp, M.A., Baumgärtner, S., Quaas, M.F. (2018). Inter- and Intragenerational Distribution and the Valuation of Natural Capital. Conference paper at SURED 2018 and WCERE 2018. 


\subsection{Introduction}

Sustainability economics is concerned with a just distribution of economic resources within and across generations, and efficiency in the attainment of these normative goals (Baumgärtner and Quaas 2010). The economic valuation of environmental goods and natural capital has gained considerable interest both in science (Kinzig et al. 2011, Fenichel and Abbott 2014, Pascual et al. 2017) and policy advice (UN et al. 2014, Inclusive Wealth Project 2016). Likewise, recent years have shown an increased interest in the effects of economic inequality that has been rising in many countries around the world (Piketty 2014, Alvaredo et al. 2017, 2018).

Economic efficiency requires that non-market environmental goods that have public good characteristics are supplied to the extent that the aggregate willingness to pay (WTP), that is the sum of household WTPs, equals the marginal (opportunity) cost of supplying environmental goods (Lindahl 1928, Samuelson 1954). This requires determining society's aggregate WTP, which in general depends on the distribution of income within and across generations. Yet, the literature on non-market valuation does not explicitly consider the distribution of income with very few exceptions (Kriström and Riera 1996, Drupp et al. 2018b, Hsiang et al. 2018).

This paper studies how the intra- and intertemporal distribution of income affect the economic valuation of environmental goods derived from natural capital that exhibit characteristics of public goods. We thereby extend upon the static setting in the recent literature on how the intra-temporal distribution of income affects the valuation of environmental public goods (Ebert 2003, Baumgärtner et al. 2017a). To examine the effect of economic inequality on societal valuation of environmental goods, this literature employs a stylized modelling framework that abstracts from how natural capital translates into ecosystem services or environmental goods. Specifically, Baumgärtner et al. (2017a) study a setting in which a household has constant-elasticity-of-substitution (CES) preferences concerning a market-traded consumption good and a non-market traded environmental public good. For households that have identical preferences but differ in exogenously given income approximated with a log-normal distribution, they find that societal WTP for environmental public goods decreases (increases) with income inequality if and only if the environmental public good and manufactured goods are substitutes (complements).

Since a core aspect of sustainability concerns distributional issues over time and how scarce natural resources and services can be managed to the benefit of future generations, 
an analysis of how the intertemporal distribution of income affects mean WTP is lacking for a comprehensive valuation from a sustainability perspective (Drupp et al. 2018b). This is important not least because currently living societies value environmental goods that derive from a stock of natural capital and evolve over time-for example, the existence of evolving species or climate stability, just to name a few. Extending the analysis of how the intra- and intertemporal distribution affects society's intertemporal WTP for environmental goods relates to recent work in the literature on social discounting. For example, Fleurbaey and Zuber (2015), Gollier (2015) and Emmerling (2018) study inter- and intra-generational distribution in the context of discounting of a single consumption good. As far as the intertemporal distribution of market-traded and non-market-traded goods is concerned, our paper is related to the literature on dual discounting and relative price changes (e.g. Weikard and Zhu 2005, Gollier 2010, Traeger 2011, Baumgärtner et al. 2015, Drupp 2018). The change in relative prices of non-market environmental goods is determined by their degree of substitutability vis-a-vis market goods as well as the difference in their good specific growth rates. These determinants will also feature prominently in our analysis.

This paper generalizes the static model of Baumgärtner et al. (2017a) to an intertemporal setting. To capture the intertemporal dimension in a way that allows for closed-form solutions, we make a number of simplifying assumptions. First, we consider a proportional mapping of natural capital to the environmental goods and services it provides. We thereby focus in particular on non-use environmental services, such as the existence value of biodiversity. ${ }^{64}$ It is in particular for these non-use services that WTP information is crucial for public policy; Second, we consider specific exogenously given time paths of consumption or income and the provision of environmental goods. We thus abstract from savings and optimal management and follow the approach that Arrow et al. (2003) have taken for computing shadow prices in non-optimal economies to determine the household and aggregate WTP for environmental goods for a given 'resource allocation mechanism'. In particular, we study the case of exponential growth or decline as a special case. However, we also show how this setting of exponential growth of income can be derived from an endogenous growth model; Third, we assume that income and consumption are log-normally distributed in each period. This implies that given positive growth, absolute income inequality will increase over time while relative income inequality will remain constant; Fourth, in extending the instantaneous CES utility function to a dynamic setting, we assume-following recent models

\footnotetext{
${ }^{64}$ For an analysis of wealth reallocation due to climate change of provisioning services derived from natural capital, such as the fishery, featuring more complex dynamics see, e.g., Fenichel et al. (2016).
} 
on intertemporal decision-making (e.g. Golosov et al. 2014, Quaas and Bröcker 2016) - that there is a specific relationship between the elasticity of substitution and the intertemporal elasticity of substitution with respect to the aggregate consumption bundle. This allows deriving a closed-form intertemporal utility function under reasonable conditions on the relationship between growth rates, discount rates and the elasticity of substitution. Given this set-up, we consider compensating surplus as WTP for two different payment schemes-a single payment in the initial period as well as a constant payment fraction paid at each point in time - and for two different marginal changes to the provision of the environmental public good - a change in the initial level as well as in the growth rate of the environmental good.

We confirm key results from the static analysis in this more general dynamic setting and derive novel results regarding the effect of intergenerational distribution on non-use natural capital valuation. We show that societal WTP as single or constant payment fractions elicited for levels or growth rates of the environmental goods increases with initial mean income, and decreases (increases) with initial relative income inequality if and only if the environmental good and the manufactured are substitutes (complements). In addition, we show that societal WTP elicited as a constant payment fraction increases with income growth for complements or the Cobb-Douglas case, but that it is possible that societal WTP declines in the case of substitutes. Furthermore, we show that societal WTP elicited for the level of the environmental goods increases (decreases) with the growth rate of environmental goods if and only if environmental goods are a substitute (complement) to manufactured goods. Finally, we derive transfer factors for value or benefit transfer to account for differences in the distribution of income, income growth, growth of the environmental good, interest rates and other characteristic between a study and a policy site. We illustrate and quantify the effect sizes of our results for a global case study on the intertemporal valuation of non-use environmental public goods.

Our results are relevant for the economic appraisal of environmental policy. The incomes of those who benefit from natural capital are highly unequal. An adequate valuation of natural capital requires taking the effects of inequality into account. Failing to do so may lead to inadequate values for natural capital accounting, among others. Our model provides a guideline on how practical studies can proceed to adequately take the distribution of income into account in natural capital valuation. Furthermore, our results add to the emerging literature on structural benefit transfer (e.g. Smith et al. 2002, 2006, Baumgärtner et al. 
2017a, Meya et al. 2017, Meya 2018). We derive novel closed-form adjustment factors for benefit transfer to control for differences in dynamic aspects between study and policy sites, such as income growth, the growth rate of the environmental goods, and interest rates. This is in particular needed when valuing ecosystem services derived from natural capital.

The remainder of the paper is structured as follows. We present the model in Section 5.2, our valuation concepts in Section 5.3 and results in Section 5.4. We apply our findings empirically for global biodiversity conservation in Section 5.5. We discuss limitations in Section 5.6 and conclude in Section 5.7. The Appendix contains all proofs.

\subsection{Model}

We generalize the static model of Baumgärtner et al. (2017a) to an intertemporal setting. A society $s$ consists of a population of $n$ households, labelled $i=1, \ldots, n$, who derive utility from the consumption of two composite goods-a market-traded private consumption good $C^{i}$ and an environmental good $E$. The environmental good derives from a stock of natural capital $N$ in the form of instantaneous dividends or services, with $E=\psi \times N$, where $\psi$ maps the stock of natural capital into environmental goods provided at each point in time. While this mapping is very simple, it is a useful approximation among others for non-use environmental services derived from natural capital, such as the existence value of biodiversity. Furthermore, all households consume the environmental good at the same fixed level, i.e. $E^{i}=E$. We therefore consider a pure public good. Individuals have identical preferences over the human-made consumption good and the environmental public good, represented by the instantaneous constant-elasticity-of-substitution (CES) utility function

$$
u^{i}\left(C^{i}, E\right)=\left(\alpha C^{i \frac{\theta-1}{\theta}}+(1-\alpha) E^{\frac{\theta-1}{\theta}}\right)^{\frac{\theta}{\theta-1}}
$$

where $\theta$, with $0<\theta<+\infty$, is the CES between the two goods, and $0<\alpha<1$ is a share parameter determining the initial weight of the consumption good in utility. The CES function contains the special cases where the consumption good and the environmental good are substitutes $(\theta>1)$, Cobb-Douglas $(\theta=1)$ and perfect complements $(\theta<1)$.

To focus the model on the task of valuation only, both goods evolve over time $t$ and their time path is exogenously given, with $t=0, \ldots, T$. This implies that we are not concerned here about the optimal management of natural capital and abstract from the possibility of optimal intertemporal consumption smoothing through savings. The time path of the environmental 
public good is denoted $\left\{E_{t}\right\}$, and consumption at time $t$ as $E_{t}$. Furthermore, all exogenously provided income $Y_{t}$ is consumed at each point in time and has to be paid for at given market prices $P_{t}$, i.e. $C_{t}=Y_{t} / P_{t}$. In the remainder of the paper, we set $P_{t}=1$. We therefore refer to the distribution of consumption $C$ and income $Y$ interchangeably and substitute income $Y$ for the level of consumption of market goods $C$ in the remainder of this paper. Where appropriate, we refer to their distribution over time as 'intertemporal distribution', and to the distribution over households at a given point in time as 'intratemporal distribution'.

As exemplary time paths for income and the environmental public good we study

$$
\begin{aligned}
Y_{t}^{i} & =Y_{0}^{i}\left(1+g_{Y}\right)^{t}, \quad \text { and } \\
E_{t} & =E_{0}\left(1+g_{E}\right)^{t},
\end{aligned}
$$

where $Y_{0}^{i}$ is household $i$ 's levels of income and thus private consumption in period $t=0$, $E_{0}$ is the level of the environmental good in period $t=0, g_{E} \in(-1,0)$ is the growth rate of the environmental good, and $g_{Y}>0$ is the growth rate of income. We demonstrate in Appendix 5.8.1 how the time-constant income growth rate, $g_{Y}$, can be derived as the balanced growth path of a general equilibrium endogenous growth model. As in Baumgärtner et al. (2017a) we moreover assume that consumption in $t=0$ is log-normally distributed over households $i$

$$
Y_{0}^{i} \propto \operatorname{LN}\left(\mu_{Y_{0}}, \sigma_{Y_{0}}\right)
$$

where $\mu_{Y_{0}}$ is the mean level of income in society at $t=0$, and $\sigma_{Y_{0}}$ is the standard deviation of income in $t=0 .^{65}$

To measure inequality, we focus on the coefficient of variation $C V_{Y_{0}}:=\frac{\sigma_{Y_{0}}}{\mu_{Y_{0}}}$ as a measure of relative income inequality in society. It captures the width of the distribution of income relative to mean income. While there are a number of different notions of income inequality in use, concepts of relative income inequality —often in the form of income shares-feature prominently in academic and policy circles, such as in the recent World Inequality Report (Alvaredo et al. 2018). Note that our model set-up makes the assumption that the growth rate of consumption is the same for all households, i.e. $g_{Y}^{i}=g_{Y}$. This implies that absolute income inequality — as measured by the standard deviation, for example —will increase

\footnotetext{
${ }^{65}$ There is empirical evidence that the income distribution can be approximated with a log-normal distribution (Pinkovskiy and Sala-i-Martin 2009). This assumption is also used to study the related issue of inequality and discounting (Emmerling et al. 2017).
} 
over time, while relative income inequality, as measured by the $C V$, will stay constant. In particular, income at each later point in time, $Y_{t}$, is also log-normally distributed.

In our benchmark model, households have the same pure rates of time preference and household $i$ 's intertemporal utility is given as aggregated discounted instantaneous utility

$$
U^{i}\left(\left\{Y_{t}^{i}\right\},\left\{E_{t}\right\}\right)=\sum_{t=0}^{\infty} \rho^{t} \frac{1}{1-\eta} u^{i}\left(Y_{t}^{i}, E_{t}\right)^{1-\eta},
$$

where $0<\rho<1$ is the pure time discount factor and $\eta$, with $0 \leq \eta<\infty$, is the inverse of the constant intertemporal elasticity of substitution with respect to the within-period aggregate consumption bundle, composed of $E$ and $Y$. Thus, we consider a setting in which each (dynastic) household only cares about the consumption of her own dynasty, has a preference against inequality in comprehensive consumption over time but only a limited altruism towards future selves or decendants (see, for example, Asheim and Nesje (2016) for a discussion of intergenerational altruism).

As the measure of economic value for household $i$, we consider the time path $\left\{x_{t}^{i}\right\}$ of compensating surplus for a change in the time path of environmental goods from $\left\{E_{t}\right\}$ to $\left\{E_{t}^{\prime}\right\}{ }^{66}$ We often just consider the willingness-to-pay (WTP) for a marginal improvement of $\left\{E_{t}\right\}$ instead of compensating surplus, as WTP features more prominently in the (applied) environmental valuation literature. In general, we measure the value of environmental good in units of the market consumption good or income, respectively:

$$
U^{i}\left(\left\{Y_{t}^{i}-x_{t}^{i}\right\},\left\{E_{t}^{\prime}\right\}\right)=U^{i}\left(\left\{Y_{t}^{i}\right\},\left\{E_{t}\right\}\right)
$$

The time path $x_{t}^{i}$ is not a scalar, and for general preferences it is not uniquely defined. We therefore add more structure to our model to be able to capture compensating surplus or WTP as a scalar. One may consider the problem of the household as a hypothetical choice problem (Neary and Roberts 1980, Hanemann 1991, Flores and Carson 1997), where each household maximizes her intertemporal utility subject to each period's intra-temporal budget constraint, $C_{t}=Y_{t}$, as well as the exogenously fixed levels of the environmental good $E_{t}$ and the market consumption good $C_{t}$ :

$$
\max _{\left\{C_{t}^{i}\right\},\left\{E_{t}\right\}} U^{i}\left(\left\{C_{t}^{i}\right\},\left\{E_{t}\right\}\right) \quad \text { s.t. } \quad C_{t}^{i}=Y_{t}^{i} \text { and } E_{t} \text { fixed } .
$$

\footnotetext{
${ }^{66}$ In a similar fashion, one can consider the equivalent surplus.
} 
A households income-equivalent valuation of the environmental good is the valuation per unit (Lindahl price) times the level of the environmental good. We study WTP for two different types of environmental policies, so that $\left\{E_{t}\right\}$ and $\left\{E_{t}^{\prime}\right\}$ differ in either $E_{0}$ or $g_{E}$. When the environmental good differs only in $E_{0}$, but not in $g_{E}$, we refer to this as a (marginal) change in the level of the environmental good. This might be, for instance, an increase in forest cover or a small re-establishment of a species. When the environmental good differs in $g_{E}$ but not in $E_{0}$, we refer to this as a (marginal) change in the growth rate of the environmental good. This might be, for instance, protecting breeding or enhancing nursing ground for pollinators or birds, or slowing down coral bleaching.

To facilitate closed-form analytic solutions, we assume that the inverse of the constant intertemporal elasticity of substitution with respect to the aggregate consumption bundle, $\eta$, equals the inverse of the elasticity of substitution between market consumption goods and environmental goods, $1 / \theta$. This assumption follows theoretic work by Quaas and Bröcker (2016), who build a solvable analytic climate-economy model that extends upon the previous Cobb-Douglas cases in the literature (cf. Golosov et al. 2014). While there is no apparent reason why the assumption $\eta=1 / \theta$ should be fulfilled, there is considerable scope for it to hold if we consider suggested values for $\eta$, which range from 0 to 5 (e.g. Drupp et al. 2018, Groom and Maddison 2018), and those for 1/ $\theta$, which range from 0.14 to 2 (e.g. Sterner and Persson 2008, Drupp 2018).

For these assumptions we obtain the intertemporal utility function for the initial levels and growth rates of the market consumption good, or income respectively, and of the environmental public good (Appendix 5.8.2):

$$
U^{i}\left(\left\{Y_{t}^{i}\right\},\left\{E_{t}\right\}\right)=\frac{\theta}{\theta-1}\left(\frac{\alpha Y_{0}^{i^{\frac{\theta-1}{\theta}}}}{1-\rho\left(1+g_{Y}\right)^{\frac{\theta-1}{\theta}}}+\frac{(1-\alpha) E_{0}^{\frac{\theta-1}{\theta}}}{1-\rho\left(1+g_{E}\right)^{\frac{\theta-1}{\theta}}}\right)
$$

This intertemporal utility function (Eq. 5.6) only exist for time paths for which the following conditions for the growth rates hold

$$
\begin{aligned}
& \rho\left(1+g_{Y}\right)^{\frac{\theta-1}{\theta}}<1, \\
& \rho\left(1+g_{E}\right)^{\frac{\theta-1}{\theta}}<1 .
\end{aligned}
$$


TABLE 5.1: Overview of the four studied WTP cases.

\begin{tabular}{|c|c|c|}
\hline \multirow[t]{2}{*}{ Payment scheme } & \multicolumn{2}{|c|}{ Change in natural capital } \\
\hline & $\begin{array}{l}\text { marginal change } d E \text { in } \\
\text { initial level } E_{0}\end{array}$ & $\begin{array}{l}\text { marginal change } d g_{E} \text { in } \\
\text { growth rate } g_{E}\end{array}$ \\
\hline single payment $(\mathrm{SP})$ in $\mathrm{t}=0$ & (1) $\mathrm{WTP}_{\mathrm{SP}, d E}$ & (2) $\mathrm{WTP}_{\mathrm{SP}, d g_{E}}$ \\
\hline constant payment fraction $(\mathrm{CPF})$ & (3) $\mathrm{WTP}_{\mathrm{CPF}, d E}$ & (4) $\mathrm{WTP}_{\mathrm{CPF}, d g_{E}}$ \\
\hline
\end{tabular}

\subsection{Valuation concepts}

We now analyze the individual and societal valuation for the environmental good for different payment schemes and objects of valuation. Our analysis focusses on WTP and societal mean WTP, denoted as $\overline{\mathrm{WTP}}$. We consider WTP for two payment types, $p t$ : (i) a single payment in the initial time period $(p t=S P)$, and (ii) a constant payment fraction of income over time $(p t=C P F) .{ }^{67}$ Moreover, for each payment scheme we study WTPs for two different environmental policies, ep, that induces changes in the stream of the environmental good: marginal changes in the (a) the level $(e p=d E)$ and (b) the growth rate $\left(e p=d g_{E}\right)$ of the environmental good. This yields four cases, with two payment schemes and two changes of the environmental good (see Table 5.1).

\subsubsection{Individual Valuation}

We consider two specific cases for compensating surplus or WTP that are prevalent in the literature: First, a payment to be made in a single period only (hereafter: single payment or SP), usually in the initial period $t=0$. Second, a payment to be made as a relative fraction of consumption in each period (hereafter: constant payment fraction or $\mathrm{CPF}$ ). Both payment types are used in the applied valuation literature, while CPF accounts for the bulk of payment vehicles used, often via taxes. ${ }^{68}$

\footnotetext{
${ }^{67}$ While the dynastic household has a preference for consumption smoothing over time, our model abstracts from savings. Therefore, as noted before, a household's amount of the consumption good is equal to disposable household income $(C=Y)$.

${ }^{68}$ For instance, of the 98 reported WTP values elicited with stated preference methods ('contingent valuation', 'choice modeling') in the TEEB-Database (Van der Ploeg and de Groot 2010) 91 WTP-estimates have been elicited as annual payments (categories 'annual' and 'annual (range)') while 3 WTP-estimates have been elicited as single payments (category 'one time payment/ WTP').
} 
First, if we assume standard time preferences and that the single payment is made in period $t=0$ only, the compensating surplus $\left\{x_{t}^{i}\right\}=\left(x_{\mathrm{SP}}^{i}, 0, \ldots\right)$ is defined as

$$
\frac{1}{1-\eta} u^{i}\left(Y_{0}^{i}-x_{\mathrm{SP}}^{i}, E_{0}^{\prime}\right)^{1-\eta}+\frac{1}{1-\eta} \sum_{t=1}^{\infty} \rho^{t} u^{i}\left(Y_{t}^{i}, E_{t}^{\prime}\right)^{1-\eta}=\frac{1}{1-\eta} \sum_{t=0}^{\infty} \rho^{t} u^{i}\left(Y_{t}^{i}, E_{t}\right)^{1-\eta}
$$

Second, another straightforward way to measure the compensating surplus as a scalar is to consider a constant payment fraction $x^{i}$ by which income is reduced in each period, $\left\{x_{t}^{i}\right\}=\left\{\left(1-x_{\mathrm{CPF}}^{i}\right) Y_{t}^{i}\right\}$, given by

$$
\frac{1}{1-\eta} \sum_{t=0}^{\infty} \rho^{t} u^{i}\left(\left(1-x_{\mathrm{CPF}}^{i}\right) Y_{t}^{i}, E_{t}^{\prime}\right)^{1-\eta}=\frac{1}{1-\eta} \sum_{t=0}^{\infty} \rho^{t} u^{i}\left(Y_{t}^{i}, E_{t}\right)^{1-\eta}
$$

As a first step, we compute compensating surplus for both a single payment as well as for a constant payment fraction. To avoid notational overload, we suppress the index for individual households $i$ for now.

Regarding a single payment in the initial period (Eq. 5.8) the compensating surplus, $x$, is determined by (see Appendix 5.8.3)

$$
x_{\mathrm{SP}}=Y_{0}\left(1-\left(1+Y_{0}^{\frac{1-\theta}{\theta}}\left(\frac{\frac{1-\alpha}{\alpha} E_{0}^{\frac{\theta-1}{\theta}}}{1-\rho\left(1+g_{E}\right)^{\frac{\theta-1}{\theta}}}-\frac{\frac{1-\alpha}{\alpha} E_{0}^{\prime \frac{\theta-1}{\theta}}}{1-\rho\left(1+g_{E}^{\prime}\right)^{\frac{\theta-1}{\theta}}}\right)\right)^{\frac{\theta}{\theta-1}}\right) .
$$

The compensating surplus does not depend on the income growth rate in this case. This is due to the assumption $\eta=1 / \theta$, which links the preference for intertemporal inequality aversion in consumption or income and the substitutability between goods at each point in time. ${ }^{69}$

Regarding a constant payment fraction (Eq. 5.9) the compensating surplus, $x$, is determined by (see Appendix 5.8.4)

$$
x_{\mathrm{CPF}}=1-\left(1-\frac{1-\rho\left(1+g_{Y}\right)^{\frac{\theta-1}{\theta}}}{\alpha Y_{0}^{\frac{\theta-1}{\theta}}}\left(\frac{(1-\alpha) E_{0}^{\prime \frac{\theta-1}{\theta}}}{1-\rho\left(1+g_{E}^{\prime}\right)^{\frac{\theta-1}{\theta}}}-\frac{(1-\alpha) E_{0}^{\frac{\theta-1}{\theta}}}{1-\rho\left(1+g_{E}\right)^{\frac{\theta-1}{\theta}}}\right)\right)^{\frac{\theta}{\theta-1}}
$$

\footnotetext{
${ }^{69}$ This may also be different in a setting with endogenous saving decisions and where WTP is large enough in relation to aggregate income. In a case with endogenous savings, one would need to assume that the environmental good only has a marginal contribution to overall welfare (cf. Gollier (2017)).
} 
We are now equipped to derive the four possible cases of WTP (cf. Table 5.1), distinguished by the mode of payment (single vs. constant fraction) and whether the marginal change in the environmental goods affects only the initial level or the growth rate.

First, WTP measured as a single payment at $t=0$ for a marginal change in the initial level of the environmental good, $E_{0}^{\prime}=E_{0}+d E$, that is leaving the environmental growth rate unchanged $g_{E}=g_{E}^{\prime}$ is given by (see Appendix 5.8.5)

$$
\mathrm{WTP}_{\mathrm{SP}, \mathrm{dE}}=\frac{1-\alpha}{\alpha} \frac{Y_{0}^{1 / \theta} E_{0}^{-1 / \theta}}{1-\rho\left(1+g_{E}\right)^{\frac{\theta-1}{\theta}}} d E
$$

This is a direct generalization of Ebert (2003) and Baumgärtner et al. (2017a).

Second, the WTP for a marginal change in the growth rate of the environmental good, $g_{E}^{\prime}=g_{E}+d g_{E}$, that is leaving the level of the environmental good unchanged, $E_{0}=E_{0}^{\prime}$, measured as a single payment is (see Appendix 5.8.6)

$$
\mathrm{WTP}_{\mathrm{SP}, d g_{E}}=\frac{1-\alpha}{\alpha} E_{0}^{\frac{\theta-1}{\theta}} Y_{0}^{1 / \theta} \frac{\rho\left(1+g_{E}\right)^{-1 / \theta}}{\left(1-\rho\left(1+g_{E}\right)^{\frac{\theta-1}{\theta}}\right)^{2}} d g_{E} .
$$

Third, the WTP measured as a constant payment fraction for a marginal change in the initial level of the environmental good, $E_{0}^{\prime}=E_{0}+d E$ and $g_{E}=g_{E}^{\prime}$, is given by (see Appendix 5.8.7)

$$
\mathrm{WTP}_{\mathrm{CPF}, d E}=\frac{1-\alpha}{\alpha} \frac{1-\rho\left(1+g_{Y}\right)^{\frac{\theta-1}{\theta}}}{1-\rho\left(1+g_{E}\right)^{\frac{\theta-1}{\theta}}} Y_{0}^{\frac{1-\theta}{\theta}} E_{0}^{-1 / \theta} d E
$$

Fourth, assuming $g_{E}^{\prime}=g_{E}+d g_{E}$ and $E_{0}=E_{0}^{\prime}$, we derive the WTP as a constant payment fraction for a marginal change of the growth rate of the environmental good (see Appendix 5.8.8)

$$
\mathrm{WTP}_{\mathrm{CPF}, d g_{E}}=\frac{1-\alpha}{\alpha} \frac{\rho\left(1+g_{E}\right)^{-1 / \theta}\left(1-\rho\left(1+g_{Y}\right)^{\frac{\theta-1}{\theta}}\right)}{\left(1-\rho\left(1+g_{E}\right)^{\frac{\theta-1}{\theta}}\right)^{2}} Y_{0}^{\frac{1-\theta}{\theta}} E_{0}^{\frac{\theta-1}{\theta}} d g_{E}
$$




\subsubsection{Societal Valuation}

We now turn to aggregating individual WTPs within a society. Mean WTP in terms of a single payment at $\mathrm{t}=0$ is given by

$$
\overline{\mathrm{WTP}}_{\mathrm{SP}, \mathrm{ep}}\left(\mu_{Y_{0}}, \sigma_{Y_{0}}, g_{E}\right)=\int_{0}^{\infty} f_{\ln }\left(Y_{0} ; \mu_{Y_{0}}, \sigma_{Y_{0}}\right) \mathrm{WTP}_{\mathrm{SP}, \mathrm{ep}}\left(Y_{0}, g_{E}\right) d Y_{0}
$$

for both objects of valuation, $e p$, and where $f_{\ln }\left(Y_{0} ; \mu_{Y_{0}}, \sigma_{Y_{0}}\right)$ is the density function of the log-normal distribution of initial income $Y_{0}$ with mean $\mu_{Y_{0}}$ and standard deviation $\sigma_{Y_{0}}$. Compensating surplus for a single payment in $t=0$ and a marginal change in the initial level of the environmental good is given by Eq. (5.12). Mean WTP in terms of a single payment at $t=0$ (Eq. 5.16) for a marginal change in the initial level of the environmental good can be reformulated as (see Appendix 5.8.9)

$$
\begin{aligned}
\overline{\mathrm{WTP}}_{\mathrm{SP}, \mathrm{dE}}\left(\mu_{Y_{0}}, \mathrm{CV}_{Y_{0}}, g_{E}\right) & =\kappa \mu_{Y_{0}}^{1 / \theta}\left(1+\mathrm{CV}_{Y_{0}}^{2}\right)^{\frac{1-\theta}{2 \theta^{2}}} \\
\text { with } \quad \kappa & =\frac{1-\alpha}{\alpha} \frac{E_{0}^{-1 / \theta} d E}{1-\rho\left(1+g_{E}\right)^{\frac{\theta-1}{\theta}}},
\end{aligned}
$$

where $C V_{Y_{0}}$ is the initial relative income inequality.

The corresponding mean WTP as single payment for a marginal change in the growth rate is given by (see Appendix 5.8.10)

$$
\begin{aligned}
\overline{\mathrm{WTP}}_{\mathrm{SP}, d g_{E}}\left(\mu_{Y_{0}}, \mathrm{CV}_{Y_{0}}, g_{E}\right) & =\kappa^{\prime} \mu_{Y_{0}}^{1 / \theta}\left(1+\mathrm{CV}_{Y_{0}}^{2}\right)^{\frac{1-\theta}{2 \theta^{2}}} \\
\text { with } \quad \kappa^{\prime} & =\frac{1-\alpha}{\alpha} E_{0} \frac{\theta-1}{\theta} \frac{\rho\left(1+g_{E}\right)^{-1 / \theta}}{\left(1-\rho\left(1+g_{E}\right)^{\frac{\theta-1}{\theta}}\right)^{2}} d g_{E} .
\end{aligned}
$$

Thus, the value of a marginal increase in the level of the environmental good elicited as a single payment in $t=0$ (Eqs. 5.17 and 5.18) does not depend on income growth, $g_{Y}$. The mean WTP function obtained (Eq. 5.17) is structurally identical to the one in the static setting obtained by Baumgärtner et al. (2017a), with differences in $\kappa$.

Next, we turn to societal WTP elicited as a constant payment fraction. Note that we now have to multiply the $\mathrm{CPF}$ with the respective level of income in each period, with $Y_{t}=\left(1+g_{Y}\right)^{t} Y_{0}$, to obtain the overall mean WTP. While individual pure time preferences affect the individual CPF, the planner applies her own discount rate when aggregating yearly mean WTPs over time. The planner's discount rate may be given by the (risk-free) market 
discount rate, where $0<\delta_{\tau}<1$ is the interest factor at time $\tau .^{70}$

The (undiscounted) mean WTP at time $t$ for an environmental policy $(e p)$ that induces a marginal change in $E_{0}$ or $g_{E}$ is

$\overline{\mathrm{WTP}}_{\mathrm{CPF}, e p ; t}\left(\mu_{Y_{0}}, \sigma_{Y_{0}}, g_{Y}, g_{E}\right)=\int_{0}^{\infty} f_{1 \mathrm{n}}\left(Y_{0} ; \mu_{Y_{0}}, \sigma_{Y_{0}}\right) \mathrm{WTP}_{\mathrm{CPF}, e p}\left(Y_{0}, g_{Y}, g_{E}\right)\left(1+g_{Y}\right)^{t} Y_{0} d Y_{0}$

with the associated present value - discounted at market interest rates - given by

$$
\overline{\mathrm{WTP}}_{\mathrm{CPF}, e p}\left(\mu_{Y_{0}}, \mathrm{CV}_{Y_{0}}, g_{Y}, g_{E}\right)=\sum_{t=0}^{\infty}\left(\prod_{\tau=0}^{t} \delta_{\tau}\right) \overline{\mathrm{WTP}}_{\mathrm{CPF}, e p ; t}\left(\mu_{Y_{0}}, \mathrm{CV}_{Y_{0}}, g_{Y}, g_{E}\right)
$$

For a marginal change in the initial level of the environmental good the (undiscounted) mean WTP at time $t$ measured as a constant payment fraction can be rewritten as a function of the moments of the income distribution and the growth rates (see Appendix 5.8.11)

$$
\begin{aligned}
& \overline{\mathrm{WTP}}_{\mathrm{CPF}, d E ; t}\left(\mu_{Y_{0}}, \mathrm{CV}_{Y_{0}}, g_{Y}, g_{E}\right)=\kappa^{\prime \prime} \mu_{Y_{0}}^{1 / \theta}\left(1+\mathrm{CV}_{Y_{0}}^{2}\right)^{\frac{1-\theta}{2 \theta^{2}}} \\
& \text { with } \quad \kappa^{\prime \prime}=\frac{1-\alpha}{\alpha} \frac{\left(1-\rho\left(1+g_{Y}\right)^{\frac{\theta-1}{\theta}}\right)\left(1+g_{Y}\right)^{t}}{1-\rho\left(1+g_{E}\right)^{\frac{\theta-1}{\theta}}} E_{0}^{-1 / \theta} d E,
\end{aligned}
$$

with the following associated present value mean WTP (see Appendix 5.8.11)

$$
\begin{aligned}
& \overline{\mathrm{WTP}}_{\mathrm{CPF}, d E}\left(\mu_{Y_{0}}, \mathrm{CV}_{Y_{0}}, g_{Y}, g_{E}\right)=\kappa^{\prime \prime \prime} \mu_{Y_{0}}^{1 / \theta}\left(1+\mathrm{CV}_{Y_{0}}^{2}\right)^{\frac{1-\theta}{2 \theta^{2}}} \\
& \text { with } \quad \kappa^{\prime \prime \prime}=\frac{1-\alpha}{\alpha} \frac{1-\rho\left(1+g_{Y}\right)^{\frac{\theta-1}{\theta}}}{1-\rho\left(1+g_{E}\right)^{\frac{\theta-1}{\theta}}} E_{0}^{-1 / \theta} d E\left[\sum_{t=0}^{\infty}\left(\prod_{\tau=0}^{t} \delta_{\tau}\right)\left(1+g_{Y}\right)^{t}\right] .
\end{aligned}
$$

Analogously, for a marginal change in the growth rate of the environmental good the mean WTP at time $t$ as constant payment fraction is (see Appendix 5.8.12)

$$
\begin{aligned}
& \overline{\mathrm{WTP}}_{\mathrm{CPF}, d g_{E} ; t}\left(\mu_{Y_{0}}, \mathrm{CV}_{Y_{0}}, g_{Y}, g_{E}\right)=\kappa^{\prime \prime \prime \prime} \mu_{Y_{0}}^{1 / \theta}\left(1+\mathrm{CV}_{Y_{0}}^{2}\right)^{\frac{1-\theta}{2 \theta^{2}}} \\
& \text { with } \quad \kappa^{\prime \prime \prime \prime \prime}=\frac{1-\alpha}{\alpha} \frac{\rho\left(1+g_{E}\right)^{-1 / \theta}\left(1-\rho\left(1+g_{Y}\right)^{\frac{\theta-1}{\theta}}\right)}{\left(1-\rho\left(1+g_{E}\right)^{\frac{\theta-1}{\theta}}\right)^{2}} d g_{E}\left(1+g_{Y}\right)^{t} E_{0}^{\frac{\theta-1}{\theta}}
\end{aligned}
$$

\footnotetext{
${ }^{70}$ We show in Appendix 5.8.1 how the time-constant interest factor, $\delta_{t}=\delta$, can be derived from an one-sector endogenous growth model.
} 
with the corresponding present value (see Appendix 5.8.12)

$$
\begin{aligned}
& \overline{\mathrm{WTP}}_{\mathrm{CPF}, d g_{E}}\left(\mu_{Y_{0}}, \mathrm{CV}_{Y_{0}}, g_{Y}, g_{E}\right)=\kappa^{\prime \prime \prime \prime \prime \prime} \mu_{Y_{0}}^{1 / \theta}\left(1+C V_{Y_{0}}^{2}\right)^{\frac{1-\theta}{2 \theta^{2}}}, \\
& \text { with } \quad \kappa^{\prime \prime \prime \prime \prime \prime}=\frac{1-\alpha}{\alpha} \frac{\rho\left(1+g_{E}\right)^{-1 / \theta}\left(1-\rho\left(1+g_{Y}\right)^{\frac{\theta-1}{\theta}}\right)}{\left(1-\rho\left(1+g_{E}\right)^{\frac{\theta-1}{\theta}}\right)^{2}} d g_{E} E_{0}^{\frac{\theta-1}{\theta}}\left[\sum_{t=0}^{\infty}\left(\prod_{\tau=0}^{t} \delta_{\tau}\right)\left(1+g_{Y}\right)^{t}\right] .
\end{aligned}
$$

\subsection{Results}

In this section, we study how a change in (i) mean income, $\mu_{Y_{0}}$, or (ii) intratemporal income inequality, $\mathrm{CV}_{Y_{0}}$, affects societal intertemporal WTP for an increase in the level or the growth rate of the environmental public good (Eqs. 5.17, 5.18, 5.22, and 5.24). Moreover, we study how a change in (iii) the growth rate of income, $g_{Y}$, determining the intertemporal distribution of income, affects WTP measured as a constant payment (Eqs. 5.22 and 5.24) or (iv) the growth rate of the environmental good, $g_{E}$, affects societal WTP for the level of the environmental public good (Eqs. 5.17 and 5.22). Finally, we (v) derive adjustment factors for applications such as benefit transfer, environmental cost-benefit analysis or natural capital accounting. We address these five analyses in turn.

First, how does society's current mean income affect the intertemporal mean WTP?

\section{Proposition 5.1}

Mean WTP elicited as a single payment or a constant payment fraction for an increase in the level or the growth rate of the environmental public good - $\overline{\mathrm{WTP}}_{\mathrm{SP}, \mathrm{dE}}$ (Eq. 5.17), $\overline{\mathrm{WTP}}_{\mathrm{SP}, d g_{E}}$ (Eq. 5.18), $\overline{\mathrm{WTP}}_{\mathrm{CPF}, d E}$ (Eq. 5.22), and $\overline{\mathrm{WTP}}_{\mathrm{CPF}, d g_{E}}$ (Eq. 5.24)-increases with initial mean income, $\mu_{Y_{0}}$ :

$$
\frac{\partial \overline{\mathrm{WTP}}_{\mathrm{pt}, e p}\left(\mu_{Y_{0}}, \mathrm{CV}_{Y_{0}}, g_{Y}, g_{E}\right)}{\partial \mu_{Y_{0}}}>0
$$

Proof. See Appendix 5.8.13.

Proposition 5.1 states that the effect of societies (initial) mean income on societal WTP is unambiguous: Mean WTP for the level or the growth rate of the environmental good increase with mean income. Proposition 5.1 generalizes the result from the static setting obtained in Baumgärtner et al. (2017a) to a dynamic setting and to different objects of valuation. 
Second, how does the current relative income inequality affect intertemporal mean WTP?

\section{Proposition 5.2}

Mean WTP elicited as a single payment or a constant payment fraction for an increase in the level or the growth rate of the environmental public good- $\overline{\mathrm{WTP}}_{\mathrm{SP}, \mathrm{dE}}$ (Eq. 5.17), $\overline{\mathrm{WTP}}_{\mathrm{SP}, d g_{E}}$ (Eq. 5.18), $\overline{\mathrm{WTP}}_{\mathrm{CPF}, d E}$ (Eq. 5.22), $\overline{\mathrm{WTP}}_{\mathrm{CPF}, d g_{E}}$ (Eq. 5.24)-decreases (increases) with relative intratemporal income inequality, $\mathrm{CV}_{Y_{0}}$, if and only if the environmental public good and the private consumption good are substitutes (complements):

$$
\frac{\partial \overline{\mathrm{WTP}}_{\mathrm{pt}, e p}\left(\mu_{Y_{0}}, \mathrm{CV}_{Y_{0}}, g_{Y}, g_{E}\right)}{\partial \mathrm{CV}_{Y_{0}}} \lesseqgtr 0 \text { if and only if } \theta \gtreqless 1 .
$$

Proof. See Appendix 5.8.14.

Proposition 5.2 states that (initial) relative intratemporal income inequality affects mean WTP for natural capital and that the sign of the effect depends on whether the environmental public goods derived from natural capital are a substitute or a complement to markettraded manufactured consumption goods. If they are substitutes, mean WTP for natural capital decreases with income inequality. If they are complements, mean WTP for natural capital increases with income inequality. Proposition 5.2 generalizes the central finding in Baumgärtner et al. (2017a) to an intertemporal setting: The degree of substitutability is the key determinant of how intratemporal income inequality affects societal WTP. Having established these two findings for the intratemporal distribution, we now turn to scrutinizing the intertemporal distribution and specifically examine how growth rates affect WTP.

Third, how does the intertemporal distribution of income, given by the growth rate of income, affect intertemporal mean WTP?

\section{Proposition 5.3}

Mean WTP elicited as a constant payment fraction for an increase in the level or the growth rate of the environmental public good- $\overline{\mathrm{WTP}}_{\mathrm{CPF}, d E}$ (Eq. 5.22), $\overline{\mathrm{WTP}}_{\mathrm{CPF}, d g_{E}}$ (Eq. 5.24)—for a time-constant market interest factor, $\delta<\frac{1}{1+g_{Y}}$, increases with the growth rate of income, $g_{Y}$, if the environmental public good and the private consumption good are complements or Cobb-Douglas:

$$
\frac{\partial \overline{\mathrm{WTP}}_{\mathrm{CPF}, e p}\left(\mu_{Y_{0}}, \mathrm{CV}_{Y_{0}}, g_{Y}, g_{E}\right)}{\partial g_{Y}}>0 \quad \text { if } \quad \theta \leq 1
$$


Proof. See Appendix 5.8.15.

How the intertemporal distribution of income affects societal WTP depends on the level of the growth rate of income, the relative sizes of the pure time discount and market interest factors as well as the degree of substitutability. For the case of complements, we find that an increase in intertemporal inequality in terms of consumption goods increases societal WTP for the public environmental good. As a larger growth rate of consumption leads to more private goods consumption relative to the complementary environmental good, the household is willing to sacrifice more of the private good to have a more balanced consumption of private and environmental goods when the two goods are complements. We find the same effect for the special case of Cobb-Douglas substitutability. However, if the environmental good is a substitute to manufactured goods there are cases where an increase in intertemporal inequality in terms of consumption goods leads to a decrease of societal WTP, depending on the relative magnitudes of the elasticity of substitution, the growth rate of income as well as pure time and market interest rate factors. We illustrate the range of conditions for which WTP for an increase in the level of the environmental good and the case of substitutes may fall with the growth rate of income in Figures 5.7 and 5.8 in Appendix 5.8.16.

Societal WTP elicited as a single payment - $\overline{W T P}_{\mathrm{SP}, d E}$ (Eq. 5.17) and $\overline{W T P}_{\mathrm{SP}, d g_{E}}$ (Eq. 5.18) - does not depend on the growth rate of income, $g_{Y}$. Thus, WTP measured as a single payment is not affected by a change in the $g_{Y}$.

Fourth, how does the intertemporal distribution, given by the growth rate of the environmental good, affect intertemporal mean WTP for a change in the level of the environmental good?

\section{Proposition 5.4}

Mean WTP elicited as a single payment or a constant payment fraction for an increase in the level of the environmental public good- $\overline{\mathrm{WTP}}_{\mathrm{SP}, d E}$ (Eq. 5.17), $\overline{\mathrm{WTP}}_{\mathrm{CPF}, d E}$ (Eq. 5.22)increases (decreases) with the growth rate of the environmental good, $g_{E}$, if and only if the environmental public good and the private consumption good are substitutes (complements):

$$
\frac{\partial \overline{\mathrm{WTP}}_{\mathrm{pt}, d E}\left(\mu_{Y_{0}}, \mathrm{CV}_{Y_{0}}, g_{Y}, g_{E}\right)}{\partial g_{E}} \gtreqless 0 \text { if and only if } \theta \gtreqless 1 \text {. }
$$

Proof. See Appendix 5.8.17. 
The intertemporal distribution of natural capital, captured by the growth rate of environmental goods, has no effect on societal WTP for the special case of Cobb-Douglas substitutability. For substitutes, an increase in intertemporal inequality in terms of environmental goods increases societal WTP, while it is the reverse case when the environmental good is a complement to manufactured goods. Thus, if there is a complementarity relationship, a ceteris paribus higher growth rate and thus consumption of environmental goods tends to make consumption goods relatively scarcer and thus decreases WTP for an extra unit of the environmental goods.

Fifth, how should one adjust intertemporal mean WTP for differences in the distribution of income when conducting value transfer from a study to a policy site?

We now derive adjustment factors for site specific differences in the distribution of income, growth rates and interest rates. Benefit transfer has become a primary method of environmental valuation (Richardson et al. 2015) and a crucial input to inform government decision making (OECD 2018). As most of the benefit transfer literature and practice employs empirical meta-regression approaches, there have been calls to base benefit transfers approaches more firmly in economic theory (Bateman et al. 2011). Several government guidelines for economic appraisal already propose to use an explicit transfer factor to account for differences in mean income between the study context of the primary valuation ('study site') and the decision making contest ('policy site'), e.g. in Germany (UBA 2012) and the UK (Defra 2007). This was complemented and taken further by Baumgärtner et al. (2017a), who provided additional theory-driven adjustment factors, in particular for income inequality. Empirical evidence from a multi-country valuation study shows that employing this theory-driven adjustment factor for income inequality increases the accuracy of benefit transfers (Meya et al. 2017).

With the model setting presented here we can show that these transfer factors for differences in the income distribution also hold more generally in a dynamic setting and we derive additional transfer factors for growth rates and market interest rates. Thereby, we specify the benefit transfer function (e.g. Loomis 1992) to explicitly account for the time dimension. These generalizations and extensions make the benefit function approach more suitable for natural capital accounting. Mean WTP for a policy site, $\overline{\mathrm{WTP}}^{\text {policy }}$, can than be estimated as the product of a simple transfer function $\mathcal{T}$ with the mean WTP elicited at a study site, $\overline{\mathrm{WTP}}^{\text {study }}$. 


\section{Proposition 5.5}

Assume that households' preferences $(\theta, \alpha, \rho)$ are identical in the study and the policy sites. Mean WTP as a single payment for a marginal change in the level of the environmental public good in a policy site, $\overline{\mathrm{WTP}}_{\mathrm{SP}, d E}^{\text {policy }}$, is given by

$$
\begin{aligned}
\overline{\mathrm{WTP}}_{\mathrm{SP}, \mathrm{dE}}^{\text {policy }}= & \mathcal{T}_{\mathrm{SP}, \mathrm{dE}}\left(E_{0}^{\text {policy }}, d E^{\text {policy }}, g_{E}^{\text {policy }}, \mu_{Y_{0}}^{\text {policy }}, \mathrm{CV}_{Y_{0}}^{\text {policy }} ;\right. \\
& \left.E_{0}^{\text {study }}, d E^{\text {study }}, g_{E}^{\text {study }}, \mu_{Y_{0}}^{\text {study }}, \mathrm{CV}_{Y_{0}}^{\text {study }}\right) \cdot \overline{\mathrm{WTP}}_{\mathrm{SP}, d E}^{\text {study }},
\end{aligned}
$$

with the following transfer function

$$
\begin{aligned}
\mathcal{T}_{\mathrm{SP}, d E}(\ldots)= & \mathcal{T}_{E}^{(d E)}\left(E_{0}^{\text {policy }}, E_{0}^{\text {study }} ; \theta\right) \cdot \mathcal{T}_{d E}\left(d E^{\text {policy }}, d E^{\text {study }}\right) \cdot \mathcal{T}_{g_{E}}^{(d E)}\left(g_{E}^{\text {policy }}, g_{E}^{\text {study }} ; \theta, \rho\right) \\
& \cdot \mathcal{T}_{\mu}\left(\mu_{Y_{0}}^{\text {policy }}, \mu_{Y_{0}}^{\text {study }} ; \theta\right) \cdot \mathcal{T}_{\mathrm{CV}}\left(\mathrm{CV}_{Y_{0}}^{\text {policy }}, \mathrm{CV}_{Y_{0}}^{\text {study }} ; \theta\right) .
\end{aligned}
$$

The mean WTPs, $\overline{\mathrm{WTP}}_{\mathrm{pt}, \mathrm{ep}}$, for the other three cases of payment types and environmental good changes yield the following transfer functions for transferring $\overline{\mathrm{WTP}}_{\mathrm{pt}, \mathrm{ep}}^{\text {study }}$ into $\overline{\mathrm{WTP}}_{\mathrm{pt}, \mathrm{ep}}^{\mathrm{policy}}$ :

$$
\begin{aligned}
\mathcal{T}_{\mathrm{SP}, d g_{E}}(\ldots)= & \mathcal{T}_{E}^{\left(d g_{E}\right)}\left(E_{0}^{\text {policy }}, E_{0}^{\text {study }} ; \theta\right) \cdot \mathcal{T}_{d g_{E}}\left(d g_{E}^{\text {policy }}, d g_{E}^{\text {study }}\right) \cdot \mathcal{T}_{g_{E}}^{\left(d g_{E}\right)}\left(g_{E}^{\text {policy }}, g_{E}^{\text {study }} ; \theta, \rho\right) \\
& \cdot \mathcal{T}_{\mu}\left(\mu_{Y_{0}}^{\text {policy }}, \mu_{Y_{0}}^{\text {study }} ; \theta\right) \cdot \mathcal{T}_{\mathrm{CV}}\left(\mathrm{CV}_{Y_{0}}^{\text {policy }}, \mathrm{CV}_{Y_{0}}^{\text {study }} ; \theta\right), \\
\mathcal{T}_{\mathrm{CPF}, d E}(\ldots)= & \mathcal{T}_{E}^{(d E)}\left(E_{0}^{\text {policy }}, E_{0}^{\text {study }} ; \theta\right) \cdot \mathcal{T}_{d E}\left(d E^{\text {policy }}, d E^{\text {study }}\right) \cdot \mathcal{T}_{g_{E}}^{(d E)}\left(g_{E}^{\text {policy }}, g_{E}^{\text {study }} ; \theta, \rho\right) \\
& \cdot \mathcal{T}_{\mu}\left(\mu_{Y_{0}}^{\text {policy }}, \mu_{Y_{0}}^{\text {study }} ; \theta\right) \cdot \mathcal{T}_{\mathrm{CV}}\left(\mathrm{CV}_{Y_{0}}^{\text {policy }}, \mathrm{CV}_{Y_{0}}^{\text {study }} ; \theta\right) \\
& \cdot \mathcal{T}_{g_{Y}, \delta_{\tau}}\left(g_{Y}^{\text {policy }}, \delta_{\tau}^{\text {policy }}, g_{Y}^{\text {study }}, \delta_{\tau}^{\text {study }} ; \theta, \rho\right), \\
\mathcal{T}_{\mathrm{CPF}, d g_{E}}(\ldots)= & \mathcal{T}_{E}^{\left(d g_{E}\right)}\left(E_{0}^{\text {policy }}, E_{0}^{\text {study }} ; \theta\right) \cdot \mathcal{T}_{d g_{E}}\left(d g_{E}^{\text {policy }}, d g_{E}^{\text {study }}\right) \cdot \mathcal{T}_{g_{E}}^{\left(d g_{E}\right)}\left(g_{E}^{\text {policy }}, g_{E}^{\text {study }} ; \theta, \rho\right) \\
& \cdot \mathcal{T}_{\mu}\left(\mu_{Y_{0}}^{\text {policy }}, \mu_{Y_{0}}^{\text {study }} ; \theta\right) \cdot \mathcal{T}_{\mathrm{CV}}\left(\mathrm{CV}_{Y_{0}}^{\text {policy }}, \mathrm{CV}_{Y_{0}}^{\text {study }} ; \theta\right) \\
& \cdot \mathcal{T}_{g_{Y}, \delta_{\tau}}\left(g_{Y}^{\text {policy }}, \delta_{\tau}^{\text {policy }}, g_{Y}^{\text {study }}, \delta_{\tau}^{\text {study }} ; \theta, \rho\right),
\end{aligned}
$$


The corresponding disentangled transfer factors are given by:

$$
\begin{aligned}
& \mathcal{T}_{E}^{(d E)}\left(E_{0}^{\text {policy }}, E_{0}^{\text {study }} ; \theta\right)=\left(\frac{E_{0}^{\text {policy }}}{E_{0}^{\text {study }}}\right)^{-1 / \theta} \\
& \mathcal{T}_{E}^{\left(d g_{E}\right)}\left(E_{0}^{\text {policy }}, E_{0}^{\text {study }} ; \theta\right)=\left(\frac{E_{0}^{\text {policy }}}{E_{0}^{\text {study }}}\right)^{\frac{\theta-1}{\theta}}, \\
& \mathcal{T}_{d E}\left(d E^{\text {policy }}, d E^{\text {study }}\right)=\frac{d E^{\text {policy }}}{d E^{\text {study }}}, \\
& \mathcal{T}_{g_{E}}^{(d E)}\left(g_{E}^{\text {policy }}, g_{E}^{\text {study }} ; \theta, \rho\right)=\frac{1-\rho\left(1+g_{E}^{\text {study }}\right)^{\frac{\theta-1}{\theta}}}{1-\rho\left(1+g_{E}^{\text {policy }}\right)^{\frac{\theta-1}{\theta}}}, \\
& \mathcal{T}_{g_{E}}^{\left(d g_{E}\right)}\left(g_{E}^{\text {policy }}, g_{E}^{\text {study }} ; \theta, \rho\right)=\frac{\rho\left(1+g_{E}^{\text {policy }}\right)^{-1 / \theta}\left(1-\rho\left(1+g_{E}^{\text {study }}\right)^{\frac{\theta-1}{\theta}}\right)^{2}}{\rho\left(1+g_{E}^{\text {study }}\right)^{-1 / \theta}\left(1-\rho\left(1+g_{E}^{\text {policy }}\right)^{\frac{\theta-1}{\theta}}\right)^{2}}, \\
& \mathcal{T}_{d g_{E}}\left(d g_{E}^{\text {policy }}, d g_{E}^{\text {study }}\right)=\frac{d g_{E}^{\text {policy }}}{d g_{E}^{\text {study }}}, \\
& \mathcal{T}_{\mu}\left(\mu_{Y_{0}}^{\text {policy }}, \mu_{Y_{0}}^{\text {study }} ; \theta\right)=\left(\frac{\mu_{Y_{0}}^{\text {policy }}}{\mu_{Y_{0}}^{\text {study }}}\right)^{1 / \theta}, \\
& \mathcal{T}_{\mathrm{CV}}\left(\mathrm{CV}_{Y_{0}}^{\text {policy }}, \mathrm{CV}_{Y_{0}}^{\text {study }} ; \theta\right)=\left(\frac{1+\mathrm{CV}_{Y_{0}}^{\text {policy } 2}}{1+\mathrm{CV}_{Y_{0}}^{\text {study } 2}}\right)^{\frac{1-\theta}{2 \theta^{2}}}, \\
& \mathcal{T}_{g_{Y}, \delta_{\tau}}\left(g_{Y}^{\text {policy }}, \delta_{\tau}^{\text {policy }}, g_{Y}^{\text {study }}, \delta_{\tau}^{\text {study }} ; \theta, \rho\right) \\
& =\frac{1-\rho\left(1+g_{Y}^{\text {policy }}\right)^{\frac{\theta-1}{\theta}}}{1-\rho\left(1+g_{Y}^{\text {study }}\right)^{\frac{\theta-1}{\theta}}} \cdot \frac{\sum_{t=0}^{\infty}\left(\prod_{\tau=0}^{t} \delta_{\tau}^{\text {policy }}\right)\left(1+g_{Y}^{\text {policy }}\right)^{t}}{\sum_{t=0}^{\infty}\left(\prod_{\tau=0}^{t} \delta_{\tau}^{\text {study }}\right)\left(1+g_{Y}^{\text {study }}\right)^{t}} .
\end{aligned}
$$

Proof. See Appendix 5.8.18.

Proposition 5.5 develops a set of four specific transfer functions for different payment vehicles and objects of valuation. It shows that adjustment for differences in the income distribution can be done in the same way for all four cases by exploiting information on the intratemporal income distribution. Thereby, $\mathcal{T}_{\mathrm{CV}}\left(\mathrm{CV}_{Y_{0}}^{\text {policy }}, \mathrm{CV}_{Y_{0}}^{\text {study }} ; \theta\right)$ and $\mathcal{T}_{\mu}\left(\mu_{Y_{0}}^{\text {policy }}, \mu_{Y_{0}}^{\text {study }} ; \theta\right)$ make the results in Baumgärtner et al. (2017a) applicable for the specific intertemporal setting considered here. Moreover, Proposition 5.5 shows that one has to apply specific transfer factors for differences in the level of the environmental public good or the growth ratesdepending on the component of natural capital one seeks to value. Finally, for WTP elicited as a constant payment fraction - which is the more common approach in primary valuation 
- our dynamic model shows how to adjust mean WTP for differences in income growth and interest rates by using $\mathcal{T}_{g_{Y}, \delta_{\tau}}\left(g_{Y}^{\text {policy }}, \delta_{\tau}^{\text {policy }}, g_{Y}^{\text {study }}, \delta_{\tau}^{\text {study }} ; \theta, \rho\right)$.

Furthermore, our dynamic model provides guidance how to adjust mean WTP for differences in the growth rate of the environmental good by employing $\mathcal{T}_{g_{E}}^{(d E)}\left(g_{E}^{\text {policy }}, g_{E}^{\text {study }} ; \theta, \rho\right)$ or $\mathcal{T}_{g_{E}}^{\left(d g_{E}\right)}\left(g_{E}^{\text {policy }}, g_{E}^{\text {study }} ; \theta, \rho\right)$ depending on whether a change in the level or the growth rate of the environmental good is valued.

\subsection{Application: Global biodiversity conservation}

\subsubsection{Data}

This section introduces our case study on WTP for global ecosystem services and biodiversity. An overview of the inputs to our empirical application is given in Table 5.2.

For the initial global income distribution we draw on Pinkovskiy and Sala-i-Martin (2009), who estimate the global per-capita income distribution for 2006 finding a mean of $\mu_{Y_{0}}=9,550$ [2006-PPP-USD] and a standard deviation of $\sigma_{Y_{0}}=15,400$ [2006-PPPUSD] (Pinkovskiy, personal communication). This corresponds to a coefficient of variation of $\mathrm{CV}_{Y_{0}}=1.61$. For the forecasted growth rate of income, $g_{Y}$, we draw on an expert survey by Drupp et al. (2018). Almost two hundred experts on long-term societal decision-making were asked to provide their best guess of the global average, long-term ( $>100$ years) annual growth rate of real per-capita consumption. They find a mean consumption growth rate of $g_{Y}^{\text {mean }}=1.7$ percent. The lower bound (abbreviated as 'lb') is -2 percent and the upper bound ('ub') is $g_{E}^{\mathrm{ub}}=5$ percent. As only three experts stated negative growth rates and, in order to stay consistent with our model assumptions, we take $g_{Y}^{\text {lb }}=0.1$ percent as lower bound value in our application.

We normalize the initial level of the global environmental good to $E_{0}=1$. For the growth rate of the environmental good, $g_{E}$, we focus on non-use ecosystem services, as this provides the best fit for our simple mapping from natural capital to ecosystem service provisioning. We take the global mean annual growth rate of cultural ecosystem services estimated by Baumgärtner et al. (2015), based on the best available time-series data for different ecosystem services and countries. These include as ecosystem service measures landscape connectedness, forest area, living planet index, red-list-index and national biodiversity indicators. Baumgärtner et al. (2015) estimate the global average growth rate as $g_{E}^{\text {mean }}=-0.52$ with a lower bound of $g_{E}^{\mathrm{lb}}=-1.28$ percent and an upper bound of $g_{E}^{\mathrm{ub}}=-0.08$ percent. 
TABLE 5.2: Variable and parameter values used in the application

\begin{tabular}{|c|c|c|c|}
\hline Parameter & Value(s) & Description & Source \\
\hline $\mathrm{CV}_{Y_{0}}$ & 1.61 & $\begin{array}{l}\text { Coefficient of variation of global per- } \\
\text { capita income }\end{array}$ & $\begin{array}{l}\text { Pinkovskiy and Sala-i- } \\
\text { Martin (2009) }\end{array}$ \\
\hline$\mu_{Y_{0}}$ & 9,550 & $\begin{array}{l}\text { Mean global per-capita income in } \\
\text { 2006-PPP-USD }\end{array}$ & $\begin{array}{l}\text { Pinkovskiy and Sala-i- } \\
\text { Martin (2009) }\end{array}$ \\
\hline$g_{Y}$ & $\begin{array}{c}0.017 \\
{[0.001 ; 0.050]}\end{array}$ & $\begin{array}{l}\text { Annual real per-capita } \\
\text { (consumption) growth rate }\end{array}$ & Drupp et al. (2018) \\
\hline$E_{0}$ & 1 & Normalized to one & - \\
\hline$g_{E}$ & $\begin{array}{c}-0.0052 \\
{[-0.0128 ;-0.0008]}\end{array}$ & $\begin{array}{l}\text { Growth rate of global non-use } \\
\text { environmental goods }\end{array}$ & $\begin{array}{l}\text { Baumgärtner } \\
\text { et al. (2015) }\end{array}$ \\
\hline$\alpha$ & $0.85[0.7 ; 1]$ & $\begin{array}{l}\text { Utility share parameter for con- } \\
\text { sumption goods }\end{array}$ & Kopp et al. (2012) \\
\hline$\theta$ & $2.31[0.86 ; 7.14]$ & Elasticity of substitution & Drupp (2018) \\
\hline$\rho$ & $0.989[0.926 ; 1]$ & Pure time discounting factor & Drupp et al. (2018) \\
\hline$\delta$ & $0.977[0.94 ; 1]$ & Risk-free market interest factor & Drupp et al. (2018) \\
\hline
\end{tabular}

Note: Numbers in brackets correspond to lower and upper bound values. We approximate the upper bound discount and interest factors with 0.999 instead of 1.

We take preference parameters from the literature, in particular from meta-studies and international expert surveys. For the utility share parameter of consumptions goods relative to environmental goods, $\alpha$, we draw on the parameter range considered by Kopp et al. (2012), ranging from 0 to 0.3 , with a mean of 0.15 , for the environmental good. Thus, the parameter value for the consumption good ranges from 0.7 to 1 , with a mean of $0.85 .{ }^{71}$ For the elasticity of substitution between the environmental and the market-traded consumption good, we use data from a meta-study by Drupp (2018), who gathers indirect evidence from 18 environmental valuation studies. This yields a mean elasticity of substitution of $\theta^{\text {mean }}=2.31$, implying that environmental goods are considered as substitutes to market-traded goods on average, with a lower and upper bound of $\theta^{\mathrm{lb}}=0.86$ and $\theta^{\mathrm{ub}}=7.14$ respectively. ${ }^{72}$ For the pure time discount factor, the elasticity of marginal utility of consumption and the market interest factor, we again draw on survey data from Drupp et al. (2018), who elicited expert recommendations and long-run forecasts. They obtain a mean rate of pure time preference of 1.1 percent, with a lower and upper bound of 0 and 8 percent. This translates into an initial mean pure time discount factor of $\rho^{\text {mean }}=0.989$, with a lower and upper bound of

\footnotetext{
${ }^{71}$ This encompasses parameter values chosen by Sterner and Persson (2008), who assume $1-\alpha=0.1$, and Gollier (2010), who assumes $1-\alpha=0.29$.

${ }^{72}$ Note that values implying stronger complementarity have been used in the applied theory and modelling literature. For example, Sterner and Persson (2008) used a central value of 0.5.
} 
0.926 and $1 .{ }^{73}$ The mean forecasted real risk-free market interest rate is 2.38 percent, with a lower and upper bound of 0 and 6 percent. This translates into an initial mean market interest factor $\delta^{\text {mean }}=0.977$, with a lower and upper bound of $\delta^{\mathrm{lb}}=0.943$ and $\delta^{\mathrm{ub}}=1 .^{74}$

We quantify our results for a time horizon of hundred years, $T=100$, and a hypothetical one percent increase in the level of the environmental good. The corresponding change $d E=$ 0.01 that we seek to value is a pure scaling factors in the mean WTP-function (Eq. 5.14).

Before quantifying our main results, we need to make sure, that the conditions on the growth paths hold (Eqs. 5.7a and 5.7b). The set of growth rates that meet the existence condition for the closed-form intertemporal utility function for a given elasticity of substitution, $\theta$, and discount factor, $\rho$, is given as ${ }^{75}$

$$
\rho(1+g)^{\frac{\theta-1}{\theta}}<1 \Longleftrightarrow\left\{\begin{array}{l}
g<\rho^{\frac{-\theta}{\theta-1}}-1=: g^{\max } \text { for } \quad \theta>1 \\
g>\rho^{\frac{-\theta}{\theta-1}}-1=: g^{\text {min }} \text { for } \quad \theta<1
\end{array} .\right.
$$

Thus, the growth path condition for substitutes implies a supremum defined by $g^{\max }$, which is always positive and thus bites only for the income growth rate $g_{Y}$, but not for the growth rate of the environmental good which is by definition always negative, $g_{E}<0$. In contrast, the growth rate condition for complements implies a infimum for the growth rates $g^{\text {min }}$, below which the closed-form intertemporal utility function does not exist. As $g^{\text {min }}$ is always negative, this condition is generally fulfilled for the income growth rate, $g_{Y}>0$, but applies for the growth rate of the environmental good, $g_{E}<0$.

Figure 5.1 displays this frontier for the growth rates of income and the environmental good for a range of empirical elasticities of substitution, $\theta$, and pure time discount factors, $\rho$, depicted in Table 2. The supremum for the income growth rate in the mean case of substitutes, with $\theta^{\text {mean }}=2.31$, depends on $\rho=0.989[0.926 ; 0.999]$ and is given by $g_{\theta=2.31}^{\max }=0.0197[0.1452,0.0018]$. For the upper bound substitutability, with $\theta^{\mathrm{ub}}=7.14$ it is given by $g_{\theta=7.14}^{\max }=0.0129[0.0935 ; 0.0012]$. For the lower bound complementarity case, with $\theta^{\mathrm{lb}}=0.86$, the infimum for the growth rate of the environmental good is $g_{\theta=0.86}^{\min }=-0.0657[-0.3764 ;-0.0061]$. We observe that the closer the discount factor $\rho$ is to one, i.e. the closer the pure time prefernece rate is to zero, the smaller is the set of $g_{E}$ in case of complements and of $g_{Y}$ in case of substitutes that fulfils the growth path condition.

\footnotetext{
${ }^{73}$ We use a value of 0.999 instead of 1 to ensure that our intertemporal welfare function is bounded.

${ }^{74}$ We use a value of 0.999 instead of 1 to ensure that the present value WTP as a constant payment fraction is bounded.

${ }^{75}$ As the condition is identical for $g_{E}$ and $g_{Y}$ we suppress the subscript on the growth rate in the following formula and only write $g$.
} 

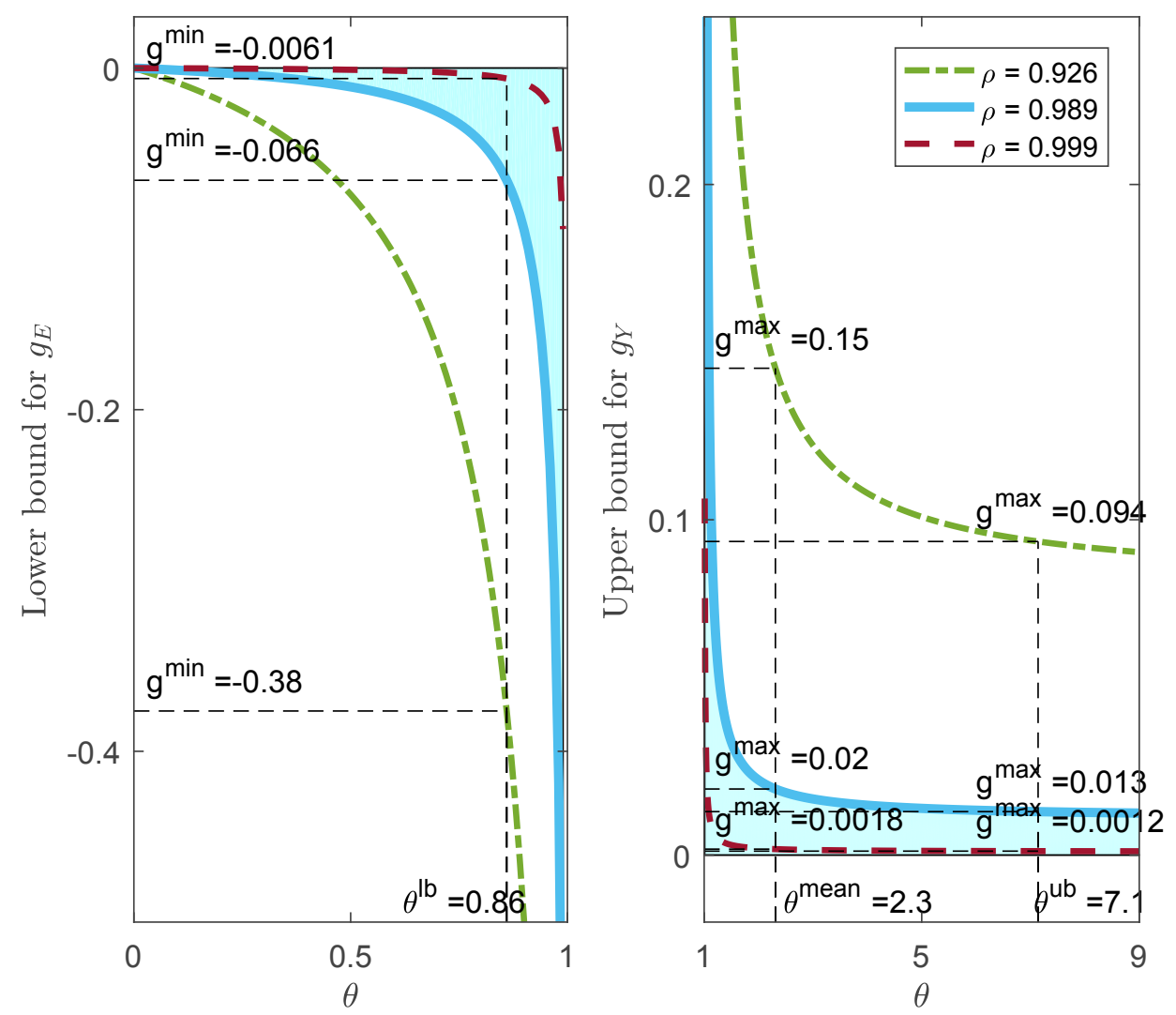

Figure 5.1: Minimal value for $g_{E}$ in case of complements, $\theta<1$, (left side) and maximal value for $g_{Y}$ in case of substitutes, $\theta>1$, (right side) to ensure the existence of a closed-form intertemporal utility function (Eq. 5.3) for different values of the discount factor, $\rho$, and the elasticity of substitution, $\theta$. The shaded area depicts the set of growth rates $g_{E}$ (left side) or $g_{Y}$ (right side) that meets the growth path condition (Eq. 5.7b or 5.7a) for the transfer factor for the mean pure time discount factor, $\rho=0.989$.

Moreover, the higher the degree of substitutability, $\theta \rightarrow \infty$, the smaller is the set of $g_{Y}$ that still meets the condition, and the stronger the complementarity, $\theta \rightarrow 0$, the larger is the set of $g_{E}$ that meets the condition.

When we compare these infima and suprema of the growth rates, $g_{E}$ and $g_{Y}$, for which a closed-form intertemporal utility function exists, with empirical data on growth rates, we see that these conditions appear generally uncritical for the loss rate of ecosystem services $g_{E}$. This is not the case for the income growth rate $g_{Y}$. For the mean estimate on the pure time discount factor, $\rho^{\text {mean }}=0.989$, and complements with the strongest complementarity, $\theta^{\mathrm{lb}}=0.86$, estimated from valuation studies reviewed in Drupp (2018), the growth rate infimum $g_{\theta=0.86}^{\min }=-0.0657$ is well below the lower bound rate of global loss of ecosystem services $g_{E}^{\mathrm{lb}}=-0.0128$ estimated by Baumgärtner et al. (2015). Also for the mean pure time discount factor and the best guess estimate for the degree of substitutability, $\theta^{\text {mean }}=2.31$, the income growth rate supremum is with $g_{\theta=2.31}^{\max }=0.0197$ higher than the mean of the long term growth rate expected by international experts of $g_{Y}^{\text {mean }}=0.017$. Thus, for the main 
specification of our model the growth path condition is fulfilled. However, the upper bound of the expected annual global income growth rate of $g_{Y}^{\mathrm{ub}}=0.05$ does not meet the growth path condition for the mean substitutability parameter $g_{\theta=2.31}^{\max }$. Moreover, for the upper bound of the substitutability parameter, $\theta=7.14$, the mean growth rate, $g_{Y}^{\text {mean }}$, is already higher than the supremum $g_{\theta=7.14}^{\max }$ and thus the growth path condition is not fulfilled.

\subsubsection{Quantification of main results}

We estimate how intra- and intertemporal distribution affects mean WTP for global ecosystem services derived from biodiversity. Moreover, we compute transfer factors that allow controlling for the intertemporal aspects of natural capital valuation. We focus on the case of mean WTP measured as a constant payment fraction for a marginal change in the environmental good, $\overline{W T P}_{\mathrm{CPF}, d E}$, throughout this subsection, as the bulk of empirical valuation studies falls within this category.

Figure 5.2 depicts how mean income (left side) and income inequality (right side) affect global mean WTP measured as a constant payment fraction for an initial increase in global ecosystem services. First of all, it is apparent that the degree of substitutability, $\theta$, is crucial in determining mean WTP, $\overline{\mathrm{WTP}}_{\mathrm{CPF}, d E}$. For initial global mean income and the mean substitutability estimate $\theta^{\text {mean }}=2.31$, we obtain a mean WTP of 0.63 [2006-PPP-USD]. However, if ecosystem services were a complement to manufactured consumption goods, $\theta^{\mathrm{lb}}=0.86$, mean WTP would be magnitudes higher and amount to $8.40 \times 10^{3}$ [2006-PPPUSD]. These estimates highlight that the societal value of global ecosystem services strongly depends on their substitutability: The harder it is to substitute ecosystem services with human-made goods, the higher is their societal value.

Mean WTP for global biodiversity conservation is increasing with mean income (see Proposition 5.1). For substitutes mean WTP is a strictly increasing concave function of mean income (Figure 5.2 top left subplot), while it is a convex function for complements (bottom left subplot). For a hypothetical doubling of global per-capita income, mean WTP would be $34.99 \%$ higher for the mean substitutability estimate. In this case WTP-estimates would need to be adjusted with a factor of $\mathcal{T}_{\mu}\left(2 \mu_{Y_{0}}^{\mathrm{GLO}}, \mu_{Y_{0}}^{\mathrm{GLO}} ; \theta^{\text {mean }}\right)=1.35$. For the lower bound range of complements, $\theta^{\mathrm{lb}}=0.86$, it would be even $123.89 \%$ higher as initially, corresponding to an adjustment factor of $\mathcal{T}_{\mu}\left(2 \mu_{Y_{0}}^{\mathrm{GLO}}, \mu_{Y_{0}}^{\mathrm{GLO}} ; \theta^{\mathrm{lb}}\right)=2.24$.

The subplots on the right of Figure 5.2 illustrate how mean WTP for global biodiversity conservation changes for a change in relative intratemporal income inequality as measured 

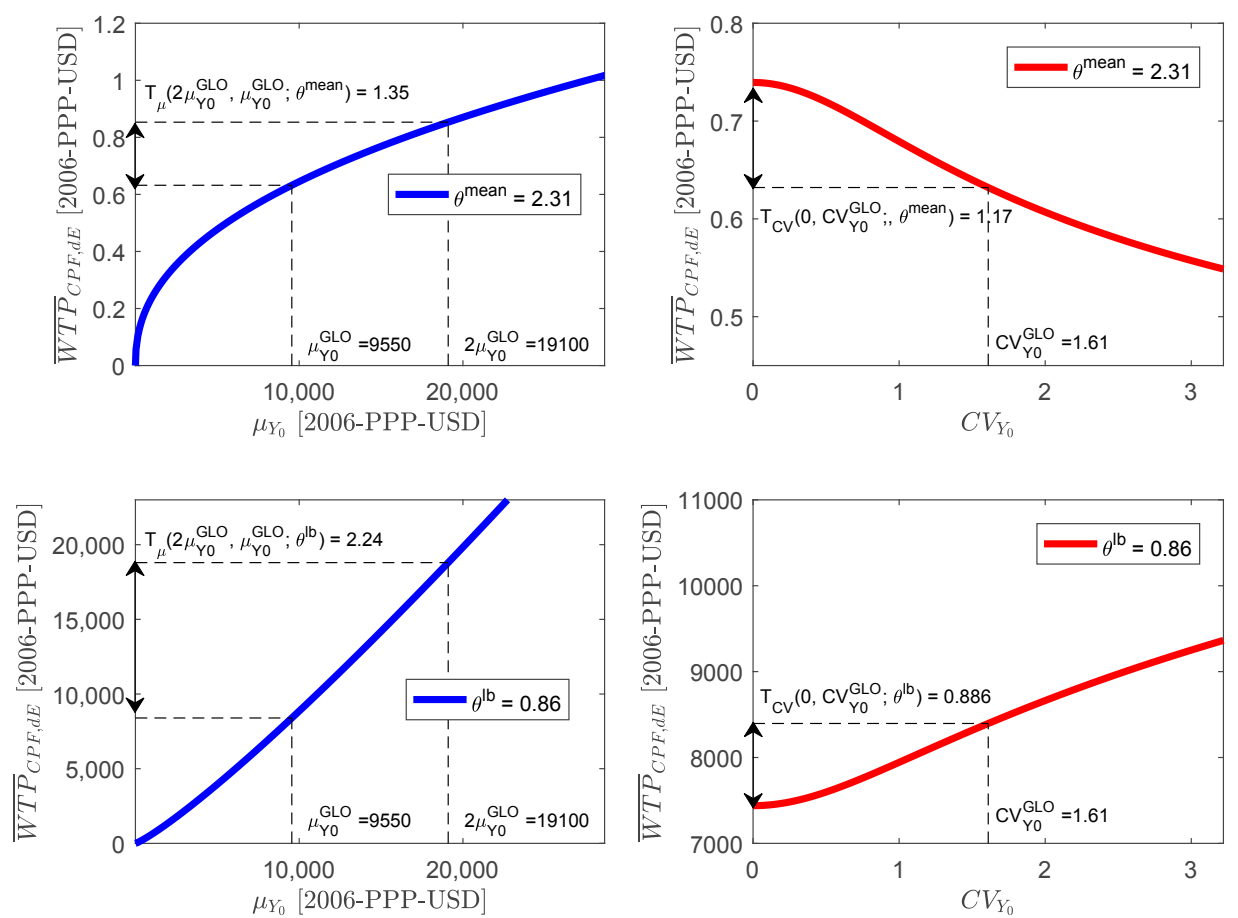

Figure 5.2: Effect of mean income, $\mu_{Y_{0}}$, (left side) or relative intratemporal income inequality, $\mathrm{CV}_{Y_{0}}$, (right side) on the present value mean WTP for a one percent increase in global non-use environmental goods measured as a constant payment fraction, $\overline{W T P}_{\mathrm{CPF}, d E}$, for different degrees of substitutability between the consumption and the environmental good, $\theta$.

by the coefficient of variation of per-capita income, $\mathrm{CV}_{Y_{0}}$. While mean WTP decreases with income inequality for the mean case of substitutes (top right subplot), it increases for complements (bottom right subplot) (see Proposition 5.2). A hypothetical reduction of the current level of global income inequality, $\mathrm{CV}_{Y_{0}}^{\mathrm{GLO}}=1.61$, to zero would increase mean WTP by $17.00 \%$ corresponding to a transfer factor of $\mathcal{T}_{\mathrm{CV}}\left(0, \mathrm{CV}_{Y_{0}}^{\mathrm{GLO}} ; \theta^{\text {mean }}\right)=1.17$ given the mean empirical estimate for the elasticity of substitution, $\theta^{\text {mean }}=2.31$. To the contrary, the lower bound elasticities of substitution, $\theta^{\mathrm{lb}}=0.86$, produces a decrease by $11.40 \%$ corresponding to a transfer factor of $\mathcal{T}_{\mathrm{CV}}\left(0, \mathrm{CV}_{Y_{0}}^{\mathrm{GLO}} ; \theta^{\mathrm{lb}}\right)=0.89$.

The left side of Figure 5.3 illustrates how mean WTP for global biodiversity conservation changes with the income growth rate. Mean WTP increases with income growth for complements and Cobb-Douglas substitutability (Proposition 5.3). Yet, for the case of substitutes, mean WTP can also decreases with income growth. ${ }^{76}$ We find that for a hypothetical reduction of the currently expected global income growth rate by half, mean WTP would increase by $192.83 \%$ for a substitutability of $\theta^{\text {mean }}=2.31$ and decrease by $36.54 \%$ for a substitutability of $\theta^{l b}=0.86$.

\footnotetext{
${ }^{76}$ In our central calibration and for an infinite time horizon, mean WTP starts to decrease with income growth at $g_{Y}^{\text {mean }}$ already for a medium-degree of substitutability $\theta^{*}=1.93$ (see Figure 5.8 and Eq. 5.96).
} 

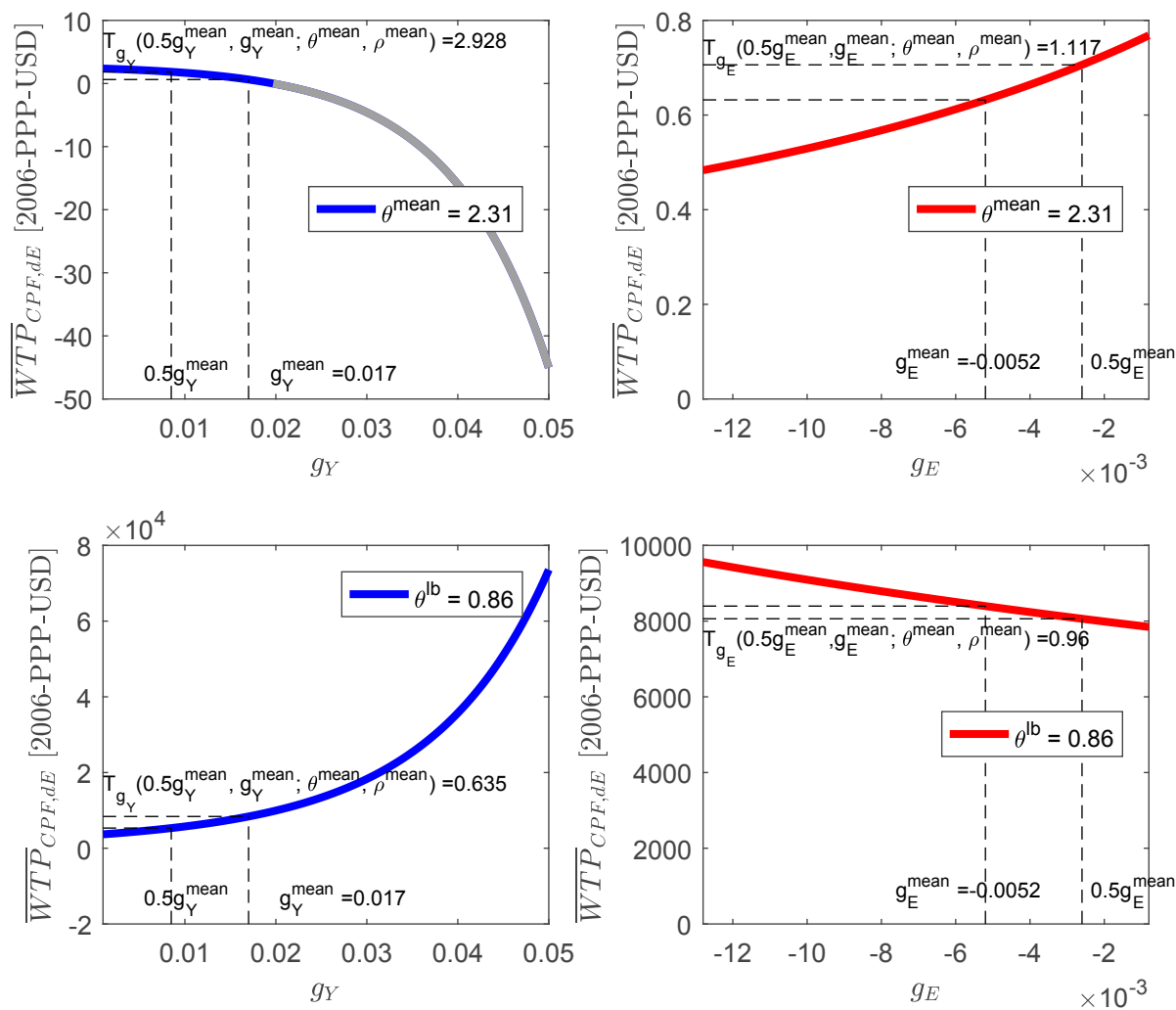

Figure 5.3: Effect of global per-capita income growth rate, $g_{Y}$, (left side) or growth rate of non-use environmental goods, $g_{E}$, (right side) on the present value mean WTP for a one percent increase in global non-use environmental goods measured as a constant payment fraction, $\overline{W T P}_{\mathrm{CPF}, d E}$, for different degrees of substitutability between the consumption and the environmental good, $\theta$. Grey coloured lines indicate parameter combinations that do not meet the growth path condition for the closed-form intertemporal utility function (Eq. 5.7a).

Concerning the effect of the growth rate of environmental goods, the right side of Figure 5.3 shows that mean WTP increases with the growth rate of the environmental good for substitutes, but decreases for complements (Proposition 5.4). For the non-use environmental goods from global biodiversity, a hypothetically slowing down of the loss rate by half will increase mean WTP by $11.72 \%$ for substitutes, $\theta^{\text {mean }}=2.31$, and decrease mean WTP by $3.97 \%$ for complements, $\theta^{\mathrm{lb}}=0.86$. In this empirical illustration, the effect of income growth on societal WTP is relatively stronger as compared to the growth rate of environmental goods.

Next, we study whether the new structural benefit transfer factors for differences in growth rates and market interest rates (Proposition 5.5) lead to notable WTP adjustments. Specifically, we perform hypothetical transfers of mean WTP elicited at the mean of empirical estimates to a site characterised with the lower or upper bound parameters within the empirically plausible parameter a value ranges (cf. Table 5.2). 


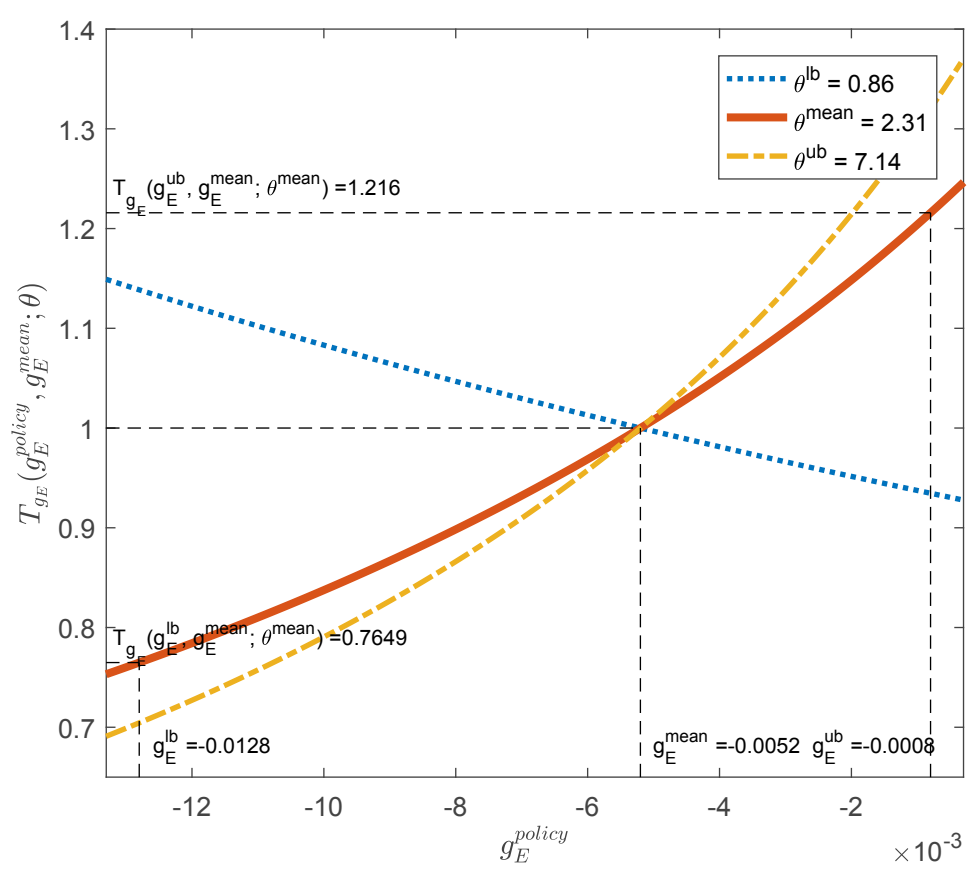

Figure 5.4: Transfer factor to adjust mean WTP for a one percent increase in the level of the environmental good from a study site with a growth rate of $g_{E}^{\text {study }}=-0.0052$ to the growth rate at a policy site. Colours depict different degrees of substitutability between the manufactured consumption and the environmental good, $\theta$.

First, we turn to the transfer factor for differences in the growth rate of the environmental good $\mathcal{T}_{g_{E}}^{(d E)}$ (Eq. 5.38). Figure 5.4 displays the required adjustment when transferring mean WTP from a study site with the global average growth rate of non-use ecosystem services, $g_{E}^{\text {mean }}=-0.0052$, to a policy site with a growth rate within the range of global growth rates for different non-use ecosystem services estimated by Baumgärtner et al. (2015). Applying environmental values elicited at a study site with $g_{E}^{s t u d y}:=g_{E}^{\text {mean }}$ at a policy site with a higher growth rate of the environmental good, that is where the loss of biodiversity is at a lower rate, equal to $g_{E}^{\mathrm{ub}}=-0.0008$, would require an upward adjustment of societal WTP by $21.58 \%$, corresponding to a transfer factor of $\mathcal{T}_{g_{E}}^{(d E)}\left(g_{E}^{\text {ub }}, g_{E}^{\text {mean }} ; \theta^{\text {mean }}\right)=1.22$. To the contrary, societal WTP-estimates for a transfer to a policy context with a higher rate of biodiversity loss of $g_{E}^{\mathrm{lb}}=-0.0128$ would need to be lowered by $23.51 \%$, i.e. be adjusted by the factor $\mathcal{T}_{g_{E}}^{(d E)}\left(g_{E}^{\mathrm{lb}}, g_{E}^{\text {mean }} ; \theta^{\text {mean }}\right)=0.77$. Again, the transfer factor crucially depends on the substitutability between the two goods. A higher degree of substitutability would reinforce these required adjustments, $\mathcal{T}_{g_{E}}^{(d E)}\left(g_{E}^{\mathrm{ub}}, g_{E}^{\text {mean }} ; \theta^{\mathrm{ub}}\right)=1.32$ and $\mathcal{T}_{g_{E}}^{(d E)}\left(g_{E}^{\mathrm{lb}}, g_{E}^{\text {mean }} ; \theta^{\mathrm{ub}}\right)=0.70$, but complementarity would reverse the direction of the required adjustments, $\mathcal{T}_{g_{E}}^{(d E)}\left(g_{E}^{\mathrm{ub}}, g_{E}^{\text {mean }} ; \theta^{\mathrm{lb}}\right)=0.94$ and $\mathcal{T}_{g_{E}}^{(d E)}\left(g_{E}^{\mathrm{lb}}, g_{E}^{\text {mean }} ; \theta^{\mathrm{lb}}\right)=1.14$.

Second, adjusting environmental values for differences in income growth rates, $\mathcal{T}_{g_{Y}, \delta_{\tau}}$ (Eq. 5.42), can be substantial (Figure 5.5). To isolate the effect of the income growth rate, 
we assume for now that the market interest factor is identical at the policy and the study site and constant over time, $\delta^{\text {policy }}=\delta^{\text {study }}$. Thus, the market interest factors cancel out of the transfer factor $\mathcal{T}_{g_{Y}, \delta_{\tau}}$ (Eq. 5.42). Note that depending on the degree of substitutability, $\theta$, we end up in parameter constellations in which the growth path condition on $g_{Y}$ is not fulfilled and the closed-form transfer factor $\mathcal{T}_{g_{Y}, \delta_{\tau}}$ cannot be applied any more. In Figure 5.5 the estimates of the transfer factor for income growth rates are coloured grey at growth rate where the growth path condition does not hold (Eq. 5.7a). Applying WTP-estimates elicited for an income growth rate at the expected global mean, $g_{Y}^{\text {study }}:=g_{Y}^{\text {mean }}=0.017$, in a policy context where the income growth rate is $g_{Y}^{\text {lb }}=0.001$ would imply a transfer factor of $\mathcal{T}_{g_{Y}, \delta_{\tau}}\left(g_{Y}^{\text {lb }}, g_{Y}^{\text {mean }} ; \theta^{\text {mean }}\right)=3.75$. That is, the societal WTP-estimate would have to be adjusted upwards by $274.65 \%$. The direction of adjustment is reversed for complements requiring a downward adjustment with $\mathcal{T}_{g_{Y}, \delta_{\tau}}\left(g_{Y}^{\mathrm{lb}}, g_{Y}^{\text {mean }} ; \theta^{\mathrm{lb}}\right)=0.44$. For the upper bound substitutability estimate, $\theta^{\mathrm{ub}}=7.14$, the growth path condition is not meet at $g_{Y}^{\text {mean }}$. Hence, we cannot apply the transfer factor. The required adjustments $\mathcal{T}_{g_{Y}, \delta_{\tau}}$ are even more pronounced, when applying WTP-estimates in contexts with higher income growth equal to the maximal expected rate, $g_{Y}^{\mathrm{ub}}=0.05$. However, for the parameter constellation in this empirical application the growth path condition is also not met for the mean substitutability estimate, $\theta^{\text {mean }}$, at $g_{Y}^{\mathrm{ub}}=0.05 .{ }^{77}$ For the case of complements, $\theta^{\mathrm{lb}}=0.86$, applying WTP-estimates from a site characterised by the mean expected income growth rate in a context characterised by the maximal expected rate implies a transfer factor of $\mathcal{T}_{g_{Y}, \delta_{\tau}}\left(g_{Y}^{\mathrm{ub}}, g_{Y}^{\text {mean }} ; \theta^{\mathrm{lb}}\right)=8.76$ and thus an upward adjustment of societal WTP of $776.30 \%$.

Third, Figure 5.6 depicts again the transfer factor $\mathcal{T}_{g_{Y}, \delta_{\tau}}$, but this time for differences in the market interest factor between a study and a policy site. For illustration, the market interest rate is kept constant over time at both sites, thus $\delta_{\tau}=\delta \forall \tau$, and the income growth rate at policy and study site are identical and equal to the global average, $g_{Y}^{\text {study }}=g_{Y}^{\text {policy }}=$ $g_{Y}^{\text {mean }}$. For identical growth rates at both sites the first factor in $\mathcal{T}_{g_{Y}, \delta}$ reduces to one and hence the entire transfer factor does not depend on the elasticity of substitution, $\theta$, any more. It shows that differences in market interest rates within the range expected by international experts lead to substantial WTP adjustments: For a hypothetical transfer of mean WTP elicited at $\delta^{\text {mean }}=0.977$ to a policy site with $\delta^{u b}=0.999$ the required adjustment would be $\mathcal{T}_{g_{Y}, \delta}\left(g_{Y}^{\text {mean }}, \delta^{\mathrm{ub}}, g_{Y}^{\text {mean }}, \delta^{\text {mean }}\right)=3.35$ and thus increase mean WTP by $235.39 \%$. To the contrary a hypothetical transfer to the lower bound forecasted market interest factor,

\footnotetext{
${ }^{77}$ The maximum value for applying $\mathcal{T}_{g_{Y}}, \delta_{\tau}$ is for $\theta^{\text {mean }}=2.31$ at $g_{\theta=2.31}^{\max }=0.0197$, where the transfer factor approaches zero, while it is generally uncritical for complements.
} 

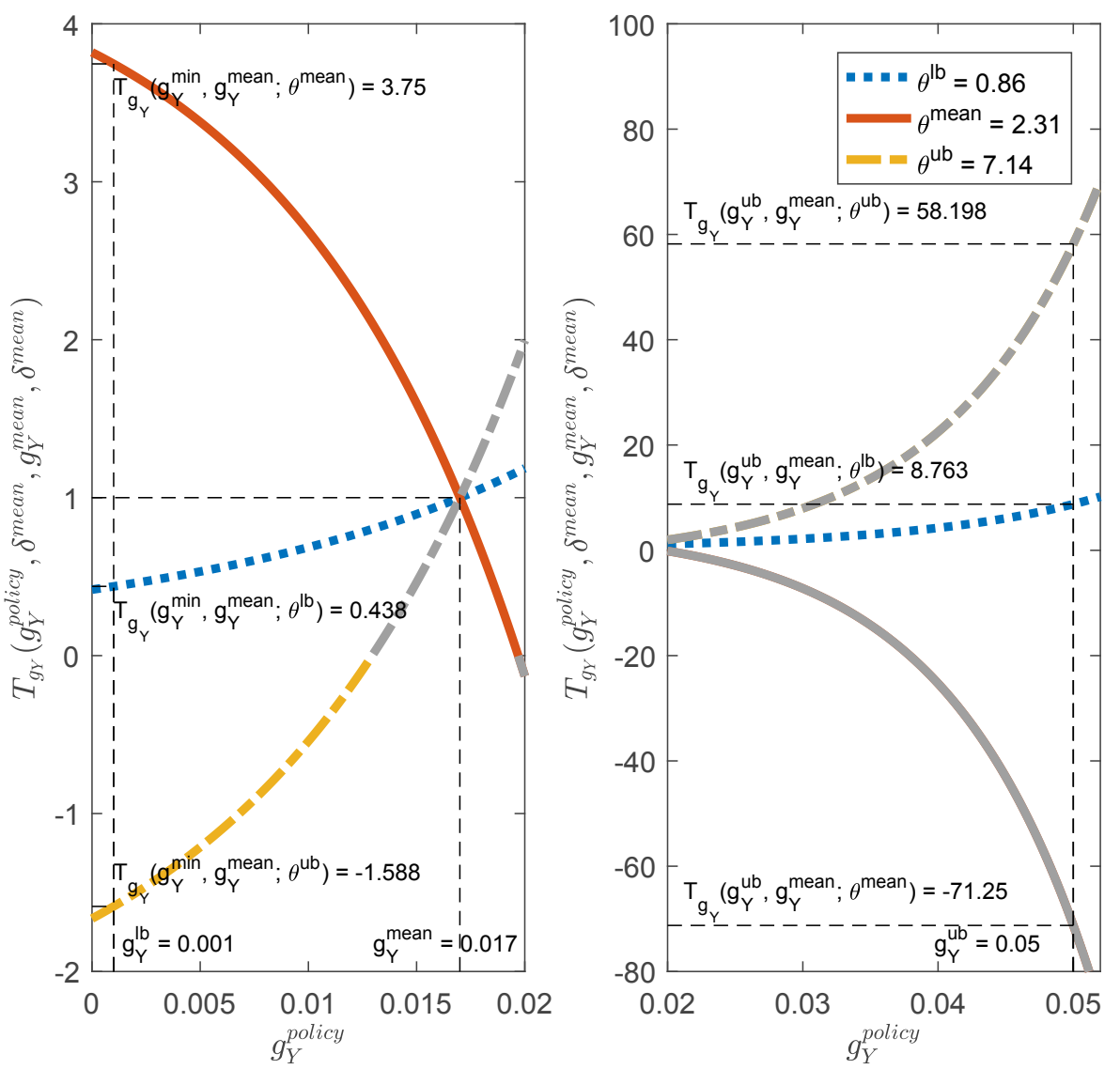

Figure 5.5: Transfer factor to adjust societal WTP for a one percent increase in the level of the environmental good from a study site with an income growth rate of $g_{Y}^{\text {study }}:=g_{Y}^{\text {mean }}=0.017$ to an income growth rate at a policy site, such as the lower bound growth rate $g_{Y}^{\mathrm{lb}}=0.001$. Coloured lines depict different degrees of substitutability between the manufactured consumption and the environmental good, $\theta$. Grey coloured lines indicate parameter combinations that do not meet the growth path condition for the closed-form intertemporal utility function (Eq. 5.7a).

$\delta^{\mathrm{lb}}=0.94$, i.e. a situation with a high market interest rate, would imply a transfer factor of $\mathcal{T}_{g_{Y}, \delta}\left(g_{Y}^{\text {mean }}, \delta^{\mathrm{lb}}, g_{Y}^{\text {mean }}, \delta^{\text {mean }}\right)=0.29$. Moreover, we see that the required adjustment of mean WTP in absolute terms, i.e. $\left|\mathcal{T}_{g_{Y}, \delta}-1\right|$, is larger for higher levels of the common income growth rate at study and policy site. 


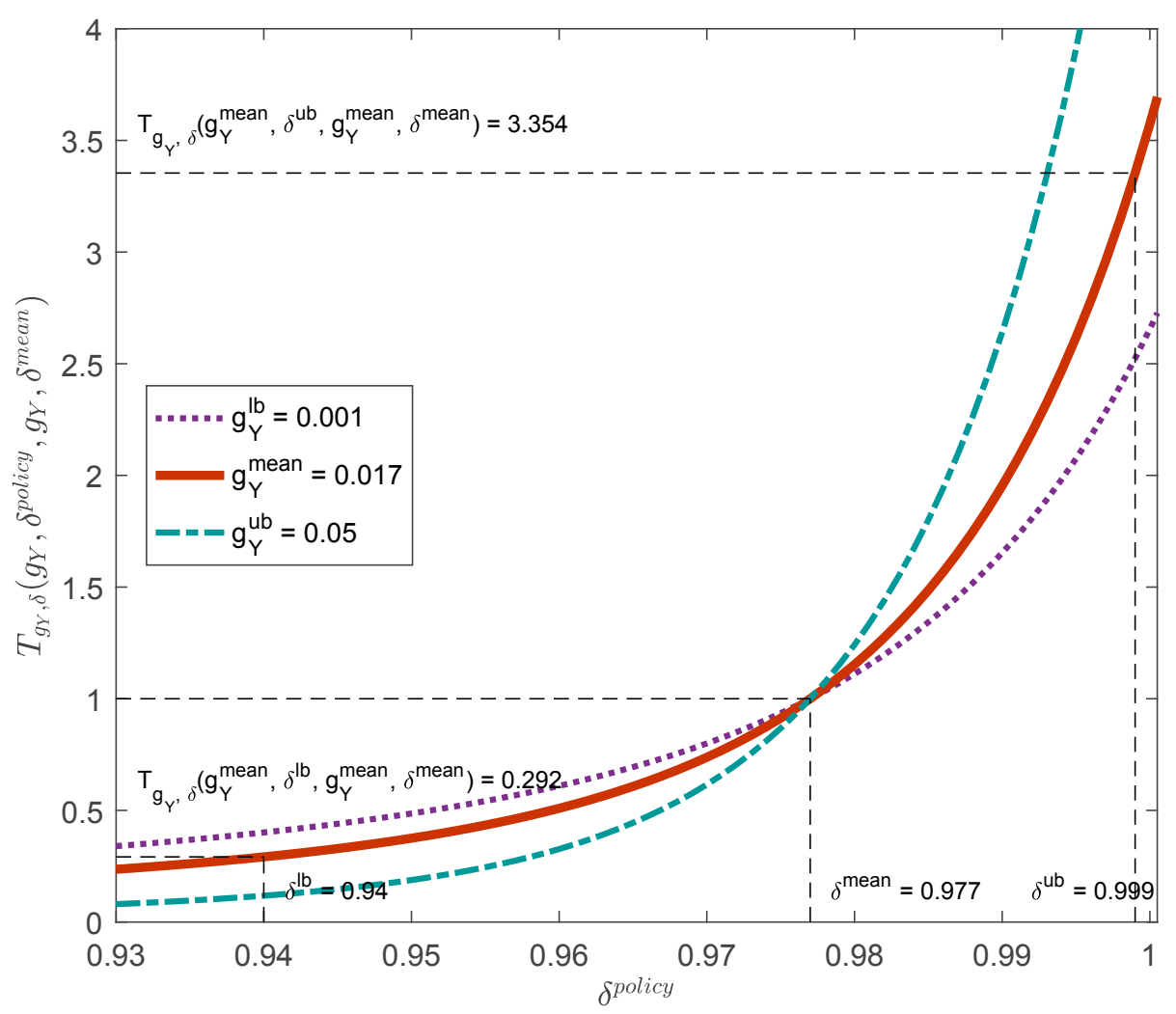

Figure 5.6: Transfer factor to adjust mean WTP for a one percent increase in the level of the environmental good from a study site with a market interest rate of $\delta^{\text {study }}=0.977$ to the market interest rate at the policy site when the income growth rate at both the study and policy site is identical. Colours indicate different levels of the income growth rate common to the study and policy site.

\subsection{Discussion}

In this section we discuss several assumption that limit the generality of our analysis. Among others, these encompass (i) the proportional mapping between natural capital and environmental services, (ii) the exponential growth of income or decline of environmental services derived from natural capital, (iii) the self-regarding dynastic household, (iv) the direct relationship between the intertemporal elasticity of substitution and the inverse of the elasticity of substitution between consumption goods and environmental goods, (v) the representative household setting, (vi) the intragenerational (spatial) distribution of environmental goods, as well as (vii) uncertainty about growth rates and other model parameters.

First, we considered a simple proportional mapping between natural capital and environmental good and services. Certainly, the mapping of different forms of natural capital into the services it provides are multifaceted (Fenichel and Abbott 2014). At this stage, it is therefore clear that our analysis is only relevant for those cases of non-use environmental 
services that may be reasonably described by this simplification. In particular, our work focusses on non-use services derived from natural capital for which WTP information is crucial for public policy. Moreover, our analyses might by relevant for other non-use environmental services like regulatory services as well as provisioning services of sustainably managed stocks of natural capital.

Second, as exemplary paths for the development of income, respectively consumption, and environmental services derived from natural capital we have considered exponential growth or decline. While this is a prominent case in the long-term analysis of environmentaleconomic problems (e.g. Hoel and Sterner 2007, Baumgärtner et al. 2015), ${ }^{78}$ there may be many different relevant growth or decline paths. As non-market valuation studies often do not specify the exact time path of the evolution of natural capital or environmental goods and services, we leave an analysis of other types of growth dynamics that may be relevant for natural capital valuation for future research.

Third, our analysis assumes purely self-regarding dynastic households. Yet, there may also be behavioral responses to income inequality within and across generations. These may include relative consumption concerns (e.g. Johansson-Stenman and Sterner 2015) or variants of inequality aversion. Again, we leave these extensions to future work.

Fourth, we made the rather strong assumption of a direct relationship between the inverse of the intertemporal elasticity of substitution and the inverse of the elasticity of substitution between consumption goods and environmental goods, $\eta=1 / \theta$, to be able to derive a closedform solution of the intertemporal utility function. This assumption follows theoretic work by Quaas and Bröcker (2016), who build a solvable analytic climate-economy model that extends upon the previous Cobb-Douglas cases in the literature (cf. Golosov et al. 2014). In our central calibration, the inverse of the elasticity of substitution, $1 / \theta$, equals 0.43 . This is considered a rather low value of $\eta$ by most experts (Drupp et al. 2018). Future work should try to relax this assumption drawing, for example, on simulations. An alternative route would be to model diverse direct relationships between $\eta$ and $\theta$ that are more suitable in the context of natural capital and biodiversity. For instance future research could assume $\frac{3}{2 \theta}=\eta$ implying for our central calibration a $\eta=0.65$ closely related to the $\frac{2}{3}$ found in the asset pricing literature (cf. Gollier et al. 2017).

Fifth, we have assumed that dynastic households are identical except that they differ in initial income. Yet, households may have heterogenous preferences. They may also differ

\footnotetext{
${ }^{78}$ We derive this case for income as the result of a balanced growth path in an endogenous growth model in Appendix 5.8.1.
} 
not only in their initial income but can also face different income or consumption growth rates. For example, recent empirical evidence from the World Inequality Report (Alvaredo et al. 2018) shows that the growth rate of income differs substantially over income groups. Expert forecasts on consumption growth rates also differ substantially, but appear to be roughly normally distributed (Drupp et al. 2018). Different growth rates of income give rise to convergence or divergence of income and hence a change in relative income inequality over time. Future work should try to relax the assumption of equal growth rates for all households. With respect to heterogenous preferences, Baumgärtner et al. (2017, Appendix A.12) have already shown how the static results can be extend to feature a normal distribution of preference parameters for the utility weight of environmental goods, $\alpha$, as well as for the degree of substitutability, $\theta$. We expect that similar extensions could be made-perhaps under stronger assumptions - in an intertemporal context such as we consider in the present paper. Furthermore, there is a literature on heterogeneity in pure rates of time preference (Gollier and Zeckhauser 2005, Millner 2016). This emerging body of research tends to suggest that the societal pure time discount rate falls over time in the presence of such heterogeneities. In our setting, this may imply that over time the WTPs of the more patient households will dominate. Again, we leave an extension to heterogenous discount rates to future work.

Sixth, we have restricted our analysis to the case of pure public environmental goods. While this is a reasonable representation for several important goods and services humans derive from natural capital, such as the existence value of biodiversity studied in our application, there are certainly several environmental goods that vary spatially. The provision of these locally public environmental goods will frequently be correlated with income. For instance, Lee and Lin (2018) show for US metropolitan areas that neighbourhoods close to environmental amenities, such as hills or coastlines, have persisted a high level of income since 1880, and that a heterogeneous endowment with environmental amenities shapes the spatial distribution of incomes. An extension of the model from Baumgärtner et al. (2017a) to local public goods is developed in Meya (2018). He shows that for local public goods the effect of income inequality on mean WTP generally also depends on how their provision is correlated with income. The main result of Baumgärtner et al. (2017a) on how income inequality affects mean WTP generalizes to local public goods being distributed independently of income. We leave an extension of our analysis to a heterogeneous endowment with environmental goods from natural capital and how this distribution evolves over time for 
future research.

Finally, we have considered a deterministic setting throughout. However, when it comes to issues of intertemporal distribution the world is, of course, full of uncertainties. Besides parameter uncertainty, this applies in particular to uncertainty about the growth rates of income or consumption and of environmental goods derived from natural capital. There is a large body of literature on discounting in the presence of uncertainty about baseline consumption growth (e.g. Gollier 2002, 2008). Gollier (2010) considers uncertainty about the growth rate of environmental goods. More recently, Gollier (2017) analyzes how uncertainty about the elasticity of substitution interacts with other forms of uncertainty about growth rates.

\subsection{Conclusion}

We have studied how the intra- and intergenerational distribution of income affects the intertemporal valuation of non-use environmental goods derived from natural capital. To this end we developed a model in which income is distributed unevenly among otherwise identical households, who have constant-elasticity-of-substitution preferences and whose intertemporal elasticity of substitution is the inverse of the elasticity of substitution between environmental goods and manufactured consumption goods.

We find that (i) societal WTP for a marginal increase in the initial stock or the growth rate of natural capital increases with society's mean income; (ii) societal WTP for a marginal increase in the stock or the growth rate of natural capital decreases (increases) with society's income inequality at the time of the valuation if and only if natural capital is a substitute (complement) to manufactured consumption goods; (iii) societal WTP for a marginal increase in stock of natural capital increases with income growth for the case of Cobb-Douglas and complements, but it might decrease for substitutes; (iv) societal WTP for a marginal increase in the stock of natural capital increases (decreases) with the growth rate of environmental goods if and only if natural capital is a substitute (complement) to manufactured goods. Moreover, we derive closed-form adjustment factors for differences in the initial income distribution, growth rates and interest rates. Note that our findings are not confined to environmental public goods, but hold more generally for the valuation of public goods, such as culture, knowledge, open access journals or national security.

Our results are relevant in several respects: First, for benefit transfer in the context of natural capital accounting. Most countries of the world committed themselves to mainstream 
the value of biodiversity in decision making and to integrate biodiversity in national accounts (Convention on Biological Diversity, Aichi Target 2). For instance, EU member states agreed to "promote the integration of these [economic values of ecosystems and their services] into accounting and reporting systems at EU and national level by 2020" (European Commission 2011, p.15). Approaches to account for natural capital and ecosystem services in monetary units, usually draw on a set of environmental values and scale these up by means of benefit transfer. As the value of natural capital in accounting systems is defined as the net present values of future ecosystem flows (Obst et al. 2016), the need to apply benefit transfer methods becomes even more evident implying to estimate future flows based on existing valuation studies. Consequently, within the revision process of the System of Environmental-Economic Accounting - Experimental Ecosystem Accounting its is emphasised that "[g]enerally, it will be necessary to apply benefit transfer methods" (United Nations 2017, p.102) for natural capital accounting. However, so far there is limited theory-based guidance for benefit transfer (Bateman et al. 2011) and several international government bodies call for improving benefit transfer methods to enable more accurate ecosystem service and national capital accounting (UN et al. 2014). Here we derive theory-based transfer factors for a dynamic context, which is necessary for a sound accounting of natural capital. In particular, we show that adjustment can be done by exploiting information on the income distribution at the time of valuation and develop transfer factors to control for expected income growth, rates of environmental degradation as well as interest rates.

Second, these adjustment factors can also be used for sustainability policies targeted at natural capital management that are concerned with both efficiency and equity by employing equity-adjusted societal WTP-estimates in environmentally-extended cost-benefit analysis (Drupp et al. 2018b).

Finally, our results hold implications for the economic valuation of natural capital. In particular, primary valuation studies should pay attention to the income distribution in the process of aggregating WTPs and report the necessary data to enable a more sophisticated natural capital accounting and determination distributional effects. 
Acknowledgments: We are very grateful for helpful comments from Joshua Abbott, Klaus Eisenack and Reyer Gerlagh as well as seminar participants at HU Berlin, Hohwacht, SURED 2018, Oldenburg and WCERE 2018. Meya gratefully acknowledges financial support from the Ministry for Science and Culture of Lower Saxony (Germany) and the Volkswagen Foundation within the program Science for Sustainable Development under grant VWZN3045. Drupp gratefully acknowledges financial support from the German Ministry of Education and Research under grant 01UT1410. 


\section{Bibliography}

Alvaredo, F., Chancel, L., Piketty, T., Saez, E. and Zucman, G. (2017), Global Inequality Dynamics: New Findings from WID.world. American Economic Review: Papers 63 Proceedings, 107(5): 404-409.

Alvaredo, F., Chancel, L., Piketty, T., Saez, E. and Zucman, G. (2018), World Inequality Report 2018. World Inequality Lab, available online at: http://wir2018.wid.world.

Arrow, K. J., Dasgupta, P., and Mäler, K.G. (2003), Evaluating projects and assessing sustainable development in imperfect economies. Environmental and Resource Economics, 26(4): 647-685.

Asheim, G. B., and Nesje, F. (2016), Destructive intergenerational altruism. Journal of the Association of Environmental and Resource Economists, 3(4): 957-984.

Bateman, I. J., R. Brouwer, S. Ferrini, M. Schaafsma, D.N. Barton, A. Dubgaard, B. Hasler, S. Hime, I. Liekens, S. Navrud, L. De Nocker R. Šceponaviciute and D. Semeniene (2011), Making benefit transfers work: deriving and testing principles for value transfers for similar and dissimilar sites using a case study of the non-market benefits of water quality improvements across Europe. Environmental and Resource Economics, 50(3): 365-387.

Baumgärtner, S., A.-M. Klein, D. Thiel and K. Winkler (2015), Ramsey Discounting of Ecosystem Services, Environmental and Resource Economics, 61: 273-296.

Baumgärtner, S., M.A. Drupp, J. Munz, J.N. Meya and M.F. Quaas (2017), Income inequality and willingness to pay for environmental public goods. Journal of Environmental Economics and Management, 85: 35-61.

Baumgärtner, S. and M.F. Quaas (2010), What is sustainability economics? Ecological Economics, 69(3): 445-450. 
[Defra] Department for Environment, Food and Rural Affairs (2007), An introductory guide to valuing ecosystem services. London: Department for Environment, Food and Rural Affairs. 66pp.

Drupp, M.A. (2018), Limits to Substitution between Ecosystem Services and Manufactured Goods and Implications for Social Discounting. Environmental and Resource Economics, 69(1): 135-158.

Drupp, M.A., M.C. Freeman, B. Groom and F. Nesje (2018a), Discounting Disentangled, Forthcoming in the American Economic Journal: Economic Policy.

Drupp, M.A. , J.N. Meya, S. Baumgärtner and M.F. Quaas (2018b), Economic Inequality and the Value of Nature. Ecological Economics, 150: 340-345.

Ebert, U. (2003), Environmental goods and the distribution of income, Environmental and Resource Economics, 25(4): 435-459.

Emmerling, J., Groom, B., and Wettingfeld, T. (2017), Discounting and the representative median agent. Economics Letters, 161: 78-81.

Emmerling, J. (2018), Discounting and intragenerational equity, Environment and Development Economics, forthcoming, doi: 10.1017/S1355770X17000365.

European Commission (2011), The EU Biodiversity Strategy to 2020. Luxembourg: Publications Office of the European Union.

Fenichel, E.P., and Abbott, J.K. (2014), Natural capital: from metaphor to measurement. Journal of the Association of Environmental and Resource Economists, 1(1/2): 1-27.

Fenichel, E.P., Levin, S.A., McCay, B., Martin, K.S., Abbott, J.K., and Pinsky, M.L. (2016), Wealth reallocation and sustainability under climate change. Nature Climate Change, 6(3): $237-244$.

Fleurbaey, M., and Zuber, S. (2015), Discounting, risk and inequality: A general approach. Journal of Public Economics, 128: 34-49.

Flores, N.E. and R.T. Carson (1997), The relationship between the income elasticities of demand and willingness to pay, Journal of Environmental Economics and Management, 33(3): 287-295. 
Gollier, C. (2002), Time horizon and the discount rate. Journal of Economic Theory, 107: $463-473$.

Gollier, C. (2008), Discounting with fat-tailed economic growth. Journal of Risk and Uncertainty, 37 (2-3): 171-186.

Gollier, C. (2010), Ecological discounting, Journal of Economic Theory, 145: 812-829.

Gollier, C. (2015), Discounting, inequality and economic convergence, Journal of Environmental Economics and Management, 69: 53-61.

Gollier, C. (2017), Valuation of natural capital under uncertain substitutability, TSE Working Paper No. TSE-813. Available at: https://www.tsefr.eu/sites/default/files/TSE/documents/doc/wp/2017/wp_tse_813.pdf

Gollier, C., Mahul, O.,Meddahia, N., Nzesseua, J.T. (2017), Term structures of discount rates: An international perspective. mimeo, Toulouse School of Economics. Available at: http://fleximeets.com/wcere2018/getpaper.php?fid=175

Gollier, C., and Zeckhauser, R. (2005), Aggregation of heterogeneous time preferences. Journal of Political Economy, 113 (4): 878-896.

Golosov, M., Hassler, J., Krusell, P. and Tsyvinski, A., (2014), Optimal taxes on fossil fuel in general equilibrium. Econometrica, 82(1): 41-88.

Groom, B. and D. Maddison (2018), New Estimates of the Elasticity of Marginal Utility for the UK. Environmental and Resource Economics, https://doi.org/10.1007/s10640-0180242-z.

Hanemann, W.M. (1991), Willingness to pay and willingness to accept: how much can they differ? American Economic Review, 81: 635-647.

Hoel, M., and Sterner, T. (2007), Discounting and relative prices. Climatic Change, 84(3-4), $265-280$.

Hsiang, S., Oliva, P., and Walker, R. (2018), The Distribution of Environmental Damages. Forthcoming in the Review of Environmental Economics and Policy.

Jacobsen, J. and N. Hanley (2009), Are there income effects on global willingness to pay for biodiversity conservation? Environmental and Resource Economics, 43(2): 137-160. 
Johansson-Stenman, O., and Sterner, T. (2015), Discounting and relative consumption. Journal of Environmental Economics and Management, 71, 19-33.

Kinzig, A. P., Perrings, C., Chapin, F. S., Polasky, S., Smith, V. K., Tilman, D., and Turner, B. L. (2011), Paying for ecosystem services_- promise and peril. Science, 334(6056), 603604 .

Kopp, R.E., Golub, A., Keohane, N.O., and C. Onda (2012), The Influence of the Specification of Climate Change Damages on the Social Cost of Carbon, Economics: The Open-Access, Open-Assessment E-Journal, 6: 1-40,.

Kriström, B. and P. Riera (1996), Is the income elasticity of environmental improvements less than one? Environmental and Resource Economics, 7: 45-55.

Lee, S., and J. Lin (2018), Natural Amenities, Neighbourhood Dynamics, and Persistence in the Spatial Distribution of Income. The Review of Economic Studies, 85: 663-694.

Lindahl, E. (1928), Einige strittige Fragen der Steuertheorie. In: Meyer, H. (Ed.), Die Wirtschaftstheorie der Gegenwart, vol. IV, pp. 282-304.

Loomis, J.B. (1992), The evolution of a more rigorous approach to benefit transfer: Benefit function transfer, Water Resources Research, 28: 701-705.

Meya, J.N., Drupp, M.A., and N. Hanley (2017), Income inequality and the international transfer of environmental values. Kiel Economics Working Paper, No 2017-03.

Meya, J.N. (2018), Environmental inequality and economic valuation. Unpublished manuscript. Humboldt-Universität zu Berlin.

Millner, A. (2016), Non-paternalistic social discounting. Mimeo, London School of Economics and Political Science.

Neary, J.P. and K.W.S. Roberts (1980), The theory of household behaviour under rationing, European Economic Review, 13: 25-42.

OECD (2018), Cost-benefit analysis and the environment: further developments and policy use, OECD Publishing, Paris.

Obst, C., L. Hein, and B. Edens (2016), National accounting and the valuation of ecosystem assets and their services. Environmental and Resource Economics, 64(1): 1-23. 
Pascual, U., Balvanera, P., Díaz, S., Pataki, G., Roth, E., Stenseke, M., Watson, R.T., Dessane, E.B., Islar, M., Kelemen, E., Maris, V., Quaas, M.F., Subramanian, S.M., Wittmer, H., Adlan, A., Ahn, S., Al-Hafedh, Y.S., Amankwah, E., Asah, S.T., Berry, P., Bilgin, A., Breslow, S.J., Bullock, C., Cáceres, D., Daly-Hassen, H., Figueroa, E., Golden, C.D., Gómez-Baggethun, E., González-Jiménez, D., Houdet, J., Keune, H., Kumar, R., Ma, K., May, P.H., Mead, A., O'Farrell, P., Pandit, R., Pengue, W., Pichis-Madruga, R., Popa, F., Preston, S., Pacheco-Balanza, D., Saarikoski, H., Strassburg, B.B., van den Belt, M., Verma, M., Wickson, F., and Yagi, N. (2017), Valuing nature's contributions to people: the IPBES approach. Current Opinion in Environmental Sustainability, 26: 7-16.

Piketty, T. (2014), Capital in the twenty-first century, Cambridge, MA: The Belknap Press of Harvard University Press. University College London.

Pinkovskiy, M. and X. Sala-i-Martin (2009), Parametric estimations of the world distribution of income, NBER Working Paper No. 15433.

Quaas, M. F., Bröcker, J.(2016), Substitutability and the social cost of carbon in a solvable growth model with irreversible climate change, Kiel Economics Working Paper, No. 201609.

Richardson, L. J. Loomis T. Kroeger and F. Casey (2015), The role of benefit transfer in ecosystem service valuation, Ecological Economics, 115: 51-58.

Samuelson, P.A. (1954), The pure theory of public expenditure. The Review of Economics and Statistics, 36(4): 387-389.

Smith, V.K., Van Houtven, G., and S.K. Pattanayak (2002), Benefit transfer via preference calibration: "Prudential algebra" for policy, Land Economics 78(1): 132-152.

Smith, V.K., Pattanayak, S.K., and G.L. Van Houtven (2006), Structural benefit transfer: An example using VSL estimates, Ecological Economics 60(2): 361-371.

Sterner, T., and M. Persson (2008), An Even Sterner Review: Introducing Relative Prices into the Discounting Debate, Review of Environmental Economics and Policy, 2(1): 61-76.

Traeger, C.P. (2011), Sustainability, limited substitutability, and non-constant social discount rates, Journal of Environmental Economics and Management, 62(2): 215-228. 
[UBA] Umweltbundesamt (2012), Methoden der ökonomischen Bewertung. Anhang A der "Methodenkonvention 2.0 zur Schätzung von Umweltkosten", Dessau-Roßlau: Umweltbundesamt.

United Nations (2017), SEEA Experimental Ecosystem Accounting: Technical Recommendations.

United Nations, European Commission, Food and Agriculture Organization of the United Nations, Organisation for Economic Co-operation and Development, World Bank Group (2014), System of Environmental-Economic Accounting 2012-Experimental Ecosystem Accounting, New York: United Nations.

Van der Ploeg, S. and R.S. de Groot (2010), The TEEB Valuation Database - a searchable database of 1310 estimates of monetary values of ecosystem services. Foundation for Sustainable Development, Wageningen, The Netherlands.

Weikard, H.-P. and X. Zhu (2005), Discounting and environmental quality: when should dual rates be used?, Economic Modelling, 22: 868-878. 


\subsection{Appendix}

\subsubsection{Endogenizing the growth and interest rates in a general equilibrium endogenous growth model}

The constant growth rate of income, $g_{Y}$, considered in this paper can be derived as the balanced growth path outcome of an endogenous growth model. To demonstrate this, consider a model with product innovation. Output $Y_{t}$ is produced by means of labor $L$ and a mass $M_{t}$ of different types $i$ of machines with input quantities $q_{t}(i)$, according to the constant-returns-to-scale production function

$$
Y_{t}=\frac{1}{\varphi} L^{1-\varphi} \int_{0}^{M_{t}} q_{t}(i)^{\varphi} d i
$$

where $\varphi$ is the output elasticity of machinery input.

We normalize labor input to one, $L=1$, based on the assumption that each of the $n$ households inelastically supplies $1 / n$ units of labor. We choose the final output good as the numeraire. Machines fully depreciate after one period of use.

Using $p_{t}(i)$ to denote the price of a machine of type $i$, input demand by competitive firms in the final goods sector is given by the condition that the value of the marginal product of this machine is equal to its price, i.e.

$$
q_{t}(i)^{\varphi-1}=p_{t}(i)
$$

Blueprints for new types of machines are generated by research and development, which uses the output as the final good as input. Using $Z_{t}$ to denote the input into $\mathrm{R} \& \mathrm{D}$ at time $t$, the expected mass of new varietis developed is

$$
M_{t+1}=M_{t}+\frac{1}{\Phi} Z_{t}
$$

with a constant $\Phi>0$. A firm being successful in R\&D becomes the monopolistic supplier for this type of machine. Machines are produced using the final good, such that one unit of the final good is required to build one unit of a machine. The profit-maximizing price $p_{t}(i)$ of a machine of type $i$ is obtained by maximizing $p_{t}(i) q_{t}(i)-q_{t}(i)$ subject to 5.45 , which yields $p_{t}(i)=1 / \varphi$. Using this in 5.45, market equilibrium input of machine type $i$ is 
$q_{t}(i)=\varphi^{1 /(1-\varphi)}$, and total output is

$$
Y_{t}=M_{t} \varphi^{\frac{1}{1-\varphi}}
$$

We consider a balanced growth path, such that the interest factor $\delta_{t}$ is constant, $\delta_{t}=\delta$. The present value of monopoly profits for a firm successful in R\&D is $(p-1) q / \delta=(1-\varphi) /(\delta \varphi)$. Under free entry, the expected present value of profits from one dollar spent on $R \& D$ must just be equal to this one dollar, i.e.

$$
\Phi \frac{\delta}{1-\delta} \frac{1-\varphi}{\varphi}=1
$$

from which we obtain the interest factor

$$
\delta=\left(1+\frac{1-\varphi}{\Phi \varphi}\right)^{-1}
$$

Market equilibrium for final goods implies

$$
Y_{t}=n C_{t}+Z_{t}+\int_{0}^{M_{t}} q_{t}(i) d i=n C_{t}+\Phi\left(M_{t+1}-M_{t}\right)+M_{t} \varphi^{\frac{\varphi}{1-\varphi}}
$$

In a balanced growth path, $Y_{t}, C_{t}$, and $M_{t}$ must thus all grow at the same rate $g_{Y}$.

Households choose the intertemporal distribution of consumption such as to maximize

$$
\sum_{t=0}^{\infty} \rho^{t} \frac{\theta}{\theta-1}\left(\alpha C_{t}^{\frac{\theta-1}{\theta}}+(1-\alpha) E_{t}^{\frac{\theta-1}{\theta}}\right)
$$

where $\rho$ is the pure time discount factor of the household. As households are facing a constant interest factor $\delta$, the optimal intertemporal distribution of consumption is determined by the discrete-time Keynes-Ramsey rule

$$
\begin{aligned}
\left(1+g_{Y}\right)^{\frac{1}{\theta}} & =\frac{\rho}{\delta} \\
\Leftrightarrow \quad g_{Y} & =(\rho / \delta)^{\theta}-1=\left(\rho\left(1+\frac{1-\varphi}{\Phi \varphi}\right)\right)^{\theta}-1 .
\end{aligned}
$$




\subsubsection{Derivation of the intertemporal utility function (Eq. 5.6)}

Using Eq. 5.1 in Eq. 5.3, and suppressing the index for household $i$, gives

$$
\begin{aligned}
U\left(\left\{Y_{t}\right\},\left\{E_{t}\right\}\right) & =\sum_{t=0}^{\infty} \rho^{t} \frac{1}{1-\eta}\left(\alpha Y_{t}^{\frac{\theta-1}{\theta}}+(1-\alpha) E_{t}^{\frac{\theta-1}{\theta}}\right)^{\frac{(1-\eta) \theta}{\theta-1}} \\
& \stackrel{\eta=}{=} \sum_{t=0}^{\infty} \rho^{t} \frac{\theta}{\theta-1}\left(\alpha Y_{t}^{\frac{\theta-1}{\theta}}+(1-\alpha) E_{t}^{\frac{\theta-1}{\theta}}\right) \\
& \stackrel{5.2 a, 5.2 b}{=} \sum_{t=0}^{\infty} \rho^{t} \frac{\theta}{\theta-1}\left(\alpha\left(Y_{0}\left(1+g_{Y}\right)^{t}\right)^{\frac{\theta-1}{\theta}}+(1-\alpha)\left(E_{0}\left(1+g_{E}\right)^{t}\right)^{\frac{\theta-1}{\theta}}\right) \\
& =\frac{\theta}{\theta-1}\left(\sum_{t=0}^{\infty} \rho^{t} \alpha\left(Y_{0}\left(1+g_{Y}\right)^{t}\right)^{\frac{\theta-1}{\theta}}+\sum_{t=0}^{\infty} \rho^{t}(1-\alpha)\left(E_{0}\left(1+g_{E}\right)^{t}\right)^{\frac{\theta-1}{\theta}}\right) \\
& =\frac{\theta}{\theta-1}\left(\alpha \sum_{t=0}^{\infty}\left(\rho\left(1+g_{Y}\right)^{\frac{\theta-1}{\theta}}\right)^{t} Y_{0}^{\frac{\theta-1}{\theta}}+(1-\alpha) \sum_{t=0}^{\infty}\left(\rho\left(1+g_{E}\right)^{\frac{\theta-1}{\theta}}\right)^{t} E_{0}^{\frac{\theta-1}{\theta}}\right)
\end{aligned}
$$

As $\left|\rho\left(1+g_{Y}\right)^{\frac{\theta-1}{\theta}}\right|<1$ and $\left|\rho\left(1+g_{E}\right)^{\frac{\theta-1}{\theta}}\right|<1$ hold by assumption (Eq. 5.7a and Eq. 5.7b), the geometric series can be simplified so that one derives the following intertemporal utility function

$$
U\left(Y_{0}, g_{Y}, E_{0}, g_{E}\right)=\frac{\theta}{\theta-1}\left(\alpha \frac{Y_{0}^{\frac{\theta-1}{\theta}}}{1-\rho\left(1+g_{Y}\right)^{\frac{\theta-1}{\theta}}}+(1-\alpha) \frac{E_{0}^{\frac{\theta-1}{\theta}}}{1-\rho\left(1+g_{E}\right)^{\frac{\theta-1}{\theta}}}\right) .
$$

\subsubsection{Derivation of the compensating surplus measured as a single pay- ment, $x_{\mathrm{SP}}$ (Eq. 5.10)}

The compensating surplus, $x_{\mathrm{SP}}$, measured as a single payment in $t=0$ is derived by using the instantaneous utility function (Eq. 5.1) in the definition of the compensation surplus for a single payment in $\mathrm{t}=0$ (Eq. 5.8):

$$
\begin{aligned}
& \frac{1}{1-\eta}\left(\alpha\left(Y_{0}-x_{\mathrm{SP}}\right)^{\frac{\theta-1}{\theta}}+(1-\alpha) E_{0}^{\prime \frac{\theta-1}{\theta}}\right)^{\frac{(1-\eta) \theta}{\theta-1}}+\sum_{t=1}^{\infty} \rho^{t} \frac{1}{1-\eta}\left(\alpha Y_{t}^{\frac{\theta-1}{\theta}}+(1-\alpha) E_{t}^{\prime \frac{\theta-1}{\theta}}\right)^{\frac{(1-\eta) \theta}{\theta-1}} \\
& =\sum_{t=0}^{\infty} \rho^{t} \frac{1}{1-\eta}\left(\alpha Y_{t}^{\frac{\theta-1}{\theta}}+(1-\alpha) E_{t}^{\frac{\theta-1}{\theta}}\right)^{\frac{(1-\eta) \theta}{\theta-1}} \text {. }
\end{aligned}
$$


Assuming $\eta=\frac{1}{\theta}$ this simplifies to

$$
\begin{aligned}
& \alpha\left(Y_{0}-x_{\mathrm{SP}}\right)^{\frac{\theta-1}{\theta}}+(1-\alpha) E_{0}^{\prime \frac{\theta-1}{\theta}}+\sum_{t=1}^{\infty} \rho^{t}\left(\alpha Y_{t}^{\frac{\theta-1}{\theta}}+(1-\alpha) E_{t}^{\prime \frac{\theta-1}{\theta}}\right) \\
& =\sum_{t=0}^{\infty} \rho^{t}\left(\alpha Y_{t}^{\frac{\theta-1}{\theta}}+(1-\alpha) E_{t}^{\frac{\theta-1}{\theta}}\right) \\
& \Leftrightarrow \alpha\left(Y_{0}-x_{\mathrm{SP}}\right)^{\frac{\theta-1}{\theta}}+\sum_{t=1}^{\infty} \rho^{t} \alpha Y_{t}^{\frac{\theta-1}{\theta}}+\sum_{t=0}^{\infty} \rho^{t}(1-\alpha) E_{t}^{\prime \frac{\theta-1}{\theta}}=\sum_{t=0}^{\infty} \rho^{t}\left(\alpha Y_{t}^{\frac{\theta-1}{\theta}}+(1-\alpha) E_{t}^{\frac{\theta-1}{\theta}}\right) \\
& \stackrel{\text { Appendix }}{\Leftrightarrow} \alpha .8 .2 \alpha\left(Y_{0}-x_{\mathrm{SP}}\right)^{\frac{\theta-1}{\theta}}+\sum_{t=1}^{\infty} \rho^{t} \alpha Y_{t}^{\frac{\theta-1}{\theta}}+\frac{(1-\alpha) E_{0}^{\prime \frac{\theta-1}{\theta}}}{1-\rho\left(1+g_{E}^{\prime}\right)^{\frac{\theta-1}{\theta}}} \\
& =\frac{\alpha Y_{0}^{\frac{\theta-1}{\theta}}}{1-\rho\left(1+g_{Y}\right)^{\frac{\theta-1}{\theta}}}+\frac{(1-\alpha) E_{0}^{\frac{\theta-1}{\theta}}}{1-\rho\left(1+g_{E}\right)^{\frac{\theta-1}{\theta}}} \text {. }
\end{aligned}
$$

Where

$$
\begin{aligned}
\sum_{t=1}^{\infty} \rho^{t} \alpha Y_{t}^{\frac{\theta-1}{\theta}} & =\sum_{t=1}^{\infty}\left(\rho\left(1+g_{Y}\right)^{\frac{\theta-1}{\theta}}\right)^{t} \alpha Y_{t}^{\frac{\theta-1}{\theta}} \\
& =\sum_{t=0}^{\infty}\left(\rho\left(1+g_{Y}\right)^{\frac{\theta-1}{\theta}}\right)^{t} \alpha Y_{t}^{\frac{\theta-1}{\theta}}-\left(\rho\left(1+g_{Y}\right)^{\frac{\theta-1}{\theta}}\right)^{0} \alpha Y_{t}^{\frac{\theta-1}{\theta}} \\
& =\frac{\alpha Y_{0}^{\frac{\theta-1}{\theta}}}{1-\rho\left(1+g_{Y}\right)^{\frac{\theta-1}{\theta}}}-\alpha Y_{t}^{\frac{\theta-1}{\theta}} \\
& =\frac{\left(1-1-\rho\left(1+g_{Y}\right)^{\frac{\theta-1}{\theta}}\right) \alpha Y_{0}^{\frac{\theta-1}{\theta}}}{1-\rho\left(1+g_{Y}\right)^{\frac{\theta-1}{\theta}}} \\
& =\frac{\rho\left(1+g_{Y}\right)^{\frac{\theta-1}{\theta}} \alpha Y_{0}^{\frac{\theta-1}{\theta}}}{1-\rho\left(1+g_{Y}\right)^{\frac{\theta-1}{\theta}}}
\end{aligned}
$$

so that Eq. 5.57 becomes

$$
\begin{aligned}
\alpha\left(Y_{0}-x_{\mathrm{SP}}\right)^{\frac{\theta-1}{\theta}}+\frac{\alpha Y_{0}^{\frac{\theta-1}{\theta}} \rho\left(1+g_{Y}\right)^{\frac{\theta-1}{\theta}}}{1-\rho\left(1+g_{Y}\right)^{\frac{\theta-1}{\theta}}} & +\frac{(1-\alpha) E_{0}^{\prime \frac{\theta-1}{\theta}}}{1-\rho\left(1+g_{E}^{\prime}\right)^{\frac{\theta-1}{\theta}}} \\
= & \frac{\alpha Y_{0}^{\frac{\theta-1}{\theta}}}{1-\rho\left(1+g_{Y}\right)^{\frac{\theta-1}{\theta}}}+\frac{(1-\alpha) E_{0}^{\frac{\theta-1}{\theta}}}{1-\rho\left(1+g_{E}\right)^{\frac{\theta-1}{\theta}}} .
\end{aligned}
$$

On the left side of this equation is the intertemporal utility (in present value) from consumption of manufactured goods or income and environmental goods split in two terms: The first term represents the utility from consumption of manufactured goods in period $t=0$, for which consumption or income $Y_{0}$ is reduced by the one-time paid compensating surplus $x_{\mathrm{SP}}$. The second term represents the utility from consumption of manufactured 
goods starting in period $t=1$ until the infinite future, for which consumption or income $Y_{0}\left(1+g_{Y}\right)$ increases with the constant growth rate $g_{Y}$. Finally, the third term is the share of utility from the consumption of environmental goods, which decrease from $E_{0}^{\prime}$ at the constant rate $g_{E}^{\prime}$. The right side of this equation is the the present value of the intertemporal utility from the stream of consumption, growing from $Y_{0}$ at the constant rate $g_{Y}$, and the stream of environmental goods, that decreases from $E_{0}$ by the constant rate $g_{E}$.

This can be reformulated for the compensating surplus, $x_{\mathrm{SP}}$, as follows

$$
\begin{aligned}
& \alpha\left(Y_{0}-x_{\mathrm{SP}}\right)^{\frac{\theta-1}{\theta}}+\frac{(1-\alpha) E_{0}^{\prime \frac{\theta-1}{\theta}}}{1-\rho\left(1+g_{E}^{\prime}\right)^{\frac{\theta-1}{\theta}}}=\frac{\alpha Y_{0}^{\frac{\theta-1}{\theta}}\left(1-\rho\left(1+g_{Y}\right)^{\frac{\theta-1}{\theta}}\right)}{1-\rho\left(1+g_{Y}\right)^{\frac{\theta-1}{\theta}}}+\frac{(1-\alpha) E_{0}^{\frac{\theta-1}{\theta}}}{1-\rho\left(1+g_{E}\right)^{\frac{\theta-1}{\theta}}} \\
& \left(Y_{0}-x_{\mathrm{SP}}\right)^{\frac{\theta-1}{\theta}}=Y_{0}^{\frac{\theta-1}{\theta}}+\frac{\frac{1-\alpha}{\alpha} E_{0}^{\frac{\theta-1}{\theta}}}{1-\rho\left(1+g_{E}\right)^{\frac{\theta-1}{\theta}}}-\frac{\frac{1-\alpha}{\alpha} E_{0}^{\prime \frac{\theta-1}{\theta}}}{1-\rho\left(1+g_{E}^{\prime}\right)^{\frac{\theta-1}{\theta}}} \\
& x_{\mathrm{SP}}=Y_{0}-\left(Y_{0}^{\frac{\theta-1}{\theta}}+\frac{\frac{1-\alpha}{\alpha} E_{0}^{\frac{\theta-1}{\theta}}}{1-\rho\left(1+g_{E}\right)^{\frac{\theta-1}{\theta}}}-\frac{\frac{1-\alpha}{\alpha} E_{0}^{\prime \frac{\theta-1}{\theta}}}{1-\rho\left(1+g_{E}^{\prime}\right)^{\frac{\theta-1}{\theta}}}\right)^{\frac{\theta}{\theta-1}} \\
& =Y_{0}-\left(Y_{0}^{\frac{\theta-1}{\theta}}\left(1+Y_{0}^{-\frac{\theta-1}{\theta}}\left(\frac{\frac{1-\alpha}{\alpha} E_{0}^{\frac{\theta-1}{\theta}}}{1-\rho\left(1+g_{E}\right)^{\frac{\theta-1}{\theta}}}-\frac{\frac{1-\alpha}{\alpha} E_{0}^{\prime \frac{\theta-1}{\theta}}}{1-\rho\left(1+g_{E}^{\prime}\right)^{\frac{\theta-1}{\theta}}}\right)\right)\right)^{\frac{\theta}{\theta-1}} \\
& =Y_{0}\left(1-\left(1+Y_{0}^{\frac{1-\theta}{\theta}}\left(\frac{\frac{1-\alpha}{\alpha} E_{0}^{\frac{\theta-1}{\theta}}}{1-\rho\left(1+g_{E}\right)^{\frac{\theta-1}{\theta}}}-\frac{\frac{1-\alpha}{\alpha} E_{0}^{\prime \frac{\theta-1}{\theta}}}{1-\rho\left(1+g_{E}^{\prime}\right)^{\frac{\theta-1}{\theta}}}\right)\right)^{\frac{\theta}{\theta-1}}\right) \text {. }
\end{aligned}
$$

\subsubsection{Derivation of the compensating surplus measured as a constant pay- ment fraction, $x_{\mathrm{CPF}}$ (Eq. 5.11)}

Compensating surplus, $x_{\mathrm{CPF}}$, measured as a constant fraction of consumption (Eq. 5.9) for the intertemporal utility function specified in Eq. 5.6 is given as

$$
\begin{gathered}
U\left(\left(1-x_{\mathrm{CPF}}\right) Y_{0}, g_{Y}, E_{0}^{\prime}, g_{E}^{\prime}\right)=U\left(Y_{0}, g_{Y}, E_{0}, g_{E}\right) \\
\frac{\alpha\left(1-x_{\mathrm{CPF}}\right)^{\frac{\theta-1}{\theta}} Y_{0}^{\frac{\theta-1}{\theta}}}{1-\rho\left(1+g_{Y}\right)^{\frac{\theta-1}{\theta}}}+\frac{(1-\alpha) E_{0}^{\prime \frac{\theta-1}{\theta}}}{1-\rho\left(1+g_{E}^{\prime}\right)^{\frac{\theta-1}{\theta}}}=\frac{\alpha Y_{0}^{\frac{\theta-1}{\theta}}}{1-\rho\left(1+g_{Y}\right)^{\frac{\theta-1}{\theta}}}+\frac{(1-\alpha) E_{0} \frac{\theta-1}{\theta}}{1-\rho\left(1+g_{E}\right)^{\frac{\theta-1}{\theta}}}
\end{gathered}
$$




$$
\begin{gathered}
\frac{\alpha\left(1-\left(1-x_{\mathrm{CPF}}\right)^{\frac{\theta-1}{\theta}}\right) Y_{0}^{\frac{\theta-1}{\theta}}}{1-\rho\left(1+g_{Y}\right)^{\frac{\theta-1}{\theta}}}=\frac{(1-\alpha) E_{0}^{\prime} \frac{\theta-1}{\theta}}{1-\rho\left(1+g_{E}^{\prime}\right)^{\frac{\theta-1}{\theta}}}-\frac{(1-\alpha) E_{0}^{\frac{\theta-1}{\theta}}}{1-\rho\left(1+g_{E}\right)^{\frac{\theta-1}{\theta}}} \\
1-\left(1-x_{\mathrm{CPF}}\right)^{\frac{\theta-1}{\theta}}=\frac{1-\rho\left(1+g_{Y}\right)^{\frac{\theta-1}{\theta}}}{\alpha Y_{0}^{\frac{\theta-1}{\theta}}}\left(\frac{(1-\alpha) E_{0}^{\prime} \frac{\theta-1}{\theta}}{1-\rho\left(1+g_{E}^{\prime}\right)^{\frac{\theta-1}{\theta}}}-\frac{(1-\alpha) E_{0}^{\frac{\theta-1}{\theta}}}{1-\rho\left(1+g_{E}\right)^{\frac{\theta-1}{\theta}}}\right) \\
x_{\mathrm{CPF}}=1-\left(1-\frac{1-\rho\left(1+g_{Y}\right)^{\frac{\theta-1}{\theta}}}{\alpha Y_{0}^{\frac{\theta-1}{\theta}}}\left(\frac{(1-\alpha) E_{0}^{\frac{\theta-1}{\theta}}}{1-\rho\left(1+g_{E}^{\prime}\right)^{\frac{\theta-1}{\theta}}}-\frac{(1-\alpha) E_{0}^{\frac{\theta-1}{\theta}}}{1-\rho\left(1+g_{E}\right)^{\frac{\theta-1}{\theta}}}\right)\right)^{\frac{\theta}{\theta-1}}
\end{gathered}
$$

\subsubsection{Derivation of WTP as a single payment for a marginal change in} the initial environmental good, $\mathrm{WTP}_{\mathrm{SP}, d E}(\mathrm{Eq}$. 5.12)

Assuming $g_{E}=g_{E}^{\prime}$ and $E_{0}^{\prime}=E_{0}+d E$ in Eq. 5.59 we can consider the WTP at $t=0$ for a marginal change in the initial environmental good

$$
\begin{aligned}
\left(Y_{0}-\mathrm{WTP}_{\mathrm{SP}, d E}\right)^{\frac{\theta-1}{\theta}} & =Y_{0}^{\frac{\theta-1}{\theta}}+\frac{\frac{1-\alpha}{\alpha} E_{0}^{\frac{\theta-1}{\theta}}}{1-\rho\left(1+g_{E}\right)^{\frac{\theta-1}{\theta}}}-\frac{\frac{1-\alpha}{\alpha}\left(E_{0}+d E\right)^{\frac{\theta-1}{\theta}}}{1-\rho\left(1+g_{E}\right)^{\frac{\theta-1}{\theta}}} \\
& =Y_{0}^{\frac{\theta-1}{\theta}}+\frac{1-\alpha}{\alpha} \frac{E_{0}^{\frac{\theta-1}{\theta}}-\left(E_{0}+d E\right)^{\frac{\theta-1}{\theta}}}{1-\rho\left(1+g_{E}\right)^{\frac{\theta-1}{\theta}}}
\end{aligned}
$$

Using first degree Taylor expansion evaluated at $\mathrm{WTP}_{\mathrm{SP}, d E}=0$ we approximate $\left(Y_{0}-\right.$ $\left.\mathrm{WTP}_{\mathrm{SP}, d E}\right)^{\frac{\theta-1}{\theta}} \approx Y_{0}^{\frac{\theta-1}{\theta}}-\frac{\theta-1}{\theta} Y_{0}^{-1 / \theta} \mathrm{WTP}_{\mathrm{SP}, d E}$ and again using first degree Taylor expansion evaluated at $d E=0$ we approximate $\left(E_{0}+d E\right)^{\frac{\theta-1}{\theta}} \approx E_{0}^{\frac{\theta-1}{\theta}}+\frac{\theta-1}{\theta} E_{0}^{-1 / \theta} d E$. This gives

$$
\begin{aligned}
Y_{0}^{\frac{\theta-1}{\theta}}-\frac{\theta-1}{\theta} Y_{0}^{-1 / \theta} \mathrm{WTP}_{\mathrm{SP}, d E} & =Y_{0}^{\frac{\theta-1}{\theta}}+\frac{1-\alpha}{\alpha} \frac{E_{0}^{\frac{\theta-1}{\theta}}-E_{0}^{\frac{\theta-1}{\theta}}-\frac{\theta-1}{\theta} E_{0}^{-1 / \theta} d E}{1-\rho\left(1+g_{E}\right)^{\frac{\theta-1}{\theta}}} \\
Y_{0}^{-1 / \theta} \mathrm{WTP}_{\mathrm{SP}, d E} & =\frac{1-\alpha}{\alpha} \frac{E_{0}^{-1 / \theta} d E}{1-\rho\left(1+g_{E}\right)^{\frac{\theta-1}{\theta}}} \\
\mathrm{WTP}_{\mathrm{SP}, d E} & =\frac{1-\alpha}{\alpha} \frac{Y_{0}^{1 / \theta} E_{0}^{-1 / \theta}}{1-\rho\left(1+g_{E}\right)^{\frac{\theta-1}{\theta}}} d E .
\end{aligned}
$$




\subsubsection{Derivation of WTP as a single payment for a marginal change in} the growth rate, $\mathrm{WTP}_{\mathrm{SP}, d g_{E}}$ (Eq. 5.13)

Assuming $g_{E}^{\prime}=g_{E}+d g_{E}$ and $E_{0}=E_{0}^{\prime}$ in Eq. 5.59 we can consider the WTP at $t=0$ for a marginal change in the growth rate of environmental goods:

$$
\begin{aligned}
& \left(Y_{0}-\mathrm{WTP}_{\mathrm{SP}, d g_{E}}\right)^{\frac{\theta-1}{\theta}}=Y_{0}^{\frac{\theta-1}{\theta}}+\frac{\frac{1-\alpha}{\alpha} E_{0}^{\frac{\theta-1}{\theta}}}{1-\rho\left(1+g_{E}\right)^{\frac{\theta-1}{\theta}}}-\frac{\frac{1-\alpha}{\alpha} E_{0}^{\frac{\theta-1}{\theta}}}{1-\rho\left(1+g_{E}+d g_{E}\right)^{\frac{\theta-1}{\theta}}} \\
& =Y_{0}^{\frac{\theta-1}{\theta}}+\frac{1-\alpha}{\alpha} E_{0}{ }^{\frac{\theta-1}{\theta}}\left(\frac{1}{1-\rho\left(1+g_{E}\right)^{\frac{\theta-1}{\theta}}}-\frac{1}{1-\rho\left(1+g_{E}+d g_{E}\right)^{\frac{\theta-1}{\theta}}}\right) .
\end{aligned}
$$

Conducting a first degree Taylor expansion for $f\left(d g_{E}\right)=\frac{1}{1-\rho\left(1+g_{E}+d g_{E}\right)^{\frac{\theta-1}{\theta}}}$ at $d g_{E}=0$ yields

$$
\frac{1}{1-\rho\left(1+g_{E}+d g_{E}\right)^{\frac{\theta-1}{\theta}}} \approx \frac{1}{1-\rho\left(1+g_{E}\right)^{\frac{\theta-1}{\theta}}}+\frac{\frac{\theta-1}{\theta} \rho\left(1+g_{E}\right)^{-1 / \theta}}{\left(1-\rho\left(1+g_{E}\right)^{\frac{\theta-1}{\theta}}\right)^{2}} d g_{E}
$$

Using 5.71 and $\left(Y_{0}-\mathrm{WTP}_{\mathrm{SP}, d g_{E}}\right)^{\frac{\theta-1}{\theta}} \approx Y_{0}^{\frac{\theta-1}{\theta}}-\frac{\theta-1}{\theta} Y_{0}^{-1 / \theta} \mathrm{WTP}_{\mathrm{SP}, d g_{E}}$ we get

$$
\begin{aligned}
& Y_{0}^{\frac{\theta-1}{\theta}}-\frac{\theta-1}{\theta} Y_{0}^{-1 / \theta} \mathrm{WTP}_{\mathrm{SP}, d g_{E}}= \\
& Y_{0}^{\frac{\theta-1}{\theta}}+\frac{1-\alpha}{\alpha} E_{0}^{\frac{\theta-1}{\theta}}\left(\frac{1}{1-\rho\left(1+g_{E}\right)^{\frac{\theta-1}{\theta}}}-\frac{1}{1-\rho\left(1+g_{E}\right)^{\frac{\theta-1}{\theta}}}-\frac{\frac{\theta-1}{\theta} \rho\left(1+g_{E}\right)^{-1 / \theta}}{\left(1-\rho\left(1+g_{E}\right)^{\frac{\theta-1}{\theta}}\right)^{2}} d g_{E}\right) \\
& -\frac{\theta-1}{\theta} Y_{0}^{-1 / \theta} \mathrm{WTP}_{\mathrm{SP}, d g_{E}}=-\frac{1-\alpha}{\alpha} E_{0}^{\frac{\theta-1}{\theta}} \frac{\frac{\theta-1}{\theta} \rho\left(1+g_{E}\right)^{-1 / \theta}}{\left(1-\rho\left(1+g_{E}\right)^{\frac{\theta-1}{\theta}}\right)^{2}} d g_{E} \\
& \operatorname{WTP}_{\mathrm{SP}, d g_{E}}=\frac{1-\alpha}{\alpha} E_{0} \frac{\theta-1}{\theta} Y_{0}^{1 / \theta} \frac{\rho\left(1+g_{E}\right)^{-1 / \theta}}{\left(1-\rho\left(1+g_{E}\right)^{\frac{\theta-1}{\theta}}\right)^{2}} d g_{E} .
\end{aligned}
$$

\subsubsection{Derivation of WTP as a constant payment fraction for a marginal} change in the initial environmental good, $\mathrm{WTP}_{\mathrm{CPF}, d E}$ (Eq. 5.14)

Assuming $g_{E}=g_{E}^{\prime}$ and $E_{0}^{\prime}=E_{0}+d E$ in Eq. 5.62 we can consider the WTP in terms of a constant payment fraction for a marginal change in the initial environmental good

$$
\begin{aligned}
& \frac{\alpha\left(1-\mathrm{WTP}_{\mathrm{CPF}, d E}\right)^{\frac{\theta-1}{\theta}} Y_{0}^{\frac{\theta-1}{\theta}}}{1-\rho\left(1+g_{Y}\right)^{\frac{\theta-1}{\theta}}}+\frac{(1-\alpha)\left(E_{0}+d E\right)^{\frac{\theta-1}{\theta}}}{1-\rho\left(1+g_{E}\right)^{\frac{\theta-1}{\theta}}}=\frac{\alpha Y_{0}^{\frac{\theta-1}{\theta}}}{1-\rho\left(1+g_{Y}\right)^{\frac{\theta-1}{\theta}}}+\frac{(1-\alpha) E_{0}^{\frac{\theta-1}{\theta}}}{1-\rho\left(1+g_{E}\right)^{\frac{\theta-1}{\theta}}} \\
& 0=\frac{\alpha\left(1-\mathrm{WTP}_{\mathrm{CPF}, d E}\right)^{\frac{\theta-1}{\theta}} Y_{0}^{\frac{\theta-1}{\theta}}-\alpha Y_{0}^{\frac{\theta-1}{\theta}}}{1-\rho\left(1+g_{Y}\right)^{\frac{\theta-1}{\theta}}}+\frac{(1-\alpha)\left(E_{0}+d E\right)^{\frac{\theta-1}{\theta}}-(1-\alpha) E_{0}^{\frac{\theta-1}{\theta}}}{1-\rho\left(1+g_{E}\right)^{\frac{\theta-1}{\theta}}} .
\end{aligned}
$$


Applying Taylor series expansion of degree one at $\mathrm{WTP}_{\mathrm{CPF}, d E}=0$ and $d E=0$, respectively, yields the following approximations $\left(1-\mathrm{WTP}_{\mathrm{CPF}, d E}\right)^{\frac{\theta-1}{\theta}} \approx 1+\frac{1-\theta}{\theta} \mathrm{WTP}_{\mathrm{CPF}, d E}$ and $\left(E_{0}+d E\right)^{\frac{\theta-1}{\theta}} \approx E_{0}^{\frac{\theta-1}{\theta}}+\frac{\theta-1}{\theta} E_{0}^{-1 / \theta} d E$. Using these in the formula above yields

$$
\begin{aligned}
0 & =\frac{\alpha \frac{1-\theta}{\theta} Y_{0}^{\frac{\theta-1}{\theta}}}{1-\rho\left(1+g_{Y}\right)^{\frac{\theta-1}{\theta}}} \mathrm{WTP}_{\mathrm{CPF}, d E}+\frac{(1-\alpha) \frac{\theta-1}{\theta} E_{0}{ }^{-1 / \theta}}{1-\rho\left(1+g_{E}\right)^{\frac{\theta-1}{\theta}}} d E \\
\frac{\alpha Y_{0}^{\frac{\theta-1}{\theta}}}{1-\rho\left(1+g_{Y}\right)^{\frac{\theta-1}{\theta}}} \mathrm{WTP}_{\mathrm{CPF}, d E} & =\frac{(1-\alpha) E_{0}^{-1 / \theta}}{1-\rho\left(1+g_{E}\right)^{\frac{\theta-1}{\theta}}} d E \\
\mathrm{WTP}_{\mathrm{CPF}, d E} & =\frac{1-\alpha}{\alpha} \frac{1-\rho\left(1+g_{Y}\right)^{\frac{\theta-1}{\theta}}}{1-\rho\left(1+g_{E}\right)^{\frac{\theta-1}{\theta}}} Y_{0}^{\frac{1-\theta}{\theta}} E_{0}^{-1 / \theta} d E .
\end{aligned}
$$

\subsubsection{Derivation of WTP as a constant payment fraction for a marginal change in the growth rate of the environmental good, $\mathrm{WTP}_{\mathbf{C P F}, d g_{E}}$}

(Eq. 5.15)

Assuming $E_{0}=E_{0}^{\prime}$ and $g_{E}^{\prime}=g_{E}+d g_{E}$ in Eq. 5.62 we can consider the WTP in terms of a constant payment fraction for a marginal change in the growth rate of the environmental good

$$
\begin{aligned}
& \frac{\alpha\left(1-\mathrm{WTP}_{\mathrm{CPF}, d g_{E}}\right)^{\frac{\theta-1}{\theta}} Y_{0}^{\frac{\theta-1}{\theta}}}{1-\rho\left(1+g_{Y}\right)^{\frac{\theta-1}{\theta}}}+\frac{(1-\alpha) E_{0}^{\frac{\theta-1}{\theta}}}{1-\rho\left(1+g_{E}+d g_{E}\right)^{\frac{\theta-1}{\theta}}}=\frac{\alpha Y_{0}^{\frac{\theta-1}{\theta}}}{1-\rho\left(1+g_{Y}\right)^{\frac{\theta-1}{\theta}}}+\frac{(1-\alpha) E_{0}^{\frac{\theta-1}{\theta}}}{1-\rho\left(1+g_{E}\right)^{\frac{\theta-1}{\theta}}} \\
& 0=\frac{\alpha Y_{0}^{\frac{\theta-1}{\theta}}-\alpha\left(1-\mathrm{WTP}_{\mathrm{CPF}, d g_{E}}\right)^{\frac{\theta-1}{\theta}} Y_{0}^{\frac{\theta-1}{\theta}}}{1-\rho\left(1+g_{Y}\right)^{\frac{\theta-1}{\theta}}} \\
& +(1-\alpha) E_{0}^{\frac{\theta-1}{\theta}}\left(\frac{1}{1-\rho\left(1+g_{E}\right)^{\frac{\theta-1}{\theta}}}-\frac{1}{1-\rho\left(1+g_{E}+d g_{E}\right)^{\frac{\theta-1}{\theta}}}\right) .
\end{aligned}
$$

Applying Taylor series expansion of degree one at $\mathrm{WTP}_{\mathrm{CPF}, d g_{E}}=0$ and $d g_{E}=0$, respectively, yields the following approximations $\left(1-\mathrm{WTP}_{\mathrm{CPF}, d g_{E}}\right)^{\frac{\theta-1}{\theta}} \approx 1-\frac{\theta-1}{\theta} \mathrm{WTP}_{\mathrm{CPF}, d g_{E}}$ and $\frac{1}{1-\rho\left(1+g_{E}+d g_{E}\right)^{\frac{\theta-1}{\theta}}} \approx \frac{1}{1-\rho\left(1+g_{E}\right)^{\frac{\theta-1}{\theta}}}+\frac{\frac{\theta-1}{\theta} \rho\left(1+g_{E}\right)^{-1 / \theta}}{\left(1-\rho\left(1+g_{E}\right)^{\frac{\theta-1}{\theta}}\right)^{2}} d g_{E}$. Using these in the formula above 
yields

$$
\begin{aligned}
0 & =\frac{\alpha Y_{0}^{\frac{\theta-1}{\theta}}-\alpha\left(1-\frac{\theta-1}{\theta} \mathrm{WTP}_{\mathrm{CPF}, d g_{E}}\right) Y_{0}^{\frac{\theta-1}{\theta}}}{1-\rho\left(1+g_{Y}\right)^{\frac{\theta-1}{\theta}}}-(1-\alpha) E_{0}^{\frac{\theta-1}{\theta}} \frac{\rho \frac{\theta-1}{\theta}\left(1+g_{E}\right)^{-1 / \theta}}{\left(1-\rho\left(1+g_{E}\right)^{\frac{\theta-1}{\theta}}\right)^{2}} d g_{E} \\
0 & =\frac{\alpha \frac{\theta-1}{\theta} Y_{0}^{\frac{\theta-1}{\theta}}}{1-\rho\left(1+g_{Y}\right)^{\frac{\theta-1}{\theta}}} \mathrm{WTP}_{\mathrm{CPF}, d g_{E}}-(1-\alpha) E_{0}^{\frac{\theta-1}{\theta}} \frac{\rho \frac{\theta-1}{\theta}\left(1+g_{E}\right)^{-1 / \theta}}{\left(1-\rho\left(1+g_{E}\right)^{\frac{\theta-1}{\theta}}\right)^{2}} d g_{E} \\
\mathrm{WTP}_{\mathrm{CPF}, d g_{E}} & =(1-\alpha) E_{0}^{\frac{\theta-1}{\theta}} \frac{\frac{\theta-1}{\theta} \rho\left(1+g_{E}\right)^{-1 / \theta}}{\left(1-\rho\left(1+g_{E}\right)^{\frac{\theta-1}{\theta}}\right)^{2}} d g_{E} \frac{1-\rho\left(1+g_{Y}\right)^{\frac{\theta-1}{\theta}}}{\alpha \theta Y_{0}^{\frac{\theta-1}{\theta}}} \\
\mathrm{WTP}_{\mathrm{CPF}, d g_{E}} & =\frac{1-\alpha}{\alpha} \frac{\rho\left(1+g_{E}\right)^{-1 / \theta}\left(1-\rho\left(1+g_{Y}\right)^{\frac{\theta-1}{\theta}}\right)}{\left(1-\rho\left(1+g_{E}\right)^{\frac{\theta-1}{\theta}}\right)^{2}} Y_{0}^{\frac{1-\theta}{\theta}} E_{0}^{\frac{\theta-1}{\theta}} d g_{E} .
\end{aligned}
$$

\subsubsection{Derivation of mean WTP as a single payment for a marginal change} in the initial level of the environmental good, $\overline{\mathrm{WTP}}_{\mathrm{SP}, d E}$ (Eq. 5.17)

The density function of the log-normal distribution of income $Y_{0}$ in $t=0$ with mean $\mu_{Y_{0}}$ and standard deviation $\sigma_{Y_{0}}$ is given by

$$
\begin{aligned}
f_{\ln }\left(Y_{0} ; \mu_{Y_{0}}, \sigma_{Y_{0}}\right) & =\frac{1}{Y_{0} \sqrt{2 \pi s^{2}}} \exp \left(-\frac{\left(\ln Y_{0}-m\right)^{2}}{2 s^{2}}\right) \\
\text { with } m & =\ln \mu_{Y_{0}}-\frac{1}{2} \ln \left(1+\sigma_{Y_{0}}^{2} / \mu_{Y_{0}}^{2}\right) \\
s^{2} & =\ln \left(1+\sigma_{Y_{0}}^{2} / \mu_{Y_{0}}^{2}\right) .
\end{aligned}
$$


Then mean compensating surplus in terms of a single payment at $t=0$ (Eq. 5.16) can be reformulated as

$$
\begin{aligned}
& \overline{\mathrm{WTP}}_{\mathrm{SP}, d E}\left(\mu_{Y_{0}}, \sigma_{Y_{0}}, g_{E}\right) \\
& =\int_{0}^{\infty} f_{\ln }\left(Y_{0} ; \mu_{Y_{0}}, \sigma_{Y_{0}}\right) \mathrm{WTP}_{\mathrm{SP}, d E}\left(Y_{0}, g_{E}\right) d Y_{0} \\
& \stackrel{5.12,5.74}{=} \int_{0}^{\infty} \frac{1}{Y_{0} \sqrt{2 \pi s^{2}}} \exp \left(-\frac{\left(\ln Y_{0}-m\right)^{2}}{2 s^{2}}\right) \frac{1-\alpha}{\alpha} \frac{Y_{0}^{1 / \theta} E_{0}^{-1 / \theta} d E}{1-\rho\left(1+g_{E}\right)^{\frac{\theta-1}{\theta}}} d Y_{0} \\
& =\underbrace{\frac{1-\alpha}{\alpha} \frac{E_{0}^{-1 / \theta} d E}{1-\rho\left(1+g_{E}\right)^{\frac{\theta-1}{\theta}}}}_{=: \kappa} \int_{0}^{\infty} \frac{Y_{0}^{1 / \theta}}{Y_{0} \sqrt{2 \pi s^{2}}} \exp \left(-\frac{\left(\ln Y_{0}-m\right)^{2}}{2 s^{2}}\right) d Y_{0} \\
& =\kappa \int_{0}^{\infty} \frac{Y_{0}^{\frac{1-\theta}{\theta}}}{\sqrt{2 \pi s^{2}}} \exp \left(-\frac{\left(\ln Y_{0}-m\right)^{2}}{2 s^{2}}\right) d Y_{0} \\
& =\kappa \exp \left[\frac{1}{2 \theta^{2}} s^{2}+\frac{1}{\theta} m\right] \\
& \stackrel{5.75,5.76}{=} \kappa \exp \left[\frac{1}{2 \theta^{2}} \ln \left(1+\frac{\sigma_{Y_{0}}^{2}}{\mu_{Y_{0}}^{2}}\right)+\frac{1}{\theta} \ln \mu_{Y_{0}}-\frac{1}{2 \theta} \ln \left(1+\frac{\sigma_{Y_{0}}^{2}}{\mu_{Y_{0}}^{2}}\right)\right] \\
& =\kappa \exp \left[\frac{1-\theta}{2 \theta^{2}} \ln \left(1+\frac{\sigma_{Y_{0}}^{2}}{\mu_{Y_{0}}^{2}}\right)+\frac{1}{\theta} \ln \left(\mu_{Y_{0}}\right)\right] \\
& =\kappa \exp \left[\ln \left(\left(1+\frac{\sigma_{Y_{0}}^{2}}{\mu_{Y_{0}}^{2}}\right)^{\frac{1-\theta}{2 \theta^{2}}}\right)\right] \exp \left[\ln \left(\mu_{Y_{0}}^{\frac{1}{\theta}}\right)\right] \\
& =\kappa \mu_{Y_{0}}^{1 / \theta}\left(1+\frac{\sigma_{Y_{0}}^{2}}{\mu_{Y_{0}}^{2}}\right)^{\frac{1-\theta}{2 \theta^{2}}}
\end{aligned}
$$

or, equivalently, for relative inequality in initial income $C V_{Y_{0}}=\frac{\sigma_{Y_{0}}}{\mu_{Y_{0}}}$

$$
\overline{\mathrm{WTP}}_{\mathrm{SP}, d E}\left(\mu_{Y_{0}}, \mathrm{CV}_{Y_{0}}, g_{E}\right)=\kappa \mu_{Y_{0}}^{1 / \theta}\left(1+\mathrm{CV}_{Y_{0}}^{2}\right)^{\frac{1-\theta}{2 \theta^{2}}}
$$


5.8.10 Derivation of mean WTP as a single payment for a marginal change in the growth rate of the environmental good, $\overline{\mathbf{W T P}}_{\mathbf{S P}, d g_{E}}$ (Eq. 5.18)

Analogue to Appendix 5.8.9 we derive the mean WTP for a marginal change in the growth rate as follows

$$
\begin{aligned}
& \overline{\mathrm{WTP}}_{\mathrm{SP}, d g_{E}}\left(\mu_{Y_{0}}, \sigma_{Y_{0}}, g_{E}\right)=\int_{0}^{\infty} f_{\ln }\left(Y_{0} ; \mu_{Y_{0}}, \sigma_{Y_{0}}\right) \mathrm{WTP}_{\mathrm{SP}, d g_{E}}\left(Y_{0}, g_{E}\right) d Y_{0} \\
& \stackrel{5.13,5.74}{=} \int_{0}^{\infty} \frac{1}{Y_{0} \sqrt{2 \pi s^{2}}} \exp \left(-\frac{\left(\ln Y_{0}-m\right)^{2}}{2 s^{2}}\right) \frac{1-\alpha}{\alpha} E_{0}{ }^{\frac{\theta-1}{\theta}} Y_{0}^{1 / \theta} \frac{\rho\left(1+g_{E}\right)^{-1 / \theta}}{\left(1-\rho\left(1+g_{E}\right)^{\frac{\theta-1}{\theta}}\right)^{2}} d g_{E} d Y_{0} \\
& =\underbrace{\frac{1-\alpha}{\alpha} E_{0} \frac{\theta-1}{\theta} \frac{\rho\left(1+g_{E}\right)^{-1 / \theta}}{\left(1-\rho\left(1+g_{E}\right)^{\frac{\theta-1}{\theta}}\right)^{2}} d g_{E}}_{=: \kappa^{\prime}} \int_{0}^{\infty} \frac{Y_{0}^{\frac{1-\theta}{\theta}}}{\sqrt{2 \pi s^{2}}} \exp \left(-\frac{\left(\ln Y_{0}-m\right)^{2}}{2 s^{2}}\right) d Y_{0} \\
& =\kappa^{\prime} \exp \left[\frac{1}{2 \theta^{2}} s^{2}+\frac{1}{\theta} m\right] \\
& =\kappa^{\prime} \mu_{Y_{0}}^{1 / \theta}\left(1+\frac{\sigma_{Y_{0}}^{2}}{\mu_{Y_{0}}^{2}}\right)^{\frac{1-\theta}{2 \theta^{2}}}
\end{aligned}
$$

or, equivalently, for relative inequality in initial income $C V_{Y_{0}}=\frac{\sigma_{Y_{0}}}{\mu_{Y_{0}}}$

$$
\overline{\mathrm{WTP}}_{\mathrm{SP}, d g_{E}}\left(\mu_{Y_{0}}, \mathrm{CV}_{Y_{0}}, g_{E}\right)=\kappa^{\prime} \mu_{Y_{0}}^{1 / \theta}\left(1+\mathrm{CV}_{Y_{0}}^{2}\right)^{\frac{1-\theta}{2 \theta^{2}}}
$$


5.8.11 Derivation of mean WTP at time $t, \overline{\mathrm{WTP}}_{\mathrm{CPF}, d E ; t}$ (Eq. 5.21), and the present value of mean WTP, $\overline{\mathrm{WTP}}_{\mathrm{CPF}, d E}$ (Eq. 5.22), as a constant payment fraction for a marginal change in initial level of the environmental good

The mean WTP at time $t$ measured as a constant payment fraction is

$$
\begin{aligned}
& \overline{\mathrm{WTP}}_{\mathrm{CPF}, d E ; t}\left(\mu_{Y_{0}}, \sigma_{Y_{0}}, g_{Y}, g_{E}\right) \\
& =\int_{0}^{\infty} f_{\ln }\left(Y_{0} ; \mu_{Y_{0}}, \sigma_{Y_{0}}\right) \mathrm{WTP}_{\mathrm{CPF}, d E}\left(Y_{0}, g_{Y}, g_{E}\right) Y_{t}\left(Y_{0}\right) d Y_{0} \\
& \stackrel{5.2 a}{=} \int_{0}^{\infty} f_{\ln }\left(Y_{0} ; \mu_{Y_{0}}, \sigma_{Y_{0}}\right) \mathrm{WTP}_{\mathrm{CPF}, d E}\left(Y_{0}, g_{Y}, g_{E}\right)\left(1+g_{Y}\right)^{t} Y_{0} d Y_{0} \\
& \stackrel{5.74,5.14}{=} \int_{0}^{\infty} \frac{1}{Y_{0} \sqrt{2 \pi s^{2}}} \exp \left(-\frac{\left(\ln Y_{0}-m\right)^{2}}{2 s^{2}}\right) \frac{1-\alpha}{\alpha} \frac{1-\rho\left(1+g_{Y}\right)^{\frac{\theta-1}{\theta}}}{1-\rho\left(1+g_{E}\right)^{\frac{\theta-1}{\theta}}} E_{0}^{-1 / \theta} Y_{0}^{\frac{1-\theta}{\theta}} d E\left(1+g_{Y}\right)^{t} Y_{0} d Y_{0} \\
& = \\
& \underbrace{\frac{1-\alpha}{\alpha}}_{=: \kappa^{\prime \prime}} \frac{\left(1-\rho\left(1+g_{Y}\right)^{\frac{\theta-1}{\theta}}\right)\left(1+g_{Y}\right)^{t}}{1-\rho\left(1+g_{E}\right)^{\frac{\theta-1}{\theta}}} E_{0}^{-1 / \theta} d E \int_{0}^{\infty} \frac{Y_{0}^{\frac{1-\theta}{\theta}}}{\sqrt{2 \pi s^{2}}} \exp \left(-\frac{\left(\ln Y_{0}-m\right)^{2}}{2 s^{2}}\right) d Y_{0} \\
& \operatorname{Sec.5.8.9}_{=} \kappa^{\prime \prime} \mu_{Y_{0}}^{1 / \theta}\left(1+\frac{\sigma_{Y_{0}}^{2}}{\mu_{Y_{0}}^{2}}\right)^{\frac{1-\theta}{2 \theta^{2}}},
\end{aligned}
$$

and for relative inequality in initial income, $C V_{Y_{0}}=\frac{\sigma_{Y_{0}}}{\mu_{Y_{0}}}$,

$$
\overline{\mathrm{WTP}}_{\mathrm{CPF}, d E ; t}\left(\mu_{Y_{0}}, \mathrm{CV}_{Y_{0}}, g_{Y}, g_{E}\right)=\kappa^{\prime \prime} \mu_{Y_{0}}^{1 / \theta}\left(1+\mathrm{CV}_{Y_{0}}^{2}\right)^{\frac{1-\theta}{2 \theta^{2}}} .
$$

The associated present value - discounted at market interest rates - is

$$
\begin{aligned}
& \overline{\mathrm{WTP}}_{\mathrm{CPF}, d E}\left(\mu_{Y_{0}}, \mathrm{CV}_{Y_{0}}, g_{Y}, g_{E}\right) \\
& =\sum_{t=0}^{\infty}\left(\prod_{\tau=0}^{t} \delta_{\tau}\right) \overline{\mathrm{WTP}}_{\mathrm{CPF}, d E ; t}\left(\mu_{Y_{0}}, \mathrm{CV}_{Y_{0}}, g_{Y}, g_{E}\right) \\
& \stackrel{5.21}{=} \sum_{t=0}^{\infty}\left(\prod_{\tau=0}^{t} \delta_{\tau}\right) \frac{1-\alpha}{\alpha} \frac{\left(1-\rho\left(1+g_{Y}\right)^{\frac{\theta-1}{\theta}}\right)\left(1+g_{Y}\right)^{t}}{1-\rho\left(1+g_{E}\right)^{\frac{\theta-1}{\theta}}} E_{0}^{-1 / \theta} d E \mu_{Y_{0}}^{1 / \theta}\left(1+\mathrm{CV}_{Y_{0}}^{2}\right)^{\frac{1-\theta}{\theta^{2}}} \\
& =\underbrace{\frac{1-\alpha}{\alpha} \frac{1-\rho\left(1+g_{Y}\right)^{\frac{\theta-1}{\theta}}}{1-\rho\left(1+g_{E}\right)^{\frac{\theta-1}{\theta}}} E_{0}^{-1 / \theta} d E\left[\sum_{t=0}^{\infty}\left(\prod_{\tau=0}^{t} \delta_{\tau}\right)\left(1+g_{Y}\right)^{t}\right]}_{=: \kappa^{\prime \prime \prime}} \mu_{Y_{0}}^{1 / \theta}\left(1+\mathrm{CV}_{Y_{0}}^{2}\right)^{\frac{1-\theta}{2 \theta^{2}}} \\
& =\kappa^{\prime \prime \prime} \mu_{Y_{0}}^{1 / \theta}\left(1+\mathrm{CV}_{Y_{0}}^{2}\right)^{\frac{1-\theta}{2 \theta^{2}}} .
\end{aligned}
$$


5.8.12 Derivation of mean WTP at time $t, \overline{\mathrm{WTP}}_{\mathrm{CPF}, d g_{E} ; t}$ (Eq. 5.23), and the present value of mean WTP, $\overline{\mathrm{WTP}}_{\mathrm{CPF}, d g_{E}}$ (Eq. 5.24), as a constant payment fraction for a marginal change in the growth rate of the environmental good

$$
\begin{aligned}
& \overline{\mathrm{WTP}}_{\mathrm{CPF}, d g_{E} ; t}\left(\mu_{Y_{0}}, \sigma_{Y_{0}}, g_{Y}, g_{E}\right) \\
& =\int_{0}^{\infty} f_{\ln }\left(Y_{0} ; \mu_{Y_{0}}, \sigma_{Y_{0}}\right) \mathrm{WTP}_{\mathrm{CPF}, d g_{E}}\left(Y_{0}, g_{Y}, g_{E}\right) Y_{t}\left(Y_{0}\right) d Y_{0} \\
& \stackrel{5.2 a}{=} \int_{0}^{\infty} f_{\ln }\left(Y_{0} ; \mu_{Y_{0}}, \sigma_{Y_{0}}\right) \mathrm{WTP}_{\mathrm{CPF}, d g_{E}}\left(Y_{0}, g_{Y}, g_{E}\right)\left(1+g_{Y}\right)^{t} Y_{0} d Y_{0} \\
& \stackrel{5.74,5.15}{=} \int_{0}^{\infty} \frac{1}{Y_{0} \sqrt{2 \pi s^{2}}} \exp \left(-\frac{\left(\ln Y_{0}-m\right)^{2}}{2 s^{2}}\right) \frac{1-\alpha}{\alpha} \frac{\rho\left(1+g_{E}\right)^{-1 / \theta}\left(1-\rho\left(1+g_{Y}\right)^{\frac{\theta-1}{\theta}}\right)}{\left(1-\rho\left(1+g_{E}\right)^{\frac{\theta-1}{\theta}}\right)^{2}} \\
& =\frac{\underbrace{1-\alpha}_{=: \kappa^{\prime \prime \prime \prime}}}{\alpha} \frac{\left(1+g_{E}\right)^{-1 / \theta}\left(1-\rho\left(1+g_{Y}\right)^{\frac{\theta-1}{\theta}}\right)}{\left(1-\rho\left(1+g_{E}\right)^{\frac{\theta-1}{\theta}}\right)^{2}} d g_{E}\left(1+g_{Y}\right)^{t} E_{0}^{\frac{\theta-1}{\theta}} \int_{0}^{\infty} \frac{Y_{0}^{\frac{1-\theta}{\theta}}}{\sqrt{2 \pi s^{2}}} \exp \left(-\frac{\left(\ln Y_{0}-m\right)^{2}}{2 s^{2}}\right) d Y_{0} \\
& = \\
& \kappa^{\prime \prime \prime \prime \prime} \mu_{Y_{0}}^{1 / \theta}\left(1+\frac{\sigma_{Y_{0}}^{2}}{\mu_{Y_{0}}^{2}}\right)^{\frac{1-\theta}{2 \theta^{2}}}, \\
& g_{E}\left(1+g_{Y}\right)^{t} Y_{0} d Y_{0}
\end{aligned}
$$

and for relative inequality in initial income, $C V_{Y_{0}}=\frac{\sigma_{Y_{0}}}{\mu_{Y_{0}}}$,

$$
\overline{\mathrm{WTP}}_{\mathrm{CPF}, d g_{E} ; t}\left(\mu_{Y_{0}}, \mathrm{CV}_{Y_{0}}, g_{Y}, g_{E}\right)=\kappa^{\prime \prime \prime \prime \prime} \mu_{Y_{0}}^{1 / \theta}\left(1+\mathrm{CV}_{Y_{0}}^{2}\right)^{\frac{1-\theta}{2 \theta^{2}}}
$$

The associated present value - discounted at market interest rates - is

$$
\begin{aligned}
& \overline{\mathrm{WTP}}_{\mathrm{CPF}, d g_{E}}\left(\mu_{Y_{0}}, \mathrm{CV}_{Y_{0}}, g_{Y}, g_{E}\right) \\
& =\sum_{t=0}^{\infty}\left(\prod_{\tau=0}^{t} \delta_{\tau}\right) \overline{\mathrm{WTP}}_{\mathrm{CPF}, d g_{E} ; t}\left(\mu_{Y_{0}}, \mathrm{CV}_{Y_{0}}, g_{Y}, g_{E}\right) \\
& \stackrel{5.85}{=} \sum_{t=0}^{\infty}\left(\prod_{\tau=0}^{t} \delta_{\tau}\right) \frac{1-\alpha}{\alpha} \frac{\rho\left(1+g_{E}\right)^{-1 / \theta}\left(1-\rho\left(1+g_{Y}\right)^{\frac{\theta-1}{\theta}}\right)}{\left(1-\rho\left(1+g_{E}\right)^{\frac{\theta-1}{\theta}}\right)^{2}} d g_{E}\left(1+g_{Y}\right)^{t} E_{0}^{\frac{\theta-1}{\theta}} \mu_{Y_{0}}^{1 / \theta}\left(1+C V_{Y_{0}}^{2}\right)^{\frac{1-\theta}{2 \theta^{2}}} \\
& =\underbrace{\frac{1-\alpha}{\alpha} \frac{\rho\left(1+g_{E}\right)^{-1 / \theta}\left(1-\rho\left(1+g_{Y}\right)^{\frac{\theta-1}{\theta}}\right)}{\left(1-\rho\left(1+g_{E}\right)^{\frac{\theta-1}{\theta}}\right)^{2}} d g_{E} E_{0}^{\frac{\theta-1}{\theta}} \sum_{t=0}^{\infty}\left(\prod_{\tau=0}^{t} \delta_{\tau}\right)\left(1+g_{Y}\right)^{t}}_{=: \kappa^{\prime \prime \prime \prime \prime}} \mu_{Y_{0}}^{1 / \theta}\left(1+C V_{Y_{0}}^{2}\right)^{\frac{1-\theta}{2 \theta^{2}}} \\
& =\kappa^{\prime \prime \prime \prime \prime \prime} \mu_{Y_{0}}^{1 / \theta}\left(1+C V_{Y_{0}}^{2}\right)^{\frac{1-\theta}{2 \theta^{2}}} .
\end{aligned}
$$




\subsubsection{Proof of Proposition 5.1}

Differentiating $\overline{\mathrm{WTP}}_{\mathrm{SP}, d E}$ (Eq. 5.17) with respect to initial mean income, $\mu_{Y_{0}}$, yields

$$
\begin{aligned}
\frac{\partial \overline{\mathrm{WTP}}_{\mathrm{SP}, d E}\left(\mu_{Y_{0}}, \mathrm{CV}_{Y_{0}}, g_{E}\right)}{\partial \mu_{Y_{0}}}= & \kappa \frac{1}{\theta} \mu_{Y_{0}}^{\frac{1-\theta}{\theta}}\left(1+\mathrm{CV}_{Y_{0}}^{2}\right)^{\frac{1-\theta}{2 \theta^{2}}} \\
\text { with } & \kappa=\frac{1-\alpha}{\alpha} \frac{E_{0}^{-1 / \theta} d E}{1-\rho\left(1+g_{E}\right)^{\frac{\theta-1}{\theta}}},
\end{aligned}
$$

which is strictly greater zero for a marginal increase in the environmental good $(d E>0)$, as $E_{0}, \mu_{Y_{0}}, \mathrm{CV}_{Y_{0}}, \theta>0, \alpha \in(0,1)$ and by assumption $\rho\left(1+g_{E}\right)^{\frac{\theta-1}{\theta}}<1$.

Differentiating $\overline{\mathrm{WTP}}_{\mathrm{SP}, d g_{E}}$ (Eq. 5.18) with respect to initial mean income, $\mu_{Y_{0}}$, yields

$$
\begin{aligned}
\frac{\partial \overline{\mathrm{WTP}}_{\mathrm{SP}, d g_{E}}\left(\mu_{Y_{0}}, \mathrm{CV}_{Y_{0}}, g_{E}\right)}{\partial \mu_{Y_{0}}}= & \kappa^{\prime} \frac{1}{\theta} \mu_{Y_{0}}^{\frac{1-\theta}{\theta}}\left(1+\mathrm{CV}_{Y_{0}}^{2}\right)^{\frac{1-\theta}{2 \theta^{2}}} \\
\text { with } \quad & \kappa^{\prime}=\frac{1-\alpha}{\alpha} E_{0} \frac{\theta-1}{\theta} \frac{\rho\left(1+g_{E}\right)^{-1 / \theta}}{\left(1-\rho\left(1+g_{E}\right)^{\frac{\theta-1}{\theta}}\right)^{2}} d g_{E},
\end{aligned}
$$

which is strictly greater zero for a marginal increase in the growth rate of the environmental $\operatorname{good}\left(d g_{E}>0\right)$, as $E_{0}, \mu_{Y_{0}}, \mathrm{CV}_{Y_{0}}, \theta, \rho>0, \alpha \in(0,1)$ and $g_{E}>-1$.

Differentiating $\overline{\mathrm{WTP}}_{\mathrm{CPF}, d E}$ (Eq. 5.22) with respect to initial mean income, $\mu_{Y_{0}}$, yields

$$
\begin{aligned}
& \frac{\partial \overline{\mathrm{WTP}}_{\mathrm{CPF}, d E}\left(\mu_{Y_{0}}, \mathrm{CV}_{Y_{0}}, g_{E}, g_{Y}\right)}{\partial \mu_{Y_{0}}}=\kappa^{\prime \prime \prime} \frac{1}{\theta} \mu_{Y_{0}}^{\frac{1-\theta}{\theta}}\left(1+\mathrm{CV}_{Y_{0}}^{2}\right)^{\frac{1-\theta}{2 \theta^{2}}} \\
& \text { with } \kappa^{\prime \prime \prime}=\frac{1-\alpha}{\alpha} \frac{1-\rho\left(1+g_{Y}\right)^{\frac{\theta-1}{\theta}}}{1-\rho\left(1+g_{E}\right)^{\frac{\theta-1}{\theta}}} E_{0}^{-1 / \theta} d E\left[\sum_{t=0}^{\infty}\left(\prod_{\tau=0}^{t} \delta_{\tau}\right)\left(1+g_{Y}\right)^{t}\right],
\end{aligned}
$$

which is strictly greater zero for a marginal increase in the environmental good $(d E>0)$, as $E_{0}, \mu_{Y_{0}}, \mathrm{CV}_{Y_{0}}, \theta>0, \alpha \in(0,1)$ and by assumption $\rho\left(1+g_{E}\right)^{\frac{\theta-1}{\theta}}<1, \rho\left(1+g_{Y}\right)^{\frac{\theta-1}{\theta}}<1$.

Differentiating $\overline{\mathrm{WTP}}$ (Eq. 5.24) with respect to initial mean income, $\mu_{Y_{0}}$, yields

$$
\begin{gathered}
\frac{\partial \overline{\mathrm{WTP}}_{\mathrm{CPF}, d g_{E}}\left(\mu_{Y_{0}}, \mathrm{CV}_{Y_{0}}, g_{Y}, g_{E}\right)}{\partial \mu_{Y_{0}}}=\kappa^{\prime \prime \prime \prime \prime} \frac{1}{\theta} \mu_{Y_{0}}^{\frac{1-\theta}{\theta}}\left(1+\mathrm{CV}_{Y_{0}}^{2}\right)^{\frac{1-\theta}{2 \theta^{2}}} \\
\text { with } \kappa^{\prime \prime \prime \prime \prime \prime}=\frac{1-\alpha}{\alpha} \frac{\rho\left(1+g_{E}\right)^{-1 / \theta}\left(1-\rho\left(1+g_{Y}\right)^{\frac{\theta-1}{\theta}}\right)}{\left(1-\rho\left(1+g_{E}\right)^{\frac{\theta-1}{\theta}}\right)^{2}} d g_{E} E_{0}^{\frac{\theta-1}{\theta}} \sum_{t=0}^{\infty}\left(\prod_{\tau=0}^{t} \delta_{\tau}\right)\left(1+g_{Y}\right)^{t},
\end{gathered}
$$

which is strictly greater zero for a marginal increase in the growth rate of the environmental $\operatorname{good}\left(d g_{E}>0\right)$, as $\alpha \in(0,1), g_{E}>-1, \rho\left(1+g_{Y}\right)^{\frac{\theta-1}{\theta}}<1$ and $g_{Y}, E_{0}, \mathrm{CV}_{Y_{0}}, \mu_{Y_{0}}, \theta, \rho>0$. 


\subsubsection{Proof of Proposition 5.2}

Differentiating $\overline{\mathrm{WTP}}_{\mathrm{SP}, d E}$ (Eq. 5.17) with respect to relative intratemporal income inequality, $\mathrm{CV}_{Y_{0}}$, yields

$$
\frac{\partial \overline{\mathrm{WTP}}_{\mathrm{SP}, d E}\left(\mu_{Y_{0}}, \mathrm{CV}_{Y_{0}}, g_{E}\right)}{\partial \mathrm{CV}_{Y_{0}}}=\kappa \frac{1-\theta}{\theta^{2}} \mu_{Y_{0}}^{1 / \theta} \mathrm{CV}_{Y_{0}}\left(1+\mathrm{CV}_{Y_{0}}^{2}\right)^{\frac{1-\theta-2 \theta^{2}}{2 \theta^{2}}}
$$

The sign of the derivative is determined by the sign of the factor $(1-\theta)$, as $\mu_{Y_{0}}, \mathrm{CV}_{Y_{0}}, \kappa>0$. It holds that $1-\theta \lesseqgtr 0$ if and only if $\theta \gtreqless 1$.

Differentiating $\overline{\mathrm{WTP}}_{\mathrm{SP}, d g_{E}}$ (Eq. 5.18) with respect to relative intratemporal income inequality, $\mathrm{CV}_{Y_{0}}$, yields

$$
\frac{\partial \overline{\mathrm{WTP}}_{\mathrm{SP}, d g_{E}}\left(\mu_{Y_{0}}, \mathrm{CV}_{Y_{0}} g_{E}\right)}{\partial \mathrm{CV}_{Y_{0}}}=\kappa^{\prime} \frac{1-\theta}{\theta^{2}} \mu_{Y_{0}}^{1 / \theta} \mathrm{CV}_{Y_{0}}\left(1+\mathrm{CV}_{Y_{0}}^{2}\right)^{\frac{1-\theta-2 \theta^{2}}{2 \theta^{2}}}
$$

The sign of the derivative is determined by the sign of the factor $(1-\theta)$, as $\mu_{Y_{0}}, \mathrm{CV}_{Y_{0}}, \kappa^{\prime}>0$. It holds that $1-\theta \lesseqgtr 0$ if and only if $\theta \gtreqless 1$.

Differentiating $\overline{\mathrm{WTP}}_{\mathrm{CPF}, d E}$ (Eq. 5.22) with respect to relative intratemporal income inequality, $\mathrm{CV}_{Y_{0}}$, yields

$$
\frac{\partial \overline{\mathrm{WTP}}_{\mathrm{CPF}, d E}\left(\mu_{Y_{0}}, \mathrm{CV}_{Y_{0}}, g_{Y}, g_{E}\right)}{\partial \mathrm{CV}_{Y_{0}}}=\kappa^{\prime \prime \prime} \frac{1-\theta}{\theta^{2}} \mu_{Y_{0}}^{1 / \theta} \mathrm{CV}_{Y_{0}}\left(1+\mathrm{CV}_{Y_{0}}^{2}\right)^{\frac{1-\theta-2 \theta^{2}}{2 \theta^{2}}}
$$

The sign of the derivative is determined by the sign of the factor $(1-\theta)$, as $\mu_{Y_{0}}, \mathrm{CV}_{Y_{0}}, \kappa^{\prime \prime \prime}>0$. It holds that $1-\theta \lesseqgtr 0$ if and only if $\theta \gtreqless 1$.

Differentiating $\overline{\mathrm{WTP}}_{\mathrm{CPF}, d g_{E}}$ (Eq. 5.24) with respect to relative intratemporal income inequality, $\mathrm{CV}_{Y_{0}}$, yields

$$
\frac{\partial \overline{\mathrm{WTP}}_{\mathrm{CPF}, d g_{E}}\left(\mu_{Y_{0}}, \mathrm{CV}_{Y_{0}}, g_{Y}, g_{E}\right)}{\partial \mathrm{CV}_{Y_{0}}}=\kappa^{\prime \prime \prime \prime \prime} \frac{1-\theta}{\theta^{2}} \mu_{Y_{0}}^{1 / \theta} \mathrm{CV}_{Y_{0}}\left(1+\mathrm{CV}_{Y_{0}}^{2}\right)^{\frac{1-\theta-2 \theta^{2}}{2 \theta^{2}}}
$$

The sign of which is determined by the factor $(1-\theta)$, as $\mu_{Y_{0}}, \mathrm{CV}_{Y_{0}}, k^{\prime \prime \prime \prime}>0$. It again holds that $1-\theta \lesseqgtr 0$ if and only if $\theta \gtreqless 1$. 


\subsubsection{Proof of Proposition 5.3}

Assume time-constant market interest factor, i.e. $\delta_{t}=\delta \forall t$. Differentiating $\overline{W T P}_{C P F, d E}$ (Eq. 5.22) with respect to the growth rate of income, $g_{Y}$, yields

$$
\begin{aligned}
& \frac{\partial \overline{W T P}_{C P F, d E}\left(\mu_{Y_{0}}, \mathrm{CV}_{Y_{0}}, g_{Y}, g_{E}\right)}{\partial g_{Y}} \\
& =K\left(\left[1-\rho\left(1+g_{Y}\right)^{\frac{\theta-1}{\theta}}\right] \sum_{t=0}^{\infty} t \delta^{t}\left(1+g_{Y}\right)^{t-1}-\frac{\theta-1}{\theta} \rho\left(1+g_{Y}\right)^{-1 / \theta} \sum_{t=0}^{\infty} \delta^{t}\left(1+g_{Y}\right)^{t}\right) \\
& =K\left(\frac{1-\rho\left(1+g_{Y}\right)^{\frac{\theta-1}{\theta}}}{\delta} \sum_{t=1}^{\infty} t\left[\delta\left(1+g_{Y}\right)\right]^{t-1}-\frac{\theta-1}{\theta} \rho\left(1+g_{Y}\right)^{-1 / \theta} \sum_{t=0}^{\infty}\left[\delta\left(1+g_{Y}\right)\right]^{t}\right) \\
& \text { with } K:=\frac{1-\alpha}{\alpha} \frac{E_{0}^{-1 / \theta} d E \mu_{Y_{0}}^{1 / \theta}\left(1+\mathrm{CV}_{Y_{0}}^{2}\right)^{\frac{1-\theta}{2 \theta^{2}}}}{1-\rho\left(1+g_{E}\right)^{\frac{\theta-1}{\theta}}}>0 .
\end{aligned}
$$

For

$$
\delta\left(1+g_{Y}\right)<1
$$

the geometric series converge as $t \rightarrow \infty$ and this becomes

$$
\begin{aligned}
\frac{\partial \overline{W T P}_{C P F, d E}}{\partial g_{Y}} & =K\left[\frac{\left(1-\rho\left(1+g_{Y}\right)^{\frac{\theta-1}{\theta}}\right)}{\delta\left(1-\delta\left(1+g_{Y}\right)\right)^{2}}-\frac{\frac{\theta-1}{\theta} \rho\left(1+g_{Y}\right)^{-\frac{1}{\theta}}}{1-\delta\left(1+g_{Y}\right)}\right] \\
& =K \frac{1-\rho\left(1+g_{Y}\right)^{\frac{\theta-1}{\theta}}-\delta\left(1-\delta\left(1+g_{Y}\right)\right) \rho \frac{\theta-1}{\theta}\left(1+g_{Y}\right)^{-\frac{1}{\theta}}}{\delta\left(1-\delta\left(1+g_{Y}\right)\right)^{2}} \\
& =\frac{K}{\delta\left(1-\delta\left(1+g_{Y}\right)\right)^{2}}\left[1-\rho\left(1+g_{Y}\right)^{-\frac{1}{\theta}}\left(\left(1+g_{Y}\right)+\frac{\theta-1}{\theta} \delta\left(1-\delta\left(1+g_{Y}\right)\right)\right)\right] \\
& =\frac{K}{\delta\left(1-\delta\left(1+g_{Y}\right)\right)^{2}}\left[1+\rho\left(1+g_{Y}\right)^{-\frac{1}{\theta}}\left(-\left(1+g_{Y}\right)+\frac{1-\theta}{\theta} \delta\left(1-\delta\left(1+g_{Y}\right)\right)\right)\right] \\
& =\frac{K\left(1+g_{Y}\right)^{-\frac{1}{\theta}}}{\delta\left(1-\delta\left(1+g_{Y}\right)\right)^{2}}\left[\left(1+g_{Y}\right)^{\frac{1}{\theta}}+\rho\left(-\left(1+g_{Y}\right)+\frac{1-\theta}{\theta} \delta\left(1-\delta\left(1+g_{Y}\right)\right)\right)\right] \\
& =\frac{K\left(1+g_{Y}\right)^{-\frac{1}{\theta}}}{\delta\left(1-\delta\left(1+g_{Y}\right)\right)^{2}}\left[\left(1+g_{Y}\right)^{\frac{1}{\theta}}-\rho\left(1+g_{Y}\right)+\frac{1-\theta}{\theta} \rho \delta\left(1-\delta\left(1+g_{Y}\right)\right)\right] \\
& =\frac{K\left(1+g_{Y}\right)^{-\frac{1}{\theta}}}{\delta\left(1-\delta\left(1+g_{Y}\right)\right)^{2}}[\left(1+g_{Y}\right) \underbrace{\left(\left(1+g_{Y}\right)^{\frac{1-\theta}{\theta}}-\rho\right)}_{>0, \text { cf. Eq. 5.7a }}+\frac{1-\theta}{\theta} \rho \delta \underbrace{\left(1-\delta\left(1+g_{Y}\right)\right)}_{>0, \text { cf. Eq. } 5.95}] .
\end{aligned}
$$

Recall the growth path condition $\rho\left(1+g_{Y}\right)^{\frac{\theta-1}{\theta}}<1$ (Eq. 5.7a) which is equivalent to $(1+$ $\left.g_{Y}\right)^{\frac{1-\theta}{\theta}}>\rho$, and thus $\left(1+g_{Y}\right)\left(\left(1+g_{Y}\right)^{\frac{1-\theta}{\theta}}-\rho\right)>0$. As $E_{0}, \mu_{Y_{0}}, \mathrm{CV}_{Y_{0}}, \theta, \rho, g_{Y}, \delta_{\tau}>0, \alpha \in$ $(0,1), \rho\left(1+g_{E}\right)^{\frac{\theta-1}{\theta}}<1$ (Eq. 5.7b) the only term that can turn negative is $\frac{1-\theta}{\theta} \rho\left(1-\delta\left(1+g_{Y}\right)\right)$.

The sign of this term is fully determined by the factor $1-\theta$, as by assumption $\delta\left(1+g_{Y}\right)<1$ (Eq. 5.95). It thus holds that 


$$
\frac{\partial \overline{W T P}_{C P F, d E}}{\partial g_{Y}}>0 \quad \text { if } \quad \theta \leq 1
$$

The reader might stumble when comparing the term in square brackets of Eq. 5.96, with Figure 5.3 or Figure 5.7. The difference in parameter values zeroing the derivative $\frac{\partial \overline{W T P}_{C P F, d E}}{\partial g_{Y}}$ results from different time horizons. While we here consider $t \rightarrow \infty$, we assume $t \in(0, T)$ with $T=100$ for the application (Section 5.5) as this is a common time horizon in cost-benefit analysis. For longer time horizons the parameter values setting the derivative to zeros in the Figures 5.3 and Figure 5.7 converge to the ones implicit given by Eq. 5.96.

As the components relating to the growth rate of income in Eq. (5.24) are the same as those in Eq. (5.22), the proof for $\frac{\partial \overline{W T P}_{C P F, d g_{E}}}{\partial g_{Y}}>0$ if $\theta \leq 1$ proceeds analogously. Likewise, the conditions for which the sign of the effect changes from positive to negative are the same. Figures 5.7 and 5.8 in Appendix 5.8.16 is therefore relevant for both WTP cases. 


\subsubsection{Conditions for WTP that declines with income growth}

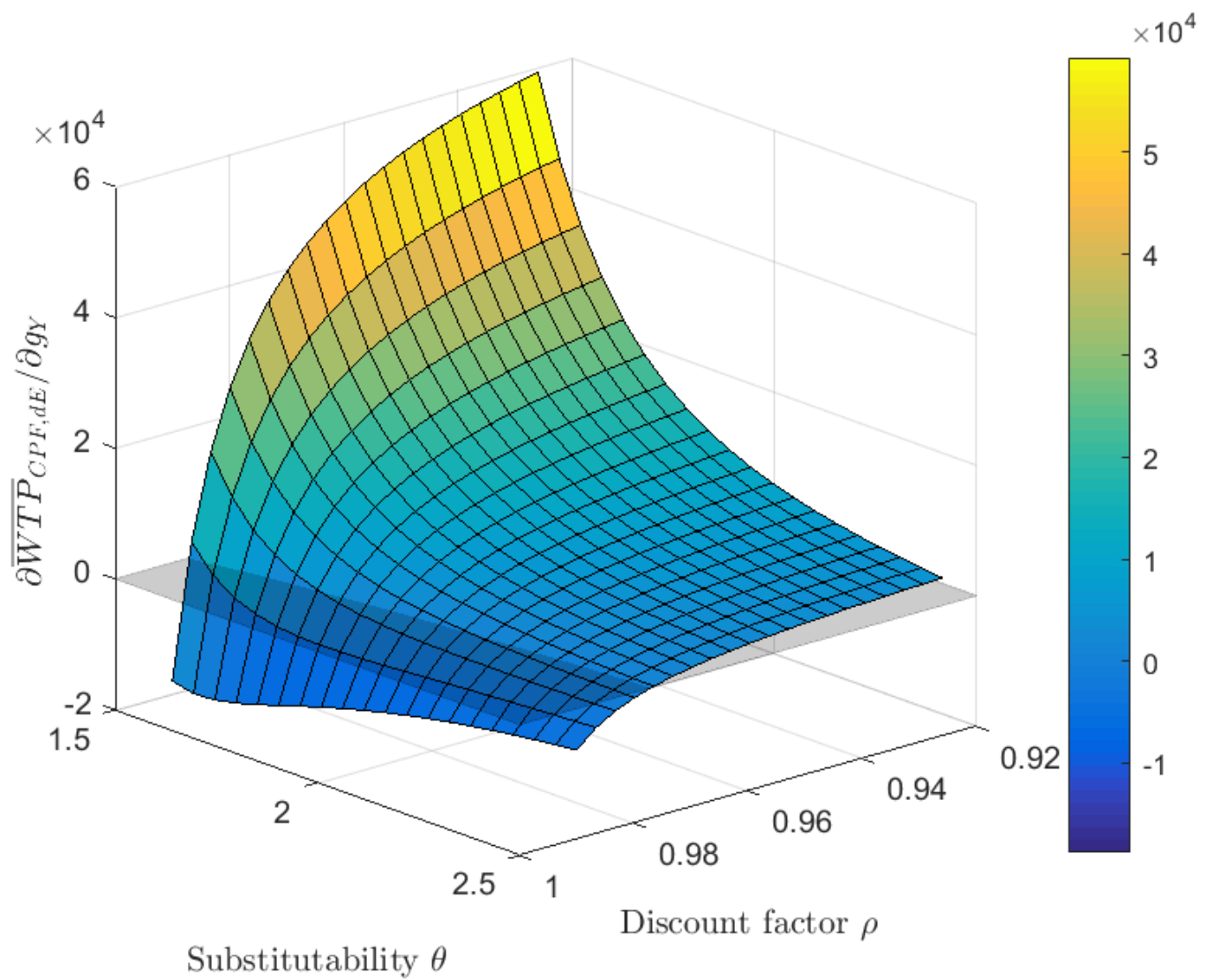

Figure 5.7: The derivative of mean WTP for a constant payment fraction with respect to the growth rate of income and how its sign and magnitude depend on the elasticity of substitution, $\theta$, and the pure time discount factor, $\rho$. The remaining parameter values are those of the central calibration in the global biodiversity conservation case study (Table 5.2), in particular the time horizon goes to $T=100$. 

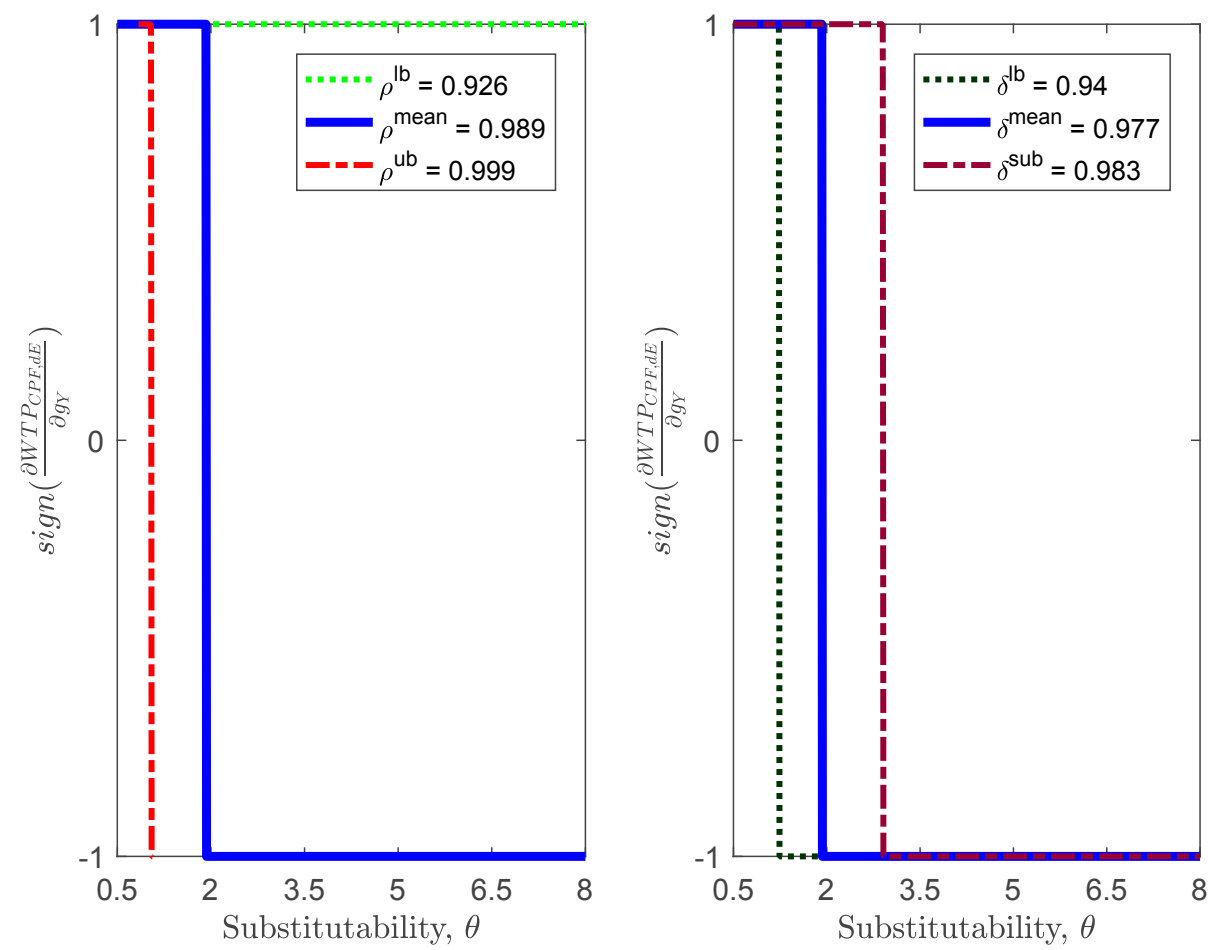

Figure 5.8: The derivative of mean WTP for a constant payment fraction with respect to the growth rate of income and how its sign depends on the elasticity of substitution, $\theta$, for different pure time discount factors, $\rho$, (left subplot) or market interest rates, $\delta$ (right subplot). In the left subplot the sign of the derivative is only depicted where the growth path conditions are fulfilled (Eqs. 5.7a and 5.7b). In the right subplot the convergence condition given by Eq. 5.95 is not fulfilled for the upper bound interest factor, $\delta^{\text {ub }}$, and therefore the supremum $\delta^{\text {sup }}=\left(1+g_{Y}^{\text {mean }}\right)^{-1}$ is depicted. Results are given for $t \rightarrow \infty$ by populating Equation 5.96 with the parameter values of the central calibration in the global biodiversity conservation case study (Table 5.2).

\subsubsection{Proof of Proposition 5.4}

Differentiating $\overline{W T P}_{\mathrm{SP}, d E}$ (Eq. 5.17) with respect to the growth rate of the environmental good, $g_{E}$, yields

$$
\begin{aligned}
& \frac{\partial \overline{W T P}_{S P, d E}\left(\mu_{Y_{0}}, \mathrm{CV}_{Y_{0}}, g_{Y}, g_{E}\right)}{\partial g_{E}}=K^{\prime} \frac{\theta-1}{\theta} \rho \frac{\left(1+g_{E}\right)^{-1 / \theta}}{\left(1-\rho\left(1+g_{E}\right)^{\frac{\theta-1}{\theta}}\right)^{2}} \\
& \text { with } K^{\prime}:=\frac{1-\alpha}{\alpha} E_{0}^{-1 / \theta} d E \mu_{Y_{0}}^{1 / \theta}\left(1+\mathrm{CV}_{Y_{0}}^{2}\right)^{\frac{1-\theta}{2 \theta^{2}}} .
\end{aligned}
$$

As $E_{0}, \mu_{Y_{0}}, \mathrm{CV}_{Y_{0}}, \theta, \rho, \alpha \in(0,1), g_{E}>-1, \rho\left(1+g_{E}\right)^{\frac{\theta-1}{\theta}}<1$ (Eq. 5.7b) the sign of $\frac{\partial \overline{W T P}_{S P, d E}}{\partial g_{E}}$ is determined by the sign of $\theta-1$ and it follows directly that

$$
\frac{\partial \overline{\mathrm{WTP}}_{\mathrm{SP}, d E}\left(\mu_{Y_{0}}, \mathrm{CV}_{Y_{0}}, g_{Y}, g_{E}\right)}{\partial g_{E}} \gtreqless 0 \text { if and only if } \theta \gtreqless 1 .
$$


Differentiating $\overline{W T P}_{\mathrm{CPF}, d E}$ (Eq. 5.22) with respect to the growth rate of the environmental good, $g_{E}$, yields

$$
\begin{aligned}
& \frac{\partial \overline{W T P}_{\mathrm{CPF}, d E}\left(\mu_{Y_{0}}, \mathrm{CV}_{Y_{0}}, g_{Y}, g_{E}\right)}{\partial g_{E}}=K^{\prime \prime} \frac{\theta-1}{\theta} \rho \frac{\left(1+g_{E}\right)^{-1 / \theta}}{\left(1-\rho\left(1+g_{E}\right)^{\frac{\theta-1}{\theta}}\right)^{2}} \\
& \text { with } K^{\prime \prime}:=\frac{1-\alpha}{\alpha}\left(1-\rho\left(1+g_{Y}\right)^{\frac{\theta-1}{\theta}}\right) E_{0}^{-1 / \theta} d E\left[\sum_{t=0}^{\infty}\left(\prod_{\tau=0}^{t} \delta_{\tau}\right)\left(1+g_{Y}\right)^{t}\right] \mu_{Y_{0}}^{1 / \theta}\left(1+\mathrm{CV}_{Y_{0}}^{2}\right)^{\frac{1-\theta}{\theta^{2}}}
\end{aligned}
$$

As $E_{0}, \mu_{Y_{0}}, \mathrm{CV}_{Y_{0}}, \theta, \rho, g_{Y}, \delta_{\tau}>0, \alpha \in(0,1), \rho\left(1+g_{Y}\right)^{\frac{\theta-1}{\theta}}<1$ (Eq. 5.7a), $\rho\left(1+g_{E}\right)^{\frac{\theta-1}{\theta}}<1$ (Eq. 5.7b) the sign of $\frac{\partial \overline{W T P}_{C P F, d E}}{\partial g_{E}}$ is determined by the sign of $\theta-1$ and it follows directly

$$
\frac{\partial \overline{\mathrm{WTP}}_{\mathrm{CPF}, d E}\left(\mu_{Y_{0}}, \mathrm{CV}_{Y_{0}}, g_{Y}, g_{E}\right)}{\partial g_{E}} \gtreqless 0 \text { if and only if } \theta \gtreqless 1 \text {. }
$$

\subsubsection{Proof of Proposition 5.5}

The transfer function is defined by the quotient of the mean WTPs at the policy site and study site. For mean WTP elicited at study site and policy site as a single payment for a change in the initial level of the environmental good, $\overline{\mathrm{WTP}}_{\mathrm{SP}, d E}$ (Eq. 5.17), the transfer function is given as

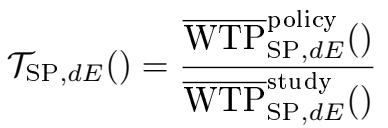

$$
\begin{aligned}
& E q \stackrel{(5.17)}{=} \frac{\frac{1-\alpha}{\alpha} \frac{E_{0}^{\text {policy }-1 / \theta} d E^{\text {policy }}}{1-\rho\left(1+g_{E}^{\text {policy }}\right)^{\frac{\theta-1}{\theta}}} \mu_{Y_{0}}^{\text {policy }}{ }^{1 / \theta}\left(1+\mathrm{CV}_{Y_{0}}{ }^{\text {policy }}{ }^{2}\right)^{\frac{1-\theta}{2 \theta^{2}}}}{\frac{1-\alpha}{\alpha} \frac{E_{0}^{\text {study }-1 / \theta} d E^{\text {study }}}{1-\rho\left(1+g_{E}^{\text {study }}\right)^{\frac{\theta-1}{\theta}}} \mu_{Y_{0}}^{\text {study }}{ }^{1 / \theta}\left(1+C V_{Y_{0}} \text { study }^{2}\right)^{\frac{1-\theta}{2 \theta^{2}}}} \\
& =\left(\frac{E_{0}^{\text {policy }}}{E_{0}^{\text {study }}}\right)^{-1 / \theta} \cdot \frac{d E^{\text {policy }}}{d E^{\text {study }}} \cdot \frac{1-\rho\left(1+g_{E}^{\text {study }}\right)^{\frac{\theta-1}{\theta}}}{1-\rho\left(1+g_{E}^{\text {policy }}\right)^{\frac{\theta-1}{\theta}}} \cdot\left(\frac{\mu_{Y_{0}}^{\text {policy }}}{\mu_{Y_{0}}^{\text {study }}}\right)^{1 / \theta} \cdot\left(\frac{1+\mathrm{CV}_{Y_{0}}^{\text {policy } 2}}{1+\mathrm{CV}_{Y_{0}}^{\text {study } 2}}\right)^{\frac{1-\theta}{2 \theta^{2}}} .
\end{aligned}
$$


For WTP as a single payment and a change in the growth rate of the environmental good, $\overline{\mathrm{WTP}}_{\mathrm{SP}, d g_{E}}$ (Eq. 5.18), the transfer function is given as

$$
\begin{aligned}
& \mathcal{T}_{\mathrm{SP}, d g_{E}}()=\frac{\overline{\mathrm{WTP}}_{\mathrm{SP}, d g_{E}}^{\text {policy }}()}{\overline{\mathrm{WTP}}_{\mathrm{SP}, d g_{E}}^{\mathrm{study}}()} \\
& E q . \stackrel{(5.18)}{=} \frac{\frac{1-\alpha}{\alpha} E_{0}^{\text {policy } \frac{\theta-1}{\theta}} \frac{\rho\left(1+g_{E}^{\text {policy }}\right)^{-1 / \theta}}{\left(1-\rho\left(1+g_{E}^{\text {policy }}\right)^{\frac{\theta-1}{\theta}}\right)^{2}} d g_{E}^{\text {policy }} \mu_{Y_{0}}^{\text {policy } 1 / \theta}\left(1+\mathrm{CV}_{Y_{0}}^{\text {policy }}\right)^{\frac{1-\theta}{2 \theta^{2}}}}{\frac{1-\alpha}{\alpha} E_{0}^{\text {study }} \frac{\theta-1}{\theta} \frac{\rho\left(1+g_{E}^{\text {study }}\right)^{-1 / \theta}}{\left(1-\rho\left(1+g_{E}^{\text {study }}\right)^{\frac{\theta-1}{\theta}}\right)^{2}} d g_{E}^{\text {study }} \mu_{Y_{0}}^{\text {study }}{ }^{1 / \theta}\left(1+\mathrm{CV}_{Y_{0}}^{\text {study }}\right)^{\frac{1-\theta}{2 \theta^{2}}}} \\
& =\left(\frac{E_{0}^{\text {policy }}}{E_{0}^{\text {study }}}\right)^{\frac{\theta-1}{\theta}} \cdot \frac{d g_{E}^{\text {policy }}}{d g_{E}^{\text {study }}} \cdot \frac{\rho\left(1+g_{E}^{\text {policy }}\right)^{-1 / \theta}\left(1-\rho\left(1+g_{E}^{\text {study }}\right)^{\frac{\theta-1}{\theta}}\right)^{2}}{\rho\left(1+g_{E}^{\text {study }}\right)^{-1 / \theta}\left(1-\rho\left(1+g_{E}^{\text {policy }}\right)^{\frac{\theta-1}{\theta}}\right)^{2}} \\
& \cdot\left(\frac{\mu_{Y_{0}}^{\text {policy }}}{\mu_{Y_{0}}^{\text {study }}}\right)^{1 / \theta} \cdot\left(\frac{1+\mathrm{CV}_{Y_{0}}^{\text {policy } 2}}{1+\mathrm{CV}_{Y_{0}}^{\text {study } 2}}\right)^{\frac{1-\theta}{2 \theta^{2}}} .
\end{aligned}
$$

For WTP as a constant payment fraction and a change in the initial level of the environmental good, $\overline{\mathrm{WTP}}_{\mathrm{CPF}, d E}$ (Eq. 5.22), the transfer function is given as

$$
\begin{aligned}
& \mathcal{T}_{\mathrm{CPF}, d E}()=\frac{\overline{\mathrm{WTP}}_{\mathrm{CPF}, d E}^{\text {policy }}()}{\overline{\mathrm{WTP}}_{\mathrm{CPF}, d E}^{\text {study }}()}
\end{aligned}
$$

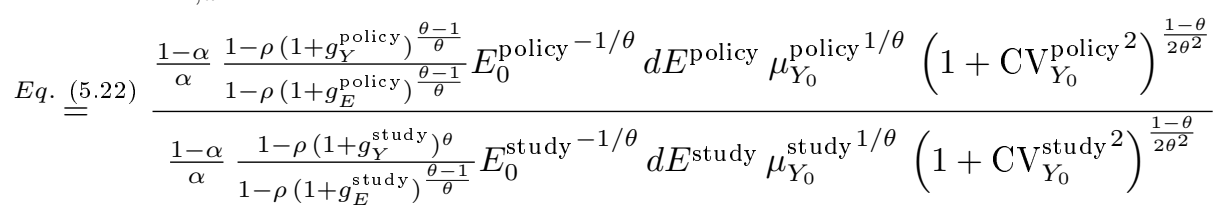

$$
\begin{aligned}
& \cdot \frac{\sum_{t=0}^{\infty}\left(\prod_{\tau=0}^{t} \delta_{\tau}^{\text {policy }}\right)\left(1+g_{Y}^{\text {policy }}\right)^{t}}{\sum_{t=0}^{\infty}\left(\prod_{\tau=0}^{t} \delta_{\tau}^{\text {study }}\right)\left(1+g_{Y}^{\text {study }}\right)^{t}} \\
& =\left(\frac{E_{0}^{\text {policy }}}{E_{0}^{\text {study }}}\right)^{-1 / \theta} \cdot \frac{d E^{\text {policy }}}{d E^{\text {study }}} \cdot \frac{1-\rho\left(1+g_{E}^{\text {study }}\right)^{\frac{\theta-1}{\theta}}}{1-\rho\left(1+g_{E}^{\text {policy }}\right)^{\frac{\theta-1}{\theta}}} \cdot\left(\frac{\mu_{Y_{0}}^{\text {policy }}}{\mu_{Y_{0}}^{\text {study }}}\right)^{1 / \theta} \cdot\left(\frac{1+\mathrm{CV}_{Y_{0}}^{\text {policy }}{ }^{2}}{1+\mathrm{CV}_{Y_{0}}^{\text {study }}{ }^{2}}\right)^{\frac{1-\theta}{2 \theta^{2}}} \\
& \cdot \frac{1-\rho\left(1+g_{Y}^{\text {policy }}\right)^{\frac{\theta-1}{\theta}}}{1-\rho\left(1+g_{Y}^{\text {study }}\right)^{\frac{\theta-1}{\theta}}} \cdot \frac{\sum_{t=0}^{\infty}\left(\prod_{\tau=0}^{t} \delta_{\tau}^{\text {policy }}\right)\left(1+g_{Y}^{\text {policy }}\right)^{t}}{\sum_{t=0}^{\infty}\left(\prod_{\tau=0}^{t} \delta_{\tau}^{\text {study }}\right)\left(1+g_{Y}^{\text {study }}\right)^{t}} .
\end{aligned}
$$


For WTP as a constant payment fraction and a change in the growth rate of the environmental good, $\overline{\mathrm{WTP}}_{\mathrm{CPF}, d g_{E}}$ (Eq. 5.24), the transfer function is

$$
\begin{aligned}
& \mathcal{T}_{\mathrm{CPF}, d g_{E}}()=\frac{\overline{\mathrm{WTP}}_{\mathrm{CPF}, d g_{E}}^{\text {policy }}()}{\overline{\mathrm{WTP}}_{\mathrm{CPF}, d g_{E}}^{\text {study }}()} \\
& E q .5 .24 \frac{\frac{\rho\left(1+g_{E}^{\text {policy }}\right)^{-1 / \theta}}{\left(1-\rho\left(1+g_{E}^{\text {policy }}\right)^{\frac{\theta-1}{\theta}}\right)^{2}}\left(1-\rho\left(1+g_{Y}^{\text {policy }}\right)^{\frac{\theta-1}{\theta}}\right) d g_{E}^{\text {policy }} E_{0}^{\text {policy }} \frac{\theta-1}{\theta} \mu_{Y_{0}}^{\text {policy }}{ }^{1 / \theta}\left(1+C V_{Y_{0}}^{\text {policy }}{ }^{2}\right)^{\frac{1-\theta}{2 \theta^{2}}}}{\frac{\rho\left(1+g_{E}^{\text {study }}\right)^{-1 / \theta}}{\left(1-\rho\left(1+g_{E}^{\text {study }}\right)^{\frac{\theta-1}{\theta}}\right)^{2}}\left(1-\rho\left(1+g_{Y}^{\text {study }}\right)^{\frac{\theta-1}{\theta}}\right) d g_{E}^{\text {study }} E_{0}^{\text {study }} \frac{\theta-1}{\theta} \mu_{Y_{0}}^{\text {study }}{ }^{1 / \theta}\left(1+C V_{Y_{0}}^{\text {study }}{ }^{\frac{1-\theta}{2 \theta^{2}}}\right.} \\
& \frac{\sum_{t=0}^{\infty}\left(\prod_{\tau=0}^{t} \delta_{\tau}^{\text {policy }}\right)\left(1+g_{Y}^{\text {policy }}\right)^{t}}{\sum_{t=0}^{\infty}\left(\prod_{\tau=0}^{t} \delta_{\tau}^{\text {study }}\right)\left(1+g_{Y}^{\text {study }}\right)^{t}} \\
& =\left(\frac{E_{0}^{\text {policy }}}{E_{0}^{\text {study }}}\right)^{\frac{\theta-1}{\theta}} \cdot \frac{d g_{E}^{\text {policy }}}{d g_{E}^{\text {study }}} \cdot \frac{\rho\left(1+g_{E}^{\text {policy }}\right)^{-1 / \theta}\left(1-\rho\left(1+g_{E}^{\text {study }}\right)^{\frac{\theta-1}{\theta}}\right)^{2}}{\rho\left(1+g_{E}^{\text {study }}\right)^{-1 / \theta}\left(1-\rho\left(1+g_{E}^{\text {policy }}\right)^{\frac{\theta-1}{\theta}}\right)^{2}} \cdot\left(\frac{\mu_{Y_{0}}^{\text {policy }}}{\mu_{Y_{0}}^{\text {study }}}\right)^{1 / \theta} \\
& \cdot\left(\frac{1+\mathrm{CV}_{Y_{0}}^{\text {policy }}{ }^{2}}{1+\mathrm{CV}_{Y_{0}}^{\text {study }}{ }^{2}}\right)^{\frac{1-\theta}{2 \theta^{2}}} \cdot \frac{1-\rho\left(1+g_{Y}^{\text {policy }}\right)^{\frac{\theta-1}{\theta}}}{1-\rho\left(1+g_{Y}^{\text {study }}\right)^{\frac{\theta-1}{\theta}}} \cdot \frac{\sum_{t=0}^{\infty}\left(\prod_{\tau=0}^{t} \delta_{\tau}^{\text {policy }}\right)\left(1+g_{Y}^{\text {policy }}\right)^{t}}{\sum_{t=0}^{\infty}\left(\prod_{\tau=0}^{t} \delta_{\tau}^{\text {study }}\right)\left(1+g_{Y}^{\text {study }}\right)^{t}}
\end{aligned}
$$




\section{Part III}

\section{Empirical applications}




\title{
6 Income Inequality and the International Transfer of Environmental Values
}

\begin{abstract}
How the valuation of non-market environmental goods is related to income is a key question for economics, but the role of income inequality is often neglected. We study how income inequality affects the international transfer of the estimated value of non-market goods - a practice called value or benefit transfer. Specifically, we apply theorydriven, structural transfer factors to examine whether adjusting for income inequality affects errors made in benefit transfer, drawing on a multi-country valuation study on water quality improvement. Our convergent validity analysis shows that the structural income inequality adjustment reduces benefit transfer errors by more than 1.5 percentage points on average across all transfers. The adjustment for inequality is particularly important when income is distributed more unequally at the policy site relative to the study site, yielding reductions in transfer errors of up to 33 percentage points. Our results are relevant for policy appraisal, environmental accounting, and more generally for the role of income inequality in non-market valuation.
\end{abstract}

Keywords: benefit transfer, convergent validity, income, inequality, stated preferences, transfer errors

Reference: Meya, J.N., Drupp. M.A., Hanley, N. (2017). Income inequality and the international transfer of environmental values. Kiel Economics Working Paper No 2017-03. 


\subsection{Introduction}

There is a growing interest within economics and in society at large in the implications of income inequality. ${ }^{79}$ A crucial question for economics concerns how the valuation of non-market environmental goods is related to income. Numerous studies investigate this relationship by estimating how willingness to pay (WTP) for environmental goods depends on the level of income. They usually find that WTP increases with individual income, but at a lower than proportionate rate. ${ }^{80}$ This implies that poorer households value these non-market benefits disproportionately and it suggests an important role of economic distribution for environmental valuation that has been neglected until recently (Drupp et al. 2018). In a recent Science perspective, Frank and Schlenker (2016: 652) conjecture that "the income distribution might $[\ldots]$ be as important as overall economic growth" for the valuation of environmental goods. Related to this conjecture, Baumgärtner et al. (2017a) theoretically examine how mean WTP for environmental public goods within a society depends on the distribution of income. They find that mean WTP decreases (increases) with income inequality if the income elasticity of WTP is below (above) one, but that it-except for extreme cases - changes more elastically with mean income than with income inequality.

In this paper, we demonstrate that adjusting for income inequality in a structural, theorydriven fashion can improve one of the most frequently used methods for non-market valuation: benefit transfer. Benefit transfer-also often called value transfer-makes use of WTP estimates for an environmental good derived from a study site to estimate values for a policy site, where this information is to be used to inform decision-making for environmental management (Johnston et al. 2015). As sites and affected populations often differ in many ways, it is crucial to control for variations in key explanatory variables, including income, as part of the transfer. This paper is the first to utilize theory-driven benefit transfer factors for income inequality, which have recently been developed by Baumgärtner et al. (2017a), to scrutinize whether controlling for differences in income inequality across sites improves the WTP estimates derived from benefit transfer in a multi-country convergent validity study.

Obtaining theoretically sound, empirically relevant and easy-to-use methods for benefit transfer is of first order importance as WTP-estimates from such transfers are increasingly

\footnotetext{
${ }^{79}$ For example, Piketty's (2014) work on economic inequality has received widespread attention, and while Google searches for "income inequality" have increased by more than 200 [110] percent in the USA [UK] from 2008 to 2016, searches for "income" only increased by 10 [19] percent (cf. Google Trends).

${ }^{80}$ Technically, these studies estimate the income elasticity of WTP for environmental goods, which is the percentage change in WTP relative to a percentage change in income. Almost all studies thus find that the income elasticity of WTP is positive and smaller than unity.
} 
used to inform policy decisions (Richardson et al. 2015). International and inter-regional benefit transfer have been frequently applied to inform environmental policy making in the European Union and the United States. For example, to inform the policy process on Natura 2000, the economic benefits from Natura 2000 sites were assessed for all of Europe (European Commission 2013). ${ }^{81}$ As only limited primary valuations for ecosystem services from Natura 2000 sites were available (34 values from 20 studies), these were scaled up using the benefit transfer method. Consequently, the resulting value estimates entail scope for substantial benefit transfer errors. Furthermore, the U.S. EPA has been required to conduct benefitcost analysis on environmental regulation for more than three decades (Griffiths et al. 2012). Benefit transfer has been applied, for instance, to estimate the recreational benefits of water quality improvements under the 2002 Combined Animal Feeding Operations rule (U.S. EPA 2014). WTP estimates from a national contingent valuation survey by Carson and Mitchell (1993) were used to value predicted water quality improvements across U.S. states.

As benefit transfer has become "the bedrock of practical policy analysis" to inform regulatory decision-making (Pearce et al. 2006: 266), improving its accuracy is an important research area. Kaul et al. (2013) review 20 years of studies that scrutinize the errors made by using benefit transfer. Their analysis suggests that benefit transfer should control for a range of covariates of WTP with their levels calibrated to policy-case conditions. Other studies find that simple transfers adjusted for only purchasing power parity and income perform best (Czajkowski et al. 2017, Ready et al. 2004). A central finding of most studies is that accounting for income plays an important role for the accuracy of benefit transfer. Many policy applications of international benefit transfer, such as for Natura 2000, adjust WTP estimates exclusively for differences mean income, government guidance documents suggest the use of formulas for mean income correction (UBA 2012, Pearce et al. 2006, Defra 2007), and many academic studies on benefit transfer have employed this approach (e.g. Krupnick et al. 1996, Ready et al. 2004). However, while it is common practice to control for differences in mean income across sites, adjusting for differences in income inequality has, to our knowledge, not been considered in benefit transfer evaluations. ${ }^{82}$

\footnotetext{
${ }^{81}$ Natura 2000 is Europe's most important legislation to protect nature and biodiversity. The network of protected areas has the objective to conserve Europe's unique biodiversity including endangered species, rare habitats and genetic diversity. Covering over 18 percent of the EU's terrestrial area it is globally the largest coordinated network of protected areas (European Commission 2008, 2013).

${ }^{82}$ We surveyed a number of academics and practitioners working on benefit transfer and the general response was that 'no study ever controlled for differences in income inequality'. Furthermore, it is not mentioned as a potential control factor in the guidelines of i.a. Germany (UBA 2012), the OECD (Pearce et al. 2006), the UK (Defra 2007, HM Treasury 2011) as well as the USA (U.S. EPA 2014).
} 
The literature on benefit transfer has been mainly driven by empirical approaches such as using meta-regressions, with only very few exceptions of studies following a more structural utility theoretic approach. ${ }^{83}$ Bateman et al. (2011) argue that parameters controlled for in benefit transfer should be based on economic theory rather than ad-hoc statistical approaches that may be over parametrized when applied out of the sample. As far as we know, Smith et al. (2002) first proposed a structural approach to benefit transfer, which requires specifying a utility function as well as all relevant additional conditions, such as the budget constraint, and then calibrating the function's parameters with information from the study site. Despite several advantages of such a theory-driven approach, its application has been limited among others due to the advanced micro-economic skills that may be required (Phaneuf and Requate 2017). Recently, Baumgärtner et al. (2017a) have shown how aggregate WTP for an environmental public good depends on the distribution of income, based on a structural model with constant-elasticity-of-substitution preferences and an unequal distribution of income, and have derived theory-based and easy-to-apply benefit transfer factors, in particular for mean income and income inequality.

This paper builds on these theory-driven transfer factors to systematically examine the effects of a structural benefit transfer approach to income inequality adjustment using data from a valuation study on water quality improvement in all nine Baltic Sea countries (Ahtiainen et al. 2014). The unique feature of this study making it an ideal test-bed for our theory-driven approach to benefit transfer is that the contingent valuation study employed the same survey instrument across countries with substantial differences in income distributions for a well-defined change in environmental quality that has region-wide public good characteristics. It thereby offers the possibility to compare transferred WTPs across countries with actual primary valuations. Specifically, we calculate transfer factors to account for differences in mean income, income inequality and combinations of both, and evaluate transfer errors on a country-by-country basis.

By confronting theory-driven benefit transfer factors with a unique multi-country data set, this paper adds to the literature by providing a convergent validity excercise to test whether structual adjustment for income inequality can reduce errors made in benefit transfer. For the nine-country Baltic Sea study on water quality improvement, we find that (i)

\footnotetext{
${ }^{83}$ Bergstrom and Taylor (2006) survey theory-based approaches to benefit transfer and distinguish three approaches: non-structural as well as weak and strong structural utility theoretic approaches. While the strong structural approach explicitly specifies the relationship between WTP and its explanatory variables, this is only loosely the case in the weak structural approach. We are only aware of very few strong structural approach studies (Baumgärtner et al. 2017a; Smith et al. 2002, 2006).
} 
income inequality adjustment decreases transfer errors by more than 1.5 percentage points on average; (ii) Income inequality adjustment becomes particularly relevant when income is more unequally distributed at the policy relative to the study site. It decreases transfer errors by more than 5 percentage points on average when inequality at the study site is less than $80 \%$ of the policy site's income inequality; (iii) Even though adjustment for income inequality is of second-order compared to adjusting for the level of mean income, our study shows that accounting for income inequality can further improve benefit transfers and that its application is straightforward. We perform a number of robustness checks and find that our main conclusion is not affected by considering other transfer factors - for differences in the price level or the mean level of the environmental goods accross countries-in addition. Finally, we show that a naive transfer adjustment for income inequality would increase benefit transfer errors, emphasizing the importance of employing structural theory-driven factors.

The remainder of the paper is organized as follows. We introduce the model framework and transfer factors derived from this in Section 6.2. In Section 6.3 we present data from the Baltic Sea study and describe in Section 6.4 our strategy to empirically test the proposed transfer factors. We report our main results in Section 6.5.1 and test their robustness in Section 6.5.2. Finally, we discuss limitations to our analysis in Section 6.6 and conclude in Section 6.7.

\subsection{Theory-driven benefit transfer factors}

This paper tests the effect of income inequality on the convergent validity of benefit transfer. For this, we draw on recent theoretical work by Baumgärtner et al. (2017a), who have derived a generic transfer function, which disentangles transfer factors for mean income and income inequality. In the following, we apply their modelling framework for our setting of benefit transfer, which seeks to transfer willingness to pay (WTP) estimates from a primary valuation study in one country or region $s$ (the 'study site') to inform environmental policy making in another country or contect $p$ (the 'policy site'):

Assume that in each country $c$, with $c \in\{s, p\}$, there are $N^{c}$ individuals, denoted by $i$, who derive utility from the consumption of a market-traded private good, $X_{i}^{c}$, and a nonmarket-traded pure public environmental good, $E^{c}$. The consumption good $X_{i}^{c}$ is traded at a given market price $P^{c}>0$, while the consumption of the environmental good is fixed at 
level $E^{c}>0 .^{84}$ Individuals have identical preferences over the two goods represented by a constant elasticity of substitution (CES) utility function

$$
U\left(X_{i}^{c}, E\right)=\left(\alpha X_{i}^{c^{\frac{\theta-1}{\theta}}}+(1-\alpha) E^{c^{\frac{\theta-1}{\theta}}}\right)^{\frac{\theta}{\theta-1}}
$$

where $\theta \in(0,+\infty)$ is the CES between market-traded consumption goods and non-markettraded public environmental goods, and $\alpha \in(0,1)$ is a preference parameter capturing the weight of market-traded consumption goods as part of overall utility. ${ }^{85}$

The decision problem of each individual $i$ is then to maximize utility over the consumption of these two goods subject to the income constraint and the fixed level of $E^{c}$. While we assume that individuals have the same preferences, they differ in their individual incomes $Y_{i}^{c}$, which are given exogenously. Specifically, income is assumed to be distributed lognormally with mean, $\mu_{Y}^{c}$, and standard deviation, $\sigma_{Y}^{c}{ }^{86}$

Individual $i$ 's WTP for the environmental good $E^{c}$ is then determined by the level of income $Y_{i}^{c}$ and the parameters of the utility function and the level of $E^{c}$

$$
\operatorname{WTP}\left(Y_{i}^{c}\right)=\kappa^{c} Y_{i}^{c^{\eta}} \quad \text { with } \quad \kappa^{c}=\frac{1-\alpha}{\alpha}\left(P^{c} E^{c}\right)^{1-\eta}, \quad \eta=\frac{1}{\theta}
$$

where $\eta$ is the income elasticity of WTP. The CES utility function implies that the income elasticity of WTP, $\eta$, is the inverse of the CES, $\theta$, between the market-traded consumption good, $X_{i}^{c}$, and non-market-traded public environmental good, $E^{c}$, and thus also a constant. ${ }^{87}$ While this simple model of individual WTP explicitly captures some fundamental determinants of WTP, such as individual income, the level of the environmental good and the price level, the parameter $\alpha$ can be thought of as a residual that may capture, for example, the effect of culture on WTP for environmental goods.

\footnotetext{
${ }^{84}$ In Section 6.5.2, we discuss how this theory can be extended to the case of local public goods. We can show that if the consumption of a local environmental public good is uncorrelated with income, then the transfer factors for mean income and income inequality remain unchanged.

${ }^{85}$ While the assumption of identical preferences may seem demanding, it is often implicitly made in the benefit transfer literature. We discuss how this assumption can be relaxed in Section 6.6.

${ }^{86}$ The assumption of log-normality allows for simple closed-form solutions (Baumgärtner et al. 2017a). While there may often be more complex distributions that yield better fits (McDonald 1984), the log-normal distribution provides a decent approximation for many income distributions at a national level, as well as for the world as a whole (Pinkovskiy and Sala-i-Martin 2009).

${ }^{87}$ While the assumption of a constant income elasticity of WTP has been challenged (Barbier et al. 2016), it is superior to other functional forms in benefit transfer for the Baltic Sea study that we use in this paper (Czajkowski et al. 2017), and it is typically applied by practitioners of benefit transfer.
} 
Based on this modelling set-up, mean WTP for a marginal change in $E^{c}$ depends, inter alia, on mean income and income inequality as follows

$$
\mu_{\mathrm{WTP}}^{\mathrm{c}}\left(\mu_{Y}^{\mathrm{c}}, \mathrm{CV}_{Y}^{\mathrm{c}}, P^{\mathrm{c}}, E^{\mathrm{c}}\right)=\mu_{Y}^{\mathrm{c} \eta}\left(1+\mathrm{CV}_{Y}^{\mathrm{c}}\right)^{\frac{\eta(\eta-1)}{2}} \frac{1-\alpha}{\alpha}\left(P^{\mathrm{c}} E^{\mathrm{c}}\right)^{1-\eta}
$$

where $\mathrm{CV}_{Y}^{c}:=\sigma_{Y}^{c} / \mu_{Y}^{c}$ is the coefficient of variation of income, which measures the spread of the income distribution relative to the income level. Equation 6.3 implies that mean WTP increases with mean income in society, yet decreases (increases) with income inequality if the income elasticity of WTP is below (above) unity (cf. Baumgärtner et al. 2017a). The effect of income inequality on mean WTP can intuitively be explained as follows: For the case of an income elasticity of WTP smaller than unity, an increase in an individuals income results in an increase in WTP, but at a lower-than-proportional rate as compared to the increase in income (cf. Equation 6.2). Thus, individuals with a low income are willing to pay a larger share of their income than individuals with a higher income. Now, consider a society in which income is redistributed such that income inequality decreases but mean income remains constant, i.e. at least one individual with income below average has more and one individual with income above average has less income. As WTP increases at a lower-than-proportional rate than income, the increase in WTP of the poorer individual overcompensate the decrease in WTP of the richer individual, thus establishing the effect of changes in income inequality on mean WTP that we will make use of for our analysis of benefit transfers. ${ }^{88}$

The benefit transfer function, $\mathcal{T}(\cdots)$, for transferring mean WTPs from the study site, $\mu_{\mathrm{WTP}}^{s}$, to the policy site, $\mu_{\mathrm{WTP}}^{p}$, while controlling for the variables that differ across sites in this theoretical equal-preference framework, is now defined as the ratio of the mean WTPs at the policy and the study sites:

$$
\begin{aligned}
& \mathcal{T}\left(\mu_{Y}^{\mathrm{p}}, \mathrm{CV}_{Y}^{\mathrm{p}}, P^{\mathrm{p}}, E^{\mathrm{p}} ; \mu_{Y}^{\mathrm{s}}, \mathrm{CV}_{Y}^{\mathrm{s}}, P^{\mathrm{s}}, E^{\mathrm{s}}\right) \quad:=\frac{\mu_{\mathrm{WTP}}^{\mathrm{p}}\left(\mu_{Y}^{\mathrm{p}}, \mathrm{CV}_{Y}^{\mathrm{p}}, P^{\mathrm{p}}, E^{\mathrm{p}}\right)}{\mu_{\mathrm{WTP}}^{\mathrm{s}}\left(\mu_{Y}^{\mathrm{s}}, \mathrm{CV}_{Y}^{\mathrm{s}}, P^{\mathrm{s}}, E^{\mathrm{s}}\right)} \\
& \stackrel{\text { Equ. 6.3) }}{=} \frac{\left(\mu_{Y}^{\mathrm{p}}\right)^{\eta}\left(1+\mathrm{CV}_{Y}^{\mathrm{p}} 2\right)^{\frac{\eta(\eta-1)}{2}}\left(P^{\mathrm{p}} E^{\mathrm{p}}\right)^{1-\eta}}{\left(\mu_{Y}^{\mathrm{s}}\right)^{\eta}\left(1+\mathrm{CV}_{Y}^{\mathrm{s}}{ }^{2}\right)^{\frac{\eta(\eta-1)}{2}}\left(P^{\mathrm{s}} E^{\mathrm{s}}\right)^{1-\eta}}
\end{aligned}
$$

\footnotetext{
${ }^{88}$ The rationale is reversed for an income elasticity of WTP larger than unity: In this case, an increase in income inequality would lower mean WTP.
} 
This transfer function neatly disentangles into four individual transfer factors, with:

$$
\begin{aligned}
\mu_{\mathrm{WTP}}^{p} & =f\left(\mu_{W T P}^{s}\right) \\
& =\mathcal{T}_{\mu}\left(\mu_{Y}^{p}, \mu_{Y}^{s}\right) \cdot \mathcal{T}_{\mathrm{CV}}\left(\mathrm{CV}_{Y}^{p}, \mathrm{CV}_{Y}^{s}\right) \cdot \mathcal{T}_{p}\left(P^{p}, P^{s}\right) \cdot \mathcal{T}_{E}\left(E^{p}, E^{s}\right) \cdot \mu_{\mathrm{WTP}}^{s}
\end{aligned}
$$

In particular, this transfer function yields the transfer factors for differences in the level of mean income and income inequality that will be the main focus of our analysis: ${ }^{89}$

$$
\begin{aligned}
\mathcal{T}_{\mu}\left(\mu_{Y}^{p}, \mu_{Y}^{s}\right) & =\left(\frac{\mu_{Y}^{p}}{\mu_{Y}^{s}}\right)^{\eta} \\
\mathcal{T}_{\mathrm{CV}}\left(\mathrm{CV}_{Y}^{p}, \mathrm{CV}_{Y}^{s}\right) & =\left(\frac{1+\mathrm{CV}_{Y}^{p}{ }^{2}}{1+\mathrm{CV}_{Y}^{s}{ }^{2}}\right)^{\frac{\eta(\eta-1)}{2}}
\end{aligned}
$$

It is common practice in benefit transfer to adjust WTP-estimates for differences in mean income using $\mathcal{T}_{\mu}\left(\mu_{Y}^{p}, \mu_{Y}^{s}\right)$. For instance, Krupnick et al. (1996) adjusted estimates in this fashion for health impacts from Western Europe and the US to evaluate benefits from reductions in ambient air pollution in Central and Eastern European countries. Pearce (2000) stated this formula in policy advice used by the European Commission for international benefit transfer on health estimates. Moreover, policy guidance on benefit transfer, for instance for the UK (Defra 2007), Germany (UBA 2012) and from the OECD (Pearce et al. 2006), propose this formula to adjust WTP estimates for differences in mean income. Yet, none of these studies or guidelines on benefit transfer (UBA 2012, Defra 2007, Pearce et al. 2006, U.S. EPA 2014) mentions income inequality.

The income elasticity of WTP for environmental goods, $\eta$, plays a central role for the transfer factors. We therefore discuss different parameter values for $\eta$. First, we focus on the simplest case of $\eta=1$ that is most often assumed in the literature on benefit transfer (see, e.g., Barton (2002) and Czajkowski and Scasny (2010)) and in policy applications (see, e.g.,

\footnotetext{
${ }^{89}$ The theory also yields transfer factors for the market price level $\mathcal{T}_{P}\left(P^{p}, P^{s}\right)=\left(\frac{P^{p}}{P^{s}}\right)^{1-\eta}$ and the quantity of the environmental good $\mathcal{T}_{E}\left(E^{p}, E^{s}\right)=\left(\frac{E^{p}}{E^{s}}\right)^{1-\eta}$. As there is empirical evidence that the environmental good under study is a region-wide public good (see Section 6.3), we assume $E^{p}=E^{s}$ for the main part of our analysis. We ease this assumption to a local public good in a sensitivity analysis in Section 6.5.2, where we apply $\mathcal{T}_{E}\left(E^{p}, E^{s}\right)$. We show that including this additional transfer factor does not alter our main result. Furthermore, we directly use the income and WTP data from the Baltic Sea study, which have already been made internationally comparable by using PPP-corrected currency exchange rates. As such our analysis starts out from a situation where differences in the market price levels between policy and study site are accounted for and hence we take $P^{p}=P^{s}$. To further establish the robustness of our main result for inequality, we also explicitly apply $\mathcal{T}_{P}\left(P^{p}, P^{s}\right)$ in Section 6.5.2.
} 


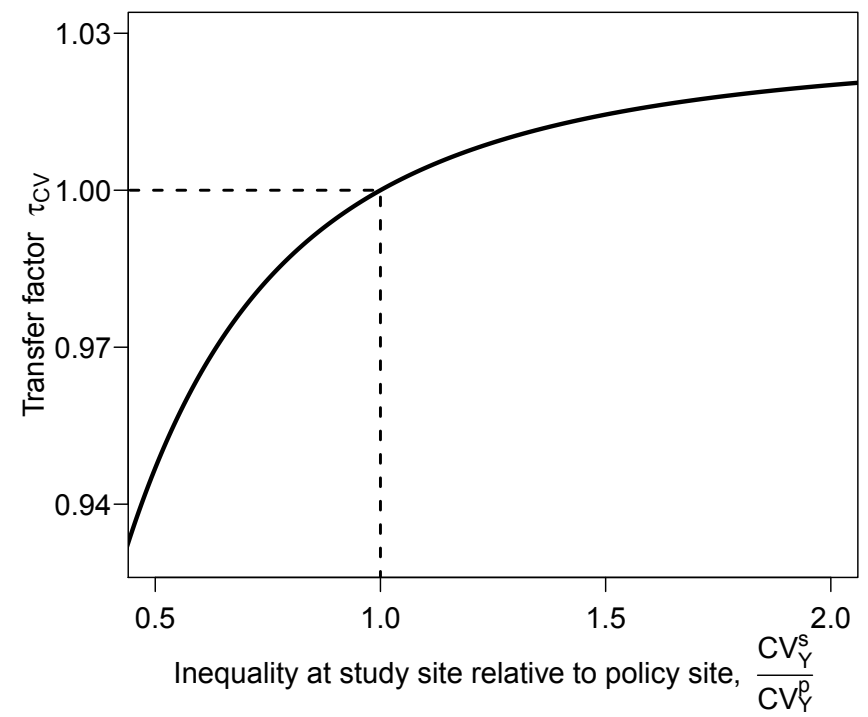

Figure 6.1: Relationship between the transfer factor for income inequality $\mathcal{T}_{\mathrm{CV}}(\cdot)$ and the ratio of income inequality in the study and policy country for $\eta=0.28$ and $C V_{Y}^{s}=0.56$.

ten Brink et al. (2011)). The theory-driven transfer factors suggest that controlling only for the difference in mean incomes is correct if and only if the income elasticity is equal to unity, which is often assumed for simplicity. However, as the income elasticity of WTP for environmental goods is in general not equal to unity, we also have to consider not only the transfer factor for mean income but also income inequality.

As there is only sparse empirical evidence for $\eta>1$, we focus on the empirically most relevant case of $\eta<1$ (see Figure 6.1). ${ }^{90}$ For income elasticities below unity, $\eta<1$, WTPestimates have to be adjusted by the ratio of mean income in the policy and study sites to the power of the income elasticity of WTP, $\mathcal{T}_{\mu}\left(\mu_{Y}^{p}, \mu_{Y}^{s}\right)$. A closer inspection of this theory-driven transfer factor from Baumgärtner et al. (2017a) for income inequality, $\mathcal{T}_{\mathrm{CV}}\left(\mathrm{CV}_{Y}^{p}, \mathrm{CV}_{Y}^{s}\right)$, reveals that it increases in the ratio of income inequality at the study and the policy site, $\frac{C V_{Y}^{s}}{C V_{Y}^{p}}$, at a decreasing rate (Figure 6.1). This suggests that it is in particular relevant to control for income inequality when income inequality is higher at the policy site than on the study site (i.e. in the lower-left part of Figure 6.1).

\subsection{Data}

We investigate the empirical relevance of income inequality adjustment in benefit transfer using data from a multi-country contingent valuation study on the benefits of a water quality

\footnotetext{
${ }^{90}$ Most studies find an income elasticity of WTP between 0 and 1 . This is also the case for the Baltic Sea study (Barbier et al. 2016). Surveying recent evidence on income elasticities, Drupp (2018) finds that only two of 18 considered studies imply mean income elasticities greater than unity.
} 
improvement in the Baltic Sea (Ahtiainen et al. 2014). Respondents were asked for their WTP for a nutrient reduction programme with associated consequences for water clarity, blue-green algal blooms, the abundance of sea grass beds, and fish species composition. Figure 6.2 shows a map of the Baltic sea and its neighboring countries, with levels of income inequality and mean WTP for water quality improvement.

The data is particularly suitable to study the performance of the theory-driven transfer factors as the same survey instrument was used to elicit the WTP for a common change in this environmental good across populations with substantially different mean income levels and income inequalities. Ahtiainen et al. (2014) designed the survey such that it is both comparable and meaningful to the population in each country bordering the Baltic See. Respondents were informed that the benefits of nutrient reductions would occur in open-sea areas across the whole Baltic Sea (Czajkowski et al. 2017), suggesting region-wide public good characteristics. ${ }^{91}$

The payment vehicle was framed as a 'Baltic Sea tax' for nutrient reduction levied in all countries bordering the Baltic Sea. A payment card with country specific bid vectors based on the WTP distributions in pilot studies was employed to elicit WTP. In the following we take individual maximum WTP to equal the mid point of the stated WTP interval, as previously done by Ahtiainen et al. (2014) and Barbier et al. (2016).

The survey was conducted from October to December 2011 in all nine countries bordering the Baltic Sea: Denmark (DEN), Estonia (EST), Finland (FIN), Germany (GER), Latvia (LAT), Lithuania (LIT), Poland (POL), Russia (RUS) and Sweden (SWE). For comparison all WTP figures were converted to units of 2011-purchasing-power-converted-EUR ["2011PPP-EUR"]. Country samples show substantially different estimated mean WTPs, $\tilde{\mu}_{\mathrm{WTP}}^{c}$ (Table 6.1). ${ }^{92}$ These range from 5.74 [2011-PPP-EUR] elicited in Latvia to 80.64 [2011PPP-EUR] in Sweden.

Respondents were asked to state their personal mean monthly net income by selecting the applicable interval. Income was then set to the interval mean, for all but the highest category, where it was set to the lower interval boundary.

\footnotetext{
${ }^{91}$ Respondents understanding was validated by the following survey questions: "Did you consider the whole Baltic Sea or a certain area of the Baltic Sea when answering how much you were willing to pay?", "To what extent did you consider open sea and coastal areas when answering how much you were willing to pay?" It shows that respondents indeed predominantly state that they considered the whole Baltic Sea opposed to the shore line when stating their WTP values. Moreover, Ahtiainen et al. (2014) find in their fully specified regression models a significant negative effect of respondents distance to the Baltic Sea on WTP for water quality improvement in only one out of nine countries.

${ }^{92}$ We qualify estimates with a tilde to distinguish them from the true values in the population.
} 


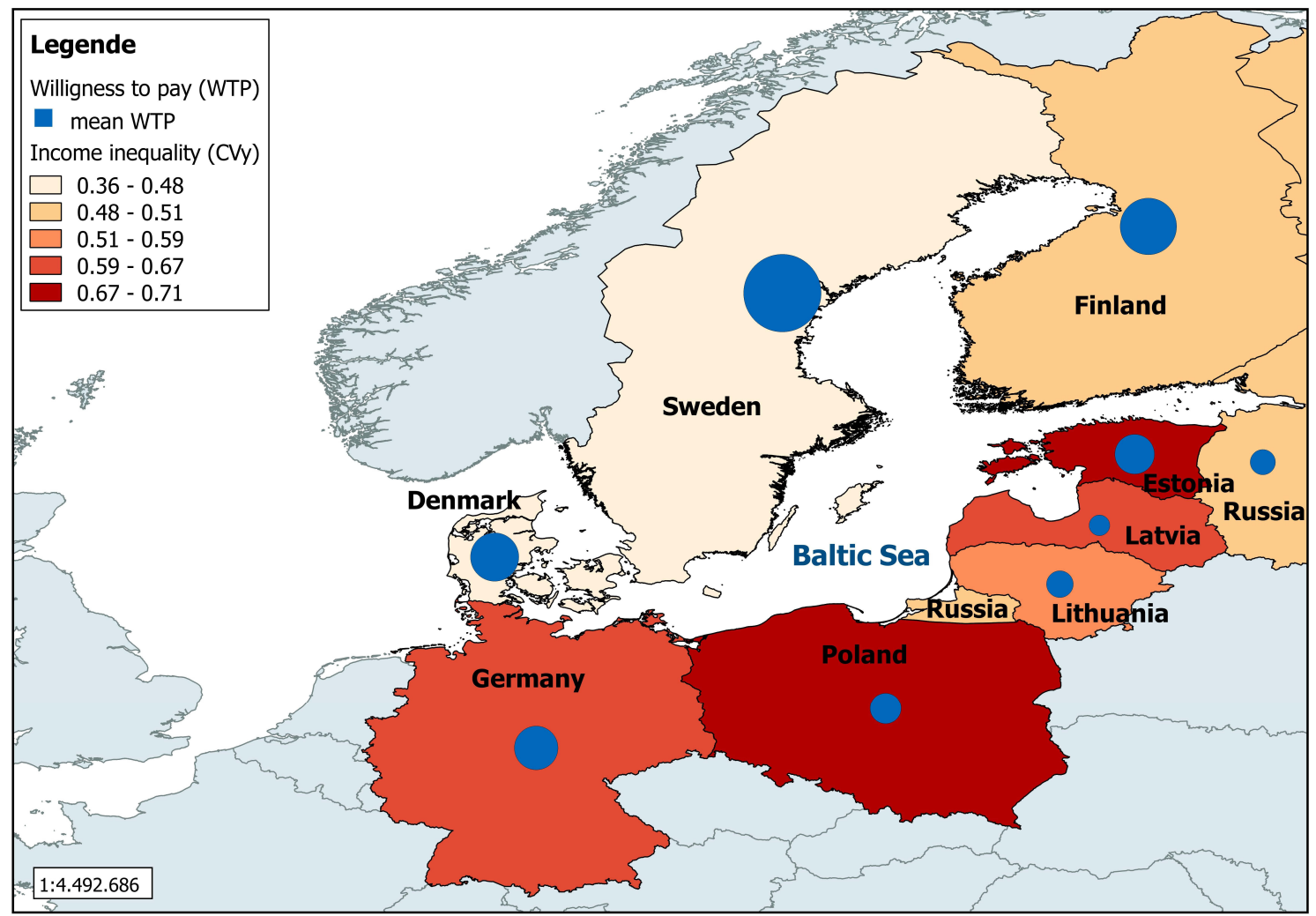

Figure 6.2: Countries neighboring the Baltic Sea with mean WTP for water quality improvement, $\tilde{\mu}_{\mathrm{WTP}}^{c}$, and income inequality, $\tilde{C V} V_{Y}^{c}$, of surveyed population.

Income distributions of the countries bordering the Baltic Sea differ substantially regarding both mean income and income inequality (Figure 6.2). Respondents mean monthly net income, $\tilde{\mu}_{Y}^{c}$, ranges from 343 [2011-PPP-EUR] in Lithuania up to 1,659 [2011-PPP-EUR] in Denmark. The surveyed income inequality is lowest in Sweden with a coefficient of variation, $\tilde{C V_{Y}^{c}}$, of 0.36 and highest in Estonia with a $\tilde{C V}_{Y}^{c}$ of 0.71 , corresponding to Gini-coefficients, $\operatorname{Gini}_{Y}^{c}$, of 0.20 and 0.37 , respectively. ${ }^{93}$

\footnotetext{
${ }^{93}$ Compared to national statistics, sample mean income is below the national averages for most countries (exceptions are Poland and Estonia where sample mean income is slightly higher). The mean absolute deviation from the national income level is $14.48( \pm 15.09) \%$. Concerning income inequality the picture is more mixed: Income inequality within the sample as measured with the Gini $i_{Y}$ is below official national figures for four countries (DEN, LIT, RUS, SWE), but higher for the other five countries (EST, FIN, GER, LAT, POL). The majority of differences are mostly below ten percentages points, with mean absolute deviation of $11.95( \pm 8.92) \%$. Russia is an exception, where the surveyed income in the exclave Kaliningrad Oblasthas shows a substantially lower Gini $_{Y}$ than for the whole country.
} 
TABLE 6.1: Sample statistics by country

\begin{tabular}{lrrrrr}
\hline \hline Country & \multicolumn{1}{c}{$\tilde{N}^{c}$} & \multicolumn{1}{c}{$\tilde{\mu}_{Y}^{c}$} & $\tilde{C V}_{Y}^{c}$ & Gini $_{Y}^{c}$ & \multicolumn{1}{c}{$\tilde{\mu}_{\text {WTP }}^{c}$} \\
\hline Denmark (DEN) & 1,061 & 1,659 & 0.46 & 0.26 & 31.50 \\
Estonia (EST) & 505 & 857 & 0.71 & 0.37 & 21.23 \\
Finland (FIN) & 1,645 & 1,585 & 0.51 & 0.28 & 42.84 \\
Germany (GER) & 1,495 & 1,559 & 0.60 & 0.33 & 25.59 \\
Latvia (LAT) & 701 & 483 & 0.66 & 0.36 & 5.74 \\
Lithuania (LIT) & 617 & 343 & 0.53 & 0.30 & 9.61 \\
Poland (POL) & 2,029 & 841 & 0.69 & 0.33 & 12.99 \\
Russia (RUS) & 1,508 & 666 & 0.50 & 0.28 & 8.57 \\
Sweden (SWE) & 1,003 & 1,431 & 0.36 & 0.20 & 80.64 \\
\hline
\end{tabular}

Note: Monthly net income and WTP per year in 2011-PPP-EUR.

\subsection{Empirical strategy}

For each pair of countries in our dataset we hypothetically transfer WTP-estimates from one country to the other and compare the transferred WTP with the actually surveyed WTPestimates. This approach is often termed convergent validity, as it cross-validates the results of the benefit transfer with another estimate for the true WTP. ${ }^{94}$

The accuracy of benefit transfer is assessed by calculating transfer errors, which are a common measurement to study the convergent validity of benefit transfers (e.g. Kaul et al. 2013). Accordingly, the relative transfer error associated with a single benefit transfer is measured as the difference between the mean WTP estimate transferred from the study site $f\left(\tilde{\mu}_{W T P}^{s}\right)$, and the actually observed mean WTP-estimate at the policy site, $\tilde{\mu}_{W T P}^{p}$, expressed as a percentage (Kirchhoff et al. 1997):

$$
|T E|=\frac{\left|W T P_{t r a n s}-W T P_{o b s}\right|}{W T P_{o b s}}=\frac{\left|f\left(\tilde{\mu}_{W T P}^{s}\right)-\tilde{\mu}_{W T P}^{p}\right|}{\tilde{\mu}_{W T P}^{p}} .
$$

Each transfer is conducted using unadjusted unit transfer, income inequality adjusted transfer, mean income adjusted transfer as well as mean income and income inequality adjusted transfer.

For simple unit transfer the transferred WTP-estimate, $f\left(\tilde{\mu}_{W T P}^{s}\right)$, equals the WTP surveyed at the study site, $\tilde{\mu}_{W T P}^{s}$, and this becomes:

$$
|T E|_{\text {unit }}=\frac{\left|\tilde{\mu}_{W T P}^{s}-\tilde{\mu}_{W T P}^{p}\right|}{\tilde{\mu}_{W T P}^{p}} .
$$

\footnotetext{
${ }^{94}$ Note that the estimate from the primary valuation at the policy site, $\tilde{\mu}_{W T P}^{s}$, might itself be a biased estimate of the 'true' WTP, $\mu_{W T P}^{s}$.
} 
To adjust for differences in income inequality, the level of mean income between policy and study sites, or the combination of both we draw on the theory-driven benefit transfer factors for income inequality $\mathcal{T}_{C V}\left(\tilde{C V} V_{Y}^{p}, \tilde{C V_{Y}^{s}}\right)=\left(\frac{1+\tilde{C V_{Y}^{p 2}}}{1+\tilde{C} V_{Y}^{s 2}}\right)^{\frac{\tilde{\eta}(\tilde{\eta}-1)}{2}}$ (Equation 6.6), and for mean income $\mathcal{T}_{\mu}\left(\tilde{\mu_{Y}}{ }^{p},{\tilde{\mu_{Y}}}^{s}\right)=\left(\frac{\tilde{\mu}_{\tilde{Y}}^{p}}{\mu_{Y}^{s}}\right)^{\tilde{\eta}} \quad$ (Equation 6.5). The transfer errors after correcting for income inequality, $|T E|_{\mathcal{T}_{C V}}$, mean income, $|T E|_{\mathcal{T}_{\mu}}$, as well as both income inequality and mean income, $|T E|_{\mathcal{T}_{C V, \mu}}$, read:

$$
\begin{aligned}
|T E|_{\mathcal{T}_{C V}} & =\frac{\left|\mathcal{T}_{C V}\left(\tilde{C V} V_{Y}^{p}, \tilde{C V} V_{Y}^{s}, \tilde{\eta}\right) \cdot \tilde{\mu}_{W T P}^{s}-\tilde{\mu}_{W T P}^{p}\right|}{\tilde{\mu}_{W T P}^{p}}, \\
|T E|_{\mathcal{T}_{\mu}} & =\frac{\left|\mathcal{T}_{\mu}\left(\tilde{\mu}_{Y}^{p}, \tilde{\mu}_{Y}^{s}, \tilde{\eta}\right) \cdot \tilde{\mu}_{W T P}^{s}-\tilde{\mu}_{W T P}^{p}\right|}{\tilde{\mu}_{W T P}^{p}},
\end{aligned}
$$

and

$$
|T E|_{\mathcal{T}_{C V, \mu}}=\frac{\left|\mathcal{T}_{C V}\left(\tilde{C V} V_{Y}^{p}, \tilde{C V} V_{Y}^{s}, \tilde{\eta}\right) \cdot \mathcal{T}_{\mu}\left(\tilde{\mu}_{Y}^{p}, \tilde{\mu}_{Y}^{s}, \tilde{\eta}\right) \cdot \tilde{\mu}_{W T P}^{s}-\tilde{\mu}_{W T P}^{p}\right|}{\tilde{\mu}_{W T P}^{p}} .
$$

The performances of benefit transfers after adjusting for income inequality, mean income and both, $\mathcal{T}_{C V}, \mathcal{T}_{\mu}, \mathcal{T}_{C V, \mu}$, are evaluated against unit transfer. Accordingly, reductions in mean transfer errors are measured (in percentage points) as

$$
\begin{aligned}
\Delta|T E|_{\mathcal{T}_{C V}} & :=|T E|_{\mathcal{T}_{C V}}-|T E|_{\text {unit }}, \\
\Delta|T E|_{\mathcal{T}_{\mu}} & :=|T E|_{\mathcal{T}_{\mu}}-|T E|_{\text {unit }},
\end{aligned}
$$

and

$$
\Delta|T E|_{\mathcal{T}_{C V, \mu}}:=|T E|_{\mathcal{T}_{C V, \mu}}-|T E|_{\text {unit }}
$$

To investigate whether income inequality adjustment increases the validity of benefit transfers, we are interest in the change in transfer errors when adjusting for income inequality and mean income compared to pure income-adjustment, and refer to this as additional income inequality adjustment, $\Delta|T E|_{\mathcal{T}_{C V, \mu}}-\Delta|T E|_{\mathcal{T}_{\mu}}=|T E|_{\mathcal{T}_{C V, \mu}}-|T E|_{\mu}$.

The theory assumes that the income elasticity of WTP, $\eta$, is common to the population at the study and the policy site. In practical applications of benefit transfer this would 
be reflected in applying an estimate for the income elasticity, $\tilde{\eta}$, from a meta-study such as Jacobsen and Hanley (2009). ${ }^{95}$ In the context of this Baltic Sea study, we assume that there is an income elasticity of the WTP for water quality improvements of the Baltic Sea common to all neighboring countries. We therefore rely on the estimate for pooling income and WTP data across all countries in Barbier et al. (2016), who estimate a pooled income elasticity for a range of model specifications, and use the estimate of $\tilde{\eta}=0.28$ from the Box-Cox regression in the constant income elasticity specification with heteroskedascity and apply it throughout formulas (6.9) to $(6.11) . .^{96}$

For nine countries this yields a set of $9 \times 8=72$ possible transfers for each specification, based on which we calculate summary statistics (mean, standard deviation and median) for the transfer errors $|T E|$. We perform this analysis for the full set of benefit transfers as well as for sub-samples for different ratios in income inequality between study site and policy site in order to identify conditions under which income adjustment is likely to reduce transfer errors.

\subsection{Results}

\subsubsection{Main result}

Calculating transfer factors for mean income, $\mathcal{T}_{\mu}(\cdot)$, for income inequality, $\mathcal{T}_{C V}(\cdot)$, and for both together, $\mathcal{T}_{C V, \mu}=\mathcal{T}_{\mu}(\cdot) \times \mathcal{T}_{C V}(\cdot)$, is straightforward by plugging in countries' mean income, CV of income (from Table 6.1) and income elasticities of WTP for the environmental good, $\tilde{\eta}$, in Equations (6.5) and (6.6).

Transfer factors for income inequality, $\mathcal{T}_{C V}(\cdot)$, range from 0.97 (Sweden to Estonia) to 1.03 (Estonia to Sweden), which have the lowest (Sweden) and highest (Estonia) levels of income inequality. Populating the conceptual sketch from Figure 6.1 with data from our case study, Figure 3 now depicts the relationship between the transfer factor for income inequality $\mathcal{T}_{C V}(\cdot)$ and the ratio of income inequality in the study and policy sites. In particular, we depict the two extreme cases, using Estonia (left panel) and Sweden (right panel) as the study sites and all countries as potential policy sites, respectively.

\footnotetext{
${ }^{95}$ We also explore the option of country-specific income elasticities and report the corresponding results in the discussion (Section 6.6).

${ }^{96}$ Alternatives to determine a pooled income elasticity of WTP could be to use an estimate from another global case study, such as Jacobsen and Hanley (2009), to use an average of individual country's income elasticities, $\mu_{\eta_{i}}$, or to construct a pooled estimates of the income elasticity that incorporates subjects from individual countries relative to the countries' population sizes.
} 

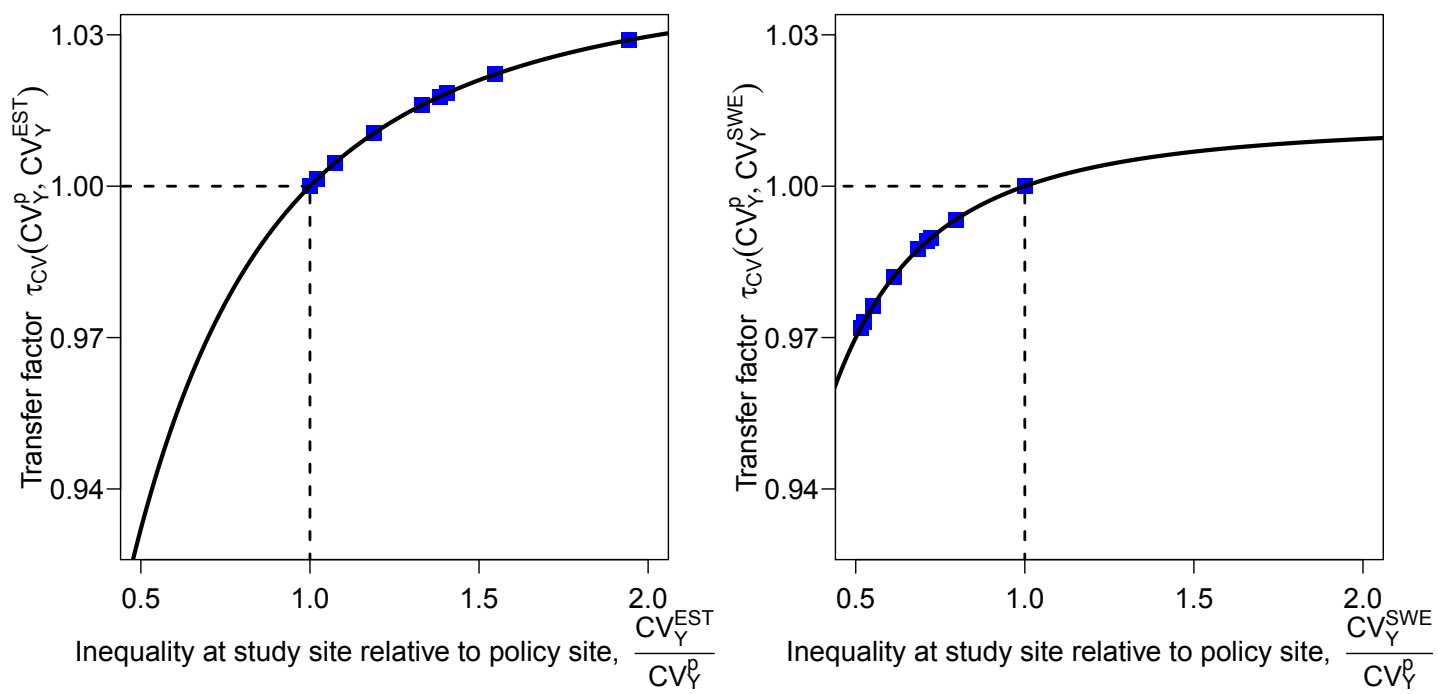

FigURE 6.3: Relationship between the transfer factor for income inequality $\mathcal{T}_{C V}(\cdot)$ and the ratio of income inequality in the study and policy sites, for Estonia (Sweden) as the study site in the left (right) panel. Each blue dot represents a possible benefit transfer.

Adjusting WTP-estimates for differences in mean income requires higher transfer factors, $\mathcal{T}_{\mu}(\cdot)$, ranging from 0.64 (Denmark to Lithuania) to 1.56 (Lithuania to Denmark), which have the highest and lowest mean income in our data set.

Simple unit transfers result in substantial transfer errors, with a mean absolute transfer error of $152.35 \%$. This mean transfer error is reduced by $\Delta|T E|_{\mathcal{T}_{C V}}=-1.80$ percentage points to $|T E|_{\mathcal{T}_{C V}}=150.55 \%$ when WTP-estimates are adjusted for income inequality. ${ }^{97}$ It is reduced by $\Delta|T E|_{\mathcal{T}_{\mu}}=-36.88$ percentage points to $|T E|_{\mathcal{T}_{\mu}}=115.48 \%$ when adjusting for mean income, underscoring that this is the more important adjustment in quantitative terms. Combining income inequality with mean income adjustment produces the best result $\left(|T E|_{\mathcal{T}_{C V, \mu}}=114.02 \%\right)$, where mean transfer errors are reduced by $\Delta|T E|_{\mathcal{T}_{C V, \mu}}=-38.33$ percentage points. Thus, additional income inequality adjustment reduces mean transfer errors by $\Delta|T E|_{\mathcal{T}_{C V, \mu}}-\Delta|T E|_{\mathcal{T}_{\mu}}=-1.46$ percentage points (see Table 6.2 , row 1 ). We find that changes in transfer errors from both income inequality adjustment, $\Delta|T E|_{\mathcal{T}_{C V}}$, and additional income inequality, $\Delta|T E|_{\mathcal{T}_{C V, \mu}}$, are significantly different from a zero transfer error reduction at $p<0.01$ for all 72 transfers. ${ }^{98}$

\footnotetext{
${ }^{97}$ The transfer errors associated with each individual benefit transfer are reported on a country-by-country basis in Tables 6.3 to 6.6 in the Appendix. Summary statistics on the absolute transfer errors for each specification of the benefit transfers are reported in Table 6.8 .

${ }^{98}$ This also holds for non-parametric tests, such as the Wilcoxon signed-rank test. If we only consider uni-directional transfers, i.e. half the sample, we find that the results still hold at $p<0.05$ on average. Moreover, if we measure transfer errors as absolute changes instead of relative changes, i.e. define
} 
TABle 6.2: Mean differences in transfer errors (in percentage points) for pure and additional income inequality adjustment, $\Delta|T E|_{\mathcal{T}_{C V}}$ and $\Delta|T E|_{\mathcal{T}_{C V, \mu}}-\Delta|T E|_{\mathcal{T}_{\mu}}$.

\begin{tabular}{lccc}
\hline \hline & $\Delta|T E|_{\mathcal{T}_{C V}}$ & $\Delta|T E|_{\mathcal{T}_{C V, \mu}}-\Delta|T E|_{\mathcal{T}_{\mu}}$ & $N_{\text {transfer }}$ \\
\hline all & -1.80 & -1.46 & 72 \\
$\frac{C V^{s}}{C V^{p}}<1$ & -3.82 & -3.01 & 36 \\
$\frac{C V^{s}}{C V^{p}}<0.8$ & -6.31 & -4.96 & 20 \\
\hline
\end{tabular}

We now examine under which conditions (additional) income inequality adjustment particularly reduces benefit transfer errors. ${ }^{99}$ Figure 6.4 depicts the relationship between reductions in absolute transfer errors through additional income inequality adjustment, $\Delta|T E|_{\mathcal{T}_{C V, \mu}}$, and the ratio of income inequality at study and policy site, $\frac{\tilde{C V^{s}}}{\widetilde{C V^{p}}}$. We find that income inequality adjustment substantially reduces transfer errors in cases where income inequality is higher at the policy compared to the study site. For the 36 transfers where income inequality is higher at the policy site than at the study site, reduction in mean transfer errors roughly doubles compared to the whole set of transfers to $\Delta|T E|_{\mathcal{T}_{C V}}=-3.82$ percentage points for pure income inequality adjustment and to $\Delta|T E|_{\mathcal{T}_{C V, \mu}}-\Delta|T E|_{\mathcal{T}_{\mu}}-3.01$ percentage points for additional income inequality adjustment (see Table 6.2, row 2). The improvements in transfer accuracy due to income inequality adjustment are even more pronounced for the 20 transfers where inequality in the study sites is less than $80 \%$ of the policy site's estimate. Here, reductions in mean transfer errors are $\Delta|T E|_{\mathcal{T}_{C V}}=-6.31$ and $\Delta|T E|_{\mathcal{T}_{C V, \mu}}-\Delta|T E|_{\mathcal{T}_{\mu}}=-4.96$ percentage points for pure and additional income inequality adjustment (see Table 6.2, row 3). The most substantial reduction of transfer errors is for a benefit transfer from Sweden to Latvia. Here, accounting for income inequality, over and above adjusting for differences in mean income, reduces the transfer error by 24.51 percentage points. Compared to the unit transfer, accounting for income inequality even reduces transfer errors by up to 33.31 percentage points. This is driven by both the large differences in mean WTP and income inequality between Sweden and Latvia.

$\left|T E^{\prime}\right|:=\left|\mathrm{WTP}_{\text {trans }}-\mathrm{WTP}_{\text {obs }}\right|$, two-sided t-tests reveal that (additional) income inequality adjustment reduces transfer errors even at $p<0.001$.

${ }^{99}$ Note that transfers for mean income as well as income inequality lead to some cases in which adjustments to not improve transfer errors. See Tables 6.4 to 6.6 in the Appendix, and Figure 6.5 for the case of additional income inequality adjustment. 


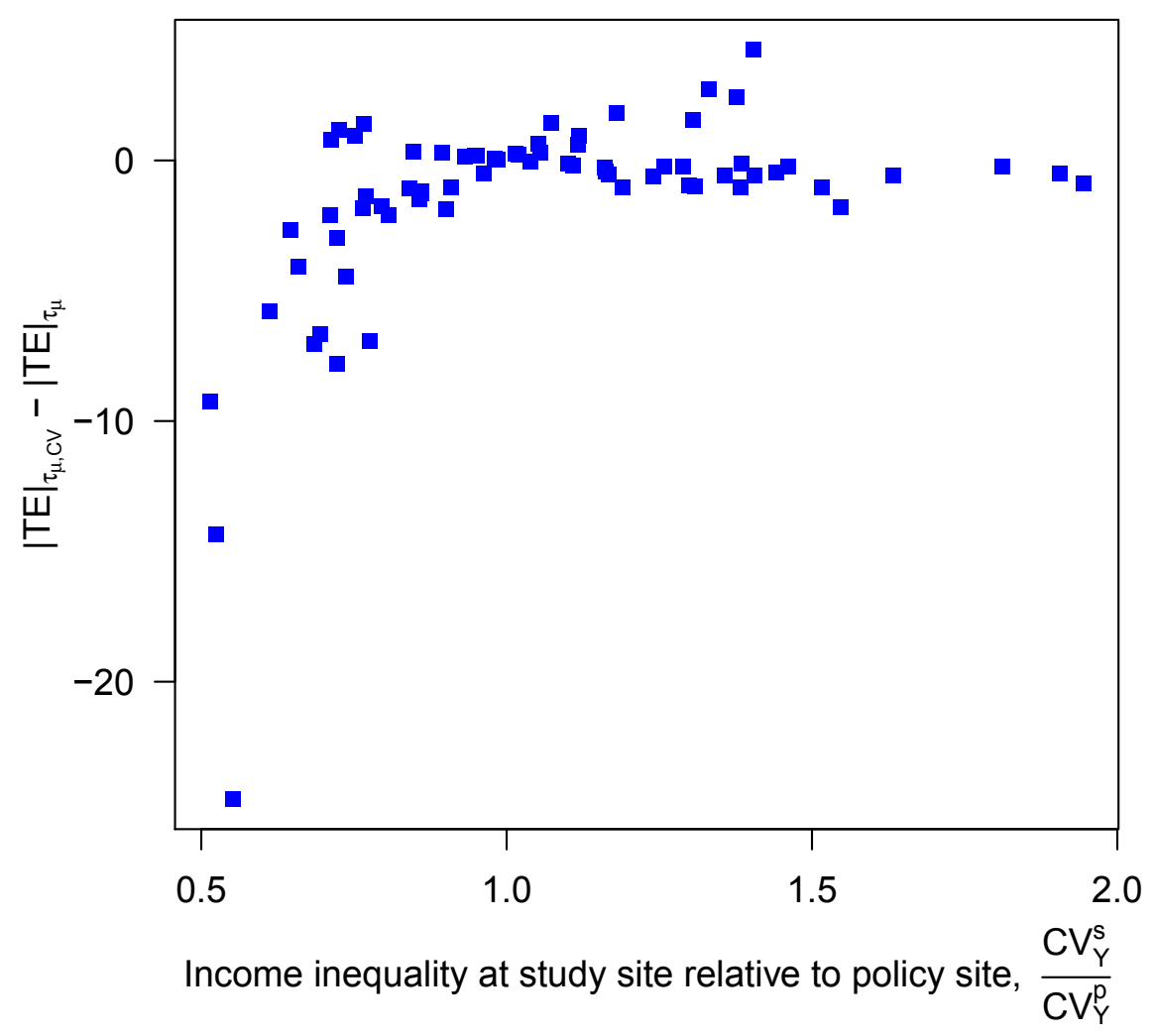

Figure 6.4: Relationship between reductions in transfer errors after additional income inequality adjustment, $|T E|_{\mathcal{T}_{C V, \mu}}-|T E|_{\mathcal{T}_{\mu}}$, and the ratio of income inequality in the study and policy country for $\tilde{\eta}=0.28$.

\subsubsection{Robustness checks}

We perform a number of checks to examine the robustness of our main result - that theorydriven (additional) adjustment for income inequality improves benefit transfer. In particular, we extend our main analysis to consider (i) differences in level of the environmental good, (ii) differences in market prices as well as (iii) naive, non-structural adjustment for income inequality.

First, we test whether our main result still holds when we also consider differences in the level of the environmental good across countries. We thus depart from the simplifying assumption of a region-wide public good and allow $\tilde{E}^{\mathrm{p}} \neq \tilde{E}^{\mathrm{s}}$. We assume that a respondent's level of consumption of the environmental good depends on her exposure to it, approximated by her distance to the shore. A respondent's distance to the Baltic Sea, $d_{i}$, is measured from the geometrical centre point of the municipality or postal codes area they live in to the Baltic Sea (Ahtiainen et al. 2014). There are large country differences in respondents' mean distance to the Baltic Sea reflecting that countries vary substantially in length of their 
coastline relative to their land area and geographical population density. ${ }^{100}$ Since distance would give disutility, we take as an estimate for a country's level of the environmental good, $\tilde{E}^{c}$, the average of respondent's negative distance rescaled to the [0,1]-interval

$$
\tilde{E}^{c}=\frac{1}{N^{c}} \sum_{1}^{N^{c}} \frac{\max (d)-d_{i}^{c}}{\max (d)-\min (d)},
$$

where the sample's minimum and maximum distance to the Baltic Sea are $\min (d)=0$ and $\max (d)=9.300 \mathrm{~km} .{ }^{101}$ Thus, to stay in line with the model, we consider differences in the level of the environmental good across countries, but not within a country. ${ }^{102}$

We adjust WTP-estimates for differences in the closeness to the Baltic Sea in the hypothetical benefit transfers by using $\tilde{E}^{c}$ in $\mathcal{T}_{E}\left(\tilde{E}^{p}, \tilde{E}^{s}\right)=\left(\frac{\tilde{E}^{p}}{\tilde{E}^{s}}\right)^{1-\eta}$ and additionally adjusting for differences in mean income and income inequality. We find that the adjustment for the level of the environmental good, $\Delta|T E|_{\mathcal{T}_{E}}$, reduces the average transfer error compared to the unit transfer by 2.87 percentage points. ${ }^{103}$ However, this does not much affect our main results on how adjusting for income inequality affects transfer errors: We find that accounting for income inequality over and above for differences in the level of the environmental good, $\Delta|T E|_{\mathcal{T}_{E}}-\Delta|T E|_{\mathcal{T}_{E, C V}}$, reduces transfer errors on average by 1.78 percentage points. This is almost the same effect size as if we had not controlled for differences in the level of the environmental good, which leads to a reduction of 1.80 percentage points. When adjusting for income inequality additionally to both transfers for the environmental good and mean income differences, $\Delta|T E|_{\mathcal{T}_{E, C V, \mu}}-\Delta|T E|_{\mathcal{T}_{E, \mu}}$, we find that it further reduces average transfer errors by 1.45 percentage points. Recall that the effect size without controlling for differences in the level of the environmental good was 1.46. Thus the effect sizes presented in the main results section remain largely unchanged.

\footnotetext{
${ }^{100}$ Denmark and Estonia have the shortest average distances to the Baltic Sea $\left(d^{D E N}=10 \mathrm{~km}\right.$ and $d^{E S T}=$ $30 \mathrm{~km})$, while Germany and Russia have the largest $\left(d^{G E R}=360 \mathrm{~km}\right.$ and $\left.d^{R U S}=880 \mathrm{~km}\right)$.

${ }^{101} \mathrm{As}$ an alternative proxy one could also use a country's average inverse distance (restricting $d_{i}$ to a minimum of $0.1 \mathrm{~km}$ to avoid infinite values of $E_{i}$ ), with $E_{i}=d_{i}{ }^{-1}$ for $d_{i}>0.001$ and $E_{i}=0.001^{-1}=1000$ for $d_{i}<0.001$. While this approach would increase transfer errors compared to a unit transfer, adjusting for inequality still reduces transfer errors on a comparable magnitude.

${ }^{102}$ Meya (2018) extends the theory of Baumgärtner et al. (2017a) to local public goods. He shows that the transfer factors for income inequality employed here also hold for environmental local public goods if their consumption is uncorrelated with income. Otherwise, one also needs to account for environmental inequality and the correlation between the environmental good and income when adjusting for income inequality. Yet, in this case, one cannot neatly disentangle transfer factors. For the Baltic Sea dataset correlating a possibly differential level of the environmental good, approximated as respondents' closeness to the Baltic Sea, and income produces mixed results, As there is no significant correlation (at $p<0.05$ ) in the majority of cases, we refrained from further extending our analysis in this direction.

${ }^{103}$ Summary statistics on the absolute transfer errors for the closeness-adjusted benefit transfers are depicted in Table 6.9 in the Appendix.
} 
Second, we test whether our main result still holds when we explicitly adjust for difference in the market price level, that is allowing $\tilde{P}^{p} \neq \tilde{P}^{s}$. For this we take the annual average exchange rates of the national currency in Euro for 2011 from OECD.Stat. Dividing countries PPP-estimates used in Czajkowski et al. (2017) by their exchange rates yields their market price level, $\tilde{P}^{\mathrm{c}}{ }^{104}$ In contrast to our previous approach of starting off with PPP-corrected WTP-estimates, we now first convert WTP-estimates to 2011-EUR and then explicitly adjust for differences in the market price level in benefit transfers by applying $\mathcal{T}_{P}\left(\tilde{P}^{p}, \tilde{P}^{s}\right)=\left(\frac{\tilde{P}^{p}}{\tilde{P}^{s}}\right)^{1-\eta}$. Simple unit transfer to a single currency converted WTP-estimates results in a mean transfer error of $302.01 \%$, which is substantially reduced when adjusting for the market price level, $|T E|_{\mathcal{T}_{P}}=179.91 \%$. Thus, this approach yields higher transfer errors than in our main results specification (compare it to the mean transfer error of 152.35 for unit transfer of the PPP-adjusted WTP-estimates). However, additional income inequality adjustments continue to reduce transfer errors: Adjusting for income inequality in addition to the market price level reduces mean transfer errors by $\Delta|T E|_{\mathcal{T}_{\mathrm{CV}, P}}-\Delta|T E|_{\mathcal{T}_{P}}=-2.28$ percentage points. When also adjusting for mean income or for mean income and the level of the environmental good the reduction are still $\Delta|T E|_{\mathcal{T}_{\mathrm{CV}, P, \mu}}-\Delta|T E|_{\mathcal{T}_{P, \mu}}=-1.85$ and $\Delta|T E|_{\mathcal{T}_{\mathrm{CV}, P, \mu, E}}-\Delta|T E|_{\mathcal{T}_{P, \mu, E}}=-1.84$ percentage points, respectively.

Finally, we test whether adjusting WTP-estimates for income inequality in a naive, nontheory driven fashion also reduces transfer errors. Without being informed by economic theory, a natural 'naive' approach to adjust for income inequality in benefit transfer would most likely be to follow common practice in mean income adjustment using income ratios and thus to adjust WTP-estimates from the study site by the ratio of income inequality at policy and study site, i.e. applying $\mathcal{T}^{\prime}{ }_{\mathrm{CV}}\left(\mathrm{CV}_{Y}^{p}, \mathrm{CV}_{Y}^{s}\right)=\frac{\mathrm{CV}_{Y}^{p}}{\mathrm{CV}_{Y}^{s}}=\frac{\sigma_{Y}^{p}}{\sigma_{Y}^{s}}$. All other things equal to Section 6.5.1, using such a naive income inequality adjustment increases transfer errors compared to unadjusted unit transfer by $\Delta|T E|_{\mathcal{T}^{\prime} C V}=57.55$ percentage points instead of reducing them and results in mean transfer errors of $|T E|_{\mathcal{T}^{\prime} C V}=209.90 \%$. Compared with mean income adjustment additional inequality adjustment in such a naive way worsens the accuracy of benefit transfer by $\Delta|T E|_{\mathcal{T}^{\prime} C V, \mu}-\Delta|T E|_{\mathcal{T}^{\prime}{ }_{\mu}}=47.54$ percentage points. ${ }^{105}$ This finding highlights the important role of theory for specifying functional forms.

\footnotetext{
${ }^{104}$ The estimated market price level is only $\tilde{P}^{L A T}=0.48$ in Latvia but $\tilde{P}^{D E N}=1.37$ in Denmark.

${ }^{105}$ Adjusting WTP-estimates adhoc for differences in the Gini-coefficient yields similar results. Applying naively $\mathcal{T}_{\text {Gini }}\left(\operatorname{Gini}_{Y}^{p}, \operatorname{Gini}_{Y}^{s}\right)=\frac{\operatorname{Gini}_{Y}^{p}}{\operatorname{Gini}_{Y}^{s}}$ would worse the accuracy of benefit transfer by $\Delta|T E|_{\mathcal{T}_{\text {Gini }}}=55.01$ and $\Delta|T E|_{\mathcal{T}_{\text {Gini, }}}-\Delta|T E|_{\mathcal{T}_{\mu}}=44.51$ percentages points.
} 


\subsection{Discussion}

This section provides a discussion of crucial assumptions and major limitations of our analysis. These include (i) the public good characteristics of the environmental quality improvement employed in the contingent valuation survey, (ii) the quality of the income data, (iii) alternative measures of income inequality, (iv) the potential for non-constant income elasticities, as well as (v) the assumption of identical preferences.

First, our theoretical basis for the benefit transfer factors relies on the assumption of a pure public good character of the environmental good in question. Yet, water quality improvement is not always a pure public good and may entail a number of benefits that have a mixed-use character. As such it may also be classified as a local public good, in which exposure to the good differs depending on one's distance to it. In our case, however, respondents were informed that the benefits of nutrient reductions would occur in open-sea areas across the whole Baltic Sea. Indeed, respondents predominantly stated that they considered the whole Baltic Sea, as opposed to only their country's shore line when stating their WTP values (Czajkowski et al. 2017). This is also reflected in the finding by Ahtiainen et al. (2014) that respondents' distance to the Baltic Sea negatively effects their WTP in only one out of nine countries. It thus seems a reasonable assumption that the environmental good in question matches the pure (region-wide) public good characteristics in the theoretical model used to derive the transfer factors. Nevertheless, we eased this assumption in Section 6.5.2 finding that the effect of (additional) income inequality adjustment remains unchanged.

Second, the quality of the income data is not ideal, as income was only elicited on a limited interval scale (Ahtiainen et al. 2014). As such this is a typical initial situation for benefit transfer, since income data elicited in valuation studies is usually coarsely-grained. We followed Ahtiainen et al. (2014) in setting individual income estimates to the interval mean for all but the highest category, where it was set to the lower interval boundary. This provides conservative estimates of both mean income and income inequality and implies that the reported effect of inequality adjustment is likely a conservative estimate of the actual effect of inequality. This limited information on income data also does not allow for a proper test of the assumption of a log-normal distribution of income. As there is mixed evidence on how well the log-normal distribution fits actual income data within countries and for the world as a whole (e.g. McDonald 1984, Pinkovskiy and Sala-i-Martin 2009), our results only hold in approximation.

Third, there are a number of different measures for income inequality that one could 
use to develop transfer functions (see, e.g., Cowell 2009). In particular, one can distinguish notions of absolute and relative income inequality. Measures of absolute income inequality include the standard deviation of income, $\sigma_{Y}^{c}$, as well as the $\operatorname{Gini}_{Y}$-coefficient. It is possible to derive transfer factors for benefit transfer for differences in these measures of absolute income inequality (Baumgärtner et al. 2017a). However, as transfer factors for mean income and income inequality cannot be disentangled for these two absolute measures of income inequality, we have restricted our analysis to the coefficient of variation, $C V_{Y}^{c}$, as a measure of relative income inequality to isolate the effects. As country-level Gini $_{Y}$-coefficient data may be more widely accessible, we also conduct a simple check on whether it is particularly worthwhile to adjust for income inequality in benefit transfer, based on the $\operatorname{Gini}_{Y}$ for data from the Baltic Sea study. For this, we consider those 16 cases for which a Gini $_{Y}$-coefficient ratio between the study and the policy site is smaller than 0.8 and compute mean reductions in transfer errors by including the transfer factors. For these cases, we find that as compared to unit transfer or mean income adjustment, respectively, additionally considering income inequality adjustment reduces transfer errors by 7.73 percentage points for $\Delta|T E|_{\mathcal{T}_{C V}}$ and by 6.15 percentage points for $\Delta|T E|_{\mathcal{T}_{C V, \mu}}-\Delta|T E|_{\mathcal{T}_{\mu}}$. This suggests that our rule-of-thumbthat income inequality adjustment is particularly relevant for cases in which inequality at the study site is below 80 percent of the policy site's level of inequality - might even be more pronounced when considering the Gini $_{Y}$-coefficient.

Fourth, the theory-driven transfer factors employed in our analysis rest on the assumption of a constant elasticity of substitution utility function and an associated constant income elasticity of WTP. This assumption is most often adopted in the practice of benefit transfer (e.g. ten Brink et al. 2011), is supported by some primary valuation studies (e.g. Jacobsen and Hanley 2009, Broberg 2010) and has been shown to produce the best fit in terms of reducing transfer errors in the benefit transfer analysis of the Baltic Sea study by Czajkowski et al. (2017). Despite these encouraging results and the attractiveness of a constant elasticity approach for tractability reasons, it is unlikely that the elasticity is constant in general. Recently, Barbier et al. (2016) have provided evidence that suggests a non-constant income elasticity of WTP, varying with the level of mean income, based on a different analysis of the Baltic Sea study. Additionally, some theoretical studies have provided arguments for nonconstant income elasticities, for example, by taking into account a subsistence consumption level of environmental goods (Baumgärtner et al. 2017b, Drupp 2018), or environmental risk 
and individual risk-aversion (Baumgärtner et al. 2017c). While this paper provides a theorydriven analysis of income inequality adjustment in benefit transfer that rests on the most widely used framework, further theoretical research on benefit transfer functions is required.

Finally, the theory-driven transfer factors rely on the assumption of homogeneous preferences within and across countries. Specifically, we assumed (a) that the utility weight individuals put on the environmental good relative to consumption good, $\alpha$, is the same, and (b) that the elasticity of substitution and thus the income elasticity of WTP, $\eta$, is the same for all individuals. However, it is possible to introduce heterogeneities. First, we address assumption (a), i.e. the share parameter $\alpha$. For simplicity consider a case where the mean weight parameters differ across countries, perhaps due to cultural differences or education leading to a higher or lower weight put on environmental goods (think, for example, of Sweden versus Latvia). ${ }^{106}$ The transfer function would then need to be extended by a factor for the weight parameter: $\mathcal{T}_{\alpha}\left(\alpha^{p}, \alpha^{s}\right)=\frac{\alpha^{s}}{\alpha^{p}}\left(\frac{1-\alpha^{p}}{1-\alpha^{s}}\right)$.

Assumption (b) has implicitly been made also by benefit transfer approaches that assume a single, constant income elasticity of WTP. It is, however, possible to relax this assumption. For example, Baumgärtner et al. (2017a) consider heterogenous preferences for the case where individual-specific income elasticities are normally distributed and uncorrelated with income. Different distributions of $\eta$-types in two countries would then lead to mean income elasticities that differ across countries. Detailed data on $\eta$-estimates in both countries is usually not available in the context of benefit transfer and often times no pertinent metastudy is available. The more relevant case in practice is to only consider the income elasticity from the study country. We therefore also estimated the income elasticity of WTP, $\tilde{\eta}_{i}$, for all nine countries individually and applied the study sites estimate in the transfer factors given in formulas (6.9) to (6.11). ${ }^{107}$ We find that income elasticities of WTP of seven out of nine countries fall within the usual range of 0.1 to 0.6. Yet, the estimates vary substantially. Employing the country specific income elasticities, $\tilde{\eta}_{i}$, in the benefit transfers further reduces transfer errors over the case of a common income elasticity, $\tilde{\eta}$. It shows that mean transfer errors decrease by $\Delta|T E|_{\mathcal{T}_{C V}}=-2.26$ and $\Delta|T E|_{\mathcal{T}_{C V, \mu}}-\Delta|T E|_{\mathcal{T}_{\mu}}=-1.69$ percentages points for pure and additional income inequality adjustment down to a total average transfer errors of $|T E|_{\mathcal{T}_{C V, \mu}}=108.28$ percent when controlling for mean income and income inequality. This shows that our main results also hold when the income elasticity

\footnotetext{
${ }^{106}$ Hynes et al. (2013) study how international benefit transfer may be adjusting for cultural differences.

${ }^{107}$ We assume that the income elasticity is constant within each country, estimated with an OLS regression in log-log specification without control variables. The assumption of a log-log WTP-income relation seems to outperform other functional forms in benefit transfer (Czajkowski et al. 2017).
} 
from the study site is applied, and that this might even be more accurate than using the pooled estimate. ${ }^{108}$

\subsection{Conclusion}

This paper has shown how benefit transfer can account for differences in income inequality in a theory-driven fashion and has scrutinized the applicability of this approach drawing on a multi-country study on water quality improvement in the Baltic Sea.

Improving benefit transfer is of tremendous importance for environmental policy appraisal, as it has perhaps become the most important method of environmental valuation (Richardson et al. 2015). A number of different approaches to benefit transfer have been developed over the past decades, ranging from simple unit transfer to sophisticated individual study based calibrations. Kaul et al. (2013) review studies including more than 1000 benefit transfers and find substantial mean (median) transfer errors of 172 (39) percent. Based on the same Baltic Sea data employed in the present paper, Czajkowski et al. (2017) analyze which functional form should be chosen for international benefit transfer. They find that a constant income elasticity function that controls for differences in the level of mean income between the study and the policy site performs best. As many previous approaches to benefit transfer have been somewhat ad-hoc, Bateman et al. (2011) among others have called for benefit transfer parameters to be more firmly grounded in economic theory and underlying preferences. Responding to these calls, we build on theory-driven transfer factors for mean income and income inequality that were recently developed by Baumgärtner et al. (2017a) to scrutinize whether and to what degree income inequality adjustments can improve benefit transfer.

We find that income inequality adjustment reduces benefit transfer errors by more than 1.5 percentage points on average for the Baltic sea data. We show that this main finding is robust to considering a number of model variations. While our main finding may seem as a rather small effect, it will often be economically substantial. Furthermore, income inequality adjustment becomes particularly relevant when income at the policy site is more unequally distributed than at the study site. On average the reduction in transfer errors amounts to more than 5 percentage points when income inequality at the study site is more than 20 percent lower than the level of inequality at the policy site. We perform a number of

\footnotetext{
${ }^{108}$ Country-specific income elasticities, aggregate statistics on transfer errors and transfer errors for all country-to-country benefit transfers are available from the authors upon request.
} 
checks and show that our main result is robust to additionally considering other possible transfer factors for differences in the price level or the mean level of the environmental goods accross countries. Finally, we show that a naive a-theoretic transfer adjustment for income inequality would increase benefit transfer errors. This emphasizes the importance of employing the structural theory-driven factors that we draw on in our convergent validity excercise.

Our findings are relevant in several respects: First, practitioners of benefit transfers should consider employing transfer factors for differences in income inequality, in particular when income is distributed more unequally at the policy site compared to the study site. Our study has shown how this can be undertaken easily by drawing on simple, theory-driven transfer factors. This would be, for example, particularly relevant for transferring values from European countries to applications in the USA, where income is distributed considerably more unequally. Moreover, inter-country differences in income inequality are considerable for many pairs of European countries. Thus, studies assessing EU-wide benefits by scaling up a small number of WTP-estimates from a subset of member states, should take into account income inequality effects on value transfer. For instance, the benefit streams from ecosystems services from all Natura 2000 sites have been estimated to be 314 billion Euros per year using benefit transfer (ten Brink et al. 2011: 59-64, European Commission 2013). A simple, conservative extension of this analysis - additionally applying benefit transfer factors for income inequality - would increase benefits by only 0.13 percent on average, which would however translate into a sizable economic effect size of 446 million Euros per year. ${ }^{109}$ This simple application highlights that although adjustments for income inequality may seem of minor importance in percentage terms, they can imply substantial effects in absolute economic terms.

Second, theory-driven transfer factors reveal that the frequent use of an income elasticity of one in benefit transfers neglects income inequality, as the transfer factor for income inequality becomes one for different income inequalities if and only if the income elasticity

\footnotetext{
${ }^{109}$ Our simple extended analysis follows the Natura 2000 steps, except that we additionally account for income inequality assuming that the income elasticity of WTP of 0.38 is given by the mean estimate from most comprehensive global meta-study on WTP for biodiversity conservation (Jacobsen and Hanley 2009). Data on the income distribution of European countries was taken from the European Survey on Income and Living Conditions provided by eurostat. The survey contains upper limits of percentiles for disposable household income in 2011 per capita (equivalised). Dencentiles and 95th, 96th, 97th, 98th, 99th percentiles were taken to construct national income distributions (taking the interval values as means of lower and upper limits) and estimate mean income and relative income inequality. This approach yields only a conservative estimate for the reduction in transfer errors from additional income inequality adjustment, as in Natura 2000 WTPs are transferred to the European average rather than on a country-by- country basis, where differences in relative income inequality are much higher.
} 
of WTP is unity. Our analysis shows that this shortcut might perform well if income at the policy site is distributed more equally and is relatively similar to the study site. However this shortcut can result in serious transfer errors when income is distributed substantially more unequally at the policy site. Thus, our study underscores once more the importance of conducting theory-driven benefit transfer as proposed, among others, by Bateman et al. (2011).

Thirdly, the collection of value estimates for different environmental goods in benefits transfer databases is often hailed to be the "holy grail of benefits transfer" (Pearce et al. 2006: 267). There are several attempts in this direction, such as the The Environmental Valuation Reference Inventory (EVRI 2017), a database including information on over 4, 000 international valuation studies, that is also mentioned in several guidelines on benefit transfer (e.g. UBA 2012, Pearce et al. 2006). For instance, the UK sees a further increasing scope of benefit transfer as value databases expand (HM Treasury 2011: 21) and actively supports their development (Defra 2007). One of such future applications might be the use of benefit transfer to inform government project appraisal by drawing on information gathered in environmental impact assessments, e.g. for economic analysis in the context of the EU Water Framework Directive (Droste and Meya 2016). The increasing availability of WTP-estimates for different environmental goods should be accompanied by methodological developments to increase the accuracy of benefit transfer (Pearce et al. 2006) that are sufficiently easy to apply—as the theory-driven benefit transfer factors tested in this study — such as to be used widely in practice.

Fourth and relatedly, there are several efforts underway to link ecosystem services to economic activities in national accounts. Recently, the UN, EU, OECD, FAO and World Bank (2014) proposed the system of environmental economic accounting - experimental ecosystem accounting to facilitate further explorations on a country's ecosystem accounting. This is accompanied by a discussion of the conceptual foundations and appropriate valuation methods to integrate ecosystem services in accounting standards (e.g. Droste and Bartkowski 2017, Obst et al. 2016). One approach is to make changes in ecosystem services directly comparable to market activities through monetary valuation. As primary valuations are usually site-specific, this will regularly involve scaling-up estimates to the national level. The UN et al. (2014: 127) thus call for "efforts aimed at improving benefit transfer methods". Our analysis suggests that this should include accounting for the effects of income inequality when conducting benefit transfer. 
Finally, primary non-market valuation studies should report measures on income elasticities and on income inequality to facilitate the application of more sophisticated and accurate benefit transfers. Ideally, studies would always state standard deviations of respondent's income besides relevant means, or even make the full income distribution available in supplementary online material.

Overall, our findings add empirical evidence to the debate on the importance of economic growth and changes in inequality for the valuation of non-marketed environmental goods. They suggest that while accounting for differences in mean income is relatively more important, taking into account income inequality results in considerable improvements in the performance of benefits transfers.

Acknowledgments: We are indebted to Stefan Baumgärtner and Mikolaj Czajkowski for their valuable feedback and are very grateful for comments from Nils Droste, Klaus Eisenack, Roger von Haefen, Frikk Nesje, Martin Quaas, Arnaud Reynaud as well as seminar participants at Basel, BIOECON 2017, EAERE 2017, EnvEcon 2017, HU Berlin, Kiel, UFZ Leipzig and WCERE 2018. We thank all collectors of the dataset, including researchers from nine countries and the BalticSTERN Secretariat, as well as the funders (Finnish Ministry of Agriculture and Forestry, Finnish Ministry of Environment, Finnish Ministry of Transport and Communications and Finnish Ministry of Finance, Swedish Research Council for Environment, Agricultural Sciences and Spatial Planning (Formas); Danish Strategic Research Council; German Federal Environment Agency (UBA); Swedish Environmental Protection Agency) for their willingness to share the data for our research purposes. Drupp gratefully acknowledges financial support from the German Ministry of Education and Research under grant 01UT1410. Meya gratefully acknowledges financial support from the Ministry for Science and Culture of Lower Saxony (Germany) and the Volkswagen Foundation within the program Science for Sustainable Development under grant VWZN3045. 


\section{Bibliography}

Ahtiainen, H., J. Artell, M. Czajkowski, B. Hasler, L. Hasselström, A. Huhtala, J. Meyerhoff, J. Smart, T. Söderqvist, M. Alemu, D. Angeli, K. Dahlbo, V. Fleming-Lehtinen, K. Hyytiänen, A. Karõševa, Y. Khaleeva, M. Maar, L. Martinsen, T. Nõmmann, K. Pakalniete, I. Oskolokaite, D. Semeniene (2014), Benefits of meeting nutrient reduction targets for the Baltic Sea - contingent valuation study in the nine coastal states, Journal of Environmental Economics and Policy 3(3): 278-305.

Barbier, E.B., M. Czajkowski and N. Hanley (2016), Is the income elasticity of the willingness to pay for pollution control constant? Environmental and Resource Economics, 1-.20, doi:10.1007/s10640-016-0040-4.

Barton, D.N. (2002), The transferability of benefit transfer: contingent valuation of water quality improvements in Costa Rica, Ecological Economics, 42(1), 147-164.

Bateman, I. J., R. Brouwer, S. Ferrini, M. Schaafsma, D.N. Barton, A. Dubgaard, B. Hasler, S. Hime, I. Liekens, S. Navrud, L. De Nocker R. Šceponaviciute and D. Semeniene (2011), Making benefit transfers work: deriving and testing principles for value transfers for similar and dissimilar sites using a case study of the non-market benefits of water quality improvements across Europe. Environmental and Resource Economics 50(3): 365-387.

Baumgärtner, S., M.A. Drupp, J. Munz, J.N. Meya and M.F. Quaas (2017a), Income inequality and willingness to pay for environmental public goods. Journal of Environmental Economics and Management, 85: 35-61.

Baumgärtner, S., Drupp, M.A. and M.F. Quaas (2017b), Subsistence, substitutability and sustainability in consumption, Environmental and Resource Economics, 67(1): 47-66.

Baumgärtner, S., W. Chen, and A.M.T. Hussain (2017c), Willingness to pay for environmental goods under uncertainty. Mimeo, University of Freiburg. 
Bergstrom, J.C., and L.O. Taylor (2006), Using meta-analysis for benefits transfer: Theory and practice. Ecological Economics 60(2): 351-360.

Broberg, T. (2010), Income treatment effects in contingent valuation: the case of the Swedish predator policy, Environmental and Resource Economics 46(1): 1-17.

Carson, R.T. and R.C. Mitchell (1993), The Benefits of National Water Quality Improvements: A Contingent Valuation Study. Water Resources Research 29: 2445-2454.

Cowell, F. (2009), Measuring Inequality, Oxford: Oxford University Press.

Czajkowski, M., H. Ahtiainen, J. Artell and J. Meyerhoff (2016), Choosing a functional form for an international benefit transfer: Evidence from a nine-country valuation experiment. Ecological Economics 134: 104-113.

Czajkowski, M. and M. Ščasný (2010), Study on benefit transfer in an international setting. How to improve welfare estimates in the case of the countries' income heterogeneity? Ecological Economics 69(12): 2409-2416.

[Defra] Department for Environment, Food and Rural Affairs (2007), An introductory guide to valuing ecosystem services. London: Department for Environment, Food and Rural Affairs. 66pp.

Droste, N., and B. Bartkowski (2017), Ecosystem Service Valuation for National Accounting: A Reply to Obst, Hein and Edens (2016). Environmental and Resource Economics, forthcoming.

Droste, N., and J.N. Meya (2016), Ecosystem services in infrastructure planning - a case study of the projected deepening of the Lower Weser river in Germany. Journal of Environmental Planning and Management, 60(2): 231-248.

Drupp, M.A. (2018), Limits to Substitution between Ecosystem Services and Manufactured Goods and Implications for Social Discounting. Environmental and Resource Economics 69(1): 135-158.

Drupp, M.A. J.N. Meya, S. Baumgärtner and M.F. Quaas (2018), Economic Inequality and the Value of Nature. Ecological Economics, forthcoming.

Ebert, U. (2003), Environmental goods and the distribution of income, Environmental and Resource Economics 25(4): 435-459. 
European Commission (2013), The economic benefits of the Natura 2000 network. Synthesis report. Luxembourg: Publications Office of the European Union, 74pp.

European Commission (2008), NATURA 2000 protecting Europe's biodiversity. Oxford: Information Press, 281pp.

[EVRI 2017] The Environmental Valuation Reference Inventory (2017), available at: https://www.evri.ca/Global/HomeAnonymous.aspx. Last accessed: 21.02.2017.

Frank, E. G. and W. Schlenker (2016), Balancing economic and ecological goals. Science 353(6300): 651-652.

Griffiths, C., Klemick, H., Massey, M., Moore, C., Newbold, S., Simpson, D., Walsh, P. and W. Wheeler (2012), US Environmental Protection Agency valuation of surface water quality improvements. Review of Environmental Economics and Policy 6(1): 130-146.

Her Majesty's Treasury (2011), The Green Book. Appraisal and Evaluation in Central Government. London: TSO. 114 pp.

Hynes, S., Norton, D. and N. Hanley (2009), Adjusting for cultural differences in international benefit transfer. Environmental and Resource Economics 56(4): 499-519.

Jacobsen, J. and N. Hanley (2009), Are there income effects on global willingness to pay for biodiversity conservation? Environmental and Resource Economics 43(2): 137-160.

Johnston, R.J., Rolfe, J., Rosenberger, R.S. and R. Brouwer (2015), Introduction to Benefit Transfer Methods. In Benefit Transfer of Environmental and Resource Values (pp. 19-59). Springer Netherlands.

Kaul, S., K.J. Boyle, N.V. Kuminoff, C.F. Parmeter and J.C. Pope (2013), What can we learn from benefit transfer errors? Evidence from 20 years of research on convergent validity, Journal of Environmental Economics and Management 66(1): 90-104.

Kirchhoff, S., B.G. Colby, J.T. LaFrance (1997), Evaluating the performance of benefit transfer: An empirical inquiry. Journal of Environmental Economics and Management 33 $75-93$.

Krupnick, A. Harrison, K. Nickell, E. and M. Toman (1996), The value of health benefits from ambient air quality improvements in Central and Eastern Europe: An exercise in benefits transfer, Environmental and Resource Economics 7: 307-332. 
McDonald, J.B. (1984), Some generalized functions for the size distribution of income, Econometrica 52(3): 647-663.

Meya, J.N. (2018), Environmental inequality and economic valuation. Unpublished manuscript. Humboldt-Universität zu Berlin.

Obst, C., Hein, L. and B. Edens (2016), National accounting and the valuation of ecosystem assets and their services. Environmental and Resource Economics, 64(1), 1-23.

Ready, R. and S. Navrud (2006), International benefit transfer: Methods and validity tests, Ecological Economics 60(2): 429-434.

Ready, R., S. Navrud, B. Day, R. Dubourg, F. Machado, S. Mourato, F. Spanninks and M.X.V. Rodriquez (2004), Benefit transfer in Europe: how reliable are transfers between countries?, Environmental and Resource Economics 29(1): 67-82.

Richardson, L. J. Loomis T. Kroeger and F. Casey (2015), The role of benefit transfer in ecosystem service valuation, Ecological Economics 115: 51-58.

Pearce, D. (2000), Valuing Risks to Life and Health. Towards Consistent Transfer Estimates in the European Union and Accession States, Paper prepared for the European Commission Workshop on Valuing Mortality and Valuing Morbidity. University College London.

Pearce, D. Atkinson, G. and S. Mourato, S. (2006), Cost-benefit analysis and the environment: recent developments, Organisation for Economic Co-operation and Development (OECD).

Phaneuf, D.J. and Requate, T. (2017), A Course in Environmental Economics: Theory, Policy, and Practice, Cambridge University Press.

Piketty, T. (2014), Capital in the Twenty-First Century, Cambridge, MA: The Belknap Press of Harvard University Press. University College London.

Pinkovskiy, M. and X. Sala-i-Martin (2009), Parametric estimations of the world distribution of income, NBER Working Paper No. 15433.

Smith, V.K., Van Houtven, G., and S.K. Pattanayak (2002), Benefit transfer via preference calibration: "Prudential algebra" for policy, Land Economics 78(1): 132-152.

Smith, V.K., Pattanayak, S.K., and G.L. Van Houtven (2006), Structural benefit transfer: An example using VSL estimates, Ecological Economics 60(2): 361-371. 
ten Brink, P. T. Badura, S. Bassi, E. Daly, I. Dickie, H. Ding, S. Gantioler, H. Gerdes, M. Kettunen, M. Lago, S. Lang, A. Markandya, P.A.L.D. Nunes, M. Pieterse, M. Rayment and R. Tinch (2011), Estimating the overall economic value of the benefits provided by the Natura 2000 Network. Final Report to the European Commission, Brussels.

[UBA] Umweltbundesamt (2012), Methoden der ökonomischen Bewertung. Anhang A der "Methodenkonvention 2.0 zur Schätzung von Umweltkosten", Dessau-Roßlau: Umweltbundesamt.

United Nations, European Commission, Food and Agriculture Organization of the United Nations, Organisation for Economic Co-operation and Development, World Bank Group (2014), System of Environmental-Economic Accounting 2012-Experimental Ecosystem Accounting, New York: United Nations.

U.S. EPA (2014), Guidelines for preparing economic analysis. Washington, DC: U.S. Environmental Protection Agency, Office of Policy, National Center for Environmental Economics. 


\subsection{Appendix}

TABLE 6.3: Transfer errors $|T E|$ (in percent) for unit transfer

\begin{tabular}{lrrrrrrrrr}
\hline \hline $\begin{array}{c}\text { to: } \\
\text { from: }\end{array}$ & DEN & EST & FIN & GER & LAT & LIT & POL & RUS & SWE \\
\hline DEN & 0 & 48.35 & 26.47 & 23.12 & 448.65 & 227.82 & 142.52 & 267.59 & 60.93 \\
EST & 32.59 & 0 & 50.44 & 17.01 & 269.83 & 120.97 & 63.47 & 147.78 & 73.67 \\
FIN & 36.00 & 101.76 & 0 & 67.45 & 646.19 & 345.84 & 229.83 & 399.94 & 46.87 \\
GER & 18.78 & 20.49 & 40.28 & 0 & 345.63 & 166.26 & 96.98 & 198.56 & 68.27 \\
LAT & 81.77 & 72.96 & 86.60 & 77.56 & 0 & 40.25 & 55.80 & 33.00 & 92.88 \\
LIT & 69.50 & 54.75 & 77.57 & 62.44 & 67.37 & 0 & 26.02 & 12.13 & 88.08 \\
POL & 58.77 & 38.83 & 69.68 & 49.23 & 126.23 & 35.17 & 0 & 51.57 & 83.89 \\
RUS & 72.80 & 59.64 & 80.00 & 66.51 & 49.26 & 10.82 & 34.03 & 0 & 89.37 \\
SWE & 155.98 & 279.75 & 88.22 & 215.16 & $1,304.44$ & 739.15 & 520.80 & 840.96 & 0 \\
\hline
\end{tabular}

TABLE 6.4: $\Delta|T E|_{\mathcal{T}_{C V}}=|T E|_{\mathcal{T}_{C V}}-|T E|_{\text {unit }}$ (in percentage points)

\begin{tabular}{lrrrrrrrrr}
\hline \hline to: & DEN & EST & FIN & GER & LAT & LIT & POL & RUS & SWE \\
from: & & & & & & & & & \\
DEN & 0 & -3.21 & 0.31 & -1.40 & -9.43 & -1.94 & -4.94 & -1.34 & -0.26 \\
EST & -1.49 & 0 & -0.88 & -0.87 & 1.69 & 3.55 & 0.22 & 4.56 & -0.76 \\
FIN & 0.58 & -3.52 & 0 & -1.19 & -9.68 & -0.75 & -5.33 & 0.31 & -0.59 \\
GER & -0.93 & -1.26 & -0.43 & 0 & -2.63 & 1.46 & -1.79 & 2.32 & -0.58 \\
LAT & -0.32 & 0.12 & -0.18 & -0.13 & 0 & -0.68 & 0.14 & -0.92 & -0.17 \\
LIT & -0.18 & 0.72 & -0.04 & 0.20 & -1.89 & 0 & 1.07 & 0.26 & -0.15 \\
POL & -0.86 & 0.08 & -0.50 & -0.47 & 0.73 & 1.99 & 0 & 2.58 & -0.44 \\
RUS & -0.10 & 0.73 & 0.01 & 0.26 & -2.03 & 0.20 & 1.11 & 0 & -0.11 \\
SWE & -1.70 & -10.69 & -2.05 & -5.65 & -33.31 & -10.53 & -16.68 & -9.67 & 0 \\
\hline
\end{tabular}

TABLE 6.5: $\Delta|T E|_{\mathcal{T}_{\mu}}=|T E|_{\mathcal{T}_{\mu}}-|T E|_{\text {unit }}$ (in percentage points)

\begin{tabular}{lrrrrrrrrr}
\hline \hline \multicolumn{1}{c}{ to: } & DEN & EST & FIN & GER & LAT & LIT & POL & RUS & SWE \\
from: & & & & & & & & & \\
\hline DEN & 0 & -25.24 & 0.94 & -2.13 & -161.45 & -117.84 & -42.33 & -83.48 & 1.59 \\
EST & -13.82 & 0 & -9.40 & -15.28 & -55.32 & -50.42 & -0.87 & -17.01 & -4.10 \\
FIN & 1.76 & -32.16 & 0 & -0.77 & -212.77 & -156.58 & -54.05 & -108.55 & 1.51 \\
GER & -1.43 & -18.74 & -0.28 & 0 & -125.60 & -92.71 & -31.52 & -63.74 & 0.76 \\
LAT & -7.60 & -4.76 & -5.35 & -8.81 & 0 & 5.52 & -7.50 & -6.38 & -2.56 \\
LIT & -17.12 & -13.38 & -12.14 & -20.06 & 17.04 & 0 & -21.36 & 23.17 & -5.93 \\
POL & -8.72 & -0.33 & -5.94 & -9.67 & -32.81 & -30.28 & 0 & -9.65 & -2.61 \\
RUS & -7.99 & -2.98 & -5.55 & -9.09 & -12.97 & 15.27 & -4.49 & 0 & -2.56 \\
SWE & 10.88 & -51.21 & 5.50 & 7.72 & -371.13 & -278.81 & -86.57 & -182.78 & 0 \\
\hline
\end{tabular}


TABLE 6.6: $\Delta|T E|_{\mathcal{T}_{C V, \mu}}=|T E|_{\mathcal{T}_{C V, \mu}}-|T E|_{\text {unit }}$ (in percentage points)

\begin{tabular}{|c|c|c|c|c|c|c|c|c|c|}
\hline from: & DEN & EST & FIN & GER & LAT & LIT & POL & RUS & SWE \\
\hline DEN & 0 & -27.90 & 1.25 & -3.50 & -168.10 & -119.09 & -46.40 & -84.52 & 1.34 \\
\hline EST & -15.62 & 0 & -10.45 & -16.32 & -53.88 & -47.68 & -0.65 & -12.77 & -4.99 \\
\hline FIN & 2.35 & -35.12 & 0 & -1.96 & -219.69 & -157.07 & -58.51 & -108.30 & 0.94 \\
\hline GER & -2.38 & -19.80 & -0.71 & 0 & -127.48 & -91.76 & -33.03 & -61.92 & 0.19 \\
\hline LAT & -8.05 & -4.61 & -5.59 & -8.99 & 0 & 4.90 & -7.33 & -7.39 & -2.79 \\
\hline LIT & -17.40 & -12.45 & -12.20 & -19.75 & 14.96 & 0 & -19.98 & 23.49 & -6.16 \\
\hline POL & -9.76 & -0.25 & -6.54 & -10.23 & -32.18 & -28.74 & 0 & -7.23 & -3.13 \\
\hline RUS & -8.12 & -2.19 & -5.53 & -8.76 & -14.82 & 15.44 & -3.31 & 0 & -2.70 \\
\hline SWE & 9.11 & -60.46 & 3.39 & 1.93 & -395.64 & -285.84 & -100.92 & -190.57 & 0 \\
\hline
\end{tabular}

TABLE 6.7: Transfer error changes for additional income inequality adjustment $\quad \Delta|T E|_{\mathcal{T}_{C V, \mu}}-\Delta|T E|_{\mathcal{T}_{\mu}}$ (in percentage points)

\begin{tabular}{lrrrrrrrrr}
\hline \multicolumn{1}{r}{ to: } & DEN & EST & FIN & GER & LAT & LIT & POL & RUS & SWE \\
from: & & & & & & & & & \\
\hline DEN & 0 & -2.67 & 0.31 & -1.37 & -6.65 & -1.25 & -4.07 & -1.04 & -0.25 \\
EST & -1.80 & 0 & -1.05 & -1.04 & 1.44 & 2.74 & 0.22 & 4.25 & -0.88 \\
FIN & 0.59 & -2.96 & 0 & -1.19 & -6.92 & -0.48 & -4.46 & 0.24 & -0.57 \\
GER & -0.95 & -1.06 & -0.43 & 0 & -1.89 & 0.95 & -1.51 & 1.83 & -0.57 \\
LAT & -0.45 & 0.14 & -0.25 & -0.19 & 0 & -0.62 & 0.17 & -1.01 & -0.24 \\
LIT & -0.28 & 0.93 & -0.06 & 0.31 & -2.09 & 0 & 1.38 & 0.31 & -0.23 \\
POL & -1.04 & 0.08 & -0.60 & -0.56 & 0.63 & 1.54 & 0 & 2.42 & -0.52 \\
RUS & -0.13 & 0.78 & 0.02 & 0.33 & -1.85 & 0.17 & 1.18 & 0 & -0.14 \\
SWE & -1.78 & -9.25 & -2.11 & -5.79 & -24.51 & -7.03 & -14.36 & -7.79 & 0 \\
\hline
\end{tabular}

TABle 6.8: Transfer errors $|T E|$ summary statistics (in percent)

\begin{tabular}{rrrrr}
\hline \hline & $|T E|_{\text {unit }}$ & $|T E|_{\mathcal{T}_{C V}}$ & $|T E|_{\mathcal{T}_{\mu}}$ & $|T E|_{\mathcal{T}_{C V, \mu}}$ \\
\hline mean & 152.35 & 150.55 & 115.48 & 114.02 \\
median & 72.88 & 72.80 & 67.44 & 66.07 \\
sd & 215.57 & 211.27 & 152.70 & 149.43 \\
\hline
\end{tabular}

TABLE 6.9: Transfer errors $|T E|$ summary statistics (in percent) when also adjusting for differences in the level of the environmental good, $\tilde{E}^{c}$.

\begin{tabular}{rrrrr}
\hline \hline & $|T E|_{\mathcal{T}_{E}}$ & $|T E|_{\mathcal{T}_{E, \mathrm{CV}}}$ & $|T E|_{\mathcal{T}_{E, \mu_{Y}}}$ & $|T E|_{\mathcal{T}_{E, \mu_{Y}, \mathrm{CV}_{Y}}}$ \\
\hline mean & 149.48 & 147.70 & 113.05 & 111.60 \\
median & 71.86 & 71.82 & 67.21 & 66.04 \\
sd & 211.56 & 207.26 & 149.24 & 145.96 \\
\hline
\end{tabular}




\title{
7 How Empirical Uncertainties Influence the Stability of Climate Coalitions
}

\begin{abstract}
International climate agreements are negotiated in the face of uncertainties concerning the costs and benefits of abatement and in the presence of incentives for free-riding. Numerical climate coalition models provide estimates of the challenges affecting cooperation, but often resort to assuming certainty with respect to the values of model parameters. We study the impact of uncertainty on the stability of coalitions in the Model of International Climate Agreements (MICA) using the technique of Monte-Carlo analysis. We extend the existing literature by (i) calibrating parametric uncertainty about damages and abatement costs to estimates from meta-studies and by (ii) explicitly considering uncertainty in the curvature of the damage function. We find that stability is more sensitive to uncertainty in damages than in abatement costs, and most sensitive to uncertainty about the regional distribution of damages. Our calculations suggest that heterogeneity can increase stability of coalitions; however this depends on the availability of transfers.
\end{abstract}

Keywords: International environmental agreements - Climate coalition formation - Uncertainty - Monte-Carlo analysis - Numerical modelling

Reference: Meya, J.N., Kornek, U., Lessmann, K. (2018). How empirical uncertainties influence the stability of climate coalitions. International Environmental Agreements: Politics, Law and Economics, 18(2): 175-198.

This is a pre-print of an article published in International Environmental Agreements: Politics, Law and Economics. The final authenticated version is available online at: https://doi.org/10.1007/s10784-017-9378-5. 


\subsection{Introduction}

To address climate change, countries need to cooperate, as emission reductions represent a global public good. Global climate governance relies on international environmental agreements like the Kyoto Protocol to set up cooperation on climate change but participation and ambition is impeded by incentives for free-riding (Barrett 2003). Theoretical and numerical analysis have been applied to the design of agreements in order to overcome free-riding (e.g. Barrett 2005; Dellink 2011). In these studies, the incentive to sign self-enforcing climate agreements is calculated based on valuing abatement costs against avoided damages when a country joins the agreement (Barrett 1994; Lessmann et al. 2015). However, abatement costs and especially climate damages are subject to large uncertainties (e.g. Tavoni and Tol 2010; Tol 2012) and conclusions are therefore limited. The present analysis studies the impact of uncertainty on the stability of agreements in a numerical climate coalition model - the Model of International Climate Agreements (MICA) - using the technique of Monte-Carlo analysis.

Monte-Carlo analysis allows us to draw conclusions about the quantitative influence of different uncertainties on the incentive to join an agreement. However, we abstract from decision making under uncertainty, which is difficult to implement in numerical models. While a recent academic debate has highlighted the importance of uncertainty for climate change decision making (Weitzman 2009; Nordhaus 2012), there are only few studies that look at the effect of uncertainty on the incentive to sign an agreement, and most of these are theoretical analyses (Kolstad 2007; Kolstad and Ulph 2008, 2011; Na and Shin 1998). Due to different assumptions about uncertainty, some studies find uncertainty to be conducive to cooperation while others find that it has a negative impact. Finus and Pintassilgo (2013) recently showed that the way in which uncertainty influences cooperation depends on the availability of transfers in the climate agreement. Depending on the realization of random variables uncertainty increases or decreases asymmetry in the distribution of damages across countries; more asymmetry hinders coalition formation without transfers, but can foster it with transfers as countries can be compensated (see also Weikard 2009).

A recent comparison among numerical models that seeks to extend these theoretical insights by incorporating quantitative results finds that model assumptions on the distribution of damages varies widely (Lessmann et al. 2015). However, representing such uncertainty explicitly in numerical models is very challenging, and only a few applications go beyond 
simple sensitivity analysis. These studies have been mainly applied to the Stability of Coalitions (STACO) model using Monte-Carlo analysis (Dellink et al. 2013; Dellink 2011; Dellink and Finus 2012; Dellink et al. 2008), with the exception of an application of stochastic programming in the CWS model (Bréchet et al. 2012). Uncertainty analyses in STACO show that the stability of coalitions is mainly determined by the distribution of damages rather than by the distribution of abatement costs (Dellink et al. 2008; Dellink 2011). Olieman and Hendrix (2006) introduce the concept of the "stability likelihood of an international climate agreement". Given a probability distribution of uncertain model parameters, the indicator specifies the probability that a coalition (in which members have chosen to participate under certainty) can be labeled as stable. This metric, therefore, is driven by and reflects the uncertainty of model input, but decisions of players are taken under certainty for each possible parameter value. Dellink and Finus (2012) apply the concept and confirm the results from the theoretical literature, finding that heterogeneity across regions increases or decreases coalition stability depending on whether or not transfers are available.

The present study extends previous ones in several ways in order to draw a more comprehensive picture of the effect of uncertainty on coalition stability. Firstly, we improve the numerical representation by calibrating the uncertainty about abatement costs and climate damages to evidence from meta-studies. A robust comparison of the magnitude of effects is thereby made possible. Secondly, we consider uncertainty not only about the level of damages but also regarding the curvature of the damages function, which reflects their sensitivity to temperature increase. This allows us to assess the implications of uncertainty in the curvature of the damage function, whose importance for coalition formation has recently been highlighted (Barrett 2013). Additionally, we go beyond previous studies by incorporating the (arguably more realistic case of) concave utility functions, i.e. decreasing marginal utility of consumption.

We use the numerical Model of International Climate Agreements (MICA) to study the relative effect of different uncertain parameters on the stability of coalitions without and with transfers. We limit our analysis to studying the incentive to stay in the coalition, without and with transfers, as the incentive to remain a non-member to the coalition has been described not to be the bottleneck of stability (Dellink 2011). Uncertainty in three key parameters is specified and propagated through the model using Monte-Carlo analysis, similar to the approach previously taken by Dellink et al. (2008). Our analysis therefore abstracts from decision making under uncertainty but allows derivation of probabilities of different model 
outputs and comparison of the relative importance of the specified uncertainties. Specifically, we consider (i) perfectly correlated global uncertainty vs. independent uncertainties across regions; (ii) uncertainty in abatement costs vs. uncertainty in climate change damages; and (iii) uncertainty about the curvature of climate change damages. This enables us to assign stability likelihoods to specific climate coalitions and assess the extent to which transfers among signatories may contribute to a stable agreement.

As our most important result, we find that the stability likelihood of coalitions is mainly driven by uncertainty about damages through various determinants. Firstly, stability is more affected by uncertainty about damages compared to uncertain abatement costs, and mostly affected by uncertainty about the interregional distribution of damages. Secondly, transfers become an important instrument when there is uncertainty about the distribution of damages. Our scenarios show that stability is sensitive to uncertainty when no transfers between regions are allowed but that the availability of transfers increases the robustness of stability under uncertainty. Each realization of climate change damages produces distinct winners and losers within the coalition. With transfers as an additional measure, worse-off regions can be compensated to remain in the coalition by winners that experience larger gains, i.e. adverse effects of the realizations of uncertainty are shared within coalitions. Furthermore, while large coalitions with ambitious abatement targets are not stable under certainty, we find that they have a positive probability to be stable under an uncertain distribution of damages when transfers are available. Lastly, we present scenarios in which uncertainty about the curvature of damages has a positive effect on stability. A higher sensitivity of damages towards a temperature increase tends to increase stability. Steeper damages resemble a critical threshold, which is known to improve the incentives to cooperate.

The remainder of this article is structured as follows: The next section defines the concepts of coalition stability employed in the analysis. Section 7.3 briefly describes the MICA model of coalition formation and specifies the probability density functions for the uncertain parameters. Section 7.4 presents the results of the Monte-Carlo analysis. Finally, Section 7.5 discusses and concludes. 


\subsection{Formation of climate coalitions}

\subsubsection{Coalition stability}

We follow the standard approach in the literature and describe climate coalition formation as a cartel formation game (Hoel 1992; Carraro and Siniscalco 1993; Barrett 1994). Consider a set of $N$ heterogeneous regions, for which the incentive to sign is modelled as a two-stage game. At the first stage regions decide whether they want to become a signatory or remain a singleton and at the second stage regions choose their emission abatements. The game is solved by backward induction, assuming that signatories maximise their payoffs jointly and non-signatories maximise their payoff individually, given the abatement decisions of the coalition and all other non-signatories. Abatement decisions are taken simultaneously.

The stability and performance of coalitions then depend on a vector of model parameters

$d \in \hat{R}^{l}$. To study uncertainty, this vector is replaced by a vector $\mathbf{d}$ that is stochastic in one dimension and has the probability density function $p d f(\mathbf{d})$. To describe the impact of uncertainty on coalition formation, we apply the concept of stability likelihood developed by Olieman and Hendrix (2006) and Dellink et al. (2008). The stability likelihood of a coalition is the "the probability that the coalition stability claim is correct" (Olieman and Hendrix 2006). Before applying the concept to our analysis, we need to introduce some more terminology.

In MICA all decisions are taken under certainty. We hence draw a realization $d$ of $\mathbf{d}$ as a Monte-Carlo run to calculate the model output of MICA, yielding a distribution for each stability and performance indicator. We analyse the formation of coalitions by applying the concept of cartel stability introduced by d'Aspremont and Gabszewicz (1986) and applied to international environmental agreements by Barrett (1994). Formally, a coalition is stable if no member has an incentive to leave the coalition (internal stability) and no non-member has an incentive to join (external stability). For our Monte-Carlo analysis, we only look at internal stability, without and with transfers, in order to reduce the computational burden and, more importantly, as the incentive to remain a non-member to the coalition has been described not be the bottleneck of stability (Dellink 2011). We limit our analysis to studying the incentive to stay in the coalition, without and with transfers.

The incentive to stay in a coalition $S$, a subset of all regions, for a signatory $i \in S$ is defined as the difference between the payoff $\pi_{i}$ upon joining to form $S$ and the payoff from free-riding by leaving $S$, for a given value of the parameter $d$ : 


$$
\Delta_{i}(S, d)=\pi_{i}(S, d)-\pi_{i}(S \backslash\{i\}, d) .
$$

A coalition $S$ is called internally stable (IS) if for every signatory $i \in S$ the coalition payoff is higher than the free-rider payoff:

$$
i s(S, d):=\left\{\begin{array}{ll}
1, & \text { for } \pi_{i}(S, d) \geq \pi_{i}(S \backslash\{i\}) \forall i \in S \\
0, & \text { else }
\end{array} .\right.
$$

Furthermore, a coalition $S$ is potential internally stable (PIS) if a transfer scheme $\tau$ exists that guarantees every coalition member at least its free-rider payoff, i.e. compensation equal to the value of benefits from leaving the coalition (Carraro et al. 2006). If consumption rather than utility is transferable, as is the case in MICA (see below), the concept has to be adapted (Kornek et al. 2014). Accordingly, a coalition in MICA is PIS if a transfer scheme $\tau$ exists that redistributes consumption within the coalition, providing a payoff for every signatory that is at least equal to its free-rider payoff at all times $t \in\left[t_{0}, t_{m}\right]$ (Kornek et al. 2014):

$\operatorname{pis}(S, d):=\left\{\begin{array}{l}1, \text { if } \exists \tau: \pi_{i}\left(c_{i, t}(S, d)+\tau_{i, t}(S, d)\right) \geq \pi_{i}(S \backslash\{i\}, d) \forall i \in S, \sum_{i \in S} \tau_{i, t}(S, d)=0 \forall t \in\left[t_{0}, t_{m}\right] \\ 0, \text { else. }\end{array}\right.$

Here $c_{i, t}$ is total consumption of each player and $\tau_{i, t}(S, d)$ is the transfer paid or received.

Finally, we can apply the concept of stability likelihood developed by Olieman and Hendrix (2006) and Dellink et al. (2008) to IS and PIS. The internal stability likelihood and the potential internal stability likelihood of a coalition $S$ are then defined as the means of IS and PIS across the Monte-Carlo runs and can be interpreted as the probability that coalition $S$ is IS and PIS respectively for the assigned $p d f \mathrm{~s}$ of the uncertain parameters (Olieman and Hendrix 2006).

\subsubsection{Coalition performance}

Next, we are interested in the ability of a coalition to enhance global welfare and reduce environmental damages. The performance of a coalition $S$ is defined relative to the performance of the non-cooperative outcome (all countries are singletons) and the fully cooperative outcome (grand coalition) as a closing-the-gap index, originally developed by Eyckmans and Finus (2006), and applied to study coalition performance under uncertainty by Dellink et 
al. (2013) and Dellink and Finus (2012). In the grand coalition (GC) the climate change externality is fully internalized and hence the outcome is most efficient, while in the case of all singletons (AS) regions only internalize their own damages and the outcome is noncooperative.

Performance regarding global welfare $W P$ is defined for a coalition $S$ as:

$$
W P(S, d)=\frac{\sum_{i=1}^{N} \pi_{i}(S, d)-\sum_{i=1}^{N} \pi_{i}(A S, d)}{\sum_{i=1}^{N} \pi_{i}(G C, d)-\sum_{i=1}^{N} \pi_{i}(A S, d)} .
$$

Performance regarding environmental quality EP is defined as the ability to reduce global temperature increase $(\Delta T)$ by 2195 :

$$
E P(S, d)=\frac{\Delta T(S, d)-\Delta T(A S, d)}{\Delta T(G C, d)-\Delta T(A S, d)} .
$$

The effect of uncertainty on the level and uncertainty of $W P$ and EP are estimated using standard statistical measures on the sample of MC runs.

\subsection{The numerical model and uncertainty distributions}

This section first introduces the numerical coalition formation model MICA and describes how the uncertain parameters enter the model (Section 7.3.1). Subsequently, probability distribution functions for uncertain parameters are specified and the associated scenarios are presented (Section 7.3.2).

\subsubsection{Model of International Climate Agreements}

We conduct our study in the Model of International Climate Agreements (MICA), developed by Lessmann et al. (2009) and extended by Kornek et al. (2017). MICA is a numerically calibrated model of coalition formation encompassing eleven heterogeneous world regions (see Table 7.6) in the Appendix for a description of their makeup): Africa (AFR), China (CHN), the European Union with 27 member states (EUR), India (IND), Japan (JPN), Latin America (LAM), Arabic countries (MEA), other Asian countries (OAS), Russia (RUS), USA (USA) and the "rest of the world" (ROW). ${ }^{110}$ These eleven world regions yield 2037 different possible coalitions.

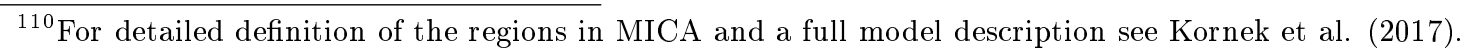


TABLE 7.1: Composition of the studied coalitions

\begin{tabular}{ll}
\hline \hline Coalition & Signatories \\
\hline EJ & EUR, JPN \\
ER & EUR, ROW \\
EU & EUR, USA \\
JR & JPN, ROW \\
JU & JPN, USA \\
RU & ROW, USA \\
EJR & EUR, JPN, ROW \\
EJU & EUR, JPN, USA \\
ERU & EUR, ROW, USA \\
JRU & JPN, ROW, USA \\
OECD & EUR, JPN, ROW, USA \\
Major Emitters & AFR, CHN, EUR, IND, RUS, USA \\
GC & AFR, CHN, EUR, IND, JPN, LAM, \\
& MEA, OAS, RUS, USA, ROW \\
\hline
\end{tabular}

In our analysis we focus on twelve coalitions, which correspond to cooperation among key players in the international climate negotiations (see Table 7.1). ${ }^{111}$ The OECD coalition comprises four regions, which have been main actors in past climate negotiations and are often held to be both the most responsible and capable. Our decision whether to consider a particular aggregate world region as part of the coalition of OECD countries was based on the relative influence of OECD member countries within this region as represented by their GDP. We also consider all possible coalition structures (ten in total) in which two or three of the OECD regions cooperate, in order to elucidate the effect of coalition size on internal stability. Additionally, we study a scenario in which the most relevant current and future emitters - China, India, Europe, USA as well as Africa and Russia - cooperate. Within our model the countries of this coalition of 'major emitters' are responsible for $67.59 \%$ of the global emissions in 2015 and for $62.15 \%$ of predicted emissions in 2105 (in the absence of a climate agreement). The large size of this coalition provides strong incentives for freeriding. Finally, we also calculate the fully cooperative outcome of the grand coalition (GC), where all regions cooperate in climate change mitigation, as a reference point for coalition effectiveness.

MICA combines an integrated assessment model (IAM) with a coalition formation game. Thereby MICA uses a Ramsey-type optimal growth model with a representative agent for each region. The payoff $\pi_{i}$ of region $i$ is regional welfare defined as the aggregation of

\footnotetext{
${ }^{111}$ The computational burden of Monte-Carlo analysis for coalition stability is substantial. Altogether, this manuscript is based on four Monte-Carlo ensembles: for parameters in mitigation costs, marginal damages (perfectly correlated and independent), and the slope of marginal damages. We execute the model 500 times per parameter and for 21 coalition equilibria. Thus we arrive at a total of $4 * 500 * 21=42$, 000 Monte-Carlo runs and, at approximately 1 minute CPU time per shot, 42, 000 minutes or 700 hours, or about 30 days of CPU time. To explore, for example, the stability of the grand coalition would add its ten subcoalitions to the list, raising the computation time by 50 percent.
} 
(discounted) instantaneous utility of consumption of the representative agent of the region, with utility rising in per capita consumption and marginal utility decreasing in per capita consumption:

$$
\pi_{i}=\sum_{t=t_{0}}^{t_{m}} \frac{1}{(1+\rho)^{t-t_{0}}} p_{i t} \log \left(\frac{c_{i, t}}{p_{i, t}}\right),
$$

where $c_{i t}$ is the consumption and $p_{i t}$ is the population in region $i$ at time $t$ and $\rho$ is the pure rate of time preference. The time horizon $t$ goes from $t_{0}=2005$ to $t_{m}=2195 \mathrm{in}$ steps of ten years.

Economic output can either be consumed or invested and is reduced by damages caused by climate change and expenditures for abatement. To assess the stability and performance of self-enforcing coalitions, two parts of the model are of particular importance: climate damages and abatement costs.

For each region the damages $\Omega_{i t}$ of temperature increase is represented by

$$
\Omega_{i t}=\theta_{1, i} \Delta T_{t}^{\theta_{2}}
$$

where $\Delta T_{t}$ is the temperature increase at time $t$ compared to the pre-industrial level and $\theta_{1, i}$ and $\theta_{2}$ are parameters. This functional form and the quadratic exponent $\theta_{2}=2$ go back to the RICE model ${ }^{112}$ of Nordhaus and Yang (1996). The coefficients of the damage functions $\theta_{1, i}$ are taken from Dellink et al. (2004) and were spatially rescaled to the eleven world regions.

Abatement costs $\Lambda_{i t}$ are a function of the rate of emission control $\mu_{i t}$ :

$$
\Lambda_{i t}=b_{1, i t} \mu_{i t}^{b_{2, i}}
$$

Again, the relationship employed originates from the RICE model (Nordhaus and Yang 1996). The regional parameters of the abatement cost function $b_{1, i t}$ and $b_{2, i}$ are calibrated to the Regionalized Model of Investments and Development (Leimbach et al. 2010), a largescale, state-of-the-art IAM. ${ }^{113}$

In principle all model parameters are uncertain. But incorporating the full range of uncertainty would place a tremendous computational burden on the Monte-Carlo analysis. To focus on key variables, we restrict our analysis to uncertainty in the abatement cost and damage function parameters $b_{1, i t}, \theta_{1, i}$ and $\theta_{2}$. Abatement costs and climate damages

\footnotetext{
${ }^{112}$ Regional Integrated Model of Climate and the Economy.

${ }^{113}$ For a description of the calibration procedure see Kornek et al. (2017).
} 
are identified as the determinants of coalition stability in the majority of the literature (for a review see Finus 2008), and Dellink et al (2008) also limit their analysis to costs and damages. In MICA, these three parameters selected for analysis are main determinants of coalition formation: The balance between costs of abatement and benefits, in terms of reduced damages, of internalizing emission externalities among members of the coalition determines changes in consumption and hence welfare. These changes are, in turn, assumed to determine decisions by members on whether or not to remain in the coalition.

\subsubsection{Uncertainty distributions}

We are interested in how uncertainty in the distribution of abatement costs shapes coalition formation. To this end we incorporate independent uncertainties in the coefficient of the abatement cost function $b_{1, i}$, while the functional form is taken as certain (as in e.g. Dellink et al. 2008; Nordhaus 2008).

To specify the probability distribution for the abatement cost coefficient $b_{1, i t}$, we make the common assumption of a normal distribution (Dellink et al. 2008) but assign zero probability to negative values, as negative abatement costs throughout the whole study period 2005-2195 seem unrealistic.

As it is not evident ex ante which probability distribution is most suitable to describe uncertainty in abatement costs over a long time horizon, assumption of a normal distribution appears to us to be the most conservative approach. We set parameter means equal to the deterministic version of MICA, since values are calibrated to a multi-regional IAM with technologically disaggregated abatement costs. It is assumed that the uncertainty is identical across regions, represented by the same coefficient of variation. Furthermore, it seems unrealistic that the uncertainty in the abatement costs for every time step is independent from the abatement costs in the previous period. Thus, rather than drawing a $b_{1, i t}$ for each time step from probability density functions $(p d f)$, we assume that there is uncertainty about the path of abatement costs as a whole.

\section{Level of abatement costs}

We therefore introduce a random variable $k \sim N(1,0.61)$. The variable has a multiplicative effect on costs, hence we choose a unity mean, i.e. no effect on average. We choose a standard deviation that reflects the variation reported in the meta-study by Tavoni and Tol (2010) of the results from the EMF 22 International Scenarios (Clarke et al. 2009) as 
follows: In the model comparison ten IAMs were running scenarios with different emissions stabilization targets for 2100 , with and without the possibility of temporarily overshooting these targets and delayed or full participation in an international climate agreement (Clarke et al. 2009). We take the average coefficient of variation (CV) 0.24 of the global abatement costs of the two scenarios from Tavoni and Tol (2010) most closely related to MICA. ${ }^{114}$ Based on this we calibrate the standard deviation of the global abatement costs, measured as a fraction of output from 2005 to 2105 and discounted at a rate of 5\%. Finally, the corresponding distribution of $k$ is calculated, yielding a standard deviation of 0.61686. In each Monte-Carlo run we draw a realization of $k$ independently for every region and calculate the corresponding values of $b_{1, i t}$, so that regional heterogeneity varies between runs.

\section{Level of damages}

Damages caused by climate change are particularly uncertain regarding both their global level and their regional distribution. Not only might climate change damages become more or less severe in all regions, but also the regional distribution of damages might differ from today's best guess estimates. As both uncertainties are likely to affect coalition formation differently, we study uncertainty in global climate change damages and their regional distribution separately.

To this end we simulate uncertainty in the level of damages in two ways. Firstly, we model uncertainty in global damages as perfectly correlated uncertainty in the damage function coefficient $\theta_{1, i}$. Therefore, in each Monte-Carlo run a quantile is randomly drawn and the corresponding values for $\theta_{1, i}$ are taken from their regional distributions. This approach leaves the heterogeneity of damages across regions unchanged. Secondly, we model uncertainty in regional damages as independent uncertainty by drawing the values of the damage function coefficient $\theta_{1, i}$ independently from their regional distributions. Consequently, uncertainty in regional damages changes the heterogeneity across regions. The two scenarios are directly comparable, as regional distributions are calibrated to produce the same mean global damages across Monte-Carlo runs.

We take the distribution of estimates from 14 major IAMs as reviewed by Tol (2012) for a temperature increase of $2.5^{\circ} \mathrm{C}$ as proxy for the probability of different climate change damages. This implicitly assumes that each of the 14 estimates is certain. We then model the damage coefficients $\theta_{1, i}$ to be distributed according to a pdf that reproduces the mean

\footnotetext{
${ }^{114}$ These scenarios are $650 \mathrm{CO} 2 \mathrm{e} /$ full participation/ no overshoot and $550 \mathrm{CO} 2 \mathrm{e} /$ full participation/ overshoot with a CV of 0.27 and 0.21 , respectively.
} 
TABLE 7.2: Distribution of $\theta_{1, i}$ for uncertainty in global and regional damages

\begin{tabular}{cccccc}
\hline \hline Region & \multicolumn{3}{c}{$\begin{array}{c}\text { Uncertainty in global } \\
\text { damages }\end{array}$} & \multicolumn{2}{c}{$\begin{array}{c}\text { Uncertainty in regional } \\
\text { damages }\end{array}$} \\
& Mean $\mu$ & $\begin{array}{c}\text { Standard } \\
\text { deviation } \sigma\end{array}$ & $\begin{array}{c}\text { Coefficient } \\
\text { of variation }\end{array}$ & $\begin{array}{c}\text { Standard } \\
\text { deviation } \sigma\end{array}$ & $\begin{array}{c}\text { Coefficient } \\
\text { of variation }\end{array}$ \\
\hline ROW & 0.00073 & 0.00072 & 0.97872 & 0.00177 & 2.41984 \\
AFR & 0.00111 & 0.00109 & 0.97872 & 0.00269 & 2.41984 \\
LAM & 0.00094 & 0.00092 & 0.97872 & 0.00229 & 2.41984 \\
IND & 0.00322 & 0.00315 & 0.97872 & 0.00779 & 2.41984 \\
CHN & 0.00266 & 0.00260 & 0.97872 & 0.00643 & 2.41984 \\
MEA & 0.00117 & 0.00114 & 0.97872 & 0.00283 & 2.41984 \\
OAS & 0.00118 & 0.00115 & 0.97872 & 0.00285 & 2.41984 \\
JPN & 0.00136 & 0.00133 & 0.97872 & 0.00329 & 2.41984 \\
RUS & 0.00228 & 0.00223 & 0.97872 & 0.00551 & 2.41984 \\
USA & 0.00088 & 0.00086 & 0.97872 & 0.00213 & 2.41984 \\
EUR & 0.00080 & 0.00079 & 0.97872 & 0.00194 & 2.41984 \\
\hline
\end{tabular}

and standard deviation of the global damages from Tol (2012). The mean values for $\theta_{1, i}$ are taken from the deterministic version of MICA and are rescaled by a common factor to meet the mean global damages for a temperature increase of $2.5 \mathrm{C}^{\circ}$ in Tol (2012). For uncertainty in both global and regional damages, all regions are exposed to the same degree of uncertainty, represented by a uniform coefficient of variation across regions. Again, the standard deviations of $\theta_{1, i}$ are calibrated to produce the standard deviation of global damage estimates as reviewed in Tol (2012). This procedure gives higher standard deviations for uncertainty in regional damages compared to uncertainty in global damages (see Table 7.2). This is because regional uncertainties partly cancel each other out in the calculation of global damages.

We employ different $p d f$ s to model uncertainty in global and regional damages. The choice was between normal or lognormal distributions, both of which have been applied in previous studies of climate change damages (Tol 1995, Crost and Traeger 2011). For uncertainty in global damages, we assume a normal distribution and assign zero probability to negative damages, as it is very unlikely that a temperature increase of 2.5 degrees would be beneficial across all eleven world regions. A similar approach was previously taken by Hwang et al. (2013). By contrast, we assume a lognormal distribution for uncertainty in regional damages. In principle, the idea of negative damage costs might seem less problematic when modelling uncertainty in regional damages. However, negative coefficients in the damage function would imply regional benefits from climate change even at very high temperatures. Tol's (2014) survey of economic impacts of warming does not show a single study that projects benefits for the range of warming in our scenarios, and we therefore find it prudent 
to preclude benefits in our study. Moreover, in this case, the assumption of a truncated normal distribution would result in very distorted global damages, as a lot of probability mass would be cut off due to the large standard deviations - which are substantially larger for regional uncertainty than for uncertainty in global damages. We therefore opt for a lognormal distribution of the damage function coefficient $\theta_{1, i}$ for uncertainty in regional damages, as this allows us to reproduce the mean and standard deviation of the damages reviewed by Tol (2012) exactly and satisfies our assumption of zero likelihood of negative damages. This assumption follows earlier studies on coalition formation that also implicitly assume zero likelihood of negative damages (Dellink et al. 2008). Both $p d f$ s for uncertainty in regional and global damages are in line with the result across IAMs that uncertainty about damages is right-skewed (Tol 2012).

\subsubsection{Curvature of the damage function}

Lastly, we look at how uncertainty about the curvature of the damage function affects coalition formation. This is particularly relevant, as this 'damage function' is both subject to large uncertainties (Weitzman 2012) and strongly influences model results (IPCC 2001), in particular for large temperature increases (Weitzman 2010). Most commonly, regionally disaggregated IAMs assume a polynomial of second degree (Bosetti et al. 2006; 2013; Bréchet et al. 2011; 2012; Nordhaus 2010). However, the functional form is controversial. In particular, Weitzman (2009) has highlighted the importance of low-probability high-impact events, which might be underestimated by quadratic damage functions.

We therefore employ a lognormal distribution for the exponent of the damage function $\theta_{2}$, as specified by Dietz (2013), based on the following assumptions: (1) zero warming has zero economic cost, (2) the best guess is $\theta_{2}=2$ and (3) the 90th percentile is $\theta_{2}=$ 3. For computational reasons we truncate the lognormal distribution at $\theta_{2}=4$, in effect incorporating the assumption that (4) values above 4 have a probability of zero. ${ }^{115}$ Note that this procedure neglects recently highlighted issues for cost-benefit analyses associated with 'fat-tail' damage probability distributions (Weitzman 2007, 2009), as Weitzman's 'Dismal Theorem' only holds for unlimited parametric uncertainty (Nordhaus 2011).

While other similar studies incorporate uncertainty indirectly in models by increasing global damages (Dellink et al. 2013), we take a different approach and isolate the effect of the functional form from the level of global damages. Therefore, for every random draw of

\footnotetext{
${ }^{115}$ An exponent of 4 equals the $90 \%$ percentile of Nordhaus's (1994) subjective cumulative probability function in the explorative stage of his sensitivity analysis.
} 
TABLE 7.3: Overview on modelled uncertainties

\begin{tabular}{lcll}
\hline \hline Scenario & Parameter & Type of uncertainty & pdf \\
\hline abatement costs & $b_{1}$ & independent & normal (truncated) \\
global damages & $\theta_{1}$ & perfectly correlated & normal (truncated) \\
regional damages & $\theta_{1}$ & independent & lognormal \\
damage curvature & $\theta_{2}$ & perfectly correlated & lognormal (truncated) \\
\hline
\end{tabular}

$\theta_{2}$ we recalibrate the best guess of $\theta_{1, i}$ so that the global damages for a temperature increase of $2.5{ }^{\circ} \mathrm{C}$ are equal to the mean of the damages reviewed by Tol (2012).

It is common practise in regionally disaggregated IAMs to assume a constant curvature for the damage function across regions (e.g. Bosetti et al. 2013; Bréchet et al. 2011; Dellink et al. 2013; Nordhaus 2010); correspondingly, we assume that there is common uncertainty about $\theta_{2}$ to all regions. This is implemented by simply drawing a single $\theta_{2}$ in every MonteCarlo run for all regions, thereby, leaving the heterogeneity of regions unaffected.

\subsection{Results}

We studied the effect of the four specified uncertainties on coalition performance and stability separately. To this end, we conducted numerical experiments for uncertainty in abatement costs, global damages, regional damages and the curvature of the damage function (for an overview see Table 7.3). For each scenario (and coalition) we ran the model 500 times. We reserved one model run for the deterministic default parameter values, leaving four samples each with 499 runs for the Monte-Carlo analysis.

Our choice of the number of Monte-Carlo runs was guided by the trade-off between the computational costs of the model runs and the precision of the estimated mean and variance of the Monte-Carlo ensemble (for the computational burden, see Footnote 111). For precision, we need the number of Monte-Carlo runs to be large enough for robust estimates of sample mean and sample variance. Higher moments are more demanding, so we consider the standard error of the uniform minimum variance unbiased estimator for the sample standard deviation. For large sample sizes $n$ (here, more than 50 can be considered large), we have $\frac{\sigma_{S}}{\sigma}=\sqrt{2(n-1))}^{-1}$. Applying this equation, for $n=500$ the standard error of the estimated standard deviation is just over 3 percent (compared to the estimated standard deviation). For $n=100$, the error is 7 percent, and doubling $\mathrm{n}$ (i.e. $n=1000$ ) only reduces the error to 2.2 percent. 
In this section the results are reported successively for coalition performance (Section 7.4.1), coalition stability without transfers (Section 7.4.2) and coalition stability with transfers (Section 7.4.3). Histograms for all specified distributions can be found in the Appendix.

\subsubsection{Coalition performance}

In general, economic output, e.g. discounted consumption, the endogenous discount rate and welfare, are little affected by the imposed uncertainties. For instance, global discounted consumption in the cases where no regions or all regions cooperate shows very small coefficients of variation and the uncertainty for each region is negligible compared to interregional differences.

This is in line with the findings of many IAMs that aggregated climate change damages in monetary terms makes up only a small fraction of global economic output (Tol 2013). The environmental variables temperature, cumulative emissions and carbon price are more sensitive to the uncertainty in abatement and damages costs, as one would expect given the more direct link to the uncertain variables.

The performance of all studied coalitions in both welfare and environmental respects follow a similar pattern. In both cases, the major emitter coalition achieves around half of the social optimum, due to its size, while all smaller coalitions achieve little. Generally, performance tends to increase with the size of coalitions.

Figure 7.1 displays the performance of three selected coalitions to facilitate global welfare and limit the temperature increase by 2195 . The applied uncertainties do not lead to substantially different mean values of the coalition performance indicators, which stay relatively constant across all four scenarios. The induced uncertainty, as displayed by the confidence intervals, is also low and shows only minor differences among the four modelled uncertainties. The only exception is the uncertainty in regional damages which substantially increases uncertainty about welfare.

\subsubsection{Coalition stability without transfers}

In this section we discuss the effect of uncertainty on coalition stability when no transfers are available, as measured by internal stability likelihood (ISL) indicator. Figure 7.2 displays the relative effect of the four simulated uncertainties on ISL. It shows that uncertainty affects the internal stability of all coalitions except the major emitter coalition, but that differences between scenarios are considerable. For the major emitter coalition incentives for free-riding 

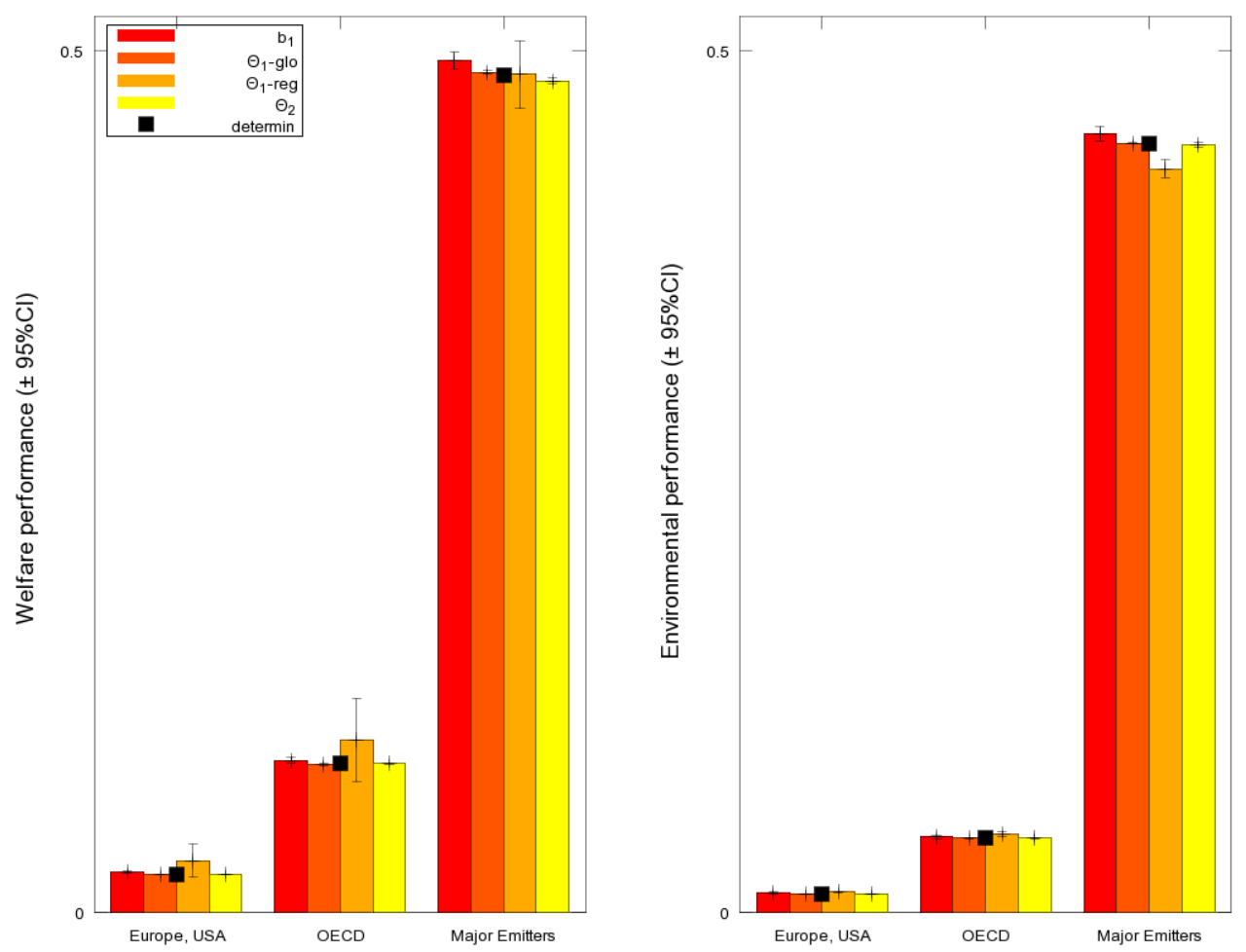

Figure 7.1: Mean welfare performance $(W P)$ and environmental performance $(E P)$ and corresponding $95 \%$ confidence intervals (whiskers) for uncertainty in abatement costs $\left(b_{1}\right)$, global damages $\left(\theta_{1}\right.$-glo), regional damages $\left(\theta_{1}\right.$-reg) and curvature of the damage function $\left(\theta_{2}\right)$. The figure shows results for the coalitions Europe and USA (EU), OECD and 'major emitters'. Black boxes indicate welfare performance and environmental performance for the deterministic case.

are so high - due to its size - that we did not find a scenario for which internal stability holds.

The relative effect of the uncertainties depends on the coalition. However, all the coalitions that are internally stable in the deterministic setting become unstable in many runs in the scenario with uncertainty in the regional distribution of damages. Compared to the binary result for stability in the deterministic setting, the internal stability likelihood reveals much more mixed results. Coalitions that were internally stable in the deterministic setting are less often internally stable in the scenario with uncertainty in the regional distribution of damages; conversely, some coalitions that were not internally stable are sometimes internally stable when uncertainty is concerned. In other words, parameter variation within the ranges of uncertainty changes the incentive to participate from positive to negative and vice versa. The only exception is the major emitter coalition, for which the incentives to free-ride are so large that it is not affected by the imposed uncertainty at all.

It is particularly interesting to compare the effect of uncertainty in regional and global 


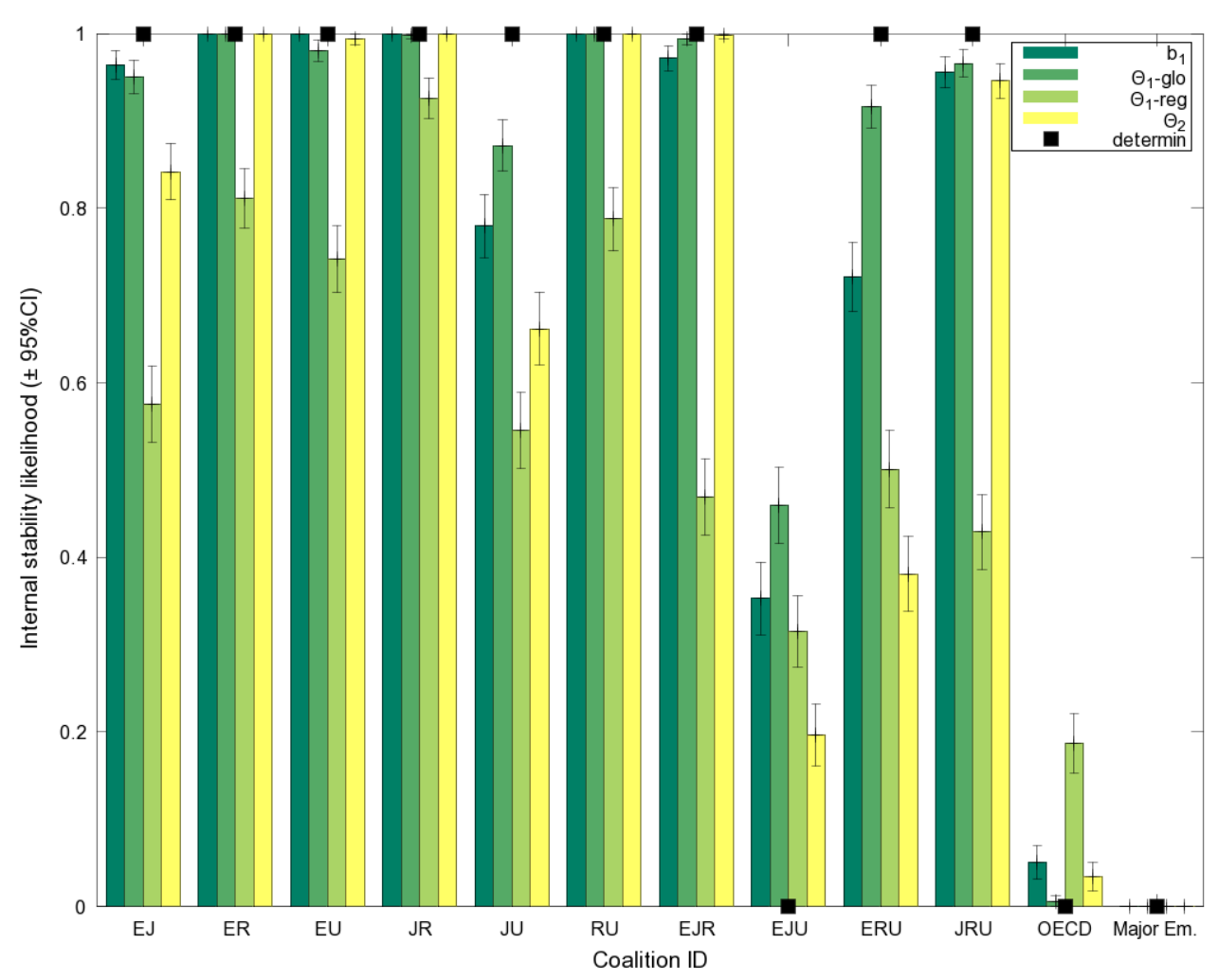

FigURE 7.2: Internal stability likelihood and corresponding confidence intervals (whiskers) by coalitions for uncertainty in abatement costs $\left(b_{1}\right)$, global damages $\left(\theta_{1}\right.$-glo), regional damages $\left(\theta_{1}\right.$-reg) and curvature of the damage function $\left(\theta_{2}\right)$. Black boxes indicate the internal stability likelihood for the deterministic case.

damages, as only the former affects the heterogeneity of damages among signatories. For all coalitions that were internally stable in the deterministic setting, the internal stability likelihood is lower in the scenario with uncertainty in the regional distribution of damages, compared with uncertainty in global damages. However, for coalitions that were not internally stable in the deterministic setting results are less clear cut: while the internal stability likelihood of the OECD coalition is higher for uncertainty in regional damages than for uncertainty in global damages, the reverse is true for the EJU coalition. Overall, this suggests that without transfers the internal stability of coalitions is lost by changes in the heterogeneity of damages. When heterogeneity, i.e. the regional pattern of damages, changes, the incentives of single regions frequently flip from positive to negative. Transfers could (at least in part) even out these changes. But in their absence these changes affect the internal stability of the coalition more frequently than in the scenario with uncertainty in global damages.

Furthermore, it is instructive to compare the effects of uncertainties in abatement and 
TABle 7.4: Summary statistics (mean [min; $\max ]$ ) for uncertain parameters in runs in which the OECD coalition is internally stable relative to means across all Monte-Carlo runs.

\begin{tabular}{ccccc}
\hline \hline & 'rest of the world' & Japan & USA & European Union \\
\hline$b_{1}$ & $1.293[0.307 ; 2.243]$ & $1.092[0.212 ; 2.206]$ & $0.249[0.005 ; 1.931]$ & $0.821[0.009 ; 1.966]$ \\
$\theta_{1}$-glo & & $0.013[0.008 ; 0.022]$ & \\
$\theta_{1}$-reg & $1.013[0.009 ; 11.74]$ & $0.84[0.062 ; 6.77]$ & $0.296[0.011 ; 1.324]$ & $0.237[0.003 ; 1.463]$ \\
$\theta_{2}$ & & \multicolumn{2}{c}{$1.868[1.71 ; 2.081]$} & \\
\hline
\end{tabular}

regional damages, as both scenarios lead to changes in heterogeneity among signatories. The results of our numerical experiments suggest that uncertainty in damages matters more to signatories than uncertainties in abatement costs, indicated by the more pronounced changes in internal stability likelihood values compared to the deterministic setting. These results reflect the greater degree of uncertainty associated with the estimation of damages compared to abatement costs. Moreover, uncertainty about the curvature of the damages function, i.e. the sensitivity of damages to the magnitude of temperature increase, affects internal stability more than uncertainty about the level of global damages.

For insights into the underlying reasons for these observations, we investigate what drives internal stability for the example of the OECD coalition, consisting of the European Union, Japan, 'rest of the world' and the USA. The conditions under which the OECD becomes internally stable are elicited by comparing parameter values in runs that are internally stable with their mean values across all Monte-Carlo runs (Table 7.4). This allows us to study parameter values for which the OECD becomes internally stable. For mean parameter values greater than one (smaller than one), uncertainty increases stability in cases where there is an increase (decrease) in the respective parameter relative to the whole sample mean. For instance for $b_{1 i}$ a value larger than unity indicates that for region $i$ the abatement costs have to increase on average relative to whole sample mean in order for the OECD to become internally stable.

Within the OECD coalition, the 'rest of the world' region has a high abatement burden, as a result of its relatively cheap mitigation options, ${ }^{116}$ which however mainly benefits the other signatories (when no transfers are available). As the 'rest of the world' suffers relatively little from climate change, cooperation is unattractive for the region when the deterministic case is considered. The simulated uncertainties display that in order to give the 'rest of the world' an incentive to remain in the OECD, its abatement burden needs to drop, while

\footnotetext{
${ }^{116}$ Abatement costs are measured by an abatement cost index, which is defined as the reciprocal of the cumulative abatement over the 21st century by each region in the coalition of all regions compared to the all singletons scenario. The rationale for this approach is that within the grand coalition abatement is done where it is less costly and if marginal abatement costs are well-behaved, abatement costs are inversely related to the abatement done in the grand coalition. This approach was developed by Lessmann et al. (2015).
} 
the European Union and especially the USA have to increase abatement efforts. This is reflected in higher European Union and US abatement costs and lower 'rest of the world' abatement costs in the IS runs compared to the whole sample means. Or alternatively, the relative economic impact of climate change to the 'rest of the world' has to increase to give it sufficiently high benefits from cooperation. Note that for the scenarios of uncertainty about abatement $\operatorname{costs} b_{1}$ and especially for uncertainty about regional damages $\theta_{1}$-reg the OECD can become stable for a wide range of parameter values of each signatory, suggesting that stability is most affected by uncertainty about the distributional effects of climate coalitions, especially relating to damages.

Comparison of the effects of uncertainty in global damages and uncertainty in the curvature of the damage function reveals the importance of functional uncertainty for coalition stability. Regarding the former, the OECD becomes only internally stable if there are hardly any damages, which is the trivial case of no climate change externality. In contrast the likelihood that the OECD is internally stable increases with uncertainty in the curvature of the damage function. Specifically, the OECD becomes internally stable when the sensitivity of damages to the magnitude of temperature increase is high - more than 1.7 times the mean. This suggests that cooperation is induced by common interest of avoiding a temperature threshold above which severe damage will occur.

\subsubsection{Coalition stability with transfers}

To study how coalition stability is affected by uncertainty when transfers between signatories are available, we now analyse the relative effect of different uncertainties on the potential internal stability likelihood. Almost all studied coalitions are potentially internally stable (PIS) in the deterministic setting (Figure 7.3), as the coalition payoff is high enough to compensate signatories with a negative incentive. However, the large coalition of all major emitters is not internally stable, even with transfers, as free-rider incentives are so high that not all signatories can be kept within the coalition.

Transfers increase the stability of coalitions under uncertainty. When transfers are possible the internal stability of coalitions is less sensitive to the applied uncertainties compared to a situation with no transfers, measured as the deviation from the deterministic case. However, some coalitions, especially the coalition between the European Union and Japan (EJ) and Japan and USA (JU), are unstable in the potential internal stability sense in many runs. Remarkably, the major emitter coalition, the only coalition which is not potentially 


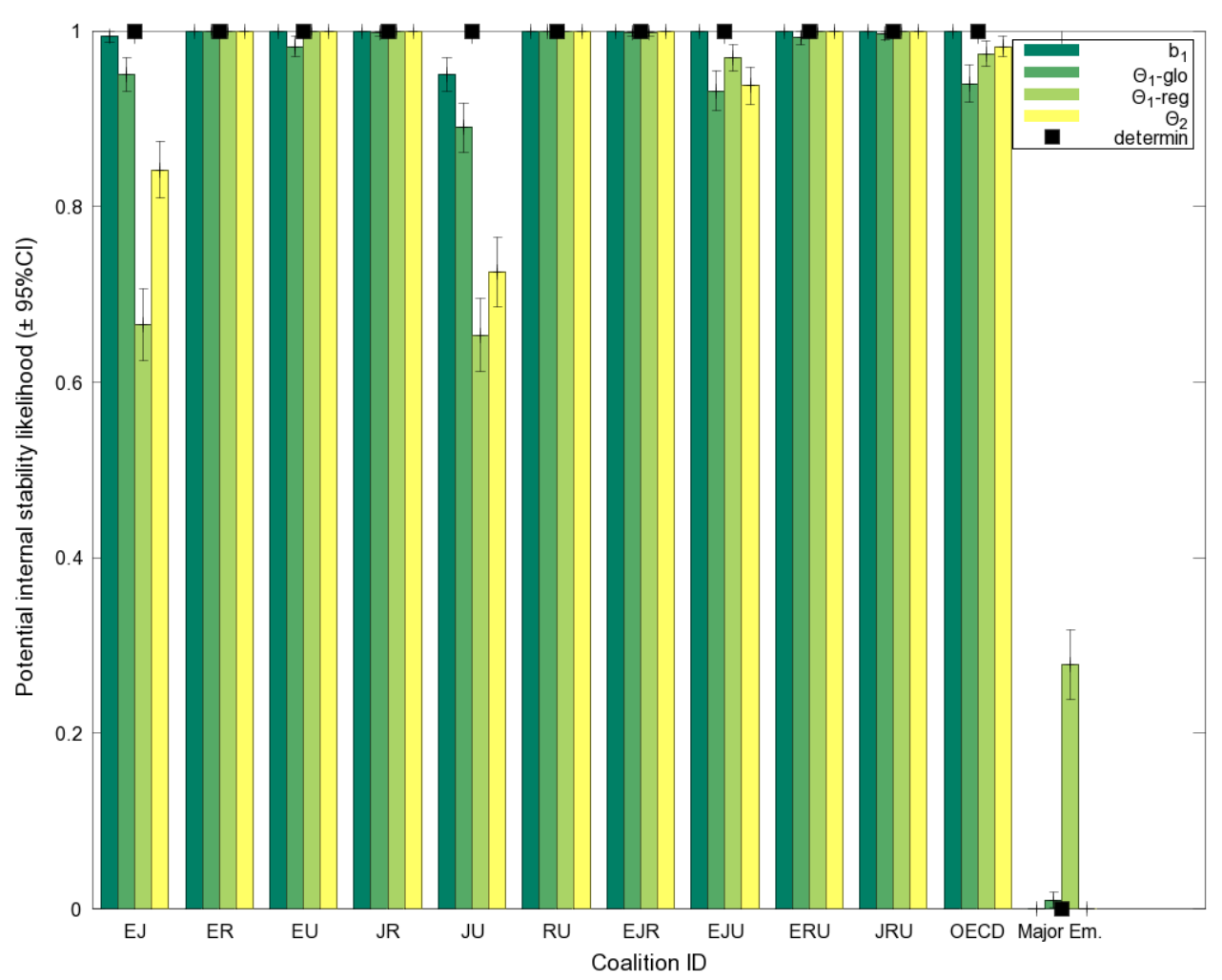

Figure 7.3: Potential internal stability likelihood and corresponding confidence intervals (whiskers) by coalitions for uncertainty in abatement costs (b1), global damages $\left(\theta_{1}\right.$-glo), regional damages $\left(\theta_{1}\right.$-reg) and curvature of the damage function $\left(\theta_{2}\right)$. Black boxes indicate the potential internal stability likelihood for the deterministic case.

internally stable in the deterministic case, has a considerable likelihood to be potentially internally stable under uncertainty.

The differences between the internal stability likelihood (Figure 7.2) and potential internal stability likelihood (Figure 7.3) indicate that the effect of heterogeneity on stability depends on the availability of transfers. In particular, the higher potential internal stability likelihood of the major emitter coalition under uncertainty in the regional distribution of damages is in line with the theoretical result that any coalition can become potentially internally stable if the heterogeneity between players is sufficiently high (Finus and Pintassilogo 2013; Weikard 2009). However, for coalitions that are already potentially internally stable in the deterministic case the PIS likelihood indicator does not reveal the increasing incentives that may result from uncertainty for signatories to stay in the coalition.

A different indicator is necessary to gain a better understanding of how uncertainty influences the incentive to stay within a coalition when transfers are available but the value of the PIS likelihood is already one. To this end, we studied the amount of consumption that 
each player can pass on while still having an incentive to stay inside the coalition, denoted as the surplus (Carraro et al. (2006) introduce a similar concept for transferable utility models). ${ }^{117}$ We find that the surplus, used as a continuous indicator of potential internal stability, yields more detailed and more positive conclusions than the PIS likelihood about the effect of uncertainty on the stability of (already stable) coalitions.

Figure 7.4 shows the change in the surplus under uncertainty relative to the absolute estimate in the deterministic case (ratio). When negative, the surplus illustrates how far off a coalition is from being potentially internally stable; when positive, the surplus is a measure of the extent to which the coalition is generating a positive incentive for its members to participate. For coalitions that are always potentially internally stable, a higher surplus indicates that under uncertainty the regions within the coalition have a stronger incentive to stay after redistribution, as the higher surplus is shared among the signatories.

The surpluses shown in Figure 7.4 indicate that even coalitions where the potential internal stability under uncertainty drops below one have on average greater incentives to stay in the coalition, compared to the deterministic case, since they can expect to gain substantial benefits from cooperation. A remarkable exception is the coalition of major emitters. The negative incentives for signatories to stay in this coalition, due to its size, are reinforced under uncertainty in abatement costs, global damages and the shape of the damage function. Only uncertainty about regional damages causes the incentive for signatories to stay to increase. This finding is in line with the theoretical result that when transfers are available any coalition can become stable if heterogeneity between signatory is sufficiently high (Finus and Pintassilogo 2013; Weikard 2009).

\footnotetext{
${ }^{117}$ Kornek et al. (2014) define a measure for the surplus in the non-transferable utility framework and develop an algorithm to compute it, which we describe here. For a coalition $S$ consider the transfer scheme $\tau$ that redistributes consumption so that the payoff of each signatory $k$ is at least at its free-rider level. The surplus can then be defined as the maximal consumption per coalition member every signatory $j$ could lose, still having a positive incentive to stay, discounted at rate $r_{t}$ over time $t_{0}$ to $t_{m}$ :

$$
\begin{aligned}
\operatorname{lo}(S, d)= & \max _{\tau_{k, t}, \Delta C_{t}}\left(\sum_{t=t_{0}}^{t_{n}} \frac{1}{1+r_{t}} \Delta C_{t}(S, d)\right) \\
\text { subject to } & \pi_{k}\left(c_{j}(S, d)+\tau_{k, t}(S, d)-\Delta C_{t}(S, d)\right) \geq \pi_{k}(S \backslash\{j\}, d), \forall k \in S .
\end{aligned}
$$

The surplus aggregates the consumption streams of all members of the coalition that are available for arbitrary redistribution when the coalition is internally stable after transfers. To gain an indicator of how much additional transfers each member could receive, we divide the sum of consumption by the number of members. If the surplus is positive, each member has an incentive to stay inside the coalition after redistribution and the magnitude of the surplus indicates how strong the incentives to stay are. If the surplus is negative, the coalition is not PIS and the negative magnitude of the surplus indicates how much more consumption would be necessary inside the coalition in order for the incentive for members to stay to become positive.
} 


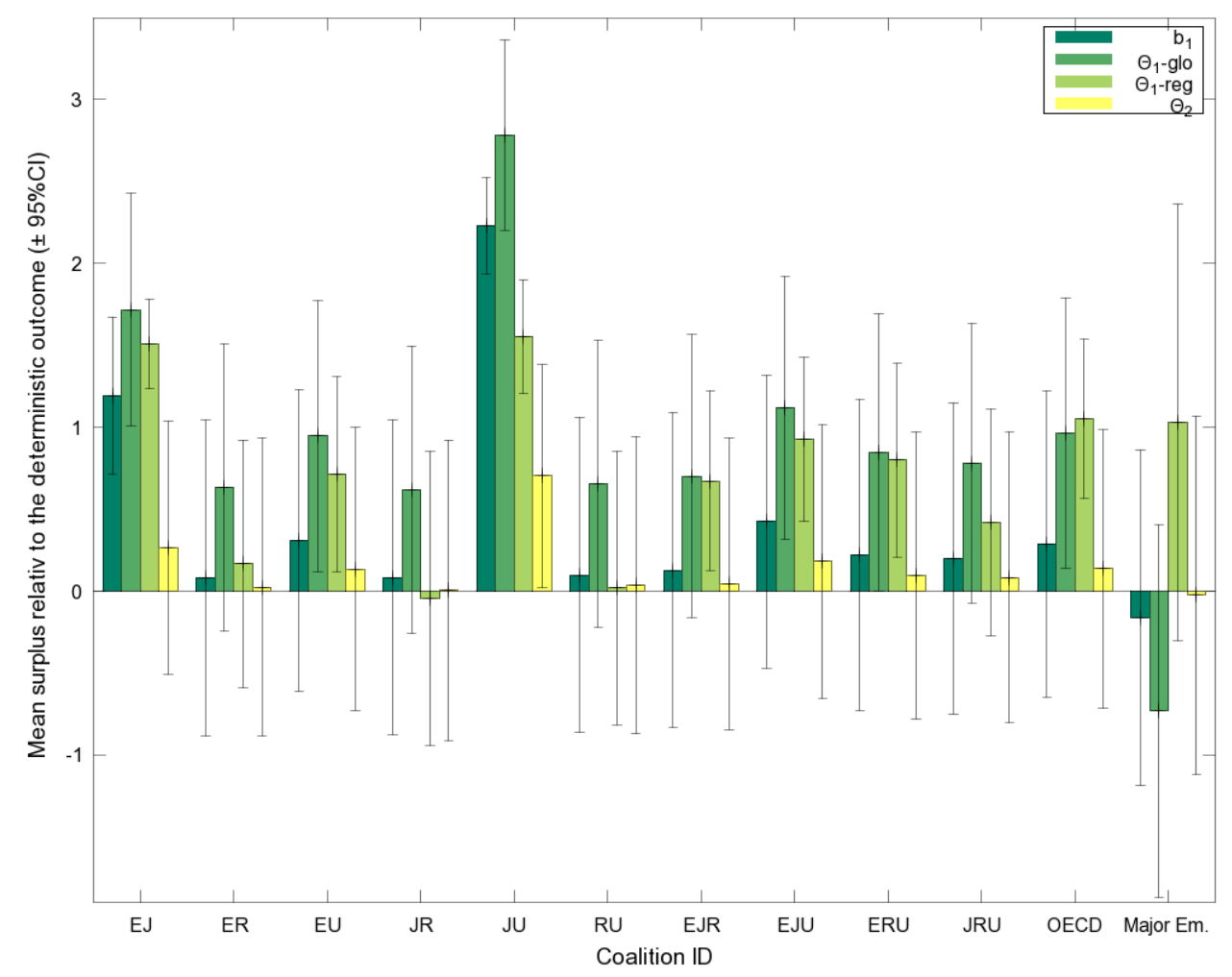

Figure 7.4: Mean surplus relative to the absolute estimate in the deterministic case (ratio) and corresponding confidence intervals (whiskers) for uncertainty in abatement costs $\left(b_{1}\right)$, global damages $\left(\theta_{1}\right.$-glo), regional damages $\left(\theta_{1}\right.$-reg) and damage curvature $\left(\theta_{2}\right)$.

A more detailed view of how the incentive to stay within a coalition with transfers is affected by uncertainty can be gained by looking at the distribution of the surpluses (Table 7.7 in the Appendix). The uncertainty in the surplus - measured by the standard deviation - is in most cases highest for uncertainty in the regional distribution of damages. For the majority of the studied coalitions the mean of the surplus is higher than the median and hence the probability density of the surplus is right-skewed. The only exception is again the major emitter coalition, which has a left-skewed distribution of the incentive to stay in all uncertainty scenarios except in the case of uncertainty about regional damages.

Uncertainty in the regional distribution of damages produces the most skewed distributions of the incentive to stay within the coalitions, as the difference between the median and the mean surplus is always highest in this scenario. Furthermore, for uncertainty in regional damages the likelihood of having a strong incentive to stay goes up for all studied coalitions, including even the major emitter coalition. Thus, when transfer schemes are available, uncertainty about regional damages increases the internal stability of coalitions. However, these observations have an explorative character due to the limited sample of coalitions in 
TABLE 7.5: Correlations between the heterogeneity in abatement costs $\left(\mathrm{CV}_{\Lambda}\right)$ or damages $\left(\mathrm{CV}_{\Omega}\right)$ and coalition stability without transfers $(I S)$ and with transfers (surplus)

\begin{tabular}{lcccc}
\hline \hline Coalition & $r\left(\mathrm{CV}_{\Lambda}, I S\right)$ & $r\left(\mathrm{CV}_{\Lambda}\right.$, surplus $)$ & $r\left(\mathrm{CV}_{\Omega}, I S\right)$ & $r\left(\mathrm{CV}_{\Omega}\right.$, surplus $)$ \\
\hline EJ & $0.689^{* *}$ & $-0.438^{* *}$ & -0.063 & $0.332^{* *}$ \\
ER & - & $0.557^{* *}$ & $-0.396^{* *}$ & $0.183^{* *}$ \\
EU & - & $0.562^{* *}$ & $-0.388^{* *}$ & $0.254^{* *}$ \\
JR & - & 0.037 & $-0.371^{* *}$ & $0.192^{* *}$ \\
JU & $0.475^{* *}$ & $-0.456^{* *}$ & 0.021 & $0.371^{* *}$ \\
RU & - & $0.549^{* *}$ & $-0.369^{* *}$ & $0.197^{* *}$ \\
EJR & $0.742^{* *}$ & $-0.151^{* *}$ & $-0.334^{* *}$ & $0.216^{* *}$ \\
EJU & $0.339^{* *}$ & -0.061 & -0.051 & $0.248^{* *}$ \\
ERU & $-0.320^{* *}$ & $0.477^{* *}$ & $-0.368^{* *}$ & $0.305^{* *}$ \\
JRU & $0.812^{* *}$ & $-0.133^{*}$ & $-0.279^{* *}$ & $0.212^{* *}$ \\
OECD & 0.091 & -0.011 & $-0.178^{* *}$ & $0.276^{* *}$ \\
Major Emitters & - & 0.014 & - & $0.188^{* *}$ \\
\hline Correlation coefficients (Pearson's R) for $\mathrm{n}=500 ;\left(^{*}\right)\left({ }^{* *}\right)$ indicate significance at the $p<0.01$ \\
and $p<0.001$ level, respectively; coalitions with missing values are either always or never \\
internally stable.
\end{tabular}

this study.

A principal result of the above analysis is that uncertainty in damage and abatement costs mainly affects coalition stability through its effect on the heterogeneity of signatories and that the direction of the effect depends on the availability of transfers. To test the link between the heterogeneity of signatories and the stability of coalitions without and with transfers we study correlations between the coalition stability and the distribution of damages and abatement costs (Table 7.5), an approach employed by Eyckmans and Bréchet (2012). For each coalition, heterogeneity is measured as the coefficient of variation (CV) across all signatories in abatement, $\mathrm{CV}_{\Lambda}$, and damage cost, $\mathrm{CV}_{\Omega}$, respectively. Table 7.5 compares the two measures of heterogeneity against internal stability of coalitions without and with transfers, using 'surplus' as a measure of stability when transfers are available for the reasons explained above.

Regarding abatement costs, the relationship between heterogeneity and coalition stability is not clear cut. By contrast, for damages we find that heterogeneity is negatively correlated with coalition stability when countries have no possibility to transfer consumption. However, the relationship is reversed when transfers schemes are available. In this case heterogeneity in damages is always significantly positively correlated with the internal stability of coalitions. This means that when transfers are available, uncertainty in the regional distribution of damages is likely to increase the stability of coalitions. Thus, our experiments add numerical evidence to the analytical results regarding the relationship between heterogeneity and stability of coalitions (Weikard 2009) and link these to the issue of uncertainty in coalition 
formation (Finus und Pintassilgo 2013).

\subsection{Conclusion}

We have studied how uncertainties about climate change damages and abatement costs affect the stability of coalitions in a numerical model of coalition formation (MICA). While we do not explicitly consider decision making under uncertainty, our numerical Monte-Carlo analysis allowed us to quantify the probability that the claim that certain coalitions are stable is correct. To this end, we have translated estimates of uncertainty about abatement costs and climate change damages from empirical studies into four probability distributions for parameters in our model, and propagated these distributions through the model using Monte-Carlo analysis.

We found, firstly, that stability is very sensitive to uncertainty. As parameter variations within the bounds of uncertainty frequently change the stability of coalitions, whether or not a coalition is stable often appears to be a knife-edge case. Finding a specific coalition to be stable (or not) should therefore not be mistaken for a prediction. This underlines the value of more comprehensive indicators of the incentives to cooperate, such as stability likelihood, which reveals the robustness of such incentives.

Second, uncertainty about damages matters more than uncertainty about abatement costs. This is, of course, partly due to the larger empirical uncertainty in the case of damages, and highlights once again the pressing need for more research on the economic impacts of climate change. Furthermore, uncertainty in the regional distribution of damages has a stronger impact on stability than uncertainty in global damages. This, too, highlights the need for more accurate information on climate change impacts. The strong effect of uncertainty about regional damages implies that heterogeneity in regional damages, i.e. how the burden of climate change impacts is shared, matters more for cooperation than the magnitude of the global burden. It is therefore important to understand impacts on the regional level.

Third, we find evidence that heterogeneity increases coalition stability when transfers are available and decreases coalition stability when they are not. This result has already been demonstrated in the theoretical literature (Finus and Pintassilgo 2013; Weikard 2009); our calculations suggest that it also applies to more complex models incorporating non-linear relationships. As such, we view this as encouraging for climate change negotiations. While real-world heterogeneity may initially present an obstacle to cooperation, as it inevitably 
creates losers (along with the winners), there is a rich set of transfer and compensation schemes that can potentially turn heterogeneity from an obstacle into an opportunity, e.g. by burden sharing schemes (Lessmann et al. 2015) or introducing trade in emission permits (Jakob et al. 2014).

The analysis presented here shows that results regarding the stability of coalitions derived from models of international climate cooperation should be interpreted with some caution. Interestingly, for some coalitions, our analysis indicates that outcomes may be more positive than those suggested by deterministic analyses. Under uncertainty the likelihood of important coalitions like the OECD being internally stable might increase, and even large coalitions have a considerable chance to become internally stable when appropriate transfer schemes are in place.

The methods employed in this study limit the generalizability of our results. Results are derived from analysis of a small set of coalitions and should be tested in a wider sample of all possible coalitions. We chose to focus on a limited set of coalitions to identify the major effects and to examine the underlying mechanics, and while we would not expect qualitatively different results, an extension to a larger set of coalitions would strengthen our argument. Finally, while uncertainty propagation by Monte-Carlo analysis allows us to study the effect of real-world uncertainty on model results, uncertainty does not enter the strategic decision making on whether or not to cooperate. This requires a modelling approach which incorporates decision making under uncertainty, e.g. stochastic programming. While our study reveals which uncertainties drive the stability of coalitions, future research could explicitly incorporate decision making under uncertainty in order to gain an in-depth understanding of how uncertainty influences their formation.

Acknowledgments: We thank Achim Hagen, Andrew Halliday as well as conference participants at ICP 2015, EAERE 2016 and especially two anonymous reviewers for helpful comments on earlier drafts of this paper. 


\section{Bibliography}

Barrett, S. (1994). Self-enforcing international environmental agreements. Oxford Economic Papers, 46, 878-894.

Barrett, S. (2003). Environment and Statecraft: The Strategy of Environmental TreatyMaking. Oxford: Oxford University Press.

Barrett, S. (2005). The theory of international environmental agreements. In K.-G. Mäler, J. R. Vincent, (Ed.), Handbook of Environmental Economics (pp. 1457-1516). Amsterdam: Elsevier.

Barrett, S. (2013). Climate treaties and approaching catastrophes. Journal of Environmental Economics and Management, 66(2), 235-250.

Bosetti, V., Carraro, C., De Cian, E., Massetti, E., \& Tavoni, M.(2013). Incentives and stability of international climate coalitions: An integrated assessment. Energy Policy, 55, 44-56.

Bosetti, V., Carraro, C., Galeotti, M., Massettti, E. \& Tavoni, M. (2006). WITCH: a world induced technical change hybrid model. The Energy Journal, 27, 13-37.

Bréchet, T., Gerard, F. \& Tulkens, H. (2011). Efficiency vs. stability in climate coalitions: A conceptual and computational appraisal. The Energy Journal, 31(1), 49-75.

Bréchet, T., Thénié, J., Zeimes, T. \& Zuber, S. (2012). The benefits of cooperation under uncertainty: the case of climate change. Environmental Modelling and Assessment, 17(1), $149-162$.

Carraro, C., Eyckmans, J. \& Finus, M. (2006). Optimal transfers and participation decisions in international environmental agreements. The Review of International Organizations, 1(4), 379-396. 
Carraro, C. \& Siniscalco, D. (1993). Strategies for the international protection of the environment. Journal of Public Economics, 52(3), 309-328.

Clarke, L., Edmonds, J., Krey, V., Richels, R., Rose, S. \& Tavoni, M. (2009). International climate policy architectures: Overview of the EMF 22 international scenarios. Energy Economics, 31, 564-581.

Crost, B., \& Traeger, C. P. (2011). Risk and aversion in the integrated assessment of climate change. CUDARE Working Papers. Department of Agricultural \& Resource Economics, University of Carlifornia, Berkeley.

Dellink, R., Dekker, T. \& Ketterer, J. (2013). The fatter the tail, the fatter the climate agreement. Simulating the influence of fat tails in climate change damages on the success of international climate negotiations. Environmental and Resource Economics, 56(2), 277305.

Dellink, R. (2011). Drivers of stability of climate coalitions in the STACO model. Climate Change Economics, 2(2), 105-128.

Dellink, R., Altamirano-Cabrera, J. C., Finus, M., von Ireland, E. \& Weikard, H. (2004). Empirical background paper of the STACO model. http://www.wageningenur.nl/web/file?uuid=9115e403-7832-48d6-ac1ceb61f67edbec\&owner=d1bd6906-08fd-4139-956f-b8004307a16e. Accessed 01 August 2013.

Dellink, R. \& Finus, M. (2012). Uncertainty and climate treaties: Does ignorance pay? Resource and Energy Economics, 34(4), 565-584.

Dellink, R., Finus, M. \& Olieman, N. (2008). The stability likelihood of an international climate agreement. Environmental and Resource Economics, 39(4), 537-377.

Dietz, S. (2011). High impact, low probability? An empirical analysis of risk in the economics of climate change. Climatic Change, 108(3), 519-541.

Eyckmans, J. \& Bréchet, T. (2012). Coalitions in the 18 region stochastic CWS model, presented at the Workshop on Modeling Climate Coalitions, Potsdam Institute for Climate Impact Research, February 8-9, 2012.

Finus, M. \& Pintassilgo, P. (2013). The role of uncertainty and learning for the success of international climate agreements. Journal of Public Economics, 103, 29-43. 
Hoel, M. (1992). International environmental conventions: the case of uniform reductions of emissions. Environmental and Resource Economics, 2(2), 141-159.

Hwang, I. C., Reynès, F. \& Tol, R. S. J. (2013). Climate policy under fat-tailed risk: an application of dice. Environmental and Resource Economics, 56(3), 415-436.

IPCC (2001). Climate Change 2001: Impacts, Adaptation, and Vulnerability. Cambridge: Cambridge University Press.

Jakob, M., Lessmann, K. \& Wildgrube, T. (2014). The role of emissions trading and permit allocation in international climate agreements with asymmetric countries. Strategic Behavior and the Environment, 4(4), 361-392.

Kolstad, C. D. (2007). Systematic uncertainty in self-enforcing international environmental agreements. Journal of Environmental Economics and Management, 53, 88-79.

Kolstad, C. D. \& Ulph A. (2008). Learning and international environmental agreements. Climatic Change, 89, 125-141.

Kolstad, C. D. \& Ulph A. (2011). Uncertainty, learning and heterogeneity in international environmental agreements. Environmental and Resource Economics, 50, 389 - 403.

Kornek U., Lessmann K. \& Tulkens H. (2014). Transferable- and non-transferable utility implementations of coalitional stability in integrated assessment models. CORE Discussion Paper, No. 35.

Kornek, U., Steckel, J., Lessmann, K. \& Edenhofer, O. (2017). The climate rent curse: new challenges for burden sharing. Int Environ Agreements, DOI:10.1007/s10784-017-9352-2

Leimbach, M., Bauer, N., Baumstark, L. \& Edenhofer, O. (2010). Mitigation costs in a globalized world: climate policy analysis with REMIND-R. Environmental Modelling and Assessment, 15(3), 155-173.

Lessmann, K., Kornek, U., Bosetti, V., Dellink, R., Emmerling, J., Eyckmans, J., Nagashima, M., Weikard, H. \& Yang, Z. (2015). The stability and effectiveness of climate coalitions: A comparative analysis of multiple integrated assessment models. Environmental and Resource Economics, 62(4), 811-836.

Lessmann, K., Marschinski, R. \& Edenhofer, O. (2009). The effects of tariffs on coalition formation in a dynamic global warming game. Economic Modelling, 26(3), 641-649. 
Na, S. \& Shin, H. S. (1998). International environmental agreements under uncertainty. Oxford Economic Papers, 50(2), 173-1785.

Nordhaus, W. D. \& Yang, Z. (1996). A regional dynamic general-equilibrium model of alternative climate-change-strategies. The American Economic Review, 86(4), 741-765.

Nordhaus, W. D. (1994). Managing the Global Commons. The Economics of Climate Change. London: MIT Press.

Nordhaus, W. D. (2008). A question of balance: weighting the options on global warming. New Heaven: Yale University Press.

Nordhaus, W. D. (2010). Economic aspects of global warming in a post-Copenhagen environment. PNAS, 107(26), 11721-11726.

Nordhaus, W. D. (2011). The economics of tail events with an application to climate change. Review of Environmental Economics and Policy, 5(2), 240-257.

Nordhaus, W. D. (2012). Economic Policy in the face of severe tail events. Journal of Public Economic Theory, 14(2), 197-219.

Olieman, N. J. \& Hendrix, E. M. T. (2006). Stability likelihood of coalitions in a two-stage cartel game: An estimation method. European Journal of Operational Research, 174(1), 333-348.

Tavoni, M. \& Tol, R. S. J. (2010). Counting only the hits? The risk of underestimating the cost of stringent climate policy. A letter. Climatic Change, 100, 769-778.

Tol, R. S. T. (1995). The damage costs of climate change toward more comprehensive calculations. Environmental and Resource Economics, 5(4), 353-374.

Tol, R. S. J. (2012). On the uncertainty about the total economic impact of climate change. Environmental and Resource Economics, 53, 97-116.

Tol, R. S. J. (2013). Targets for global climate policy: An overview. Journal of Economic Dynamics \& Control, 37, 911-928.

Tol, R. S. J. (2014). Correction and update: The economic effects of climate change. The Journal of Economic Perspectives, 28(2): 221-225. 
Weikard, H. P. (2009). Cartel stability under optimal sharing rule. The Manchester School, $77,575-593$.

Weitzman, M. L. (2007). A review of the stern review on the economics of climate change. Journal of Economic Literature, 45(3), 703-724.

Weitzman, M. L. (2009). On modelling and interpreting the economics of catastrophic climate change. The Review of Economics and Statistics, 91(1), 1-19.

Weitzman, M. L. (2010). What is the "damage function" for global warming - and what difference might it make? Climate Change Economics, 1(1), 57-69.

Weitzman, M. L. (2012). GHG targets as insurance against catastrophic climate damages. Journal of Public Economic Theory, 14(2), 221-244. 


\subsection{Appendix}

TABLe 7.6: Makeup of regions studied in the Model of International Climate Agreements

\begin{tabular}{ll}
\hline \hline Model region & Countries \\
\hline AFR & Sub-Saharan Africa without South Africa \\
CHN & China \\
EUR & EU27 countries \\
IND & India \\
JPN & Japan \\
LAM & All American countries but Canada and the US \\
MEA & North Africa, Middle Eastern and Arab Gulf Countries, \\
& Resource exporting countries of former Soviet Union (FSU), Pakistan \\
OAS & South East Asia, both Koreas, Mongolia, Nepal, Afghanistan \\
ROW & Non-EU27 European states without Russia, Australia, Canada, \\
RUS & New Zealand and South Africa \\
USA & Russia \\
\hline
\end{tabular}




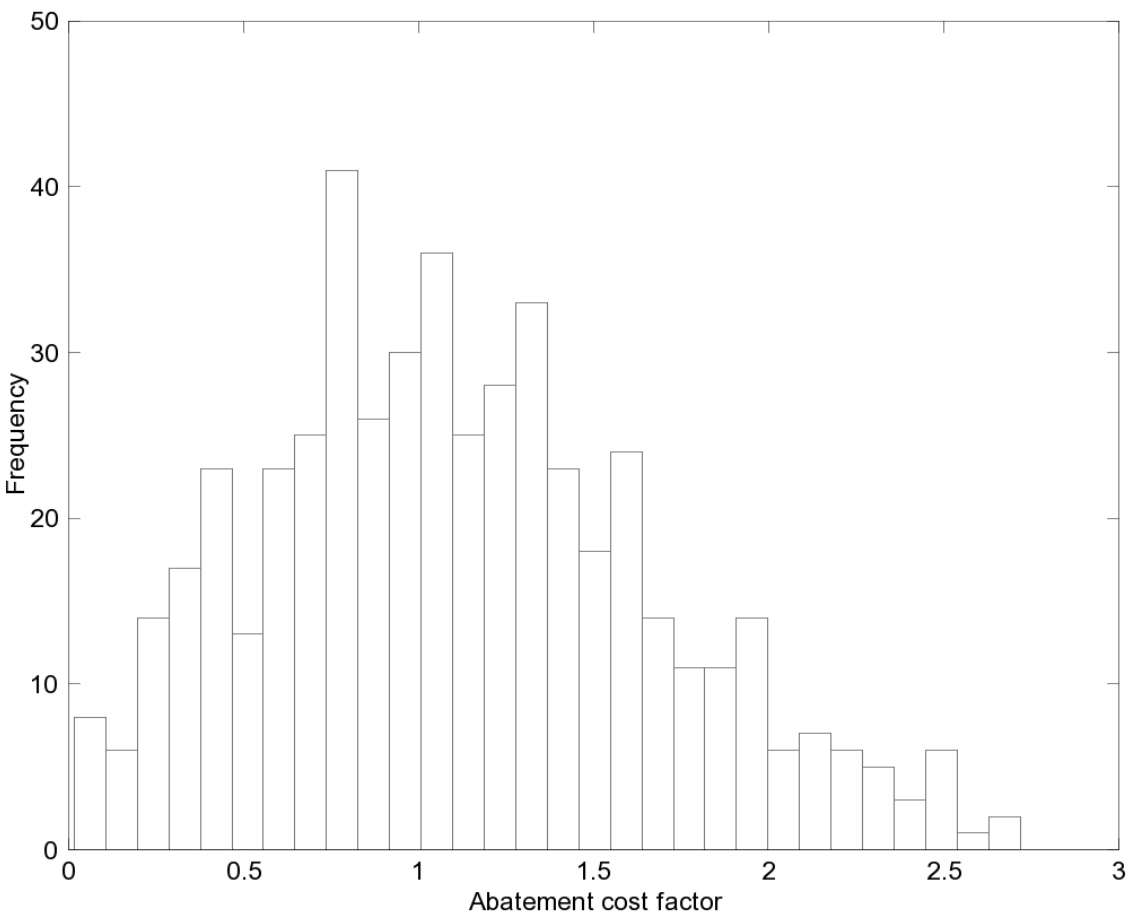

Figure 7.5: Histogram of the realization of the abatement cost factor $k$. 


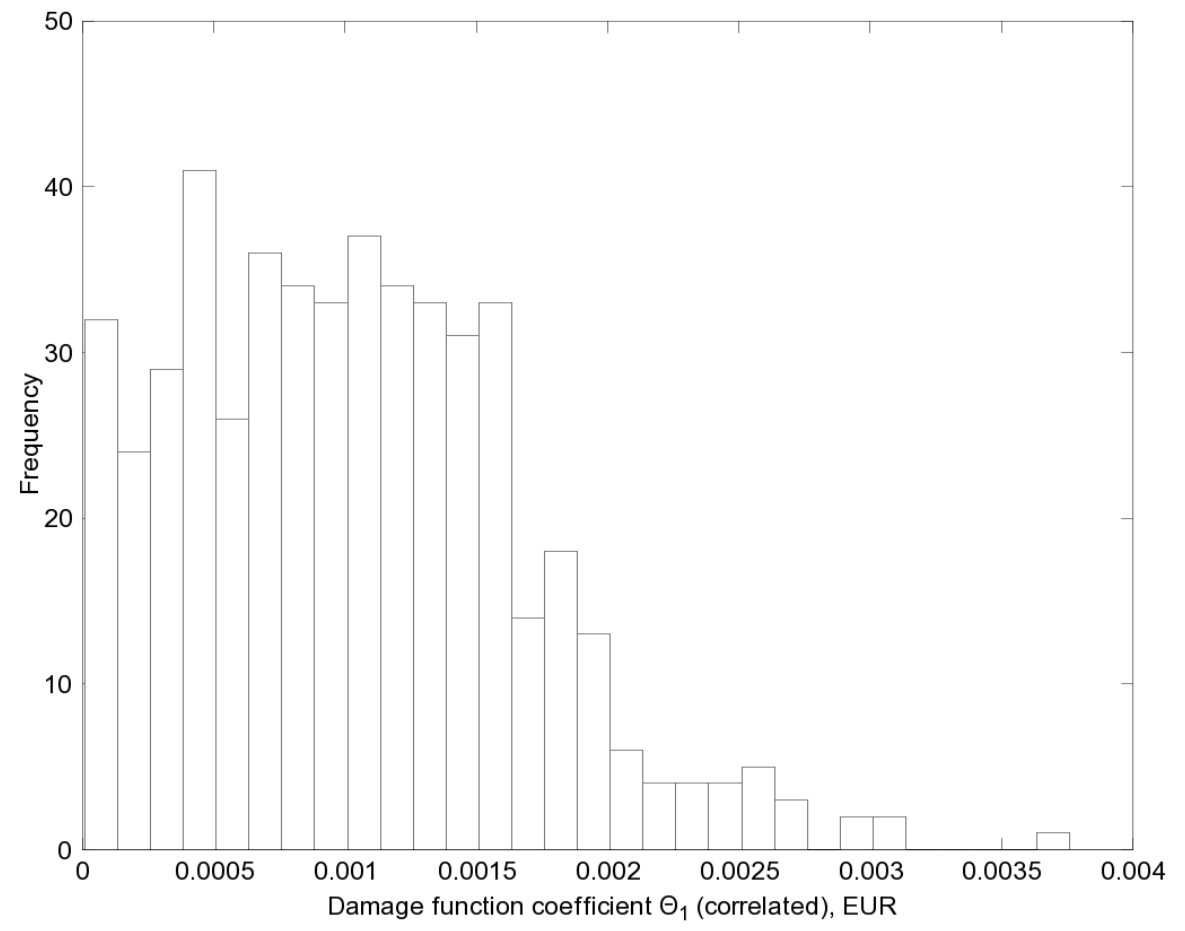

Figure 7.6: Histogram of the realization of $\theta_{1}$ in case of uncertainty in global damages for EUR.

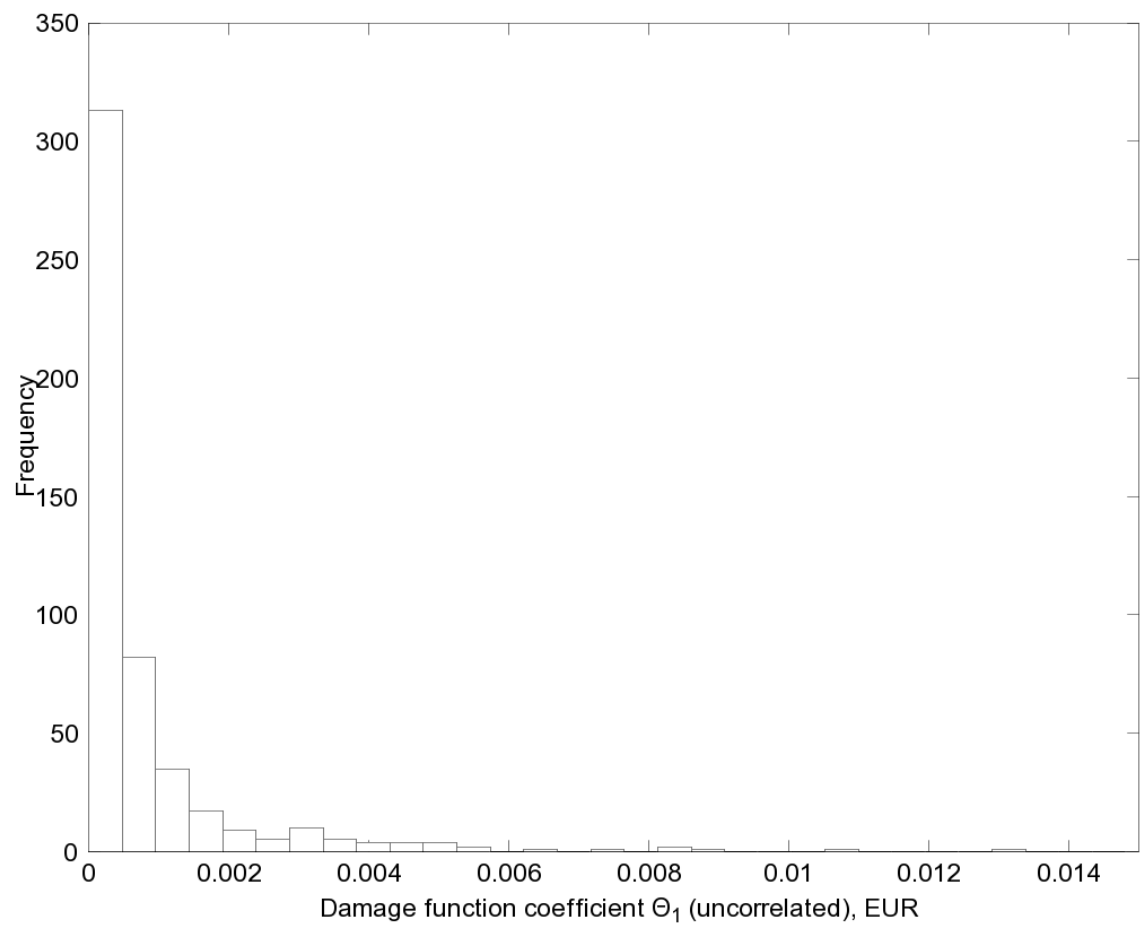

FIGURE 7.7: Histogram of the realization of $\theta_{1}$ in case of uncertainty in regional damages for EUR. 


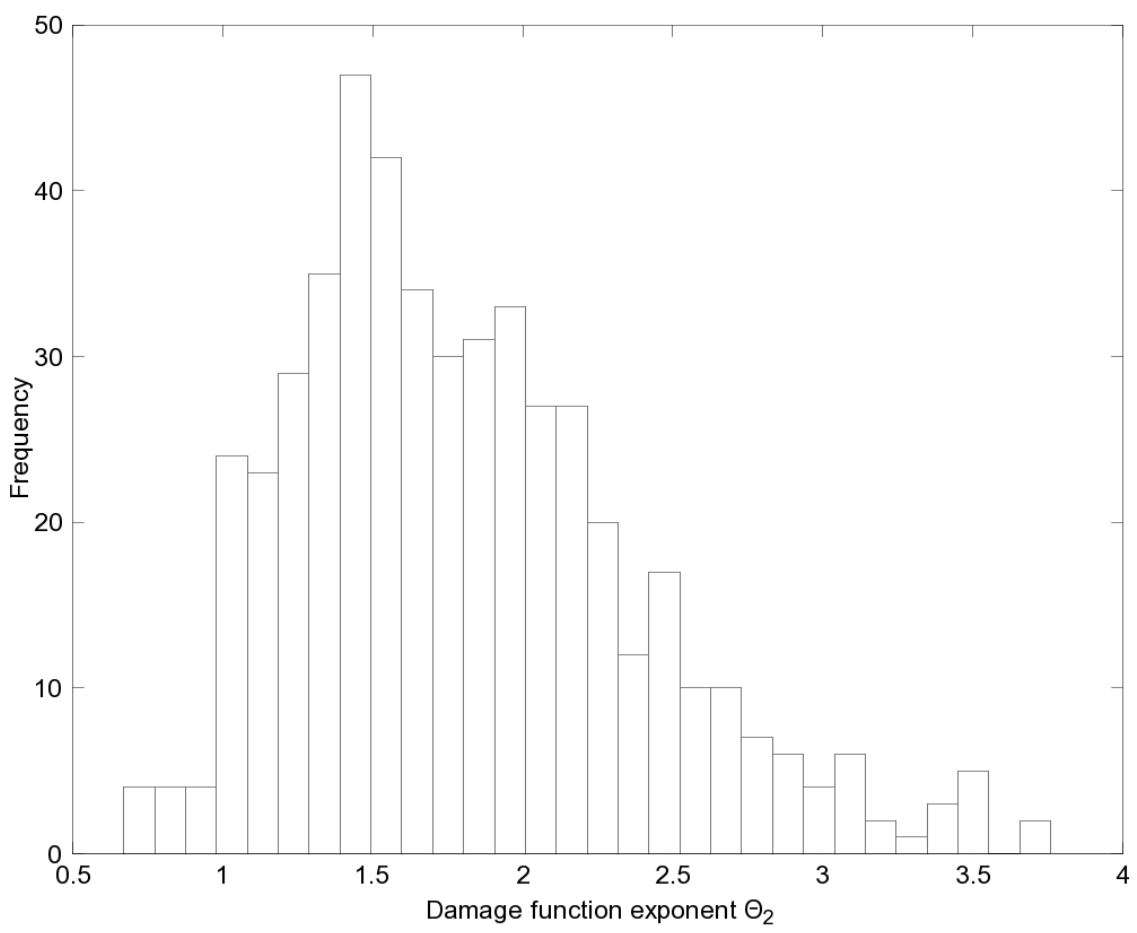

Figure 7.8: Histogram of the realization of $\theta_{2}$. 


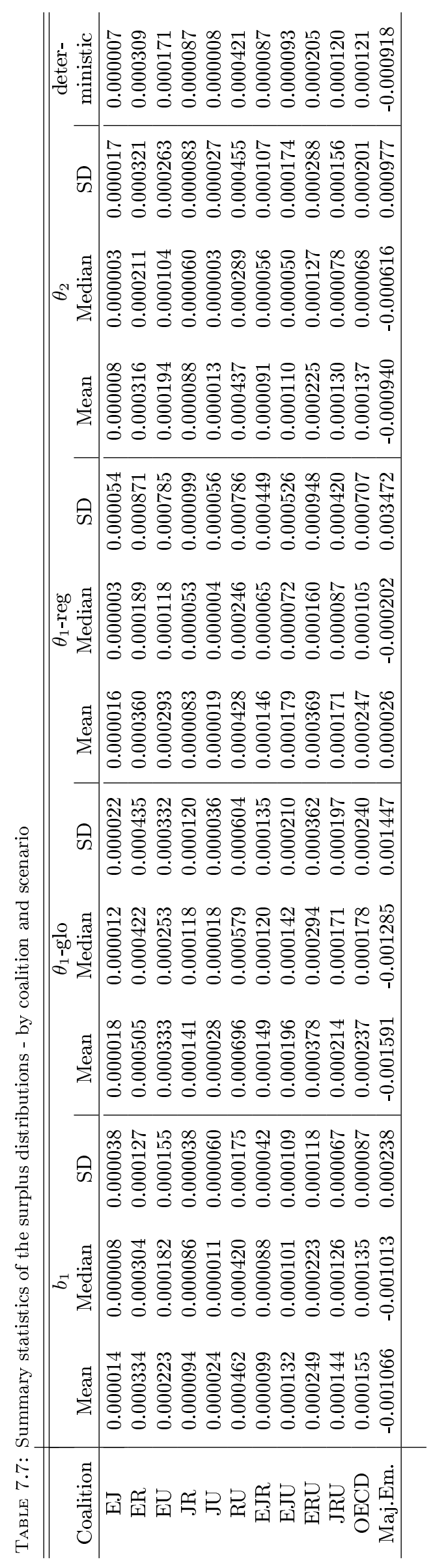




\title{
8 Ecosystem Services in Infrastructure
}

\section{Planning}

\begin{abstract}
We consider how ecosystem services can be incorporated into water infrastructure planning by studying the projected deepening of the Lower Weser river channel in Germany. We recalculate the project's benefit-cost ratio by integrating the monetary value of changes in different ecosystem services, as follows: (1) the restoration costs of a mitigation measure for a loss in fresh water supply for agricultural production in the estuary region, (2) the costs of a loss in habitat services, transferring the willingness to pay from a contingent valuation study to the area assessed in the environmental impact assessment, and (3) the benefits of emissions savings induced by more efficient shipping, taking a marginal abatement cost approach. We find that including monetary values for ecosystem service changes leads to a substantial drop in the benefit-cost ratio. On this basis, we argue for a reform of the standard cost-benefit analysis to facilitate more complete welfare assessments.
\end{abstract}

Keywords: ecosystem services; cost-benefit analysis; infrastructure planning; river deepening; Weser estuary

Reference: Droste, N., Meya, J.N. (2017). Ecosystem services in infrastructure planning - a case study of the projected deepening of the Lower Weser river in Germany. Journal of Environmental Planning and Management, 60(2), 231-248.

This is the original manuscript of an article published by Taylor \& Francis in the Journal of Environmental Planning and Management, available online:

https://doi.org/10.1080/09640568.2016.1151405. 


\subsection{Introduction}

The effects of a region's infrastructure on the integrity of ecosystems, including both the changes brought about by new infrastructure in the provision of ecosystem services ${ }^{118}$ and their impacts on human well-being, have attracted much attention since the Millennium Ecosystem Assessment (MEA 2005) and The Economics of Ecosystems and Biodiversity (TEEB 2010a) reports. Despite the growing literature on ecosystem services, however, hardly any attempts have been made to account for monetary values of ecosystem service changes in infrastructure legislation and planning. ${ }^{119}$

In European, international and national infrastructure planning, welfare assessments such as cost-benefit analysis (CBA) are a common tool (EC 2008; Pearce, Atkinson, and Mourato 2006; World Bank 2006). In order to fully assess the effects of infrastructure projects on social welfare, all related costs and benefits should be integrated into a CBA (Hanley and Barbier 2009), including monetary values of changes in ecosystem services (Russi et al. 2013). In cases where the ecosystem services concerned are considered to be highly valuable, neglecting them would lead to an inefficient allocation of public investment. In the context of waterbody-related infrastructure planning, the European Water Framework Directive (WFD), for example, sets standards for the quality of water bodies and mentions economic analysis explicitly as a central decision support tool (cf. Meyerhoff and Dehnhardt 2007). However, the effects of waterway infrastructure projects on the waterbody quality and the respective aquatic ecosystem services have rarely been assessed in monetary terms (for CBA in the WFD context, see Hanley and Black 2006).

In this paper, we aim at assessing the importance of ecosystem service changes for CBA in (water) infrastructure planning. To this end, we critically review the German infrastructure legislation regarding the inclusion of ecosystem services and present a case study in which ecosystem services are integrated into the CBA of deepening the Lower Weser river channel in Germany. ${ }^{120}$ Thus, we ask: How does the cost-benefit ratio change for the projected Lower Weser deepening when ecosystem service values are integrated?

\footnotetext{
${ }^{118}$ Ecosystem services are 'the benefits that people obtain from ecosystems' (MEA 2005: preface) or, for a more precise definition, '[f]inal ecosystem services are components of nature, directly enjoyed, consumed, or used to yield human well-being' (Boyd and Banzhaf 2007, 619).

${ }^{119}$ For both the reasons and challenges of integrating ecosystem services into decision-making, see de Groot et al. (2010).

${ }^{120}$ The Weser river in northwest Germany has been deepened several times (Franzius, Franzius, and Rudloff 2010; Wetzel 1988), leading to drastic alterations in the river flow regime (Schuchardt et al. 2007). The deepening project currently being planned (WSV 2011) has been challenged by environmental NGOs and farmers at the German Federal Administrative Court, where it was referred to the European Court of Justice with regard to the 'no deterioration' rule in the EU Water Framework Directive (Ekardt and Weyland 2014).
} 
We find it a particularly interesting case study for the following three reasons: (1) estuaries are well known as areas of high economic activity, as well as of significant ecosystem service provision (Liekens, Broekx, and De Nocker 2013, 15); (2) the project is of considerable political relevance, as it was the principal case used to debate the WFD at the European Court of Justice regarding when development goals such as infrastructure improvements are allowed to overrule environmental standards such as the no-deterioration rule (Ekardt and Weyland 2014); and (3) its benefit-cost ratio was assessed as being extremely high (PLANCO 2002).

The paper structure is as follows. In Section 8.2, we review the methodology and role of CBA in the Federal Transportation Infrastructure Plan (BVWP). Turning to the case of the Lower Weser deepening in Section 8.3, we provide exemplary monetary valuations of changes in ecosystem services in order to compare the original CBA with an ecologically extended one. In Section 8.4, we discuss the limitations and assumptions involved in our approach to integrate ecosystem services into infrastructure planning. Finally, Section 8.5 concludes and proposes unresolved questions for future research.

\subsection{Critical review of the German federal infrastructure plan- ning process}

In this section, we review the methodology and decision-making process in German infrastructure planning, as laid down in the 2003 Federal Transportation Infrastructure Plan (BVWP) (Section 8.2.1), the classification of maintenance costs (Section 8.2.2), and the valuation of ecosystem services (Section 8.2.3).

\subsubsection{Cost-benefit analysis in infrastructure planning processes}

The aim of the BVWP is to channel public investments in a way that maximises social welfare (BMVBW 2003b). It is generated by conducting an integrated assessment across different transportation carriers. Based on scenario planning and traffic forecasts ${ }^{121}$ (ISL et al. 2000; PLANCO 2005), it presents infrastructure investment plans for about 10 years ahead. The Ministry of Transportation assesses the proposed infrastructure developments mainly according to a monetary benefit-cost ratio. The overall ranking is furthermore subject to public budget constraints and federal financial planning, and considers non-monetary criteria of

\footnotetext{
${ }^{121}$ Traffic forecasts and the implicitly assumed development of demand constitute a key source of uncertainty (cf. Næss et al. 2012).
} 
spatial relevance and environmental risk (BMVBW 2003b; Meyerhoff and Petschow 1995; Petry and Klauer 2005). Finally, a consultation process involving the relevant ministries, transport associations and federal states is conducted before the BVWP is enacted by legislative procedures (Petry and Klauer 2005). The assessment criteria and methodology for ranking infrastructure projects bodies and mentions economic analysis explicitly as a central decision support tool (cf. Meyerhoff and Dehnhardt 2007). However, the effects of waterway infrastructure projects on the waterbody quality and the respective aquatic ecosystem services have rarely been assessed in monetary terms (for CBA in the WFD context, see Hanley and Black 2006).

Figure 8.1 displays a combination of partial assessments taken as a basis for assessing the overall priority of projects (Petry and Klauer 2005). CBA plays a key role within this decision-making process. The aim of the CBA is to assess economic welfare effects measured in monetary terms; this makes it possible to compare the different consequences of a given project with one another. The benefit-cost ratio defines whether or not a project falls into the category of 'priority needs', 'further needs' or 'no needs'. Furthermore, it is the only criterion that will rule out those projects with a benefit-cost ratio of less than one (BMVBW 2003a). Projects which are very important in spatial terms may achieve a higher priority ranking. A project that entails very high environmental risks (e.g. due to potential damage in protected areas) will not be ranked lower or ruled out. Environmental risks need to be assessed further in terms of the potential to avoid or at least mitigate them.

\subsubsection{Classification of costs and benefits}

The key variable in the infrastructure planning decision-making process is the benefit-cost ratio. In order to assess the costs and benefits of a given infrastructure investment, a net present value is calculated based on annual flows (BMVBW 2003b). The present value $V$ of a flow $X$ is given by

$$
V(X, t, p)=\sum_{t=0}^{T}(1+p)^{-t} X_{t} .
$$

The annual flows are discounted at rate $p$, and $t$ is the time period. ${ }^{122}$ The benefit-cost

\footnotetext{
${ }^{122}$ According to current legislation (BVWP 2003), costs and benefits are measured in present values with a base year $t_{0}=2000$ and prices of 1998 . The discount rate is $3 \%$. For waterway infrastructure investments on river and canal beds, a use value of more than $t=100$ years is assumed (BMVBW 2003b, 99). For the Lower Weser deepening, the first year of operation is assumed to be 2015 (PLANCO2002). The formula is simplified for constant flows (BVWP 2003).
} 


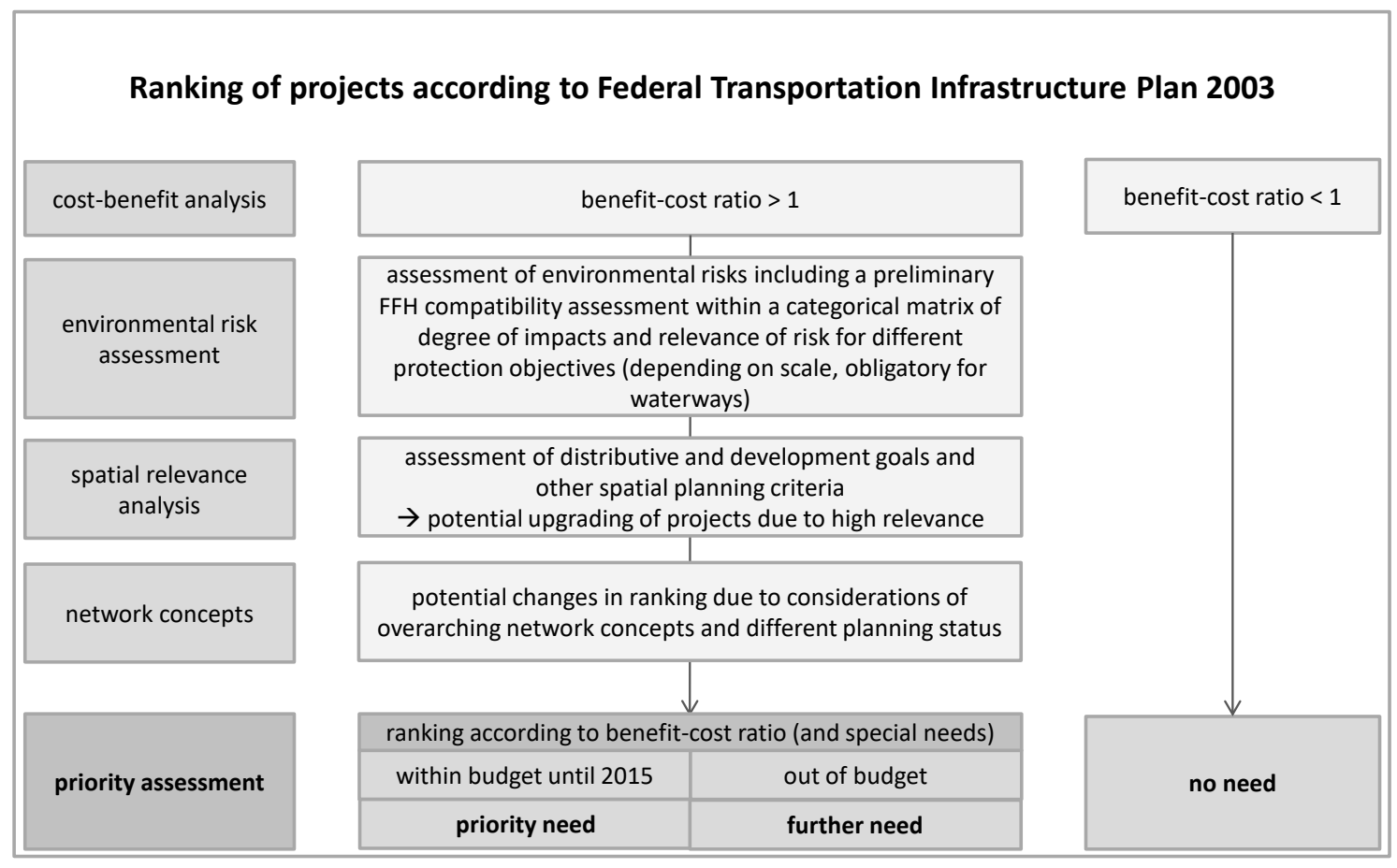

Figure 8.1: Schematic representation of the planning procedure within the 2003 Federal Transportation Infrastructure Plan (adapted by the authors from Petry and Klauer 2005, 49).

ratio BCR is then calculated as the sum of present value benefits $B$ of $m$ categories divided by the sum of present value costs $C$ of $n$ categories.

$$
B C R=\frac{\sum_{m=0}^{M} V\left(B_{m}\right)}{\sum_{n=0}^{N} V\left(C_{n}\right)} .
$$

This measurement is sensitive to the classification of cost and benefits. However, a decision rule should be independent of whether or not costs are accounted for as negative benefits (Pearce, Atkinson, and Mourato 2006). This is particularly important, since standard increased maintenance costs are accounted for in the BVWP as negative benefits. The classification of maintenance costs $(x)$ as benefits $(B)$ instead of costs $(C)$ biases the benefitcost ratio towards greater economic profitability because

$$
\frac{B-x}{C}>\frac{B}{C+x}
$$

for positive values of $x$. It never biases a profitable benefit-cost ratio below 1 , but leads to a biased ranking of infrastructure projects and, consequently, to an inefficient allocation of public spending.

More specifically, the bias - measured as the fraction of the two cost-benefit ratios increases in the ratio of all other costs and benefits. Thus, the more beneficial a project is, 
the more its cost-benefit ratio is exaggerated. To see this point, let $b=\frac{B}{C}>1$ denote the ratio of all other costs and benefits except maintenance costs $(x)$ and let $\mu$ measure the bias. Then, (8.3) is rewritten as:

$$
\frac{b C-x}{C}=\mu \frac{b C}{C+x}
$$

Rearranging for $\mu$ and differentiating with respect to $b$ yields a positive first derivative:

$$
\frac{\partial \mu}{\partial b}=\frac{C x+x^{2}}{C^{2}}>0
$$

This means, the bias from classifying maintenance cost as negative benefits $(x)$ increases in the ratio of all other benefits and costs $(b)$ and the more beneficial the project, the greater the bias.

\subsubsection{Valuation of environmental impacts}

In Germany, benefits are assessed according to nine different categories, including reduced transport costs and regional benefits such as an increase in regional employment (BMVBW 2003b). The assessment also includes external effects such as accidents, noise or emissions. Environmental benefits are assessed in terms of noise reduction and reduced airborne emissions. Costs are included using a single factor representing investment costs.

The BVWP does not explicitly recognise any negative external effects of infrastructure planning on the environment, such as losses in ecosystem services (cf. Meyerhoff and Petschow 1995; Meyerhoff and Dehnhardt 2007; Petry and Klauer 2005; Zabel 2011). ${ }^{123}$ However, German nature conservation law stipulates that the impacts of infrastructure projects must be minimised and compensation provided for residual environmental impacts. To some extent, therefore, changes in ecosystem services are implicitly included in a lumpsum portion of the investment costs (Petry and Klauer 2005) - yet without being properly assessed. ${ }^{124}$

To assess the ecosystem service-related welfare effects of infrastructure projects within a CBA, it is necessary first to establish the monetary value of changes in ecosystem services. This can be done using a range of methods (Russi et al. 2013; TEEB 2010a). Since many

\footnotetext{
${ }^{123}$ The currently developed BVWP 2015 does not differ in this respect and will not explicitly include environmental costs (Intraplan, Planco, and TUBS 2015, Section 2.11).

${ }^{124}$ The initial CBA for the Weser deepening was conducted (PLANCO 2002), before the environmental impact assessment (GfL, BioConsult, and KÜFOG 2006a) and the landscape conservation plan (GfL, BioConsult, and KÜFOG 2006b) existed and is therefore inevitably inaccurate in estimating environmental costs.
} 
ecosystem services are public in nature and are therefore not traded, no market price is available. In such cases, the monetary value of changes in ecosystem service provision can be estimated by either the willingness to accept or the willingness to pay, ${ }^{125}$ determined by revealed or stated preference methods (e.g. Brouwer et al. 2009; Hanley and Barbier 2009; TEEB 2010b). Other options for assessing changes in ecosystem services in monetary values include cost-based approaches such as avoided cost, replacement cost, mitigation or restoration cost methods (Brouwer et al. 2009). However, cost-based measures are not necessarily a good measure of welfare effects, since they give no indication whether there is an actual demand for a specific service or whether preferences are met (cf. Bockstael et al. 2000). Thus, further information on preferences is needed.

\subsection{Integrating ecosystem services into a cost-benefit analysis of the projected deepening of the Lower Weser}

In the following, we discuss the original CBA (PLANCO 2002) (26 $^{126}$ that enabled the deepening of the Lower Weser to be included in the 2003 Federal Transportation Infrastructure Plan (BVWP) as a high-priority project (Section 8.3.1). Furthermore, we monetise the projected changes in the ecosystem services concerned (Section 8.3.2) in order to re-estimate the benefit-cost ratio for the deepening of the Lower Weser (Section 8.3.3) and report on a sensitivity analysis for the resulting ecologically extended CBA (Section 8.3.4).

\subsubsection{Original cost-benefit analysis}

The first planning procedures for a further deepening of the Weser were initiated in the early 2000s. PLANCO was commissioned by the Federal Ministry of Transportation to provide a CBA for the river deepening project (PLANCO 2002).

According to PLANCO (2002), the deepening of the Weser river channel would deliver the following benefits each year: improvements in the utilisation of shipping capacity would yield an annual benefit of $€^{1998} 6.54$ million $^{127}$ because a deeper channel would allow ships with a heavier cargo to enter the river, so that fewer ships would be required and hence

\footnotetext{
${ }^{125}$ The willingness to pay is the amount of money an individual is willing to pay to obtain a certain good or service. Conversely, the willingness to accept is the amount of money an individual requires in order to go without a certain good or service.

${ }^{126}$ There is an additional and partly revised CBA (PLANCO 2009). In comparison to the original CBA, it is even less explicit in its assumptions and methodology, which makes it harder to reproduce.

${ }^{127}$ Monetary values are converted to $€^{1998}$ throughout the text using the annual consumer price indices for Germany (Statistisches Bundesamt 2014).
} 
transport costs would be reduced. Time savings in terms of waiting times incurred by tidal phases would deliver benefits because the tide-related time frame to access ports would be extended for larger ships ( $€^{1998} 0.05$ million). The deepening of the channel would cause increased maintenance costs due to a greater need for maintenance dredging; these costs are accounted for as negative benefits ( $€^{1998}-1.99$ million). Regional employment would increase during the phase of deepening the Lower Weser ( $€^{1998} 0.01$ million). $\mathrm{CO}_{2}$ and $\mathrm{NO}_{x}$ emissions would be mitigated, as better used capacity would require fewer ships and therefore less fuel per transported ton of cargo. This constitutes the largest annual benefit ( $€^{1998} 8.64$ million) of deepening the Lower Weser in the original CBA (PLANCO 2002). Finally, the promotion of international trade would improve the international division of labour and is therefore beneficial in terms of welfare (BMVBW 2003b). This is calculated as benefit of $10 \%$ of the savings in operational costs ( $€^{1998} 0.66$ million). The only costs considered are investment costs, estimated at a total of $€^{1998} 15.34$ million, with $57 \%$ accruing in the first year and the remainder being equally distributed over the subsequent years of activity (20112014) (PLANCO 2002). The planned deepening of the Weser was given 'high priority' in the BVWP 2003 because, based on these figures, it was estimated that the benefit-cost ratio would be greater than $26: 1$ (PLANCO 2002, 2009).

\subsubsection{Valuation of affected ecosystem services}

Next, we monetise two main ${ }^{128}$ losses in ecosystem services and adjust the prices for a reduction in greenhouse gas emissions in order to illustrate the magnitude of the effects on the environment caused by the Weser channel adjustment.

First, one major impact of the Weser deepening is an associated loss in provisioning fresh water (Russi et al. 2013) for agricultural production in the region. Dredging results in a stronger upstream intrusion of brackish waters into the estuary and increased salinity (BAW 2004; Johnston 1981; Luo et al. 2007; National Research Council Marine Board 1985). This changes the fresh water supply in a region called Wesermarsch (IDN 2008). The farmers in this region use the system of canals and ditches to water their cattle and land this is a provisioning ecosystem service that would be affected by the dredging of the Lower

\footnotetext{
${ }^{128}$ Very likely these are not the only effects. Potentially, the deepening would also have negative impacts on cultural ecosystem services such as amenity and recreational services, e.g. for biking and hiking along the Lower Weser, due to a more confined river (cf. Russi et al. 2013). Regulating services are also likely to be affected negatively, given that dredging and the associated loss of habitats affect the nutrient retention capacity of estuaries (cf. Dehnhardt 2002; Liekens, Broekx, and De Nocker 2013; Jacobs et al. 2013). Including such potential ecosystem service losses in monetary terms would further lower the benefit-cost ratio.
} 
Weser. The Generalplan Wesermarsch is a plan that has been produced to improve the supply of fresh water in the Wesermarsch region by changing the ditch system to provide less salty water for agricultural production. Administratively, it is a different project and the relation between the two has been challenged in the political discourse. It has been argued that the Wesermarsch planning is not intended to compensate for damage caused by the planned Lower Weser deepening, but for damage done by a previous deepening of the river (Niedersächsischer Landtag 2012). Assuming increasing marginal costs, the environmental damage caused by a previous deepening of the channel would be a conservative estimate of the environmental damage caused by the deepening currently being planned. Hence, we assume that the costs of the plan can be used as a proxy for the restoration costs of losses in provisioning fresh water ecosystem services for agricultural production. ${ }^{129}$ The two federal states of Lower Saxony and Bremen budgeted $€^{2011} 50$ million for the compensation measure. A study commissioned to elaborate the plan estimated $€^{2011} 86.7$ million as the most cost-efficient measure (NLWKN 2011), whilst the ongoing political discourse has stated that costs may increase up to $€^{2011} 120$ million (Niedersächsischer Landtag 2012). We use the $€^{2011} 86.7$ million as a best guess estimate, the politically budgeted sum as a lower bound and the maximum cost mentioned as an upper bound estimate to indicate the range of uncertainty. We assume that the costs accrue constantly over the 14 years (NLWKN 2011) of planning and implementation, which gives an average yearly flow of $€^{1998} 6.19$ million with an uncertainty range from 3.57 to 8.57 million.

Second, habitat and gene pool protection services are affected by the dredging activities in the river bed. Such bio-physical data of the effects of the Weser deepening are reported in the environmental impact assessment and in the planning documents concerning required mitigation and compensation measures. The procedure is described briefly in the following (cf. Rundcrantz and Skärbäck 2003 for more detail). First, there is an environmental impact assessment (GfL, BioConsult, and KÜFOG 2006a) which, in the case of the Weser, concludes that there would be an unavoidable 'significantly negative' impact on different ecosystems along the river and its tributaries. According to the German nature conservation law, such unavoidable impacts must be mitigated or compensated for. In a second step, the landscape conservation plan specifies the mitigation and compensation measures (GfL, BioConsult, and KÜFOG 2006b). This plan finds a total of 109.8 ha subject to different

\footnotetext{
${ }^{129}$ As noted in Section 8.2.3, cost-based methods are not necessarily a good measure of welfare since they do not contain information about individual and social preferences (and marginal WTP). In this case, preferences are revealed in the political process entailing negotiations over an actual compensation measure - the Generalplan Wesermarsch - which was not part of the initial planning.
} 
types of encroachments by dredging. It assesses the value or quality of the affected 'subject of protection' (Schutzgut, e.g. soil, waterbodies, climate, biotopes, landscape, flora, fauna and humans) as well as the expected loss of value (Rundcrantz and Skärbäck 2003). Weighting factors apply for different depths and durations of encroachment effects (Wende, Herberg, and Herzberg 2005; GfL, BioConsult, and KÜFOG 2006b). By factoring in these weights, the landscape conservation plan estimates compensation needs for permanent damage to 32.9 ha (GfL, BioConsult, and KÜFOG 2006b). The overall area for planned compensation measures to offset all the losses (including those that are not permanent) relating to the different subjects of protection is 61.16 ha (GfL, BioConsult, and KÜFOG 2006b). To estimate the change in habitat and gene pool protection services, we take the area of compensation measures as a best guess estimate (61.16 ha), and use the area of compensation need for permanent damages (32.9 ha) and actual encroachment (109.8 ha) as lower and upper bound estimates.

The cost of the compensation measures are estimated at $€^{1998} 4$ million (WSA Bremerhaven, personal communication, 2014). From an ecological perspective, such compensation measures do not necessarily offset all residual losses with regard to spatial and temporal ecological equivalence (cf. Quétier and Lavorel 2011), especially for the biodiverse and unique Weser estuary. In addition, from a welfare economics perspective, cost-based methods are not always a good proxy for welfare effects, as cost-based proxies do not consider whether or not the preferences of the population concerned have been met. To account for both areas of uncertainty, welfare effects could alternatively be measured by the extent to which people value these ecosystem services. Therefore, we estimate the value of the losses in habitat services by applying a benefit transfer from a contingent valuation study of the willingness to pay (WTP) of households in the nearby Elbe region. The study's value we transfer is the Elbe, Weser and Rhine region inhabitants' WTP for the restoration of natural floodplains by relocating dykes, extensifying agriculture and implementing species protection measures, mainly the restoration of 15,000 ha of flood plains in the Elbe region to a near-natural state (Meyerhoff 2002; Meyerhoff and Dehnhardt 2007). ${ }^{130}$ Here, we make the very conservative assumption that WTP equals willingness to accept (cf. Horowitz and McConnell 2002). Meyerhoff (2002) elicits under cautious assumptions (exclusion of protest votes, correction of embedding effect and $2.5 \%$ reduced arithmetic mean) a yearly WTP of $e^{2001} 108$ million,

\footnotetext{
${ }^{130}$ The fact that the participants in Meyerhoff's (2002) WTP study also included households from the Weser region makes the transfer of their WTP to the area affected by a Weser deepening plausible: some of the stakeholders are the same, and although the affected river is different, it is geographically close by (cf. Brouwer 2000 for quality criteria of benefit transfers).
} 
which we scale down to the area affected and the number of households in the Lower Weser region. ${ }^{131}$ This results in annual costs through the loss of habitat and species protection of $€^{1998} 2.07$ million with an uncertainty range from 1.11 to 3.71 million.

Third, the planned channel adjustment would allow larger ships to transport the same amount of cargo and thereby use less fuel per transported ton of cargo. The savings in fuel lead to emissions abatement. This constitutes a benefit through mitigation of airborne emissions $^{132}$ since damages are avoided (BMVBW 2003b). The BVWP method ${ }^{133}$ uses average abatement cost with values that are high compared to recent estimates ${ }^{134}$ (Kuik, Brander, and Tol 2009; Umweltbundesamt 2012a). Because marginal abatement costs increase over time, using an average cost approach without great care overweighs current emissions and tends to exaggerate the net present value of emission reductions due to discounting. Therefore, we recalculate the benefits of emissions reductions based on the results of a recent meta-study and use a marginal cost approach for greater accuracy. We follow the approach of the German Federal Environmental Agency and assume that the national political mitigation target in the BVWP (BMVBW 2003b) is equivalent to limiting global warming to a $2 \mathrm{C}^{\circ}$ temperature rise (Umweltbundesamt 2012a; Wille, Preiss, and Friedrich 2012). However, with current international mitigation efforts corresponding to scenarios of 550-650 ppm $\mathrm{CO}_{2}$ eq by 2100 (Edenhofer et al. 2014), we assume a stabilisation around $500 \mathrm{ppm} \mathrm{CO}_{2} \mathrm{eq}$, which is still likely to keep the rise in global temperature below $2 \mathrm{C}^{\circ}$ (IPCC 2014). Estimates of marginal abatement costs are available from Kuik, Brander, and Tol (2009), who conducted a meta-study based on 62 estimates from 26 different models presented at the Energy Modelling Forum (EMF) and the Innovative Modelling Comparison Project (IMCP) in 2006. Accordingly, marginal abatement costs for stabilising the atmospheric concentration of greenhouse gases at $500 \mathrm{ppm} \mathrm{CO}_{2}$ eq are predicted as $66.00 €^{2005} / \mathrm{tCO}_{2}$ eq for 2025 (with 36.50 and 119.40 being lower and upper bounds, respectively) and $133.90 €^{2005} / \mathrm{tCO}_{2}$ eq for

\footnotetext{
${ }^{131}$ We scaled down the area from 15,000 ha of the Elbe floodplain as assessed in Meyerhoff (2002) to the area affected by the Weser river dredging $(32.9,61.16$ or 109.8 ha, respectively) and adjusted the WTP from 8.6 million households in the Elbe catchment area to 4.2 million households in the Weser catchment area.

${ }^{132}$ Lieken, Broekx, and De Nocker (2013) consider water quantity available for transportation as an ecosystem service. Deepening the channel may thus yield benefits through an increased water flow that allows for more efficient shipping.

${ }^{133}$ Emissions are valued with the average abatement cost to reach $80 \%$ emission reduction in 2050 , approximated as 205 and $365 €^{1998} / \mathrm{t}$ for $\mathrm{CO}_{2}$ and $\mathrm{NO}_{\mathrm{x}}$ emissions, respectively (BMVBW 2003b). These estimates are based on studies by Jochem et al. (1997) and Masuhr et al. (1991).

${ }^{134}$ In fact, not only the price, but also the quantity of emissions savings, appears to be highly uncertain. In the revised CBA from PLANCO (2009), the benefits from emissions reduction fall from the originally reported $€^{1998} 175.25$ million to just $€^{1998} 21.4$ million.
} 
2050 (ranging from 79.40 to 226.00) (Kuik, personal communication, 2014). ${ }^{135}$ Marginal abatement costs are highly convex in emissionscontrol rate (IPCC 2007; Kuik, Brander, and Tol 2009) and are hence expected to rise over time. Assuming zero abatement costs in 1987 (the reference point in the BVWP 2003), we calibrate a second-degree polynomial to the abatement costs mentioned in 1987, 2025 and 2050. This gives yearly benefits of abated emissions of $€^{1998} 1.63$ million in 2015 (with a range from 0.86 to 3.05 million) and $€^{1998}$ 14.58 million in 2115 (with a range from 9.48 to 22.09 million).

\subsubsection{Ecologically extended cost-benefit analysis}

Next, we adapt the original CBA conducted for the Lower Weser river channel by applying our three main points of criticism: integrating ecosystem services, valuing carbon emissions with marginal abatement costs based on recent studies and correcting the accounting bias.

We find a present value (sum of discounted annual flows with lower and upper uncertainty bounds in parenthesis) of the loss of habitat and gene pool protection services of $€^{1998} 47.18$ (ranging from 25.38 to 84.71 ) million and of the loss of provisioning ecosystem services of $€^{1998} 44.90$ (25.89 up to 62.15 ) million. Each of these figures is, on the lower bound, already twice as high as the investment costs, highlighting the relative importance of environmental costs compared to purely financial costs. Moreover, we recalculate emissions reductions due to more efficient shipping using marginal abatement costs. Leaving the value for $\mathrm{NO}_{\mathrm{x}}$ emissions untouched gives a present value of emissions reductions of $€^{1998} 97.69$ (ranging from 61.19 to 158.91$)$ million, with the higher bound still being below the original figure. This illustrates that, due to discounting and the long time horizon, it makes a substantial difference whether average or marginal abatement costs are considered.

Recalculating the original CBA using these figures and classifying maintenance costs as costs, the benefit-cost ratio drops from 26.12 to 1.71 (ranging from 1.05 to 2.99) (see Table 8.1). Hence, the benefit-cost ratio appears to be very sensitive to our amendments and this sensitivity appears to be relatively robust in relation to the uncertainties considered in the ecosystem service valuation. Remarkably, the results of the ecologically extended CBA hardly change when maintenance costs remain classified as negative benefits; this leads to a benefit-cost ratio of 1.99 (ranging from 1.07 to 4.28 as lower and upper bounds). This

\footnotetext{
${ }^{135}$ Note that the marginal abatement cost strongly depends on the stringency of the long-term political target (Edenhofer et al. 2014; Kuik, Brander, and Tol 2009) and results hence rest on the assumed stabilisation target with both nationally and globally less stringent climate goals resulting in substantially lower abatement costs.
} 
mirrors the fact that, for given maintenance costs, the accounting bias decreases as the ratio of all other costs and benefits approaches unity.

TABLE 8.1: Original and ecologically extended cost-benefit analysis, present values in million $€^{1998}$.

\begin{tabular}{|c|c|c|}
\hline & Original $\mathbf{C B A}^{a}$ & $\begin{array}{c}\text { Ecologically } \\
\text { extended CBA }\end{array}$ \\
\hline \multicolumn{3}{|l|}{ Benefits } \\
\hline Benefits from improved shipping capacity utilisation & 132.74 & 132.74 \\
\hline Benefit from time savings & 1.04 & 1.04 \\
\hline Increased maintenance costs & -40.44 & \\
\hline Regional employment during investment phase & 0.28 & 0.28 \\
\hline Benefits from abated $\mathrm{CO}_{2}$ and $\mathrm{NO}_{\mathrm{x}}$ emissions & 175.25 & $\begin{array}{c}97.69 \\
{[61.69 ; 158.91]}\end{array}$ \\
\hline Benefits from advancing international trade & 13.48 & 13.48 \\
\hline Sum of benefits & 282.35 & $\begin{array}{c}245.22 \\
{[208.73 ; 306.44]}\end{array}$ \\
\hline \multicolumn{3}{|l|}{ Costs } \\
\hline Investment costs & 10.81 & 10.81 \\
\hline Increased maintenance costs & & 40.44 \\
\hline Loss of habitat and gene pool protection service & & $\begin{array}{c}47.18 \\
{[25.38 ; 84.71]}\end{array}$ \\
\hline Loss of freshwater provisioning service & & $\begin{array}{c}44.90 \\
{[25.89 ; 62.15]}\end{array}$ \\
\hline Sum of costs & 10.81 & $\begin{array}{c}143.34 \\
{[102.53 ; 198.10]}\end{array}$ \\
\hline \multicolumn{3}{|l|}{ Benefit-cost ratio } \\
\hline With maintenance cost as negative benefits & 26.12 & $\begin{array}{c}1.99 \\
{[1.07 ; 4.28]}\end{array}$ \\
\hline With maintenance cost as cost & 6.38 & $\begin{array}{c}1.71 \\
{[1.05 ; 2.99]}\end{array}$ \\
\hline
\end{tabular}

Lower and upper bounds are reported in square brackets.

${ }^{a}$ Values are reproduced by the authors based on annual figures from PLANCO (2002). There remains a difference of less than $2 \%$ compared to the CBA by PLANCO.

\subsubsection{Sensitivity analysis}

Finally, we study the robustness of our results by means of a Monte-Carlo simulation. In addition to the uncertainty ranges reported so far, this allows us to investigate the likelihood of different benefit-cost ratios.

The value for the ecosystem service of habitat and gene pool protection seems particularly uncertain, as a simple benefit transfer is required to estimate it. Therefore, we first conduct a partial sensitivity analysis in which we specify probability distributions for the two main sources of uncertainty: the area affected and the willingness to pay. We assume a normal 
distribution for both parameters, which we truncate at zero, as negative values seem very unlikely. Mean values are set to equal our best guess estimates. For the uncertainty in the area of ecosystem service loss, we assume a probability density function so that the upper bound of the $95 \%$ confidence interval equals the overall area exposed to dredging activities (our upper bound estimate). Furthermore, we calculate standard deviation in the WTP to be equal to the coefficient of variation of 0.9 in the primary study (Meyerhoff 2002). Holding all other parameters constant and conducting 10,000 Monte-Carlo runs produces a net present value for the ecosystem service of habitat and gene pool protection with a mean $( \pm$ standard deviation) of $57.80( \pm 43.31)$, which translates into a benefit-cost ratio for the ecologically extended CBA of $1.71( \pm 0.42)$. Thus, the estimated benefit-cost ratio appears to be rather robust in relation to the relatively high uncertainty associated with this ecosystem service.

Next, we consider the joint effect of uncertainty in all cost and benefit positions. For the annual loss in freshwater provisioning as an ecosystem service, we assume again a truncated normal distribution, where we calibrate the standard deviation so that the lower bound of the 95\% confidence interval reflects the minimum budgeted expenditure. Regarding uncertainty in the abatement cost price, we assume a triangular distribution to account for right-skewed nature, with mode, minimum and maximum being equal to the estimated best guess, lower and upper bounds, respectively. For the remaining benefit and cost estimates from the original study, we assume truncated normal distributions with means equal to the best guess values in Table 8.1, and set the standard deviation ad hoc to $25 \%$ of the mean, as no further information is reported.

The resulting right-skewed distribution of the benefit-cost ratio is displayed in Figure 8.2. Under the assumed uncertainties, the benefit-cost ratio is distributed with a mean of 1.78 and a standard deviation of 0.58 . Hence, the results of the ecologically extended CBA appear to be robust to the specified uncertainties and we can be confident that even a few additions to the official CBA lead to a substantial drop in the benefit-cost ratio of the projected river deepening.

\subsection{Discussion}

The key finding of our analysis is that integrating the impacts of infrastructure projects on ecosystem services in monetary terms into their CBA is likely to substantially alter the results. In this section, we discuss key assumptions taken in our case study for the projected 


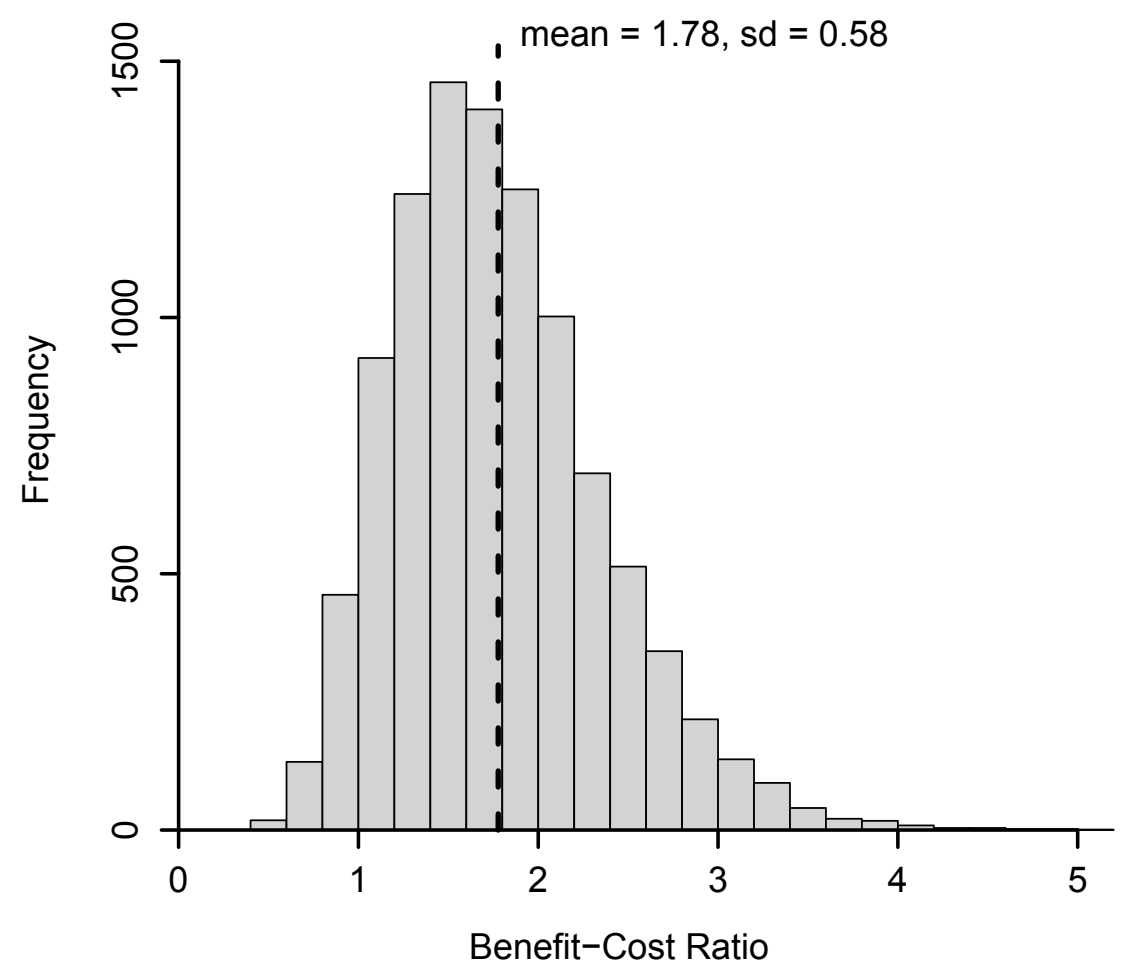

Figure 8.2: Results of the Monte-Carlo simulation of ecologically extended CBA $(N=10,000)$, with mean at dashed line.

Lower Weser deepening, and several critical issues for a more general integration of ecosystem services into CBAs in infrastructure planning procedures.

First, our method of monetising the changes in ecosystem services is based on proxies which require certain assumptions. For example, in order to assess the loss of habitat and gene pool protection, we assume that the habitat services of both floodplains and river beds of these two Northern German rivers are sufficiently similar to safely transfer the benefits. For the loss in freshwater ecosystems, we assume that the cost-based method used is adequate to give an approximation of welfare changes. For climate regulation services, we assume a certain development scenario. For the illustrative purposes of this study, such an approximation seems appropriate. However, a more precise approach would be to value all the different ecosystem services changes and welfare effects of a project such as the Weser deepening separately and based on preferences. Such an approach to integrate ecosystem services would depend on the availability not only of bio-physical data, which can be gathered to some extent from an environmental impact assessment, but also on societal preferences, 
which are often not readily available. ${ }^{136}$

Second, the widely discussed limitations of CBA also apply to an ecologically extended CBA (Hanley and Barbier 2009; Hansjürgens 2004; Pearce, Atkinson, and Mourato 2006; Sen 2000). Distributive effects are not explicitly considered in the welfare analysis according to the BVWP. In general, who benefits and who bears the costs are often not explicitly stated, but could be (cf. Hanley and Black 2006). This applies especially when ecosystem services are considered, as these are often public goods and are enjoyed by many. In a further step, inequalities could be accounted for in CBA, for instance through distributive weights (HM Treasury 2013). Case studies have also suggested that, in addition to economic valuation, public participation schemes may improve planning processes for rivers (Newson and Chalk 2007) and estuaries (Fidélis and Carvalho 2015). By integrating ecosystem service values into CBA, these wider societal issues of justice and participation in planning are not addressed. However, methods such as deliberative monetary valuations might be able to increase participation, at least in the assesssment of values (cf. Spash 2007).

Third, within BVWP 2003, uncertainty is systematically considered neither in the CBA nor in the environmental risk assessments (Petry and Klauer 2005). Long time horizons inevitably entail uncertainty regarding the estimated cost and benefit streams. For instance, marginal abatement costs depend on technical innovation as well as on national and global stabilisation targets and mitigation pathways. Considering uncertainty ex ante requires the specification of probability distributions (cf. Arrow and Lind 2014). Often, such probability is not known for future events beyond an extrapolation of empirical patterns - for example, the chances of cost overruns (Flyvbjerg, Skamris Holm, and Buhl 2003). A pragmatic approach to improve CBAs further by integrating uncertainty in the mild form of risk might be to employ probability distributions based on expert interviews (cf. Petry and Klauer 2005), potentially with risk aversion factors gleaned from discursive processes, as has been done in Switzerland (Umweltbundesamt 2012b).

\subsection{Conclusion}

In this paper, we have analysed the integration of ecosystem services within a cost-benefits analysis for infrastructure planning, using the example of a German infrastructure planning

\footnotetext{
${ }^{136}$ However, recent studies have gathered more information on the value of ecosystem services on the basis of various water ecosystems (Russi et al. 2013), while Liekens, Broekx, and De Nocker (2013), in a regionally more specific study, identified values for individual ecosystem services in estuaries around the North Sea region.
} 
process, the projected Lower Weser deepening.

We find that the Federal Transportation Infrastructure Plan ranks projects based on economic feasibility, which is measured by a benefit-cost ratio and is subject to public budget constraints. Effects on ecosystem services are not considered in monetary terms, apart from a lump-sum portion of the investment costs which are used for compensation measures. To ignore ecosystems changes is to ignore the effects of ecosystem services on human well-being (cf. MEA 2005); this effectively contradicts the goal of methods used to assess infrastructure planning in terms of welfare effects. In addition, we find that a classification of costs as negative benefits systematically biases the benefit-cost ratio towards greater profitability.

We reassessed the CBA of the Weser channel deepening and illustrated the relevance of these shortcomings in the German infrastructure legislation. We have shown that by integrating the values of two major ecosystem service changes, namely, the loss of 'fresh water supply for agricultural production' in the Wesermarsch region and the loss of 'habitat and gene pool protection services' in the bio-diverse river estuary, the benefit-cost ratio drops substantially. We have thus provided case study evidence that ecosystem services are highly significant and that integrating ecosystem services into the infrastructure planning process can substantially alter its outcome. This demonstrates that if projects are ranked mainly on the basis of monetary criteria, then ecosystem service changes should be included in monetary terms in order to avoid an inefficient allocation of public spending - which is generally relevant beyond the German context. For Germany in particular, our results call for a substantial improvement in the methodology used to make infrastructure investment decisions, particularly with regard to the encountered accounting bias and to including ecosystem services as standard.

Much of the bio-physical information required is already available in the mandatory environmental impact assessments ${ }^{137}$ and, in the case of Germany, in the related landscape conservation plan. In addition, the assumption that a loss in ecosystem services can be completely substituted through compensation measures is not only a question of natural science but also of human preferences for certain ecosystem services. Welfare-related changes in ecosystem services can, in principle, be valued in monetary terms using existing tools such as preference-based methods and, in some cases, cost-based methods (cf. Brouwer et

\footnotetext{
${ }^{137}$ See e.g. the EU directive on environmental impact assessment. Furthermore, there are attempts to integrate ecosystem services into strategic environmental assessments (Honrado et al. 2013; Karjalainen et al. 2013; Kumar, Esen, and Yashiro 2013; Partidario and Gomes 2013; Presnall, López-Hoffman, and Miller 2015) which might result in easier integration into CBAs.
} 
al. 2009). However, elaborating standardised methods for integrating ecosystem services systematically into infrastructure planning processes remains a key task for future research.

Acknowledgments: We are grateful to Stefan Baumgärtner, Moritz Drupp, Klaus Eisenack, Bernd Klauer, Sean Nino Lotze, Martin Rode, Burkhard Schweppe-Kraft, Heinz Welsch, Martina Wernick, Ulrich Zabel, participants of the ISEE 2014 session T3 R4 1.3.O, Kathleen Cross for a language check, and especially three anonymous reviewers for helpful comments and suggestions on earlier drafts of this paper. Nils Droste is grateful for doctoral scholarship by the Heinrich-Böll Foundation (grant no. P118873). 


\section{Bibliography}

BMVBW, 2003a. Bundesverkehrswegeplan 2003 [Federal Transportation Infrastructure Plan 2003], Berlin: Bundesministerium für Verkehr, Bau- und Wohnungswesen.

BMVBW, 2003b. Die gesamtwirtschaftliche Bewertungsmethodik Bundesverkehrswegeplan -Bundesverkehrswegeplan 2003 [Federal Transportation Infrastructure Plan Assessment Methodology], Berlin: Bundesministerium für Verkehr, Bau- und Wohnungswesen.

Bockstael, N. E., Freeman, A. M., Kopp, R. J., Portney, P. R., and Smith, V. K. 2000. On measuring economic values for nature. Environmental Science and Technology, 34(8), pp. 1384-1389.

Boyd, J., and Banzhaf, S., 2007. What are ecosystem services? The need for standardized environmental accounting units. Ecological Economics, 63(2), pp. 616-626.

Brouwer, R., 2000. Environmental value transfer: state of the art and future prospects. Ecological Economics, 32(1), pp.137-152.

Brouwer, R., Barton, D. N., Bateman, I. J., Brander, L., Georgiou, S., Martín-Ortega, J., Navrud, S., Pulido-Velazquez, M., Schaafsma, M., Wagtendonk, A., 2009. Economic Valuation of Environmental and Resource Costs and Benefits in the Water Framework Directive: Technical Guidelines for Practitioners. Institute for Environmental Studies, VU University Amsterdam: Amsterdam.

de Groot, R.S., Alkemade, R., Braat, L., Hein, L., Willemen, L., 2010. Challenges in integrating the concept of ecosystem services and values in landscape planning, management and decision making. Ecological Complexity, 7(3), pp.260-272.

Dehnhardt, A., 2002. Der ökonomische Wert der Elbauen als Nährstoffsenke. In A. Dehnhardt and J. Meyerhoff, eds. Nachhaltige Entwicklung der Stromlandschaft Elbe. Kiel: Vauk, pp. 185-218. 
Edenhofer, O., Pichs-Madruga, R., Sokona, Y., Kadner, S., Minx, J.C., Brunner, S., Agrawala, S., et al., 2014. Technical Summary. In O. Edenhofer et al., eds. Climate Change 2014: Mitigation of Climate Change. Contribution of Working Group III to the Fifth Assessment Report of the Intergovernmental Panel on Climate Change. Cambridge: Cambridge University Press.

Ekardt, F. and Weyland, R., 2014. Neues vom wasserrechtlichen Verschlechterungsverbot und Verbesserungsgebot [News on the no deterioration rule]. Natur und Recht, 36(1), pp.12-20.

EC - European Commission DG General Regional Policy, 2006. Guide to Cost-Benefits Analysis of investment projects. EU: Brussels.

Fidélis, T. and Carvalho, T., 2014. Estuary planning and management: the case of Vouga Estuary (Ria de Aveiro), Portugal. Journal of Environmental Planning and Management, pp.1-23.

Flyvbjerg, B., Skamris Holm, M. K., Buhl, S. L. 2003. How common and how large are cost overruns in transport infrastructure projects? Transport reviews, 23(1), pp.71-88.

Franzius, L., Franzius, G. and Rudloff, R., [1894] 2010. Seekanäle, Strommündungen und Seehäfen: Handbuch der Ingenieurwissenschaften.[Channel, Mouth and Ports Engineering Manual] Bremen: Salzwasserverlag.

GfL, BioConsult and KÜFOG, 2006a. Fahrrinnenanpassung der Unter- und Außenweser an die Entwicklungen im Schiffsverkehr mit Tiefenanpassung der hafenbezogenen Wendestelle Umweltverträglichkeitsuntersuchung Auswirkungsprognose Überlagerungsvariante, [Environmental Impact Assessment for the Weser Deepening] Bremen.

GfL, BioConsult and KÜFOG, 2006b. Fahrrinnenanpassung der Unterweser an die Entwicklungen im Schiffsverkehr Landschaftspflegerischer Begleitplan [Compensation and Mitigation Measure Plan for the Lower Weser Deepening], Bremen.

Hanley, N. and Barbier, E.B., 2009. Pricing Nature: Cost-benefit Analysis and Environmental Policy, Cheltenham: Edward Elgar.

Hanley, N. and Black, A.R., 2006. Cost-benefit analysis and the water framework directive in Scotland. Integrated environmental assessment and management, 2(2), pp.156-165. 
Hansjürgens, B., 2004. Economic valuation through cost-benefit analysis-possibilities and limitations. Toxicology, 205(3), pp.241-52.

HM Treasury, 2013. The Green Book. Appraisal and Evaluation in Central Government, London.

Honrado, J. P., Vieira, C., Soares, C., Monteiro, M. B., Marcos, B., Pereira, H. M. Partidário, M. R., 2013. Can we infer about ecosystem services from EIA and SEA practice? A framework for analysis and examples from Portugal. Environmental Impact Assessment Review, 40, pp.14-24.

Horowitz, J.K. and McConnell, K.E., 2002. A Review of WTA/WTP Studies. Journal of Environmental Economics and Management, 44(3), pp.426-447.

IDN, 2008. Fahrrinnenanpassung der Unter- und Außenweser an die Entwicklungen im Schiffsverkehr mit Tiefenanpassung der hafenbezogenen Wendestelle - Maßnahmen zur Vermeidung nachteiliger Auswirkungen auf die Zuwässung, [Avoidance Measures for Negative Consequences for Watering by the Weser Deepening ]. Oyten.

Intraplan, Planco and TUBS, 2014. Grundsätzliche Überprüfung und Weiterentwicklung der Nutzen-Kosten-Analyse im Bewertungsverfahren der Bundesverkehrswegeplanung [Assessment of CBA Methods and Improvements in Federal Transportation Planning], Essen, Berlin, München.

IPCC, 2014. Summary for Policymakers. In O. Edenhofer et al., eds. Climate Change 2014: Mitigation of Climate Change. Contribution of Working Group III to the Fifth Assessment Report of the Intergovernmental Panel on Climate Change. Cambridge: Cambridge University Press.

IPCC, 2007. Summary for Policymakers. In B. Metz et al., eds. Climate Change 2007: Mitigation. Contribution of Working Group III to the Fourth Assessment Report of the Intergovernmental Panel on Climate Change. Cambridge: Cambridge University Press.

ISL, BLG, HPC, OIR, PLANCO., 2000. Entwicklungstendenzen der deutschen Nordseehäfen bis zum Jahre 2015 [Development Tendencies for German North Sea Ports until 2015], Bremen.

Jacobs, S., Vandenbruwaene, W., Vrebos, D., Beauchard, O., Boerema, A., Wolfstein, K., Maris, T., Saathoff, S., Meire, P., 2013. Ecosystem Service Assessment of TIDE Estuaries. 
Jochem, E., Landwehr, M., Mannsbart, W., Tönsing, E., Nölscher, C., Vollmar, H. E., 1997. Energieszenarien mit reduziertem CO2-Emissionen bis 2050 [Energy Scenarios with reduced CO2 Emissions until 2050]. Energiewirtschaftliche Tagesfragen, 47(8), pp.474 481.

Johnston, S., 1981. Estuarine dredge and fill activities: a review of impacts. Environmental Management, 5(5), pp.427-440.

Karjalainen, T. P., Marttunen, M., Sarkki, S., Rytkönen, A.-M., 2013. Integrating ecosystem services into environmental impact assessment: An analytic-deliberative approach. Environmental Impact Assessment Review, 40, pp.54-64.

Kuik, O., Brander, L. and Tol, R.S.J., 2009. Marginal abatement costs of greenhouse gas emissions: A meta-analysis. Energy Policy, 37(4), pp.1395-1403.

Kumar, P., Esen, S. E., Yashiro, M., 2013. Linking ecosystem services to strategic environmental assessment in development policies. Environmental Impact Assessment Review, 40, pp.75-81.

Liekens, I., Broekx, S. and De Nocker, L., 2013. Manual for the valuation of ecosystem services in estuaries.

Luo, X.-L., Zeng, E. Y., Ji, R.-Y., Wang, C.-P., 2007. Effects of in-channel sand excavation on the hydrology of the Pearl River Delta, China. Journal of Hydrology, 343(3-4), pp.230-239.

Masuhr, K. P., Echerle, K., Bradeke, H., Brakhage, A., Lyons, B., Rochert, J., Treber, M., 1991. Konsistenzprüfung einer denkbaren zukünftigen Wasserstoffwirtschaft [Assessing Consistency of a potential future Hydrogen System], Basel.

Meyerhoff, J. and Petschow, U., 1995. Natur und Umwelt in der Kosten-Nutzen-Analyse der Bundesverkehrswegeplanung. [Nature and Environment in Cost-Benefit-Analysis in Federal Transportation Planning]. Zeitschrift für angewandte Umweltforschung, 8(4), pp.544556.

Meyerhoff, J., 2002. Der Nutzen aus einem verbesserten Schutz biologischer Vielfalt in den Elbauen: Ergebnisse einer Kontigenten Bewertungsstudie. [Benefits of Improving Protection of Biological Diversity in the Elbe floodplains. Results of a Contigent Valuation Study] In A. Dehnhardt and J. Meyerhoff, eds. Nachhaltige Entwicklung der Stromlandschaft Elbe. Kiel: Vauk, pp. 155-185. 
Meyerhoff, J. and Dehnhardt, A., 2007. The European water framework directive and economic valuation of wetlands: The restoration of floodplains along the river Elbe. European Environment, 17(1), pp.18-36.

MEA - Millenium Ecosystem Assessment, 2005. Ecosystems and Human Well-being: Synthesis, Washington, D.C.: Island Press.

Næss, P., Nicolaisen, M. S., Strand, A. 2012. Traffic forecasts ignoring induced demand: a shaky fundament for cost-benefit analyses. European Journal of Transport and Infrastructure Research, 12(3), pp.291-309.

National Research Council Marine Board, 1985. Dredging Coastal Ports: An Assessment of the Issues, Washington, D.C.: National Academy Press.

Newson, M. and Chalk, L., 2007. Environmental capital: an information core to public participation in strategic and operational decisions - the example of river "Best Practice" projects. Journal of Environmental Planning and Management, 47(6), pp.899-920.

Niedersächsischer Landtag, 2012. Stenografischer Bericht 139. Sitzung am 21. Juni 2012 [Stenographic Report Caucus 139, June 21st 2012], Hannover: Niedersächsischer Landtag.

NLWKN, 2011. Generalplan Wesermarsch Realisierungsstudie Gewässerregelung [General Plan Wesermarsch Realisation Study Regulation of Water Bodies], Norden.

Partidario, M. R. and Gomes, R. C., 2013. Ecosystem services inclusive strategic environmental assessment. Environmental Impact Assessment Review, 40, pp. 36-46.

Pearce, D., Atkinson, G. and Mourato, S., 2006. Cost-Benefit Analysis and the Environment Recent Developments, Paris: OECD Publishing.

Pearce, D. and Turner, R., 1989. Economics of natural resources and the environment, Baltimore: Johns Hopkins University Press.

Petry, D., Klauer, B. and with contributions from T. Döring and F. Rauschmayer, 2005. Umweltbewertung und politische Praxis in der Bundesverkehrswegeplanung: eine Methodenkritik illustriert am Beispiel des geplanten Ausbaues der Saale [Environmental Assessment and Political Practice of Federal Transportation Planning: a Methodological Critique on the Example of the Projected Deepening of the Saale River], Marburg: Metropolis. 
PLANCO, 2009. Ergänzende Stellungnahme zu den Fahrrinnenanpassungen der Unter- und Außenweser an die Entwicklung im Schiffsverkehr - Analyse und Bewertung [Additional Statement on the Lower and Outer Weser Deepening], Essen.

PLANCO, 2002. Gesamtwirtschaftliche Bewertung erwogener Wasserstrassenprojekte - Teilbericht Vertiefung der Unterweser [Economic Assessment of projected Waterway Project - Report on the Lower Weser Deepening], Essen.

PLANCO, 2005. Prognose der deutschlandweiten Verkehrsverflechtung - Seeverkehrsprognose [Forecast of the German Traffic Networks - Forecast of Maritime Traffic], Essen.

Presnall, C., López-Hoffman, L. and Miller, M.L., 2015. Adding ecosystem services to environmental impact analyses: More sequins on a "bloated Elvis" or rockin' idea? Ecological Economics, 115, pp.29-38.

Quétier, F., and Lavorel, S., 2011. Assessing ecological equivalence in biodiversity offset schemes: key issues and solutions. Biological Conservation, 144(12), pp.2991-2999.

Rundcrantz, K. and Skärbäck, E., 2003. Environmental compensation in planning: a review of five different countries with major emphasis on the German system. European Environment, 13, pp.204-226.

Russi, D., ten Brink, P., Farmer, A., Badura, T., Coates, D., Förster, J., Kumar, R., Davidson, N., 2013. The Economics of Ecosystems and Biodiversity for Water and Wetlands, IEEP, Ramsar Secretariat: London, Brussels, Gland.

Schuchardt, B., Scholle, J., Schulze, S., Bildstein, T., 2007. Vergleichende Bewertung der ökologischen Situation der inneren Ästuare von Eider, Elbe, Weser und Ems: Was hat sich nach 20 Jahren verändert [Compartive Study of the Ecological Sitation ot the Inner Estuaries of Eider, Elber, Weser and Ems Rivers after 20 years]. Coastline reports, 9, pp.15-26.

Sen, A., 2000. The discipline of cost-benefit analysis. The Journal of Legal Studies, 29(S2), pp.931-952.

Spash, C.L., 2007. Deliberative monetary valuation (DMV): Issues in combining economic and political processes to value environmental change. Ecological Economics, 63(4), pp.690-699. 
Statistisches Bundesamt, 2014. Verbraucherpreisindex für Deutschland. Veränderungsraten zum Vorjahr in Prozent [Consumer Price Index Change Rates to Previous Year in percent].

TEEB, 2010a. The Economics of Ecosystems and Biodiversity: Mainstreaming the Economics of Nature: A synthesis of the approach, conclusions and recommendations of TEEB.

TEEB, 2010b. The Economics of Ecosystems and Biodiversity: The Ecological and Economic Foundations P. Kumar, ed., London and Washington: Earthscan.

Umweltbundesamt, 2012a. Best-Practice-Kostensätze für Luftschadstoffe, Verkehr, Stromund Wärmeerzeugung. Anhang B der "Methodenkonvention 2.0 zur Schätzung von Umweltkosten" [Best-Practice-Cost-Estimates for Airborne Emissions, Traffic, Energy Methodological Convention on Environmental Costs], Dessau-Roßlau.

Umweltbundesamt, 2012b. Methodenkonvention 2.0 zur Schätzung von Umweltkosten [Methodological Convention on Environmental Costs], Dessau-Roßlau.

Wende, W., Herberg, A. and Herzberg, A., 2005. Mitigation banking and compensation pools: improving the effectiveness of impact mitigation regulation in project planning procedures. Impact Assessment and Project Appraisal, 23(2), pp.101-111.

Wetzel, V., 1988. Der Ausbau des Weserfahrwassers von 1921 bis heute [Deepening the Weser Waterway from 1921 until today], Berlin: Springer.

Wille, V., Preiss, P. and Friedrich, R., 2012. Sachstandspapier zu Treibhausgase and Klimawandel, Sachstandspapier im Rahmen des Vorhabens "Schätzung Externer Umweltkosten und Vorschläge zur Kosteninternalisierung in ausgewählten Politikfeldern" [Report on Emissions and Climate Change to Estimate External Environmental Costs and Internalisation Options for Policies], Umweltbundesamt: Dessau-Roßlau.

World Bank, 2006. Cost-Benefits Analysis in World Bank Projects. The World Bank: Washington, DC.

WSV, 2011. Planfeststellungsbeschluss für den Ausbau der Bundeswasserstraße Weser durch die Anpassung der Unterweser von Weser-km 8 bis Weser-km 65 und die Anpassung der Außenweser von Weser-km 65 bis Weser-km 130 an die Entwicklung im Schiffsverkehr [Plan Approval Order for the Lower and Outer Weser Deepening], Aurich. 
Zabel, H.-U., 2011. Saaleausbau - wissenschaftliche Aspekte der Entscheidungsfindung [Deepening the Saale River - Scientific Aspects of the Decision Making]. UmweltWirtschaftsForum, 19(1-2), pp.5-17. 


\section{List of Papers}

This dissertation builds upon seven independent research papers. Except for one singleauthored paper, these research papers have been developed in fruitful collaborations. In the following, I report for chapter 2 to 8 the references of the corresponding research paper.

- Chapter 2: Drupp, M.A., Meya, J.N., Baumgärtner, S. Quaas, M.F. (2018). Economic inequality and the value of nature, Ecological Economics, 150: 340-345.

- Chapter 3: Baumgärtner, S., Drupp, M.A., Meya, J.N., Munz, J.M., Quaas, M.F. (2017). Income inequality and willingness to pay for public environmental goods. Journal of Environmental Economics and Management, 85: 35-61.

- Chapter 4: Meya, J.N. (2018). Environmental inequality and economic valuation. Oldenburg Discussion Papers in Economics, V-416-18.

- Chapter 5: Meya, J.N., Drupp, M.A., Baumgärtner, S., Quaas, M.F. (2018). Interand Intragenerational Distribution and the Valuation of Natural Capital. Conference paper at WCERE 2018.

- Chapter 6: Meya, J.N., Drupp. M.A., Hanley, N. (2017). Income inequality and the international transfer of environmental values. Kiel Economics Working Paper No 2017-03.

- Chapter 7: Meya, J.N., Kornek, U., Lessmann, K. (2018). How empirical uncertainties influence the stability of climate coalitions. International Environmental Agreements: Politics, Law and Economics, 18(2): 175-198.

- Chapter 8: Droste, N., Meya, J.N. (2016). Ecosystem services in infrastructure planning - a case study of the projected deepening of the Lower Weser river in Germany. Journal of Environmental Planning and Management, 60(2), 231-248. 
